QA: QA

MDL-NBS-HS-000001 REV 04

February 2005

BECHTEL

SAIC Comparruc

\title{
Drift-Scale THC Seepage Model
}

Prepared for:

U.S. Department of Energy

Office of Civilian Radioactive Waste Management

Office of Repository Development

1551 Hillshire Drive

Las Vegas, Nevada 89134-6321

Prepared by:

Bechtel SAIC Company, LLC

1180 Town Center Drive

Las Vegas, Nevada 89144

Under Contract Number

DE-AC28-01RW12101 


\section{DISCLAIMER}

This report was prepared as an account of work sponsored by an agency of the United States Government. Neither the United States Government nor any agency thereof, nor any of their employees, nor any of their contractors, subcontractors or their employees, makes any warranty, express or implied, or assumes any legal liability or responsibility for the accuracy, completeness, or any third party's use or the results of such use of any information, apparatus, product, or process disclosed, or represents that its use would not infringe privately owned rights. Reference herein to any specific commercial product, process, or service by trade name, trademark, manufacturer, or otherwise, does not necessarily constitute or imply its endorsement, recommendation, or favoring by the United States Government or any agency thereof or its contractors or subcontractors. The views and opinions of authors expressed herein do not necessarily state or reflect those of the United States Government or any agency thereof. 
QA: QA

\section{Drift-Scale THC Seepage Model MDL-NBS-HS-000001 REV 04 \\ February 2005}


2. Type of Mathematical Model

$\triangle$ Process Model

Abstraction Model

System Model

Describe Intended Use of Model

The purpose of this report is to document predictive simulations of the thermal-hydrologic-chemical behavior in the repository host rock, evaluating the effect of water/rock interactions at elevated temperature on potential seepage water compositions.

3. Title

Drift-Scale THC Seepage Model

4. DI (including Rev. No.):

MDL-NBS-HS-000001 REV 04

\begin{tabular}{|c|c|c|c|}
\hline & Printed Name & Signature & Date \\
\hline 5. Originator & C. R. Bryan & 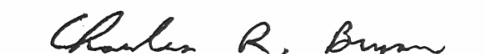 & $2 / 17 / 05$ \\
\hline $\begin{array}{l}\text { 6. Independent Technical } \\
\text { Reviewer }\end{array}$ & R. L. Howard & & \\
\hline 7. Checker & B. E. Kirstein & $c$. & $2 / 17 / 05$ \\
\hline 8. QER & D. K. Svalstad & Laveret Dowactop & 211705 \\
\hline 9. Responsible Manager/Lead & W. J. Duffy & & $2 / 17 / 05$ \\
\hline 10. Responsible Manager & E. L. Hardin & & $2 / 17 / 05$ \\
\hline
\end{tabular}

11. Remarks

Two errata were prepared for REV02 of this document. For REV03, the document has been extensively rewritten, and the issues in the errata were addressed as applicable. In most cases, the resolutions proposed in the errata are no longer applicable (e.g., the proposed resolution involves replacing a superseded input with a newer input, which has since been superseded as well). All errata have been resolved.

Eric Sonnenthal and Nicholas Spycher, originators of previous revisions of this document, developed the THC seepage model and the parameters used in the model, and are responsible for the technical content of this document.

\begin{tabular}{|l|l|}
\hline \multicolumn{2}{|c|}{ Change History } \\
\hline 12. Revision No. & \multicolumn{1}{c|}{ 13. Description of Change } \\
\hline REV 00 & Initial Issue \\
\hline REV 01 & $\begin{array}{l}\text { Incorporated additional data from DST for model validation. Incorporated sensitivity studies, } \\
\text { including effect of backfill versus no backfill. Additional Models/Updates: REV01 DST THC } \\
\text { Model; Tptpmn THC No-Backfill Model; Tptpmn THC Heterogeneous Model; Tptpll THC } \\
\text { Model; Plug-Flow Reactor Model Validation }\end{array}$ \\
\hline REV 01 ICN 01 & $\begin{array}{l}\text { Incorporated minor editorial changes to text and references. Incorporated additional figure } \\
\text { (Figure 32b). Incorporated auditor's recommendations (Audit M\&O-APR-01-02). All } \\
\text { changes are marked by a black vertical line on the margin of the affected page. }\end{array}$ \\
\hline
\end{tabular}




\begin{tabular}{|c|c|}
\hline REV 01 ICN 02 & $\begin{array}{l}\text { Removed incorrect reference DTN: MO0008THRMODYN.000 [DIRS 153742], inserted } \\
\text { correct reference DTN: MO0009THRMODYN.001 [DIRS 152576] (this impacted sections 4, } \\
8.3 \text { and attachments V and VI). } \\
\text { Made editorial correction in section 5.A.7. } \\
\text { Added assumption } 20 \text { to section 5.A, to identify DTN: LA0008SC12213N.001 [DIRS 153386] } \\
\text { as data that augments DTN: MO0009THRMODYN.001 [DIRS 152576]. } \\
\text { Revised three assumptions to indicate no further confirmation is required as the assumptions } \\
\text { were adequately justified (C-1, C-4, and C-6). Revision of assumptions resulted in the removal } \\
\text { of TBVs 5028, 5029, and 5030 in the Document Input Reference System (DIRS). } \\
\text { Updated section 8.3 to remove URNs where appropriate. } \\
\text { Changes to the data status made in DIRS. } \\
\text { The following sections were revised in REV 01 ICN 02: } \\
\text { Section } 1 \text { (p. 23), 2 (p. 27), } 3 \text { (p. 30), } 4 \text { (pp. 33, 37-38, } 42), 5 \text { (pp. 50, 53, 55), } 6 \text { (p. 107), } 7 \text { (p. } \\
\text { 225), } 8 \text { (pp. 228-229, 235-240), Att V (p. V-3), and VI (p. VI-3). }\end{array}$ \\
\hline REV 02 & $\begin{array}{l}\text { Entire model documentation was revised. Side bars are not used because the changes were too } \\
\text { extensive to use Step 5.9d)1) per AP-SIII.10Q/REV.1/ICN } 2 .\end{array}$ \\
\hline REV 03 & $\begin{array}{l}\text { Entire model documentation was revised. Side bars are not used because the changes were too } \\
\text { extensive to use Step 5.8f)1), AP-SIII.10Q/REV 02/ICN 5. All Revision 01 THC Seepage } \\
\text { Model simulations (Sections 6.5, 6.6, 6.7 of REV 02) and Revision 01 DST THC model } \\
\text { simulations (in Section 7.1 of REV 02) and associated inputs that are not used by the current } \\
\text { revision were removed. In Section 4.1, superseded or historical inputs to the current model } \\
\text { were justified for intended use. Section } 5 \text { was expanded to include more assumptions. Several } \\
\text { subsections of Section } 6 \text { were removed, and a new section, documenting a sensitivity analysis } \\
\text { relating to host rock thermal properties has been added. Section } 7.1 \text { was rewritten to more } \\
\text { explicitly address procedural requirements. Sections } 7.2 \text { and } 7.3 \text { were reduced to short } \\
\text { descriptions. The errata associated with the previous revision were fixed. Regulatory } \\
\text { Integration Team review items were addressed through more thorough descriptions of the } \\
\text { process model, justification of assumptions, evaluation of the model validation, and discussion } \\
\text { of propagation of model uncertainty to downstream models. The report also addresses } \\
\text { Condition Reports CR79, CR168, CR821, CR938, CR1805, CR1821, CR2049, CR2050, and } \\
\text { CR2104. }\end{array}$ \\
\hline REV 04 & $\begin{array}{l}\text { Revisions to the validation section (Section 7) of the document, to address CR99 and CR4888. } \\
\text { Specifically, changes were made to Sections } 1.1,1.3,4.2,7.1 .7,7.1 .7 .2 \text {, and 7.1.11.3. Side } \\
\text { bars are not used because the changes were too extensive to use Step 5.7.2c)1) per } \\
\text { LP-SIII.10Q-BSC REV. 0/ICN 0. }\end{array}$ \\
\hline
\end{tabular}




\section{CONTENTS}

Page

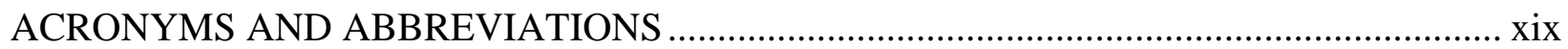

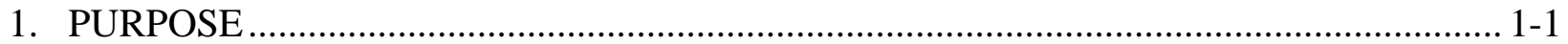

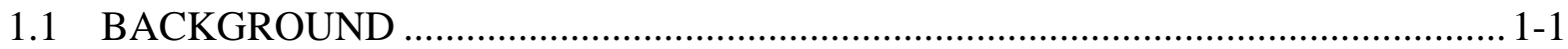

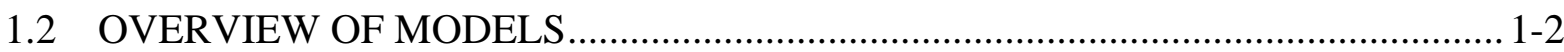

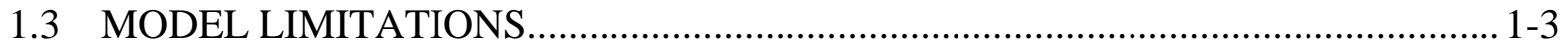

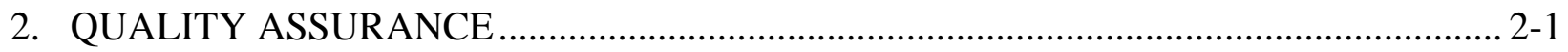

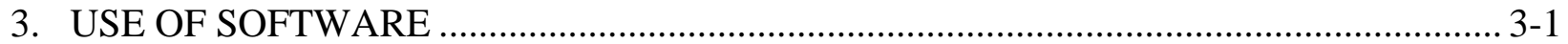

3.1 QUALIFIED SOFTWARE........................................................................... 3-1

3.2 EXEMPT SOFTWARE .....................................................................................

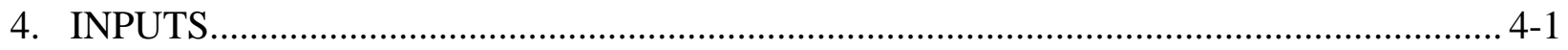

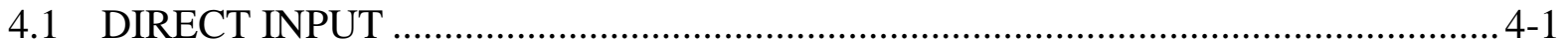

4.1.1 Hydrologic and Thermal Properties................................................................. 4-1

4.1.1.1 Fracture Tortuosity..................................................................... 4-3

4.1.1.2 Mean Infiltration Rates ................................................................. 4-3

4.1.1.3 Thermal Properties............................................................................. 4-5

4.1.1.4 Effective Thermal Conductivities for In-Drift Open Spaces .............. 4-5

4.1.2 Mineralogical Data..................................................................................... 4-6

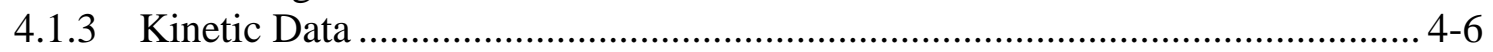

4.1.4 Thermodynamic Data......................................................................... 4-8

4.1.5 Water and Gas Chemistry …………………............................................ 4-10

4.1.6 Tptpll THC Model Grid........................................................................ 4-12

4.1.7 Design Information ............................................................................ 4-14

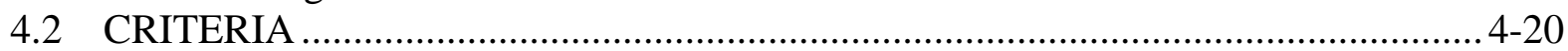

4.3 CODES, STANDARDS, AND REGULATIONS ............................................... 4-26

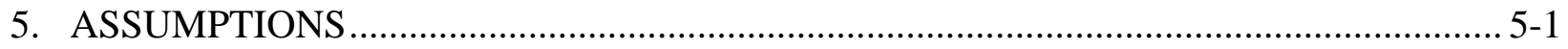

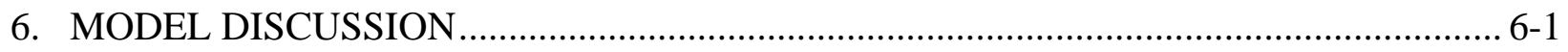

6.1 RELEVANT FEATURES, EVENTS, AND PROCESSES ...................................... 6-3

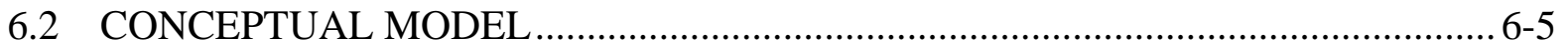

6.2.1 Conceptualization of Coupled THC Processes ..................................................... 6-5

6.2.1.1 TH Processes....................................................................................6-6

6.2.1.2 THC Processes ............................................................................. 6-7

6.2.1.3 Effects of Infiltration and Climate Changes on THC Processes...... 6-10

6.2.1.4 Hydrologic Property Changes in Fractures and Matrix .................... 6-10

6.2.1.5 Dual-Permeability Model for THC Processes ................................. 6-10

6.2.2 Conceptualization of the Geochemical System ............................................. 6-11

6.2.2.1 Initial Pore-Water and Pore-Gas Chemistry ..................................... 6-11

6.2.2.2 Geochemical Systems ................................................................... 6-18 


\section{CONTENTS (Continued)}

6.2.3 Conceptualization of the Model Domain........................................................ 6-19

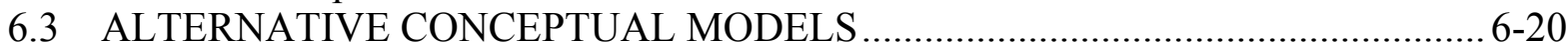

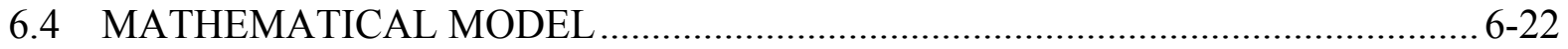

6.4.1 General Numerical Model for Coupled THC Processes................................... 6-23

6.4.2 Kinetic Rate Laws.......................................................................... 6-25

6.4.3 Fracture and Matrix Mineral Reactive Surface Areas .................................... 6-27

6.4.3.1 Fracture Mineral Reactive Surface Areas ..................................... 6-27

6.4.3.2 Matrix Mineral Reactive Surface Areas ………………………...... 6-29

6.4.4 Effects of Mineral Precipitation/Dissolution on Hydrologic Properties......... 6-29

6.4.4.1 Porosity Changes ........................................................................ 6-29

6.4.4.2 Fracture Permeability Changes ........................................................ 6-29

6.4.4.3 Matrix Permeability Changes ............................................................ 6-31

6.4.4.4 Effects of Permeability and Porosity Changes on Capillary Pressures .............................................................................. 6-31

6.4.5 Mineral Precipitation in Dry Grid Blocks....................................................... 6-31

6.4.6 Principal Model Approximations and Approaches....................................... 6-32

6.4.7 Summary of Hydrologic and Thermal Properties ........................................ 6-36

6.4.8 Thermodynamic Data Sensitivity .......................................................... 6-37

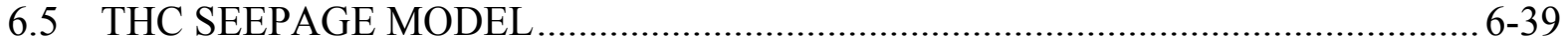

6.5.1 Numerical Mesh (Tptpll) ...................................................................... 6-40

6.5.2 Boundary Conditions ............................................................................... 6-44

6.5.3 Input Data and Modeling Procedure ......................................................... 6-45

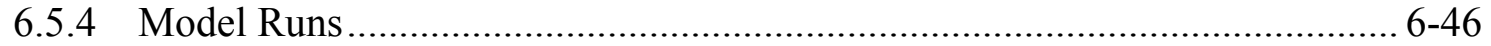

6.5.5 Simulation Results (THC Seepage Model; Tptpll Unit)............................... 6-47

6.5.5.1 TH Results (No Chemical Reactions)............................................. 6-48

6.5.5.2 Water Chemistry Trends ............................................................. 6-55

6.5.5.2.1 Drift Wall Results ..................................................... 6-55

6.5.5.2.2 High-Liquid Saturation Zone above Drift Crown....... 6-70

6.5.5.3 Mineral Alteration and Porosity/Permeability Changes (Tptpll)..... 6-93

6.5.5.4 Simulations of Ambient Conditions (Thermodynamic Data

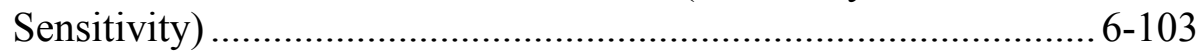

6.5.5.5 Sensitivity to Revised Matrix Porosity and Thermal Values......... 6-107

6.6 MODEL UNCERTAINTY ……………........................................................ 6-123

6.6.1 Potential Sources of Uncertainty ............................................................. 6-123

6.6.2 Evaluation of Model Result Uncertainty ................................................... 6-129

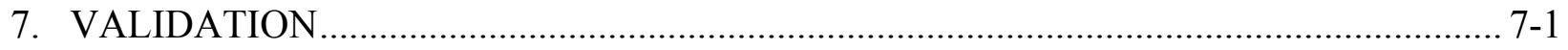

7.1 THE DRIFT SCALE TEST THC SUBMODEL ...................................................

7.1.1 Modeling Approach .............................................................................

7.1.2 Drift Scale Test Two-Dimensional Numerical Grid ...................................... 7-5

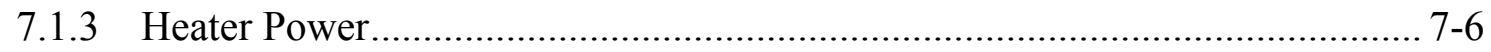

7.1.4 Hydrologic and Geochemical Input Data ………........................................ 7-10

7.1.5 Initial and Boundary Conditions: Hydrologic and Thermal ......................... 7-10

7.1.6 Initial and Boundary Conditions: Geochemical............................................ 7-11 


\section{CONTENTS (Continued)}

7.1.7 Model Validation Methods, Criteria, and Limitations................................... 7-11

7.1.7.1 Validation Method 1-Corroboration with Experimental Data ...... 7-11

7.1.7.2 Publication in a Refereed Technical Journal .................................. 7-14

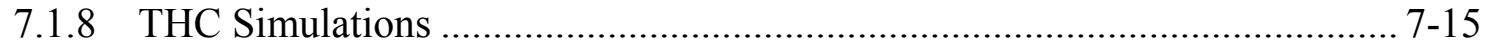

7.1.9 Simulation Results: Thermal and Hydrologic Evolution.............................. 7-16

7.1.10 Gas-Phase $\mathrm{CO}_{2}$ Evolution: Measured Compositions and Simulation

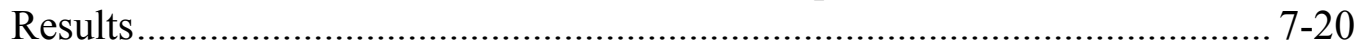

7.1.10.1 Gas Sampling and $\mathrm{CO}_{2}$ Measurements ………………………..... 7-20

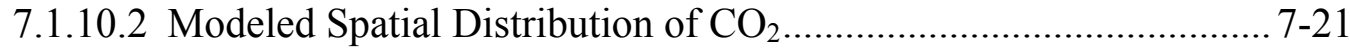

7.1.10.3 Modeled and Measured $\mathrm{CO}_{2}$ Concentrations over Time .................. 7-23

7.1.11 Aqueous Species Evolution .................................................................... 7-25

7.1.11.1 Chemistry of Waters Sampled During the Drift Scale Test............. 7-25

7.1.11.2 Evolution in the $\mathrm{pH}$ of Waters from the DST ................................ 7-34

7.1.11.3 Evolution of Anion and Cation Concentrations................................ 7-38

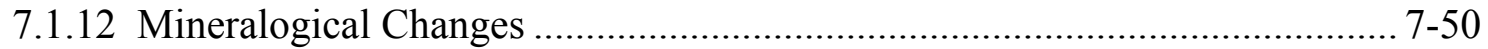

7.1.13 Porosity and Permeability Changes ........................................................ 7-57

7.1.14 Isotopic Compositions of Gases and Water: Model Corroboration Using

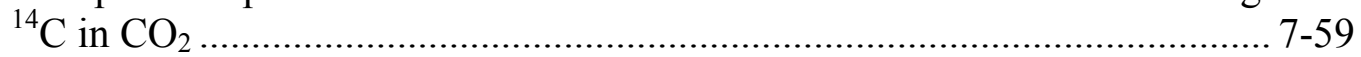

7.1.15 Summary of Model-Data Comparisons Using the Drift Scale Test ............... 7-62

7.2 SIMULATION OF THE PLUG-FLOW REACTOR EXPERIMENT ......................... 7-63

7.3 SIMULATION OF THE FRACTURE SEALING EXPERIMENT .......................... 7-64

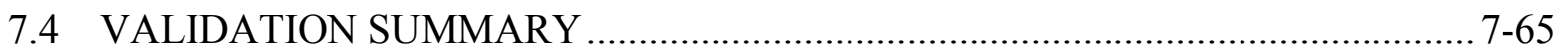

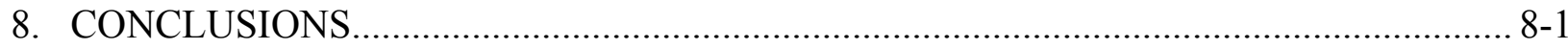

8.1 MODELED COUPLED PROCESSES AND UNCERTAINTY ……....................... $8-1$

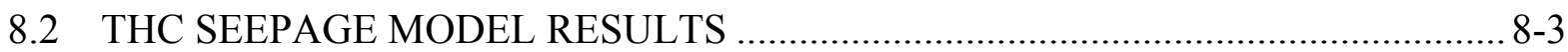

8.3 DST THC SUBMODEL RESULTS (VALIDATION) ……................................... 8-6

8.4 UNCERTAINTIES AND RESTRICTIONS FOR DOWNSTREAM USE ................. 8-7

8.5 DATA TRACKING NUMBERS FOR DATA GENERATED IN THIS REPORT .... 8-7

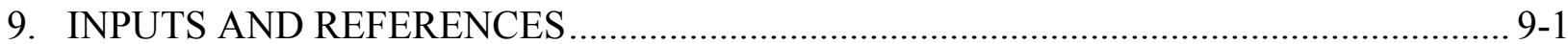

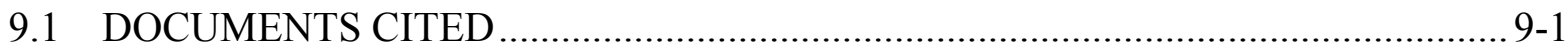

9.2 CODES, STANDARDS, REGULATIONS, AND PROCEDURES .......................... 9-13

9.3 SOURCE DATA, LISTED BY DATA TRACKING NUMBER ……………...........9-13

9.4 OUTPUT DATA, LISTED BY DATA TRACKING NUMBER ……………..........9-18

9.5 SOFTWARE CODES ………………………................................................

APPENDIX A: MINERAL INITIAL VOLUME FRACTIONS …………………............... A-1

APPENDIX B: MINERAL REACTIVE SURFACE AREAS …………………………............

APPENDIX C： THERMODYNAMIC DATABASE ………………………………...............

APPENDIX D: WASTE PACKAGE AVERAGE HEAT TRANSFER ................................... D-1 


\section{CONTENTS (Continued)}

APPENDIX E: EFFECTIVE THERMAL CONDUCTIVITY FOR IN-DRIFT OPEN SPACES

APPENDIX F： PARAMETERS FOR FRACTURE PERMEABILITY MODIFICATION....F-1

APPENDIX G: LIST OF MODEL INPUT AND OUTPUT FILES. G-1

APPENDIX H: QUALIFICATION OF MINERAL DISSOLUTION/PRECIPITATION KINETICS DATA FOR USE IN THC COUPLED PROCESS MODELING H-1

APPENDIX I: QUALIFICATION OF IN-DRIFT CONFIGURATION, DIMENSIONS, AND COMPONENT PROPERTIES 


\section{FIGURES}

Page

4.1-1. Sketch Showing Modeled In-Drift Dimensions..................................................... 4-19

6.2-1. Schematic Diagram of THC Processes around a Heated Drift ................................... 6-7

6.2-2. Schematic Diagram of Fracture-Matrix Interface Showing the Relation Between TH Processes and Geochemical Processes .................................................................... 6-8

6.2-3. Conceptual Model (Schematic) for Reaction-Transport Processes in Dual-Permeability Media................................................................................. 6-11

6.2-4. Piper Plot of Water Compositions (meq/L) from Repository Units ........................ 6-16

6.5-1. THC Model Mesh with Hydrogeologic Units Shown in the Vicinity of the Drift: Topopah Spring Tuff Middle Nonlithophysal (tsw34 - triangles), Lower Lithophysal (tsw35-dots), and Lower Nonlithophysal (tsw36-diamonds) Units....

6.5-2. Discretization of the Repository Drift in the THC Model ..................................... 6-43

6.5-3. TH Simulation (Tptpll): Time Profiles of Modeled Temperatures in Fractures . 6-49

6.5-4. TH Simulation (Tptpll): Time Profiles of Modeled Temperatures in Fractures at Three Drift-Wall Locations.

6.5-5. TH Simulation (Tptpll): Contour Plot of Modeled Temperatures $\left({ }^{\circ} \mathrm{C}\right)$ and Liquid Saturations in the Matrix and Fractures at 600 Years (Near the Time of Maximum Dryout in Fractures)

6.5-6. TH Simulation (Tptpll): Time Profiles of Modeled Liquid Saturations in Fractures at Three Drift-Wall Locations.

6.5-7. TH Simulation (Tptpll): Time Profiles of Modeled Liquid Saturations in Matrix at Three Drift-Wall Locations.

6.5-8. TH Simulation (Tptpll): Time Profiles of Modeled Air Mass Fractions in the Gas Phase in Fractures at Three Drift-Wall Locations ....

6.5-9. TH Simulation (Tptpll): Time Profiles of Modeled Water Flux at the Drift Crown......

6.5-10. THC Seepage Model (Tptpll): Time Profiles of Modeled Temperatures at Three Drift-Wall Locations with and without Water-Vapor-Pressure Lowering (eos4 and eos3, Respectively)

6.5-11. THC Seepage Model (Tptpll): Time Profiles of Modeled $\mathrm{CO}_{2}$ Concentrations in the Gas Phase in Fractures at Three Drift-Wall Locations under Heating (Heat) and Non-Heating (Ambient) Conditions, Including (eos4) and Excluding (eos3) Water-Vapor-Pressure Lowering

6.5-12. THC Seepage Model (Tptpll): Time Profiles of the Modeled pH of Fracture Water at Three Drift-Wall Locations under Heating (Heat) and Non-Heating (Ambient) Conditions, Including (eos4) and Excluding (eos3) Water-VaporPressure Lowering

6.5-13. THC Seepage Model (Tptpll): Time Profiles of Modeled Total Aqueous Carbonate Concentrations (as $\mathrm{HCO}_{3}^{-}$) in Fracture Water at Three Drift-Wall Locations, under Heating (Heat) and Non-Heating (Ambient) Conditions, Including (eos4) and Excluding (eos3) Water-Vapor-Pressure Lowering .... 


\section{FIGURES (Continued)}

Page

6.5-14. THC Seepage Model (Tptpll): Time Profiles of Modeled Total Aqueous Calcium Concentrations in Fracture Water at Three Drift-Wall Locations, under Heating (Heat) and Non-Heating (Ambient) Conditions, Including (eos4) and Excluding (eos3) Water-Vapor-Pressure Lowering.

6.5-15. THC Seepage Model (Tptpll): Time Profiles of Modeled Total Aqueous Sodium Concentrations in Fracture Water at Three Drift-Wall Locations, under Heating (Heat) and Non-Heating (Ambient) Conditions, Including (eos4) and Excluding (eos3) Water-Vapor-Pressure Lowering.

6.5-16. THC Seepage Model (Tptpll): Time Profiles of Modeled Total Aqueous Silica Concentrations in Fracture Water at Three Drift-Wall Locations, under Heating (Heat) and Non-Heating (Ambient) Conditions, Including (eos4) and Excluding (eos3) Water-Vapor-Pressure Lowering

6.5-17. THC Seepage Model (Tptpll): Time Profiles of Modeled Total Aqueous Chloride Concentrations in Fracture Water at Three Drift-Wall Locations, under Heating (Heat) and Non-Heating (Ambient) Conditions, Including (eos4) and Excluding (eos3) Water-Vapor-Pressure Lowering.

6.5-18. THC Seepage Model (Tptpll): Time Profiles of Modeled Total Fluoride Concentrations in Fracture Water at Three Drift-Wall Locations, under Heating (Heat) and Non-Heating (Ambient) Conditions, Including (eos4) and Excluding (eos3) Water-Vapor-Pressure Lowering

6.5-19. THC Seepage Model (Tptpll): Time Profiles of Modeled Total Nitrate Concentrations in Fracture Water at Three Drift-Wall Locations, under Heating (Heat) and Non-Heating (Ambient) Conditions, Including (eos4) and Excluding (eos3) Water-Vapor-Pressure Lowering

6.5-20. THC Seepage Model (Tptpll): Time Profiles of Modeled Total Nitrate to Chloride Ratio at Three Drift-Wall Locations, under Heating (Heat) and Non-Heating (Ambient) Conditions, Including (eos4) and Excluding (eos3) Water-Vapor-Pressure Lowering

6.5-21. THC Seepage Model (Tptpll): Location of Model Grid Blocks for Data Shown on Figures 6.5-22 through 6.5-37, for Each Time When Model Output Is Produced

6.5-22. THC Seepage Model (Tptpll): Time Profiles of Modeled Temperatures in Fracture Water in Areas of Highest Liquid Saturation above the Drift Crown

6.5-23. THC Seepage Model (Tptpll): Time Profiles of Modeled Liquid Saturations in Fracture Water in Areas of Highest Liquid Saturation above the Drift Crown

6.5-24. THC Seepage Model (Tptpll): Time Profiles of Modeled $\mathrm{CO}_{2} \mathrm{Gas}$ Concentrations in Fracture Water in Areas of Highest Liquid Saturation above the Drift Crown

6.5-25. THC Seepage Model (Tptpll): Time Profiles of Modeled pH in Fracture Water in Areas of Highest Liquid Saturation above the Drift Crown

6.5-26. THC Seepage Model (Tptpll): Time Profiles of Modeled Total Aqueous Carbonate Concentrations (as $\mathrm{HCO}_{3}$ ) in Fracture Water in Areas of Highest Liquid Saturation above the Drift Crown 


\section{FIGURES (Continued)}

Page

6.5-27. THC Seepage Model (Tptpll): Time Profiles of Modeled Total Aqueous Chloride Concentrations in Fracture Water in Areas of Highest Liquid Saturation above the Drift Crown

6.5-28. THC Seepage Model (Tptpll): Time Profiles of Modeled Total Aqueous Nitrate Concentrations in Fracture Water in Areas of Highest Liquid Saturation above the Drift Crown

6.5-29. THC Seepage Model (Tptpll): Time Profiles of Modeled Total Aqueous Calcium Concentrations in Fracture Water in Areas of Highest Liquid Saturation above the Drift Crown

6.5-30. THC Seepage Model (Tptpll): Time Profiles of Modeled Total Aqueous Calcium to Chloride Ratios in Fracture Water in Areas of Highest Liquid Saturation above the Drift Crown

6.5-31. THC Seepage Model (Tptpll): Time Profiles of Modeled Total Aqueous Sodium Concentrations in Fracture Water in Areas of Highest Liquid Saturation above the Drift Crown

6.5-32. THC Seepage Model (Tptpll): Time Profiles of Modeled Total Aqueous Sodium to Chloride Ratios in Fracture Water in Areas of Highest Liquid Saturation above the Drift Crown

6.5-33. THC Seepage Model (Tptpll): Time Profiles of Modeled Total Aqueous Calcium to Carbonate Ratios in Fracture Water in Areas of Highest Liquid Saturation above the Drift Crown.

6.5-34. THC Seepage Model (Tptpll): Time Profiles of Modeled Total Aqueous Nitrate to Chloride Ratios in Fracture Water in Areas of Highest Liquid Saturation above the Drift Crown

6.5-35. THC Seepage Model (Tptpll): Time Profiles of Modeled Total Aqueous Magnesium Concentrations in Fracture Water in Areas of Highest Liquid Saturation above the Drift Crown

6.5-36. THC Seepage Model (Tptpll): Time Profiles of Modeled Total Aqueous Silica Concentrations in Fracture Water in Areas of Highest Liquid Saturation above the Drift Crown

6.5-37. THC Seepage Model (Tptpll): Time Profiles of Modeled Total Aqueous Fluoride Concentrations in Fracture Water in Areas of Highest Liquid Saturation above the Drift Crown

6.5-38. TH Simulation (Tptpll): Contour Plot of Modeled Liquid Saturation and Temperature Contours $\left({ }^{\circ} \mathrm{C}\right.$ ) in Fractures at 2,400 Years (No Chemical Reactions)

6.5-39. THC Simulation (Tptpll - Water W0): Contour Plot of Modeled (a) Liquid Saturation and Temperature Contours $\left({ }^{\circ} \mathrm{C}\right)$ and (b) Permeability Change in Fractures at 2,400 Years

6.5-40. THC Simulation (Tptpll - Water W5): Contour Plot of Modeled (a) Liquid Saturation and Temperature Contours $\left({ }^{\circ} \mathrm{C}\right)$ and (b) Permeability Change in Fractures at 2,400 Years

6.5-41. TH Simulations and THC Seepage Model (Tptpll): Comparison of Modeled Liquid Flux at the Drift Crown in Fractures at 2,400 Years $6-98$ 


\section{FIGURES (Continued)}

Page

6.5-42. THC Seepage Model (Tptpll): Vertical Profile of Predicted Mineral Abundances above the Drift Crown.

6.5-43. THC Seepage Model (Tptpll): Vertical Profile of Predicted Mineral Abundances above the Drift Crown................................................................... 6-100

6.5-44. THC Seepage Model (Tptpll): Vertical Profile of Predicted Mineral Abundances above the Drift Crown

6.5-45. THC Seepage Model (Tptpll): Vertical Profile of Predicted Mineral Abundances above the Drift Crown

6.5-46. Predicted Water Compositions without Thermal Loading (in the Tptpll Lithostratigraphic Unit at the Repository Location) Using the Thermodynamic Data Adopted for this Study (Data Set 1 - Appendix C)...

6.5-47. Predicted Water Compositions without Thermal Loading (in the Tptpll Lithostratigraphic Unit at the Repository Location) Using Thermodynamic Data from Data Set 2 (Section 6.4.8)

6.5-48. Predicted Water Compositions without Thermal Loading (in the Tptpll Lithostratigraphic Unit at the Repository Location) Using Thermodynamic Data from Data Set 3 (Section 6.4.8)

6.5-49. TH Simulation (Revised vs. Original Properties): Time Profiles of Modeled Temperatures in Fractures at Three Drift-Wall Locations.

6.5-50. TH Simulation (Revised vs. Original Properties): Time Profiles of Modeled Liquid Saturations in Fractures at Three Drift-Wall Locations

6.5-51. TH Simulation (Revised vs. Original Properties): Time Profiles of Modeled Liquid Saturations in Matrix at Three Drift-Wall Locations

6.5-52. TH Simulation (Revised vs. Original Properties): Time Profiles of Modeled Air Mass Fractions in the Gas Phase in Fractures at Three Drift-Wall Locations

6.5-53. TH Simulation (Revised vs. Original Properties): Time Profiles of Modeled Downward Water Flux at the Drift Crown

6.5-54. THC Simulations (Revised vs. Original Properties): Location of Model Grid Blocks for Data Shown on Figures A-7 through A-22, for Each Time When Model Output Is Produced

6.5-55. THC Simulations (Revised vs. Original Properties): Time Profiles of Modeled Temperatures in Fractures in Areas of Highest Liquid Saturation above the Drift Crown

6.5-56. THC Simulations (Revised vs. Original Properties): Time Profiles of Modeled Liquid Saturations in Fractures in Areas of Highest Liquid Saturation above the Drift Crown.

6.5-57. THC Simulations (Revised vs. Original Properties): Time Profiles of Modeled $\mathrm{CO}_{2}$ Gas Concentrations in Fractures in Areas of Highest Liquid Saturation above the Drift Crown

6.5-58. THC Simulations (Revised vs. Original Properties): Time Profiles of Modeled $\mathrm{pH}$ in Fracture Water in Areas of Highest Liquid Saturation above the Drift Crown. 


\section{FIGURES (Continued)}

Page

6.5-59. THC Simulations (Revised vs. Original Properties): Time Profiles of Modeled Total Aqueous Carbonate Concentrations in Fracture Water in Areas of Highest Liquid Saturation above the Drift Crown

6.5-60. THC Simulations (Revised vs. Original Properties): Time Profiles of Modeled Total Aqueous Chloride Concentrations in Fracture Water in Areas of Highest Liquid Saturation above the Drift Crown

6.5-61. THC Simulations (Revised vs. Original Properties): Time Profiles of Modeled Total Aqueous Nitrate Concentrations in Fracture Water in Areas of Highest Liquid Saturation above the Drift Crown

6.5-62. THC Simulations (Revised vs. Original Properties): Time Profiles of Modeled Total Aqueous Sulfate Concentrations in Fracture Water in Areas of Highest Liquid Saturation above the Drift Crown

6.5-63. THC Simulations (Revised vs. Original Properties): Time Profiles of Modeled Total Aqueous Fluoride Concentrations in Fracture Water in Areas of Highest Liquid Saturation above the Drift Crown

6.5-64. THC Simulations (Revised vs. Original Properties): Time Profiles of Modeled Total Aqueous Calcium Concentrations in Fracture Water in Areas of Highest Liquid Saturation above the Drift Crown

6.5-65. THC Simulations (Revised vs. Original Properties): Time Profiles of Modeled Total Aqueous Calcium to Carbonate Concentration Ratios in Fracture Water in Areas of Highest Liquid Saturation above the Drift Crown

6.5-66. THC Simulations (Revised vs. Original Properties): Time Profiles of Modeled Total Aqueous Magnesium Concentrations in Fracture Water in Areas of Highest Liquid Saturation above the Drift Crown

6.5-67. THC Simulations (Revised vs. Original Properties): Time Profiles of Modeled Total Aqueous Sodium Concentrations in Fracture Water in Areas of Highest Liquid Saturation above the Drift Crown

6.5-68. THC Simulations (Revised vs. Original Properties): Time Profiles of Modeled Total Aqueous Sodium to Chloride Concentration Ratios in Fracture Water, in Areas of Highest Liquid Saturation above the Drift Crown

6.5-69. THC Simulations (Revised vs. Original Properties): Time Profiles of Modeled Total Aqueous Potassium Concentrations in Fracture Water in Areas of Highest Liquid Saturation above the Drift Crown

6.5-70. THC Simulations (Revised vs. Original Properties): Time Profiles of Modeled Total Aqueous Silica Concentrations in Fracture Water in Areas of Highest Liquid Saturation above the Drift Crown

7.1-1. Three-Dimensional Schematic Diagram of the DST Showing Perspective View of Numerical Mesh for DST THC Submodel Simulations

7.1-2. Numerical Mesh for DST THC Submodel Simulations

7.1-3. Enlarged View of the Numerical Grid Showing the Locations of Grid Blocks Representing the Heated Drift, Wing Heaters, and Concrete Invert. $7-8$

7.1-4. Locations of Hydrology Boreholes, Sampling Intervals (Numbered) and Temperature Sensors 


\section{FIGURES (Continued)}

Page

7.1-5. Drift Center and Drift Crown Modeled Temperatures over the First Six Years of

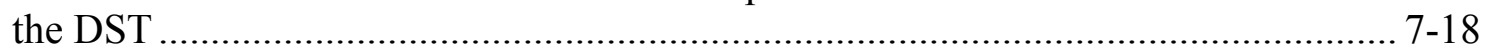

7.1-6. Comparison of Modeled and Measured Temperatures over Time for the Sensor Located at Hydrology Borehole Packer 60-4 ........................................................ 7-18

7.1-7. Liquid Saturation (Colors) and Temperature (Contour Lines) in the DST (Base Case) at One Year (Matrix - a, Fracture - b) and at Four Years (Matrix - c,

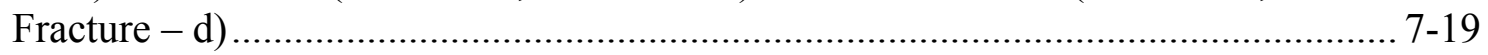

7.1-8. Measured Concentrations of $\mathrm{CO}_{2}(\log$ vol. fraction) in Gas Phase around the DST at 1 Year and at 15 Months

7.1-9. Modeled Gas Phase $\mathrm{CO}_{2}$ Concentrations (Log ppmv) in Fractures during the Heating Phase of the DST at 1, 2, 3, and 4 Years.

7.1-10. Modeled Gas Phase $\mathrm{CO}_{2}$ Concentrations (Log ppmv) in Fractures during the Cooling Phase of the DST at 5, 6, 7, and 8 Years

7.1-11. Close-Up of DST Grid, Showing Nodes Used to Extract Model Data for Comparison to Concentrations Measured in Gas Samples

7.1-12. Comparison of Modeled $\mathrm{CO}_{2}$ Concentrations in Fractures to Measured (Corrected) Concentrations in Boreholes: (a) Borehole Interval 74-3 (Average of Bounding Grid Blocks); (b) Borehole Interval 75-3; (c) Borehole Interval 76-3

7.1-13. Comparison of Measured and Corrected Concentrations for Borehole Interval 75-3 and the Model Simulation Results

7.1-14 Zones Where Water Was Collected from Hydrology Boreholes Superimposed (Thick Shading in Blue) on the Model Grid

7.1-15. Modeled Distribution of $\mathrm{pH}$ in Fractures at Various Times When Water Was Sampled from Hydrology Borehole Intervals: (a) 6 Months, (b) 11 Months, and (c) 14 Months

7.1-16. Comparison of Measured $\mathrm{pH}$ in Water Samples Collected from Borehole Intervals (a) 60-3, (b) 59-2, and (c) 76-3 to the Modeled Fracture Water pH at Representative Model Grid Blocks.....

7.1-17. Modeled Distribution of $\mathrm{Cl}^{-}$in Fractures and Matrix at One and Four Years during the Heating Phase of the DST: (a) Fracture-1 Year, (b) Matrix-1 Year, (c) Fracture-4 Years, and (d) Matrix - 4 Years

7.1-18. $\mathrm{Cl}^{-}$Concentrations $(\mathrm{mg} / \mathrm{L})$ in Water Samples Collected from Borehole Intervals (a) 60-3, (b) 59-2, and (c) 76-3 Compared to the Modeled Fracture Water $\mathrm{Cl}^{-}$ $7-40$

7.1-19. $\mathrm{SO}_{4}{ }^{2-}$ Concentrations $(\mathrm{mg} / \mathrm{L})$ in Water Samples Collected from Borehole Intervals (a) 60-3, (b) 59-2, and (c) 76-3 Compared to the Modeled Fracture Water $\mathrm{SO}_{4}^{2-}$

7.1-20. $\mathrm{Na}^{+}$Concentrations ( $\mathrm{mg} / \mathrm{L}$ ) in Water Samples Collected from Borehole Intervals (a) 60-3, (b) 59-2, and (c) 76-3 the Modeled $\mathrm{Na}^{+}$Concentrations in Fractures

7.1-21. $\mathrm{Ca}^{2+}$ Concentrations ( $\left.\mathrm{mg} / \mathrm{L}\right)$ in Water Samples Collected from Borehole Intervals (a) 60-3, (b) 59-2, and (c) 76-3 Compared to the Modeled $\mathrm{Ca}^{2+}$ in Fracture Water 


\section{FIGURES (Continued)}

Page

7.1-22. $\mathrm{SiO}_{2 \text { (aq) }}$ Concentrations $(\mathrm{mg} / \mathrm{L})$ in Water Samples Collected from Borehole Intervals (a) 60-3, (b) 59-2, and (c) 76-3 Compared to Modeled Fracture Water $\mathrm{SiO}_{2(\mathrm{aq})}$ Concentrations

7.1-23. $\mathrm{K}^{+}$Concentrations $(\mathrm{mg} / \mathrm{L})$ in Water Samples Collected from Borehole Intervals (a) 60-3, (b) 59-2, and (c) 76-3 Compared to Modeled Fracture Water $\mathrm{K}^{+}$ Concentrations

7.1-24. $\mathrm{HCO}_{3}{ }^{-}$Concentrations $(\mathrm{mg} / \mathrm{L})$ in Water Samples Collected from Borehole Intervals (a) 60-3, (b) 59-2, and (c) 76-3 Compared to the Modeled Fracture Water $\mathrm{HCO}_{3}{ }^{-}$Concentrations

7.1-25. $\mathrm{Mg}^{2+}$ Concentrations (mg/L) in Water Samples Collected from Borehole Intervals (a) 60-3, (b) 59-2, and (c) 76-3 Compared to the Modeled Fracture Water $\mathrm{Mg}^{2+}$ Concentrations

7.1-26. $\mathrm{NO}_{3}{ }^{-}$Concentrations ( $\mathrm{mg} / \mathrm{L}$ ) in Water Samples Collected from Borehole Intervals (a) 60-3, (b) 59-2, and (c) 76-3 Compared to the Modeled Fracture Water $\mathrm{NO}_{3}^{-}$Concentrations

7.1-27. $\mathrm{F}^{-}$Concentrations $(\mathrm{mg} / \mathrm{L})$ in Water Samples Collected from Borehole Intervals (a) 60-3, (b) 59-2, and (c) 76-3 Compared to the Modeled Fracture Water FConcentrations

7.1-28. Modeled Volume Percent Change in Calcite in Fractures as of November 2000 (35 Months of Heating)

7.1-29. Modeled Volume Percent Amorphous Silica in Fractures as of November 2000 (35 Months of Heating)

7.1-30. Modeled Volume Percent Gypsum in Fractures as of November 2000

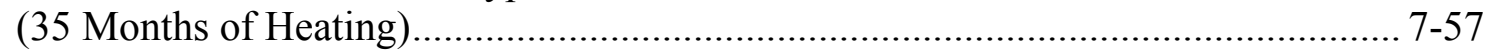

7.1-31. Change in Fracture Porosity after Four Years of Heating ……………………........ 7-58

7.1-32. Change in Matrix Porosity after Four Years of Heating .......................................... 7-59

7.1-33. Measured Activities of ${ }^{14} \mathrm{C}$ (Expressed as a Fraction of Modern Carbon) in $\mathrm{CO}_{2}$ from Gas Collected in Several Hydrology Boreholes over Most of the Heating Phase of the DST .

7.1-34. Measured Activities of ${ }^{14} \mathrm{C}$ (Expressed as a Fraction of Modern Carbon) Compared to Measured $\mathrm{CO}_{2}$ (Corrected for Water Vapor Removal) from Gas Collected in Some Hydrology Boreholes over Most of the Heating Phase of the DST.

8-1. Key Findings of the THC Seepage Model $8-4$ 


\section{INTENTIONALLY LEFT BLANK}




\section{TABLES}

Page

3-1. Qualified Software Used .............................................................................. 3-2

4.1-1. Sources of Hydrologic and Thermal Properties Used as Direct Input Data for the Drift-Scale Coupled-Processes Models That Feed TSPA-LA Activities ..................... 4-2

4.1-2. Average Infiltration Values (mm/yr) for Different Climate Periods .......................... 4-4

4.1-3. THC Model Kinetic Data.......................................................................................... 4-7

4.1-4. Input Pore-Water Compositions ................................................................... 4-11

4.1-5. Comparison of Adopted and Revised Values of Elevation and Thickness of Stratigraphic Layers for the THC Seepage Model (Tptpll Unit) ............................... 4-13

4.1-6. Drift and Committed Materials Model Parameters................................................... 4-16

4.2-1. Applicable Project Requirements and YMRP Acceptance Criteria ......................... 4-21

6-1. Summary of the Development of the THC Seepage Model ....................................... 6-1

6.1-1. Relevant Features, Events, and Processes Included in TSPA-LA .............................. 6-3

6.1-2. Relevant Features, Events, and Processes Excluded from TSPA-LA ........................ 6-5

6.2-1. Input Pore-Water Compositions for the THC Seepage Model ................................ 6-14

6.2-2. Mineral, Aqueous, and Gaseous Species Used in the THC Seepage Model ............. 6-19

6.4-1. Summary of Hydrologic and Thermal Properties of Repository Units .................... 6-38

6.5-1. Vertical Mesh Dimensions and Geologic Contacts in the THC Seepage Model

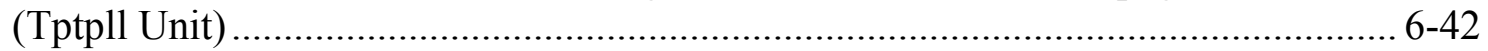

6.5-2. Tptpll THC Seepage Model (Tptpll Unit) Boundary Conditions ............................. 6-44

6.5-3. THC Seepage Model Infiltration Rates.............................................................. 6-45

6.5-4. Selected Input Waters (Section 6.2.2.1) for the Tptpll THC Seepage Model (Tptpll Unit) ................................................................................................... 6-45

6.5-5. THC Seepage Model Runs Using the Mean Infiltration Rock-Property Set for

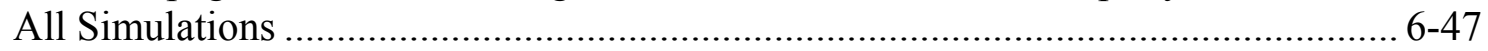

6.5-6. Tptpll THC Model Sensitivity Runs Using Revised Matrix Properties from Table 6.5-7

6.5-7. Summary of Revised and Original Rock Matrix Properties .................................. 6-108

6.6-1. Summary of Uncertainties Affecting Chemical Processes in the THC Seepage

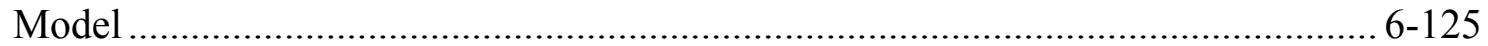

6.6-2. Standard Deviations in Water and Gas Compositions Predicted Using Five Different Input Water Compositions (W0, W4, W5, W6, and W7) ....................... 6-130

7-1. Sources of Data Used for Model Validation or Corroboration................................... 7-4

7.1-1. Input DTNs Used for Estimating Times/Dates of Power Reductions and Outages for DST THC Submodel Simulations............................................................ 7-8

7.1-2. Step-Wise Averaged Power Data for the DST THC Simulations ............................. 7-9

7.1-3. Measured Concentrations in Tptpmn Pore Water from Alcove 5 and Chemistry of Water Samples from Hydrology Boreholes....................................................... 7-29

8.5-1. Drift-Scale THC Seepage Model Output DTNs .............................................. 8-8 


\section{INTENTIONALLY LEFT BLANK}




\section{ACRONYMS AND ABBREVIATIONS}

BET Brunauer, Emmet, Teller (static volume method)

DST Drift Scale Test

DTN data tracking number

ECRB Enhanced Characterization of Repository Block

EOS Equation of State

ESF Exploratory Studies Facility

FEP feature, event, or process

$\mathrm{Kth}_{\max } \quad$ maximum thermal conductivity

LA license application

LBNL Lawrence Berkeley National Laboratory

MSTHM multiscale thermohydrologic model

NBS National Bureau of Standards

NRC U.S. Nuclear Regulatory Commission

QA Quality Assurance

TDMS Technical Data Management System

TH thermal-hydrologic

THC thermal-hydrologic-chemical

TSPA total system performance assessment

TWP technical work plan

UZ unsaturated zone

YMP Yucca Mountain Project

YMRP Yucca Mountain Review Plan

Major Hydrogeologic Units

PTn Paintbrush Tuff nonwelded hydrogeologic unit

TSw Topopah Spring welded hydrogeologic unit

TCw Tiva Canyon welded hydrogeologic unit

Tptpul Topopah Spring Tuff upper lithophysal zone

Tptpmn Topopah Spring Tuff middle nonlithophysal zone

Tptpll Topopah Spring Tuff lower lithophysal zone

Tptpln Topopah Spring Tuff lower nonlithophysal zone 


\section{Geologic and Model Layer Abbreviations}

\begin{tabular}{|c|c|c|c|c|c|c|}
\hline \multicolumn{5}{|c|}{ Stratigraphic Unit ${ }^{\mathrm{a}}$} & Abbreviation $^{a}$ & UZ Model Layer $^{\mathrm{b}}$ \\
\hline : & 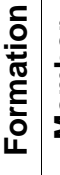 & 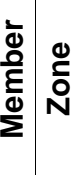 & 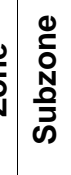 & & & \\
\hline \multicolumn{5}{|c|}{ Alluvium and Colluvium } & Qal, Qc & \\
\hline & & & & & & \\
\hline \multicolumn{5}{|c|}{ Timber Mountain Group } & $\mathrm{Tm}$ & \\
\hline \multicolumn{5}{|c|}{ Rainier Mesa Tuff } & Tmr & \\
\hline \multicolumn{5}{|c|}{ Paintbrush Group } & $\mathrm{Tp}$ & \\
\hline \multicolumn{5}{|c|}{ Post-tuff unit "x" bedded tuff } & Tpbt6 & \\
\hline \multicolumn{5}{|c|}{ Tuff unit "x" } & Tpki (informal) & \\
\hline \multicolumn{5}{|c|}{ Pre-tuff unit " $x$ " bedded tuff } & Tpbt5 & \\
\hline \multicolumn{5}{|c|}{ Tiva Canyon Tuff } & Tpc & \multirow{13}{*}{ tcw11 } \\
\hline \multicolumn{5}{|c|}{ Crystal-Rich Member } & Tpcr & \\
\hline & \multicolumn{4}{|c|}{ Vitric zone } & Tpcrv & \\
\hline & \multicolumn{4}{|c|}{ Nonwelded subzone } & Tpcrv3 & \\
\hline & \multicolumn{4}{|c|}{ Moderately welded subzone } & Tpcrv2 & \\
\hline & \multicolumn{4}{|c|}{ Densely welded subzone } & Tpcrv1 & \\
\hline & \multicolumn{4}{|c|}{ Nonlithophysal subzone } & Tpcrn & \\
\hline \multicolumn{5}{|r|}{ Subvitrophyre transition subzone } & Tpcrn4 & \\
\hline & & \multicolumn{3}{|c|}{ Pumice-poor subzone } & Tpcrn3 & \\
\hline & & \multicolumn{3}{|c|}{ Mixed pumice subzone } & Tpcrn2 & \\
\hline & & & \multicolumn{2}{|c|}{ Crystal transition subzone } & Tpcrn1 & \\
\hline & & \multicolumn{3}{|c|}{ Lithophysal zone } & Tpcrl & \\
\hline & & \multicolumn{3}{|c|}{ Crystal transition subzone } & Tpcrl1 & \\
\hline & \multicolumn{4}{|c|}{ Crystal-Poor Member } & Tpсp & \multirow{10}{*}{ tcw12 } \\
\hline & & \multicolumn{3}{|c|}{ Upper lithophysal zone } & Tpcpul & \\
\hline & & \multicolumn{3}{|c|}{ Spherulite-rich subzone } & Tpcpul1 & \\
\hline & & \multicolumn{3}{|c|}{ Middle nonlithophysal zone } & Tpcpmn & \\
\hline & & \multicolumn{3}{|c|}{ Upper subzone } & Tpcpmn3 & \\
\hline & & & Lith & ophysal subzone & Tpcpmn2 & \\
\hline & & \multicolumn{3}{|c|}{ Lower subzone } & Tpcpmn1 & \\
\hline & & & ower & lithophysal zone & Tpcpll & \\
\hline & & & $\mathrm{Hac}$ & ckly-fractured subzone & Tpcpllh & \\
\hline & & & ower & nonlithophysal zone & Tpcpln & \\
\hline
\end{tabular}




\section{Geologic and Model Layer Abbreviations (Continued)}

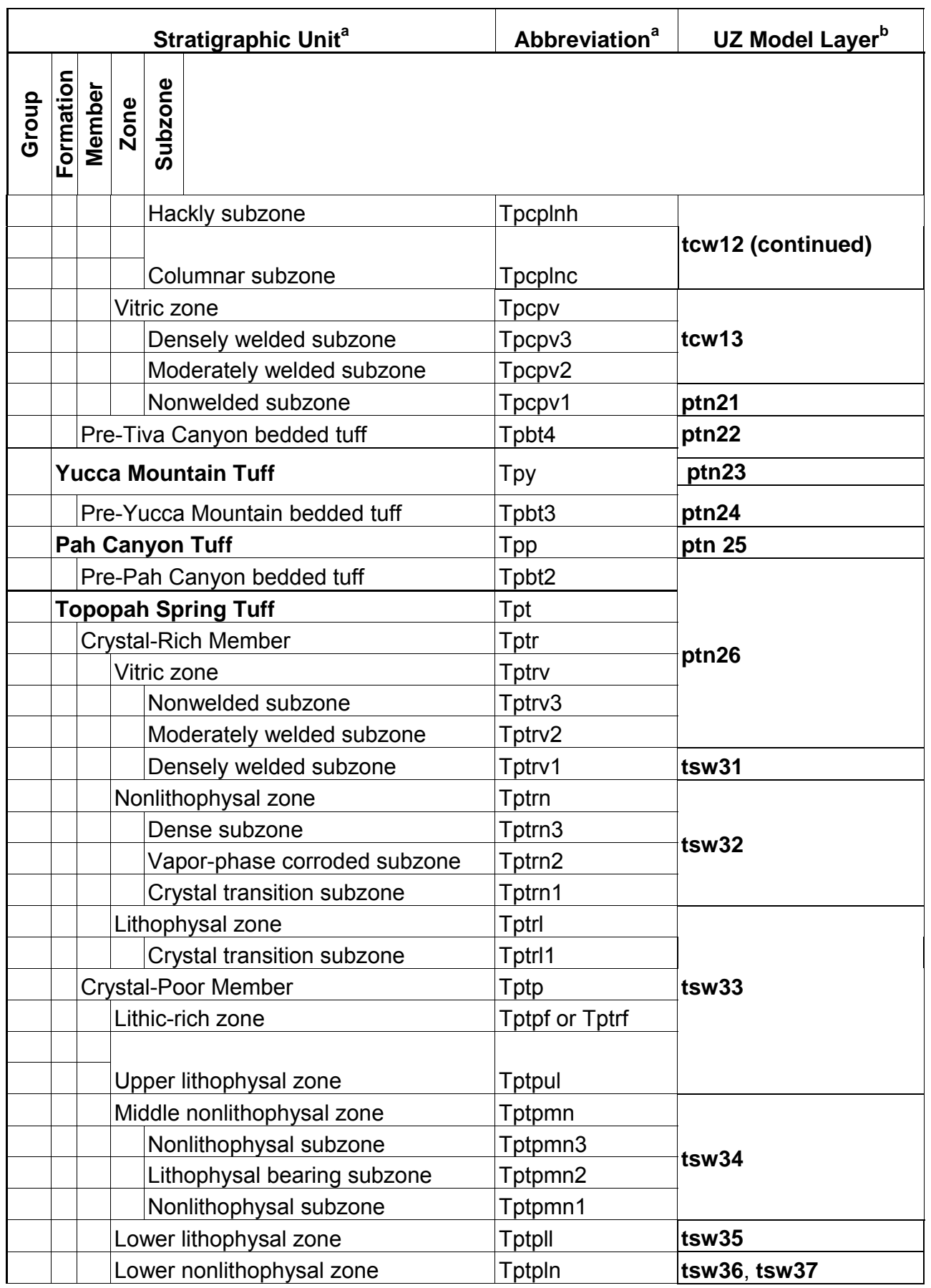




\section{Geologic and Model Layer Abbreviations (Continued)}

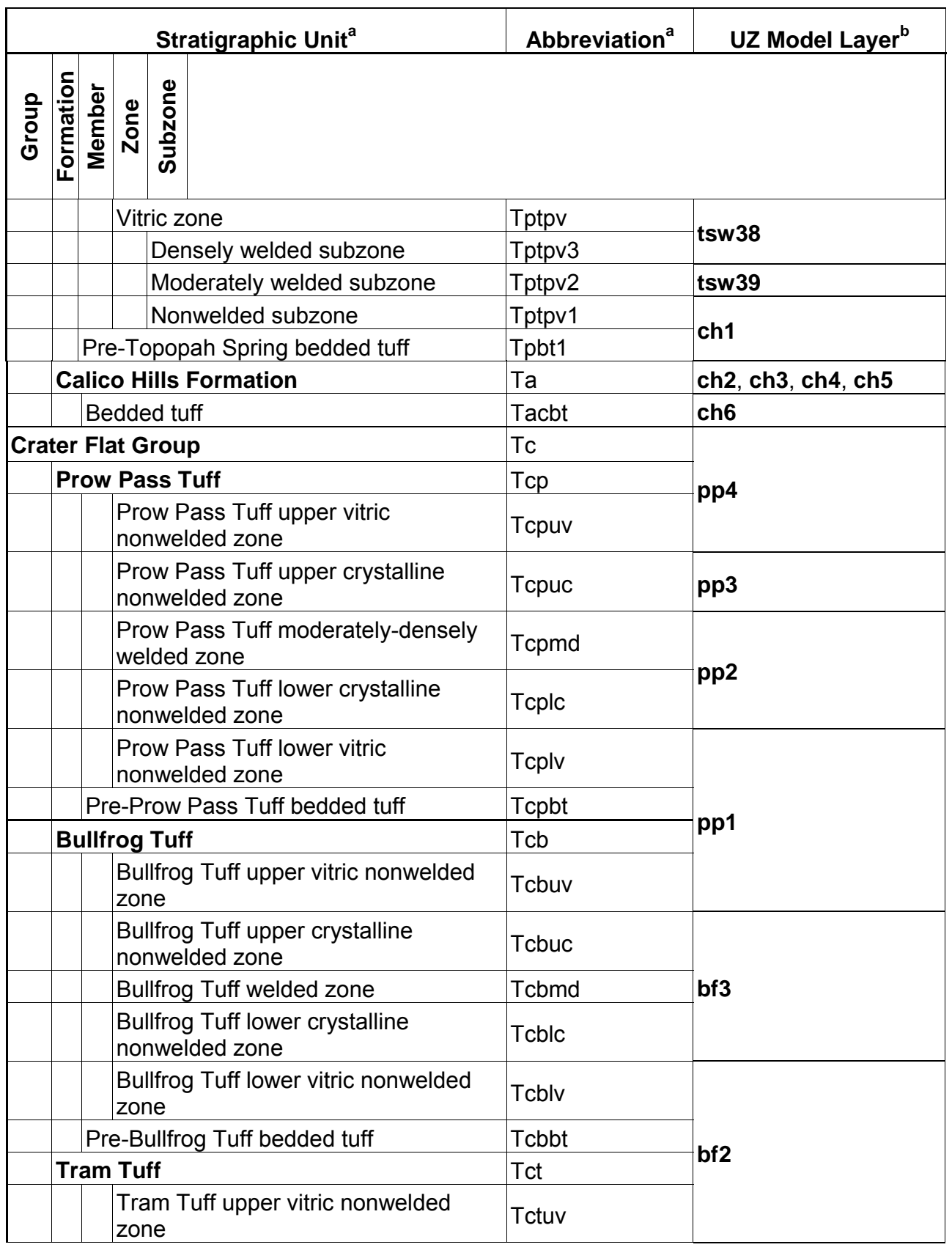




\section{Geologic and Model Layer Abbreviations (Continued)}

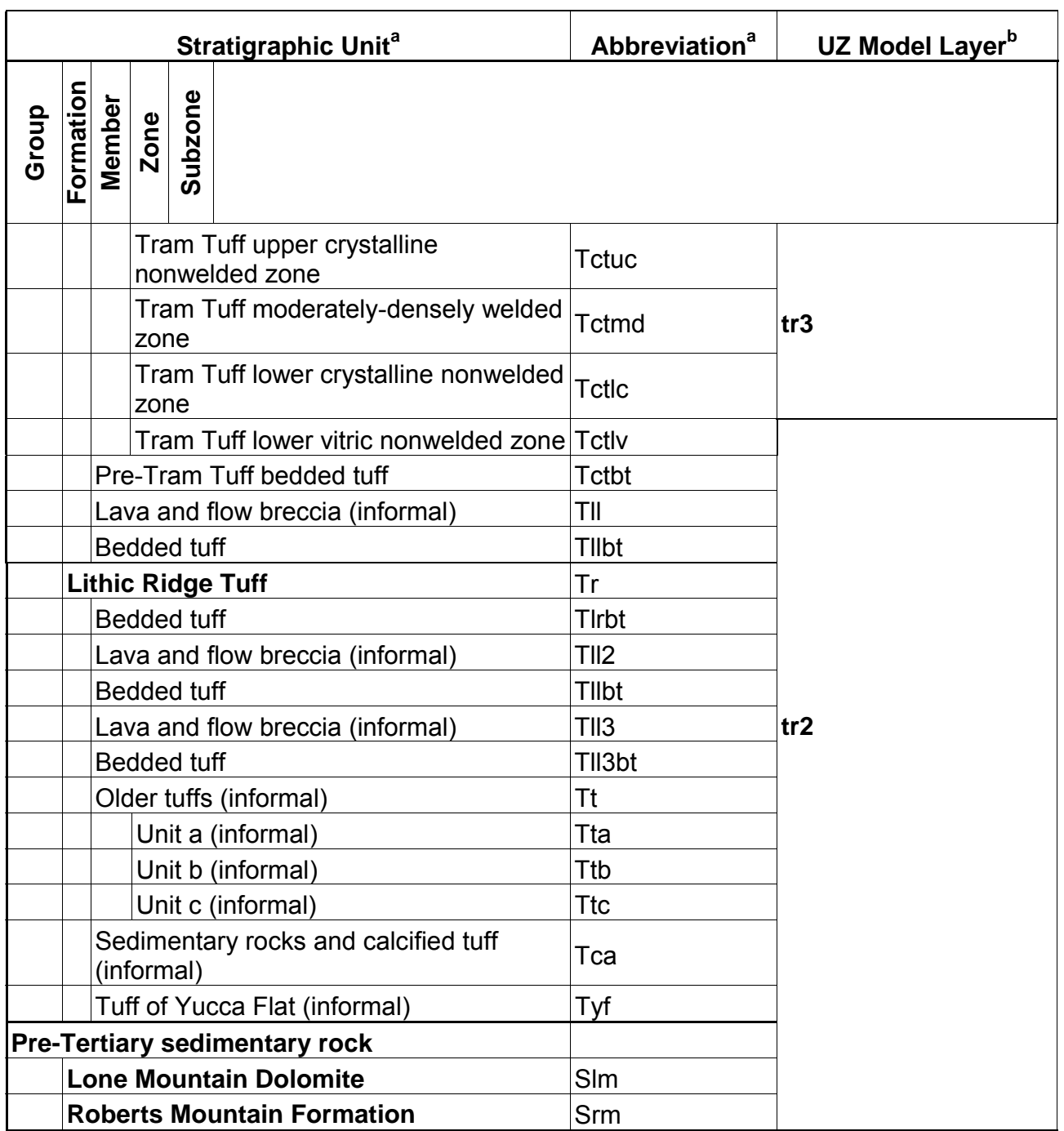

Sources: $\quad{ }^{a}$ BSC 2004 [DIRS 170029], Table 6-2

${ }^{\mathrm{b}}$ BSC 2004 [DIRS 169855], Table 6-5 


\section{CHEMICAL ABBREVIATIONS}

\section{Elements}

$\begin{array}{ll}\mathrm{Al} & \begin{array}{l}\text { Aluminum } \\ \mathrm{C}\end{array} \\ \mathrm{Ca} & \begin{array}{l}\text { Carbon } \\ \text { Calcium }\end{array} \\ \mathrm{Cl} & \begin{array}{l}\text { Chlorine } \\ \mathrm{F}\end{array} \\ \mathrm{Fe} & \text { Fluorine } \\ \mathrm{H} & \text { Iron } \\ \mathrm{K} & \text { Hydrogen } \\ \mathrm{Mg} & \text { Potassium } \\ \mathrm{N} & \text { Magnesium } \\ \mathrm{Na} & \text { Nitrogen } \\ \mathrm{O} & \text { Sodium } \\ \mathrm{S} & \text { Oxygen } \\ \mathrm{Si} & \text { Sulfur } \\ & \text { Silicon }\end{array}$

\section{Chemical Compounds, Aqueous Species, and Gases}

$\mathrm{AlO}_{2}{ }^{-} \quad$ Aluminum primary aqueous species (essentially same as $\mathrm{Al}(\mathrm{OH})_{4}{ }^{-}$); here used to describe total aqueous aluminum concentrations as $\mathrm{AlO}_{2}^{-}$

$\mathrm{CO}_{2} \quad$ Carbon dioxide gas

$\mathrm{H}_{2} \mathrm{O} \quad$ Water

$\mathrm{HCO}_{3}{ }^{-} \quad$ Bicarbonate aqueous species; used here to describe total aqueous carbon concentration

$\mathrm{HFeO}_{2}{ }^{0} \quad$ Iron primary aqueous species (essentially same as $\mathrm{Fe}(\mathrm{OH})_{3}{ }^{0}$; used here to describe total aqueous iron concentrations as $\mathrm{HFeO}_{2}{ }^{0}$

$\mathrm{K}_{2} \mathrm{SO}_{4} \quad$ Potassium sulfate (solid; mineral name: arcanite)

$\mathrm{MgSO}_{4} \quad$ Magnesium sulfate (solid)

$\mathrm{Na}_{2} \mathrm{SO}_{4} \quad$ Sodium sulfate (solid; mineral name: thenardite)

$\mathrm{NaCl}$ Sodium chloride (solid; mineral name: halite)

$\mathrm{NaNO}_{3} \quad$ Sodium nitrate (solid)

$\mathrm{NO}_{3}{ }^{-} \quad$ Nitrate aqueous species 


\section{CHEMICAL ABBREVIATIONS (Continued)}

$\mathrm{O}_{2} \quad$ Oxygen gas

$\mathrm{P}_{\mathrm{CO} 2} \quad$ Carbon dioxide partial pressure (in bars)

$\mathrm{pH} \quad$ Negative logarithm of the hydrogen ion activity

$\mathrm{SiO}_{2} \quad$ Silica

$\mathrm{SO}_{4}{ }^{-2} \quad$ Sulfate aqueous species

\section{Chemical Units}

$\begin{array}{ll}\mathrm{meq} & \text { milliequivalent }\left(\mathrm{mol} \times 10^{3} \times \text { ionic charge }\right) \\ \mathrm{meq} / \mathrm{L} & \text { milliequivalent per liter of solution } \\ \mathrm{mg} / \mathrm{L} & \text { milligram per liter of solution } \\ \mathrm{mol} & \text { moles } \\ \mathrm{mol} / \mathrm{kg} & \text { moles per kilogram water (molality) } \\ & \\ \mathrm{ppm} & \text { parts per million } \\ \mathrm{ppmv} & \text { parts per million volume }\end{array}$




\section{INTENTIONALLY LEFT BLANK}




\section{PURPOSE}

\subsection{BACKGROUND}

The purpose of this report (REV04) is to document the thermal-hydrologic-chemical (THC) seepage model, which simulates the composition of waters that could potentially seep into emplacement drifts, and the composition of the gas phase. The THC seepage model is processed and abstracted for use in the total system performance assessment (TSPA) for the license application (LA).

This report has been developed in accordance with Technical Work Plan for: Near-Field Environment and Transport: Coupled Processes (Mountain-Scale TH/THC/THM, Drift-Scale THC Seepage, and Post-Processing Analysis for THC Seepage) Report Integration (BSC 2005 [DIRS 172761]). The technical work plan (TWP) describes planning information pertaining to the technical scope, content, and management of this report. The plan for validation of the models documented in this report is given in Section 2.2.2, "Model Validation for the DS THC Seepage Model," of the TWP. The TWP (Section 3.2.2) identifies Acceptance Criteria 1 to 4 for Quantity and Chemistry of Water Contacting Engineered Barriers and Waste Forms (NRC 2003 [DIRS 163274]) as being applicable to this report; however, in variance to the TWP, Acceptance Criterion 5 has also been determined to be applicable, and is addressed, along with the other Acceptance Criteria, in Section 4.2 of this report. Also, three FEPS not listed in the TWP (2.2.10.01.0A, 2.2.10.06.0A, and 2.2.11.02.0A) are partially addressed in this report, and have been added to the list of excluded FEPS in Table 6.1-2.

This report has been developed in accordance with LP-SIII.10Q-BSC, Models.

This report documents the THC seepage model and a derivative used for validation, the Drift Scale Test (DST) THC submodel. The THC seepage model is a drift-scale process model for predicting the composition of gas and water that could enter waste emplacement drifts and the effects of mineral alteration on flow in rocks surrounding drifts. The DST THC submodel uses a drift-scale process model relying on the same conceptual model and many of the same input data (i.e., physical, hydrologic, thermodynamic, and kinetic) as the THC seepage model. The DST THC submodel is the primary means for validating the THC seepage model. The DST THC submodel compares predicted water and gas compositions, and mineral alteration patterns, with observed data from the DST. These models provide the framework to evaluate THC coupled processes at the drift scale, predict flow and transport behavior for specified thermal-loading conditions, and predict the evolution of mineral alteration and fluid chemistry around potential waste emplacement drifts. The DST THC submodel is used solely for the validation of the THC seepage model and is not used for calibration to measured data.

Data developed with the THC seepage model are analyzed in Post-Processing Analysis for THC Seepage (BSC 2004 [DIRS 169858]), for downstream use in modeling the in-drift chemical environment in Engineered Barrier System: Physical and Chemical Environment Model (BSC 2004 [DIRS 169860], Section 4.1), which directly feeds the TSPA-LA.

The work scope for this report is summarized as follows: further develop the THC seepage model; use sensitivity analyses and model-data comparisons to evaluate model, data, and 
parameter uncertainties; validate the model by comparison of derivative cases with field and experimental data; perform simulations to predict the composition of fracture water that could potentially seep into repository emplacement drifts; submit modeling results to the Technical Data Management System (TDMS) and document the models; and evaluate model uncertainty and the propagation of uncertainty to other models.

This report (REV04) is a minor revision of the previous version, and addresses shortcomings in model validation, as described in Condition Report CR99. It differs only slightly from Revision 03 with respect to technical content. Relative to previous revisions of this model, the simulations presented in this document make use of improved treatment of various modeled processes, together with updated rock properties and some new kinetic and thermodynamic input data. In addition, the uncertainties associated with the THC seepage model are represented using five different input water compositions, with consideration of sensitivity studies on the effects of variations in key parameters including infiltration rates, $\mathrm{CO}_{2}$ effective diffusivity, and vapor-pressure lowering by capillarity. Previous revisions of this model investigated model sensitivity to other parameters. Those results are discussed, as applicable, in this document, but not presented in detail. Those developmental model simulations are discussed for comparative purposes to evaluate model uncertainty and sensitivity to model parameters and are not direct inputs to TSPA-LA.

\subsection{OVERVIEW OF MODELS}

The THC seepage model provides an analysis of the effects of THC processes on percolation water chemistry and gas-phase composition in the near-field host rock around the emplacement drifts. This analysis includes a complete description of the relevant mineral-water interactions in the host rock. Sensitivity studies document the effect of varying rock properties, including fracture-permeability heterogeneity, reaction rates, repository emplacement-horizon lithology, geochemical systems, infiltration rates, and input water compositions.

The DST THC submodel, constructed for the DST, is used to investigate THC processes during the DST and validate the THC modeling approach. The spatial scale and temperatures for the DST are similar to those for current designs of the repository. This similarity, combined with the extended period of operation (four years of heating, ending in January 2002, and continued monitoring during cooling), makes the DST the best available experiment for validating drift-scale THC coupled process models (such as the THC seepage model). Measured data from the DST are used to evaluate and validate the conceptual and numerical models presented here.

The following designations are assigned for description of the work presented in this report:

- THC seepage model: Developed for use by downstream models that feed TSPA (Section 6.5). In this model, the repository is located in the Tptpll lithostratigraphic unit. Five simulations, using five different starting pore waters, provide feeds to downstream models. Several sensitivity analyses using the current model are also documented here.

- DST THC submodel: DST THC submodel simulations developed for the current revision of this report (Section 7.1). This model is derived from the THC seepage model, and used for validation of the THC seepage model. The DST is located in the middle 
nonlithophysal unit (Tptpmn) but the results are applicable to all the host rock lithostratigraphic units as discussed below.

Results of earlier developmental (REV01) versions of the THC model are discussed in this report as alternative conceptualizations and sensitivity analyses. Previous model revisions provide alternative conceptualizations of the THC seepage model and are used to evaluate the effects of mineral dissolution and precipitation; the effects of $\mathrm{CO}_{2}$ exsolution and transport in the region surrounding emplacement drifts; the potential for forming calcite, silica, or other mineral assemblage "precipitation caps" (low-permeability zones of precipitated minerals above the drifts); and the resulting changes to porosity, permeability, and percolation. The effects of various model refinements and improvements implemented through successive revisions of this report are also documented. These include, for example, the effects of improved treatment of porosity-permeability coupling, improved treatment of mineral precipitation at the boiling front, and consideration of lowering vapor pressure caused by capillary pressure.

As discussed later in this report, the THC seepage model is located in the Tptpll lithostratigraphic unit, but is run using a range of input water compositions from various host rock lithostratigraphic units (including the Tptpmn, Tptpll, and Tptpul units) and representing the natural variability in pore water compositions. The range of model results from the use of these different water compositions is representative of that associated with other factors such as host rock unit, drift location, infiltration rate, and other model conceptualizations discussed in Section 6.3. Also, the host rock lithostratigraphic units are mineralogically similar (Peterson and Cloke 2002 [DIRS 162576]). Therefore, it is assumed (Section 5) that the THC model results calculated for the Tptpll unit (taking into account the variability introduced by the different input water compositions) are applicable to the other repository host rock units.

\subsection{MODEL LIMITATIONS}

The THC seepage model has stated limitations associated with its mathematical formulation, certain assumptions (Section 5), and approximations in model development (Section 6.4.6). The THC seepage model is designed for simulation of speciation and mineral precipitation for evaporatively concentrated waters with ionic strength $<4$ molal. At ionic strengths $>4$ molal, the model uses specific approximations to represent the behavior of soluble salts. While the method is consistent with the activity model implemented here and ensures numerical stability, it introduces uncertainty with respect to the relative concentrations of soluble species (e.g. $\mathrm{NO}_{3}{ }^{-}$ and $\mathrm{Cl}^{-}$) when the salts are first redissolved. However, during this initial rewetting stage, the liquid saturation is low and the associated volume of water is small, immobile, and unlikely to contribute to seepage. This limitation and others affecting the uncertainty of model results, such as the use of average properties to describe thermal, hydrologic, and chemical characteristics of the host rock, are discussed in Section 6.6. Another limitation of the THC seepage model is that it is computationally intensive (run times up to ten days per simulation case); hence, the number of sensitivity analyses is limited. These limitations are addressed by evaluating the model sensitivity to key input parameters (Section 6.5), and by comparing model results against data from the DST and laboratory experiments (Section 7). Also, the model conceptualization and mathematical formulation (Sections 6.2 through 6.4) have been improved, through the successive revisions of this report, to achieve reasonably good agreement (generally to within an order of magnitude) between calculated and measured data. 
Although the THC seepage model provides aqueous Fe concentrations as output, these values are not used by downstream models. Because of the paucity of measured Fe values in DST waters, and the large uncertainty in these values due to the low solubility of $\mathrm{Fe}^{3+}$ (Section 7.1.11.3), Fe model predictions are not validated, and are presented in THC seepage model results for information only.

The THC seepage model represents a two-dimensional slice across a repository drift, at a representative repository-center location. This approach closely represents conditions throughout much of the repository, and gives a representation of THC effects near the repository edge, which tends to over-state the aggressiveness of the waters with respect to waste package corrosion. Water and gas compositions predicted at the edge of the repository (BSC 2001 [DIRS 155950], Section 3.3.6) are within the range of compositions simulated in this report. For these reasons, results presented here can be used to represent potential effects of THC processes on the composition of seepage at all waste package locations (BSC 2004 [DIRS 169858], Section 6.3.2). 


\section{QUALITY ASSURANCE}

Development of this report and supporting modeling activities has been determined to be subject to the Yucca Mountain Project's quality assurance (QA) program as indicated in Technical Work Plan for: Near-Field Environment and Transport: Coupled Processes (Mountain-Scale TH/THC/THM, Drift-Scale THC Seepage, and Post-Processing Analysis for THC Seepage) Report Integration (BSC 2005 [DIRS 172761]; Work Package ARTM02). Approved QA implementing procedures identified in the TWP (BSC 2005 [DIRS 172761], Section 4) have been used to conduct and document the activities described in this report. Electronic management of information has been evaluated in accordance with AP-SV.1Q, Control of the Electronic Management of Information, and controlled under YMP-LBNL-QIP-SV.0, Management of YMP-LBNL Electronic Data.

This report investigates the effect of drift-scale THC processes on the following safety category barriers that are important to the demonstration of compliance with the postclosure performance objective prescribed in 10 CFR 63.113 [DIRS 156605]:

- Unsaturated zone above the repository

- Unsaturated zone below the repository.

Therefore, the barriers are classified as Safety Category (SC) with regard to importance to waste isolation as defined in AP-2.22Q, Classification Analyses and Maintenance of the Q-List. The report contributes to the analyses and modeling data used to support performance assessment; the conclusions do not directly impact the engineered features important to safety as defined in AP-2.22Q. 


\section{INTENTIONALLY LEFT BLANK}




\section{USE OF SOFTWARE}

The following software is used in the preparation of this report:

\subsection{QUALIFIED SOFTWARE}

The qualified software used in this study is listed in Table 3-1. The software has been baselined in accordance with LP-SI.11Q-BSC, Software Management, or previous approved procedures, is adequate and appropriate for the intended use, is used strictly within the range of validation, and has been obtained from the software configuration management department. The software performs the functions described in Table 3-1 in the qualified environment described. Input limitations are discussed in table column "Range of Use." Unless specifically listed in Table 3-1, there are no limitations on the software output, provided that the appropriate input limitations are observed.

TOUGHREACT V3.0 (LBNL 2002 [DIRS 161256]) is the primary code used for the DST THC submodel and THC seepage model. SOLVEQ/CHILLER V1.0 (LBNL 1999 [DIRS 153217]) is utilized to prepare water-chemistry data for input to the model simulations, SUPCRT92 V1.0 (LBNL 1999 [DIRS 153218]) is used to generate thermodynamic data for use by SOLVEQ/CHILLER V1.0 (LBNL 1999 [DIRS 153217]) and various TOUGHREACT versions, TOUGH2 V1.4 (LBNL 2000 [DIRS 146496]) is used to generate boundary conditions, AMESH V1.0 (LBNL 1999 [DIRS 147561]) is used to generate grids for the models. Other routines listed in Table 3-1 are used for various data pre- and post-processing tasks.

This report documents the DST THC submodel and the THC seepage model as described in Section 1. The input and output files for the model runs presented in this report are listed in Appendix G.

\subsection{EXEMPT SOFTWARE}

The commercial, off-the-shelf software code Microsoft Excel has been used in the preparation of this report in an exempt manner to do basic calculations and statistical operations based on the internal functions of the code. TOUGHREACT model output is also exported to Excel for graphing and data presentation, and the primary output DTNs for this model, LB0302DSCPTHCS.002 and LB0307DSTTHCR2.002, contain data summarized in Excel spreadsheets. The individual spreadsheets are called out in the DTNs where they are used, and are summarized in Appendix G. As discussed in Appendix G, readme.doc files in each DTN contain a general description of the spreadsheets contained therein, and worksheets in the Excel spreadsheets document in detail the calculations that are performed in each spreadsheet. 


\begin{tabular}{|c|c|c|c|c|c|}
\hline $\begin{array}{l}\text { Software Name } \\
\text { and Version }\end{array}$ & $\begin{array}{l}\text { Software } \\
\text { Tracking } \\
\text { Number }\end{array}$ & Platform & OS & Range of Use & Brief Description \\
\hline $\begin{array}{l}\text { TOUGHREACT } \\
\text { V3.0 } \\
\text { [DIRS 161256] }\end{array}$ & $10396-3.0-00$ & $\begin{array}{l}\text { Alpha } \\
\text { System }\end{array}$ & OSF1 V5.1 & $\begin{array}{l}\text { Porous and fractured media in a pressure- } \\
\text { temperature-composition (P-T-X) range } \\
\text { defined by the P-T-X range of the } \\
\text { thermodynamic database. lonic strength limit } \\
\text { of } \sim 4 \text { molal ( } \mathrm{NaCl} \text {-dominant solutions). }\end{array}$ & $\begin{array}{l}\text { TOUGHREACT V3.0 is used to calculate } \\
\text { coupled thermal-hydrologic and chemical } \\
\text { processes for kinetic and/or equilibrium } \\
\text { mineral-water reactions and equilibrium } \\
\text { gas-water reactions. }\end{array}$ \\
\hline $\begin{array}{l}\text { SOLVEQ/CHILLER } \\
\text { V1.0 } \\
\text { [DIRS 153217] }\end{array}$ & $10057-1.0-00$ & PC & Windows NT & $\begin{array}{l}\text { Pressure-temperature-composition (P-T-X) } \\
\text { range defined by the } \mathrm{P}-\mathrm{T}-\mathrm{X} \text { range of the } \\
\text { thermodynamic database. lonic strength limit } \\
\text { of } \sim 4 \text { molal ( } \mathrm{NaCl} \text {-dominant solutions) }\end{array}$ & $\begin{array}{l}\text { Used to compute multicomponent } \\
\text { heterogeneous chemical equilibria among } \\
\text { solids, gases, and an aqueous phase. }\end{array}$ \\
\hline $\begin{array}{l}\text { SUPCRT92 V1.0 } \\
\text { [DIRS 153218] }\end{array}$ & $10058-1.0-00$ & PC & Windows 98/NT & $\begin{array}{l}\text { Pressure-temperature-composition (P-T-X) } \\
\text { range defined by the P-T-X range of the input } \\
\text { reference thermodynamic data and equation } \\
\text { of state parameters ( } 1 \text { to } 5000 \text { bar and } 0 \text { to } \\
1000 \mathrm{C} \text { ). }\end{array}$ & $\begin{array}{l}\text { Used to calculate the standard molal } \\
\text { thermodynamic properties of minerals, } \\
\text { gases, aqueous species and reactions from } 1 \\
\text { to } 5000 \text { bars and } 0 \text { to } 1000 \text { degrees Celsius. }\end{array}$ \\
\hline $\begin{array}{l}\text { TOUGH2 V1.4 } \\
\text { [DIRS 146496] }\end{array}$ & $10007-1.4-01$ & $\begin{array}{l}\text { Sun } \\
\text { UltraSparc }\end{array}$ & SUNOS 5.5 .1 & $\begin{array}{l}\text { Porous and fractured media, unsaturated to } \\
\text { fully saturated conditions. }\end{array}$ & $\begin{array}{l}\text { Used as an integral finite difference } \\
\text { numerical simulator for non-isothermal flows } \\
\text { of multicomponent, multiphase fluids in } \\
\text { porous and fracture media. }\end{array}$ \\
\hline $\begin{array}{l}\text { AMESH V1.0 } \\
\text { [DIRS 147561] }\end{array}$ & $10045-1.0-00$ & $\begin{array}{l}\text { Sun } \\
\text { UltraSparc }\end{array}$ & SUNOS 5.5 .1 & 1-, 2-, or 3-dimensional grids of any size. & $\begin{array}{l}\text { Generates discrete 1-D, 2-D or 3-D grids for } \\
\text { numerical modeling of flow and transport } \\
\text { problems in which the formulation is based } \\
\text { on the integral finite difference method. }\end{array}$ \\
\hline $\begin{array}{l}\text { switch V1.0 } \\
\text { [DIRS 152899] }\end{array}$ & $10322-1.0-00$ & PC & Windows NT & $\begin{array}{l}\text { Input database must be in } \\
\text { SOLVEQ/CHILLER V1.0 database format. } \\
\text { Pressure-temperature-composition (P-T-X) } \\
\text { range defined by the P-T-X range of the } \\
\text { thermodynamic database. }\end{array}$ & $\begin{array}{l}\text { Used to switch component species in } \\
\text { SOLVEQ/CHILLER V1.0. }\end{array}$ \\
\hline $\begin{array}{l}\text { regress V1.0 } \\
\text { [DIRS 152900] }\end{array}$ & $10321-1.0-00$ & PC & Windows NT & $\begin{array}{l}\text { Input database must be in } \\
\text { SOLVEQ/CHILLER V1.0 database format. } \\
\text { Pressure-temperature-composition (P-T-X) } \\
\text { range defined by the P-T-X range of the } \\
\text { thermodynamic database. }\end{array}$ & $\begin{array}{l}\text { Used to calculate regression coefficients of } \\
\text { log K data as a function of temperature for } \\
\text { SOLVEQ/CHILLER V1.0. }\end{array}$ \\
\hline $\begin{array}{l}\text { mk_incon V1.0 } \\
\text { [DIRS 152901] }\end{array}$ & $10350-1.0-00$ & $\begin{array}{l}\text { Sun } \\
\text { UltraSparc }\end{array}$ & SUNOS 5.5 .1 & $\begin{array}{l}\text { Limited to } 1-D \text { column for input, and 2-D } \\
\text { mesh for output. }\end{array}$ & $\begin{array}{l}\text { Used to create INCON files for input into } \\
\text { TOUGH } 2 \text { codes. }\end{array}$ \\
\hline
\end{tabular}




\begin{tabular}{|c|c|c|c|c|c|}
\hline $\begin{array}{l}\text { Software Name } \\
\text { and Version }\end{array}$ & $\begin{array}{l}\text { Software } \\
\text { Tracking } \\
\text { Number }\end{array}$ & Platform & OS & Range of Use & Brief Description \\
\hline $\begin{array}{l}\text { KREG V1.1 } \\
\text { [DIRS 161258] }\end{array}$ & $10318-1.1-00$ & PC & Windows NT & $\begin{array}{l}\text { Input database must be in TOUGHREACT } \\
\text { V2.4 (and above) database format. } \\
\text { Pressure-temperature-composition (P-T-X) } \\
\text { range defined by the P-T-X range of the } \\
\text { thermodynamic database. }\end{array}$ & $\begin{array}{l}\text { Used to calculate regression coefficients of } \\
\text { log K data as a function of temperature for } \\
\text { the thermodynamic database of } \\
\text { TOUGHREACT V2.4 and above. }\end{array}$ \\
\hline $\begin{array}{l}\text { KSWITCH V1.1 } \\
\text { [DIRS 161259] }\end{array}$ & 10319-1.1-00 & PC & Windows NT & $\begin{array}{l}\text { Input database must be in TOUGHREACT } \\
\text { V2.4 (and above) database format. } \\
\text { Pressure-temperature-composition (P-T-X) } \\
\text { range defined by the P-T-X range of the } \\
\text { thermodynamic database. }\end{array}$ & $\begin{array}{l}\text { Used to switch component species in the } \\
\text { thermodynamic database of TOUGHREACT } \\
\text { V2.4 and above. }\end{array}$ \\
\hline $\begin{array}{l}\text { THERMOCHK V1.1 } \\
\text { [DIRS 161262] }\end{array}$ & 10895-1.1-00 & PC & Windows NT & $\begin{array}{l}\text { Input database must be in TOUGHREACT } \\
\text { V2.4 (and above) database format, and } \\
\text { include molecular weights must be provided } \\
\text { for all species listed (aqueous, solid, and } \\
\text { gas). }\end{array}$ & $\begin{array}{l}\text { Used to check the consistency (mass } \\
\text { balance and charge balance) of reactions in } \\
\text { the thermodynamic database of the reactive } \\
\text { transport code TOUGHREACT V } 2.4 \text { and } \\
\text { above }\end{array}$ \\
\hline $\begin{array}{l}\text { DBCONV V1.0 } \\
\text { [DIRS 161263] }\end{array}$ & $10893-1.0-00$ & PC & Windows NT & $\begin{array}{l}\text { Input database must be in EQ3/6 database } \\
\text { format, with pressure-temperature- } \\
\text { composition }(\mathrm{P}-\mathrm{T}-\mathrm{X}) \text { range defined by the } \\
\text { P-T-X range of the thermodynamic database. }\end{array}$ & $\begin{array}{l}\text { Used to convert the YMP EQ3/6 } \\
\text { thermodynamic database to a format suitable } \\
\text { for input into the reactive transport model } \\
\text { TOUGHREACT V3.0 }\end{array}$ \\
\hline $\begin{array}{l}\text { CUTCHEM V1.0 } \\
\text { [DIRS 161127] }\end{array}$ & $\begin{array}{l}10898-1.0- \\
0.0\end{array}$ & PC & Windows NT & $\begin{array}{l}\text { Only for use with TOUGHREACT output files } \\
\text { TEC_nnn.dat. Limit of } 30 \text { extracted points } \\
\text { per general location per point in time. }\end{array}$ & $\begin{array}{l}\text { Used to extract automatically data from large } \\
\text { output data files created by the reactive } \\
\text { transport model TOUGHREACT V2.1 and } \\
\text { above }\end{array}$ \\
\hline $\begin{array}{l}\text { exclude.f V1.0 } \\
\text { [DIRS 153089] }\end{array}$ & $10316-1.0-00$ & $\begin{array}{l}\text { Sun } \\
\text { UltraSparc }\end{array}$ & SUNOS 5.5.1 & $\begin{array}{l}\text { Only for use with output files from mk_circ2 } \\
\text { V1.0 and mk_rect2 V1.0 }\end{array}$ & $\begin{array}{l}\text { Used to exclude points outside a specified } \\
\text { radius so that points will not overlap when } \\
\text { output is merged using merggrid.f V1.0 for } \\
\text { 2-D THC seepage model. }\end{array}$ \\
\hline $\begin{array}{l}\text { assign.f V1.0 } \\
\text { [DIRS 153090] }\end{array}$ & $10315-1.0-00$ & $\begin{array}{l}\text { Sun } \\
\text { UltraSparc }\end{array}$ & SUNOS 5.5 .1 & 2-D grids in TOUGH2 MESH format. & $\begin{array}{l}\text { Used to assign a geologic name to all } \\
\text { TOUGH2 elements according to their } \\
\text { location in the Z-direction for 2-D THC } \\
\text { seepage model. }\end{array}$ \\
\hline $\begin{array}{l}\text { merggrid2.f V1.0 } \\
\text { [DIRS 153091] }\end{array}$ & $10314-1.0-00$ & $\begin{array}{l}\text { Sun } \\
\text { UltraSparc }\end{array}$ & SUNOS 5.5 .1 & $\begin{array}{l}\text { Only for use with output files from mk_circ2 } \\
\mathrm{V} 1.0 \text {, mk_rect2 } \mathrm{V} 1.0 \text {, and exclude } \mathrm{V} 1.0\end{array}$ & $\begin{array}{l}\text { Used to merge input files into one file for } \\
\text { input into AMESH V1.0 for 2-D THC } \\
\text { seepage model. }\end{array}$ \\
\hline
\end{tabular}


Table 3-1. Qualified Software Used (Continued)

\begin{tabular}{|l|l|l|l|l|l|}
\hline $\begin{array}{l}\text { Software Name } \\
\text { and Version }\end{array}$ & $\begin{array}{l}\text { Software } \\
\text { Tracking } \\
\text { Number }\end{array}$ & Platform & \multicolumn{1}{|c|}{ OS } & \multicolumn{1}{c|}{ Range of Use } & \multicolumn{1}{c|}{ Brief Description } \\
\hline $\begin{array}{l}\text { mk circ2 V1.0 } \\
\text { [DIRS 153092] }\end{array}$ & $10312-1.0-00$ & $\begin{array}{l}\text { Sun } \\
\text { UltraSparc }\end{array}$ & SUNOS 5.5.1 & 1-D or 2-D grids only. & $\begin{array}{l}\text { Used to create a radial grid for 2-D THC } \\
\text { seepage model. }\end{array}$ \\
\hline $\begin{array}{l}\text { mk_rect2 V1.0 } \\
\text { [DIRS 153093] }\end{array}$ & $10313-1.0-00$ & $\begin{array}{l}\text { Sun } \\
\text { UltraSparc }\end{array}$ & SUNOS 5.5.1 & 1-D or 2-D grids only. & $\begin{array}{l}\text { Used to create orthogonal grid for 2-D THC } \\
\text { seepage model. }\end{array}$ \\
\hline $\begin{array}{l}\text { 2kgridv1a.for V1.0 } \\
\text { [DIRS 153067] }\end{array}$ & $10382-1.0-00$ & PC & DOS Emul-ation & $\begin{array}{l}\text { Only for use with 2-D grids in TOUGH2 } \\
\text { format. }\end{array}$ & $\begin{array}{l}\text { Generates dual-permeability grids for the } \\
\text { TOUGH2 family of codes. }\end{array}$ \\
\hline $\begin{array}{l}\text { mk_grav2.f V1.0 } \\
\text { [DIRS 153068] }\end{array}$ & $10379-1.0-00$ & $\begin{array}{l}\text { Sun } \\
\text { UltraSparc }\end{array}$ & SUNOS 5.5.1 & $\begin{array}{l}\text { Only for use with 2-D grids generated by } \\
\text { AMESH. }\end{array}$ & $\begin{array}{l}\text { Reads AMESH V1.0 output files and creates } \\
\text { TOUGH2 V1.4 mesh input file data, namely } \\
\text { the gravity vector data and grid block labeling } \\
\text { data }\end{array}$ \\
\hline $\begin{array}{l}\text { sav1d_dst2d.f V1.0 } \\
\text { [DIRS 153083] }\end{array}$ & $10381-1.0-00$ & $\begin{array}{l}\text { Sun } \\
\text { UltraSparc }\end{array}$ & SUNOS 5.5.1 & $\begin{array}{l}\text { Limited to 1-D column for input, and 2-D } \\
\text { mesh for output. }\end{array}$ & $\begin{array}{l}\text { Creates an INCON file for TOUGH2 input for } \\
\text { a 2-D mesh from existing INCON and MESH } \\
\text { data for a 1-D column }\end{array}$ \\
\hline $\begin{array}{l}\text { Mrgdrift.f V1.0 } \\
\text { [DIRS 153082] }\end{array}$ & $10380-1.0-00$ & $\begin{array}{l}\text { Sun } \\
\text { UltraSparc }\end{array}$ & SUNOS 5.5.1 & $\begin{array}{l}\text { Limited for use only with a TOUGH2 and } \\
\text { TOUGHREACT numerical mesh. The } \\
\text { connecting boundaries of the drift and } \\
\text { geologic meshes must exactly overlap. }\end{array}$ & $\begin{array}{l}\text { Merges the geologic mesh with the drift mesh } \\
\text { for TOUGH2 and TOUGHREACT } \\
\text { simulations. }\end{array}$ \\
\hline
\end{tabular}




\section{INPUTS}

\subsection{DIRECT INPUT}

This section presents all input data used for the THC seepage model (i.e., for the simulations presented in Section 6.5), which provides output for use by downstream models that feed TSPA-LA (see Section 1.1). The qualified status of all direct inputs is shown in the DIRS database. Because this report documents models of coupled phenomena, a wide variety of input data is required. The appropriateness of technical product outputs directly used by this model is discussed in the following sections, and they are justified for intended use in this model. Input data and parameter uncertainties are further addressed in Sections 6 and 7. Section 7 documents model input-related model validation.

\subsubsection{Hydrologic and Thermal Properties}

Source DTNs for hydrologic and thermal properties are listed in Table 4.1-1. All sources of direct inputs for these parameters are listed in Table 4.1-1; other DTNs and data sources discussed in this section are presented for corroborative or informational purposes only. Specific values of hydrologic and thermal properties for the repository hydrogeologic model units tsw33, tsw34, and tsw35 (Topopah Spring Tuff upper-lithophysal, middle-nonlithophysal, and lower-lithophysal units, respectively) are summarized later in Section 6 (Table 6.4-1).

Modeling analyses utilized data from the "mean-calibrated" hydrologic property sets for the present-day climate. The data sets include properties that are calibrated, such as fracture and matrix permeabilities and van Genuchten parameters, and properties such as porosity, heat capacity, and thermal conductivity that are obtained from field measurements. DTNs for model-boundary temperatures are also included in Table 4.1-1.

Transport parameters considered in the model are diffusion coefficients for aqueous and gaseous species and tortuosities of the fracture, matrix, and engineered system components. Diffusion coefficients for all aqueous species are direct inputs to the model and entered as the tracer diffusion coefficient of the chloride anion $\left(\mathrm{Cl}^{-}\right)$at infinite dilution. The aqueous diffusion coefficient of $\mathrm{Cl}^{-}$at infinite dilution is $2.03 \times 10^{-9} \mathrm{~m}^{2} / \mathrm{s}$ at $25^{\circ} \mathrm{C}$ (Lide 1993 [DIRS 123032], p. 5-111), which in the model input is rounded to $2.0 \times 10^{-9} \mathrm{~m}^{2} / \mathrm{s}$. This handbook source is Established Fact, and requires no further justification for use.

These same sources provide inputs for approximating the $\mathrm{CO}_{2}$ diffusion coefficient from ideal gas behavior as described in Section 6.4.6 (item 5), using direct inputs for molecular diameter $\left(d_{m}\right)$ and molecular weight $(M)$ as follows (unless specified otherwise in Section 6):

$$
\begin{aligned}
& d_{m}=2.5 \times 10^{-10} \mathrm{~m} \text { (Lasaga } 1998 \text { [DIRS 117091], p. 322) } \\
& M=.04401 \mathrm{~kg} / \mathrm{mol} \text { (Lide } 1993 \text { [DIRS 123032], p. 4-50). }
\end{aligned}
$$

Once again, input from Lide (1993 [DIRS 123032]) is Established Fact. The data from Lasaga (1998 [DIRS 117091], p. 322) are widely accepted and referenced throughout the scientific community and, hence, are justified for their intended use in this model. 
The diffusion coefficient for $\mathrm{CO}_{2}$ is calculated using Equation 6.4-24 (Lasaga 1998 [DIRS 117091], p. 322). This is a standard method of calculating the diffusion coefficient (see, for instance, Bird et al. 1960 [DIRS 103524], Equations 16.4 to 16.9), is quite common, and is justified for use in this document.

Table 4.1-1. Sources of Hydrologic and Thermal Properties Used as Direct Input Data for the Drift-Scale Coupled-Processes Models That Feed TSPA-LA Activities

\begin{tabular}{|c|c|}
\hline Source & Data/Parameter Description $^{a}$ \\
\hline \multicolumn{2}{|l|}{ Hydrologic and Thermal Rock Properties } \\
\hline $\begin{array}{l}\text { Penman } 1940 \text { [DIRS 109941], pp. 441, } \\
\text { 461, Eq. } 5\end{array}$ & $\begin{array}{l}\text { Fracture tortuosity applied to thermal parameters of lithologic units (see } \\
\text { text) }\end{array}$ \\
\hline LB0205REVUZPRP.001 [DIRS 159525] & $\begin{array}{l}\text { Fracture parameters: permeability, porosity, van Genuchten } \mathrm{m} \text {, } \\
\text { residual saturation, satiated saturation, fracture frequency, fracture to } \\
\text { matrix area }\end{array}$ \\
\hline LB0208UZDSCPMI.002 [DIRS 161243] & $\begin{array}{l}\text { Fracture and matrix van Genuchten alpha, matrix permeability, active } \\
\text { fracture parameter (gamma) }\end{array}$ \\
\hline $\begin{array}{l}\text { LB0207REVUZPRP.002 [DIRS 159672] } \\
\text { (file: matrix_props.xls) }\end{array}$ & $\begin{array}{l}\text { Matrix parameters: van Genuchten } \mathrm{m} \text {, residual saturation, satiated } \\
\text { saturation }\end{array}$ \\
\hline LB0210THRMLPRP.001 [DIRS 160799] & $\begin{array}{l}\text { Matrix porosity and thermal properties: dry- and wet-rock grain } \\
\text { conductivity, grain specific heat, and grain density }\end{array}$ \\
\hline LL000114004242.090 [DIRS 142884] & $\begin{array}{l}\text { Infiltration rates-average infiltration rate (mean, lower bound, and uppe } \\
\text { bound for present-day, monsoonal, and glacial transition climates) from } \\
\text { the TH drift-scale models }\end{array}$ \\
\hline SN0002T0872799.009 [DIRS 153364] & $\begin{array}{l}\text { Effective thermal conductivities for in-drift open spaces (see Appendix } \\
\text { E) }\end{array}$ \\
\hline \multicolumn{2}{|l|}{ Mineralogical Data } \\
\hline $\begin{array}{l}\text { LB0101DSTTHCR1.002 [DIRS 161277] } \\
\text { (file: ecrb_cdtt_mindata.xls) }\end{array}$ & Mineral volume fractions \\
\hline $\begin{array}{l}\text { LB0101DSTTHCR1.004 [DIRS 161279] } \\
\text { (file: ecrb_cdtt_mindata.xIs) }\end{array}$ & Mineral surface areas \\
\hline \multicolumn{2}{|l|}{ Kinetic Data } \\
\hline LB0307KNTDBRTM.001 [DIRS 164433] & Rate constants and activation energies \\
\hline \multicolumn{2}{|l|}{ Thermodynamic Data } \\
\hline LB0307THMDBRTM.001 [DIRS 164434] & $\begin{array}{l}\text { Thermodynamic data for aqueous species and minerals: equilibrium } \\
\text { constants, molecular weights, molar volumes, Debye-Hückel } \\
\text { parameters, } \mathrm{CO}_{2} \text { molecular diameter }\end{array}$ \\
\hline \multicolumn{2}{|l|}{ Analytical Water and Gas Chemistry Data } \\
\hline $\begin{array}{l}\text { MO0005PORWATER.000 [DIRS } \\
\text { 150930] }\end{array}$ & $\begin{array}{l}\text { Analyses of pore waters from Alcove } 5 \text { core samples in the ESF } \\
\text { (HD-PERM-2 and HD-PERM-3 samples) }\end{array}$ \\
\hline GS020408312272.003 [DIRS 160899] & $\begin{array}{l}\text { Pore water analyses from ECRB Cross-Drift and USW SD-9 borehole } \\
\text { core samples (Table 4.1-3) }\end{array}$ \\
\hline \multicolumn{2}{|l|}{ Tptpmn and Tptpll THC Model Grid Data } \\
\hline LB990501233129.004 [DIRS 111475] & $\begin{array}{l}\text { Stratigraphy (Z coordinates of hydrogeologic units) for central location } \\
\text { (column j34) Tptpll THC model. }\end{array}$ \\
\hline LB0011DSTTHCR1.002 [DIRS 161282] & THC model mesh with hydrogeologic units in the vicinity of the drift \\
\hline
\end{tabular}


Table 4.1-1. Sources of Hydrologic and Thermal Properties Used as Direct Input Data for the Drift-Scale Coupled-Processes Models That Feed TSPA-LA Activities (Continued)

\begin{tabular}{|l|l|}
\hline LB990701233129.002 [DIRS 125604] & $\begin{array}{l}\text { Top and bottom boundary temperatures, pressure, liquid/gas } \\
\text { saturations, and boundary elevations }\end{array}$ \\
\hline LB990601233124.001 [DIRS 105888] & Permeability Measurements in Tptpmn \\
\hline
\end{tabular}

${ }^{a}$ Values of thermal and hydrologic properties used in the THC models are summarized in Table 6.4-1

\subsubsection{Fracture Tortuosity}

Tortuosities are set to 0.7 for fractures, based upon theoretical calculations and experimental measurements given by Penman (1940 [DIRS 109941], p. 441, Eq. 5), who estimated that an isotropic porous medium has a tortuosity of $\sqrt{2}^{-1}$ or $\sim 0.707$. Penman (1940 [DIRS 109941], p. 461) also obtained an experimentally measured tortuosity value 0.66 based on steady-state vapor diffusion through soil material having porosities of up to 0.7 , thus corroborating his own theoretical value. Additional corroborative data are available from de Marsily (1986 [DIRS 100439], p. 233), who states that a tortuosity value of 0.7 is within the upper range for porous media. Its use in this model is based on the assumption that the ensemble of fractures in an unsaturated media behaves as an isotropic porous medium.

Given the similarity of Penman's two estimated values, and the corroborative data provided by de Marsily, and assuming that the actual percolation paths expected in granular materials approximate those present in a complex fractured medium, a fracture tortuosity value of 0.7 is justified for the intended use in this model. A matrix tortuosity of 0.2 is assumed, with rationale provided, in Section 6.4.6.

An additional justification for the fracture and matrix tortuosity values used here is consistency with other unsaturated zone reports. The same matrix and fracture tortuosity values are used in Multiscale Thermohydrologic Model (BSC (2004 [DIRS 169565], Section 5.3.1.9), Mountain-Scale Coupled Processes (TH/THC/THM) (BSC 2004 [DIRS 169866]), and Drift-Scale Coupled Processes (DST and TH Seepage) Models (BSC 2004 [DIRS 170338], Section 4.1.1.1).

\subsubsection{Mean Infiltration Rates}

The infiltration values used in this model are provided in DTN: LL000114004242.090 ([DIRS 142884], file "chimney_infiltration_fluxes"). The infiltration rates applied at the top of the THC seepage model are adopted from the mean infiltration scenario that includes present-day (0 to 600 years), monsoonal (600 to 2,000 years), and glacial transition climates (more than 2,000 years), as described in Simulation of Net Infiltration for Modern and Potential Future Climates (BSC 2004 [DIRS 170007], Sections 6.9 and 6.11) and, for the time interval defining each climate state, Multiscale Thermohydrologic Model (BSC 2004 [DIRS 169565], Section 5). The specific infiltration values $(6,16$, and $25 \mathrm{~mm} / \mathrm{yr}$ for the present-day, monsoonal, and glacial transition periods, respectively) represent repository-wide averages based upon historical data. These values are calculated as arithmetic averages of 31 repository locations considered in Multiscale Thermohydrologic Model (BSC 2001 [DIRS 158204], Section 6.3.1). The infiltration values used at these 31 repository locations are provided in DTN: LL000114004242.090 
([DIRS 142884], file "chimney_infiltration_fluxes," median infiltration cases) and summarized in Table 4.1-2. The calculated averages have been rounded to $6 \mathrm{~mm} / \mathrm{yr}, 16 \mathrm{~mm} / \mathrm{yr}$, and 25 $\mathrm{mm} / \mathrm{yr}$, respectively, for use in this report.

More recent estimates of the average infiltration rates under the three different climatic conditions are now available, and provide corroboration for these historic values. Table 6.1-2 in UZ Flow Models and Submodels (BSC 2004 [DIRS 169861]) provides the mean infiltration values at the top of the entire UZ model domain (not the same as the 31 locations previously averaged) as 4.4, 11.8, and $17.0 \mathrm{~mm} / \mathrm{yr}$ under present-day, monsoonal, and glacial transition climatic conditions. These numbers are obtained by averaging infiltration data in DTN: GS000308311221.005 [DIRS 147613]. Average infiltration rates at the PTn-TSw interface have also been developed based on the average surface infiltration rates given in Table 6.1-2 of UZ Flow Models and Submodels (BSC 2004 [DIRS 169861]). These average rates are summarized in Table 6.6-11 of Abstraction of Drift Seepage (BSC 2004 [DIRS 169131]). Over the entire UZ model domain, the average infiltration fluxes at the PTn-TSw interface under mean infiltration conditions are $4.8,13.2$, and $18.8 \mathrm{~mm} / \mathrm{yr}$ for the three climatic conditions. However, over the repository footprint, the average infiltration fluxes at the same location (PTn-TSw interface) are $3.8,11.7$, and $17.9 \mathrm{~mm} / \mathrm{yr}$, respectively, for the three climatic states.

Table 4.1-2. Average Infiltration Values ( $\mathrm{mm} / \mathrm{yr}$ ) for Different Climate Periods

\begin{tabular}{|c|c|c|c|}
\hline Column & Present-Day & Monsoonal & Glacial Transition \\
\hline I7c4 & 1.493 & 3.252 & 5.211 \\
\hline I7c3 & 4.677 & 10.710 & 18.418 \\
\hline 17c2 & 5.554 & 13.726 & 22.420 \\
\hline I7c1 & 1.700 & 4.588 & 7.013 \\
\hline 16c5 & 9.410 & 17.746 & 30.732 \\
\hline 16c4 & 11.302 & 32.651 & 47.872 \\
\hline 16c3 & 4.180 & 10.303 & 16.574 \\
\hline 16c2 & 3.147 & 7.163 & 10.986 \\
\hline 16c1 & 3.879 & 9.432 & 15.079 \\
\hline 15c5 & 8.428 & 17.265 & 29.872 \\
\hline 15c4 & 14.412 & 40.972 & 60.237 \\
\hline 15c3 & 5.680 & 13.120 & 19.949 \\
\hline 15c2 & 7.395 & 17.707 & 27.097 \\
\hline 15c1 & 0.663 & 0.436 & 0.816 \\
\hline 14c5 & 5.449 & 14.472 & 20.214 \\
\hline 14c4 & 10.132 & 28.876 & 41.998 \\
\hline 14c3 & 10.144 & 24.091 & 38.660 \\
\hline 14c2 & 6.909 & 16.900 & 27.923 \\
\hline 14c1 & 4.794 & 12.093 & 18.881 \\
\hline 13c4 & 15.877 & 43.993 & 65.028 \\
\hline 13c3 & 1.304 & 2.637 & 4.194 \\
\hline 13c2 & 0.485 & 0.492 & 1.271 \\
\hline 13c1 & 6.335 & 18.869 & 27.005 \\
\hline 12c4 & 15.998 & 42.285 & 58.627 \\
\hline 12c3 & 12.011 & 40.749 & 63.168 \\
\hline 12c2 & 1.416 & 9.154 & 23.399 \\
\hline & & & \\
\hline
\end{tabular}


Table 4.1-2. Average Infiltration Values $(\mathrm{mm} / \mathrm{yr})$ for Different Climate Periods (Continued)

\begin{tabular}{|c|c|c|c|}
\hline Column & Present-Day & Monsoonal & Glacial Transition \\
\hline I2c1 & 0.406 & 0.250 & 0.733 \\
\hline I1c4 & 3.015 & 11.575 & 19.057 \\
\hline I1c3 & 7.809 & 21.854 & 32.439 \\
\hline I1c2 & 0.877 & 0.940 & 2.130 \\
\hline I1c1 & 0.574 & 10.004 & 13.523 \\
\hline Average & $\mathbf{5 . 9 4 2}$ & $\mathbf{1 6 . 0 7 4}$ & $\mathbf{2 4 . 8 5 6}$ \\
\hline
\end{tabular}

Source: DTN: LL000114004242.090 [DIRS 142884].

It is evident that the average percolation fluxes $(6,16$, and $25 \mathrm{~mm} / \mathrm{yr}$ for the present-day, monsoonal, and glacial transition climatic conditions, respectively) used in the THC model simulations in this report are larger than the most recent estimates for the entire UZ domain of 4.4, 11.8, and $17.0 \mathrm{~mm} / \mathrm{yr}$. However, the UZ model domain covers a much larger area than the repository footprint, and includes more area at low elevation that, in general, has lower percolation fluxes. Also, because infiltration rates and transport through the rock matrix are so slow, processes in the high thermal gradient of the near field (evaporation, condensation, degassing) have a much greater effect on the chemical evolution of potential seepage waters than the small differences between currently accepted infiltration rates and those used in the THC seepage model. Furthermore, the present range in infiltration rates over the repository block is much greater than the small differences in the averages (BSC 2004 [DIRS 169565], Table 6.3-4), which are also a function of the actual area over which the averages are computed. This justifies the use of 6,16 , and $25 \mathrm{~mm} / \mathrm{yr}$ as the infiltration fluxes for the three climatic conditions.

\subsubsection{Thermal Properties}

The source for the thermal properties data listed in Table 4.1-1 of this report is DTN: LB0210THRMLPRP.001 [DIRS 160799]. Thermal properties for the UZ model layers have since been updated and a more recent source (DTN: LB0402THRMLPRP.001 [DIRS 168481]) is currently available. These new values provide corroboration for the older data set used here, because in most cases, especially for repository-level units, the new values are the same or very similar to the older ones. In addition, sensitivity analyses have been carried out to determine the impact of using the older thermal properties from DTN: LB0210THRMLPRP.001 [DIRS 160799] instead of the more recent values. The results of these analyses are presented in Section 6.5.5.5, and show that the choice of a thermal property data set has no significant effect on model predictions. Thus, the older data set (DTN: LB0210THRMLPRP.001 [DIRS 160799]) is justified for intended use within this model.

\subsubsection{Effective Thermal Conductivities for In-Drift Open Spaces}

The effective thermal conductivities for in-drift open spaces that are used in the THC seepage model are listed in Appendix E. The source for these numbers is an historic DTN, SN0002T0872799.009 [DIRS 153364]. These values are generated based on in-drift temperature predictions calculated for FY 01 Supplemental Science and Performance Analyses, Volume 1: Scientific Bases and Analyses (BSC 2001 [DIRS 155950], Section 5.4.1) (SSPA). 
The in-drift temperature predictions used by the SSPA are compared to those of the current multiscale thermohydrologic model (MSTHM), as given in Section 6.3 .8 of the accompanying report (BSC 2004 [DIRS 169565]). The differences are slight, indicating that the effective thermal conductivities, if recalculated, would be very similar to those used here. Because the effective thermal conductivity of the rock is much lower than that of the in-drift atmosphere, the rock properties dominate in terms of thermal-hydrologic effects, and the slight differences in the thermal conductivity of the in-drift air would have no effect on THC seepage model results. Thus, the historic values from DTN: SN0002T0872799.009 [DIRS 153364] are justified and sufficient for intended use in this model.

\subsubsection{Mineralogical Data}

These input data consist of mineral volume fractions per total solid volume and their reactive surface areas. Reactive surface areas are used to characterize minerals either in the matrix of the rock $\left(\mathrm{cm}^{2} / \mathrm{g}\right.$ mineral) or those on the surface of fractures $\left(\mathrm{m}^{2} / \mathrm{m}^{3}\right.$ of fracture medium, including pore space), respectively (see Section 6.4.3.1).

These data are taken from DTN: LB0101DSTTHCR1.002 [DIRS 161277] and DTN: LB0101DSTTHCR1.004 [DIRS 161279]. For convenience, these data are shown in Appendix A (volume fractions) and Appendix B (reactive surface areas), respectively.

The mineral abundances and surface areas used in the model simulations are calculated from core sample measurements, as explained in Section 6.2.2.2 (these data are presented and discussed here for reference only - they are not direct inputs). The rock matrix mineralogical data are for a stratigraphic column near the center of the repository, based on a surface borehole core (DTN: LA9908JC831321.001 [DIRS 113495]). The fracture mineralogical data are based on fracture mineral abundances in core from underground boreholes in the Exploratory Studies Facility (ESF), in the regions of the Single Heater Test (DTN: LA0009SL831151.001 [DIRS 153485]) and the Drift Scale Test (DTNs: LA9912SL831151.001 [DIRS 146447] and LA9912SL831151.002 [DIRS 146449]). Section 6.4.3 details the sources and methods for obtaining these data.

These two direct input DTNs are product output of a previous revision (REV01) of this report (BSC 2001 [DIRS 154426], Section 6.1.5 and Attachments II and IV). They were developed as input for model simulations. The previous report was revised because of changes in other input parameter sets and in model implementation. These changes had no effect on the mineralogical data in these DTNs, which are based upon the best available project information. Therefore, although these DTNs are product output from a superseded document, they are justified as sources for the mineralogical data used in the current report.

\subsubsection{Kinetic Data}

Kinetic data refer to the reaction rate constants $\left(k_{o}\right)$, activation energies $\left(E_{a}\right)$, and related data required to describe the rates of dissolution and precipitation of minerals as a function of temperatures and fluid chemistry. 
Reaction rate laws can take numerous forms, of which a restricted number are used for the model analyses. The form of these rate laws and their significance are described in Section 6.4.2. Listed kinetic parameters are defined and used in Equations 6.4-5 through 6.4-8.

Model simulations are conducted using the kinetic data from DTN: LB0307KNTDBRTM.001 [DIRS 164433]. These data are qualified for use in Appendix $\mathrm{H}$ of this document. For convenience, these data are shown in Table 4.1-3. Not listed in this table are salt phases that are quantitatively precipitated, using a normative approach, when grid cells dry out (Section 6.4.5). Upon rewetting, dissolution of these salt minerals (i.e., $\mathrm{NaNO}_{3}, \mathrm{~K}_{2} \mathrm{SO}_{4}, \mathrm{Na}_{2} \mathrm{SO}_{4}, \mathrm{MgSO}_{4}$, halite, sylvite) is kinetically limited (to ensure that solute concentrations do not exceed the ionic strength limit of the model), with a relatively fast rate constant $\left(10^{-6} \mathrm{~mol} / \mathrm{m}^{2} / \mathrm{s}\right)$.

Table 4.1-3. THC Model Kinetic Data

\begin{tabular}{|c|c|c|c|c|c|}
\hline MINERAL & $\begin{array}{c}\mathrm{k}_{+1-}\left(\mathrm{mol} \mathrm{m}^{-2} \mathrm{~s}^{-1}\right)^{\mathrm{a}} \\
\text { at } 298.15 \mathrm{~K}\end{array}$ & $E_{a}(\mathrm{~kJ} / \mathrm{mol})^{\mathrm{b}}$ & $\mathbf{m}^{c}$ & $n^{c}$ & Comment $^{d}$ \\
\hline $\begin{array}{c}\alpha \text {-Cristobalite } \\
\mathrm{SiO}_{2}\end{array}$ & $3.45 \times 10^{-13}$ & 68.9 & 1 & 1 & dissolution only \\
\hline $\begin{array}{l}\text { Quartz } \\
\mathrm{SiO}_{2}\end{array}$ & $4.52 \times 10^{-14}$ & 90.1 & 1 & 1 & dissolution only \\
\hline $\begin{array}{l}\text { Tridymite } \\
\mathrm{SiO}_{2}\end{array}$ & $3.45 \times 10^{-13}$ & 68.9 & 1 & 1 & dissolution only \\
\hline Amorphous silica & $7.32 \times 10^{-13}$ & 60.9 & 1 & 1 & dissolution \\
\hline $\mathrm{SiO}_{2}$ & $1.0 \times 10^{-10}$ & 50 & 4.4 & 1 & precipitation \\
\hline $\begin{array}{l}\text { Opal-proxy } \\
\mathrm{SiO}_{2}\end{array}$ & $7.32 \times 10^{-13}$ & 60.9 & 1 & 1 & dissolution only \\
\hline $\begin{array}{c}\text { Microcline }=\text { K-spar } \\
\mathrm{KAISi}_{3} \mathrm{O}_{8}\end{array}$ & $1.78 \times 10^{-13}$ & 36 & 1 & 1 & reversible \\
\hline $\begin{array}{l}\text { Albite-low } \\
\mathrm{NaAlSi}_{3} \mathrm{O}_{8}\end{array}$ & $7.08 \times 10^{-13}$ & 67.7 & 1 & 1 & reversible \\
\hline $\begin{array}{c}\text { Anorthite } \\
\mathrm{CaAl} 2 \mathrm{Si}_{2} \mathrm{O}_{8}\end{array}$ & $3.16 \times 10^{-12}$ & 67.7 & 1 & 1 & dissolution only \\
\hline $\begin{array}{c}\text { Illite } \\
\mathrm{K}_{0.5}\left(\mathrm{Mg}_{0.22} \mathrm{Al}_{1.78}\right) \\
\left(\mathrm{Si}_{3.72} \mathrm{Al}_{0.28}\right) \mathrm{O}_{10}(\mathrm{OH})_{2} \\
\end{array}$ & $2.0 \times 10^{-14}$ & 58.6 & 1 & 1 & reversible \\
\hline $\begin{array}{c}\text { Smectite-Ca } \\
\mathrm{Ca}_{0.145}\left(\mathrm{Mg}_{0.26} \mathrm{Al}_{1.74}\right) \\
\left(\mathrm{Si}_{3.97} \mathrm{Al}_{0.03}\right) \mathrm{O}_{10}(\mathrm{OH})_{2}\end{array}$ & $2.0 \times 10^{-14}$ & 58.6 & 1 & 1 & reversible \\
\hline $\begin{array}{c}\text { Smectite-Mg } \\
\left(\mathrm{Mg}_{0.405} \mathrm{Al}_{1.74}\right)\left(\mathrm{Si}_{3.97} \mathrm{Al}_{0.03}\right) \\
\mathrm{O}_{10}(\mathrm{OH})_{2}\end{array}$ & $2.0 \times 10^{-14}$ & 58.6 & 1 & 1 & reversible \\
\hline $\begin{array}{c}\text { Smectite-Na } \\
\mathrm{Na}_{0.29}\left(\mathrm{Mg}_{0.26} \mathrm{Al}_{1.74}\right) \\
\left(\mathrm{Si}_{3.97} \mathrm{Al}_{0.03}\right) \mathrm{O}_{10}(\mathrm{OH})_{2}\end{array}$ & $2.0 \times 10^{-14}$ & 58.6 & 1 & 1 & reversible \\
\hline $\begin{array}{c}\text { Sepiolite } \\
\mathrm{Mg}_{2} \mathrm{Si}_{3} \mathrm{O}_{7.5} \mathrm{OH} \cdot 3 \mathrm{H}_{2} \mathrm{O}\end{array}$ & $2.67 \times 10^{-14}$ & 58.6 & 1 & 1 & reversible \\
\hline $\begin{array}{c}\text { Kaolinite } \\
\mathrm{Al}_{2} \mathrm{Si}_{2} \mathrm{O}_{5}(\mathrm{OH})_{4}\end{array}$ & $1.0 \times 10^{-13}$ & $7.1( \pm 2.5)$ & 1 & 1 & reversible \\
\hline
\end{tabular}


Table 4.1-3. THC Model Kinetic Data (Continued)

\begin{tabular}{|c|c|c|c|c|c|}
\hline MINERAL & $\begin{array}{c}\mathrm{k}_{+1-}\left(\mathrm{mol} \mathrm{m}^{-2} \mathrm{~s}^{-1}\right)^{\mathrm{a}} \\
\text { at } 298.15 \mathrm{~K}\end{array}$ & $\mathrm{E}_{\mathrm{a}}(\mathrm{kJ} / \mathrm{mol})^{\mathrm{b}}$ & $\mathbf{m}^{\mathrm{c}}$ & $\mathrm{n}^{\mathrm{c}}$ & Comment $^{d}$ \\
\hline $\begin{array}{c}\text { Heulandite } \\
\mathrm{Ca}_{0.33} \mathrm{~K}_{0.04} \mathrm{Na}_{0.1} \\
\left(\mathrm{Al}_{0.8} \mathrm{Si}_{2.8} \mathrm{O}_{7.2}\right) \cdot 2.6 \mathrm{H}_{2} \mathrm{O}\end{array}$ & $5.66 \times 10^{-13}$ & 58.0 & 1 & 1 & dissolution \\
\hline $\begin{array}{c}\text { Clinoptilolite } \\
\mathrm{Ca}_{0.28} \mathrm{~K}_{0.08} \mathrm{Na}_{0.04} \\
\left(\mathrm{Al}_{0.68} \mathrm{Si}_{2.92} \mathrm{O}_{7.2}\right) \cdot 2.6 \mathrm{H}_{2} \mathrm{O}\end{array}$ & $2.37 \times 10^{-13}$ & 58.0 & 1 & 1 & reversible \\
\hline $\begin{array}{c}\text { Stellerite } \\
\mathrm{Ca}_{0.39} \mathrm{Na}_{0.01}\left(\mathrm{Al}_{0.79} \mathrm{Si}_{2.81} \mathrm{O}_{7.2}\right) \\
2.8 \mathrm{H}_{2} \mathrm{O}\end{array}$ & $5.66 \times 10^{-13}$ & 58.0 & 1 & 1 & reversible \\
\hline $\begin{array}{c}\text { Mordenite } \\
\mathrm{Ca}_{0.15} \mathrm{Na}_{0.21} \mathrm{~K}_{0.09}\left(\mathrm{Al}_{0.6} \mathrm{Si}_{3} \mathrm{O}_{7.2}\right) \\
2.2 \mathrm{H}_{2} \mathrm{O} \\
\end{array}$ & $5.66 \times 10^{-13}$ & 58.0 & 1 & 1 & reversible \\
\hline Calcite $^{\mathrm{e}}$ & $1.60 \times 10^{-6}$ & 48.1 & 1 & 1 & reversible \\
\hline $\mathrm{CaCO}_{3}$ & equilibrium & NA & NA & NA & local equilibrium \\
\hline $\begin{array}{c}\text { Gypsum } \\
\text { CaSO }_{4} \cdot 2 \mathrm{H}_{2} \mathrm{O}\end{array}$ & equilibrium & NA & NA & NA & local equilibrium \\
\hline $\begin{array}{l}\text { Fluorite } \\
\mathrm{CaF}_{2}\end{array}$ & $1.22 \times 10^{-7}$ & 0.0 & 1 & 2 & reversible \\
\hline $\begin{array}{c}\text { Hematite } \\
\mathrm{Fe}_{2} \mathrm{O}_{3}\end{array}$ & equilibrium & NA & NA & NA & local equilibrium \\
\hline Glass & $7.72 \times 10^{-15}$ & 91.0 & 1 & 1 & dissolution only \\
\hline
\end{tabular}

Source: DTN: LB0307KNTDBRTM.001 [DIRS 164433].

${ }^{a} \mathrm{~K}_{+/:}$: Dissolution/precipitation rate constants at $298.15 \mathrm{~K}$.

${ }^{b} E_{a}$ : Activation energy.

${ }^{c}$ Exponents $\mathrm{m}$ and $\mathrm{n}$ in Equations 6.4-5, 6.4-7, and 6.4-8.

"The comment "dissolution only" means precipitation of this mineral is not allowed; "reversible" indicates the same precipitation and dissolution rates apply.

${ }^{e}$ Calcite is fixed at local equilibrium in the THC seepage model, and kinetically limited in the DST THC submodel.

\subsubsection{Thermodynamic Data}

The source of the thermodynamic data is DTN: LB0307THMDBRTM.001 [DIRS 164434]. These data consist mostly of chemical equilibrium constants in logarithmic form, $\log (K)$, as a function of temperature (not to be confused with thermal conductivity, often described also using the letter $K$ ), for reactions describing the dissociation of secondary aqueous species, minerals, and gases involved in the model (Section 6.4.1). Molecular weight and diameter, molar volume, and ion size data for the calculation of aqueous activity coefficients are also included in the thermodynamic data sets. Kinetic rate constants, $k$ (always in lower case), are provided in a separate database discussed in Section 4.1.3 (also Sections 6.4.2 and 6.4.8) and are not to be confused with equilibrium constants, $K$.

For convenience, the thermodynamic data set is shown in Appendix C (zeolite phases used are those identified in Appendix C with names "heul/10-r02," "stell/10-r02," "mord/10-r02," and 
"clpt/10-r02," except for alternative data sets as discussed in Section 6.4.8). The mineralogical database represents a compendium of data from several sources, as described below. Only DTN: LB0307THMDBRTM.001 [DIRS164434] is direct input; the discussion below is provided so the reader can evaluate the appropriateness of the thermodynamic data in that DTN.

Most of the data in the direct input DTN (LB0307THMDBRTM.001 [DIRS164434]), are originally from the Yucca Mountain Project (YMP) thermodynamic database data0.ymp.R2 (DTN: MO0302SPATHDYN.000 [DIRS 161756]). Documentation of changes from the data0.ymp.R2 database is provided in DTN: LB0307THMDBDRTM.001 [DIRS 164434]. The most important changes from data0.ymp.R2 include:

- Aluminum aqueous species data consistent with thermodynamic data used in earlier revisions of this report. These aluminum data are derived from Pokrovskii and Helgeson (1995 [DIRS 101699]). In the weakly-acid-to-alkaline $\mathrm{pH}$ values covered in this study, and at temperatures below $150^{\circ} \mathrm{C}$, the Pokrovskii and Helgeson (1995 [DIRS 101699]) data yield essentially the same gibbsite solubility as the data currently in data0.ymp.R2 (DTN: MO0302SPATHDYN.000 [DIRS 161756]), and essentially the same pK values for the protonation of the $\mathrm{AlO}_{2}^{-}$(or $\mathrm{Al}(\mathrm{OH})_{4}{ }^{-}$) to $\mathrm{HAlO}_{2}$ (or $\left.\mathrm{Al}(\mathrm{OH})_{3}\right)$.

- Revised aqueous silica thermodynamic properties yielding solubility constants $(\log (\mathrm{K}))$ very similar to those reported by Rimstidt (1997 [DIRS 101709]) for quartz and Gunnarsson and Arnórsson (2000 [DIRS 160465]) for amorphous silica. These data are also consistent with thermodynamic data used in earlier revisions of this report, and provide more accurate amorphous silica solubilities than the data0.ymp.R2 data.

- Solubility constants for albite and anorthite from Arnórsson and Stefánsson (1999 [DIRS 153329], p. 173). These data are consistent with those used in earlier versions of this report and with the aqueous silica data used here.

- Solubility constants for K-feldspar adjusted to yield equilibration of the HD-PERM pore water (Table 6.2-1) with illite (below) and K-feldspar. This adjustment results in a Gibbs free energy value for this phase at $25^{\circ} \mathrm{C}$ within the range of literature data reported by Arnórsson and Stefánsson (1999 [DIRS 153329], Table 1) and within 700 calories of the value reported by Robie et al. (1979 [DIRS 107109]). Without this adjustment, calculated potassium concentrations in pore waters are too small.

- Revised clay (smectite and illite) data consistent with those used in earlier versions of this report. The revisions include $\log (\mathrm{K})$ values for illite derived from accurate solubility measurements by Kulik and Aja (1997 [DIRS 128132]), and $\log (\mathrm{K})$ values for smectites adjusted to yield equilibration as an ideal solid solution at $25^{\circ} \mathrm{C}$ with the HD-PERM pore water (Table 6.2-1). Without this revision, the calculated $\mathrm{pH}$ of pore waters through time, under ambient conditions (no thermal load), becomes unrealistically elevated (Section 6.5.5.2.1).

- Revised zeolite (stellerite, heulandite, mordenite, and clinoptilolite) data for consistency with new stellerite data reported by Fridriksson et al. (2001 [DIRS 160460]). Without this revision, an unrealistic calcium depletion is predicted to occur in pore waters under 
ambient conditions (no thermal load), due to the precipitation of large amounts of calcium zeolites (Section 6.5.5.2.1)

Of these changes, the last two have the most significant effect on simulation results compared to results obtained using the project database data0.ymp.R2 (DTN: MO0302SPATHDYN.000 [DIRS 161756]) (Section 6.5.5.1). The stellerite thermodynamic data in data0.ymp.R2 reflect a significantly higher stability for this mineral than what the new data from Fridriksson et al. (2001 [DIRS 160460]) suggest. The clay data in data0.ymp.R2 also reflect a greater stability than the revised data used here. More details on all changes from the data0.ymp.R2 database are provided in the documentation accompanying the data filed under DTN: LB0307THMBDRTM.001 [DIRS 164434].

Ambient simulations (Section 6.5.5.4) have been conducted using alternative data sets including the data0.ymp.R2 database. These ambient simulations have been run to provide a justification for the use of data from DTN: LB0307THMDBRTM.001 [DIRS 164434] (which include the changes described above). Sources of data for the alternative data sets are presented in Section 6.4.8.

\subsubsection{Water and Gas Chemistry}

Sources of water- and gas-chemistry data are provided in Table 4.1-1. The pore-water compositions used as inputs to the model simulations are shown in Table 4.1-4.

The only nearly complete pore-water analyses available at the start of these investigations, for samples collected from a repository unit near the repository footprint, were obtained in 1998 from the Tptpmn geologic unit in Alcove 5 near the DST. At the time, three pore-water samples were ultracentrifuged from Alcove 5 core. These analyses are reported in DTN: MO0005PORWATER.000 [DIRS 150930]. Two of these analyses with the closest compositions (HD-PERM-2 and HD-PERM-3, Table 4.1-4) have been averaged and the resulting composition, referenced hereafter as Alcove 5 or HD-PERM water (Section 6.2.2.1), is used as input to the THC model.

Although the HD-PERM waters are used as input into the THC seepage model and the DST THC submodel, storage and analysis conditions for these samples were not optimal, and may have affected sample chemistry. These samples were stored for several months prior to analysis, exceeding recommended EPA holding times for water analysis (BSC 2004 [DIRS 169900], Section 6.3.4.1.3). Such long hold times may affect the concentration of some ions-in particular, nitrate concentrations may be lowered by microbial reduction in the stored waters. Despite these issues, HD-PERM waters have been retained as model inputs because they have been used historically, and continued use allows more direct comparison with previous versions of the model. 
Table 4.1-4. Input Pore-Water Compositions

\begin{tabular}{|c|c|c|c|c|c|c|c|}
\hline \multicolumn{2}{|c|}{ Sample ID $\rightarrow$} & $\begin{array}{c}\text { ESF-HD-PERM-2 } \\
\left.\left(30.1^{\prime}-30.5\right)^{\prime}\right)^{\mathrm{a}} \\
(\text { (ESF Alcove 5) }\end{array}$ & 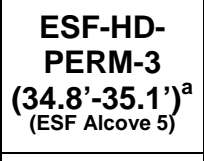 & $\begin{array}{c}\text { ECRB-SYS- } \\
\text { CS1000/7.3-7.7/UC }\end{array}$ & $\begin{array}{c}\text { ECRB-SYS- } \\
\text { CS2000/16.5- } \\
21.1 / U C^{b} \\
\end{array}$ & SD-9/990.4-991.7/UC & $\begin{array}{c}\text { ECRB-SYS- } \\
\text { CS500/12.0-16.7/UC }\end{array}$ \\
\hline \multicolumn{2}{|c|}{ Lithostratigraphic Unit $\rightarrow$} & Tptpmn & Tptpmn & Tptpul (base) & Tptpll & Tptpll & Tptpul \\
\hline & Units & & & & & & \\
\hline $\mathrm{pH}$ (measured) & $\mathrm{pH}$ & 8.32 & 8.31 & 7.6 & 7.4 & 7.9 & 8.0 \\
\hline $\mathrm{Na}^{+}$ & $\mathrm{mg} / \mathrm{L}$ & 61 & 62 & 39 & 130 & 84 & 57 \\
\hline $\mathrm{K}^{+}$ & $\mathrm{mg} / \mathrm{L}$ & 7 & 9 & 7.6 & 10.6 & 7.9 & 10.3 \\
\hline $\mathrm{Ca}^{+2}$ & $\mathrm{mg} / \mathrm{L}$ & 106 & 97 & 94 & 82 & 56 & 120 \\
\hline $\mathrm{Mg}^{+2}$ & $\mathrm{mg} / \mathrm{L}$ & 16.6 & 17.4 & 18.1 & 5.3 & 0.9 & 19.3 \\
\hline $\mathrm{SiO}_{2}$ & $\mathrm{mg} / \mathrm{L}$ & 31 (as Si) & 35 (as Si) & 42 & 48 & 50 & 49 \\
\hline $\mathrm{Cl}^{-}$ & $\mathrm{mg} / \mathrm{L}$ & 110 & 123 & 21 & 26 & 23 & 54 \\
\hline $\mathrm{SO}_{4}^{-2}$ & $\mathrm{mg} / \mathrm{L}$ & 111 & 120 & 36 & 39 & 10 & 78 \\
\hline $\mathrm{HCO}_{3}^{-}$(measured) & $\mathrm{mg} / \mathrm{L}$ & - & - & 333 & 382 & 313 & 286 \\
\hline $\mathrm{NO}_{3}^{-}$ & $\mathrm{mg} / \mathrm{L}$ & 3 & 10 & 2.6 & 4.2 & 17 & 6.1 \\
\hline $\mathrm{F}^{-}$ & $\mathrm{mg} / \mathrm{L}$ & 0.96 & 0.76 & 3.4 & 11 & 2.5 & 4.8 \\
\hline
\end{tabular}

${ }^{a}$ Pore water analyses from Alcove 5 (Tptpmn)are reported in DTN: MO0005PORWATER.000 [DIRS 150930]. The sample ID corresponds to the ESF borehole ID and is followed by the sampling depth in feet from collar.

${ }^{b}$ Pore water analyses from the ECRB cross-drift and borehole SD-9 are reported in DTN: GS020408312272.003 [DIRS 160899]. Note that, for ECRB samples, the sample ID contains the cross-drift station in meters (e.g., CS1000) and the sampled interval in feet from collar (e.g., 7.3-7.7). The ID of the SD-9 sample contains the sampled depth interval in feet from the ground surface. 
For the current THC model, five different input pore water compositions are used. In addition to HD-PERM, four additional waters have been chosen from a series of pore-water samples that were ultracentrifuged from core collected in the Enhanced Characterization of Repository Block (ECRB) Cross-Drift and from core obtained from the drilling of borehole SD-9. These samples were analyzed and the compositions are reported in DTN: GS020408312272.003 [DIRS 160899]. Four of these samples (ECRB-SYS-CS7.3-7.7/UC, ECRB-SYS-CS2000/16.521.1/UC, SD-9/990.4-991.7/UC, and ECRB-SYS-CS500/12.0-16.7/UC) and HD-PERM water have been selected as input water compositions for the THC seepage model (Table 4.1-4). The rationale for selecting these samples and determination of concentrations for constituents that were not measured is discussed in Section 6.2.2.1.

\subsubsection{Tptpll THC Model Grid}

Direct input sources of the THC model grid data are provided in Table 4.1-1. Stratigraphy is provided by DTN: LB99051233129.004 [DIRS 111475]; the THC model mesh, by DTN: LB0011DSTTHCR1.002 [DIRS 161282]; and model boundary conditions, by DTN: LB990701233129.002 [DIRS 125604]. These are historical data sets, slightly different than the current values. Justification for using older data sets for stratigraphy, THC model mesh, and boundary conditions is provided below. A more recent source of this data (DTN: LB03023DKMGRID.001 [DIRS 162354]) is referenced here for corroborative purposes only.

The geologic data for the Tptpll THC model is derived from the UZ model grid in DTN: LB99051233129.004 [DIRS 111475]. This DTN represents the UZ model grid that was current at the time the THC seepage modeling was performed; however, a more recent numerical grid for the UZ is now available (DTN: LB03023DKMGRID.001 [DIRS 162354]).

The stratigraphy of the Tptpll THC model is extracted at a location near the center of the repository (at approximately Nevada State Plane coordinates E170572, N233194). Geologic data from column ' $\mathrm{j} 34$ ' of the UZ model grid (DTN: LB990501233129.004 [DIRS 111475]) are used to map geologic contacts into the two-dimensional mesh. The elevations of the contacts between various geological layers as implemented in the Tptpll model are shown in Table 4.1-5. Table 4.1-5 also gives the thickness of each geological layer in Column ' $\mathrm{j} 34$ '. These thickness values have been adopted for the Tptpll THC model. The column closest to the location of Column ' $\mathrm{j} 34$ ' in the revised UZ numerical grid (DTN: LB03023DKMGRID.001 [DIRS 162354]) is Column ' $h 74$.' The elevations and thicknesses of each geological layer in Column ' $h 74$ ' in DTN: LB03023DKMGRID.001 [DIRS 162354] are also shown in Table 4.1-5 (fourth and fifth columns). The top elevations and thicknesses of the geological layers in Column ' $\mathrm{h} 74$ ' (revised) are comparable with those of Column 'j34' (adopted), particularly for the repository units. For example, for the 'tsw33', 'tsw34', 'tsw35', and 'tsw36' layers, the (adopted) thicknesses in Column 'j34' are $80.1 \mathrm{~m}, 37.2 \mathrm{~m}, 101.4 \mathrm{~m}$, and $33.2 \mathrm{~m}$, respectively. The respective (revised) values in Column ' $\mathrm{h} 74$ ' are $80.3,34.5,102.5$, and $32.7 \mathrm{~m}$. In the Tptpll THC model, the waste emplacement drift (and the source of heat) is located in the 'tsw35' geological layer. For this layer, the difference in adopted and revised thickness is only $1.1 \mathrm{~m}$ (or the difference is about one percent). The thickness of the 'tsw34' layer differs by about $2.7 \mathrm{~m}$ (or less than eight percent). However, the 'tsw34' layer is situated more than $50 \mathrm{~m}$ away from the source of heat in the Tptpll THC model and the impact of heating in the Tptpll THC model is 
not realizable that far away. Thus, the difference in thickness in the Tsw34 layer between the adopted and revised values is unlikely to have any impact on the thermal seepage simulations in the Tptpll model. The differences in thickness between adopted and revised values far away (both top and bottom) from the source of heat in the Tptpll THC model are similarly not expected to have any significant impact on the thermal seepage simulations. It is thus justified to use geological data from the older DTN (LB990501233129.004 [DIRS 111475]). No sensitivity analysis is considered necessary for this adaptation.

The model mesh is from DTN: LB0011DSTTHCR1.002 [DIRS 161282], which contains input and output files from an earlier revision of this document. This file has been superseded by more recent THC seepage model outputs. However, the supersession was due to changes in other input parameters (e.g., thermodynamic data) and updates in the model code to TOUGHREACT V3.0. The model mesh was not affected by these changes. In addition, the mesh is based on the stratigraphic column described in DTN: LB990501233129.004 [DIRS 111475], with node coordinates based on stratigraphic contacts between lithologic units. Thus, the stratigraphic data and model mesh are linked, and use of the stratigraphic data from DTN: LB990501233129.004 [DIRS 111475] requires use of the model mesh described in DTN: LB0011DSTTHCR1.002 [DIRS 161282]. The model boundary conditions (depth, pressure, etc.) described in DTN: LB990701233129.002 [DIRS 125604] are also, in part, linked to the assumed geologic column and dimensions of the model grid. Although the boundary conditions used in the THC model may vary slightly from currently accepted values, predicted water compositions within the near field (a few tens of meters from the drift) are not sensitive to these parameters. Therefore, stratigraphy in DTN: LB990501233129.004 [DIRS 111475], the model mesh from DTN: LB0011DSTTHCR1.002 [DIRS 161282], and the boundary conditions from DTN: LB990701233129.002 [DIRS 125604] are justified for intended use.

Table 4.1-5. Comparison of Adopted and Revised Values of Elevation and Thickness of Stratigraphic Layers for the THC Seepage Model (Tptpll Unit)

\begin{tabular}{|c|c|c|c|c|}
\hline \multirow[b]{2}{*}{$\begin{array}{l}\text { Model } \\
\text { Layer }\end{array}$} & \multicolumn{2}{|c|}{ Direct Inputs } & \multicolumn{2}{|c|}{ Corroborative Data } \\
\hline & $\begin{array}{l}\text { Adopted Elevation, } \\
\text { Column 'j34' in } \\
\text { LB990501233129.004 } \\
\text { (m) }\end{array}$ & $\begin{array}{l}\text { Adopted Thickness, } \\
\text { Column ' } \mathrm{j} 34 \text { ' in } \\
\text { LB990501233129.004 } \\
(\mathrm{m})\end{array}$ & \begin{tabular}{|c|} 
Revised Elevation, \\
Column 'h74' in \\
LB03023DKMGRID.001 \\
$(\mathrm{m})$
\end{tabular} & $\begin{array}{l}\text { Revised Thickness, } \\
\text { Column 'h74' in } \\
\text { LB03023DKMGRID.001 } \\
(\mathrm{m})\end{array}$ \\
\hline Top & 1446.6 & - & 1424.4 & - \\
\hline tcw11 & 1446.6 & 27.4 & 1424.4 & 3.6 \\
\hline tcw12 & 1419.2 & 77.1 & 1420.8 & 96.7 \\
\hline tcw13 & 1342.1 & 15.6 & 1324.1 & 5.3 \\
\hline ptn21 & 1326.5 & 3.4 & 1318.8 & 2.3 \\
\hline ptn22 & 1323.1 & 2.1 & 1316.5 & 5.1 \\
\hline ptn23 & 1321.0 & 2.8 & - & - \\
\hline ptn24 & 1318.2 & 5.5 & 1311.4 & 4.3 \\
\hline ptn25 & 1312.7 & 9.1 & 1307.1 & 7.9 \\
\hline ptn26 & 1303.6 & 9.5 & 1299.2 & 13.6 \\
\hline tsw31 & 1294.1 & 14.4 & 1285.6 & 2.0 \\
\hline \begin{tabular}{|l|} 
tsw32 \\
\end{tabular} & 1279.7 & 30.4 & 1283.6 & 39.1 \\
\hline \begin{tabular}{|l|} 
tsw33 \\
\end{tabular} & 1249.3 & 80.1 & 1244.5 & 80.3 \\
\hline tsw34 & 1169.2 & 37.2 & 1164.2 & 34.5 \\
\hline tsw35 & 1132.0 & 101.4 & 1129.7 & 102.5 \\
\hline
\end{tabular}


Table 4.1-5. Comparison of Adopted and Revised Values of Elevation and Thickness of Stratigraphic Layers for the THC Seepage Model (Tptpll Unit) (Continued)

\begin{tabular}{|c|c|c|c|c|}
\hline \multirow[b]{2}{*}{$\begin{array}{l}\text { Model } \\
\text { Layer }\end{array}$} & \multicolumn{2}{|c|}{ Direct Inputs } & \multicolumn{2}{|c|}{ Corroborative Data } \\
\hline & $\begin{array}{l}\text { Adopted Elevation, } \\
\text { Column 'j34' in } \\
\text { LB990501233129.004 } \\
(\mathrm{m})\end{array}$ & $\begin{array}{c}\text { Adopted Thickness, } \\
\text { Column 'j34' in } \\
\text { LB990501233129.004 } \\
(\mathrm{m})\end{array}$ & \begin{tabular}{|c|} 
Revised Elevation, \\
Column 'h74' in \\
LB03023DKMGRID.001 \\
$(\mathrm{m})$
\end{tabular} & $\begin{array}{l}\text { Revised Thickness, } \\
\text { Column 'h74' in } \\
\text { LB03023DKMGRID.001 } \\
\text { (m) }\end{array}$ \\
\hline tsw36 & 1030.6 & 33.2 & 1026.2 & 32.7 \\
\hline tsw37 & 997.4 & 16.6 & 993.5 & 23.1 \\
\hline tsw38 & 980.8 & 13.8 & 970.4 & 9.2 \\
\hline tsw39 & 967.0 & 10.1 & 961.2 & 4.1 \\
\hline $\operatorname{ch} 1 \mathrm{v}$ & 956.9 & 21.7 & 957.1 & 14.4 \\
\hline $\operatorname{ch} 2 \mathrm{v}$ & 945.2 & 13.3 & 942.7 & 12.9 \\
\hline $\operatorname{ch} 3 v$ & 931.9 & 12.7 & 929.8 & 12.8 \\
\hline $\operatorname{ch} 4 z$ & 919.2 & 12.8 & 917.0 & $\begin{array}{l}10.3 \\
\end{array}$ \\
\hline $\operatorname{ch} 5 z$ & 906.4 & 14.0 & 906.7 & 20.3 \\
\hline ch6 & 892.4 & 13.9 & 886.4 & 7.8 \\
\hline pp4 & 878.5 & 12.6 & 878.6 & 13.3 \\
\hline pp3 & 865.9 & 32.7 & 865.3 & 50.3 \\
\hline pp2 & 833.2 & 15.0 & - & - \\
\hline pp1 & 818.2 & 61.5 & 815.0 & 64.1 \\
\hline bf3 & 756.7 & 33.7 & - & - \\
\hline Bottom & 730.0 & - & 751.9 & 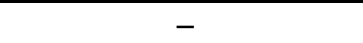 \\
\hline
\end{tabular}

Source: DTNs: LB990501233129.004 [DIRS 111475], LB03023DKMGRID.001 [DIRS 162354].

NOTE: The elevations in the second column above have been calculated by taking an average of the elevations at nodes of respective elements in the vertical column ' $j 34$.' Note also that in Column ' $h 74$ ' of DTN: LB03023DKMGRID.001 [DIRS 162354] there is no ptn23 geologic layer. Also, geologic layers pp2 and bf3 are absent in this column. The water table is located at $751.9 \mathrm{~m}$ at this column.

\subsubsection{Design Information}

Design information is specified in contrast to data resulting from measurements. Design information has evolved continuously as the THC seepage model has been developed, and current design-related parameters may vary slightly from the values used to generate the THC model output used by TSPA. Differences between the values used and currently accepted values are not expected to significantly affect model results because these results are primarily dependent on the initial water compositions, mineralogy, and applied heat load, and not on the specifics of in-drift engineered features. All direct input design parameters used in the THC model are summarized in Table 4.1-6, under the column "Model Direct Inputs." Current values are also presented in the table, for corroborative or informational purposes only. The parameters used in the model vary little from the currently accepted values, and these inputs are adequate and justified for the intended use in this model. Some design parameters are from DTN: SN9908T0872799.004 [DIRS 108437]; because the calculations summarized in that DTN were not verified, this data, specifically, has been qualified for project use in Appendix I of this document. 
Two time periods are considered in the THC seepage model:

- A 50-year preclosure period during which a large amount of the heat released by the waste packages is removed by ventilation (see below)

- A postclosure period immediately following the initial 50-year preclosure period and extending to 100,000 years (the total simulation time), during which a drip shield is located above the waste packages and no heat is removed by ventilation.

Accordingly, some of the drift-specific model-input design information is not the same for the preclosure and postclosure time periods. The model drift geometry and thermophysical properties of design elements are shown in Table 4.1-6 and Figure 4.1-1. This drift design information is the same as that used for Site Recommendation. However, an important difference from previous model revisions is that the drift is modeled here as open to both advective and diffusive fluxes of liquid and gas. As a result, hydrologic properties had to be assigned to open in-drift areas. These properties are included in Table 4.1-6. The discretization of the drift is consistent with the dimensions shown in Figure 4.1-1, within the limits imposed by the resolution of the model mesh.

The drip shield is not explicitly modeled as a barrier to gas transport, but its thickness and thermal conductivity have been considered in the width and thermal properties, respectively, of the open zone between the waste package and drip shield during the postclosure period. This has no effect on predicted THC seepage model water compositions because the thermal conductivity of the in-drift open spaces is much greater than that of the host rock. Thus, heat loss and predicted temperatures are controlled by the host rock thermal properties, and in-drift components have no significant effect. In addition, because of the high permeability of the invert, and the relative ease with which gas-phase diffusion and equilibration occur, a pathway for equilibration of in-drift atmosphere above and below the drip shield exists through the invert, and little difference in gas-phase composition would be expected.

The total (unventilated) heat load (Appendix D) in the model simulations was obtained from a historical repository design document (BSC 2002 [DIRS 159527]). The initial heat transfer from

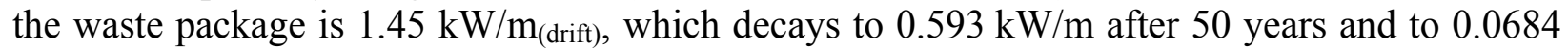
$\mathrm{W} / \mathrm{m}$ after 1,000 years. This is essentially the same heat load as the currently accepted values, as shown in D\&E / PA/C IED Typical Waste Package Components Assembly (BSC 2004

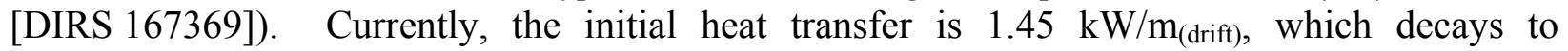
$0.592 \mathrm{~kW} / \mathrm{m}$ after 50 years and to $0.0677 \mathrm{~W} / \mathrm{m}$ after 1,000 years. The effect of such minor differences in heat load (1 percent or less at all times) is not expected to be significant relative to that of the choice of initial water composition. Because the heat loads used vary little from the currently accepted values, these inputs are adequate and justified for the intended use in this model. 


\begin{tabular}{|c|c|c|c|c|}
\hline \multirow[b]{2}{*}{ Parameter } & \multicolumn{2}{|c|}{ Model Direct Inputs $^{(\mathrm{a})}$} & \multicolumn{2}{|r|}{ Current value ${ }^{(\mathbf{b})}$} \\
\hline & Source & Value & Value & Source \\
\hline Drift spacing & $\begin{array}{l}\text { 800-IED-MGR0-00201-000-00B } \\
\text { (BSC 2004 [DIRS 168489]) }\end{array}$ & $81 \mathrm{~m}$ & $81 \mathrm{~m}$ & $\begin{array}{l}\text { 800-IED-MGR0-00201-000-00B } \\
\text { (BSC 2004 [DIRS 168489]) }\end{array}$ \\
\hline Drift diameter & $\begin{array}{l}\text { 800-IED-MGR0-00201-000-00B } \\
\text { (BSC 2004 [DIRS 168489]) }\end{array}$ & $5.5 \mathrm{~m}$ & $5.5 \mathrm{~m}$ & $\begin{array}{l}\text { 800-IED-MGR0-00201-000-00B } \\
\text { (BSC 2004 [DIRS 168489]) }\end{array}$ \\
\hline $\begin{array}{l}\text { Waste package outer } \\
\text { diameter }\end{array}$ & $\begin{array}{l}\text { 800-IED-WISO-00201-000-00E } \\
\text { (BSC } 2004 \text { [DIRS 169480]) (for } \\
\text { 44-BWR waste package) }\end{array}$ & $\begin{array}{l}1.67 \mathrm{~m} \\
\text { (rounded off from } \\
1.674 \mathrm{~m} \text { ) }\end{array}$ & $\begin{array}{l}1.318 \text { to } 2.110 \mathrm{~m} \\
(1.674 \mathrm{~m} \text { for } \\
\text { 44-BWR WP) }\end{array}$ & $\begin{array}{l}\text { 800-IED-WISO-00201-000-00E } \\
\text { (BSC } 2004 \text { [DIRS 169480]) }\end{array}$ \\
\hline $\begin{array}{l}\text { Top of invert as measured } \\
\text { from bottom of drift (invert } \\
\text { thickness) }\end{array}$ & $\begin{array}{l}\text { 800-IED-EBS0-00301-000-00A } \\
\text { (BSC } 2003 \text { [DIRS 162444]) }\end{array}$ & $\begin{array}{l}0.8 \mathrm{~m} \\
\text { (rounded off from } \\
0.806 \mathrm{~m} \text { ) }\end{array}$ & $0.864 \mathrm{~m}$ & $\begin{array}{l}\text { 800-SSO-SSE0-00102-000-00B } \\
\text { (BSC } 2004 \text { [DIRS 169776]) }\end{array}$ \\
\hline $\begin{array}{l}\text { Location of waste package } \\
\text { center above bottom of drift }\end{array}$ & $\begin{array}{l}\text { DTN: SN9908T0872799.004 } \\
\text { [DIRS 108437] }^{(\mathrm{C})}\end{array}$ & $1.945 \mathrm{~m}$ & 1.75 to $2.15 \mathrm{~m}$ & $\begin{array}{l}800-\text { IED-MGRO-00201-000-00B (BSC } \\
2004 \text { [DIRS 168489]) (center line of } \\
\text { waste package height above invert) and } \\
800-S S 0-S S E 0-00102-000-00 B \text { (BSC } \\
2004 \text { [DIRS 169776]) (invert thickness) }\end{array}$ \\
\hline $\begin{array}{l}\text { Location of waste package } \\
\text { center below the drift } \\
\text { springline }\end{array}$ & $\begin{array}{l}\text { DTN: SN9908T0872799.004 } \\
\text { [DIRS 108437] }^{\left({ }^{(0)}\right.}\end{array}$ & $0.805 \mathrm{~m}$ & 0.6 to $1.0 \mathrm{~m}$ & $\begin{array}{l}\text { BSC } 2004 \text { [DIRS 168489] (drift } \\
\text { diameter; center line of waste package } \\
\text { height above invert) and BSC } 2004 \\
\text { [DIRS 169776] (invert thickness) }\end{array}$ \\
\hline Drip shield thickness & $\begin{array}{l}\text { DTN: SN9908T0872799.004 } \\
\text { [DIRS 108437] }\end{array}$ & $0.02 \mathrm{~m}$ & $0.015 \mathrm{~m}$ & BSC 2004 [DIRS 169220], Table 5 \\
\hline $\begin{array}{l}\text { Air gap between waste } \\
\text { package surface and the } \\
\text { inside of drip shield }\end{array}$ & $\begin{array}{l}\text { DTN: SN9908T0872799.004 } \\
\text { [DIRS 108437] }^{\left({ }^{(0)}\right.}\end{array}$ & $0.396 \mathrm{~m}$ & 0.367 to $1.132 \mathrm{~m}$ & BSC 2004 [DIRS 168489], Figure 1 \\
\hline Inside radius of drip shield & $\begin{array}{l}\text { DTN: SN9908T0872799.004 } \\
\text { [DIRS 108437] }\end{array}$ & $1.231 \mathrm{~m}$ & $1.285 \mathrm{~m}$ & BSC 2004 [DIRS 168283] \\
\hline $\begin{array}{l}\text { Waste package thermal } \\
\text { conductivity }\end{array}$ & $\begin{array}{l}\text { DTN: SN9908T0872799.004 } \\
\text { [DIRS 108437] }^{(\mathrm{C})}\end{array}$ & $14.42 \mathrm{~W} / \mathrm{m} \mathrm{K}$ & $\begin{array}{l}10.1 \text { to } 15.5 \mathrm{~W} / \mathrm{m}^{*} \mathrm{~K} \\
\text { for Alloy } 22 ; 13.33 \\
\text { to } 17.83 \mathrm{~W} / \mathrm{m}^{*} \mathrm{~K} \text { for } \\
316 \text { stainless steel }\end{array}$ & $\begin{array}{l}\text { BSC } 2001 \text { [DIRS } 156276 \text { ], Table } 5-11 \\
\text { (Alloy } 22 \text {, for temperature range of } 48 \text { to } \\
300^{\circ} \mathrm{C} \text { ), Table } 5-13 \text { (316 stainless steel, } \\
\text { temperature range of } 22.11 \text { to } \\
287.78^{\circ} \mathrm{C} \text { ) }\end{array}$ \\
\hline Waste package density & $\begin{array}{l}\text { DTN: SN9908T0872799.004 } \\
\text { [DIRS 108437] }{ }^{(\mathrm{Cl})}\end{array}$ & $8189.2 \mathrm{~kg} / \mathrm{m}^{3}$ & $8690 \mathrm{~kg} / \mathrm{m}^{3}$ & $\begin{array}{l}\text { DTN: MO0003RIB00071.000 } \\
\text { [DIRS 148850] } \\
\text { Mass density of Alloy } 22\end{array}$ \\
\hline
\end{tabular}


Table 4.1-6. Drift and Committed Materials Model Parameters (Continued)

\begin{tabular}{|c|c|c|c|c|}
\hline \multirow[b]{2}{*}{ Parameter } & \multicolumn{2}{|c|}{ Model Direct Inputs $^{(a)}$} & \multicolumn{2}{|r|}{ Current value $^{(\mathbf{b})}$} \\
\hline & Source & Value & Value & Source \\
\hline Waste package specific heat & 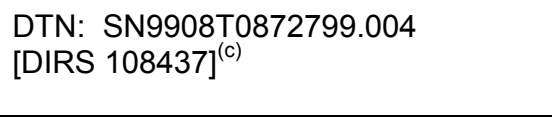 & $488.86 \mathrm{~J} / \mathrm{kg} \mathrm{K}$ & $378-731 \mathrm{~J} / \mathrm{kg} / \mathrm{K}$ & $\begin{array}{l}\text { BSC } 2004 \text { [DIRS 169990] } \\
\text { (homogeneous thermal properties for } \\
\text { waste package internal cylinder) }\end{array}$ \\
\hline Invert intrinsic permeability & $\begin{array}{l}\text { DTN: SN9908T0872799.004 } \\
\text { [DIRS 108437] }\end{array}$ & $6.152 \times 10^{-10} \mathrm{~m}^{2}$ & $\begin{array}{l}6.0 \times 10^{-10} \mathrm{~m}^{2}(3 \\
\mathrm{mm} \text { particle })^{(\mathrm{d})}\end{array}$ & $\begin{array}{l}\text { BSC } 2003 \text { [DIRS 170881], Section } 6.4 \\
\text { and Attachment XI }\end{array}$ \\
\hline Invert porosity & $\begin{array}{l}\text { DTN: SN9908T0872799.004 } \\
\text { [DIRS 108437] }{ }^{(\mathrm{C})}\end{array}$ & 0.545 & $0.55^{(\mathrm{d})}$ & $\begin{array}{l}\text { BSC } 2003 \text { [DIRS 170881], Attachment } \\
\text { XI }\end{array}$ \\
\hline Invert grain density & $\begin{array}{l}\text { DTN: SN9908T0872799.004 } \\
\text { [DIRS 108437] }{ }^{(\mathrm{C})}\end{array}$ & $2,530 \mathrm{~kg} / \mathrm{m}^{3}$ & $2530 \mathrm{~kg} / \mathrm{m}^{3(e)}$ & $\begin{array}{l}\text { BSC } 2003 \text { [DIRS 170881], Attachment } \\
\text { XI }\end{array}$ \\
\hline Invert specific heat & $\begin{array}{l}\text { DTN: SN9908T0872799.004 } \\
\text { [DIRS 108437] }{ }^{(\mathrm{C})}\end{array}$ & $948 \mathrm{~J} / \mathrm{kg} \mathrm{K}$ & $810 \mathrm{~J} / \mathrm{kg} / \mathrm{K}^{(\mathrm{f})}$ & $\begin{array}{l}\text { DTN: GS000483351030.003 } \\
\text { [DIRS 152932] }\end{array}$ \\
\hline $\begin{array}{l}\text { Invert thermal conductivity } \\
\text { (upper invert) }\end{array}$ & $\begin{array}{l}\text { BSC } 2002 \text { [DIRS 159906], Table 6-48 } \\
\left(100^{\circ} \mathrm{C} \text { data, average between ballast }\right. \\
\mathrm{K}=0.1 \text { and } 0.2 \mathrm{~W} / \mathrm{m}-\mathrm{K})\end{array}$ & $1.52 \mathrm{~W} / \mathrm{m} \mathrm{K}$ & Not in an IED & Not Applicable \\
\hline $\begin{array}{l}\text { Invert thermal conductivity } \\
\text { (lower invert) }\end{array}$ & $\begin{array}{l}\text { DTN: GS000483351030.003 } \\
\text { [DIRS 152932] }\end{array}$ & $\begin{array}{l}0.15 \mathrm{~W} / \mathrm{m} \mathrm{K} \\
\text { (value chosen based } \\
\text { on } 11 \text { samples } \\
\text { ranging from } 0.14 \text { to } \\
0.17 \text { ) }\end{array}$ & Not in an IED & Not Applicable \\
\hline $\begin{array}{l}\text { Open areas (linear capillary } \\
\text { pressure and relative } \\
\text { permeability functions) }\end{array}$ & $\begin{array}{l}\text { Model setup (Section 6.4.6, comment } \\
\text { 14) }\end{array}$ & & Not in an IED & Not Applicable \\
\hline Permeability & & $1 \times 10^{-9} \mathrm{~m}^{2}$ & & \\
\hline $\begin{array}{l}\text { Residual saturation (drift } \\
\text { wall/all other areas) }\end{array}$ & & & & \\
\hline Porosity & & 1.0 & & \\
\hline Capillary pressure & & $0.0 \mathrm{~Pa}$ & & \\
\hline
\end{tabular}


Table 4.1-6. Drift and Committed Materials Model Parameters (Continued)

\begin{tabular}{|c|c|c|c|c|}
\hline \multirow[b]{2}{*}{ Parameter } & \multicolumn{2}{|c|}{ Model Direct Inputs ${ }^{(a)}$} & \multicolumn{2}{|r|}{ Current value $^{(\mathbf{b})}$} \\
\hline & Source & Value & Value & Source \\
\hline Heat load & BSC 2002 [DIRS 159527] (Sheet 5) & $1.45 \mathrm{~kW} / \mathrm{m}$ (see text) & $1.45 \mathrm{~kW} / \mathrm{m}$ & $\begin{array}{l}\text { 800-IED-EBSO-00403-000-00B } \\
\text { (BSC } 2003 \text { [DIRS 167369]) }\end{array}$ \\
\hline Heat removal by ventilation & BSC 2002 [DIRS 160975], Table 6-6 & $86.3 \%$ & $88 \%$ & BSC 2004 [DIRS 169862], Table 8-2 \\
\hline $\begin{array}{l}\text { Invert capillarity (linear } \\
\text { capillary pressure function) }\end{array}$ & $\begin{array}{l}\text { Set equal to } 1 /(\text { Van Genuchten } \\
\text { alpha), with alpha }=1.2 \times 10^{-3} \mathrm{~Pa}^{-1} \\
\text { (rounded off from value in } \\
\text { DTN: SN9908T0872799.004 } \\
\text { [DIRS 108437]) }\end{array}$ & $833 \mathrm{~Pa}$ & 24 to $1517 \mathrm{~Pa}$ & BSC 2003 [DIRS 170881] \\
\hline Invert residual saturation & $\begin{array}{l}\text { DTN: SN9908T0872799.004 } \\
\text { [DIRS 108437] }^{(\mathrm{c})}\end{array}$ & 0.1 & $0.19^{(g)}$ & $\begin{array}{l}\text { DTN: LB0208UZDSCPMI.002 } \\
\text { [DIRS 161243] }\end{array}$ \\
\hline
\end{tabular}

(a) If a parameter value has not changed, the current source is given as direct input, rather than the original source.

(b) If current values and direct input values differ (most cases), the current values are presented as corroborative data (indirect inputs).

(c) Data from DTN: SN9908T0872799.004 [DIRS 108437] are qualified in Appendix I.

(d) The porosity of the invert is calculated using measured data (from the sources cited) for grain density $\left(2530 \mathrm{~kg} / \mathrm{m}^{3}\right)$ and bulk density (1150 $\left.\mathrm{kg} / \mathrm{m}^{3}\right)$ of crushed tuff sieved between 2.00 to $4.75 \mathrm{~mm}$.

(e) The grain density of invert material is the measured (from the source cited) grain density of crushed tuff sieved between 2.00 and 4.75 mm.

(f) The average specific heat (volumetric) of invert material for 11 samples (4-10 crushed tuff) listed in DTN: GS000483351030.003 [DIRS 152932] is 0.93 $\mathrm{J} / \mathrm{cm}^{3} /{ }^{\circ} \mathrm{C}$. Specific heat capacity (gravimetric) $=$ volumetric heat capacity $/$ bulk density. Bulk density $=$ invert grain density * $(1-$ porosity $)=\left(2530 \mathrm{~kg} / \mathrm{m}^{3}\right)$

$(1-0.545)=1151 \mathrm{~kg} / \mathrm{m}^{3}=1.15 \mathrm{~g} / \mathrm{cm}^{3}$. Thus specific heat capacity $=\left(0.93 \mathrm{~J} / \mathrm{cm}^{3} /{ }^{\circ} \mathrm{C}\right) / 1.15 \mathrm{~g} / \mathrm{cm}^{3}=0.810 \mathrm{~J} / \mathrm{g} /{ }^{\circ} \mathrm{C}=810 \mathrm{~J} / \mathrm{Kg} /{ }^{\circ} \mathrm{C}$.

(g) Residual saturation measured from rock core for the TSwM4 layer (Topopah Spring Tuff middle non-lithophysal unit). 
Ventilation efficiency denotes the fraction of heat removed from the repository as a result of ventilation during the 50-year preclosure period. The ventilation efficiency value adopted in this report is 86.3 percent. This value was reported in an earlier version of Ventilation Analysis and Model Report (BSC 2002 [DIRS 160975], Table 6-6), which has subsequently been revised to address repository design changes and to replace calculations that utilized unqualified software. The ventilation efficiency of 86.3 percent, which was the best estimate available at the time that the majority of the analyses in this report were conducted, is qualified for use in this report by corroboration with the more recent, qualified data presented above (the data qualification plan is included in Appendix H of BSC 2004 [DIRS 170338]). The integrated ventilation efficiency provided by current YMP reports is 88 percent (BSC 2004 [DIRS 169862], Table 8-2) when the emplacement drift is $600 \mathrm{~m}$ in length. The standard deviation of the calculated ventilation efficiency is 3 percent (BSC 2004 [DIRS 169862], Table 8-2). Thus, the $\pm 1 \sigma$ range is 85 percent to 91 percent for a 600 -m-long drift. The ventilation efficiency value used in this report falls within the $\pm 1 \sigma$ range of current values described above, and actually is similar to the mean ventilation efficiency of 86 percent for an 800-m-long emplacement drift (BSC 2004 [DIRS 169862], Table 8-2). Also, the impact of the minor difference between adopted and best-estimate values of ventilation efficiencies on water compositions in the drift vicinity is expected to be much smaller than the range of variability due to use of differing starting water compositions. Thus, the choice of ventilation efficiency value is justified for its intended use in this report.

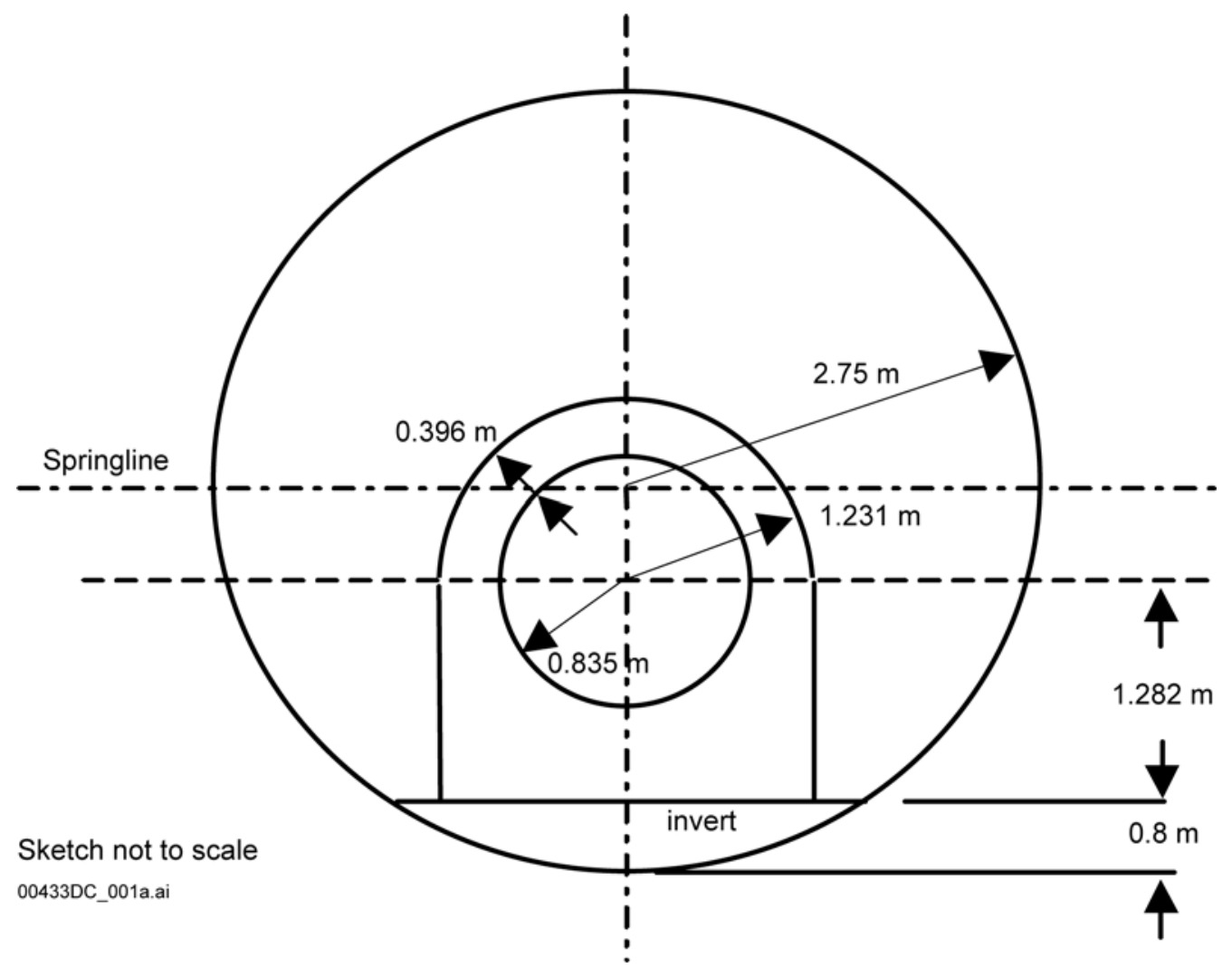

Source: Table 4.1-6.

Figure 4.1-1. Sketch Showing Modeled In-Drift Dimensions 
Heat transfer from the waste package to the drift wall is implemented in the model by using time-varying effective thermal conductivities (for open spaces within the drift) that have been calculated to account for radiative and convective heat transport. These time-varying variables are input into the model as coefficients (values between 0 and 1) for each open zone within the drift. Each zone is also assigned a constant maximum thermal conductivity $\left(K t h_{\max }\right)$, which is then multiplied by the corresponding time-varying coefficients to obtain effective conductivities as a function of time (DTN: SN0002T0872799.009 [DIRS 153364]; Appendix E).

The effective thermal conductivities (Section 4.1.1.4) and corresponding open zones of the drift prior to closure are not the same as those following closure. Only one open space between the waste package and the drift wall is considered for the preclosure period. For postclosure, two zones are considered: (1) the open space between the waste package and the drip shield (Inner Zone, drip shield included) and (2) the open space between the drip shield and the drift wall (Outer Zone) (Figure 4.1-1). Kth $h_{\max }$ values are listed in DTN: SN0002T0872799.009 [DIRS 153364]. For preclosure, $K t h_{\max }=10.568 \mathrm{~W} / \mathrm{m}-\mathrm{K}$ for the zone between the waste package and the drift wall. For postclosure, $K t h_{\max }=2.298 \mathrm{~W} / \mathrm{m}-\mathrm{K}$ for the Inner Zone (between the waste package and the drip shield), and $K t h_{\max }=14.407 \mathrm{~W} / \mathrm{m}-\mathrm{K}$ for the Outer Zone (between the drip shield and the drift wall). Accordingly, model runs are started with the preclosure thermal conductivities, then stopped after 50 years and restarted with the corresponding postclosure data.

The invert is divided into two zones with different thermal conductivities: $1.52 \mathrm{~W} / \mathrm{m}-\mathrm{K}$ for the upper half and $0.15 \mathrm{~W} / \mathrm{m}-\mathrm{K}$ for the lower half (Table 4.1-6). When the model was implemented, the design value for the invert thickness was $0.806 \mathrm{~m}$ (BSC 2003 [DIRS 162444]). The current value is $0.864 \mathrm{~m}$ (2 feet-10 inches) (BSC 2004 [DIRS 169776]). This change is minor and would not be expected to generate any difference in model output.

The implementation of the drift design in the model is further documented by Spycher (2001 [DIRS 160898], LBNL Scientific Notebook SN-LBNL-SCI-141-V1, pp. 11 to 14, 116 to 129). A summary of the hydrologic and thermal properties of repository units used in the current model is given in Table 6.4-1.

\subsection{CRITERIA}

Technical requirements to be satisfied by performance assessment are based on 10 CFR 63.114 [DIRS 156605]. These technical requirements are also identified in Project Requirements Document (Canori and Leitner 2003 [DIRS 166275], Section 3). The acceptance criteria that will be used by the U.S. Nuclear Regulatory Commission (NRC) to determine whether the technical requirements have been met are identified in Yucca Mountain Review Plan, Final Report (YMRP) (NRC 2003 [DIRS 163274]). The pertinent requirements and acceptance criteria for this report are summarized in Table 4.2-1. 
Table 4.2-1. Applicable Project Requirements and YMRP Acceptance Criteria

\begin{tabular}{|c|l|l|l|}
\hline $\begin{array}{c}\text { Requirement } \\
\text { Number }\end{array}$ & \multicolumn{1}{|c|}{ Requirement Title $^{\mathbf{a}}$} & \multicolumn{1}{|c|}{ 10 CFR 63 Link } & \multicolumn{1}{c|}{ YMRP Acceptance Criteria } \\
\hline PRD-002/T-015 & $\begin{array}{l}\text { Requirements for } \\
\text { Performance Assessment }\end{array}$ & $\begin{array}{l}\text { 10 CFR } \\
63.114(\mathrm{a})-(\mathrm{c}) \text { and } \\
\text { (e)-(g) } \\
\text { [DIRS 156605] }\end{array}$ & $\begin{array}{l}\text { Criteria 1 to 5 for Quantity and Chemistry of } \\
\text { Water Contacting Engineered Barriers and } \\
\text { Waste Forms }\end{array}$ \\
\hline
\end{tabular}

${ }^{\mathrm{a}}$ Canori and Leitner 2003 [DIRS 166275], Section 3.

The acceptance criteria identified in Section 2.2.1.3.3.3 of the YMRP (NRC 2003 [DIRS 163274]) are given below, followed by a short description of their applicability to this report:

- Acceptance Criterion 1, System Description and Model Integration Are Adequate:

The applicable subcriteria are:

Subcriterion 1. This subcriterion requires that the total system performance assessment adequately incorporates important design features, physical phenomena, and couplings, and uses consistent and appropriate assumptions throughout the quantity and chemistry of water contacting waste packages and waste forms abstraction process. This subcriterion is addressed in Sections 6.2, 6.3, and 6.4.

Subcriterion 2. This subcriterion requires that the abstraction of the quantity and chemistry of water contacting waste packages and waste forms uses assumptions, technical bases, data, and models that are appropriate and consistent with other related U.S. Department of Energy abstractions. Sections 5, 6, and 7 address this subcriterion regarding water chemistry.

Subcriterion 3. This subcriterion requires that important design features, including waste package design and thermal loading strategy, are adequately defined to determine initial and boundary conditions for calculations of the quantity and chemistry of water contacting engineered barriers and waste forms. Design criteria used as model inputs are addressed in Section 4.1.7.

Subcriterion 4. This subcriterion requires that spatial and temporal abstractions appropriately address physical couplings (thermal-hydrologic-mechanical-chemical). Sections 6.5.5.3 and 6.5.5.4 address this subcriterion.

Subcriterion 5. This subcriterion requires that sufficient technical bases and justifications be provided for total system performance assessment assumptions and approximations for modeling coupled thermal-hydrologic-mechanical-chemical effects on seepage and flow, the waste package chemical environment, and the chemical environment for radionuclide release. This subcriterion also requires that the effects of distribution of flow on the amount of water contacting the waste packages and waste forms be consistently addressed in all relevant abstractions. This report addresses coupled THC effects on 
water chemistry and flow in the UZ up to the drift wall (Section 6). It therefore addresses parts of this subcriterion.

Subcriterion 8. This subcriterion requires that adequate technical bases are provided, including activities such as independent modeling, laboratory or field data, or sensitivity studies, for inclusion of any thermal-hydrologic-mechanical-chemical couplings and features, events, and processes (FEPs). FEPs are addressed in Section 6.1, technical bases in Sections 6.2 to 6.4, modeling and sensitivity studies in Section 6.5 and in Section 6.3 , and modeling of field and laboratory experiments in Section 7.0, thus addressing this subcriterion.

Subcriterion 9. This subcriterion requires that performance-affecting processes that have been observed in thermal-hydrologic tests and experiments are included in the performance assessment. Simulations presented in this report reproduce coupled THC effects observed in thermal test (Section 7.1) and laboratory experiments (Sections 7.2 and 7.3) and, therefore, address this subcriterion.

Subcriterion 10. This subcriterion requires that likely modes for container corrosion are identified and considered in determining the quantity and chemistry of water entering the engineered barriers and contacting waste forms. The geochemical system used in the THC seepage model includes chemical components needed as inputs for modeling the corrosion environment. This subcriterion is addressed in Section 6.2.2.2, where the geochemical system is described.

Subcriterion 12. This subcriterion requires that peer review or data qualification be carried out following rigorous outlines. Peer review was not required for the analyses presented in this report. However, data collected prior to establishment of the current quality assurance program has been qualified (Section 4.0), as per LP-SIII.10Q-BSC, Models, and LP-SIII.2Q-BSC, Qualification of Unqualified Data, so this subcriterion has been addressed.

Subcriteria 6 and 7 are not applicable because they deal with the chemistry of water that could exist in the emplacement drifts in contact with engineered materials (ground support or invert materials) and with the waste package. This model considers only chemistry of water as it may exist in the volume of rock in the near-field around the repository drifts.

Subcriterion 11 is not applicable because the analyses presented in this report do not affect the evaluations of potential criticality.

- Acceptance Criterion 2, Data Are Sufficient for Model Justification:

The applicable subcriteria are:

Subcriterion 1. This subcriterion requires that geological, hydrologic, and geochemical values used in the safety case are adequately justified, and that adequate descriptions of how data are used, interpreted, and appropriately synthesized into the parameters are 
provided. This subcriterion is addressed in Sections 4.1, 6.2 (and in particular 6.2.2), 6.3, and 6.4.

Subcriterion 2. This subcriterion requires that sufficient data have been collected on the characteristics of the natural system and engineered materials to establish initial and boundary conditions for conceptual models of thermal-hydrologic-chemical coupled processes that affect seepage and flow and the waste package chemical environment. This report addresses parts of this subcriterion by considering variations in pore-water compositions (Sections 6.2.2 and 6.5.5) and rock properties (Sections 6.3 and 6.5) representative of the natural system.

Subcriterion 3. This subcriterion requires that thermal-hydrologic tests have been designed and conducted with the explicit objectives of observing thermal-hydrologic processes for the temperature ranges expected for repository conditions and making measurements for mathematical models. This subcriteria also requires that data are sufficient to verify that thermal-hydrologic conceptual models address important thermal-hydrologic phenomena. Section 7.1, which presents details on results of the Drift Scale Test and simulations reproducing results of this test, addresses this subcriterion.

Subcriterion 4. This subcriterion requires that sufficient information to formulate the conceptual approach(es) for analyzing water contact with the drip shield, engineered barriers, and waste forms be provided. Because this report determines water compositions in the host rock surrounding the drifts, which are passed to Engineered Barrier System: Physical and Chemical Environment Model (BSC 2004 DIRS 169860]) as potential seepage entering the drifts (Section 6.5.5), this subcriterion is addressed.

Subcriterion 5 is not applicable because it deals with the effects of microbial activity on the chemistry of water that could exist in the repository emplacement drifts. This model considers only chemistry of water as it may exist in the volume of rock in the near-field around the repository drifts.

- Acceptance Criterion 3, Data Uncertainty Is Characterized and Propagated Through the Model Abstraction:

Subcriterion 1. This subcriterion requires that models use parameter values, assumed ranges, probability distributions, and/or bounding assumptions that are technically defensible and that reasonably account for uncertainties and variabilities. This subcriterion is addressed by using ranges of input data (Section 6.2.2, pore-water composition) and alternative conceptualizations of the modeled systems (Section 6.3) to model uncertainty, also discussed in Section 6.6.

Subcriterion 2. This subcriterion requires that parameter values, assumed ranges, probability distributions, and bounding assumptions used in the calculations of quantity and chemistry of water contacting waste packages and waste forms are technically defensible and reasonable, based on data from the Yucca Mountain region (i.e., DST), and a combination of techniques that include laboratory experiments and field 
measurements and process-level modeling studies. This report addresses the parts of this subcriterion that relate to the uncertainty of the chemistry of water that could potentially enter drifts, with inputs and results discussed in Sections 6.2.2, 6.5.5, and 6.6 and validation, including the results of the DST and laboratory experiments, presented in Section 7.

Subcriterion 3. This subcriterion requires that input values used in the TSPA calculations of quantity and chemistry of water contacting engineered barriers (e.g., drip shield and waste package) are consistent with the initial and boundary conditions and the assumptions of the conceptual models and design concepts for the Yucca Mountain site. This criterion also requires that correlations between input values are appropriately established in the U.S. Department of Energy TSPA; that parameters used to define initial conditions, boundary conditions, and computational domain in sensitivity analyses involving coupled thermal-hydrologic-mechanical-chemical effects on seepage and flow, the waste package chemical environment, and the chemical environment for radionuclide release, are consistent with available data; and that reasonable or conservative ranges of parameters or function relations are established. This subcriterion is addressed with respect to the chemistry of water that could potentially enter drifts, with the conceptual models described in Sections 6.3 to 6.4, initial and boundary conditions discussed in Sections 6.5.2 and 6.3, and ranges of input parameters presented in Sections 6.5.3 and 6.3 .

Subcriterion 4. This subcriterion requires that adequate representation of uncertainties in the characteristics of the natural system and engineered materials be provided in parameter development for conceptual models, process-level models, and alternative conceptual models. This subcriterion also states that the U.S. Department of Energy may constrain these uncertainties using sensitivity analyses or conservative limits. This subcriterion is addressed by considering ranges of input parameters and alternative conceptualizations (Table 6-1 and Sections 6.2.2 and 6.3), as well as evaluations of the spread of model results (Section 6.6).

Subcriterion 5 is not applicable because the analyses presented in this report do not affect the evaluations of potential criticality.

Subcriterion 6 is not applicable because sufficient data were available in project sources such that expert elicitation was not required.

- Acceptance Criterion 4, Model Uncertainty Is Characterized and Propagated Through the Model Abstraction:

Subcriterion 1. This subcriterion requires that alternative modeling approaches of FEPs, consistent with available data and current scientific understanding, are investigated. This subcriterion also requires that the results and limitations are appropriately considered in the abstraction. This subcriterion is addressed by reviewing FEPs (Section 6.1), by using alternative conceptual models (Section 6.3), and evaluating model limitation and uncertainty (Sections 1.3, 6.6, and 8.4). 
Subcriterion 2. This subcriterion requires that alternative modeling approaches are considered and the selected modeling approach is consistent with available data and current scientific understanding, and the results and limitations and uncertainties of the chosen model are provided. This subcriterion is addressed by considering various model conceptualizations (Section 6.3), evaluating spread in model results (Section 6.5.5), and reporting on limitations and uncertainties (Section 1.3, 6.6, and 8.4).

Subcriterion 3. This subcriterion requires that consideration of conceptual model uncertainty is consistent with available site characterization data, laboratory experiments, field measurements, natural analogue information and process-level modeling studies; and that the treatment of conceptual model uncertainty does not result in an under-representation of the risk estimate. This subcriterion is addressed by using site-specific data (Section 4.1), as well as data from field and laboratory experiments (Section 7), and considering ranges of key input parameters (e.g. Section 6.2.2), alternative conceptualizations (Section 6.3), and spread in model results (Section 6.6).

Subcriterion 4. This subcriterion requires that adequate consideration is given to effects of thermal-hydrologic-mechanical-chemical coupled processes in the assessment of alternative conceptual models. These effects may include: (a) thermal-hydrologic effects on gas, water, and mineral chemistry; (b) effects of microbial processes on the waste package chemical environment for radionuclide release; (c) changes in water chemistry that may result from the release of corrosion products from the waste package and interactions between engineered materials and groundwater; and (d) changes in boundary conditions (e.g., drift shape and size) and hydrologic properties, relating to the response of the geomechanical system to thermal loading. This report addresses part (a) of this subcriterion through conceptual and mathematical models described in Sections 6.2 and 6.4, and model results presented in Section 6.5.5 and Section 6.3.

Subcriterion 5 is not applicable for this model because it does not contain a model for the total system performance assessment, nor does it make estimates that assess calculated compliance.

- Acceptance Criterion 5, Model Abstraction Output is Supported by Objective Comparisons:

Subcriterion 3. This subcriterion requires that accepted and well-documented procedures are used to construct and test the numerical models that simulate coupled thermalhydrologic-mechanical-chemical effects on seepage and flow, engineered barrier chemical environment, and the chemical environment for radionuclide release. It also requires that analytical and numerical models are appropriately supported, and that abstracted results are compared with different mathematical models, to judge robustness of results. This report addresses this subcriterion through conceptual and mathematical models described in Sections 6.2 and 6.4, and through evaluation of alternative conceptual models in Section 6.3.

Subcriteria 1 and 2 pertain to model abstraction results, and are not applicable to this model because the THC seepage model abstraction is done in the downstream report Post-Processing Analysis for THC Seepage (BSC 2004 [DIRS 169858]). 
Additional criteria are identified in the TWP (BSC 2005 [DIRS 172761]). Representativeness of model outputs is discussed in Section 6.2.2.1 of the report. The selection of input water compositions from various repository-level lithostratigraphic units has been made to encompass the natural variability in extant pore water compositions. In this way, the model results are sufficiently representative for locations throughout the repository footprint. Uncertainties in output parameters passed to down-stream users of the THC seepage model are discussed in Section 6.6. Boundary conditions used in the THC seepage model are established in other process model documents and in IEDs, and are presented and justified for intended use in Section 4.1. The report also addresses the following Condition Reports:

- CR79-Recategorization of Technical Information citations in DIRS.

- CR99-Model validation.

- CR168-Qualification status of the data0.ymp.R2 database.

- CR821-Ensure that adequate justification is given for use of any data formerly classified as Technical Information.

- CR938-Ensure that assumptions have sufficient basis, and do not require additional confirmation or future work.

- CR1805-Verify that software is adequate for its intended use and used within its range of validation.

- CR1821-Ensure that material included on model report Errata Sheets undergoes the same reviews as the rest of the model report.

- CR2049-The criteria used to establish the adequacy of the scientific basis for the model and to demonstrate that the model is sufficiently accurate for its intended use must be consistent with parameter uncertainties and justified in the documentation.

- CR2050-Validate the model to the required level of confidence.

- CR2104-Incorporate errata into the model report.

\subsection{CODES, STANDARDS, AND REGULATIONS}

No specific, formally established codes, standards, or regulations, other than those discussed in Section 4.2 , have been identified as applying to this modeling activity. 


\section{ASSUMPTIONS}

Development of methodology for the numerical modeling of heat and fluid flow in unsaturated fractured porous media, calculation of mineral-water reactions, and transport of aqueous and gaseous species are discussed in Section 6. Many simplifications and approximations underlie this methodology, yet other simplifications and approximations are inherent in data that describe repository designs and associated parameters on which model simulations rely. In this section, only cases in which an assumption is made where there is an absence of data or information for the parameter or concept are described. These are listed below. Approximations and simplifications related to the development and implementation of the mathematical model applied for this study are presented as part of the model documentation in Section 6.4.6.

1. The THC model results, calculated for a repository in the Tptpll lithologic unit, are applicable to all lithologies intersected by the repository drifts-Analysis and results of this model are assumed to apply across the lithology of the entire repository drift, although the current THC seepage model results only provide output from the Tptpll lithologic unit. This assumption has several bases:

- Model simulations carried out in a previous revision of this report (Section 6.3) were run in both the Tptpmn and Tptpll lithologic units, and showed that the lithology had little effect on predicted water chemistries. Although the Tptpmn simulations have not been repeated with the current THC model, which uses different input parameters and differs conceptually in some ways from the earlier model, these developmental simulations provide confidence that the current model results are applicable over the stratigraphic section intersected by the repository.

- The repository horizon within the Topopah Spring Tuff (including the Tptpln, Tptpll, Tptpmn, and Tptpul units) is relatively uniform in composition. Peterman and Cloke (2002 [DIRS 162576]) analyzed twenty core samples, in duplicate, from the cross-drift within the four lithologic units constituting the repository level. All samples were compositionally similar with respect to major oxides and trace elements (Peterman and Cloke 2002 [DIRS 162576], Table 4), and normative mineral compositions (Peterman and Cloke 2002 [DIRS 162576], Figure 4, Table 5, p. 692). Samples vary by only 2 percent in $\mathrm{SiO}_{2}$ concentration, and plot as a tight cluster in the rhyolite field on the chemical rock classification diagram for igneous rocks $\left(\mathrm{SiO}_{2}\right.$ plotted against $\mathrm{Na}_{2} \mathrm{O}+\mathrm{K}_{2} \mathrm{O}$ ) (Peterman and Cloke 2002 [DIRS 162576], Figure 3, Table 4, p. 687). The tight clustering also indicates that the effect of localized mineral heterogeneity on large-scale rock compositions, due to the presence of minerals that precipitated from the vapor phase during cooling of the tuff, and low-temperature minerals, such as calcite and amorphous $\mathrm{SiO}_{2}$ (opal), is likely very small (Peterman and Cloke 2002 [DIRS 162576], pp. 695 to 696$)$.

- The five starting waters used in the current THC seepage model simulations have been chosen to represent the entire range of available pore water compositions, and include pore waters from three of the four repository-level lithologic units (Tptpll, Tptpmn, and Tptpul) (Section 6.2.2.1). 
2. THC model runs using the five starting waters adequately represent all possible seepage waters-The five starting waters (Section 6.2.2.1) have been chosen from available measured pore water compositions for repository-level lithologic units. These waters are plotted on Figure 6.2-4, and cover the spread of measured compositions. However, pore water samples are not available from all possible locations in the repository, and available data are assumed to be representative of all water chemistries actually present in the repository units. This assumption is supported in part by the chemical similarity of the four TSw lithostratigraphic units that will host the repository, as described in the previous assumption. Reaction with these rocks should homogenize many reactive mineral species and make large variations in the concentrations of nonconservative aqueous species (i.e., those that are unreactive and nonvolatile) from any single unit unlikely. This assumption is borne out by the available data (Figure 6.2-4); when the five starting waters were originally chosen, only about half the data were available (BSC 2004 [DIRS 168848], Figure 6.2-4). Pore water samples collected more recently fall within the range of the previous data and cluster in a similar fashion.

Additional support that these five waters adequately represent the range of pore water compositions is presented in Engineered Barrier System: Physical and Chemical Environment (BSC 2004 [DIRS 169860], Section 7.2.3). There, an evaluation of 38 different pore waters shows that, upon evaporation, they cluster similarly with respect to composition, and nearly in the same proportion, as the five pore waters used as THC simulation starting waters.

3. Water compositions in the fractures and matrix are identical, and the same water is present in all hydrogeologic units-The infiltrating water and initial fracture water chemical compositions are set to be the same as the initial matrix pore-water compositions, with minor adjustments for temperature and $\mathrm{PCO}_{2}$ at the upper boundary of the model. The basis for this assumption is that the pore waters must, at any given point in time, constitute the vast majority of the water in the rock column, because the total matrix porosity is much greater than the fracture porosity. Also, it is clear from model results that water-rock interactions blend out the effect of varying starting water compositions to a significant degree by controlling the concentrations of reactive species (Section 6.6).

Also, the same initial water compositions are used in all hydrogeologic units. This model simplification is justified because the THC model provides, as output, near-field water compositions, derived from grid blocks within $10 \mathrm{~m}$ of the drift center (water compositions from greater distances are of no interest). Also, since some thermodynamic and kinetic data, and initial concentrations, were adjusted so that ambient near-field pore water compositions are stable over time (e.g., are stable over ambient steady-state flow conditions), the effects of far-field water-rock interactions and changes in pore water compositions have been effectively eliminated.

4. Aqueous species are unreactive at solution concentrations greater than $\mathbf{4}$ molal-Upon boiling or evaporation, the aqueous phase is treated as unreactive and is not concentrated further, once its ionic strength reaches an input upper limit of 4 or if the liquid saturation drops below an input lower limit of $10^{-4}$ to $10^{-5}$. This ensures that the calculated ionic strength does not exceed the range of applicability of the activity coefficient model used 
(Section 6.4.1). Thus, reaction of aqueous components in concentrated (ionic strength greater than 4 molal) solutions does not occur. Transport is neglected if the liquid saturation drops below an input lower limit of $10^{-5}$, which is also below the residual saturation, but takes place at all values of the ionic strength. At liquid saturations this low, the total amount of dissolved mass present in any given model grid block is exceedingly small. Thus, ignoring chemical reaction for such small mass amounts (and over a limited time period) does not significantly affect the general computed trends of aqueous phase concentrations and precipitated mineral amounts over long periods of time and a wide range of liquid saturations. The salt phases that are formed during dryout are described in Section 6.4.5. These phases are available for dissolution upon rewetting (using a relatively fast dissolution rate of $10^{-6} \mathrm{~mol} \mathrm{~s}^{-1} \mathrm{~kg}_{\mathrm{H} 2 \mathrm{O}}{ }^{-1}$ ).

5. Axial transport effects would not significantly impact THC Seepage Model results - The THC seepage model is a two-dimensional slice through an emplacement drift at the center of the repository. Transport of heat and mass (liquid/vapor) in the third dimension, paralleling the drift, are not incorporated into the model. The effect of such transport on water chemistry is assumed to be negligible. Confidence in this assumption is gained by comparing the two-dimensional THC model results (with water-rock interactions turned off) and the three-dimensional MSTHM results (BSC 2004 [DIRS 169565], Section 6.3) for a repository-center location. The two models predict similar drift-wall temperatures for given waste package temperatures. The maximum waste package and drift wall temperatures from the THC seepage model are around $164^{\circ} \mathrm{C}$ and $141^{\circ} \mathrm{C}$, respectively (Figure 6.5-4). The MSTHM, for a similar mean infiltration case, predicts a drift-wall temperature around $139^{\circ} \mathrm{C}$ for the same waste package temperature (around $164^{\circ} \mathrm{C}$ ) (BSC 2004 [DIRS 169565], Figure 6.3-2).

6. In the event of complete drift collapse, the composition of potential seepage is assumed to be the same as seepage for uncollapsed drifts-In the low-probability-seismic collapsed-drift scenario, the drift opening collapses, and the resulting host-rock rubble completely fills the modified drift opening, from the outer surface of the drip shield out to the modified "drift wall." It is assumed that drift collapse will have no effect on potential seepage water compositions. Thermal-hydrologic simulation results for a complete drift-collapse scenario are presented in Multiscale Thermohydrologic Model (BSC 2004 [DIRS 169565], Section 6.3.7), and show that the main effect of the rubble is to thermally insulate the waste package, resulting in higher temperatures and extended boiling duration in the drift (relative to the no-collapse scenario). The effect of drift collapse on potential seepage compositions was evaluated in the now-historic Abstraction of Drift-Scale Coupled Processes (BSC 2004 [DIRS 169617], Section 6.3). Simulation results confirmed that the maximum waste package temperature increased, but also showed that water is diverted around the rubble zone, which extends to a radius of $11 \mathrm{~m}$ from drift center, due to capillary effects, such that the wetting front and high-saturation zones in the rock actually occur further from drift-center, and at lower temperatures (BSC 2004 [DIRS 169617], Section 6.3.5.2). Because it is waters at these locations that are sampled by the THC seepage model and passed to downstream models (see Section 6.5.5.2), and because lower temperature seepage waters are less corrosive than higher temperature waters (BSC 2004 [DIRS 169860], Section 6.13), this assumption is justified because it is conservative with respect to corrosion and radionuclide release. 


\section{INTENTIONALLY LEFT BLANK}




\section{MODEL DISCUSSION}

This section presents the conceptual and mathematical models implemented for the development of the drift-scale THC seepage model. Relevant FEPs are also briefly discussed in Section 6.1. Details on the conceptualization and mathematical treatment of the various coupled processes considered in the THC seepage model follow in Sections 6.2 through 6.4. The results of the THC seepage model are presented in Section 6.5, where coupled THC processes are evaluated for 100,000 years under boundary conditions that are varied to represent the effects of potential climatic change, two repository host units, various input water compositions, and other alternative model conceptualizations. Simulations are carried to 100,000 years to capture the entire duration of the thermal pulse and the return to ambient conditions. Model uncertainty, and the propagation of that uncertainty to downstream models, is discussed in Section 6.6. The validation of the THC seepage model is presented in Section 7. The model validation consists of simulating the water, gas, and mineral evolution in the Drift Scale Test using the DST THC submodel (Section 7.1) and laboratory water-rock interaction experiments (Sections 7.2 and 7.3). The laboratory experiments are used to compare simulated and measured water compositions evolved during interaction with crushed tuff and mineral precipitation patterns in a fracture where boiling and reflux are taking place. These validation simulations were run using a previous revision of the model with different model inputs, but they rely on the same conceptualizations and mathematical formulations presented in the current model, and provide additional confidence in the model.

The development of the THC seepage model is summarized in Table 6-1, which includes changes between model revisions and a summary of the various conceptualizations and sensitivities that have been considered over the course of model development.

Table 6-1. Summary of the Development of the THC Seepage Model

\begin{tabular}{|c|c|c|c|c|}
\hline & $\begin{array}{c}\text { Tptpmn THC Model } \\
\text { (REV01) } \\
\end{array}$ & $\begin{array}{c}\text { Tptpmn THC } \\
\text { Heterogeneous } \\
\text { Model (REV01) } \\
\end{array}$ & $\begin{array}{l}\text { Tptpll THC Model } \\
\text { (REV01) } \\
\end{array}$ & $\begin{array}{c}\text { THC Seepage Model } \\
\text { (Current Report } \\
\text { Revision; Tptpll } \\
\text { Unit) }\end{array}$ \\
\hline $\begin{array}{l}\text { Chronological order of } \\
\text { model development }\end{array}$ & 1 & 2 & 3 & 4 \\
\hline $\begin{array}{l}\text { Information provided by } \\
\text { this model }\end{array}$ & $\begin{array}{l}\text { Compare with the } \\
\text { Tptpll model } \\
\text { (REV01) to evaluate } \\
\text { the effect of host } \\
\text { hydrogeologic unit } \\
\text { and stratigraphic } \\
\text { location }\end{array}$ & $\begin{array}{l}\text { Compare with the } \\
\text { homogenous } \\
\text { Tptpmn model } \\
\text { (REV01) to evaluate } \\
\text { the effect of fracture } \\
\text { permeability } \\
\text { heterogeneity }\end{array}$ & $\begin{array}{l}\text { Compare with the } \\
\text { Tptpmn model } \\
\text { (REV01) to evaluate } \\
\text { the effect of host } \\
\text { hydrogeologic unit } \\
\text { and stratigraphic } \\
\text { location }\end{array}$ & $\begin{array}{l}\text { Provides feeds to } \\
\text { downstream models } \\
\text { (and indirectly to } \\
\text { TSPA) and evaluates } \\
\text { sensitivities to } \\
\text { various model } \\
\text { parameters and } \\
\text { conceptualizations }\end{array}$ \\
\hline TOUGHREACT version & 2.3 & 2.3 & 2.3 & 3.0 \\
\hline $\begin{array}{l}\text { Model dimensions: } \\
\text { Thermal loading } \\
\text { Ambient conditions } \\
\text { (baseline) }\end{array}$ & $\begin{array}{l}\text { Two-dimensional } \\
\text { Two-dimensional } \\
\text { (with drift) }\end{array}$ & $\begin{array}{l}\text { Two-dimensional } \\
\text { Two-dimensional } \\
\text { (with drift) }\end{array}$ & $\begin{array}{l}\text { Two-dimensional } \\
\text { Two-dimensional } \\
\text { (with drift) }\end{array}$ & $\begin{array}{l}\text { Two-dimensional } \\
\text { One-dimensional (no } \\
\text { drift) }\end{array}$ \\
\hline $\begin{array}{l}\text { Stratigraphic column } \\
\text { location }\end{array}$ & SD-9 & SD-9 & Center of repository & Center of repository \\
\hline $\begin{array}{l}\text { Host lithostratigraphic } \\
\text { unit }\end{array}$ & Tptpmn & Tptpmn & Tptpll & Tptpll \\
\hline
\end{tabular}


Table 6-1. Summary of the Development of the THC Seepage Model (Continued)

\begin{tabular}{|c|c|c|c|c|}
\hline & $\begin{array}{c}\text { Tptpmn THC Model } \\
\text { (REV01) }\end{array}$ & $\begin{array}{l}\text { Tptpmn THC } \\
\text { Heterogeneous } \\
\text { Model (REV01) }\end{array}$ & $\begin{array}{l}\text { Tptpll THC Model } \\
\text { (REV01) }\end{array}$ & $\begin{array}{c}\text { THC Seepage Model } \\
\text { (Current Report } \\
\text { Revision; Tptpll } \\
\text { Unit) }\end{array}$ \\
\hline \begin{tabular}{|l|} 
Heterogeneous \\
permeability
\end{tabular} & No & Yes & No & No \\
\hline \begin{tabular}{|l||} 
Geochemical system \\
(Table 6.2-2 for the current \\
"Extended" geochemical \\
system)
\end{tabular} & $\begin{array}{l}\text { Base }^{a} \\
\text { Extended }^{b}\end{array}$ & $\begin{array}{l}\text { Base }^{a} \\
\text { Extended }^{b}\end{array}$ & $\begin{array}{l}\text { Base }^{a} \\
\text { Extended }^{b}\end{array}$ & Extended \\
\hline $\begin{array}{l}\text { Input pore water } \\
\text { composition (Table 6.2-1) }\end{array}$ & ESF Alcove 5 & ESF Alcove 5 & ESF Alcove 5 & $\begin{array}{l}\text { ESF Alcove } 5 \\
\text { ECRB, } 500 \mathrm{~m} \\
\text { ECRB, } 1000 \mathrm{~m} \\
\text { ECRB, } 2000 \mathrm{~m} \\
\text { SD-9, } 990 \mathrm{ft}\end{array}$ \\
\hline Infiltration rates $(\mathrm{mm} / \mathrm{yr})$ & Stepped up 6, 16, 25 & Stepped up 6, 16, 25 & Stepped up 6, 16, 25 & $\begin{array}{l}\text { Stepped up } 6,16,25 \\
\text { Constant } 6 \text { (sensitivity) } \\
\text { Constant } 25 \\
\text { (sensitivity) } \\
\end{array}$ \\
\hline Heat Load $(\mathrm{kW} / \mathrm{m})$ & 1.45 & 1.45 & 1.45 & 1.45 \\
\hline \begin{tabular}{|l} 
Ventilation Period (yr) \\
\end{tabular} & 50 & 50 & 50 & 50 \\
\hline $\begin{array}{l}\text { Ventilation efficiency } \\
(\% \text { heat removal) }\end{array}$ & 70 & 70 & 70 & 86.3 \\
\hline Drift wall conceptualization & $\begin{array}{l}\text { Closed } \\
\text { to advective fluid flow }\end{array}$ & $\begin{array}{l}\text { Closed } \\
\text { to advective fluid flow }\end{array}$ & $\begin{array}{l}\text { Closed } \\
\text { to advective fluid flow }\end{array}$ & Open \\
\hline Invert thickness & 0.6 & 0.6 & 0.8 & 0.8 \\
\hline $\begin{array}{l}\text { Vapor-pressure lowering } \\
\text { due to capillary pressure }\end{array}$ & No & No & No & $\begin{array}{l}\text { Yes } \\
\text { No (sensitivity) } \\
\end{array}$ \\
\hline $\begin{array}{l}\mathrm{CO}_{2} \text { diffusion coefficient } \\
\text { change }\end{array}$ & None & None & None & $\begin{array}{l}\text { Six-fold increase } \\
\text { No change (sensitivity) }\end{array}$ \\
\hline $\begin{array}{l}\text { Improved treatment of } \\
\text { mineral precipitation at } \\
\text { boiling front }\end{array}$ & No & No & No & Yes \\
\hline \begin{tabular}{|l||} 
Chronological changes in \\
Mineralogy (Table $6.2-2$ \\
and Appendix A for current \\
values)
\end{tabular} & Initial data ${ }^{a}$ & No change & $\begin{array}{l}\text { Added fluorite and opal } \\
\text { as primary minerals in } \\
\text { host rock }\end{array}$ & $\begin{array}{l}\text { Added sepiolite and } \\
\text { removed goethite as } \\
\text { possible secondary } \\
\text { minerals }\end{array}$ \\
\hline $\begin{array}{l}\text { Main chronological } \\
\text { changes in thermal } \\
\text { properties (Table 6.4-1 for } \\
\text { current values) }\end{array}$ & Initial data ${ }^{a}$ & No change & \begin{tabular}{|l|} 
In Tptpll versus \\
Tptpmn: $23 \%$ and \\
$13 \%$ decrease in \\
effective $\mathrm{K}_{\text {dry }}$ and $\mathrm{K}_{\text {wet }}$, \\
respectively
\end{tabular} & $\begin{array}{l}\text { For Tptpll, } 6 \% \text { increase } \\
\text { in } \mathrm{K}_{\text {dry }} \text { and } 6 \% \\
\text { decrease in } \mathrm{K}_{\text {wet }} \\
\text { (effective values) }\end{array}$ \\
\hline $\begin{array}{l}\text { Main chronological } \\
\text { changes in hydrologic } \\
\text { properties (Table 6.4-1for } \\
\text { current values) }\end{array}$ & Initial data ${ }^{a}$ & $\begin{array}{l}\text { In Tptpmn fractures: } \\
\text { heterogeneous, } 4- \\
\text { order-of-magnitude } \\
\text { spread in fracture } \\
\text { permeabilities in } \\
\text { Tptpmn (3 different } \\
\text { realizations) }\end{array}$ & $\begin{array}{l}\text { In Tptpll versus } \\
\text { Tptpmn fractures: six } \\
\text { times higher } \\
\text { permeability, } 80 \% \\
\text { increase in porosity, } \\
\text { and six times higher } \\
\text { capillarity (1/alpha) }\end{array}$ & $\begin{array}{l}\text { In Tptpll fractures: } \\
62 \% \text { decrease in } \\
\text { permeability, } 47 \% \\
\text { decrease in porosity } \\
\text { and } 20 \% \text { decrease in } \\
\text { capillarity (1/alpha) }\end{array}$ \\
\hline
\end{tabular}

a See BSC 2004 [DIRS 168848], Table 6.2-2, for a summary of these values.

b The REV01 "Extended" geochemical system varies slightly from the current (BSC 2004 [DIRS 168848], Table 6.2-2).

NOTE: $\quad$ Sources of model input data and technical information shown here are discussed in Section 4 . 
The results of developmental (REV01) models will be discussed in context throughout Section 6 as alternative model conceptualizations (Section 6.3) and sources of information on model sensitivities and uncertainties (Section 6.6). The current THC model implements many improvements relative to these early models, including updated model input parameters, a change in the drift wall conceptualization (open versus closed), and a more accurate treatment of mineral precipitation at the boiling front (Section 6.4.5). Results of the current simulations are presented in Section 6.5, including model results for various input water compositions, infiltration rates, and two boiling/evaporation conceptual models, (including/excluding vapor-pressure lowering caused by capillary pressure). Simulations of ambient conditions using various sources of thermodynamic data are also presented in Section 6.5.5.5 as a means of justifying the thermodynamic data (Section 4) used in the model.

Product output from the THC seepage model is analyzed in Post-Processing Analysis for THC Seepage (BSC 2004 [DIRS 169858]), for use in downstream models in the in-drift chemical environment (BSC 2004 [DIRS 169860], Section 4.1), which directly feed the TSPA-LA.

\subsection{RELEVANT FEATURES, EVENTS, AND PROCESSES}

The results of this model abstraction are part of the basis for the treatment of features, events, and processes (FEPs) as discussed in Technical Work Plan for: Near-Field Environment and Transport: Coupled Processes (Mountain-Scale TH/THC/THM, Drift-Scale THC Seepage, and Post-Processing Analysis for THC Seepage) Report Integration (BSC 2005 [DIRS 172761], Section 2.1.5). FEPs that are relevant to the subject matter of this report and that are included in TSPA-LA are summarized in Table 6.1-1. Relevant FEPS that are excluded from TSPA-LA are listed in Table 6.1-2. In variance to the TWP, three FEPS (2.2.10.01.0A, 2.2.10.06.0A, and 2.2.11.02.0A) have been added to the list of excluded FEPS in Table 6.1-2.

These FEPS have been taken from the LA FEP list (DTN: MO0407SEPFEPLA.000 [DIRS 170760]). Each FEP is cross-referenced to the relevant section (or sections) in this report in Table 6.1-1. The discussions provided in this and other model and abstraction reports form the technical basis for evaluating these FEPs for TSPA-LA.

Table 6.1-1. Relevant Features, Events, and Processes Included in TSPA-LA

\begin{tabular}{|c|c|c|}
\hline LA FEP Number & FEP Name & $\begin{array}{l}\text { Sections Discussing } \\
\text { FEPs-Related Items }\end{array}$ \\
\hline 1.1.02.02.0A & Preclosure ventilation & 4.1 .7 \\
\hline 1.2.02.01.0A & Fractures & \begin{tabular}{|l|}
4.1 .1 \\
6.2 .1 \\
6.4 .3 \\
6.4 .4 \\
Tables $4.1-4,6.4-1$
\end{tabular} \\
\hline 1.3.01.00.0A & Climate change & \begin{tabular}{|l|}
4.1 .1 .2 \\
6.2 .1 .3 \\
6.5 .2 \\
Table 4.1-2 \\
\end{tabular} \\
\hline 1.4.01.01.0A & Climate modification increases recharge & $\begin{array}{l}4.1 .1 .2 \\
6.2 .1 .3 \\
6.5 .2\end{array}$ \\
\hline
\end{tabular}


Table 6.1-1. Relevant Features, Events, and Processes Included in TSPA-LA (Continued)

\begin{tabular}{|c|c|c|}
\hline LA FEP Number & FEP Name & $\begin{array}{l}\text { Sections Discussing } \\
\text { FEPs-Related Items }\end{array}$ \\
\hline $2.1 .08 .01 .0 \mathrm{~A}$ & Water influx at the repository & \begin{tabular}{|l|}
6.5 .2 (climate) \\
6.5.5.1 (climate) \\
6.5 .5 .2 (reflux) \\
8.2 \\
\end{tabular} \\
\hline 2.2.03.01.0A & Stratigraphy & \begin{tabular}{|l}
4.1 .1 \\
4.1 .6 \\
6.5 .1 \\
Table 4.1-5 \\
\end{tabular} \\
\hline 2.2.03.02.0A & Rock properties of host rock and other units & \begin{tabular}{|l|}
4.1 .1 \\
4.1 .2 \\
6.2 .1 \\
6.3 \\
6.4 .4 \\
6.4 .6 \\
6.5 .5 .5 \\
Tables $6.4-1,6.5-7$ \\
\end{tabular} \\
\hline 2.2.07.02.0A & Unsaturated groundwater flow in the geosphere & \begin{tabular}{|l|l|}
6.2 .1 \\
6.5 .5 .3 \\
\end{tabular} \\
\hline 2.2.07.04.0A & Focusing of unsaturated flow (fingers, weeps) & \begin{tabular}{|l|}
6.2 .1 \\
6.3 \\
8.2 \\
\end{tabular} \\
\hline 2.2.07.08.0A & Fracture flow in the UZ & \begin{tabular}{|l|}
6.2 .1 \\
6.4 .3 \\
6.4 .4 \\
8.2 \\
\end{tabular} \\
\hline 2.2.07.09.0A & Matrix imbibition in the UZ & 6.2.1 \\
\hline $2.2 .07 .10 .0 \mathrm{~A}$ & Condensation zone forms around drifts & $\begin{array}{ll}6.2 .1 \\
6.5 .5 .3 \\
\end{array}$ \\
\hline 2.2.07.11.0A & Resaturation of geosphere dryout zone & \begin{tabular}{|l|}
6.2 .1 \\
6.5 .5 .1 \\
6.5 .5 .2 \\
6.5 .5 .3 \\
8.2 \\
\end{tabular} \\
\hline 2.2.07.20.0A & Flow diversion around repository drifts & \begin{tabular}{|l|}
6.2 .1 \\
6.5 .5 .1 \\
6.5 .5 .3 \\
8.2 \\
\end{tabular} \\
\hline 2.2.08.01.0B & Chemical characteristics of groundwater in the $\mathrm{UZ}$ & \begin{tabular}{|l|}
4.1 .5 \\
6.2 .2 \\
6.5 .5 .2 \\
Table 4.1-4 \\
\end{tabular} \\
\hline $2.2 .08 .04 .0 \mathrm{~A}$ & $\begin{array}{l}\text { Redissolution of precipitates directs more corrosive } \\
\text { fluids to containers }\end{array}$ & \begin{tabular}{|l|}
6.4 .5 \\
6.5 .5 .2 \\
8.2 \\
\end{tabular} \\
\hline 2.2.08.12.0A & Chemistry of water flowing into the drift & \begin{tabular}{|l}
4.1 .5 \\
6.2 .1 .2 \\
6.2 .2 \\
6.5 .5 .2 \\
8.2 \\
Table 4.1-4 \\
\end{tabular} \\
\hline 2.2.10.03.0B & Natural geothermal effects on flow in the UZ & 6.5 .2 \\
\hline 2.2.10.10.0A & Two-phase buoyant flow/heat pipes & 6.2.1 \\
\hline
\end{tabular}

Source: DTN: MO0407SEPFEPLA.000 [DIRS 170760]. 
Table 6.1-2. Relevant Features, Events, and Processes Excluded from TSPA-LA

\begin{tabular}{|l|l|l|}
\hline \multicolumn{1}{|c|}{ LA FEP Number } & \multicolumn{1}{|c|}{ FEP Name } & \multicolumn{1}{|c|}{$\begin{array}{c}\text { Sections Discussing } \\
\text { FEPs-Related Items }\end{array}$} \\
\hline $2.2 .10 .12 .0 \mathrm{~A}$ & Geosphere dry-out due to waste heat & 6.2 .1 \\
& & 6.5 .5 .1 \\
8.2
\end{tabular}

Source: DTN: MO0407SEPFEPLA.000 [DIRS 170760].

\subsection{CONCEPTUAL MODEL}

This section describes the conceptual model underlying the drift-scale THC seepage model. The THC seepage model conceptualization is presented below in several parts. The first part deals with the conceptualization of the coupled processes that need to be taken into account to model water-gas-rock interactions in a heated unsaturated and fractured rock environment. In the second part, the conceptualization of the chemical system is presented and a rationale is laid out for selecting input water compositions, mineral phases, and chemical constituents included within the model. Finally, the conceptualization of the physical domain being modeled is discussed.

\subsubsection{Conceptualization of Coupled THC Processes}

The THC conceptual model underlies the numerical simulations of THC processes in the DST THC submodel and THC seepage model. The TH conceptual model must be able to describe processes involving liquid and vapor flow, heat transport, and thermal effects resulting from boiling and condensation. The THC conceptual model must treat the transport of aqueous and gaseous species, mineralogical characteristics and changes, and aqueous and gaseous chemistry. A conceptual model of reaction-transport processes in the fractured welded tuffs of the repository host rock must also account for different rates of transport in highly permeable fractures compared to the much less permeable rock matrix (Steefel and Lichtner 1998 [DIRS 144878], pp. 186 and 187). 
In addition to the unsaturated hydrologic properties required to simulate THC processes in the $\mathrm{UZ}$, the data necessary for the evaluation of THC processes include the initial and boundary water and gas chemistry, initial mineralogy, mineral volume fractions, reactive surface areas, equilibrium thermodynamic data for minerals, aqueous and gaseous species, kinetic data for mineral-water reactions, and diffusion coefficients for aqueous and gaseous species. The following subsections describe the conceptual model for thermal-hydrologic (TH), geochemical, and coupled THC processes in the fractured tuffs.

\subsubsection{TH Processes}

TH processes in the fractured welded tuffs at Yucca Mountain have been examined theoretically and experimentally since the early 1980s (Pruess et al. 1984 [DIRS 144801]; Pruess et al. 1990 [DIRS 100818]; Buscheck and Nitao 1993 [DIRS 100617]; Pruess 1997 [DIRS 144794]; Tsang and Birkholzer 1999 [DIRS 137577]; Kneafsey and Pruess 1998 [DIRS 145636]). A conceptual model showing the important $\mathrm{TH}$ processes occurring around a drift (as derived through these studies and through observations of the single heater test and the DST) is shown in Figure 6.2-1. This diagram also indicates (in boxes) the important parameters and issues addressed in the THC seepage model simulations. To summarize the processes as depicted in the figure, heat conduction from the drift wall into the rock matrix results in vaporization and boiling, with vapor migration out of matrix blocks into fractures. The vapor moves away from the drift through the permeable fracture network by buoyancy, by the increased vapor pressure caused by heating and boiling, and through local convection. In cooler regions, the vapor condenses on fracture walls, where it drains through the fracture network either down toward the heat source from above or away from the drift into the zone underlying the heat source. Slow imbibition of water from fractures into the matrix gradually leads to increases in the liquid saturation in the rock matrix. Under conditions of continuous heat loading, a dryout zone may develop closest to the heat source separated from the condensation zone by a nearly isothermal zone maintained at about the boiling temperature. Where this nearly isothermal zone is characterized by a continuous process of boiling, vapor transport, condensation, and migration of water back to the heat source (either by capillary forces or gravity drainage), this zone may be termed a heat pipe (Pruess et al. 1990 [DIRS 100818], p. 1235). 


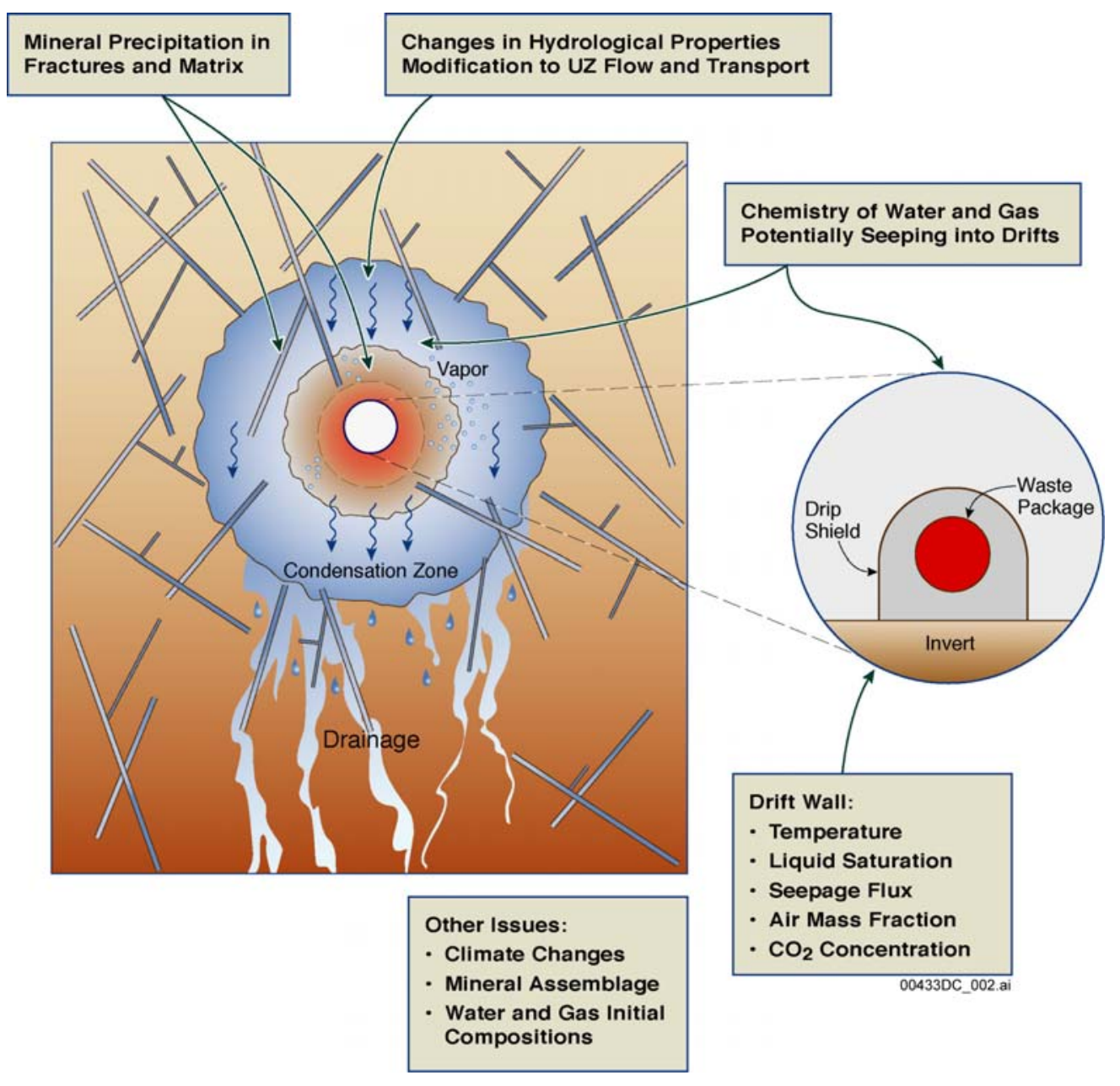

Figure 6.2-1. Schematic Diagram of THC Processes around a Heated Drift

\subsubsection{THC Processes}

The chemical evolution of waters, gases, and minerals is intimately coupled to the TH processes (boiling, condensation, and drainage) discussed in the previous section. The distribution of condensate in the fracture system determines where mineral dissolution and precipitation can occur in the fractures and where there can be direct interaction (via diffusion) between matrix pore waters and fracture waters. Figure 6.2-2 shows schematically the relationships between $\mathrm{TH}$ and geochemical processes in the zones of boiling, condensation, and drainage in the rock mass at the fracture-matrix interface outside of the drift and above the heat source. 


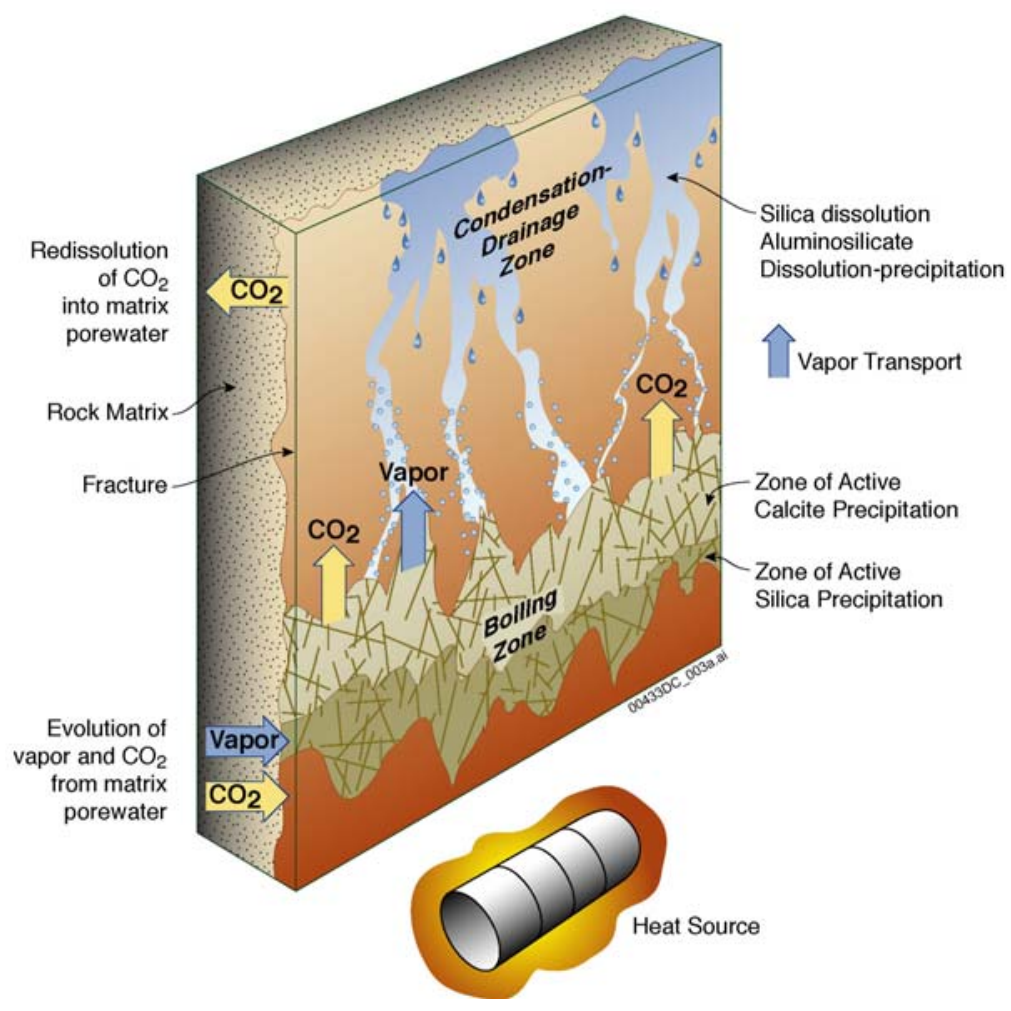

Figure 6.2-2. Schematic Diagram of Fracture-Matrix Interface Showing the Relation Between TH Processes and Geochemical Processes

One important aspect of the system is the exsolution of $\mathrm{CO}_{2}$ from the liquid phase as the temperature increases. The exsolution of $\mathrm{CO}_{2}$ in the boiling zone results in a local increase in $\mathrm{pH}$, and a decrease in $\mathrm{pH}$ in the condensation zone into which the vapor enriched in $\mathrm{CO}_{2}$ is transported and condensed. The extent to which the $\mathrm{pH}$ is shifted depends strongly on the rates of mineral-water reactions, which can buffer the change in $\mathrm{pH}$. Because the diffusivities of gaseous species are several orders of magnitude greater than those of aqueous species, and because the advective transport of gases can be more rapid than that of liquids, the region where $\mathrm{CO}_{2}$ degassing affects water and gas chemistry could be much larger than the region affected by the transport of aqueous species.

The effects of $\mathrm{TH}$ processes on water chemistry are varied and depend on the behavior of the dissolved species and their relation to mineral-water reactions. Conservative species (i.e., those that are unreactive and nonvolatile), such as chloride $\left(\mathrm{Cl}^{-}\right)$and nitrate $\left(\mathrm{NO}_{3}^{-}\right)$, become concentrated in waters undergoing vaporization or boiling, but are essentially absent from the vapor condensing in the fractures. Therefore, the concentration of conservative species in the draining condensate waters is determined by mixing with fracture waters and diffusive mixing with matrix pore waters.

More reactive aqueous species are affected by mineral precipitation-dissolution and ion exchange reactions, in addition to dilution and evaporative concentration as descirbed above. Calcium concentrations are affected by calcite dissolution or precipitation, by feldspar dissolution, and by ion exchange reactions involving $\mathrm{Ca}$-bearing zeolites and clays. Ion 
exchange is not explicitly included in the THC seepage model, but is represented by dissolution/precipitation of solid solutions for smectites, and of pure end-member compositions for other clays and zeolites. Similarly, magnesium concentrations are affected by ion exchange (the THC seepage model does not contain a magnesium zeolite, but magnesiun-bearing clay phases are included), and by precipitation-dissolution of sepiolite.

Sodium $\left(\mathrm{Na}^{+}\right)$and potassium $\left(\mathrm{K}^{+}\right)$are more conservative than the divalent ions, and concentrations are mainly controlled by evaporation (and salt precipitation at dryout conditions) and dilution, and, to a lesser degree, by feldspar dissolution reactions and ion exchange with clays and zeolites.

Aqueous silica $\left(\mathrm{SiO}_{2(\mathrm{aq})}\right)$ concentrations are controlled by precipitation of amorphous silica, as well as by dissolution and precipitation of other silicates.

Zonation in the distribution of mineral phases can occur as a result of differences in mineral solubility as a function of temperature. The inverse relation between temperature and calcite solubility (as opposed to the silica phases, which are more soluble at higher temperatures) can cause zonation in the distribution of calcite and silica phases in both the condensation and boiling zones (Figure 6.2-2). Precipitation of amorphous silica or another silica phase is likely to be confined to a narrower zone where evaporative concentration from boiling exceeds its solubility. In contrast, calcite could precipitate in fractures over a broad zone of elevated temperature and where $\mathrm{CO}_{2}$ has exsolved because of temperature increases or boiling. Alteration of feldspars to clays and zeolites is likely to be most rapid in the boiling zone because of their increased solubility (as well as having higher dissolution and precipitation rates) at higher temperatures (Lasaga 1998 [DIRS 117091], p. 66). In drainage zones, mineral alteration could be zoned within the rock matrix adjacent to a fracture, in a similar manner to that observed as a function of distance along the transport path (Steefel and Lichtner 1998 [DIRS 144878], p. 186).

In the THC seepage model, most precipitation and dissolution reactions are modeled as being kinetically limited (Section 6.4.2), with dissolution-precipitation rates that are a function of both temperature and the degree of saturation-undersaturation (the saturation index). Hence, species concentrations in solution at any given time and location are not controlled by the equilibrium thermodynamic condition, but rather by the influx rate, the rate of evaporation, and the rate of mineral dissolution in the grid cell of interest as countered by the rates of precipitation and outflow. For this reason, predicted solution compositions at any given location can be supersaturated with respect to a given mineral and remain so for extended periods of time.

When chemical species are transported in fracture waters at rates greater than the rate of equilibration with the rock matrix, disequilibrium will exist between waters in fractures and matrix, potentially leading to different precipitating mineral assemblages and differences in reaction rates. Because the system is unsaturated and undergoes boiling, the transport of gaseous species between matrix and fractures is also important. The separate yet interacting geochemical, hydrologic, and thermal processes in the fractures and the rock matrix are incorporated into a dual-permeability modeling approach. In this approach, each location in the model is represented by both matrix and fracture gridblocks, each with its own pressure and temperature, liquid saturation, water and gas chemistry, and mineralogy. Communication between the coinciding 
matrix and fracture gridblocks is implemented by advective and diffusive transport of aqueous and gaseous species (Section 6.2.1.5).

\subsubsection{Effects of Infiltration and Climate Changes on THC Processes}

Early in the thermal period of the repository, much of the chemistry of the UZ around drifts will be constrained by the chemistry of ambient fracture and matrix pore water, which could change as a result of boiling, dilution with condensate water, or mineral-water-gas reactions. Once the peak thermal period has subsided, percolating water will mix with the condensate above the repository and eventually rewet the dryout zone. The composition of the percolating waters (before mixing) could be similar to that presently found above the repository as matrix pore water, or it could be more dilute, reflecting wetter climate conditions. Changes in the percolation flux also affect the extent of mineral deposition and dissolution, because of the changes in the flux of dissolved species to the region around drifts. For example, the greater the flux of calcium, the more calcite would precipitate for a given initial calcium concentration in percolating water. Higher percolation fluxes could increase the dissolution rates of minerals that are undersaturated in the fluid because it could increase the degree to which the mineral is undersaturated.

\subsubsection{Hydrologic Property Changes in Fractures and Matrix}

Mineral precipitation and dissolution in fractures and matrix have the potential for modifying the porosity, permeability, and unsaturated hydrologic properties of the system. Because the molar volumes of minerals created by hydrolysis reactions (i.e., anhydrous phases, such as feldspars, reacting with aqueous fluids to form hydrous minerals, such as zeolites or clays) are commonly larger than the molar volumes of the primary reactant minerals, dissolution-precipitation reactions commonly lead to porosity reductions. The extent of mineral-water reaction is controlled by the surface areas of the mineral phases in contact with the aqueous fluid, and heterogeneity in the distribution of minerals in the fractures. Therefore, changes in porosity and permeability caused by these processes may also be heterogeneously distributed. Other factors that could lead to heterogeneity in property changes are the distribution of liquid saturation in fractures, proportion of fractures having actively flowing water, and rates of evaporative concentration due to boiling, which could change the dominant mechanisms of crystal growth and nucleation.

\subsubsection{Dual-Permeability Model for THC Processes}

Transport rates by fluid flow in fractures greater than the rate of equilibration via diffusion necessarily leads to disequilibrium between waters in fractures and matrix. This disequilibrium can lead to differences in the prevailing mineral assemblage and to differences in reaction rates. Because the system is unsaturated and undergoes boiling, the transport of gaseous species is an important consideration. The model must also capture the differences between the initial mineralogy in fractures and matrix and their evolution. These separate yet interacting processes in fractures and matrix have been treated by adapting the dual-permeability model to include geochemical as well as hydrologic and thermal processes. In the dual-permeability model, each grid-block is partitioned into matrix and fracture continua, each characterized by its own pressure, temperature, liquid saturation, water and gas chemistry, and mineralogy. Figure 6.2-3 
illustrates the dual-permeability conceptual model used for THC processes in the drift-scale THC seepage model and the DST THC submodel.

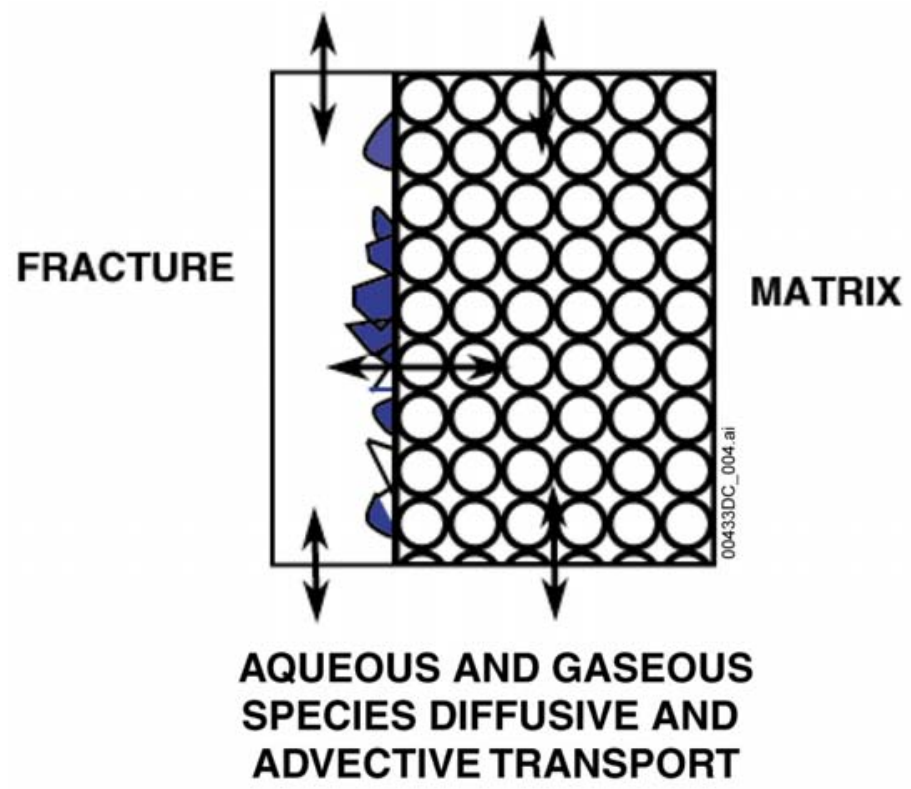

NOTE: Arrows refer to aqueous and gaseous species transport pathways. Angular objects in the fracture are minerals coating the fracture surface.

Figure 6.2-3. Conceptual Model (Schematic) for Reaction-Transport Processes in Dual-Permeability Media

As summarized in the preceding subsection, the conceptual model for THC processes incorporates a wide range of coupled physical and chemical processes. The following subsection describes the implementation of this conceptual framework into a numerical model.

\subsubsection{Conceptualization of the Geochemical System}

The rationale used for defining the types and concentrations of chemical constituents (solid and gaseous) included in the THC seepage model is presented below. This discussion includes the selection of initial pore-water and pore-gas compositions and description of the geochemical system. The geochemical system includes the aqueous components used in the model, the types and initial abundances of "primary" minerals (those already present in the rock), and "secondary" minerals that may precipitate as the result of water-gas-rock interactions.

\subsubsection{Initial Pore-Water and Pore-Gas Chemistry}

The initial water composition input into the model could be chosen from either the pore-water chemistry in the UZ at or above the repository horizon, or from the perched water or saturated zone. The perched waters are generally much more dilute than UZ pore waters. Isotopic compositions $\left({ }^{36} \mathrm{Cl} / \mathrm{Cl},{ }^{18} \mathrm{O} /{ }^{16} \mathrm{O}, \mathrm{D} / \mathrm{H},{ }^{14} \mathrm{C}\right)$ and chloride concentrations suggest that the perched waters have a large proportion of late Pleistocene/early Holocene water (Levy et al. 1997 [DIRS 126599], p. 906; Sonnenthal and Bodvarsson 1999 [DIRS 117127], pp. 107 and 108). The saturated zone water is also more dilute than pore waters, and neither saturated nor perched 
water reflect calculated $\mathrm{CO}_{2}$ partial pressures consistent with $\mathrm{CO}_{2}$ concentrations in gas measured in the unsaturated zone in repository units. The saturated zone and perched-water compositions are, therefore, deemed poor candidates as initial input water compositions for the THC seepage model. Preference is given instead to actual pore waters from unsaturated regions within or above the repository units.

A conceptual model that explains the aqueous chemistry and background ${ }^{36} \mathrm{Cl} / \mathrm{Cl}$ isotopic ratios in the Exploratory Studies Facility (ESF) holds that percolating water must pass mostly through the Paintbrush nonwelded hydrogeologic unit (PTn) matrix (because of its high permeability and low fracture density) before reverting to predominantly fracture flow in the Topopah Spring welded hydrogeologic unit (TSw). As discussed by Levy et al. (1997 [DIRS 126599], pp. 907 and 908), this seems to be true everywhere except near large structural discontinuities in the PTn (i.e., faults). Hence, percolating water in the TSw ultimately had come predominantly through the PTn matrix. Analyses of PTn pore waters (and some at the top of the TSw) and many chloride analyses of TSw pore waters are consistent with this interpretation (Sonnenthal and Bodvarsson 1999 [DIRS 117127], pp. 140 and 141). The relatively higher concentrations of anions and cations in pore waters (compared to perched water) from the TSw, similar to PTn waters, are consistent with the premise that the waters had flowed through the PTn matrix.

The initial composition of water in fractures is taken to be the same as in the rock matrix throughout the model domain, using the same initial composition in all hydrogeologic units. The composition of water infiltrating the top of the model domain (in the Tiva Canyon welded hydrogeologic unit-TCw) is also set to be the same as the initial fracture and matrix pore-water composition, with the exception of minor changes related to a $\mathrm{pH}$ adjustment, reflecting a higher $\mathrm{CO}_{2}$ partial pressure and a lower temperature at the top model boundary than deeper into the model domain (see below). Setting nearly identical compositions for infiltration at the top model boundary and initial fracture-matrix waters is a simplification of the natural system to avoid having to consider complex near-surface geochemical and transport processes, such as evapotranspiration and biologically mediated reactions.

In the early stages of development of the THC seepage model, only a few nearly complete pore-water analyses from a repository unit were available. These were water ultracentrifuged from core samples collected from the Tptpmn geologic unit in Alcove 5 near the DST. Three water samples were analyzed (HD-PERM-1, HD-PERM-2, and HD-PERM-3) from the same suite of core and yielded very similar compositions. Two of these analyses with nearly identical compositions were averaged for use as an input water composition for the developmental THC seepage models (Table 6.2-1). This water has been retained as one of the input waters in the current model. Since then, a series of pore-water samples from repository host units has been analyzed. These samples were ultracentrifuged from core collected in the ECRB Cross-Drift and in boreholes SD-9 and NRG-7/7A. The compositions of these waters are shown on a Piper diagram in Figure 6.2-4 with the composition of HD-PERM samples and groundwater from well J-13. This figure also shows the hydrogeologic units from which the water samples were extracted. It is evident from Figure 6.2-4 that the span of potential initial water compositions for use in the THC seepage model is large. This figure also shows a tendency for samples from deeper hydrogeologic units to exhibit higher sodium (plus potassium) concentrations relative to calcium (plus magnesium) concentrations, and a higher proportion of aqueous carbonate (relative to chloride and sulfate) compared to shallower waters. The sodium increase relative to calcium 
with depth has been noted previously in pore waters from hydrogeologic units above and below the repository units (Yang et al. 1996 [DIRS 100194], p. 13). It is likely caused by the hydrolysis of volcanic glass and feldspars and, mostly below the repository units, exchange reactions with zeolites (BSC 2002 [DIRS 160247]; Vaniman et al. 2001 [DIRS 157427]). The precipitation of calcite in fractures under the ambient geothermal gradient would also exacerbate the decrease in calcium relative to sodium concentrations with depth. Trends in carbonate concentrations relative to chloride and sulfate concentrations are subject to large uncertainties as a result of the determination of total aqueous carbonate concentrations. An increase in aqueous carbonate concentration with depth could be attributed to the $\mathrm{pH}$ increase expected to accompany glass and feldspar hydrolysis reactions.

The differences in the proportions (not absolute values) of cations and anions in analyzed waters have an important bearing on the types of residual brines that could develop upon evaporation and boiling due to thermal loading (BSC 2004 [DIRS 169863], Section 6.3.2). Should these waters seep onto the surface of a hot waste package, knowledge of their end-brine composition is important to assess the likelihood and intensity of waste package corrosion (BSC 2004 [DIRS 169860], Section 6.1). Therefore, the span of selected input water compositions should take into account factors that influence the end-brine composition of these waters. One important factor is whether calcium (or magnesium) chloride brines could develop instead of sodium chloride brines. Calcium chloride brines persist to higher temperatures (i.e., exist at a lower relative humidity, more hygroscopic) than sodium chloride brines, and are potentially deleterious with respect to corrosion. No simple a priori criteria have been developed to determine with certainty the end-brine composition of a given water, but calcium chloride brines are more likely to form if the total calcium concentration (in meq/L) exceeds the total aqueous carbonate concentration (in meq/L) in the initial water (calcite precipitation chemical divide, Drever 1997 [DIRS 140067]). Waters with such compositions would have a tendency to plot in the upper half of the diamond-shaped area in Figure 6.2-4, although other waters may also plot in this area if their magnesium concentrations are high relative to calcium. Other chemical divides after calcite precipitation (Drever 1997 [DIRS 140067], p. 331; Rosenberg et al. 2001 [DIRS 154862], p. 1,238) could result in the development of brines that are potentially less deleterious than calcium or magnesium chloride, even though the calcium content of the original waters (in equivalents) exceeds the total carbonate content. 
Table 6.2-1. Input Pore-Water Compositions for the THC Seepage Model

\begin{tabular}{|c|c|c|c|c|c|c|c|c|c|c|c|}
\hline \multicolumn{2}{|c|}{ Sample ID: } & \multicolumn{2}{|c|}{$\begin{array}{l}\text { HD-PERM }^{\mathrm{a}} \\
\text { (Alcove 5) }^{-}\end{array}$} & \multicolumn{2}{|c|}{$\begin{array}{c}\text { ECRB-SYS- } \\
\text { CS1000/7.3-7.7/UC }\end{array}$} & \multicolumn{2}{|c|}{$\begin{array}{c}\text { ECRB-SYS- } \\
\text { CS2000/16.5-21.1/UC2 }\end{array}$} & \multicolumn{2}{|c|}{ SD-9/990.4-991.7/UC ${ }^{b}$} & \multicolumn{2}{|c|}{$\begin{array}{c}\text { ECRB-SYS- } \\
\text { CS500/12.0-16.7/UC }^{b}\end{array}$} \\
\hline \multicolumn{2}{|c|}{ Lithostratigraphic Unit: } & \multicolumn{2}{|c|}{ Tptpmn } & \multicolumn{2}{|c|}{ Tptpul (base) } & \multicolumn{2}{|c|}{ Tptpll } & \multicolumn{2}{|c|}{ Tptpll } & \multicolumn{2}{|c|}{ Tptpul } \\
\hline \multicolumn{2}{|c|}{ Simulation Water ID: } & \multicolumn{2}{|c|}{ wo } & \multicolumn{2}{|c|}{ W5 } & \multicolumn{2}{|c|}{ W4 } & \multicolumn{2}{|c|}{ W6 } & \multicolumn{2}{|c|}{ W7 } \\
\hline \multicolumn{2}{|c|}{ Water Input Type: } & Fract/Matrix & Boundary & Fract/Matrix & Boundary & Fract/Matrix & Boundary & Fract/Matrix & Boundary & Fract/Matrix & Boundary \\
\hline & Units & & & & & & & & & & \\
\hline Temperature & ${ }^{\circ} \mathrm{C}$ & 25 & 17 & 25 & 17 & 25 & 17 & 25 & 17 & 25 & 17 \\
\hline $\mathrm{pH}$ (measured) & $\mathrm{pH}$ & 8.31 & - & 7.6 & - & 7.4 & - & 7.9 & - & 8.0 & - \\
\hline $\mathrm{pH}(\mathrm{calc})^{\mathrm{c}}$ & $\mathrm{pH}$ & - & 7.750 & 8.062 & 8.026 & 8.175 & 8.140 & 8.001 & 7.964 & 8.073 & 8.038 \\
\hline $\mathrm{Na}^{+}$ & $\mathrm{mg} / \mathrm{L}$ & 61.5 & 61.5 & 39 & 39 & 130 & 130 & 84 & 84 & 57 & 57 \\
\hline $\mathrm{K}^{+}$ & $\mathrm{mg} / \mathrm{L}$ & 8 & 8 & 7.6 & 7.6 & 10.6 & 10.6 & 7.9 & 7.9 & 10.3 & 10.3 \\
\hline $\mathrm{Ca}^{+2}$ & $\mathrm{mg} / \mathrm{L}$ & 101 & 101 & 94 & 94 & 82 & 82 & 56 & 56 & 120 & 120 \\
\hline $\mathrm{Mg}^{+2}$ & $\mathrm{mg} / \mathrm{L}$ & 17 & 17 & 18.1 & 18.1 & 5.3 & 5.3 & 0.9 & 0.9 & 19.3 & 19.3 \\
\hline $\mathrm{SiO}_{2}$ & $\mathrm{mg} / \mathrm{L}$ & 70.5 & 70.5 & 42.0 & 42.0 & 48 & 48 & 50 & 50 & 49 & 49 \\
\hline $\mathrm{Cl}^{-}$ & $\mathrm{mg} / \mathrm{L}$ & 117 & 117 & 21 & 21 & 26 & 26 & 23 & 23 & 54 & 54 \\
\hline $\mathrm{SO}_{4}^{-2}$ & $\mathrm{mg} / \mathrm{L}$ & 116 & 116 & 36 & 36 & 39 & 39 & 10 & 10 & 78 & 78 \\
\hline $\mathrm{HCO}_{3}^{-}$(measured) & $\mathrm{mg} / \mathrm{L}$ & - & - & 333 & - & 382 & 382 & 313 & - & 286 & - \\
\hline $\mathrm{HCO}_{3}^{-}(\text {calc })^{\mathrm{d}}$ & $\mathrm{mg} / \mathrm{L}$ & 200 & 216 & 395 & 400 & 515 & 515 & 335 & 338 & 412 & 417 \\
\hline $\mathrm{NO}_{3}^{-}$ & $\mathrm{mg} / \mathrm{L}$ & 6.5 & 6.5 & 2.6 & 2.6 & 4.2 & 4.2 & 17 & 17 & 6.1 & 6.1 \\
\hline $\mathrm{F}^{-}$ & $\mathrm{mg} / \mathrm{L}$ & 0.86 & 0.86 & 3.4 & 3.4 & $6.01^{\mathrm{e}}(11)$ & 5.52 & 2.5 & 2.5 & 4.8 & 4.8 \\
\hline $\mathrm{Al}^{+3}(\mathrm{calc})^{f}$ & molal & $6.173 \times 10^{-10}$ & $9.775 \times 10^{-11}$ & $1.112 \times 10^{-9}$ & $3.415 \times 10^{-10}$ & $1.082 \times 10^{-9}$ & $3.305 \times 10^{-10}$ & $1.00 \times 10^{-9}$ & $3.08 \times 10^{-10}$ & $8.061 \times 10^{-10}$ & $2.477 \times 10^{-10}$ \\
\hline $\mathrm{Fe}^{+3}(\mathrm{calc})^{\mathrm{g}}$ & molal & $1.155 \times 10^{-12}$ & $5.162 \times 10^{-13}$ & $1.138 \times 10^{-12}$ & $5.000 \times 10^{-13}$ & $1.143 \times 10^{-12}$ & $4.984 \times 10^{-13}$ & $1.14 \times 10^{-12}$ & $5.02 \times 10^{-13}$ & $1.138 \times 10^{-12}$ & $5.006 \times 10^{-13}$ \\
\hline $\log \left(\mathrm{PCO}_{2}\right)^{\mathrm{h}}$ & bar & -3.1 & -2.5 & -2.5 & -2.5 & -2.5 & -2.5 & -2.5 & -2.5 & -2.5 & -2.5 \\
\hline $\mathrm{CO}_{2}$ (approx) $)^{\mathrm{i}}$ & ppmv & 900 & 3100 & 3100 & 3100 & 3100 & 3100 & 3100 & 3100 & 3100 & 3100 \\
\hline
\end{tabular}

a Average of Tptpmn pore-water analyses ESF-HD-PERM-2 (30.1'-30.5') and ESF HD-PERM-3 (34.8'-35.1'), DTN: MO0005PORWATER.000 [DIRS 150930].

b Pore water analyses from the ECRB Cross-Drift and borehole SD-9 reported with DTN: GS020408312272.003 [DIRS 160899].

c $\mathrm{pH}$ calculated by speciation at the temperature and $\log \left(\mathrm{P}_{\mathrm{CO} 2}\right)$ shown (using SOLVEQ/CHILLER V1.0, LBNL 1999 [DIRS 153217]).

d Total aqueous carbonate as $\mathrm{HCO}_{3}^{-}$, calculated from charge balance computed by speciation at the temperature and $\mathrm{pH}$ shown (at measured $\mathrm{pH}$ for HD-PERM sample; at calculated pH for other samples) (using SOLVEQ/CHILLER V1.0). Note: these are slightly different values than values calculated from charge balance reported in DTN: GS020408312272.003 [DIRS 160899] because the latter do not include the effect of speciation.

e Value shown is calculated at equilibrium with fluorite at $25^{\circ} \mathrm{C}$. Value in parentheses is measured value.

$f$ Calculated by equilibrating with illite at the temperature and calculated pH shown (using SOLVEQ/CHILLER V1.0) (Section 6.2.2.1).

$g$ Calculated by equilibrating with hematite at the temperature and calculated pH shown (using SOLVEQ/CHILLER V1.0) (Section 6.2.2.1).

$\mathrm{h}$ Set at values shown except for HD-PERM sample at $25^{\circ} \mathrm{C}$ (calculated in this case) (Section 6.2.2.1).

i Approximate conversion assuming 1 bar total pressure.

NOTE: $\quad$ Compositions shown are those used for initial fracture and matrix water (column labeled "Fract/Matrix") and infiltration water at the model top boundary (column labeled "Boundary") 
The choice of input water composition must also consider the natural variability of pore-water compositions in the repository units. This natural variability is illustrated in Figure 6.2-4. The number of samples collected from a range of lithologies and infiltration regimes is too small to associate a probability of occurrence for any of these pore-water compositions. From the considerations discussed above, one could expect deeper waters to exhibit lower calcium and higher total carbonate concentrations and, therefore, be less conducive to the formation of calcium chloride brines. However, other factors could affect the spatial distribution of pore-water compositions in the repository units. These factors include variations in infiltration rates in various parts of the repository footprint (Sonnenthal and Bodvarsson 1999 [DIRS 117127], pp. 122 and 123) and possibly the presence or absence of ion-exchanging zeolites in areas above the repository. Furthermore, as noted above, the evolution of brine composition upon evaporation and boiling follows several other chemical divides besides the first calcite divide mentioned earlier.

Given these considerations, several initial water compositions have been selected for use in the current THC seepage model based on the following criteria:

(1) Capture the spread of pore-water compositions shown on Figure 6.2-4 and include, to the extent practicable, waters that may yield different end-brine compositions.

(2) Include at least one pore water from the most important repository host unit (Tptpll).

(3) Use analyses that show the best charge balance if more than one sample meets the other criteria.

(4) Limit the number of waters to limit overall computational effort.

On these bases, five water compositions have been selected and listed here with an arbitrary identification (W0, W5, etc.) assigned for this report:

"W0": HD-PERM water, from the Tptpmn unit in Alcove 5. This is an average composition (from Samples HD-PERM-2 and HD-PERM-3) used for all REV01 work. The HD-PERM samples plot higher than other pore waters on the diamond-shaped area in Figure 6.2-4, bounding the range of compositions in the calcium-sulfate-chloride field.

"W5": $\quad$ Sample CS-1000/7.3-7.7/UC, from the base of the Tptpul lithostratigraphic unit in the ECRB Cross-Drift. This sample was selected because it exhibits one of the highest $(\mathrm{Ca}+\mathrm{Mg}) /(\mathrm{Na}+\mathrm{K})$ ratios of the ECRB Cross-Drift samples and exhibits better charge balance than other samples with high $(\mathrm{Ca}+\mathrm{Mg}) /(\mathrm{Na}+\mathrm{K})$ ratios.

"W4": Sample CS-2000/16.5-21.1/UC, from the Tptpll lithostratigraphic unit in the ECRB Cross-Drift. This sample exhibits the lowest $(\mathrm{Ca}+\mathrm{Mg}) /(\mathrm{Na}+\mathrm{K})$ ratio of the ECRB Cross-Drift samples and exhibits better charge balance than other samples of similar composition. Also, this sample is from the main repository host unit and contains a higher fluoride concentration than the other samples. 


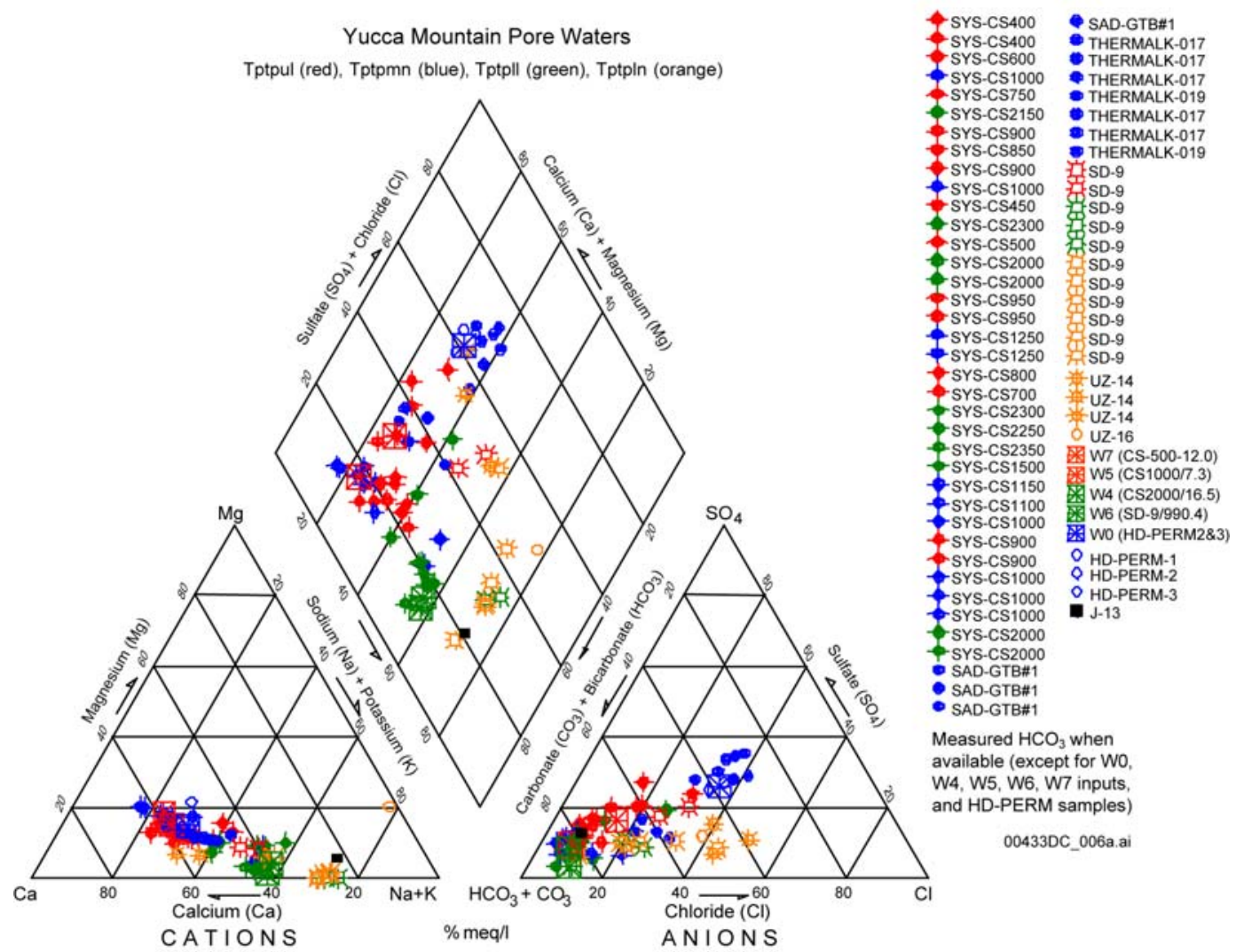

DTNs: GS030408312272.002 [DIRS 165226], GS020408312272.003 [DIRS 160899], GS020808312272.004 [DIRS 166569], GS031008312272.008 [DIRS 166570], MO0005PORWATER.000 [DIRS 150930].

NOTE: Samples labeled HD-PERM are pore waters from the Tptpmn unit in Alcove 5 of the ESF. Sample IDs starting with SYS-CS represent pore waters from the ECRB Cross-Drift and are listed in order of increasing distance $(\mathrm{m})$ into the drift (down stratigraphy). Additional borehole interval information after each SYS-CS sample labeling is sample interval distances from borehole collar given in feet. CS is the abbreviation for Construction Station, indicating distance along the ECRB Cross-Drift in meters.

THERMALK pore waters are from near the south bend of the ESF drift. SAD-GTB pore water samples are from the Alcove 7 area of the ESF. Sample ID's starting with SD-9, UZ-14, and UZ-16 represent pore waters from surface boreholes with the same names. The 5 starting waters are indicated (see text). DTN: GS020808312272.004 [DIRS 166569] is unqualified due to missing closing calibrations for electronic balances and NIST traceable weights. These data are included here to show the full spread of measured waters.

Figure 6.2-4. Piper Plot of Water Compositions (meq/L) from Repository Units

Upon further evaluation and a request from "downstream" project personnel, two additional samples have been considered:

"W6": Sample SD-9/990.4-991.7, from the Tptpll lithostratigraphic unit in borehole SD-9. This sample exhibits a low $(\mathrm{Ca}+\mathrm{Mg}) /(\mathrm{Na}+\mathrm{K})$ ratio nearly identical to that of W4, but exhibits a better charge balance than W4 and a higher nitrate concentration compared to most other samples. This water is very similar in composition to Water W4.

"W7": Sample CS500/12.0-16.7, from the Tptpul lithostratigraphic unit in the ECRB Cross-Drift. This sample plots between the HD-PERM waters and Water W5 on 
Figure 6.2-4, further capturing the variability of water compositions in the upper part of Figure 6.2-4.

The compositions of these waters are given in Table 6.2-1. This table also includes calculated concentrations used for input into the THC seepage model, and distinguishes between the compositions used for initial fracture and matrix waters and slightly adjusted compositions used for infiltration water at the top model boundary, as discussed further below.

It is shown in Figure 6.2-4 that the water compositions chosen for input into the THC seepage model capture the spread of currently available pore-water compositions in repository units. Water compositions W4, W5, and W6 plot in the lower half of the diamond-shaped area on Figure 6.2-4. The HD-PERM waters and W7 plot in the upper half of this area, and for this reason may be more likely to evolve toward a calcium chloride brine than the other waters upon evaporation.

As discussed in Section 5 (Assumption 2), binning analysis in Engineered Barrier System: Physical and Chemical Environment Model (BSC 2004 [DIRS 169860], Section 7.2.3) also indicates that the five chosen starting waters adequately encompass the variability in repository host rock pore water compositions.

The set of analyzed species for these samples does not include iron and aluminum. Because these components are needed to include aluminum silicates in simulations, their concentrations have been calculated assuming equilibrium with hematite and illite, respectively. Illite was chosen to set the initial aluminum concentration because waters from Yucca Mountain typically plot on, or near, the illite-K-feldspar equilibrium boundary (Wang 2003 [DIRS 161665], Notebook SN-LBNL-SCI-141-V2, pp. 176 and 184). Hematite is the most abundant iron oxide mineral found in the tuffs at Yucca Mountain and is a reasonable candidate to use for setting the initial iron concentration in solution.

The total aqueous carbonate concentration (reported here as $\mathrm{HCO}_{3}{ }^{-}$) was not measured in HD-PERM samples and has been calculated from charge balance, after full speciation calculations (using SOLVEQ/CHILLER V1.0 (LBNL 1999 [DIRS 153217])). Doing so yields a partial pressure of $\mathrm{CO}_{2}$ (at equilibrium with the HD-PERM water) near $10^{-3}$ bar, consistent with $\mathrm{CO}_{2}$ concentrations near 1,000 ppmv measured in repository units in the ESF (DTN: LB0208ISODSTHP.001 [DIRS 161638]) and in borehole UZ-1 (Yang et al. 1996 [DIRS 100194], p. 43).

Total aqueous carbonate concentrations were reported for the other samples. However, the analyses of these samples reflect a fairly significant charge imbalance ( 2 to 11 percent). Also, it is known that aqueous carbonate analyses can be easily impacted by interference with atmospheric carbon dioxide during sample preparation. For these reasons, the carbonate concentrations have been recalculated from charge balance after full speciation calculations.

Other adjustments have been made to some of the reported analytical data before input into the model as follows. The $\mathrm{pH}$ reported for the ECRB and SD-9 samples yield equilibrium carbon dioxide partial pressures significantly higher (up to $14,000 \mathrm{ppmv}$ ) than what is observed in the repository units (typically around $1,000 \mathrm{ppmv}$ ). For this reason, the $\mathrm{pH}$ of these waters has been 
recalculated to yield lower $\mathrm{CO}_{2}$ partial pressure values more in line with concentrations measured in repository units. Bringing the $\mathrm{CO}_{2}$ partial pressure down to near 1,000 ppmv requires raising the water $\mathrm{pH}$ to values of 8.5 and higher. Such $\mathrm{pH}$ values seem too high in comparison to values of $7.79,8.31$, and 8.32 reported for the HD-PERM samples (DTN: MO0005PORWATER.000 [DIRS 150930]). Therefore, an intermediate but still reasonable $\mathrm{CO}_{2}$ partial pressure around 3,100 ppmv $\left(\log \left(\mathrm{PCO}_{2}\right) \sim-2.5\right)$ has been used, yielding $\mathrm{pH}$ values between 8 to 8.2 (Table 6.2-1). In this respect, these water compositions are likely to represent high-end $\mathrm{CO}_{2}$ concentrations, whereas the HD-PERM samples represent a somewhat lower bound.

Another adjustment to input water concentrations involves fluoride in sample ECRB-SYSCS2000/16.5-21.1/UC. The fluoride concentration in this sample $(11 \mathrm{mg} / \mathrm{L})$ reflects a significant supersaturation with respect to fluorite $\left(\mathrm{CaF}_{2}\right.$ solid $)$ at $25^{\circ} \mathrm{C}$. The precipitation of fluorite is typically quite rapid (Section 4.1.3) and, for this reason, the fluoride concentration of this sample has been lowered to a concentration reflecting saturation with fluorite (near $6 \mathrm{mg} / \mathrm{L}$ for this water).

As mentioned earlier, infiltration water at the top model boundary is taken to have the same composition as the initial pore water, but with adjusted total aqueous carbonate, aluminum, and iron concentrations to reflect a lower temperature $\left(17^{\circ} \mathrm{C}\right)$ and higher $\mathrm{CO}_{2}$ partial pressure near the ground surface. Using this boundary water yields chemically steadier ambient water compositions at the location of the modeled drift (Section 6.5.5.4).

The initial $\mathrm{CO}_{2}$ partial pressure in fractures and matrix has been calculated as the partial pressure of $\mathrm{CO}_{2}$ in chemical equilibrium with the input water composition at $25^{\circ} \mathrm{C}$, assuming ideal gas behavior (i.e., partial pressure is equal to fugacity). The $25^{\circ} \mathrm{C}$ temperature is close to the initial temperature at the location of the drift.

\subsubsection{Geochemical Systems}

Minerals and chemical-aqueous components considered in this study are shown in Table 6.2-2. Primary mineral types and abundances are derived from X-ray diffraction (XRD) measurements on cores reported in the Yucca Mountain mineralogical model (DTN: LA9908JC831321.001 [DIRS 113495]) and analyses of fracture surfaces (Carlos et al. 1993 [DIRS 105210], p. 47; DTNs: LA9912SL831151.001 [DIRS 146447]; LA9912SL831151.002 [DIRS 146449]). Amounts of minerals observed, but present in quantities below the detection limit (typically around a percent for XRD), have been estimated. Potential secondary minerals (i.e., those allowed to precipitate but which may not necessarily form) have been determined from field observation of thermal alteration (Vaniman et al. 2001 [DIRS 157427], p. 3,409) and corroborated by running multicomponent heterogeneous equilibrium simulations of water-rock interaction (Wang 2003 [DIRS 161665], Notebook SN-LBNL-SCI-141-V2, pp. 94 and 95) using SOLVEQ/CHILLER V1.0 (LBNL 1999 [DIRS 153217]) and the current thermodynamic database (DTN: LB0307THMDBRTM.001 [DIRS 164434]). From these simulations, the stable mineral assemblage at each reaction step is calculated from a large list of possible minerals (after suppressing phases known not to form under ambient pressures and low temperatures). Anorthite is not observed as a secondary phase, so calcium enters other minerals such as zeolites and calcite. 
The bases for selection of aqueous species included in this study are: (1) use the major components of pore water, (2) use all components in major rock-forming minerals considered in the model, and (3) use additional components specifically requested by downstream users (nitrate, iron, and fluoride). Thus, the geochemical system used includes the major solid phases (minerals and glass) encountered in geologic units at Yucca Mountain, together with a range of possible reaction product minerals, $\mathrm{CO}_{2}$ gas, and aqueous species necessary to include these solid phases and the pore-water composition within the THC seepage model (Table 6.2-2 and Section 4.1).

Table 6.2-2. Mineral, Aqueous, and Gaseous Species Used in the THC Seepage Model

\begin{tabular}{|c|c|c|}
\hline Aqueous Basis Species & Minerals & Mineral Type $^{\mathrm{a}}$ \\
\hline $\mathrm{H}_{2} \mathrm{O}$ & Calcite & $\mathrm{P}, \mathrm{S}$ \\
\hline $\mathrm{H}^{+}$ & Tridymite & $\mathrm{P}$ \\
\hline $\mathrm{Na}^{+}$ & $\alpha$-Cristobalite & $\mathrm{P}$ \\
\hline $\mathrm{K}^{+}$ & Quartz & $\mathrm{P}$ \\
\hline $\mathrm{Ca}^{+2}$ & Amorphous Silica & $S$ \\
\hline $\mathrm{Mg}^{+2}$ & Hematite & $\mathrm{P}, \mathrm{S}$ \\
\hline $\mathrm{SiO}_{2}$ & Fluorite & $\mathrm{P}, \mathrm{S}$ \\
\hline $\mathrm{AlO}_{2}^{-}$ & Gypsum & S \\
\hline $\mathrm{HFeO}_{2}{ }^{-2}$ & Goethite & $S$ \\
\hline $\mathrm{HCO}_{3}{ }^{-}$ & Albite & $P, S$ \\
\hline $\mathrm{Cl}^{-}$ & K-Feldspar & $\mathrm{P}, \mathrm{S}$ \\
\hline $\mathrm{SO}_{4}^{-2}$ & Anorthite & $P$ \\
\hline $\mathrm{F}^{-}$ & Ca-Smectite & $\mathrm{P}, \mathrm{S}$ \\
\hline \multirow[t]{2}{*}{$\mathrm{NO}_{3}^{-}$} & Mg-Smectite & $\mathrm{P}, \mathrm{S}$ \\
\hline & Na-Smectite & $\mathrm{P}, \mathrm{S}$ \\
\hline Gases & Opal_proxy & $\mathrm{P}$ \\
\hline $\mathrm{CO}_{2}$ & Illite & $P, S$ \\
\hline $\mathrm{H}_{2} \mathrm{O}$ & Kaolinite & $S$ \\
\hline \multirow[t]{6}{*}{ Air } & Glass & $\mathrm{P}$ \\
\hline & Stellerite & $P, S$ \\
\hline & Heulandite & $\mathrm{P}, \mathrm{S}$ \\
\hline & Mordenite & $\mathrm{P}, \mathrm{S}$ \\
\hline & Clinoptilolite & $\mathrm{P}, \mathrm{S}$ \\
\hline & Sepiolite & $S$ \\
\hline
\end{tabular}

Source: DTN: LB0307THMDBRTM.001 [DIRS 164434].

${ }^{a}$ Primary $(\mathrm{P})$ and secondary $(\mathrm{S})$ minerals.

\subsubsection{Conceptualization of the Model Domain}

The current repository design includes a planar series of parallel, equidistant, and horizontal waste emplacement drifts that are laid out over a large surface area. As such, encompassing all areas of the repository would require a large and detailed three-dimensional model. However, the scope of this report covers THC processes at the drift-scale. Therefore, the model has been reduced and simplified to focus on areas surrounding a typical waste emplacement drift. Because the number of grid-blocks directly affects the simulation time, the model domain is reduced as much as possible without losing important information. Based on the geologic 
framework model (BSC 2002 [DIRS 170029]), the dip of repository host units is subhorizontal. Assuming that the rock properties are laterally homogeneous between drifts (Section 6.4.6, item 12), a planar and parallel drift layout can be conceptualized, in two dimensions, as a series of symmetrical, identical half-drift $X-Z$ models ( $X$ representing the horizontal distance in a direction perpendicular to the length of the drifts, and $Z$ the vertical distance) with no-flux (heat, fluid, chemical) vertical boundaries between them. Note that this half-drift simplification based on symmetry is theoretically applicable only for homogeneous properties, but is also a good approximation for heterogeneous fracture permeability fields if they display only weak spatial correlation.

Accordingly, the THC seepage model has been reduced to a half-drift model with a width corresponding to the midpoint between drifts. The model is refined in the vicinity of the drift and extends in a progressively coarser fashion to the $\mathrm{TCw}$ (near the ground surface) above the drift and to the water table below the drift. This symmetrical "chimney" model represents coupled THC processes at the drift scale in areas that are not affected by repository-edge effects (i.e., effects resulting from the cooler temperatures at the repository edge). Water and gas compositions at the edge of the repository (BSC 2004 [DIRS 169866], Section 6.4) are less concentrated and, therefore, within the range of compositions simulated in this report. However, the temperature history of the edge location is different from an interior, and therefore the compositions would not follow the same time history as the repository-center simulations for the THC seepage model. Also, drifts that do not reach boiling are likely to show a narrower range of compositions than the case simulated in this report. Even with large-scale gas transport at the repository-scale, the range of gas composition (e.g., $\mathrm{CO}_{2}$ concentration) over time is less than for the repository-center locations (BSC 2004 [DIRS 169866], Figure 6.4-16). Apart from the thermal loading and temperature history, the major contributor to variations in potential seepage chemistry is the initial water chemistry. Rock mineralogy is relatively uniform throughout the repository block (Peterman and Cloke 2002 [DIRS 162576], p. 683; see Assumption 1 for a more complete description), and pore water compositions are represented by the available data from different host rock units. Water compositions selected from the available data include samples collected from near the repository edge ("W0") as well as from the repository center in the Tptpll unit ("W4"). Based on this information the THC seepage model results can be used to represent potential effects of THC processes on seepage water compositions at all waste package locations with consideration of the temperature history at each specific location.

In the THC seepage model, perched-water effects are ignored. Perched-water conditions are confined mainly to the lower units of the Topopah Spring welded (TSw) hydrogeological unit and on top of the Calico Hills nonwelded unit (CHn). Over the repository domain, perched water locations are typically 100 to $150 \mathrm{~m}$ below the repository horizon $(\mathrm{Wu}$ et al. 1999 [DIRS 117167]). Because the dominant heat-transfer mechanism at these locations is heat conduction and boiling conditions are not attained, the effect of repository thermal load on perched-water bodies is ignored (BSC 2004 [DIRS 169866], Section 6.1.2).

\subsection{ALTERNATIVE CONCEPTUAL MODELS}

Developmental versions of the THC seepage model used alternate conceptualizations of drift location, drift representation, modeled stratigraphic column, geochemical systems, and boiling/evaporation mathematical models. These conceptualizations were implemented in 
various model variations and are discussed in detail in the previous revision of this report (BSC 2004 [DIRS 168848], Sections 6.5 to 6.7). Although the model has been significantly revised between the early Revision 1 (REV01) simulations and the current ones (Table 6-1), the early results are adequate and sufficient for their intended use in this report, which is to evaluate model sensitivity and uncertainty, and they do not provide feeds to TSPA. They are summarized below with the current model for reference:

- THC model (Section 6.5)-This model provides feeds to downstream reports and to TSPA. In this scenario, the repository drift is in the Tptpll lithostratigraphic unit, the drift wall open to gas and liquid flow, stepwise increases in infiltration rate are used (two fixed-rate simulations are run as sensitivity analyses), and the effect of vapor-pressure lowering due to capillary pressure is considered. A sensitivity analysis has also been run without this effect. (Although the current revision of this report is REV04, model inputs and outputs have not been modified from the previous model. Hence, the current model results are the same as those presented as "REV02" in the previous version of this report.)

- Developmental model simulations-These were run with thermodynamic and kinetic parameter databases that differ from those used in the current model, and differing geochemical systems. Drift walls were closed to fluid flow, and vapor pressure lowering due to capillary pressure was not implemented.

1. Tptpmn THC model REV01 (BSC 2004 [DIRS 168848], Section 6.5). This model represents a stratigraphic column on the edge of the repository (borehole SD-9) and considers a drift in the Tptpmn lithostratigraphic unit. Two alternative geochemical systems are used with this model: a base-case system and an extended-case system.

2. Tptpmn THC heterogeneous model REV01 (BSC 2004 [DIRS 168848], Section 6.6). This model includes the same conceptualizations as the above model except that it considers heterogeneous fracture permeability variations.

3. Tptpll THC model REV01 (BSC 2004 [DIRS 168848], Section 6.7). This model represents a stratigraphic column at the center of the repository with a drift in the Tptpll lithostratigraphic unit. Both base-case and extended-case geochemical systems (Section 6.2.2.2) are considered.

These historical simulations are discussed in this report where relevant. They primarily provide an assessment of the sensitivity of model results to the drift geologic host unit (Tptpmn versus Tptpll) and fracture permeability heterogeneity. The Tptpll and Tptpmn THC models do not show significantly different water chemistry in either space or time, indicating that the THC seepage model is insensitive to the choice of repository host rock, and provide the basis for extrapolation of the results of the current THC seepage model (in the Tptpll unit) to other lithostratigraphic units (Section 5). The Tptpmn Heterogeneous THC model includes the observed natural heterogeneity in fracture permeability ( 4 orders of magnitude) and does not show significantly different water chemistry when compared to the homogeneous REV01 Tptpmn THC model, justifying the use of homogenous properties in the current model (Section 6.4.6). However, the magnitude of the revisions between the historic and current models hampers pinpointing direct cause-effect relationships between a given specific change in 
the model and its effect on simulation results. For these reasons, the REV01 results are best regarded as a qualitative assessment of model sensitivity to drift location and fracture permeability heterogeneity. Because the historical model results indicate that the effect of these parameters on predicted water chemistry and mineral alteration may not be as significant as the effect of uncertainties in input water composition, thermodynamic data, and infiltration rates, evaluating the latter uncertainties is given priority in this report. For predictive evaluations, the most recent results are used, keeping in mind that the model uncertainty encompasses the results of both earlier and recent work.

Alternative conceptualizations not treated here could yield differences in model results. Examples of such alternative models include the use of more than two porous media continua (to better represent lithophysae or better capture gradients between fractures and matrix, or both), heterogeneous fracture porosity (in addition to heterogeneous permeability), or other sets of potential secondary minerals. These alternatives have not been considered because they are expected to result in smaller differences in model results than the alternatives considered here. This is primarily because the range of input water compositions considered in the model (Section 6.2.2.1), by itself, already introduces a significant spread in model results (Section 6.5.5).

\subsection{MATHEMATICAL MODEL}

This section describes the mathematical formulations that underlie the THC seepage model (and the DST THC submodel presented in Section 7). The model is implemented using the TOUGHREACT V3.0 (LBNL 2002 [DIRS 161256]) reactive transport code. Other reactive transport simulators, using various formulations, were considered by the project, including OS3D/GIMRT (Steefel and Yabusaki 1996 [DIRS 100827]) and MULTIFLO (Lichtner and Seth 1996 [DIRS 151989]). However, these simulators either have limitations that make them unsuitable for use in this study or have drawbacks in terms of availability, technical support, and qualification status. For instance, OS3D/GIMRT (Steefel and Yabusaki 1996 [DIRS 100827]) deals only with fully liquid-saturated conditions. When development of the THC seepage model was initiated in 1997, TOUGHREACT was the only code that could perform coupled thermal-hydrologic-chemical calculations in unsaturated rock, with phase changes (boiling), gaseous species transport (e.g. water vapor, $\mathrm{CO}_{2}$, air), multicomponent transport, and kinetic and equilibrium reactions, in multicontinuum and multidimensional domains with unstructured grids. TOUGHREACT is the only software of its type qualified for Yucca Mountain work. Also, the developers of the THC seepage model have contributed to the development of this software and, most particularly, to its development for applications to the repository at Yucca Mountain. They are also familiar with other thermal hydrology and transport codes used by the Yucca Mountain Project, and have repeatedly updated and re-qualified TOUGHREACT with new features to maintain consistency with the other hydrologic codes used by the project. For these reasons, TOUGHREACT and its formulation have been selected for this study. As stated in Section 3, the software is adequate and appropriate for the intended use in this model, and is used strictly within the range of validation.

For brevity, unless a formulation is used that is specific to a particular version of TOUGHREACT, hereafter the code version and reference are not cited. 


\subsubsection{General Numerical Model for Coupled THC Processes}

Thermal and hydrologic processes modeled using TOUGHREACT (all versions) are equivalent to those using TOUGH2 V1.6 (LBNL 2003 [DIRS 161491]), which are described in detail in Drift-Scale Coupled Processes (DST and TH Seepage) Models (BSC 2004 [DIRS 170338], Section 6.2.1.1) and in the TOUGHREACT V3.0 User's Manual (BSC 2002 [DIRS 164454]; LBNL 2002 [DIRS 161256]).

The geochemical module incorporated in TOUGHREACT V2.2 (LBNL 1999 [DIRS 153219]); V2.3 (LBNL 2001 [DIRS 153101]); V2.4 (LBNL 2001 [DIRS 160880]); and V3.0 (LBNL 2002 [DIRS 161256]) simultaneously solves a set of chemical mass-action, kinetic-rate expressions for mineral dissolution/precipitation and mass-balance equations. This provides the extent of reaction and mass transfer between a set of given aqueous species, minerals, and gases at each grid block of the flow model. Equations for heat, liquid and gas flow, aqueous and gaseous species transport, and chemical reactions are summarized by $\mathrm{Xu}$ and Pruess (1998 [DIRS 117170]; 2001 [DIRS 156280], p. 30, Tables A and B) and Xu et al. (1998 [DIRS 101751]; 2001 [DIRS 161864]). Flow and reaction-transport equations are solved sequentially (Steefel and Lasaga 1994 [DIRS 101480], p. 550). Equations for mineral-chemical equilibrium, kinetic rates, and permeability-porosity changes are given further below.

The setup of mass-action and mass-balance equations in TOUGHREACT is similar to the formulation implemented by Reed (1982 [DIRS 117901], pp. 514 to 516). Additional provisions are made for mineral dissolution and precipitation under kinetic constraints and a volume-dependent formulation for gas equilibrium, as described below. The chemical system is described in terms of primary aqueous species (the independent variables). Minerals, gases, and secondary aqueous species are defined in terms of reactions involving only the primary species. It has been shown that if the diffusivities of all aqueous species are equal, only the transport of primary species (in terms of total dissolved concentrations) needs to be considered to solve the entire reactive flow/transport problem (Steefel and Lasaga 1994 [DIRS 101480], p. 546).

The system of nonlinear equations describing chemical mass-balance, mass-action, and kinetic-rate expressions is solved by a Newton-Raphson iterative procedure. In TOUGHREACT V2.2 (LBNL 1999 [DIRS 153219]), activity coefficients of aqueous species are computed by an extended Debye-Hückel equation (Drever 1997 [DIRS 140067], p. 28, Equation 2-12). In TOUGHREACT V2.2 (LBNL 1999 [DIRS 153219]), activity coefficients of neutral species are assumed equal to one, and the activity of water is computed using a method described by Garrels and Christ (1990 [DIRS 144877], pp. 64 to 66), which essentially equates the water activity to its mole fraction. These methods are generally reliable for ionic strengths up to 2 molal. In TOUGHREACT V2.3 (LBNL 2001 [DIRS 153101]), V2.4 (LBNL 2001 [DIRS 160880]), and V3.0 (LBNL 2002 [DIRS 161256]), activity coefficients of charged species and the activity of water are calculated with the method of Helgeson et al. (1981 [DIRS 106024], Equations 298, 190, 106, and Tables 1, 3, 29, and 30), as further described by Wang (2003 [DIRS 161665], Notebook SN-LBNL-SCI-112-V2, pp. 21 to 27). Using this method, activities of water and activity coefficients of electrolytes typical of natural systems $\left(\mathrm{NaCl}, \mathrm{CaCl}_{2}, \mathrm{Mg}_{2} \mathrm{SO}_{4}, \mathrm{Ca}_{2} \mathrm{SO}_{4}\right)$ are fairly well reproduced up to ionic strengths of 6 molal (Wang 2003 [DIRS 161665], Notebook SN-LBNL-SCI-112-V2, pp. 28 to 30 and 32). In TOUGHREACT V2.3 (LBNL 2001 [DIRS 153101]), V2.4 (LBNL 2001 [DIRS 160880]), and V3.0 (LBNL 2002 [DIRS 161256]), 
activity coefficients of selected neutral species are calculated using salting-out coefficients as described by Langmuir (1997 [DIRS 100051], Equation 4.62 and Table 4.1-4).

Equilibration with mineral phases is computed by adding a mass-action equation, for each saturated mineral, into the system of nonlinear equations as follows:

$$
\log \left(K_{i}\right)=\log \left(Q_{i}\right)
$$

where $K_{i}$ denotes the equilibrium constant and $Q_{i}$ the product of the ion activities in the reaction that expresses mineral $i$ in terms of the primary aqueous species. A term representing the amount of primary aqueous species consumed or produced by equilibration of minerals is added to the mass-balance equation for each primary species involved in mineral reactions, and this term is solved simultaneously with the concentrations of all primary species. Minerals thus dissolve if $\log \left(\mathrm{Q}_{\mathrm{i}} / \mathrm{K}_{\mathrm{i}}\right)<0$ and precipitate if $\log \left(\mathrm{Q}_{\mathrm{i}} / \mathrm{K}_{\mathrm{i}}\right)>0$. For some minerals (Section 6.4.3, calcite), a "supersaturation gap" can be specified by which the mineral is not allowed to precipitate if $\log \left(\mathrm{Q}_{\mathrm{i}} / \mathrm{K}_{\mathrm{i}}\right)$ is greater than zero but less than a specified "gap" value (positive). This gap can be set to decrease exponentially with temperature, as described by Wang (2003 [DIRS 161665], Notebook SN-LBNL-SCI-112-V2, p. 33).

Gas species, such as $\mathrm{CO}_{2}$, are treated as ideal mixtures of gases in equilibrium with the aqueous solution. A mass-action equation is added to the system of simultaneous equations for each saturated gas present, except for $\mathrm{H}_{2} \mathrm{O}$ vapor and air, which are handled separately through the flow module in TOUGHREACT. The gas mass-action equation takes the form:

$$
\log \left(K_{i}\right)=\log \left(Q_{i}\right)-\log \left(P_{i}\right)
$$

where $P_{i}$ is the partial pressure of gaseous species $i . \quad P_{i}$ is first calculated from the advective-diffusive gas transport equation in TOUGHREACT. Then $P_{i}$ is replaced with the ideal gas law,

$$
P_{i}=\frac{n_{i} R T}{V_{g}}
$$

where $n_{i}$ denotes the number of moles of gas species $i, R$ is the gas constant, $T$ is the absolute temperature, and $V_{g}$ is the gas total volume. By expressing $V_{g}$ in terms of the gas saturation $S_{g}$, the porosity of the medium $\phi$, and the volume of each grid block in the flow model $V_{\text {block}}$, Equation 6.4-3 is rewritten as:

$$
P_{i}=\frac{n_{i} R T}{V_{\text {block }} \phi S_{g}}
$$

The gas saturation is computed in the flow module of TOUGHREACT (reflecting $\mathrm{H}_{2} \mathrm{O}$ and air partial pressures computed in this module). The amount of trace gas species $\left(n_{i} / V_{\text {block }}\right)$ is then 
obtained by substitution of Equation 6.4-4 into Equation 6.4-2 and solving together with the concentrations of all primary species.

The partial pressures of trace gas species are not fed back to the multiphase flow module of TOUGHREACT V2.2 (LBNL 1999 [DIRS 153219]) and V2.3 (LBNL 2001 [DIRS 153101]) for solving the water and gas flow equations. Therefore, this method should only be applied to gases (excluding $\mathrm{H}_{2} \mathrm{O}$ and air) with partial pressures significantly lower than the total gas pressure. No absolute cutoff exists at which this approximation breaks down, and therefore it is validated by comparison to DST-measured $\mathrm{CO}_{2}$ concentrations. For cases where the partial pressures of a trace gas become closer to the total pressure, chemical equilibrium with the aqueous phase is computed correctly, but the gas pressure will be underestimated in the mass-balance equation solved for gas flow. Because $\mathrm{CO}_{2}$ concentrations encountered in the DST and model simulations are generally less than a few percent, and rarely over 10 percent, this model for the gas species is a reasonable approximation for this particular system (Section 6.4.6).

\subsubsection{Kinetic Rate Laws}

Rates of mineral dissolution and precipitation close to equilibrium can be described via a relationship of the rate to the saturation index $(Q / K)$ as follows (Steefel and Lasaga 1994 [DIRS 101480], p. 540):

$$
\operatorname{Rate}\left(\mathrm{mol} \mathrm{s}^{-1} \mathrm{~kg}_{\text {water }}^{-1}\right)=\operatorname{sgn}[\log (\mathrm{Q} / \mathrm{K})] k A \prod_{i} a_{i}^{p}\left|\left[(\mathrm{Q} / \mathrm{K})^{m}-1\right]\right|^{n}
$$

where $a_{i}$ is the activity of each inhibiting or catalyzing species, and $p$ is an empirically determined exponent, and the variable $A$ is the reactive surface area expressed in units of $m_{\text {mineral }}^{2} / \mathrm{kg}_{\text {water }}$. The rate constant $k$ (in $\mathrm{mol} \mathrm{m}^{-2} \mathrm{~s}^{-1}$ ) is given as (Steefel and Lasaga 1994 [DIRS 101480], p. 541):

$$
k=k_{0} \exp \left\lfloor\frac{-E_{a}}{R}\left(\frac{1}{T}-\frac{1}{298.15}\right)\right\rfloor
$$

where the temperature dependence of reaction rate is related to the activation energy $\left(E_{a}\right)$ in units of $\mathrm{kJ} / \mathrm{mol}$, and $T$ is the temperature in Kelvin units. Following Steefel and Lasaga (1994 [DIRS 101480], p. 568), by neglecting the effect of $\mathrm{pH}$ or other aqueous species activities on reaction rates, $p=0$ is set for each species so that the product $\prod_{i} a_{i}^{p}=1$ has been eliminated from Equation 6.4-5. The ratio of the species activity product $(Q)$ and the equilibrium constant $(K)$ describes the extent to which a mineral is in disequilibrium with a given solution composition. For $Q / K$ equal to one, the mineral is at equilibrium, and thus the net rate of reaction becomes zero. For $Q / K$ greater than one, the mineral is oversaturated and thus the rate becomes negative. The expression "sgn $[\log (Q / K)]$ " ensures that the correct sign is enforced when the exponents $m$ and $n$ are not equal to one. The variable $A$ is the reactive surface area expressed in units of $\mathrm{m}_{\text {mineral }}^{2} / \mathrm{kg}_{\text {water }}$. In the case of ideal solutions, the saturation index of the solid solution is 
calculated as the sum of the saturation indices of the individual end members, and the reaction rate of the solid solution is calculated as described by Wang (2003 [DIRS 161665], Notebook SN-LBNL-SCI-112-V2, pp. 37 to 40).

Carroll et al. (1998 [DIRS 124275], p. 1,379) noted that the calculated rates of amorphous silica precipitation, based on research by Rimstidt and Barnes (1980 [DIRS 101708], p. 1,683), are about three orders of magnitude lower than those observed in geothermal systems. Carroll et al. (1998 [DIRS 124275], p. 1,379) presented experimental data on amorphous silica precipitation for more complex geothermal fluids at higher degrees of supersaturation, and also for a nearsaturation simple fluid chemistry. Under far from equilibrium conditions, the rate law for amorphous silica precipitation has been expressed as (Carroll et al. 1998 [DIRS 124275], p. 1,382):

$$
\operatorname{Rate}\left(\mathrm{mol} \mathrm{s}^{-1} \mathrm{~kg}_{\text {water }}^{-1}\right)=k A(\mathrm{Q} / \mathrm{K})^{m}
$$

This rate does not tend to zero as $Q / K$ goes to one; therefore, a modification has been made to this law so that it tends to zero as $Q / K$ approaches one (Wang 2003 ([DIRS 161665], Notebook SN-LBNL-SCI-109-V1, p. 45) as follows:

$$
\operatorname{Rate}\left(\mathrm{mol} \mathrm{s}^{-1} \mathrm{~kg}_{\text {water }}^{-1}\right)=k A\left[(\mathrm{Q} / \mathrm{K})^{m}-\frac{1}{(\mathrm{Q} / \mathrm{K})^{2 m}}\right]
$$

This rate law applies only to silica precipitation. For silica dissolution, the rate law expressed in Equation 6.4-8 is used. Rate constants for the two cases are different (Table 4.1-3).

Over a finite time step $(\Delta t)$, the change in the concentration of each primary species $j$ on account of mineral precipitation or dissolution under kinetic constraints is computed from the sum of the rates, $r_{i}$, of all $j$-containing minerals $i$ as follows:

$$
\Delta C_{j}=-\sum r_{i} v_{i j} \Delta t
$$

where $v_{i j}$ is the stoichiometric coefficient of component $j$ in mineral $i$. These concentration changes are incorporated into the mass-balance equation of each primary species involved in mineral reactions, using Equations 6.4-5 through 6.4-7, and solved simultaneously with the concentrations of all primary species. 


\subsubsection{Fracture and Matrix Mineral Reactive Surface Areas}

\subsubsection{Fracture Mineral Reactive Surface Areas}

Reactive surface areas of minerals on fracture walls have been calculated from the fracture-matrix interface area/volume ratio, the fracture porosity, and the derived mineral volume fractions. The fracture-matrix interface areas and fracture porosities for each unit have been taken from appropriate calibrated properties sets (Table 4.1-1). These areas are based on the fracture densities, fracture porosities, and mean fracture diameter. The wall of the fracture is treated as a surface covered by mineral grains having the form of uniform hemispheres. The grain diameter and spatial density are not included in this calculation, so that the area is actually only marginally greater than the fracture geometric surface area. An alternative method to approximating the surface area in excess of the geometric area would be to include a roughness factor. The geometric surface area of the fracture wall can be approximated by:

$$
A_{r}=\frac{\pi A_{f-m}}{2 \phi_{f-m}}
$$

where $A_{r}$ is the reactive surface area $\left(\mathrm{m}^{2} / \mathrm{m}_{\text {fracture medium }}^{3}\right), A_{f-m}$ is the fracture-matrix interface area/volume ratio $\left(\mathrm{m}_{\text {fracture }}^{2} / \mathrm{m}_{\text {fracture+matrix }}^{3}\right.$ volume $)$, and $\phi_{f-m}$ is the fracture porosity of the rock. $A_{f-m}$ is the surface area used as input to the model simulations as an approximation of the reactive surface area. This model for the fracture surface area considers that the areal coverage is approximately equivalent to the mineral volume fraction. A further modification, which was implemented in TOUGHREACT V2.3 (LBNL 2001 [DIRS 153101]), relates the three-dimensional cross-sectional area to the two-dimensional surface area in the fracture, which yields a factor of $3 / 2$, i.e., an increase of 50 percent in the reactive surface area. This relation was used for all previous DST THC model REV01 sensitivity studies, Tptpmn, and Tptpll THC simulations.

The reactive surface area of each mineral (in units of $m_{\text {mineral }}^{2} / \mathrm{kg}_{\text {water }}$ ) used in Equations 6.4-5 and 6.4-8 is then given by:

$$
A_{i}\left(\mathrm{~m}^{2} / \mathrm{kg}_{\text {water }}\right)=\frac{A_{r} f_{i}}{\rho_{w} \phi_{f}}
$$

where $f_{i}$ is the volume fraction of the mineral in the mineral assemblage, $\rho_{w}$ is the density of water (taken as a constant $1,000 \mathrm{~kg} / \mathrm{m}^{3}$ ), and $\phi_{f}$ is the porosity of the fracture medium, as opposed to the fracture porosity of the rock. This is the surface area/water mass ratio for a mineral in a liquid-saturated system. Calculated volume fractions of minerals for the current model are tabulated in Appendix A.

To provide the correct rock/water ratio in an unsaturated system, the form of this surface area can be written as: 


$$
A_{i}\left(\mathrm{~m}^{2} / \mathrm{kg}_{\text {water }}\right)=\frac{A_{r} f_{i}}{\rho_{w} \phi_{f} S_{w}}
$$

where $S_{w}$ is the water saturation. However, as $S_{w}$ goes to zero, the reactive surface area would tend to infinity. Clearly, at a very low liquid saturation, the surface area of the rock contacted by water is likely much smaller than the total area.

Two methods have been implemented to address this phenomenon. The first method considers that the surface area contacted by water diminishes proportionately to the saturation. This yields the saturated surface area given by Equation 6.4-10. The second method employs the active-fracture-model concept (Liu et al. 1998 [DIRS 105729], pp. 2,636 to 2,638) modified to consider water-rock reactions taking place below the residual saturation. The form of the active fracture parameter for reaction is then given by the following set of equations:

$$
\begin{gathered}
S_{a r}=\left(S_{w}-S_{m}\right) /\left(1-S_{m}\right) \\
a_{f m r}=S_{a r}{ }^{(1+\gamma)}
\end{gathered}
$$

where $S_{m}$ is the minimum liquid saturation for which water-rock reactions are considered and $S_{a r}$ is the effective saturation available for reaction. The active fracture parameter, $\gamma$, is obtained from the calibrated hydrologic property set (DTN: LB0208UZDSCPMI.002 [DIRS 161243]). The factor that reduces the surface area contacted by the water phase is given by $a_{f m r}$. In all simulations $S_{m}$ is set to the very small saturation of $1 \times 10^{-5}$ to ensure that reactions take place until virtually no water is left (e.g., during dryout via ventilation or heating). Finally, the reactive surface area, using this modified form of the active fracture model, is given by:

$$
A_{i}\left(\mathrm{~m}^{2} / \mathrm{kg}_{\text {water }}\right)=\frac{f_{i} A_{r} a_{f m r}}{\rho_{w} \phi_{f} S_{w}}
$$

The surface area calculated in this way is applicable only to reactions taking place in the fracture medium and is used directly in Equations 6.4-5 and 6.4-8. Note that this area is not comparable to the input surface areas that are listed in Appendix B.

In the dual permeability method, the porosity of the fracture medium can be taken as 1.0; however, for modeling of mineral dissolution and precipitation, there would then be no rock to dissolve. Because the dissolution rates of many minerals are quite slow at temperatures below $100^{\circ} \mathrm{C}$, only a small volume of rock adjoining the open space of the fracture needs to be considered as the starting rock fraction. In the REV01 Tptpmn THC model, the porosity of the fracture medium was set to 0.99 , thus making available 1 percent of the total fracture volume for reaction. In the REV01 Tptpll THC model, and in all current THC seepage model simulations, the fracture medium porosity is set to 0.5 (Section 6.4.6). 


\subsubsection{Matrix Mineral Reactive Surface Areas}

Mineral surface areas in the rock matrix (Appendix B) are taken from DTNs shown in Table 4.1-1. These values have been estimated using the geometric area of a cubic array of truncated spheres that make up the framework of the rock. Clay minerals are considered as coatings of plate-like grains. The mineral surface areas of framework grains (truncated spheres) in contact with the open pore space are calculated using an initial grain diameter, followed by successive truncation of the grains in the vertical direction until the porosity of this system is close to the measured porosity of the rock. In the welded tuff, crystals are often tightly intergrown with little or no pore space within the aggregate. Thus, a check is made so that the resultant mean pore throat size and spacing yields a permeability (from a modified Hagen-Poiseuille relation) (Ehrlich et al. 1991 [DIRS 117799], p. 1,582, Equation 11) that is relatively close to the measured saturated permeability.

The grains forming the framework of this rock are considered to be the primary high-temperature phases of the tuff (i.e., quartz, cristobalite, tridymite, and feldspars). The abundance of secondary phases (i.e., those that formed as alteration products or low-temperature coatings on the primary assemblage), such as clay minerals, are used to reduce the free surface area of the framework grains. The surface areas of the secondary phases are approximated using a tabular morphology.

\subsubsection{Effects of Mineral Precipitation/Dissolution on Hydrologic Properties}

\subsubsection{Porosity Changes}

Changes in porosity and permeability resulting from mineral dissolution and precipitation have the potential to modify percolation fluxes and seepage fluxes at the drift wall. In this analysis, porosity changes in matrix and fractures are directly tied to the volume changes that result from mineral precipitation and dissolution. The molar volumes of hydrous minerals, such as zeolites and clays, created by hydrolysis reactions with anhydrous phases, such as feldspars, are commonly larger than those of the primary reactant minerals. Therefore, constant molar dissolution-precipitation reactions can lead to porosity reductions. These changes are taken into account in this analysis. The porosity of the medium (fracture or matrix) is given by

$$
\phi=1-\sum_{m=1}^{n m} f r_{m}-f r_{u}
$$

where $n m$ is the number of minerals, $f r_{m}$ is the volume fraction of mineral $m$ in the rock

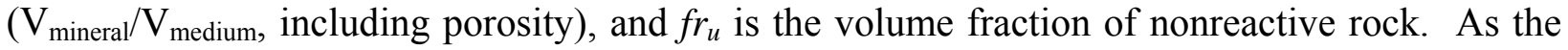
$\mathrm{fr}_{m}$ of each mineral changes, the porosity is recalculated at each time step. The porosity is not allowed to go below zero.

\subsubsection{Fracture Permeability Changes}

Fracture permeability changes can be approximated using the porosity change and considering plane parallel fractures of uniform aperture (cubic law) (Steefel and Lasaga 1994 
[DIRS 101480], p. 556). If the fracture spacing and density remain constant, the updated permeability, $k$, is given by

$$
k=k_{i}\left(\frac{\phi}{\phi_{i}}\right)^{3}
$$

where $k_{i}$ and $\phi_{i}$ are the initial permeability and porosity, respectively. This law yields zero permeability only under the condition of zero fracture porosity.

In most experimental and natural systems, permeability reductions to values near zero occur at porosities significantly greater than zero. This generally is the result of mineral precipitation preferentially closing the narrower interconnecting apertures. The hydraulic aperture, as calculated from the fracture spacing and permeability (as determined through air-permeability measurements) using a cubic law relation, is a closer measure of the smaller apertures in the flow system. Using the hydraulic aperture, a much stronger relationship between permeability and porosity can be developed. This relationship can be approximated as follows:

The initial hydraulic aperture $b_{0, h}(\mathrm{~m})$ is calculated using the following cubic law relation:

$$
b_{0, h}=\left[12 k_{0} s\right]^{1 / 3}
$$

where $k_{0}$ is the initial fracture permeability $\left(\mathrm{m}^{2}\right)$ and $s$ is the fracture spacing $(\mathrm{m})$ for a single fracture set. The permeability $(k)$ resulting from a change in the hydraulic aperture is given by

$$
k^{\prime}=\frac{\left(b_{0, h}+\Delta b\right)^{3}}{12 s}
$$

where $\Delta b$ is the aperture change resulting from mineral precipitation/dissolution. The aperture change resulting from a calculated volume change can be approximated by assuming precipitation of a uniform layer over the entire geometric surface area of the fracture, assuming also that this area (as well as the fracture spacing) remains constant. In geologic systems, the actual distribution of mineral alteration is much more heterogeneous and depends on many factors that are active at scales much smaller than the resolution of the model. The combined effect of the initial heterogeneities and localized precipitation processes can only be treated through model sensitivity studies and experiments. The initial aperture available for precipitation ( $b_{g}$, the geometric, rather than the hydraulic, aperture) can be calculated (Appendix F) from the ratio of the initial fracture porosity $\left(\phi_{f, 0}\right)$ to the fracture surface area $\left(A_{f}\right)$, as follows:

$$
b_{g}=\phi_{f, 0} / A_{f}
$$

For a dual-permeability model, changes in the fracture porosity are calculated based on the porosity of the fracture medium so that $\Delta b$ can be approximated by: 


$$
\Delta b=\frac{\left(\phi_{f m}^{\prime}-\phi_{f m, 0}\right)}{\phi_{f m, 0}} b_{g}
$$

Equations 6.4-18, 6.4-19, and 6.4-21 were implemented in TOUGHREACT V2.3 (LBNL 2001 [DIRS 153101]) and successive versions, with input parameters of $b_{g}$ and $s$. This relation was used for sensitivity studies in the REV01 Tptpmn THC model simulations discussed in Section 6.3 (heterogeneous and homogeneous permeability fields), REV01 and current Tptpll THC model simulations, and REV01 and current DST THC model simulations.

\subsubsection{Matrix Permeability Changes}

Matrix permeability changes are calculated from changes in porosity using ratios of permeabilities calculated from the Carman-Kozeny relation (Bear 1988 [DIRS 101379], p. 166, Equation 5.10.18, symbolically replacing $n$ by $\phi$ ), and neglecting changes in grain size, tortuosity, and specific surface area as follows:

$$
k=k_{i} \frac{\left(1-\phi_{i}\right)^{2}}{(1-\phi)^{2}}\left(\frac{\phi}{\phi_{i}}\right)^{3}
$$

\subsubsection{Effects of Permeability and Porosity Changes on Capillary Pressures}

Changing permeability and porosity also results in changes in the unsaturated flow properties of the rock. These effects are treated by modifying the calculated capillary pressure $(P c)$ using the Leverett scaling relation (Slider 1976 [DIRS 128146], p. 280) to obtain a scaled $P C^{\prime}$ as follows:

$$
P c^{\prime}=P c \sqrt{\frac{k_{i} \phi}{k \phi_{i}}}
$$

Simulations performed with TOUGHREACT V3.0 (LBNL 2002 [DIRS 161256]) have the maximum value of $P C^{\prime}$ (Equation 6.4-23) limited by the cutoff prescribed in the input file. All developmental simulations, done using earlier TOUGHREACT versions, have the cutoff apply to $P C$ (not $P C^{\prime}$ ) in Equation 6.4-23 unless an extrapolation in the $P c$-saturation curve was performed, in which case no cutoff was applied. Capillary pressure cutoff values used in various model revisions are discussed in Section 6.4.6 (Approximation 15).

\subsubsection{Mineral Precipitation in Dry Grid Blocks}

In certain cases of evaporation or boiling, a grid block may experience an influx of water that evaporates completely during the solution of the flow equations. After the flow equations are solved, TOUGHREACT solves the transport equations followed by the speciation and reaction equations. The speciation and reaction equations require that the grid block is "wet;" that is, the liquid saturation is greater than zero (or a small value). Because of the lack of water in the grid block, a method has been developed for storing all residual aqueous species in a solid "salt" assemblage. 
The amount of solute "stored" is simply the product of the concentration in the upstream grid block and the flux of water into the grid block that dries out. Also, any water that is initially present in the grid block, and dries out, gives rise to some solute mass that is transformed into solid phases. For these cases, the mass of each primary solute species is saved and may be assigned to minerals in a prescribed order in the chemical input file. This approximation is performed so that solute mass loss is minimized and most of the solute mass can be accounted for in a solid mineral phase. Simulations performed with TOUGHREACT V2.4 (LBNL 2001 [DIRS 160880]) and V3.0 (LBNL 2002 [DIRS 161256]) have this option, whereas V2.2 (LBNL 1999 [DIRS 153219]) and V2.3 (LBNL 2001 [DIRS 153101]) do not.

In the simulations presented in this report, for the specific cases when water flows into grid blocks that dry out in the flow calculation (by boiling or evaporation), the following solid phases are formed, stoichiometrically and in the following order: silica, calcite, gypsum, hematite, fluorite, $\mathrm{NaNO}_{3}, \mathrm{~K}_{2} \mathrm{SO}_{4}, \mathrm{Na}_{2} \mathrm{SO}_{4}, \mathrm{MgSO}_{4}$, halite, and sylvite. The order is predetermined (i.e., nitrates are formed before chlorides) to ensure nitrate mass is not lost in cases where insufficient sodium remains to form $\mathrm{NaNO}_{3}$ (in the absence of other nitrate salts that could have formed). The goal, here, is not to model evaporation accurately, but to save as much mass of the dissolved constituents as possible for grid blocks that completely dry out.

Upon rewetting, the salt minerals (i.e., $\mathrm{NaNO}_{3}, \mathrm{~K}_{2} \mathrm{SO}_{4}, \mathrm{Na}_{2} \mathrm{SO}_{4}, \mathrm{MgSO}_{4}$, halite, sylvite) are assumed to dissolve kinetically with a relatively fast rate constant (set here at $10^{-6} \mathrm{~mol} / \mathrm{m}^{2} / \mathrm{s}$ ) and a dissolution rate limited by their solubility (Section 6.4.2). The salt solubilities are from the data0.ymp.R2 database (DTN: MO0302SPATHDYN.000 [DIRS 161756]), except that $\mathrm{NaNO}_{3}$ (not in that database) is given the solubility of $\mathrm{KNO}_{3}$ in that database. Therefore, this model captures the general behavior of salt dissolution as the boiling front recedes. However, the predicted major ion concentrations during the short time when these salts dissolve are approximate because the identity of the salt phases is not based on a thermodynamic speciation/precipitation model, and their dissolution rates are only approximate.

\subsubsection{Principal Model Approximations and Approaches}

The following modeling approximations and simplifications are used in the THC seepage model.

1. The rock is described by a dual-permeability model (Section 6.2.1.5), which considers separate but interacting fracture and matrix continua, each with specified permeabilities. In the dual-permeability model, the fracture continuum is considered as co-located but interacting with the matrix continuum, in terms of the flow of heat, water, and vapor through advection, diffusion, and conduction (for heat). The aqueous and gaseous species are transported via advection and molecular diffusion between the fractures and matrix. Each continuum has its own well-defined initial physical and chemical properties. The dual-permeability approach for modeling physical processes in fractured porous media is discussed in detail by Doughty (1999 [DIRS 135997], pp. 76 and 77). This approach is validated by comparing geochemical data obtained from the DST to the results of simulations of the DST (Section 7.1), and further validated in Drift-Scale Coupled Processes (DST and TH Seepage) Models (BSC 2004 [DIRS 170338], Section 7.4). 
2. The mass of minerals precipitated is small and its thermal properties are similar to those of the host rock. Therefore, the thermal properties are not modified to account for precipitated minerals. However, the bulk heat capacity is modified to account for changes in porosity.

3. Effects of changes in the partial pressure of $\mathrm{CO}_{2}$ (resulting from heating, water reaction with calcite, and gas-phase transport) on the density of the gas phase are neglected. This is justified because, in this study, $\mathrm{CO}_{2}$ generally accounts for less than 5 percent and always less than 10 percent of the gas phase volume (air, water, and $\mathrm{CO}_{2}$ ). Although the molecular weight of $\mathrm{CO}_{2}$ is greater than that of air (approximately $44 \mathrm{~g} / \mathrm{mol}$ versus $29 \mathrm{~g} / \mathrm{mol}$ ), the density is only increased proportionally to the volume fraction of $\mathrm{CO}_{2}$ and the ratio of the molecular weights. This would result in a density increase of about 5 percent for a gas with a $\mathrm{CO}_{2}$ volume fraction of 10 percent. These conditions make the effect of evolved $\mathrm{CO}_{2}$ on the physical properties of the gas phase negligibly small and justify the use of this approximation. The effect of $\mathrm{CO}_{2}$ on the density of steam (molecular weight approximately $18 \mathrm{~g} / \mathrm{mol}$ ) would be somewhat greater; however, increases in the steam fraction accompanying boiling would tend to dilute the $\mathrm{CO}_{2}$ fraction.

4. The effects of changes in water chemistry on the water density and viscosity are neglected. This approximation is justified because aqueous-species concentrations are low in waters at most values of the liquid saturation (in the rock matrix or fractures). In cases where concentrations are significantly higher, the liquid saturation is generally much less than 1 percent. Therefore, the liquid is nearly immobile because of the very small relative permeability for the liquid phase under such conditions.

5. Diffusion coefficients of all aqueous species are set to the same value (the value for the chloride anion; Section 4.1.1). This is justified because the tracer diffusion coefficients of aqueous species differ by, at most, about one order of magnitude, with many differing by less than a factor of 2 (Lasaga 1998 [DIRS 117091], p. 315). The strong effects of water-rock interaction, boiling condensation, and rapid fracture drainage overwhelm effects of aqueous species diffusion.

Diffusion coefficients for gases are calculated. In the gas phase, $\mathrm{CO}_{2}$ is the only transported reactive species (other than $\mathrm{H}_{2} \mathrm{O}$ vapor). For an ideal gas, the tracer diffusion coefficient of a gaseous species can be expressed as a function of temperature and pressure in the following form (Lasaga 1998 [DIRS 117091], p. 322):

$$
D=\frac{R T}{3 \sqrt{2} \pi P N_{A} d_{m}^{2}} \sqrt{\frac{8 R T}{\pi M}}
$$

where

$$
\begin{aligned}
& D=\text { diffusion coefficient }\left(\mathrm{m}^{2} / \mathrm{s}\right) \\
& R=\text { gas constant }\left(8.31451 \mathrm{~m}^{2} \mathrm{~kg} \mathrm{~s}^{-2} \mathrm{~mol}^{-1} \mathrm{~K}^{-1}\right) \\
& T=\text { temperature in Kelvin units } \\
& P=\text { pressure }\left(\mathrm{kg} \mathrm{m}^{-1} \mathrm{~s}^{-2}\right) \\
& N_{A}=\text { Avogadro's number }\left(6.0221367 \times 10^{23} \mathrm{~mol}^{-1}\right)
\end{aligned}
$$




$$
\begin{aligned}
& d_{m}=\text { molecular diameter }(\mathrm{m}) \\
& M=\text { molecular weight }(\mathrm{kg} / \mathrm{mol})
\end{aligned}
$$

The $\mathrm{CO}_{2}$ diffusion coefficient is calculated using input values of $d_{m}$ and $M$ (Section 4.1.1).

6. Mineral precipitation or dissolution is modeled to occur uniformly over the smooth plane-parallel fracture walls (Section 6.4.4.2). However, mineral precipitation could be non-uniform, leading to a different relationship between changes in permeability and porosity. This approximation can be justified by the use of bulk permeabilities and porosities that initially account for the net effect of variability in fracture aperture at a macroscopic scale. Furthermore, effective (hydraulic) apertures are used instead of true apertures, the latter being much larger (Section 6.4.4.2). As a result, the permeability change is quite sensitive to porosity changes (in this study, a 10 to 14 percent drop in fracture porosity leads to zero permeability in fractures in the modeled repository units).

7. $\mathrm{CO}_{2}$ gas is treated as an ideal gas (i.e., obeys the ideal gas law and its partial pressure equals its fugacity). This approximation is valid for the low ambient pressures (near atmospheric) considered in this study (Langmuir 1997 [DIRS 100051], p. 15).

8. Except for smectites, the chemical and physical properties of minerals that form solid solutions are approximated by their individual end-member compositions and properties. Because smectite end-members are (individually) near equilibrium with pore waters, some of the smectite end members could be calculated to precipitate while others dissolve. For this reason, an ideal solid-solution model is implemented for smectite ( $\mathrm{Na}, \mathrm{Ca}$, and $\mathrm{Mg}$ end-members), with each end-member's activity equaling its mole fraction. Treating the smectite as a solid solution results in individual smectite end-members either all dissolving or all precipitating, providing a better physical representation of dissolution/precipitation processes. Feldspar solid solutions are not considered because albite (Na-feldspar) and anorthite (Ca-feldspar) are generally strongly undersaturated in the simulations and, thus, their dissolution rates are governed primarily by the kinetic-rate constant rather than the saturation index (Equation 6.4-5). In addition, nearly pure secondary K-feldspar compositions are observed in geothermal systems (Stefánsson and Arnórsson 2000 [DIRS 153578], p. 2,578). Therefore, the precipitation of secondary K-feldspar can be approximated fairly well with a pure end-member. These approximations are further validated by comparison of model results to measured water chemistry in the DST (Section 7.1).

9. The fracture continuum is modeled with grid blocks having an initial fraction of void space less than one ( 0.5 in the current THC seepage model for the Tptpll unit). This value is chosen such that the fracture medium always contains solids that can react with fluids in fractures. It is verified that there is always enough solid initially present in the fracture continuum to avoid the possibility that some of the primary rock forming minerals become exhausted (through dissolution). Note that the volume of each grid block assigned to the fracture continuum is then calculated in such a way that the true fracture porosity (i.e., the fraction of the bulk rock occupied by fracture void space) is always reproduced. 
10. The thermal conductivities of fracture and matrix grid blocks are calculated assuming a linear interpolation between dry and wet conductivities as a function of liquid saturation. These are the thermal conductivities for the solid + fluid system. For fractures, thermal conductivities are multiplied by the fracture porosity to account for the correct fracture-to-fracture connection area in calculations of heat conduction (i.e., this is needed because full grid block areas are input into the model). Fracture thermal conductivities are also multiplied by 0.1 (an arbitrary value less than 1) to account for the limited spatial continuity and connectivity between fracture grid blocks. The volume of the fracture continuum is, however, only a small fraction of the matrix continuum. Therefore, heat conduction occurs primarily through the matrix continuum and, as a result, the model is not sensitive to the amount of heat conduction in fractures. This linear interpolation approach to determine bulk thermal conductivities is discussed and validated in Thermal Conductivity of the Potential Repository Horizon (BSC 2004 [DIRS 169854], Sections 7.4.1 and 7.4.2).

11. Vapor-pressure lowering due to capillary pressure (the Kelvin effect) is implemented in simulations carried out for this current model revision (Sections 6.5 and 7.1). The impact of including or neglecting this effect is evaluated in Section 6.5.5.3.

12. Hydrogeologic rock properties in each hydrogeologic unit of the model are approximated as being laterally homogeneous. In the Tptpmn Heterogeneous THC model, an earlier, alternate conceptualization (Section 6.3), the natural heterogeneity in fracture permeability (4 orders of magnitude) was assumed. Results of the Tptpmn Heterogeneous THC model did not show significantly different water chemistry in either space or time when compared to the homogeneous model. Furthermore, good comparisons are obtained between modeled and measured water and gas chemistry for the DST, assuming homogeneous properties (Section 7.1).

13. The capillary pressure in both fractures and matrix must reach some maximum, finite value upon complete dryout (zero liquid saturation). The default limit in the THC seepage model and the DST THC submodel is set to $10^{8} \mathrm{~Pa}$. For fractures and matrix in the Tptpmn, Tptpll, and Tptpln lithostratigraphic units (model units tsw34, tsw35, and tsw36, respectively), the limit is set, as previously, by the calculated slope of the $\mathrm{P}_{\text {cap }}$ versus liquid saturation curve at a liquid saturation value equal to $\mathrm{S}_{\mathrm{r}}+\varepsilon$. For these units, $\varepsilon$ values for the matrix yield maximum $\mathrm{P}_{\text {cap }}$ values of $10^{8} \mathrm{~Pa}$ (Table 6.4-1); for fractures, $\varepsilon$ is set to 0.01 as done for REV01 simulations (maximum $\mathrm{P}_{\text {cap }}$ values around $10^{3}$ to $10^{4} \mathrm{~Pa}$ ).

14. Open spaces in the drift are approximated as a porous medium with a large permeability $\left(10^{-9} \mathrm{~m}^{2}\right)$ greater than in surrounding rocks, but not so large as to create numerical difficulties when computing flow. In addition, these open spaces are modeled with no capillarity, unit porosity, and no residual saturation except directly against the drift wall (arbitrary small value of 0.01 to account for some water condensation, if any, against the drift wall). These approximations are made because the mathematical model is not formulated to accurately treat fluid flow in non-porous media. The sensitivity to the chosen permeability value for the porous medium has been evaluated for in-drift $\mathrm{RH}$ and temperature in Multiscale Thermohydrologic Model (BSC 2004 [DIRS 169565], Section 6.3.10) and found to be insignificant. 
15. The fracture tortuosity value of 0.7 (Section 4.1.1.1) has been adopted for use with thermal and diffusive transport parameters of lithologic units. This value is based on experimental determinations of tortuosity in soils having various porosities (Penman 1940 [DIRS 109941], pp. 441 to 461), and also corresponds to the highest tortuosity value given by de Marsily (1986 [DIRS 100439], p. 233). The rationale for this value is that fracture tortuosity should be high compared to matrix tortuosity (i.e., less tortuous path in fractures than in the matrix). This fracture tortuosity is modified for fracture-fracture connections by multiplication of the tortuosity by the fracture porosity of the bulk rock. This operation yields a better approximation for the fracture-to-fracture interconnection area (only for calculation of diffusive fluxes; the entire grid block connection area is used for calculating advective fluxes, because the bulk fracture permeability of the entire grid block is entered into the model).

16. An estimated matrix tortuosity of 0.2 is assumed to be applicable to the tuff matrix at Yucca Mountain. This is in the lower part of the parameter range given by de Marsily (1986 [DIRS 100439], p. 233), consistent with the much finer pore size in the matrix. The tortuosity is a factor applied along with the porosity and the saturation to the diffusion coefficient. Common matrix tortuosity values only cover a span of about one order of magnitude, so this value has a very limited effect on reaction-transport processes. A tortuosity of 0.7 is assumed for the invert for similar reasons as described for the matrix fracture permeability above. The invert is coarse granular material and its tortuosity would be expected to be between 0.7 and 1.0. The tortuosity of sand is about 0.7 (de Marsily 1986 [DIRS 100439], p. 233). These values only slightly affect diffusive transport of $\mathrm{CO}_{2}$ in the drift. Because reactions involving $\mathrm{CO}_{2}$ are minimal in the drift, the diffusivity of $\mathrm{CO}_{2}$ within in-drift components has a negligible effect on THC processes outside of the drift.

17. The satiated saturation is the maximum liquid saturation before saturated flow conditions are reached (i.e., at which the capillary pressure reaches zero). It is typically given the value of 1 (fully saturated conditions), and is the same as $\mathrm{S}_{\max }$.

18. The drift wall is open to all fluid fluxes. No specific boundary conditions of pressure, relative humidity, or gas compositions are applied inside the drift (i.e., as if the repository is sealed off, and neglecting sources or sinks of $\mathrm{CO}_{2}$ due to microbial activity or atmospheric $\mathrm{CO}_{2}$ ). Computing fluid flow through open spaces of the drift using a model designed to calculate flow through porous media is by itself a very coarse approximation. Thus, modeling the drift wall as either open or closed to advective fluid flow yields equally coarse approximations. However, the scope of this report is to model THC processes in the near-field outside the drift and not in the drift itself. Comparisons between these alternatives are presented in Section 6.5. Note that for the open drift case used in the current THC seepage model, the invert is allowed to react with any water present in it (pore water or condensation).

\subsubsection{Summary of Hydrologic and Thermal Properties}

The hydrologic and thermal properties of repository units used in simulations presented in the following sections of this report are summarized in Table 6.4-1. Sources of properties used for all modeled hydrogeological units and other input data are listed in Sections 4.1 and 6.4.8. 


\subsubsection{Thermodynamic Data Sensitivity}

Simulations of "ambient" conditions (i.e., without thermal loading, under natural geothermal gradient, and without drift opening) have been run using alternative thermodynamic data sets to evaluate the model sensitivity to these data (Section 6.5.5.1) and to justify the thermodynamic data (Set 1, below) selected for THC seepage model simulations that provide feeds to downstream models. The following three sets of data are used for these ambient simulations:

\section{Set 1}

This is the thermodynamic data set adopted for all current THC seepage model simulations (DTN: LB0307THMDBRTM.001 [DIRS 164434]) (Appendix C) and is discussed in Section 4.1.4.

\section{Set 2}

This thermodynamic data set contains all data from the YMP thermodynamic database data0.ymp.R2 (DTN: MO0302SPATHDYN.000 [DIRS 161756]), except for necessary changes to data for a few minerals (not prevalent in the vicinity of the drift) as described below (Wang 2003 [DIRS 161665], SN-LBNL-SCI-141-V2, pp. 158 to 160).

Heulandite in database data0.ymp.R2 contains significant amounts of barium and strontium. These chemical components are not considered in this study. For this reason, the data from database data0.ymp.R2 for heulandite could not be used. Instead, $\log (\mathrm{K})$ values used in Set 2 for heulandite are taken as the uncorrected $\log (\mathrm{K})$ values given in DTN: LB0307THMDBRTM.001 [DIRS 164434] ("heuland/10" in Appendix C). The source of these data and the calculation methods are the same as those used for the stellerite $\log (\mathrm{K})$ values in the data0.ymp.R2 database (DTN: MO0302SPATHDYN.000 [DIRS 161756]).

For clinoptilolite, $\log (\mathrm{K})$ values are taken for the mineral identified as clinoptilolite-Ca in database data0.ymp.R2 because this phase has a similar composition to the phase used in Set 1. However, this phase contains a very small amount of iron, which is not included in the clinoptilolite in Set 1. By using this phase, the already very small amount of iron in the aqueous phase is completely depleted, causing chemical convergence problems in simulations. For this reason, iron has been removed from this phase. It was not deemed necessary to recompute $\log (\mathrm{K})$ values because the amount of iron in this phase is very small (approximately 0.1 percent stoichiometric proportion of Fe relative to $\mathrm{Si}$ ).

No other changes have been made to the data0.ymp.R2 database for Set 2. For calcium, magnesium, and sodium smectites, the phases identified as montmorillonite-Ca, montmorillonite- $\mathrm{Mg}$, and montmorillonite- $\mathrm{Na}$ in the data0.ymp. $\mathrm{R} 2$ database are used. For potassium feldspar, the phase identified as maximum_microcline is used. Glass data from Set 1 are included in Set 2 because no glass data are included in the data0.ymp.R2 database. Note that if a mineral is specified with different unit cell stoichiometries in Set 1 and Set 2 (i.e., some clays and zeolites), the kinetic rate of that mineral (Section 4.1.3) has been corrected to account for the same stoichiometric Si release (or consumption) per unit time for consistency between data sets. 


\section{Set 3}

This set is identical to Set 2 (data0.ymp.R2 database), except that all zeolite thermodynamic data are taken from Set 1 (minerals identified as "mord/10-r02," "heul/10-r02," "stell/10-r02," and "clpt/10-r02" in Appendix C).

Table 6.4-1. Summary of Hydrologic and Thermal Properties of Repository Units

\begin{tabular}{|c|c|c|c|c|c|}
\hline \multicolumn{2}{|c|}{$\begin{array}{c}\text { Model Layer > } \\
\text { Lithostratigraphic Unit > }\end{array}$} & \multirow[t]{2}{*}{$\begin{array}{l}\text { tsw33 } \\
\text { Tptpul }\end{array}$} & \multirow[t]{2}{*}{\begin{tabular}{|c|} 
tsw34 \\
Tptpmn \\
\end{tabular}} & \multirow[t]{2}{*}{$\begin{array}{l}\text { tsw35 } \\
\text { Tptpll }\end{array}$} & \multirow[b]{2}{*}{ DTN: } \\
\hline MATRIX DATA & & & & & \\
\hline permeability & $k_{m}\left(m^{2}\right)$ & $6.57 \mathrm{E}-18$ & 1.77E-19 & $4.48 \mathrm{E}-18$ & LB0208UZDSCPMI.002 [DIRS 161243] \\
\hline porosity & $\phi_{\mathrm{m}}$ & 0.1425 & 0.1287 & 0.1486 & LB0210THRMLPRP.001[DIRS 160799] \\
\hline van Genuchten $\alpha$ & $\alpha_{m}(1 / P a)$ & 6.17E-6 & $8.45 \mathrm{E}-6$ & $1.08 \mathrm{E}-5$ & LB0208UZDSCPMI.002 [DIRS 161243] \\
\hline van Genuchten $\mathrm{m}$ (or $\lambda$ ) & $\mathrm{m}_{\mathrm{m}}$ & 0.283 & 0.317 & 0.216 & $\begin{array}{l}\text { LB0207REVUZPRP.002 [DIRS 159672] } \\
\text { (file matrix_props.xls) }\end{array}$ \\
\hline residual saturation & $S_{\mathrm{Irm}}$ & 0.12 & 0.19 & 0.12 & $\begin{array}{l}\text { LB0207REVUZPRP.002 [DIRS 159672] } \\
\text { (file matrix_props.xls) }\end{array}$ \\
\hline satiated saturation & $S_{\text {Ism }}$ & 1.00 & 1.00 & 1.00 & $\begin{array}{l}\text { LB0207REVUZPRP.002 [DIRS 159672] } \\
\text { (file matrix_props.xls) }\end{array}$ \\
\hline epsilon (for max $P_{\text {cap }}$ ) & $\varepsilon$ & 0.138 & 0.091 & 0.216 & $\begin{array}{l}\text { Yield maximum } P_{\text {cap }}=10^{8} \mathrm{~Pa} \\
\text { (Section 6.4.6) }\end{array}$ \\
\hline rock grain density & $\rho_{\mathrm{g}}\left(\mathrm{kg} / \mathrm{m}^{3}\right)$ & 2358 & 2466 & 2325 & LB0210THRMLPRP.001[DIRS 160799] \\
\hline rock grain specific heat & $\mathrm{Cp}(\mathrm{J} / \mathrm{kg}-\mathrm{K})$ & 985 & 985 & 985 & LB0210THRMLPRP.001[DIRS 160799] \\
\hline dry conductivity & $\lambda_{\text {dry }}(W / m-K)$ & $1.164^{\mathrm{a}}$ & $1.419^{a}$ & $1.278^{\mathrm{a}}$ & LB0210THRMLPRP.001[DIRS 160799] \\
\hline wet conductivity & $\lambda_{\text {wet }}(\mathrm{W} / \mathrm{m}-\mathrm{K})$ & $1.675^{a}$ & $2.074^{a}$ & $1.890^{\mathrm{a}}$ & LB0210THRMLPRP.001[DIRS 160799] \\
\hline tortuosity & $\mathrm{t}$ & 0.2 & 0.2 & 0.2 & $\begin{array}{l}\text { Assumed (Section 6.4.6) from range of } \\
\text { accepted values (de Marsily } 1986 \\
\text { [DIRS 100439]) }\end{array}$ \\
\hline \multicolumn{6}{|l|}{ FRACTURE DATA $^{b}$} \\
\hline permeability & $k_{f}\left(m^{2}\right)$ & $7.80 \mathrm{E}-13$ & 3.30E-13 & $9.10 \mathrm{E}-13$ & LB0205REVUZPRP.001[DIRS 159525] \\
\hline porosity (Tptpll Model) & $\phi_{f}$ & $5.8 \mathrm{E}-3$ & $8.5 \mathrm{E}-3$ & $9.6 \mathrm{E}-3$ & LB0205REVUZPRP.001[DIRS 159525] \\
\hline van Genuchten $\alpha$ & $\alpha_{f}(1 / P a)$ & $1.59 \mathrm{E}-3$ & 1.04E-4 & 1.02E-4 & LB0208UZDSCPMI.002 [DIRS 161243] \\
\hline van Genuchten $\mathrm{m}$ (or $\lambda$ ) & $m_{f}$ & 0.633 & 0.633 & 0.633 & LB0205REVUZPRP.001[DIRS 159525] \\
\hline residual saturation & $S_{\text {Irf }}$ & 0.01 & 0.01 & 0.01 & LB0205REVUZPRP.001[DIRS 159525] \\
\hline satiated saturation & $S_{\text {Isf }}$ & 1.00 & 1.00 & 1.00 & LB0205REVUZPRP.001[DIRS 159525] \\
\hline active fracture parameter & gamma & 0.60 & 0.57 & 0.57 & LB0208UZDSCPMI.002 [DIRS 161243] \\
\hline frequency & $f(1 / m)$ & 0.81 & 4.32 & 3.16 & LB0205REVUZPRP.001[DIRS 159525] \\
\hline fracture to matrix area & $A\left(m^{2} / m^{3}\right)$ & 4.44 & 13.54 & 9.68 & LB0205REVUZPRP.001[DIRS 159525] \\
\hline
\end{tabular}


Table 6.4-1. Summary of Hydrologic and Thermal Properties of Repository Units (Continued)

\begin{tabular}{|c|l|l|l|l|l|}
\hline \multicolumn{2}{|c|}{$\begin{array}{c}\text { Model Layer > } \\
\text { Lithostratigraphic Unit }>\end{array}$} & $\begin{array}{c}\text { tsw33 } \\
\text { Tptpul }\end{array}$ & $\begin{array}{c}\text { tsw34 } \\
\text { Tptpmn }\end{array}$ & $\begin{array}{c}\text { tsw35 } \\
\text { Tptpll }\end{array}$ & \\
\hline $\begin{array}{c}\text { FRACTURE DATA } \\
\text { (Cont.) }\end{array}$ & & & & & \\
\hline tortuosity & $\mathrm{t}$ & 0.7 & 0.7 & 0.7 & $\begin{array}{l}\text { (Penman 1940 [DIRS 109941], pp. 441 } \\
\text { and 461) }\end{array}$ \\
\hline epsilon (for max $\mathrm{P}_{\text {cap }}$ ) & $\mathrm{E}$ & 0.01 & 0.01 & 0.01 & Model Setup (Section 6.4.6) \\
\hline
\end{tabular}

${ }^{a}$ Bulk conductivities converted from grain conductivity values and lithophysal porosities listed in the DTN are shown using $\mathrm{K}_{\text {bulk }}=\mathrm{K}_{\text {grain }}\left(1-\phi_{\text {lith }}\right)+\phi_{\text {lith }} \mathrm{K}_{\text {air, }}$ with $\mathrm{K}_{\text {air }}=0.028(\mathrm{~W} / \mathrm{m}-\mathrm{K})$ (extrapolated at $50^{\circ} \mathrm{C}$ from Lide 1993 [DIRS 123032], p. 6-172).

${ }^{\mathrm{b}}$ Fracture thermal properties are derived using matrix properties as discussed in Section 6.4.6.

NOTE: $\quad$ Also see Section 4.1.1.

\subsection{THC SEEPAGE MODEL}

Key elements of the THC seepage model include:

- Initial heat load $1.45 \mathrm{~kW} / \mathrm{m}$ (Appendix D, Section 4.1.7 and Table 4.1-6)

- 50-year preclosure period with 86.3 percent ventilation efficiency (Section 4.1.7 and Table 4.1-6)

- Drift in the Tptpll unit (Section 4.1.6)

- Model stratigraphy at a location near the center of the repository, at approximately Nevada State Plane coordinates E170572, N233195 (Section 4.1.6.1)

- Use of an extended-case geochemical system that is more complex than that used in earlier revisions (Section 6.2.2.2)

- Drift wall open to fluid and gas advective and diffusive fluxes (Section 6.4.6)

- Vapor pressure lowering due to capillary pressure (Section 6.4.6 and Table 4.1-6)

- Experimentally measured rock thermal and hydrologic properties (Section 4.1.1)

- Thermodynamic data (Section 4.1.4 and Table 4.1-1, Appendix C)

- Kinetic data (Section 4.1.3 and Table 4.1-3)

- Use of TOUGHREACT V3.0 (LBNL 2002 [DIRS 161256]). This version takes into account the precipitation of solids in dry grid blocks where water influx occurs and, therefore, models more precisely the mineral deposition at the boiling front (Section 3). 
In addition, this revised model is used to conduct a broad range of evaluations, including simulations using:

- Different input thermodynamic data (ambient conditions) (Section 6.5.5.4)

- Five different input water compositions (Section 4.1.5, Table 4.1-4, Section 6.2.2.1, Table 6.2-1)

- Fixed and variable infiltration rates (Section 4.1.1.2, Tables 4.1-1 and 4.1-2, Section 6.5.2, Table 6.5-3)

- Different water-vapor-pressure models (with and without vapor-pressure lowering)

- Two values of $\mathrm{CO}_{2}$ gas molecular diameter (resulting in a six-fold difference in the diffusion coefficient) (Section 6.5.3).

For all direct input sources, see Section 4.1.

\subsubsection{Numerical Mesh (Tptpll)}

Simulations are performed on a vertical two-dimensional mesh, using a drift spacing of $81 \mathrm{~m}$ (center to center) (BSC 2004 [DIRS 168489]) and a drift diameter of $5.5 \mathrm{~m}$ (BSC 2004 [DIRS 168489]). With rock properties laterally homogeneous between drifts (Section 6.4.6), this setup can be viewed as a series of symmetrical, identical half-drift models with vertical no-flow boundaries between them. Accordingly, the numerical mesh is reduced to a two-dimensional half-drift model with a width of $40.5 \mathrm{~m}$, corresponding to the midpoint between drifts (Figure 6.5-1). Geologic data from column "j34" of the UZ99_2_3D calibration model (DTN: LB990501233129.004 [DIRS 111475]) have been used to map geologic contacts into the two-dimensional mesh, and the mesh coordinate system is set with reference to the center of the drift (Table 6.5-1).

To limit grid orientation effects, the mesh design is mostly orthogonal, with a small radially gridded area in the immediate vicinity of the drift (Figures 6.5-1 and 6.5-2). The area extending approximately $40 \mathrm{~m}$ above the drift is more finely gridded than other areas to capture THC effects potentially affecting seepage into the drift. Outside the drift, the smallest grid spacing is specified at the drift wall $(20 \mathrm{~cm})$ and increased outward. A constant square cell size of $50 \mathrm{~cm}$ is used from approximately $5 \mathrm{~m}$ to $7 \mathrm{~m}$ above drift center, increased to a $1-\mathrm{m}$ size until $15 \mathrm{~m}$ above drift center, then a 2-m size from 15 to $30 \mathrm{~m}$ above drift center. All geologic layers down to the water table below the modeled drift are incorporated into the numerical mesh (Table 6.5-1). Grid block sizes increase significantly $100 \mathrm{~m}$ above and below the drift to increase computing efficiency. The mesh consists of 3,202 grid blocks, including those representing matrix, fracture, and in-drift design elements.

The drift discretization is shown in Figure 6.5-2. The drift is discretized to include the design elements and dimensions shown on Figure 4.1-1 (338 grid blocks total). The invert, $0.8 \mathrm{~m}$ thick, is divided into an "upper invert" and "lower invert" for assignment of different thermal conductivities in these zones (Section 4.1.7). The drip shield is not explicitly modeled 
(Section 4.1.7). The grid block size inside the drift is chosen to be small enough to provide a realistic drift model (compare Figure 6.5-2 to Figure 4.1-1). Two in-drift configurations are considered in this model:

- Preclosure configuration (during the first 50 years): waste package, upper invert, lower invert, and open space between the waste package and drift wall

- Postclosure configuration (after 50 years): waste package, upper invert, lower invert, drip shield, and two open zones (inner zone, between the waste package and drip shield; and outer zone, between the drip shield and drift wall).

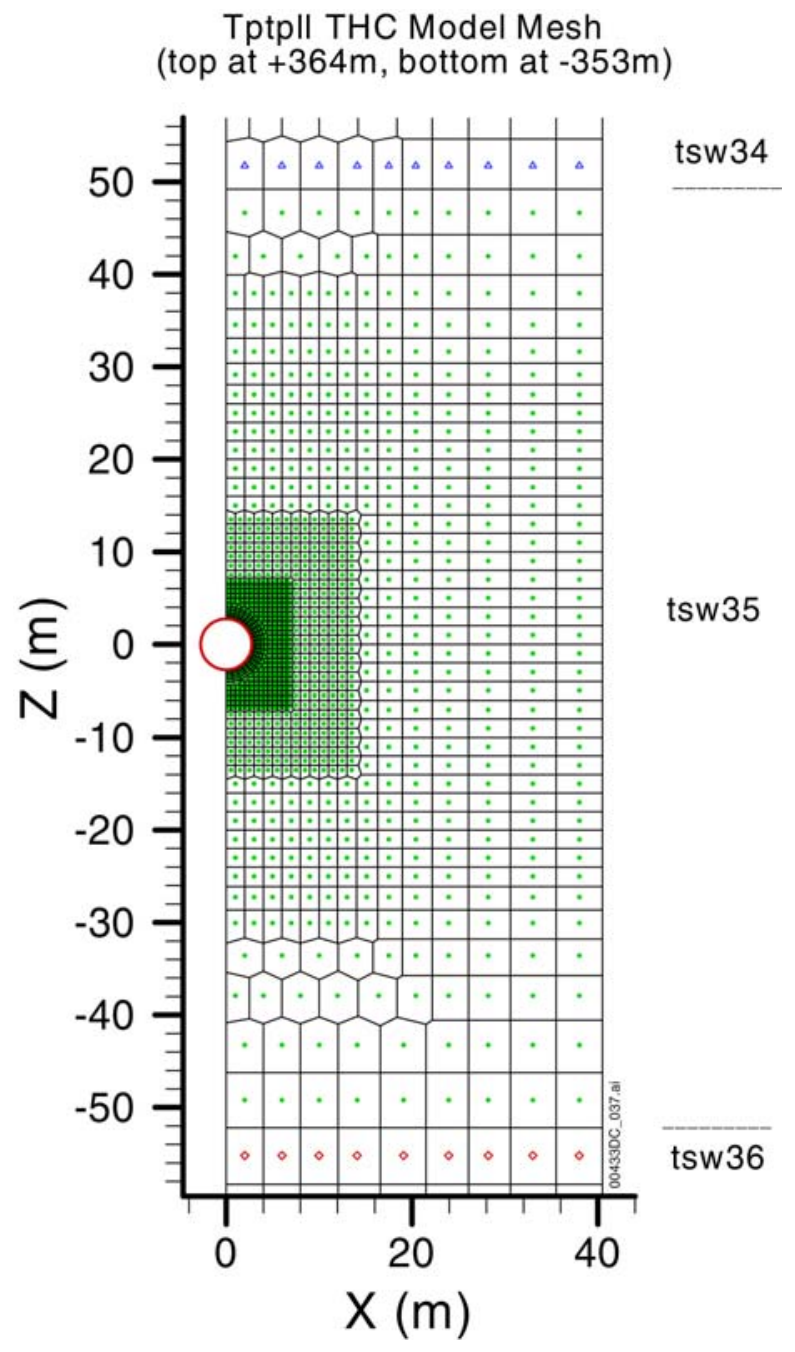

Source: DTN: LB0011DSTTHCR1.002 [DIRS 161282].

NOTE: Grid detail around $(0,0)$ is shown in Figure 6.5-2.

Figure 6.5-1. THC Model Mesh with Hydrogeologic Units Shown in the Vicinity of the Drift: Topopah Spring Tuff Middle Nonlithophysal (tsw34-triangles), Lower Lithophysal (tsw35-dots), and Lower Nonlithophysal (tsw36 — diamonds) Units 
Table 6.5-1. Vertical Mesh Dimensions and Geologic Contacts in the THC Seepage Model (Tptpll Unit)

\begin{tabular}{|c|c|c|}
\hline Model Layer & $\begin{array}{l}\text { Top of Layer } \\
\text { Elevation }(\mathrm{m})\end{array}$ & $\begin{array}{l}\text { Mesh Top of Layer } \\
\text { Z Coordinate }(\mathrm{m})\end{array}$ \\
\hline Top & 1446.6 & 363.8 \\
\hline tcw11 & 1446.6 & 363.8 \\
\hline tcw12 & 1419.2 & 336.4 \\
\hline tcw13 & 1342.1 & 259.3 \\
\hline ptn21 & 1326.5 & 243.7 \\
\hline ptn22 & 1323.1 & 240.3 \\
\hline ptn23 & 1321.0 & 238.2 \\
\hline ptn24 & 1318.2 & 235.4 \\
\hline ptn25 & 1312.7 & 229.9 \\
\hline ptn26 & 1303.6 & 220.8 \\
\hline tsw31 & 1294.1 & 211.3 \\
\hline tsw32 & 1279.7 & 196.9 \\
\hline tsw33 & 1249.3 & 166.5 \\
\hline tsw34 & 1169.2 & 86.4 \\
\hline tsw35 & 1132.0 & 49.2 \\
\hline Drift center & 1082.8 & 0.0 \\
\hline tsw36 & 1030.6 & -52.2 \\
\hline tsw37 & 997.4 & -85.4 \\
\hline tsw38 & 980.8 & -102.0 \\
\hline tsw39 & 967.0 & -115.8 \\
\hline $\operatorname{ch} 1 v$ & 956.9 & -125.9 \\
\hline $\operatorname{ch} 2 v$ & 945.2 & -137.6 \\
\hline ch3v & 931.9 & -150.9 \\
\hline $\operatorname{ch} 4 z$ & 919.2 & -163.6 \\
\hline ch5z & 906.4 & -176.4 \\
\hline $\operatorname{ch} 6$ & 892.4 & -190.4 \\
\hline pp4 & 878.5 & -204.3 \\
\hline pp3 & 865.9 & -216.9 \\
\hline pp2 & 833.2 & -249.5 \\
\hline $\mathrm{pp} 1$ & 818.2 & -264.6 \\
\hline bf3 & 756.7 & -326.1 \\
\hline Bottom & 730.0 & -352.8 \\
\hline
\end{tabular}

Source: DTNs: LB0011DSTTHCR1.002 [DIRS 161282] (model), LB990501233129.004 [DIRS 111475] (geologic column). 


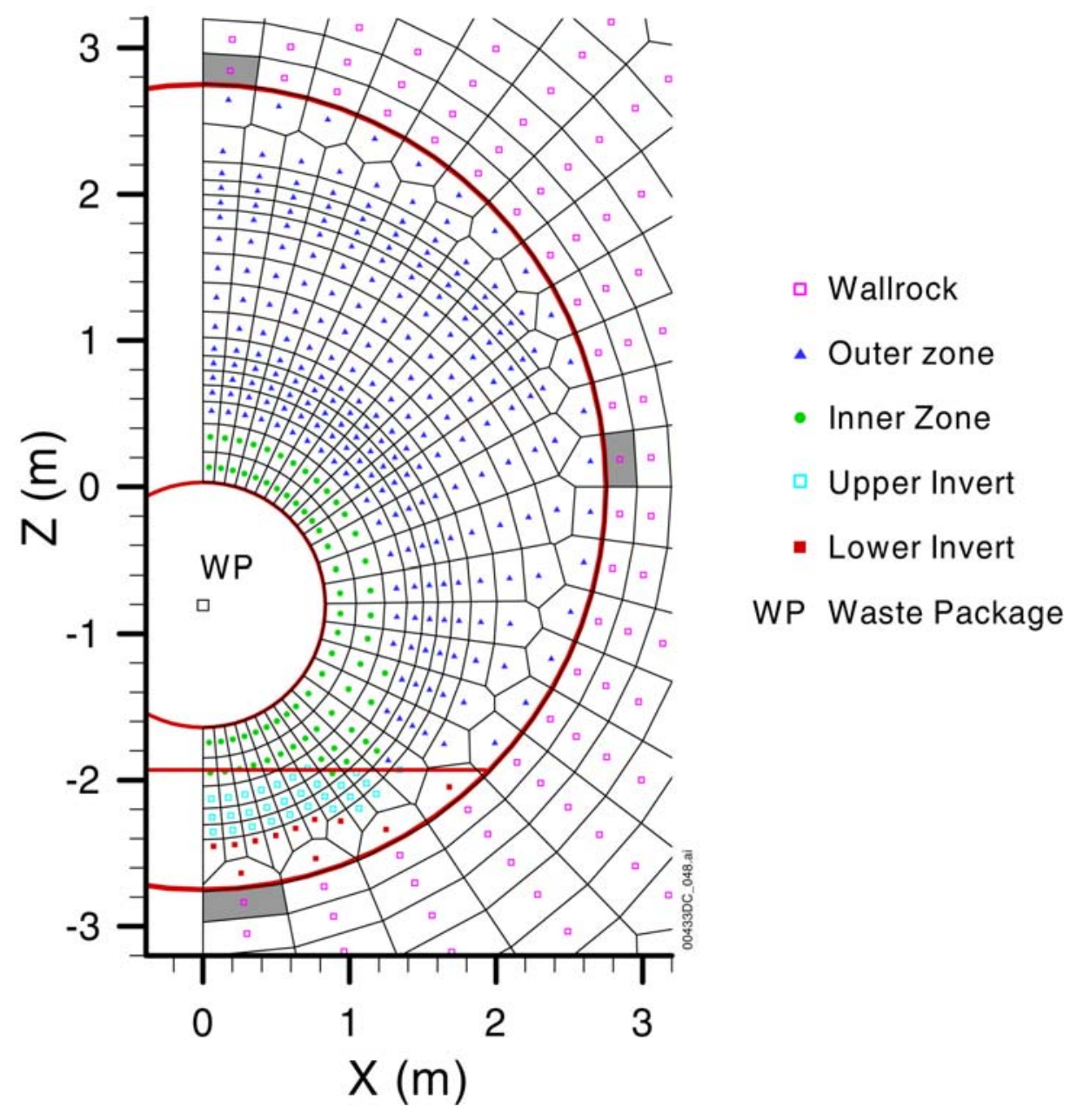

Source: DTN: LB0011DSTTHCR1.002 [DIRS 161282].

NOTE: Shaded grid blocks are those with top, side, base designations in other figures.

Figure 6.5-2. Discretization of the Repository Drift in the THC Model

The discretization of the drift is kept the same for the two configurations. As such, the preclosure period is simulated by assigning identical open-space properties to grid blocks representing the inner zone and outer zone.

Simulations of ambient conditions (no thermal load) are run with a one-dimensional (vertical column) grid having the same stratigraphy and vertical discretization as the Tptpll two-dimensional mesh. This one-dimensional model does not have a drift opening and uses uniform vertical gridding through the area cutting across the drift on Figure 6.5-2. One-dimensional columns are used to speed up the computational effort. Because of the no-flow boundary conditions existing on each side of the model mesh, the horizontal geologic contacts and laterally continuous rock properties, two-dimensional simulations under ambient conditions are essentially the same as one-dimensional simulations (vertical flow only). Close to the drift, however, flow is diverted around the drift opening because of the capillary barrier created by this opening. Therefore, the only differences between one- and two-dimensional ambient simulations result from the effect of the drift opening. 


\subsubsection{Boundary Conditions}

The boundary conditions are set according to those appropriate for the column location near the repository center (DTN: LB990701233129.002 [DIRS 125604]) (Table 6.5-2), with temperatures at the top and bottom boundary reflecting the natural geothermal gradient. The pressures and temperatures are constant at the top and bottom boundaries. The use of a constant temperature boundary at the water table is not expected to have much effect on the predicted thermal history or water chemistry in the repository drifts because the boundary is so far (more than $350 \mathrm{~m}$ ) from the repository horizon (BSC 2004 [DIRS 169866], Section 6.1.3). The initial $\mathrm{CO}_{2}$ partial pressure in the drift is set to the ambient $\mathrm{CO}_{2}$ partial pressure in the adjacent wall rock.

Three cases of infiltration are considered as shown in Table 6.5-3. The infiltration values $(6,16$, and $25 \mathrm{~mm} / \mathrm{yr}$ for the present-day, monsoonal, and glacial transition periods, respectively) represent repository-wide averages of percolation; the values are calculated as the arithmetic average of the 31 repository locations considered in Multiscale Thermohydrologic Model (BSC 2001 [DIRS 158204], Section 6.3.1). The calculated averages have been rounded to $6 \mathrm{~mm} / \mathrm{yr}, 16 \mathrm{~mm} / \mathrm{yr}$, and $25 \mathrm{~mm} / \mathrm{yr}$, respectively, for use in this report. These values vary slightly from current estimates; their use in this model is justified in Section 4.1.1.2.

One-dimensional simulations of ambient conditions are run with the same boundary conditions as the two-dimensional runs, except that these simulations do not include a drift opening. A constant infiltration rate of $6 \mathrm{~mm} / \mathrm{yr}$ is used in one-dimensional simulations to evaluate the model sensitivity to thermodynamic data (Section 6.5.5.4). The mean infiltration case in Table 6.5-3 (step-wise infiltration increase) is used for all other ambient simulations (Section 6.5.5.4).

Table 6.5-2. Tptpll THC Seepage Model (Tptpll Unit) Boundary Conditions

\begin{tabular}{|c|c|c|}
\hline Boundary & Boundary Condition & Reference \\
\hline Top & $\begin{array}{l}\mathrm{T}=16.13^{\circ} \mathrm{C} \\
\mathrm{S}_{\mathrm{g}}=0.99 \\
\mathrm{P}=84725 \mathrm{~Pa} \\
\text { Time-varying infiltration rate (mean infiltration } \\
\text { regime only) } \\
\text { Constant composition of infiltration and } \mathrm{PCO}_{2}\end{array}$ & $\begin{array}{l}\text { Table } 4.1-1 \\
\text { Table } 4.1-1 \\
\text { Table } 4.1-1 \\
\text { Table } 6.5-3 \\
\text { Table } 6.2-1\end{array}$ \\
\hline Bottom & $\begin{array}{l}\mathrm{T}=32.62^{\circ} \mathrm{C} \\
\mathrm{S}_{\mathrm{L}}=0.99999 \\
\mathrm{P}=92000 \mathrm{~Pa} \\
\text { Constant water composition and } \mathrm{PCO}_{2}\end{array}$ & $\begin{array}{l}\text { Table } 4.1-1 \\
\text { Table } 4.1-1 \\
\text { Table } 4.1-1 \\
\text { Table } 6.2-1 \\
\end{array}$ \\
\hline Sides & No flux for water, gas, heat, and chemical species & Not Applicable \\
\hline Drift Wall & $\begin{array}{l}\text { Open to gas and liquid fluxes (advective and } \\
\text { diffusive); conduction only for heat }\end{array}$ & Not Applicable \\
\hline Waste Package & $\begin{array}{l}\text { Initial full heat load of } 1.45 \mathrm{~kW} / \mathrm{m} \text { decreasing with } \\
\text { time (due to radioactive decay), and reduced by } \\
86.3 \% \text { during the first } 50 \text { years (due to heat removal } \\
\text { by ventilation) }\end{array}$ & $\begin{array}{l}\text { Appendix D and } \\
\text { Table 4.1-6 }\end{array}$ \\
\hline
\end{tabular}

\footnotetext{
NOTES: $T=$ Temperature

$\mathrm{S}_{\mathrm{g}}=$ Gas saturation

$S_{\mathrm{L}}=$ Liquid saturation

$\mathrm{P}=$ Pressure
} 
Table 6.5-3. THC Seepage Model Infiltration Rates

\begin{tabular}{|c|c|c|c|}
\hline Case & $\begin{array}{c}\text { Infiltration Rate } \\
(\mathrm{mm} / \mathrm{yr})\end{array}$ & $\begin{array}{c}\text { Time Period } \\
\text { (years) }\end{array}$ & Reference DTN \\
\hline \multirow{3}{*}{$\begin{array}{l}\text { Mean infiltration } \\
\text { (increasing } \\
\text { stepwise) }\end{array}$} & 6 & 0 to 600 (present-day) & \multirow{5}{*}{$\begin{array}{l}\text { Infiltration rates used in this model } \\
\text { taken from DTN: LLO00114004242.090 } \\
\text { [DIRS 142884] and Table 4.1.1 }\end{array}$} \\
\hline & 16 & 600 to 2000 (monsoonal) & \\
\hline & 25 & $\begin{array}{l}2,000 \text { to } 100,000 \text { (glacial } \\
\text { transition) }\end{array}$ & \\
\hline $\begin{array}{l}\text { Mean present day } \\
\text { (fixed) }\end{array}$ & 6 & 0 to 100,000 & \\
\hline $\begin{array}{l}\text { Mean glacial } \\
\text { transition (fixed) }\end{array}$ & 25 & 0 to 100,000 & \\
\hline
\end{tabular}

NOTE: $\quad$ All simulations are carried out with the present-day mean calibrated rock properties set. See Table 6.5-5.

\subsubsection{Input Data and Modeling Procedure}

The Tptpll THC model is run using TOUGHREACT V3.0 (LBNL 2002 [DIRS 161256]). Simulations are carried out using the rock properties data shown in Table 6.4-1; the geochemical system described in Table 6.2-2; thermodynamic data shown in Appendix C (Section 4.1.5); kinetic data from Table 4.1-3; and mineral abundance and surface area data tabulated in Appendices A and B, respectively. Simulations are run using the five water compositions (Table 6.2-1) discussed in Section 6.2.2.1 and summarized below in Table 6.5-4.

Table 6.5-4. Selected Input Waters (Section 6.2.2.1) for the Tptpll THC Seepage Model (Tptpll Unit)

\begin{tabular}{|c|c|c|c|}
\hline Name of Alternative & $\begin{array}{c}\text { Sample or Water } \\
\text { Name }\end{array}$ & Location & $\begin{array}{c}\text { Lithostratigraphic } \\
\text { Unit }\end{array}$ \\
\hline W0 & HD-PERM $^{\text {a }}$ & ESF Alcove 5 & Tptpmn \\
\hline W5 & CS-1000/7.3-7.7/UC & ECRB Cross-Drift & base of Tptpul \\
\hline W4 & CS-2000/16.5-21.1/UC & ECRB Cross-Drift & Tptpll \\
\hline W6 & SD-9/990.4-991.7 & Borehole SD-9 & Tptpll \\
\hline W7 & CS-500/12.0-16.7/UC & ECRB Cross-Drift & Tptpul \\
\hline
\end{tabular}

a Average of two samples as discussed in Section 6.2.2.1.

NOTE: $\quad$ See Table 6.2-1 for compositions.

For model output runs, the diffusion coefficient of $\mathrm{CO}_{2}$ in gas was unintentionally set to a default molecular diameter of $1 \times 10^{-10} \mathrm{~m}$. The $\mathrm{CO}_{2}$-specific value is $2.5 \times 10^{-10} \mathrm{~m}$ (Section 4.1.6). This change in molecular diameter, through the use of Equation 6.4-24, causes approximately a six-fold increase in the $\mathrm{CO}_{2}$ diffusion coefficient. Although this change is within the range of uncertainty affecting the calculation of gas diffusivity in the model, a sensitivity simulation has been run using the correct $\mathrm{CO}_{2}$ molecular diameter value $\left(2.5 \times 10^{-10} \mathrm{~m}\right)$ with results compared in Section 6.5.5.2.

In this model, calcite is not treated kinetically, but is rather set to remain locally at equilibrium, (although a certain degree of supersaturation is allowed for, as discussed below). Assuming equilibrium is reasonable because calcite reaction rates reported in the literature (Table 4.1-3) are quite rapid. Very similar results in simulations of the DST are obtained when using local equilibrium for calcite and assuming a kinetically controlled reaction rate (Section 7.1). Using 
equilibrium has the advantage of allowing simulations with larger time steps than would be required with a kinetically controlled fast calcite reaction rate.

Using $\mathrm{pH}$ and calcium concentrations measured in pore-water samples (Table 6.2-1), together with independently measured $\mathrm{CO}_{2}$ partial pressures in ambient pore-gas samples (Table 7-1), calcite is calculated to supersaturate in pore waters by approximately $1 \log (Q / K)$ unit at $25^{\circ} \mathrm{C}$. The reason for this supersaturation has not been determined and could be the result of various factors, including (but not limited to) analytical errors, kinetic inhibition caused by organic or other compounds in solution, or effects caused by high capillary pressure or pressures developed during the ultra-centrifuge water-extraction process. To reconcile measured $\mathrm{pH}$, calcium, and $\mathrm{CO}_{2}$ concentrations, calcite is allowed to remain supersaturated by approximately $1 \log (Q / K)$ unit at $25^{\circ} \mathrm{C}$. This "precipitation gap" is set to decrease exponentially with temperature and become negligible (one hundredth of the gap value at $25^{\circ} \mathrm{C}$ ) at an arbitrarily selected temperature of $200^{\circ} \mathrm{C}$. This approach (using a precipitation gap) can be viewed as a crude approximation of precipitation with a nucleation threshold. Note that dissolution still occurs only if $\log (Q / K)<0$. The stability of water and gas concentrations calculated for ambient conditions over long periods of time is improved by implementing the calcite supersaturation gap.

Simulations of ambient conditions (i.e., without thermal loading, under natural geothermal gradient, and without drift opening) are run using the same input data as described above. However, to evaluate the model's sensitivity to thermodynamic data (Section 6.5.5.4), three different sets of thermodynamic data are used and are described further in Section 6.4.8: "Set 1," the database used for model output runs for TSPA, and alternative data sets "Set 2" and "Set 3."

As discussed in Section 4.1.7, THC simulations are run for an initial period of 50 years, using the preclosure drift configuration and thermal properties. The simulations are then restarted using the postclosure drift configuration and properties from 50 years to a total simulation time of 100,000 years. At times corresponding to changes in infiltration rates (at 600 and 2,000 years, Table 6.5-3), the simulations are stopped and then restarted with the new infiltration rate, resulting in a stepwise change in infiltration.

Maximum time steps of 15 days, 1 month, 2 months, 1 year, and 5 years are used for the time periods spanning 0 to 50,50 to 600,600 to 2,400, 2,400 to 20,000, and 20,000 to 100,000 years, respectively. To change infiltration rates and the maximum time step length, each run is stopped and then restarted at 50,600,2,000,2,400, and 20,000 years after changing these input data.

\subsubsection{Model Runs}

Sixteen simulations have been performed, and are summarized in Table 6.5-5. 
Table 6.5-5. THC Seepage Model Runs Using the Mean Infiltration Rock-Property Set for All Simulations

\begin{tabular}{|c|c|c|c|c|c|}
\hline $\begin{array}{l}\text { Input Water } \\
\text { (Table 6.5-3) }\end{array}$ & $\begin{array}{c}\text { Thermo. Data } \\
\text { Set } \\
\text { (Section 6.4.8) }\end{array}$ & $\begin{array}{c}\text { Infiltration Case } \\
\text { (Table 6.5-2) }\end{array}$ & $\begin{array}{c}\text { Equation of State } \\
\text { (EOS) Module }\end{array}$ & Simulation Type & Run ID \\
\hline None & None & Mean Infiltration & EOS4 & TH (two-dimensional) & th6_1.45kw \\
\hline W0 & Set 1 & Mean Infiltration & EOS4 & THC (two-dimensional) & thc6_w0 \\
\hline W4 & Set 1 & Mean Infiltration & EOS4 & THC (two-dimensional) & thc6-w4 \\
\hline W5 & Set 1 & Mean Infiltration & EOS4 & THC (two-dimensional) & thc6_w5 \\
\hline W6 & Set 1 & Mean Infiltration & EOS4 & THC (two-dimensional) & thc6 w6 \\
\hline W7 & Set 1 & Mean Infiltration & EOS4 & THC (two-dimensional) & thc6_w7 \\
\hline wo & Set 1 & $\begin{array}{l}\text { Mean Present day } \\
\text { (fixed) }\end{array}$ & EOS4 & THC (two-dimensional) & thc6_w0a \\
\hline wo & Set 1 & $\begin{array}{l}\text { Mean Glacial } \\
\text { transition (fixed) }\end{array}$ & EOS4 & THC (two-dimensional) & thc25_w0 \\
\hline WO & Set $1^{b}$ & Mean Infiltration & EOS4 & THC (two-dimensional) & thc6_w0b \\
\hline Wo & Set 1 & Mean Infiltration & EOS3 & THC (two-dimensional) & thc6_w0e3 \\
\hline Wo & Set 1 & Mean Infiltration & EOS3 (isothermal) & $\begin{array}{l}\text { THC (one-dimensional, } \\
\text { ambient) }\end{array}$ & thc6_w0amb1 \\
\hline W4 & Set 1 & Mean Infiltration & EOS3 (isothermal) & $\begin{array}{l}\text { THC (one-dimensional, } \\
\text { ambient) }\end{array}$ & thc6_w4amb1 \\
\hline W5 & Set 1 & Mean Infiltration & EOS3 (isothermal) & $\begin{array}{l}\text { THC (one-dimensional, } \\
\text { ambient) }\end{array}$ & thc6_w5amb1 \\
\hline W6 & Set 1 & Mean Infiltration & EOS3 (isothermal) & $\begin{array}{l}\text { THC (one-dimensional, } \\
\text { ambient) }\end{array}$ & thc6_w6amb1 \\
\hline wo & Set 1 & $\begin{array}{l}\text { Mean Present day } \\
\text { (fixed) }\end{array}$ & EOS3 (isothermal) & $\begin{array}{l}\text { THC (one-dimensional, } \\
\text { ambient) }\end{array}$ & thc6_w0amb \\
\hline W0 & Set 2 & $\begin{array}{l}\text { Mean Present day } \\
\text { (fixed) }\end{array}$ & EOS3 (isothermal) & $\begin{array}{l}\text { THC (one-dimensional, } \\
\text { ambient) }\end{array}$ & thc6_w0_q \\
\hline wo & Set 3 & $\begin{array}{l}\text { Mean Present day } \\
\text { (fixed) }\end{array}$ & EOS3 (isothermal) & $\begin{array}{l}\text { THC (one-dimensional, } \\
\text { ambient) }\end{array}$ & thc6_w6_w0_q1 \\
\hline
\end{tabular}

a TOUGHREACT V3.0 (LBNL 2002 [DIRS 161256]) flow modules: EOS3 neglects vapor pressure lowering due to capillary pressure; EOS4 takes this effect into account.

${ }^{b} \mathrm{~A} \mathrm{CO}_{2}$ molecular diameter of $2.5 \times 10^{-10} \mathrm{~m}$ (Section 4.1.6) is used for this run instead of the value of $1 \times 10^{-10} \mathrm{~m}$ input in other simulations listed here (Section 6.5.3).

NOTE: Run ID's are used in Output DTNs: LB0307DSTTHCR2.001, LB0307DSTTHCR2.002, LB0302DSCPTHCS.001, and LB0302DSCPTHCS.002; also see Appendix G.

\subsubsection{Simulation Results (THC Seepage Model; Tptpll Unit)}

The model results are presented below in several subsections. First, the results of a simulation of thermal loading $(\mathrm{TH})$ with no chemical reactions are presented (6.5.5.1). Then, THC results are presented in two parts. Predicted water chemistry trends around the drift are presented first (Section 6.5.5.2), then the effect of water-gas-rock reaction on fracture permeability and flow patterns around the drift is assessed (Section 6.5.5.3). The results are presented in a way that allows an assessment of model sensitivity to input water compositions, infiltration rates, water-vapor pressure models, and $\mathrm{CO}_{2}$ effective diffusivity. Then, THC simulations of ambient conditions (non-heating) using different input thermodynamic data sets are discussed (Section 6.5.5.4). These simulations serve as the basis for justifying the use of revised thermodynamic data selected for this study. Finally, simulations using current, revised matrix 
porosity and thermal values are presented (Section 6.5.5.5). These simulations serve as the basis for justifying the use of the older data set used in the THC seepage model simulations that feed TSPA. All model results have been submitted to the technical database under DTNs as listed in Section 8.5.

\subsubsection{TH Results (No Chemical Reactions)}

For comparison to the THC simulations, a model run is performed considering only thermal and hydrologic (TH) processes. This simulation is run using the mean infiltration case (Table 6.5-3) and serves as a baseline for interpreting the effects of water-gas-rock chemical interaction on the thermal and hydrologic behavior of the system.

Calculated temperatures, liquid saturation, and air mass fractions around the drift are shown in Figures 6.5-3 through 6.5-9. Postclosure temperatures quickly climb above the boiling point (near $96^{\circ} \mathrm{C}$ at Yucca Mountain), with temperatures at the drift crown peaking at around $140^{\circ} \mathrm{C}$ at a time of about 75 years. The highest modeled temperature in the waste package is attained during this time interval as well (the highest output value is near $160^{\circ} \mathrm{C}$ ). Temperatures are lower at the base of the drift (approximately $10^{\circ} \mathrm{C}$ less than at the crown) because of the insulating effect of the invert (Figures 6.5-3 through 6.5-5). The return to ambient temperatures after heating takes 50,000 to 100,000 years.

Around the drift, the fractures are predicted to rewet at times between 1,000 and 2,000 years (Figure 6.5-6). Rewetting of the matrix occurs between 200 and 300 years (Figure 6.5-7). A contour plot of temperatures and matrix saturations in the vicinity of the drift at a simulated time of 600 years (near the time of maximum dryout in the fractures) shows the fracture dryout zone extending approximately $4 \mathrm{~m}$ above the drift, $5 \mathrm{~m}$ to the side of it, and $8 \mathrm{~m}$ below it (Figure 6.5-5). In fractures, liquid saturations show strong diversion of water around the dryout zone. Air mass fractions in the gas phase at the drift wall (the complement of the steam mass fraction; Figure 6.5-8) drop to near-zero values in the fractures during dryout (i.e., the gas phase is almost entirely water vapor).

The calculated rate of vertical water influx in fractures at the drift crown (Figure 6.5-9) shows a small short-lived influx peak at the time of rewetting. The intensity of this peak may only reflect the time intervals at which data are output from the model (i.e., peaks of flux in this figure may not be fully resolved because such peaks are narrow relative to the time intervals specified for data output from the simulations). The predicted ambient water flux in the model is for a one-dimensional column without a drift opening. It does not take into account the diverting effect of a drift opening (i.e., the diversion of percolating water around the drift capillary barrier). Stepped increases in the ambient flux rates reflect infiltration rate increases at 600 and 2,000 years, corresponding to changes in climate state (Table 6.5-3). At most times (except for short-lived peaks around 50 and 1,200 years), the ambient water flux without a drift opening is larger than the predicted flux above the drift under thermal loading conditions (Figure 6.5-9). Calculated temperatures, liquid saturations, and fluxes shown here are consistent with results of TH simulations presented in Drift-Scale Coupled Process (DST and TH Seepage) Models (BSC 2004 [DIRS 170338], Section 6.2.3). Predicted temperatures are also directly comparable with the results of the multiscale thermohydrologic model's LDTH (Line-averaged-heat-source, 
Drift-scale, Thermal-Hydrologic) submodel simulations (BSC 2004 [DIRS 169565] Section 6.3). The vertical flux is further discussed in Section 6.5.5.3.

Note that in all models presented in this report, the drying of the rock caused by drift ventilation (i.e., the physical removal of moisture from wall rock by ventilation) is not considered. This drying could reduce the amount of water available for mobilization by boiling during postclosure. However, sensitivity studies (BSC 2001 [DIRS 155950], Section 5.3.2.4.4) indicate that inclusion of preclosure dryout due to ventilation has little effect on $\mathrm{TH}$ conditions around the drift during the postclosure period, compared to a model that does not account for the influence of preclosure dryout. Therefore, inclusion of preclosure dryout is not expected to have a large effect on thermal seepage. The effect of evaporative concentration on pore water compositions would be more pronounced during preclosure than predicted here. However, the small effect of preclosure dryout on postclosure TH conditions is not expected to significantly affect water compositions during postclosure.

Thermal Only (Tptpll - Current Model)

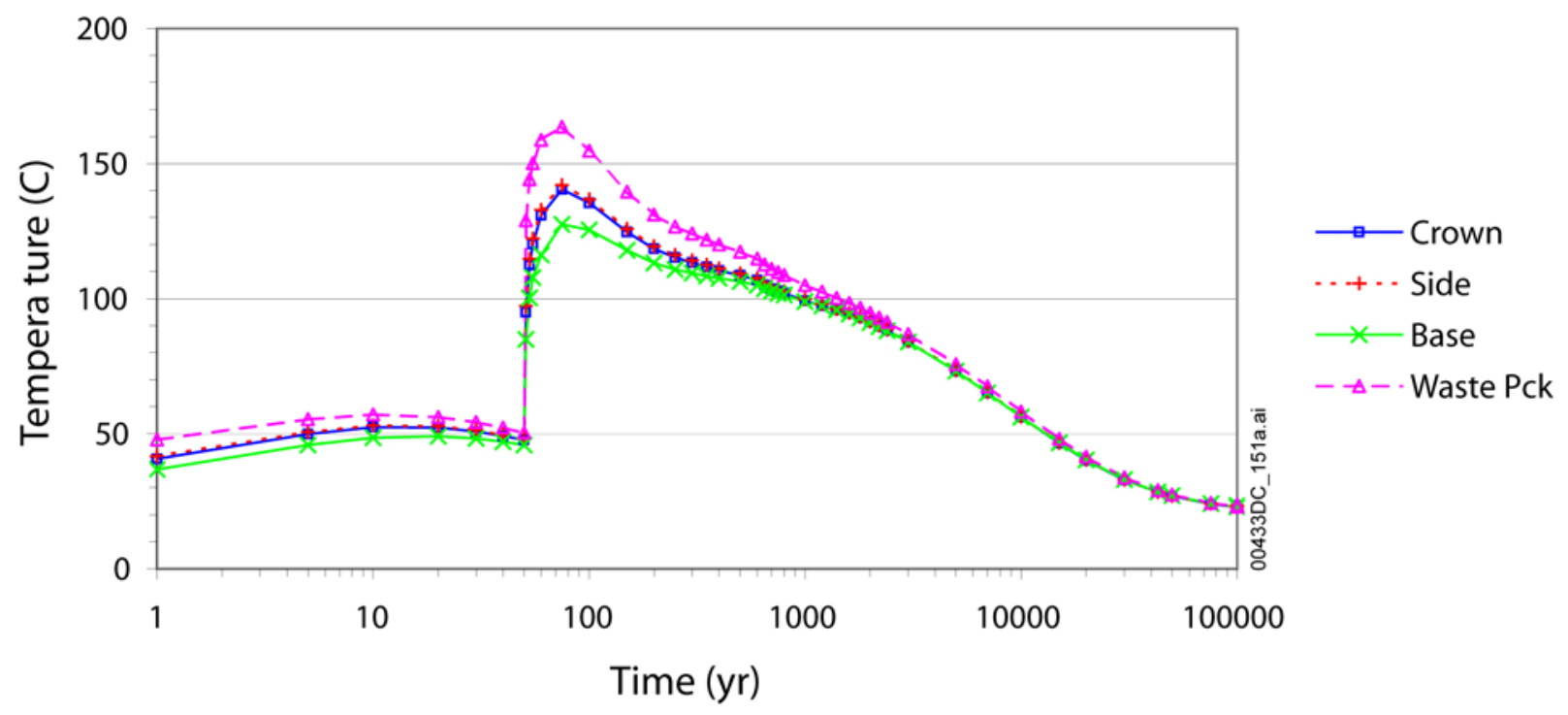

Output DTN: LB0307DSTTHCR2.002.

Figure 6.5-3. TH Simulation (Tptpll): Time Profiles of Modeled Temperatures in Fractures (Similar in Matrix) at Three Drift-Wall Locations and in the Waste Package 

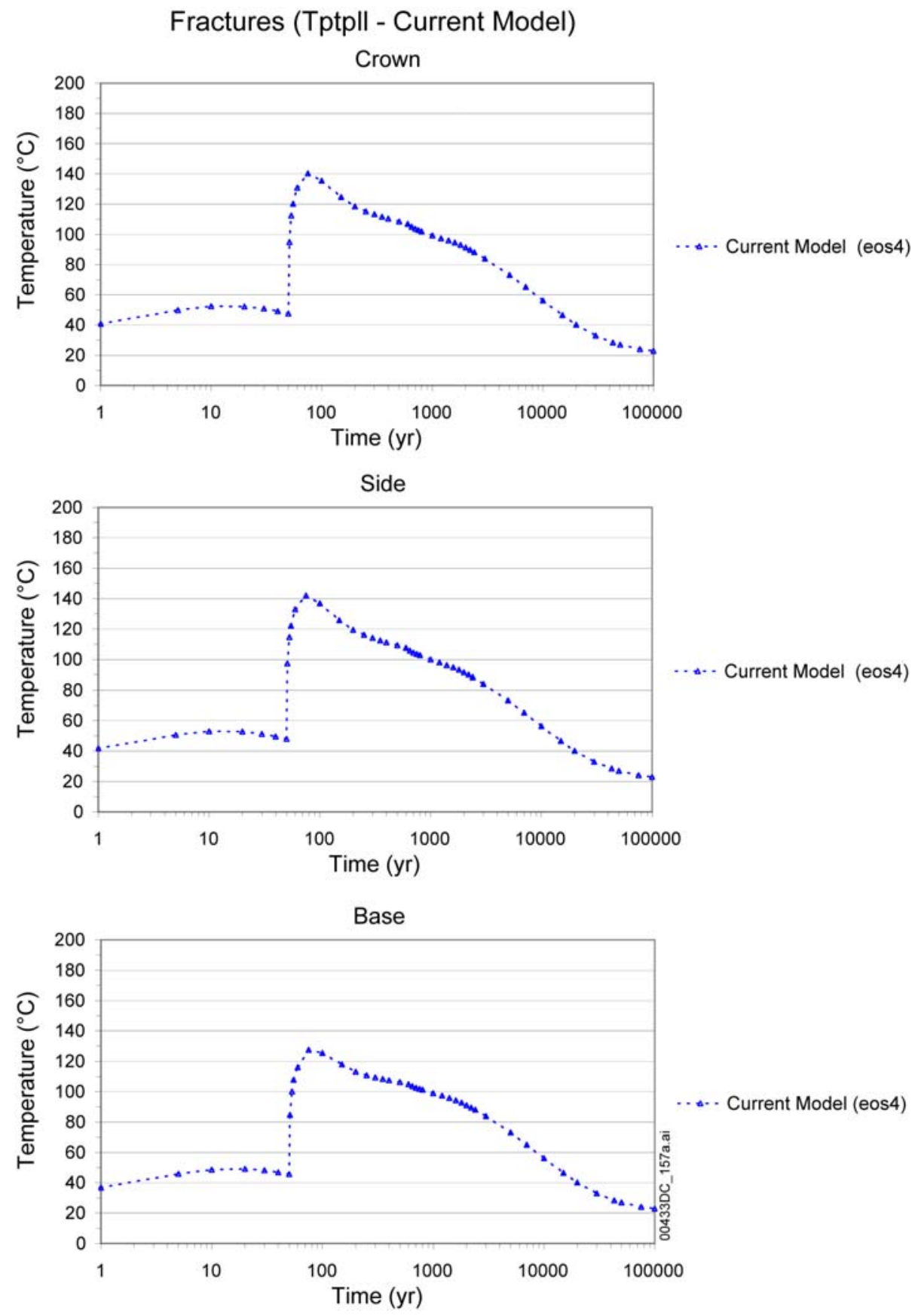

Output DTN: LB0307DSTTHCR2.002.

Figure 6.5-4. TH Simulation (Tptpll): Time Profiles of Modeled Temperatures in Fractures at Three Drift-Wall Locations 
a)

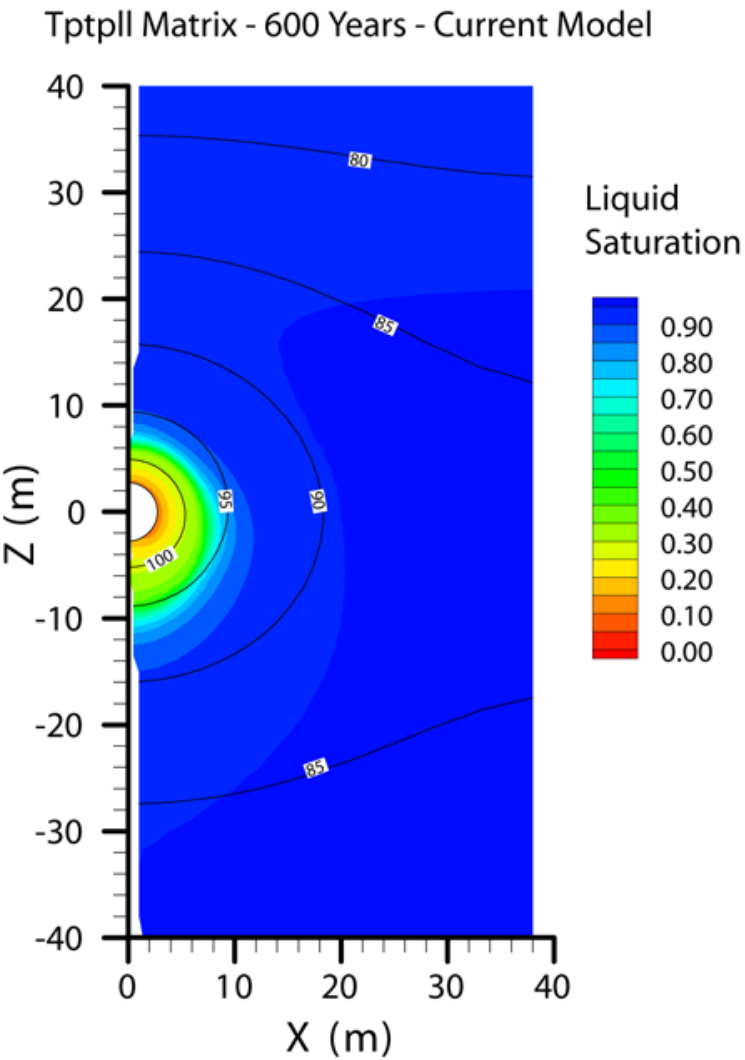

b)
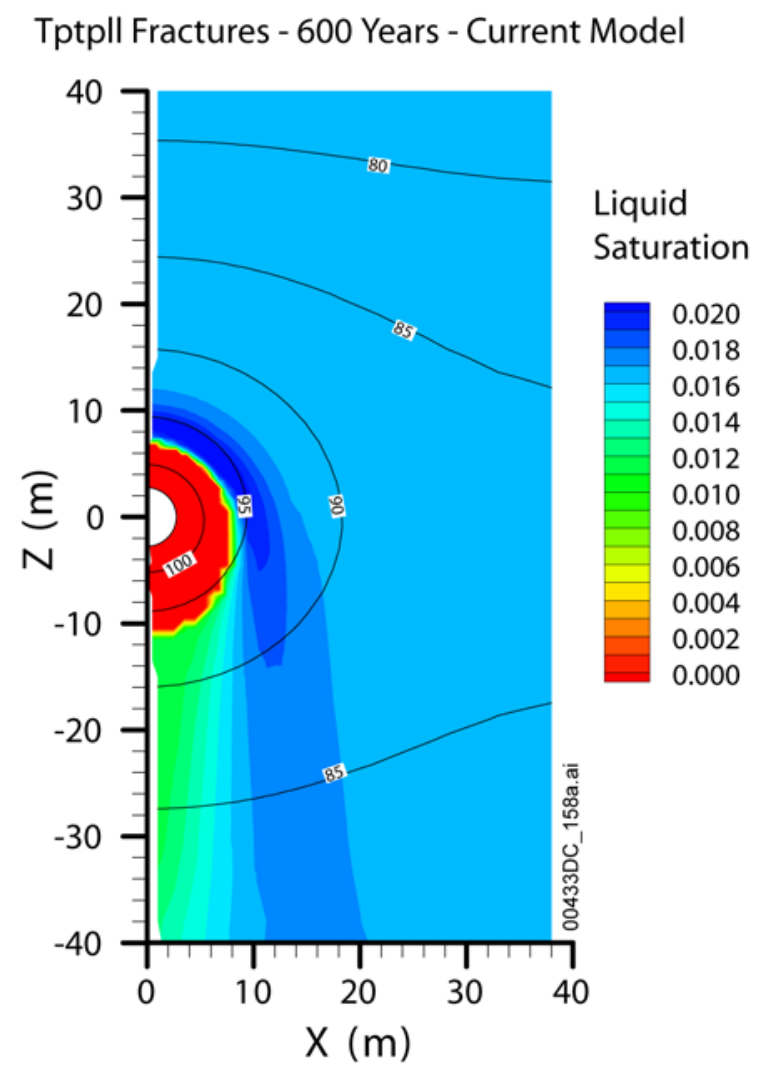

Output DTN: LB0307DSTTHCR2.001.

NOTE: $\quad$ Rewetting of the matrix at the drift wall has already occurred (Figure 6.5-7).

Figure 6.5-5. TH Simulation (Tptpll): Contour Plot of Modeled Temperatures $\left({ }^{\circ} \mathrm{C}\right)$ and Liquid Saturations in the Matrix and Fractures at 600 Years (Near the Time of Maximum Dryout in Fractures) 

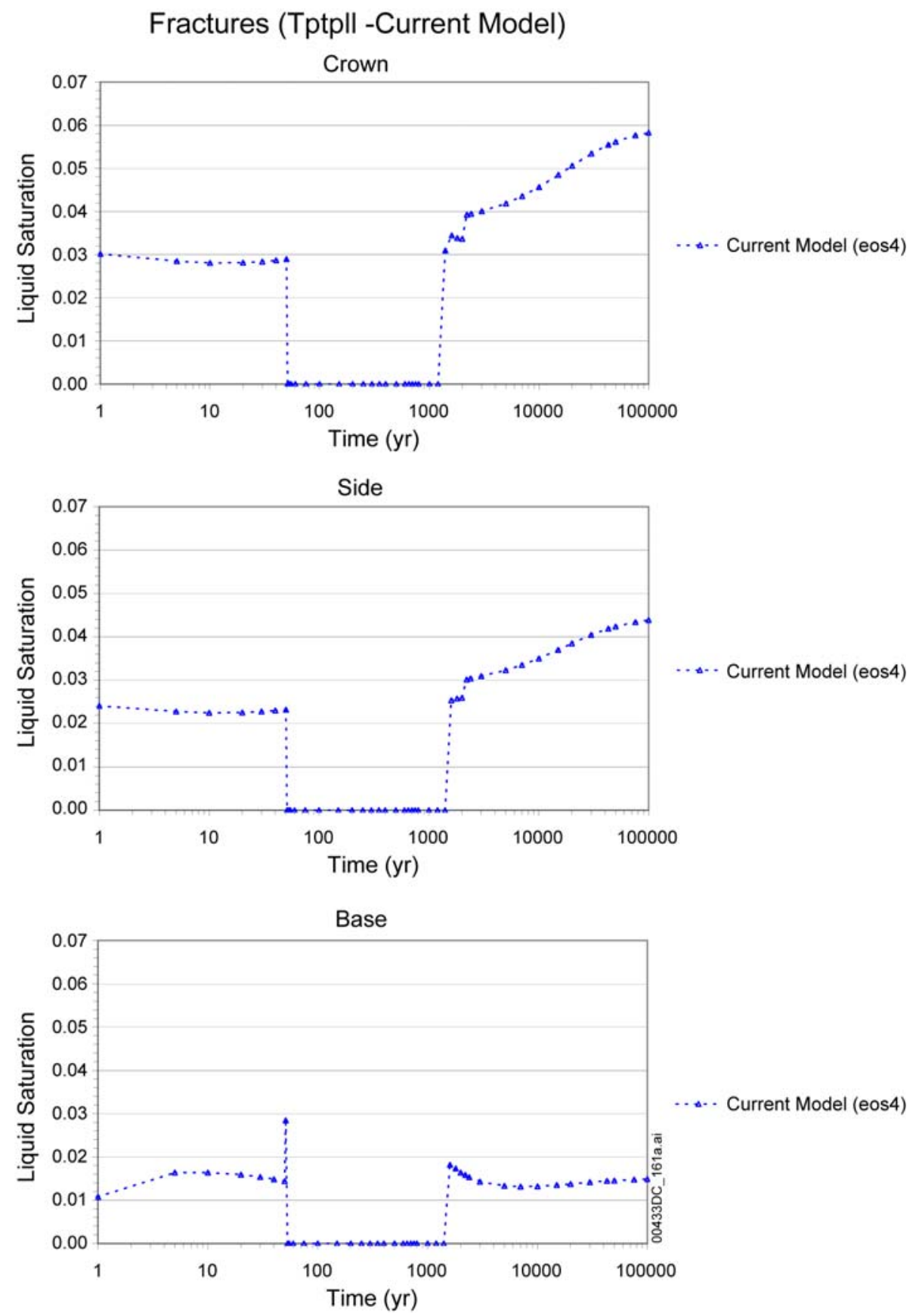

Output DTN: LB0307DSTTHCR2.002.

Figure 6.5-6. TH Simulation (Tptpll): Time Profiles of Modeled Liquid Saturations in Fractures at Three Drift-Wall Locations 

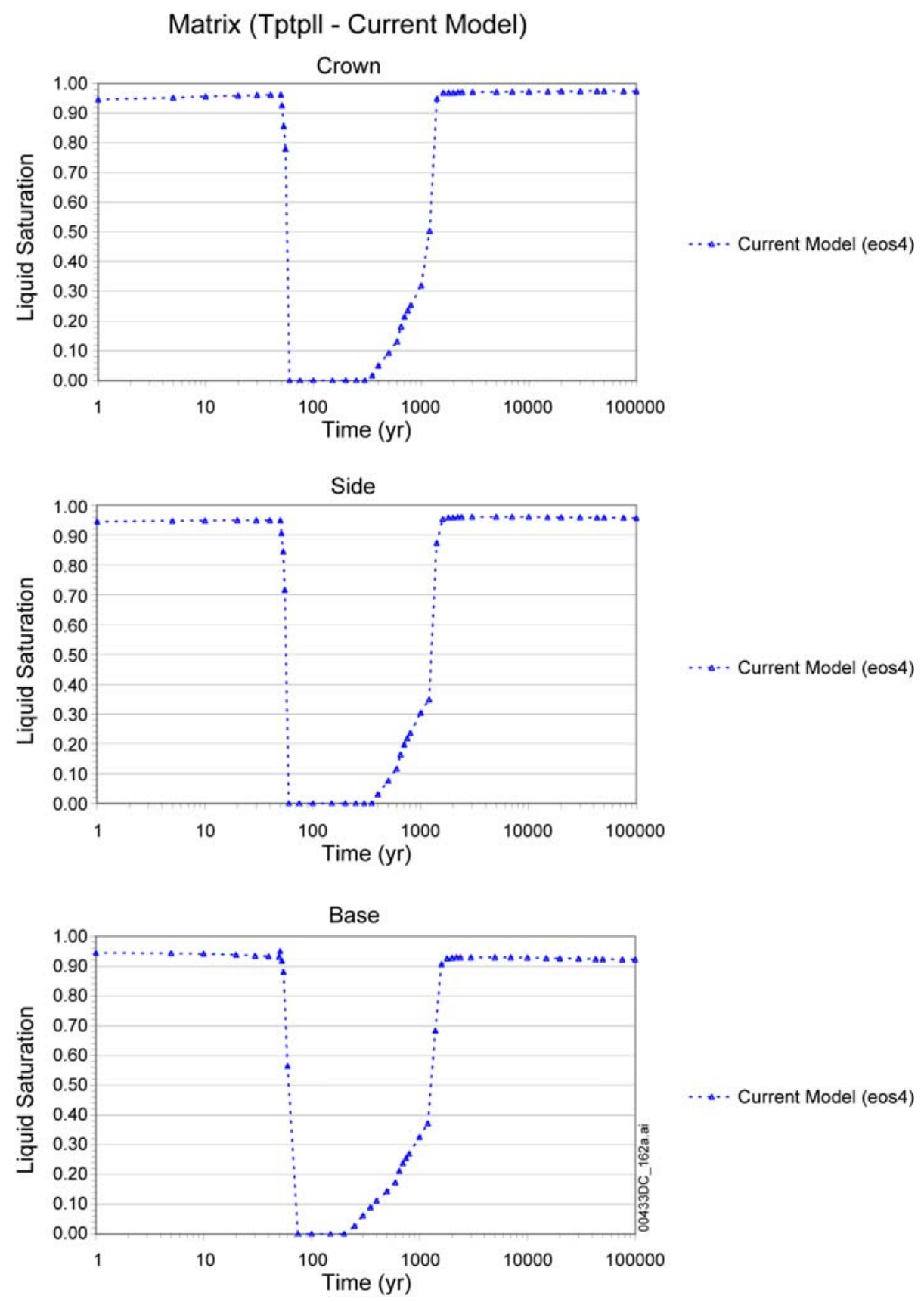

Output DTN: LB0307DSTTHCR2.002.

Figure 6.5-7. TH Simulation (Tptpll): Time Profiles of Modeled Liquid Saturations in Matrix at Three Drift-Wall Locations 

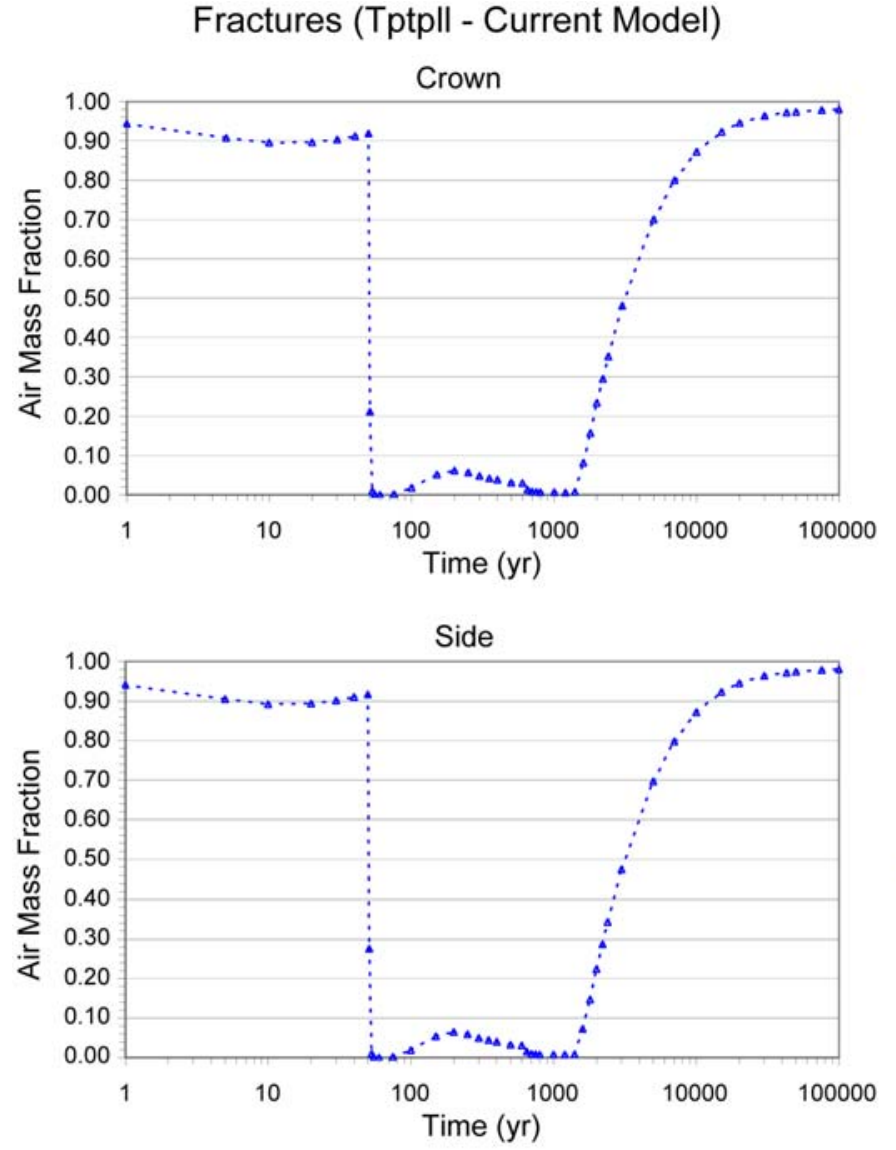

.... Current Model (eos4)

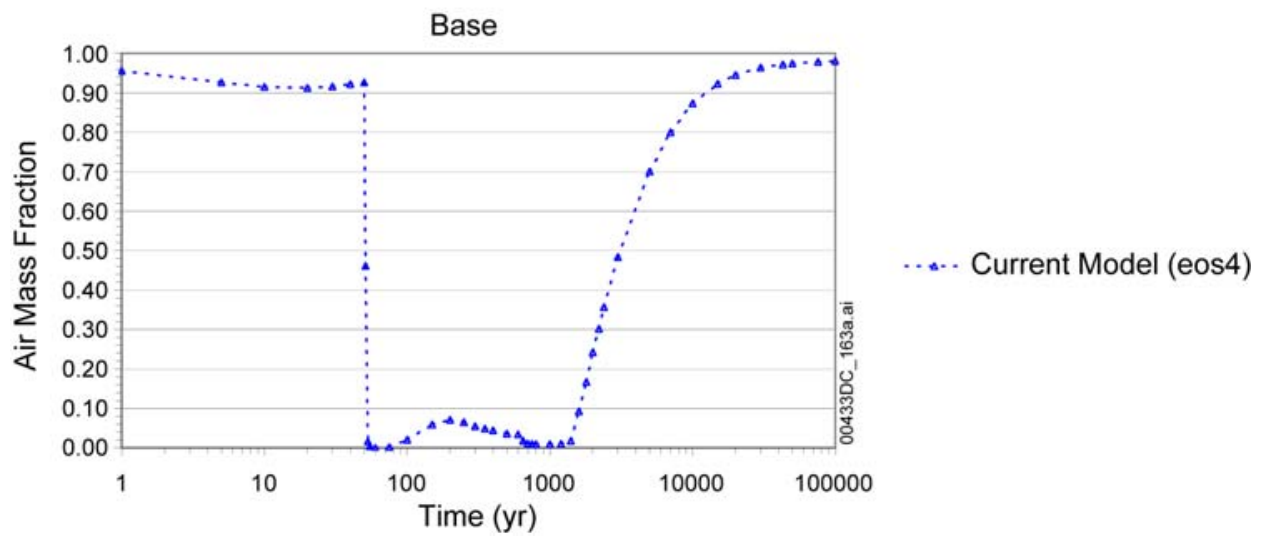

Output DTN: LB0307DSTTHCR2.002.

Figure 6.5-8. TH Simulation (Tptpll): Time Profiles of Modeled Air Mass Fractions in the Gas Phase in Fractures at Three Drift-Wall Locations 


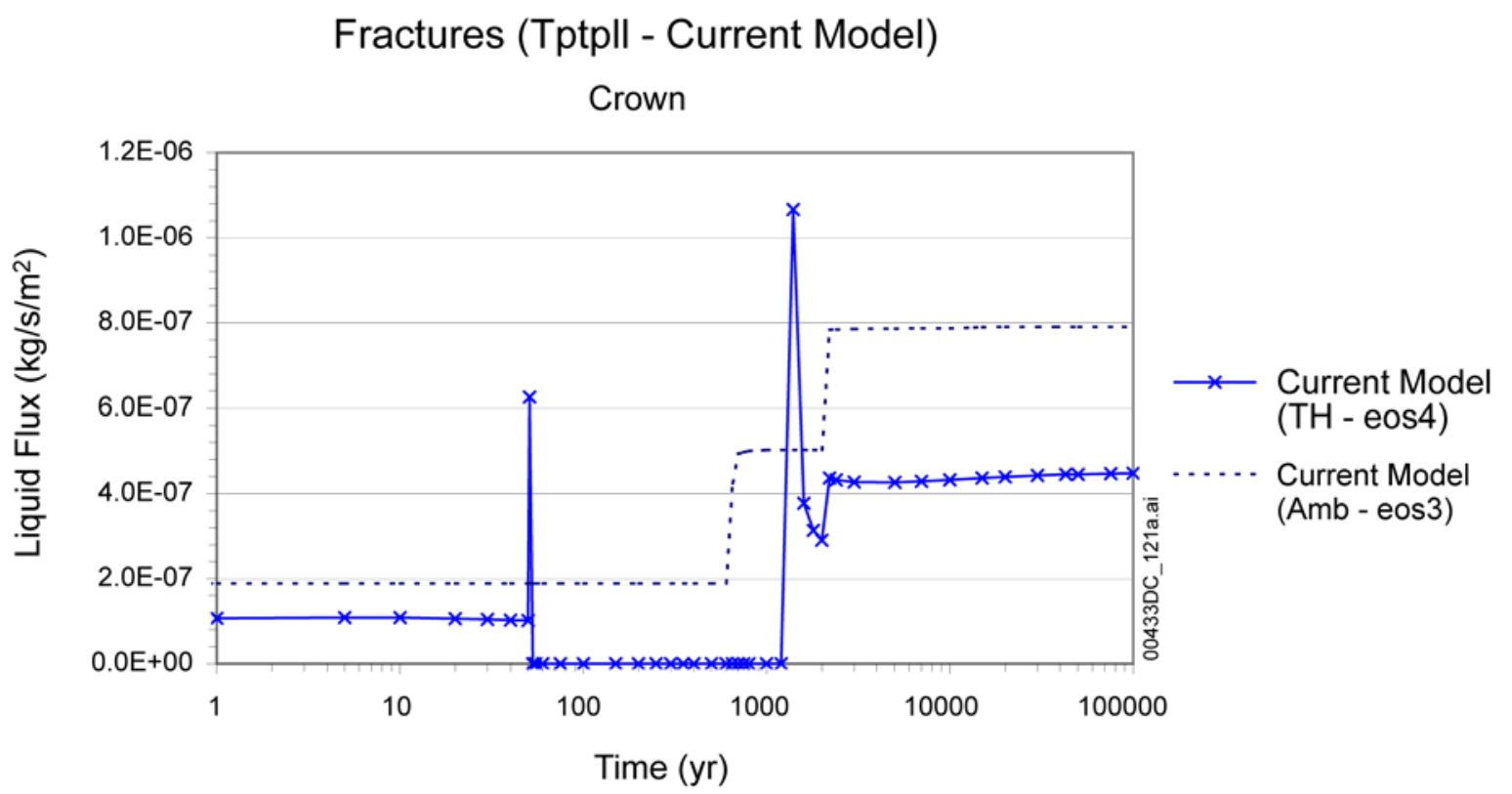

Output DTN: LB0307DSTTHCR2.002.

Figure 6.5-9. TH Simulation (Tptpll): Time Profiles of Modeled Water Flux at the Drift Crown

\subsubsection{Water Chemistry Trends}

The THC seepage model does not simulate actual seepage of water into drifts because the range of simulated infiltration rates produces liquid saturation rates below the theoretical seepage threshold for rocks around the emplacement drift. Instead, the model computes the compositions of pore water and gas throughout the host rock around an emplacement drift (i.e., in the matrix and fractures). The THC seepage model provides, for each gridblock at each time step, parameter values for thermal-hydrologic variables such as temperature, pressure, and gas and liquid saturation; concentrations of aqueous species; mineral volume fractions; and the $\mathrm{CO}_{2}$ volume fraction in matrix and fractures. Results from three fixed locations adjacent to the drift wall - the crown, the side, and the base - are used to calculate the in-drift gas composition (Section 6.5.5.2.1). Water compositions are extracted from dynamic zones that follow the boiling and condensation fronts that expand and then contract around the drift, to represent the composition of potential seepage (Section 6.5.5.2.2).

\subsection{Drift Wall Results}

Time profiles of the evolving water chemistry have been extracted from model output at three drift wall locations: crown (model grid blocks "F 121" and "M 121"), side (grid blocks "F 44" and "M 44"), and base (grid blocks "F 128" and "M 128") (Figure 6.5-2). These are calculated using the HD-PERM water (W0) as input water composition. The results are shown for the ambient case and for cases with and without water vapor pressure lowering caused by capillary pressure (runs referred to as "eos4" and "eos3," respectively). The simulations providing feed to downstream models are run using a generic value for the molecular diameter of $\mathrm{CO}_{2}$ that is smaller than the actual diameter, so the $\mathrm{CO}_{2}$ diffusion coefficient is too high by a factor of six 
(Section 6.5.3). Therefore, model results are also presented for another eos4 THC simulation, which uses the correct $\mathrm{CO}_{2}$ diffusion coefficient.

Predicted time profiles of temperature, $\mathrm{CO}_{2}$ gas concentrations, and aqueous species total concentrations (fracture medium) are shown in Figures 6.5-10 through 6.5-19. The results of the ambient condition simulation are presented to provide a baseline by which comparisons can be made with simulations of thermal loading. Obtaining an initial "steady-state" hydrochemical system yielding aqueous species concentrations consistent with measured concentrations in pore water is difficult. This is because the stability of the system depends on reaction rates and relative mineral thermodynamic stability, as well as infiltration rates and rock properties. The difficulty in reaching a chemical steady state increases with the number of reactive minerals included in the system, because each additional mineral adds its own uncertainty in reaction rate to the total model uncertainty. A reasonably "steady" ambient hydrochemical state is achieved here by reducing the stability of smectites and zeolites (Section 4.1.4), and allowing some degree of calcite supersaturation (Section 6.5.3) in pore waters. In simulations with unrevised thermodynamic data (Section 6.5.5), smectites and zeolites are too stable and form in unreasonable amounts. Thus, predicted water compositions are inconsistent with observed pore waters (e.g., $\mathrm{pH}$ values and sodium concentrations increase with time, while calcium concentrations decrease). These trends are governed by feldspar and glass alteration reactions such as those discussed below.

Model simulations are quite sensitive to the effective reaction rates of aluminum silicates, particularly clays and calcium zeolites. For example, the dissolution of albite (a sodium feldspar) to form sodium smectite (a clay) results in an increase in $\mathrm{pH}$ (decrease in $\mathrm{H}^{+}$activity), as follows:

$$
\begin{gathered}
2.33 \mathrm{NaAlSi}_{3} \mathrm{O}_{8}(\text { albite })+2 \mathrm{H}^{+}==> \\
\mathrm{Na}_{0.33} \mathrm{Al}_{2.33} \mathrm{Si}_{3.67} \mathrm{O}_{10}(\mathrm{OH})_{2}(\text { smectite })+3.32 \mathrm{SiO}_{2}+2 \mathrm{Na}^{+}
\end{gathered}
$$

The alteration of albite to stellerite (a calcium zeolite) can also drive $\mathrm{pH}$ to higher values if the calcium necessary to form stellerite originates from calcite dissolution, as in the following reaction:

$$
\begin{gathered}
2 \mathrm{NaAlSi}_{3} \mathrm{O}_{8} \text { (albite) }+\mathrm{SiO}_{2}+\mathrm{CaCO}_{3} \text { (calcite) }+\mathrm{H}^{+}+7 \mathrm{H}_{2} \mathrm{O}==> \\
\mathrm{CaAl}_{2} \mathrm{Si}_{7} \mathrm{O}_{18} \cdot 7 \mathrm{H}_{2} \mathrm{O} \text { (stellerite) }+2 \mathrm{Na}^{+}+\mathrm{HCO}_{3}^{-}
\end{gathered}
$$

In addition, the consumption of calcium to form calcium-bearing zeolites or clays inhibits calcite precipitation as a means of controlling the increase of $\mathrm{pH}$ and total aqueous carbonate concentrations.

In the model simulations, ambient trends are fairly steady, with some fluctuations resulting mostly from changes in infiltration rates, and indicate that the ambient geochemical system for the THC seepage model for the Tptpll unit is fairly well constrained by the minerals included and the thermodynamic and kinetic data incorporated into the model. 
Postclosure temperature profiles from THC simulations (Figure 6.5-10) are similar for model runs with and without vapor-pressure lowering, but with slightly higher peak temperatures predicted with the latter.

The predicted trend of $\mathrm{CO}_{2}$ concentrations with time in fracture gas (Figure 6.5-11) generally shows a large decline during dryout, followed by a steep increase during the initial cooling and rewetting stage. $\mathrm{CO}_{2}$ concentrations drop quickly at the onset of dryout, shortly after 50 years, because of displacement by steam. Fluctuations during the dryout period (Figure 6.5-11) appear to result from the competing effect of $\mathrm{CO}_{2}$ displacement by steam (from the drift outwards), and increased diffusion of $\mathrm{CO}_{2}$ towards the drift resulting from rising temperatures after all water boils out. During the cooling stage, $\mathrm{CO}_{2}$ concentrations rise above ambient values at around 600 years, and remain there for 20,000 to 50,000 years. In all simulations, the predicted $\mathrm{CO}_{2}$ concentrations at the drift wall remain below 10,000 ppmv for the entire simulated time period.

The simulation utilizing the specific molecular diameter and corresponding diffusion coefficient for $\mathrm{CO}_{2}$ predicts similar trends in the $\mathrm{CO}_{2}$ concentrations with time. The higher $\mathrm{CO}_{2}$ diffusion coefficient in the TSPA model runs (six fold here) causes somewhat higher predicted $\mathrm{CO}_{2}$ concentrations in the gas phase, although the effect is most noticeable during early stages of the dryout period (Figure 6.5-11).

The predicted $\mathrm{pH}$ of fracture water around the drift is mostly in the range of 7.6 to 8.4, but dips to as low as 7.0 for a short time interval after rewetting (Figure 6.5-12). The predicted $\mathrm{pH}$ values in fracture water (Figure 6.5-12) are consistent with modeled trends of $\mathrm{CO}_{2}$ concentrations. The choice of the water-vapor pressure model and the difference in the $\mathrm{CO}_{2}$ diffusion coefficient have only a small effect on predicted $\mathrm{pH}$ values (differences mostly within less than $0.2 \mathrm{pH}$ units; Figure 6.5-12). The predicted $\mathrm{pH}$ range of water in fractures at the drift wall for all cases is neutral to slightly alkaline ( $\mathrm{pH} 7$ to 8.6$)$, with the lowest values occurring a short period after rewetting. The $\mathrm{pH}$ remains essentially below predicted ambient values ( 8.2 to 8.6$)$ for the entire simulated time period. The total carbonate concentrations (shown as $\mathrm{HCO}_{3}{ }^{-}$on Figure 6.5-13) are depressed, relative to ambient values, because of the exsolution of $\mathrm{CO}_{2}$ gas driven by elevated temperatures.

Calcium concentrations (Figure 6.5-14) drop as temperatures rise during the preclosure, due to the inverse solubility of calcite with temperature. Predicted ambient sodium concentrations (Figure 6.5-15) approximately double over the 100,000-year simulated time period, which could reflect somewhat higher feldspar and/or glass dissolution rates relative to the precipitation rate of clay minerals. Relatively elevated calcium and sodium concentrations during rewetting at the drift wall at the base of the drift are the result of re-dissolution of salts previously concentrated by evaporation at the time of dryout (Section 6.4.5).

Upon heating, aqueous silica concentrations (Figure 6.5-16) rise significantly above ambient values because of the dissolution of silica and aluminosilicate phases at higher temperatures. Upon boiling to dryness, aqueous silica concentrations may significantly exceed the solubility of amorphous silica (near $370 \mathrm{mg} / \mathrm{L}$ at $100^{\circ} \mathrm{C}$ ) because the precipitation rate of this mineral, though quite fast, does not keep up with boiling rates. During the initial cooling stage, primarily the 600- to 2,000-year time interval, aqueous silica around the drift precipitates as amorphous silica 
and, as will be discussed later, accounts for most of the reduction in porosity around the drift during this time. Modeled ambient aqueous silica concentrations are nearly stable.

Chloride concentrations (Figure 6.5-17) increase slightly during the preclosure time because of evaporative concentration. The profiles also show, at the time of rewetting, the effect of remobilization of concentrated solutions that was mentioned earlier. After rewetting, chloride concentrations drop relatively quickly towards ambient values near $110 \mathrm{mg} / \mathrm{L}$.

Predicted fluoride concentrations in the Tptpll model under ambient and thermal loading conditions are relatively high because of fluorite $\left(\mathrm{CaF}_{2}\right)$ dissolution (Figure 6.5-18). This mineral is included as one of the mineral constituents of the Tptpll. Ambient fluoride concentrations tend toward equilibrium with fluorite $(5$ to $6 \mathrm{mg} / \mathrm{L}$ for the modeled ambient geochemical conditions) because of the fast reaction rate of this mineral. Concentrations increase during the preclosure period as the temperature rises and calcium concentrations drop. During the cooling period, fluoride concentrations remain above ambient for 10,000 to 20,000 years, while calcium values remain depressed.

Nitrate shows very similar behavior to chloride, as both are acting as conservative species at concentrations below saturation (Figure 6.5-19). At dryout, its mass inventory is accounted for by forming sodium nitrate, using all in solution (without equilibrium calculations; see Section 6.4.5). Upon rewetting, it dissolves faster than chloride salts because of its greater solubility, causing a temporary increase in the $\mathrm{NO}_{3} / \mathrm{Cl}$ ratio of rewetting waters. However, this effect is barely noticeable in fracture waters (Figure 6.5-20). Because the model is limited to moderately low ionic strengths, salt dissolution is performed using a kinetic rate, which allows dissolution to proceed somewhat more slowly than under an equilibrium approach. However, because of the nature of the dilute water rewetting the dryout zone, and its relatively high flux compared to the small quantities of salts precipitated in the rock, the lag time in dissolution is short. The increase in the nitrate to chloride ratio is consistent with the solubilities of the salt phases, yet the time period over which this "spike" occurs may be less than the model actually predicts, and the magnitude of the "spike" may be different from that predicted.

The predicted time profiles for constituents other than carbonate and $\mathrm{pH}$ (Figures 6.5-14 through 6.5-20) do not show much sensitivity to the choice of water-vapor pressure model or the $\mathrm{CO}_{2}$ diffusion coefficient. In most cases, elevated concentrations are predicted at the time the drift rewets, followed by a steep fall towards ambient values (e.g., sodium and chloride in Figures 6.5-15 and 6.5-17). As noted earlier, these transient-elevated concentrations are caused by the rewetting of areas where evaporative concentration took place during dryout. The precipitation of salts upon complete dryout is accounted for in this model, and the dissolution of these salts upon rewetting causes the concentrations of dissolved constituents to peak. Nevertheless, these relatively elevated concentrations are predicted only at small liquid saturations at which no significant fluid flow is taking place. 

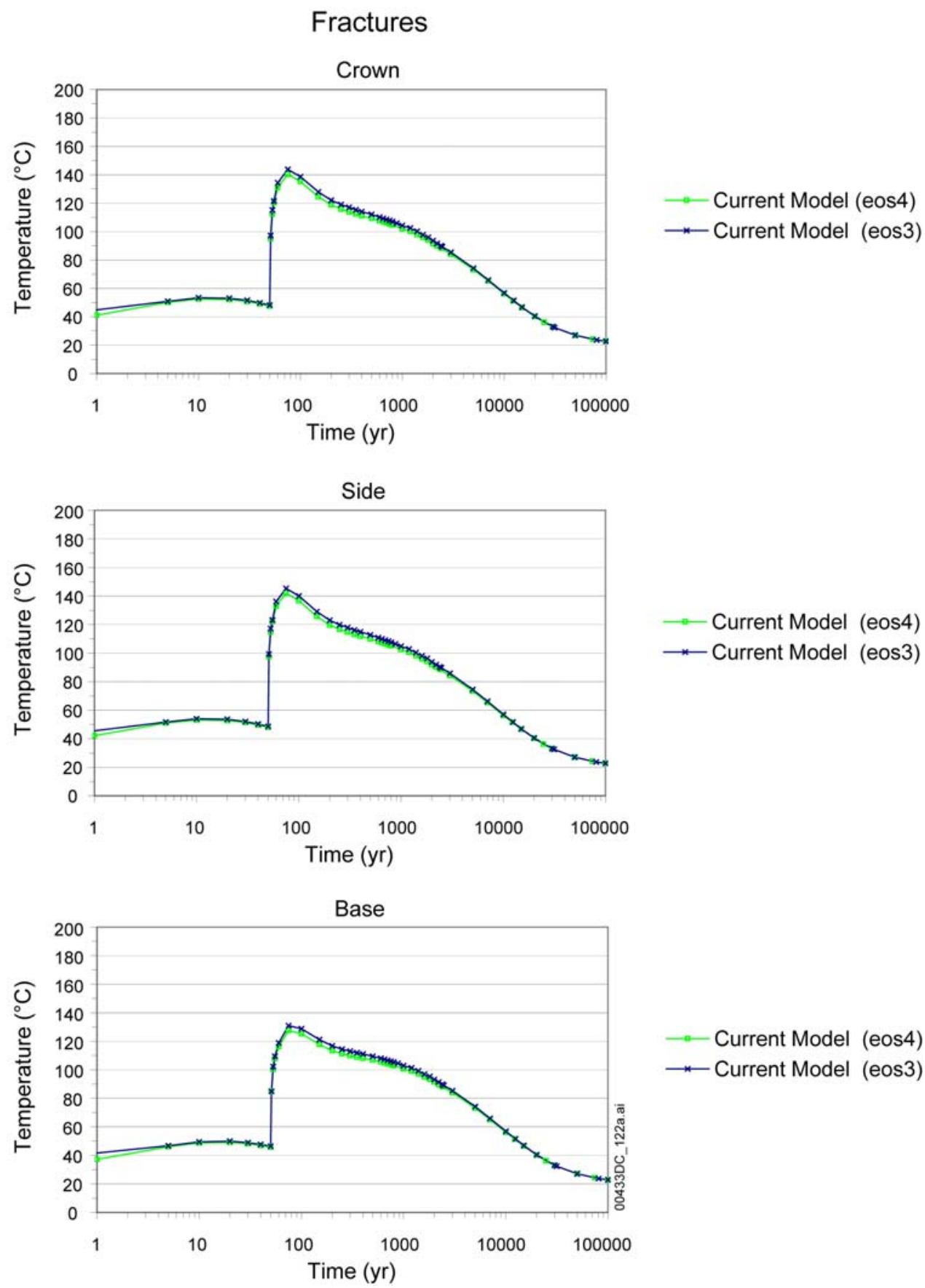

$\rightarrow$ Current Model (eos3)

Output DTNs: LB0302DSCPTHCS.002, LB0307DSTTHCR2.002.

Figure 6.5-10. THC Seepage Model (Tptpll): Time Profiles of Modeled Temperatures at Three Drift-Wall Locations with and without Water-Vapor-Pressure Lowering (eos4 and eos3, Respectively) 

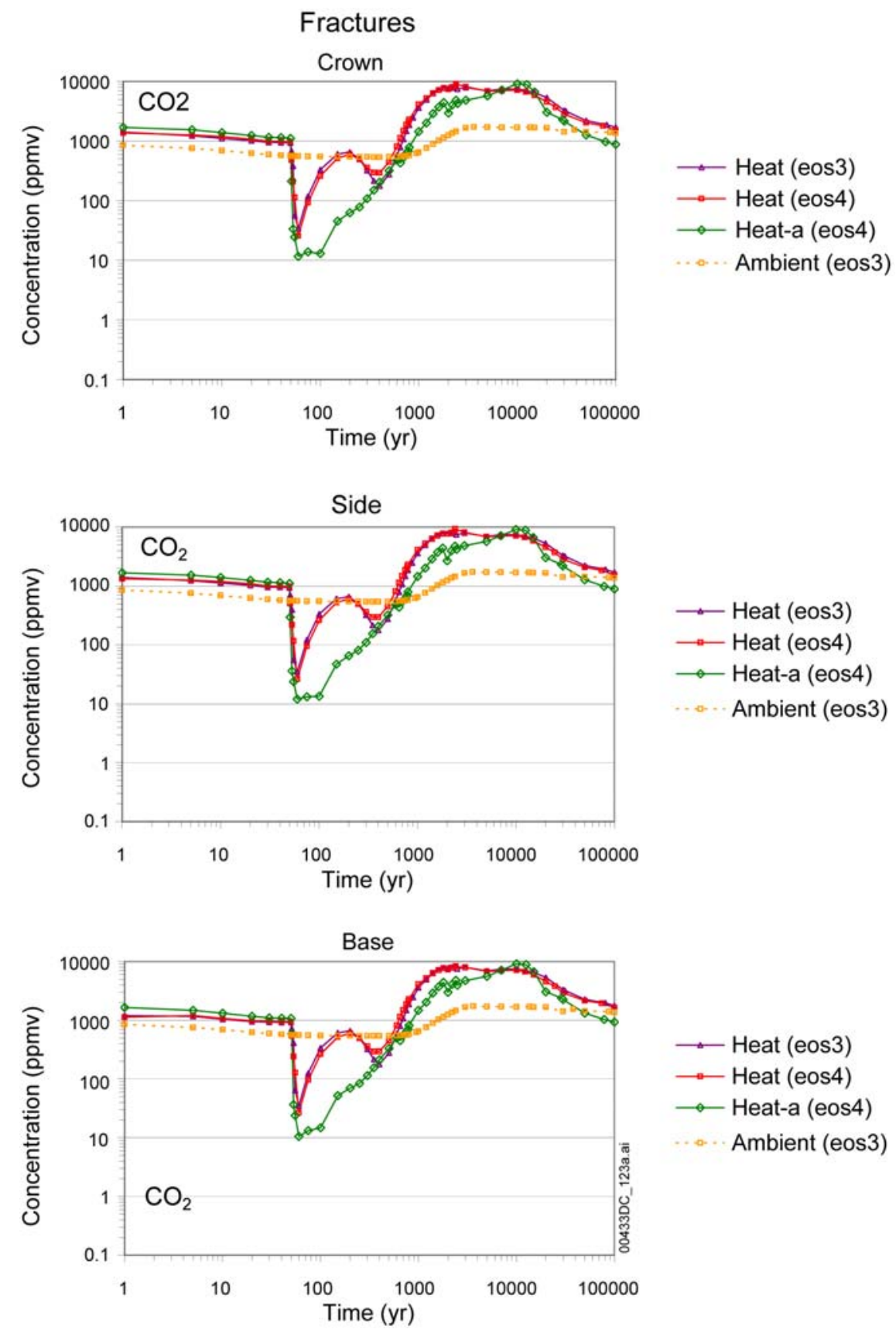

Output DTNs: LB0302DSCPTHCS.002, LB0307DSTTHCR2.002.

NOTE: Simulation labeled "Heat-a" is run with the $\mathrm{CO}_{2}$ diffusion coefficient six times smaller than other simulations (see text).

Figure 6.5-11. THC Seepage Model (Tptpll): Time Profiles of Modeled $\mathrm{CO}_{2}$ Concentrations in the Gas Phase in Fractures at Three Drift-Wall Locations under Heating (Heat) and Non-Heating (Ambient) Conditions, Including (eos4) and Excluding (eos3) Water-Vapor-Pressure Lowering 

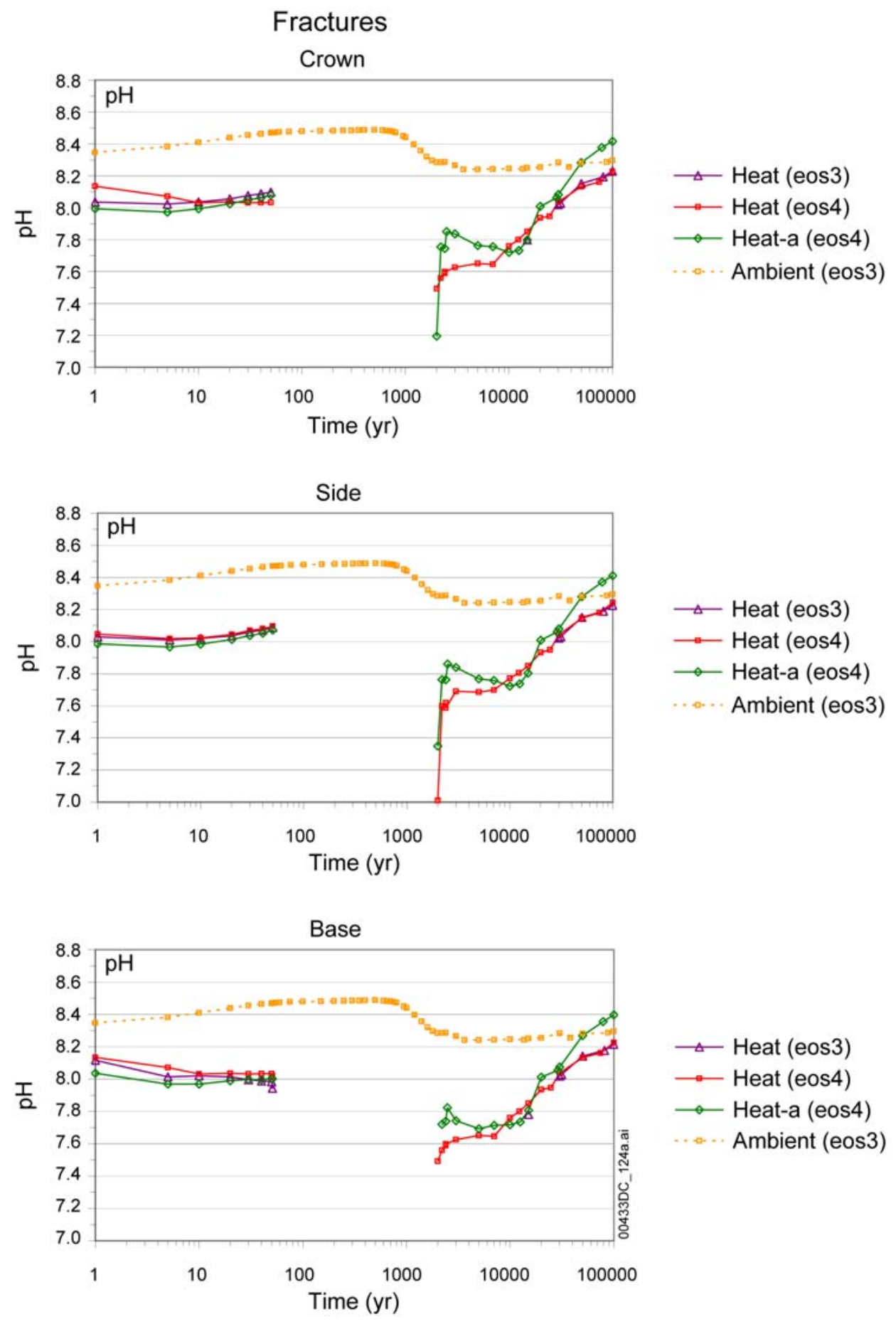

Output DTNs: LB0302DSCPTHCS.002, LB0307DSTTHCR2.002.

NOTE: Simulation labeled "Heat-a" is run with the $\mathrm{CO}_{2}$ diffusion coefficient six times smaller than other simulations (see text).

Figure 6.5-12. THC Seepage Model (Tptpll): Time Profiles of the Modeled pH of Fracture Water at Three Drift-Wall Locations under Heating (Heat) and Non-Heating (Ambient) Conditions, Including (eos4) and Excluding (eos3) Water-Vapor-Pressure Lowering 

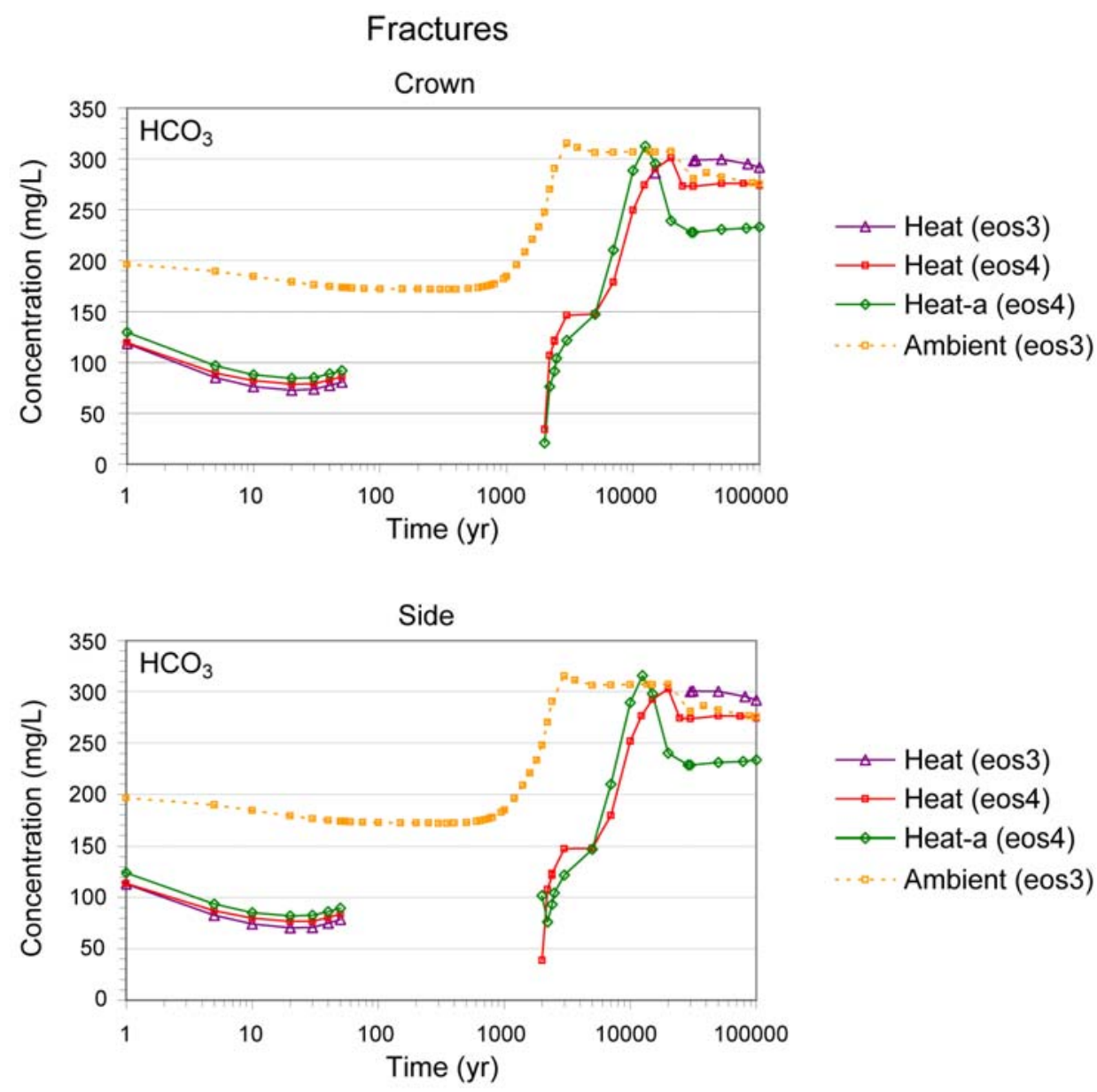

$$
\begin{aligned}
& \longrightarrow \text { Heat (eos3) } \\
& \because \text { Heat (eos4) } \\
& \because \text { Heat-a (eos4) } \\
& \cdots \text { Ambient (eos3) }
\end{aligned}
$$

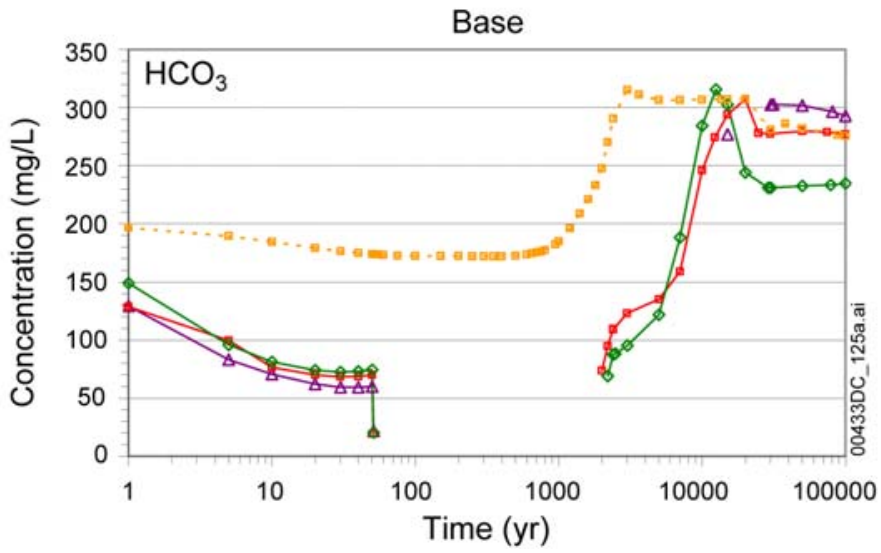

$\triangle$ Heat (eos 3$)$

$\rightarrow$ Heat (eos4)

$\rightarrow$ Heat-a (eos4)

….... Ambient (eos3)

Output DTNs: LB0302DSCPTHCS.002, LB0307DSTTHCR2.002.

NOTE: Simulation labeled "Heat-a" is run with the $\mathrm{CO}_{2}$ diffusion coefficient six times smaller than other simulations (see text).

Figure 6.5-13. THC Seepage Model (Tptpll): Time Profiles of Modeled Total Aqueous Carbonate Concentrations (as $\mathrm{HCO}_{3}^{-}$) in Fracture Water at Three Drift-Wall Locations, under Heating (Heat) and Non-Heating (Ambient) Conditions, Including (eos4) and Excluding (eos3) Water-Vapor-Pressure Lowering 

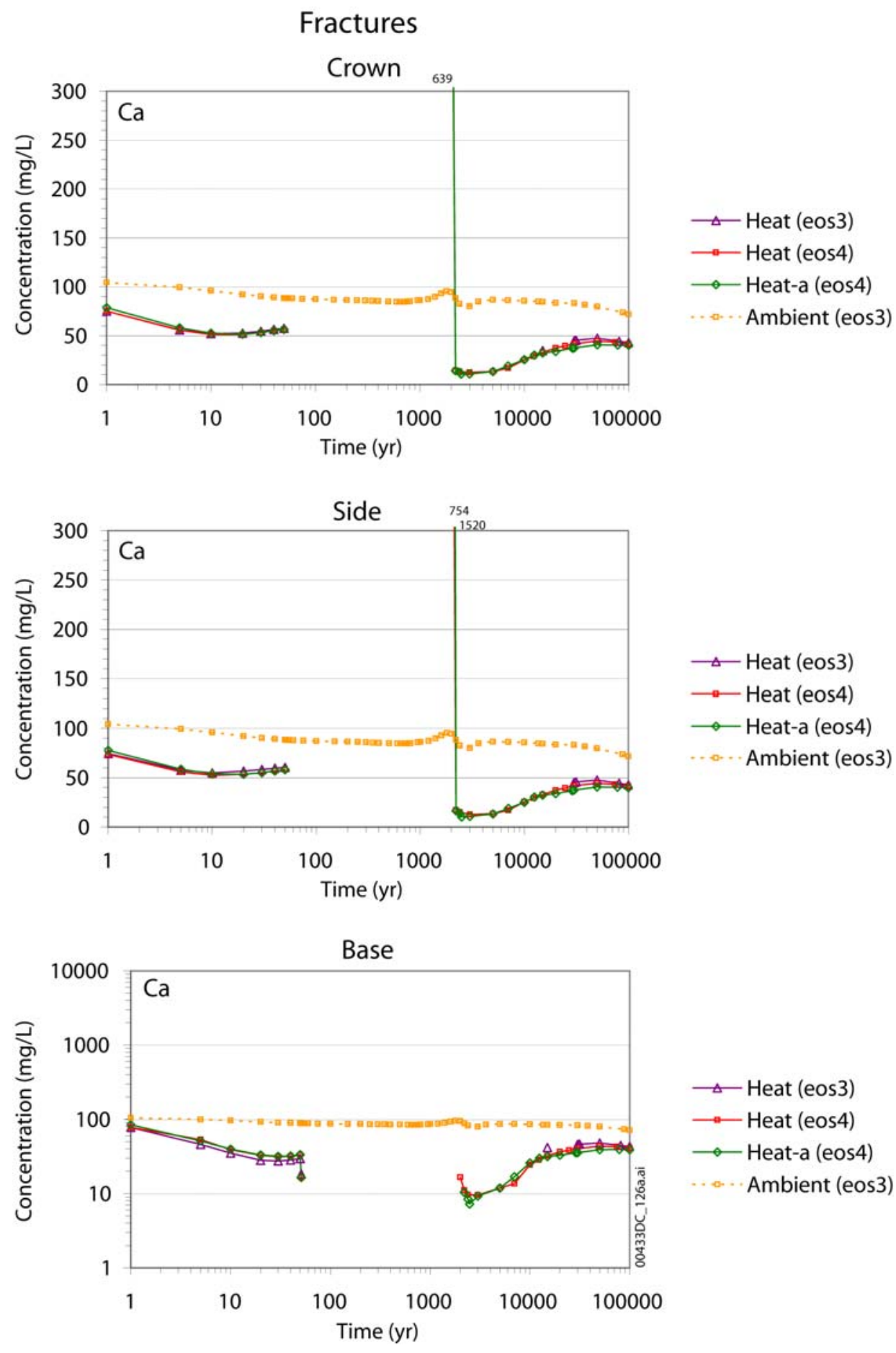

Output DTNs: LB0302DSCPTHCS.002, LB0307DSTTHCR2.002.

NOTE: Simulation labeled "Heat-a" is run with the $\mathrm{CO}_{2}$ diffusion coefficient six times smaller than other simulations (see text).

Figure 6.5-14. THC Seepage Model (Tptpll): Time Profiles of Modeled Total Aqueous Calcium Concentrations in Fracture Water at Three Drift-Wall Locations, under Heating (Heat) and Non-Heating (Ambient) Conditions, Including (eos4) and Excluding (eos3) Water-VaporPressure Lowering 

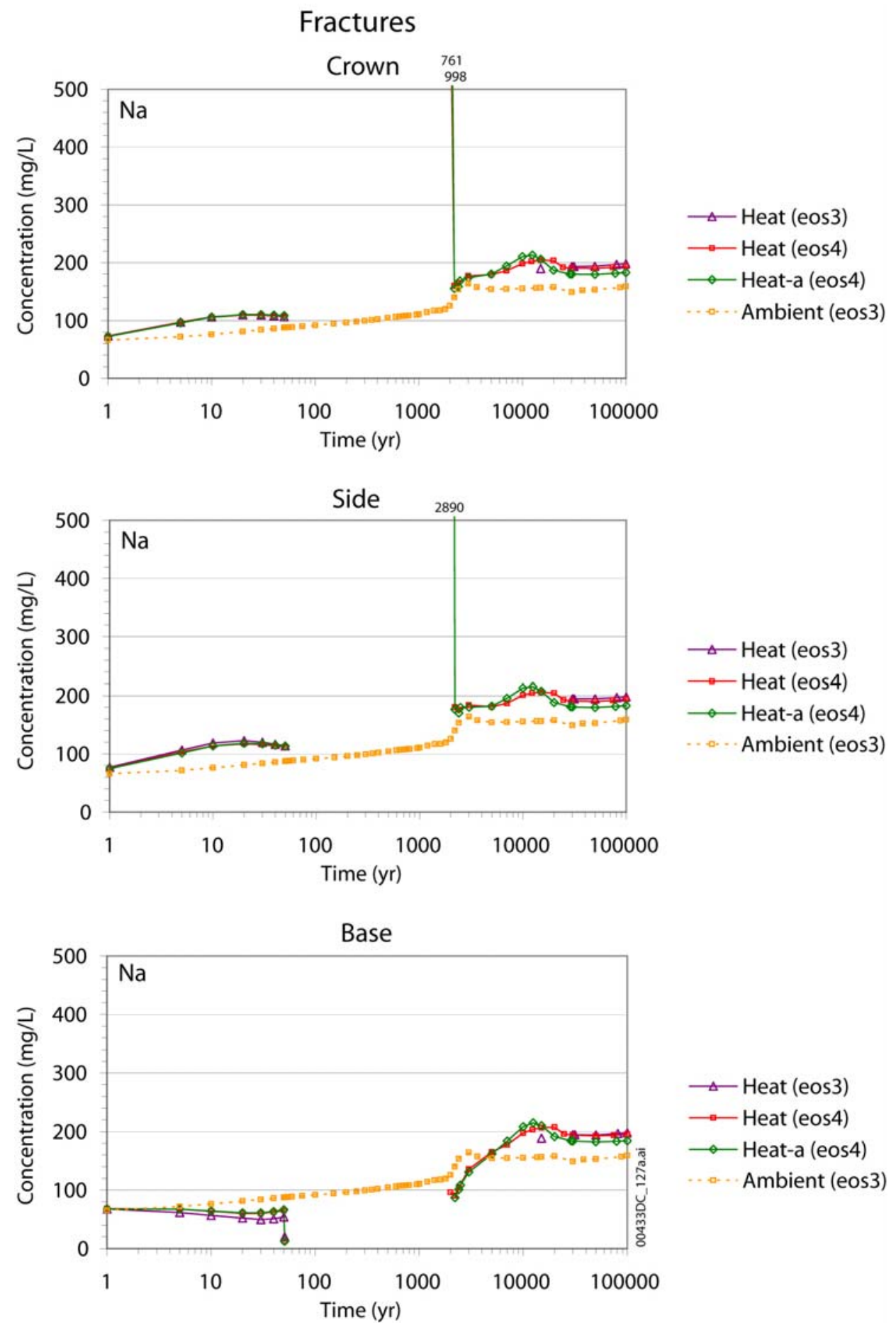

Output DTNs: LB0302DSCPTHCS.002, LB0307DSTTHCR2.002.

NOTE: Simulation labeled "Heat-a" is run with the $\mathrm{CO}_{2}$ diffusion coefficient six times smaller than other simulations (see text).

Figure 6.5-15. THC Seepage Model (Tptpll): Time Profiles of Modeled Total Aqueous Sodium Concentrations in Fracture Water at Three Drift-Wall Locations, under Heating (Heat) and Non-Heating (Ambient) Conditions, Including (eos4) and Excluding (eos3) Water-VaporPressure Lowering 


\section{Fractures}
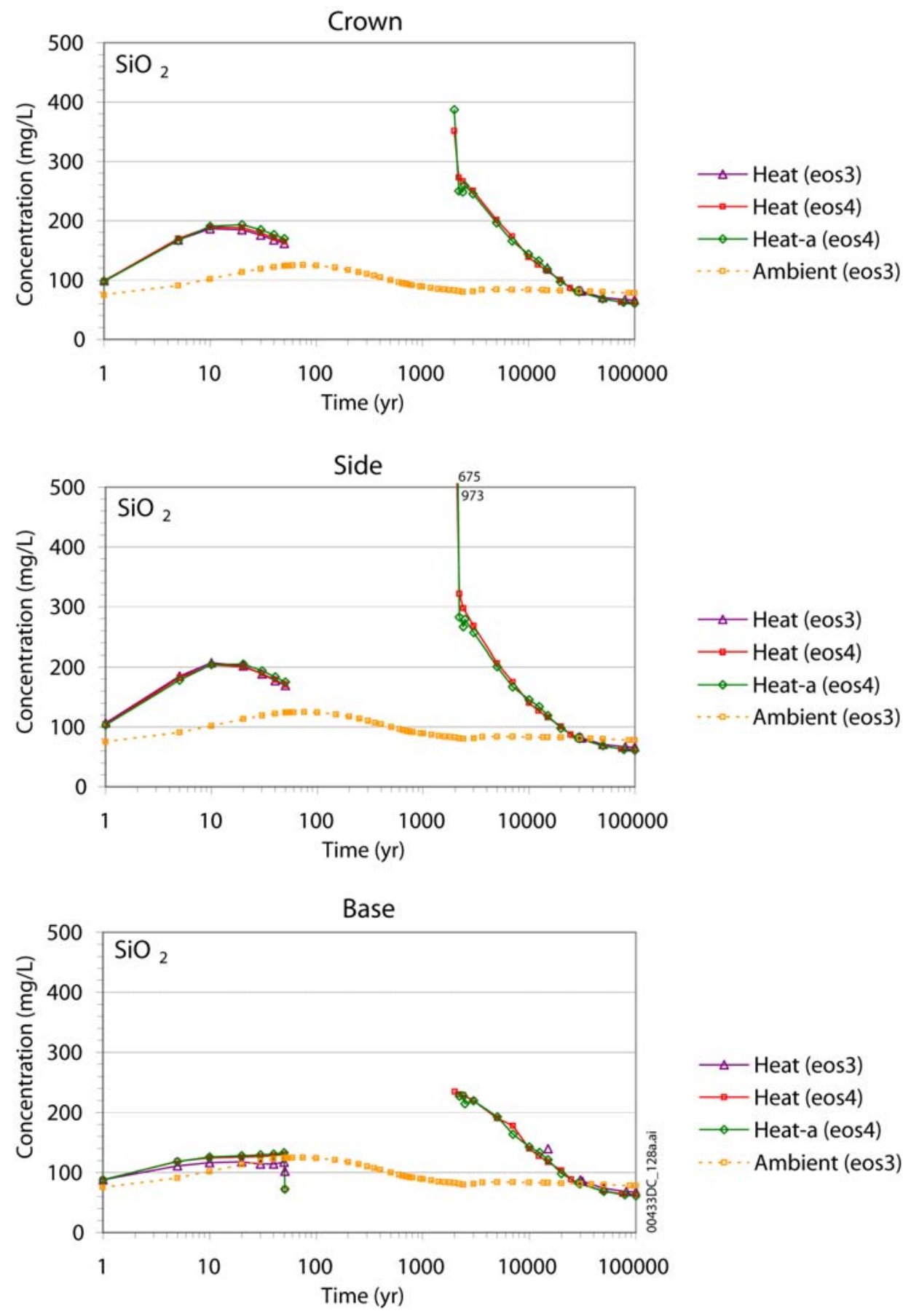

Output DTNs (REV02): LB0302DSCPTHCS.002, LB0307DSTTHCR2.002.

NOTE: Simulation labeled "Heat-a" is run with the $\mathrm{CO}_{2}$ diffusion coefficient six times smaller than other simulations (see text).

Figure 6.5-16. THC Seepage Model (Tptpll): Time Profiles of Modeled Total Aqueous Silica Concentrations in Fracture Water at Three Drift-Wall Locations, under Heating (Heat) and Non-Heating (Ambient) Conditions, Including (eos4) and Excluding (eos3) Water-Vapor-Pressure Lowering 


\section{Fractures}
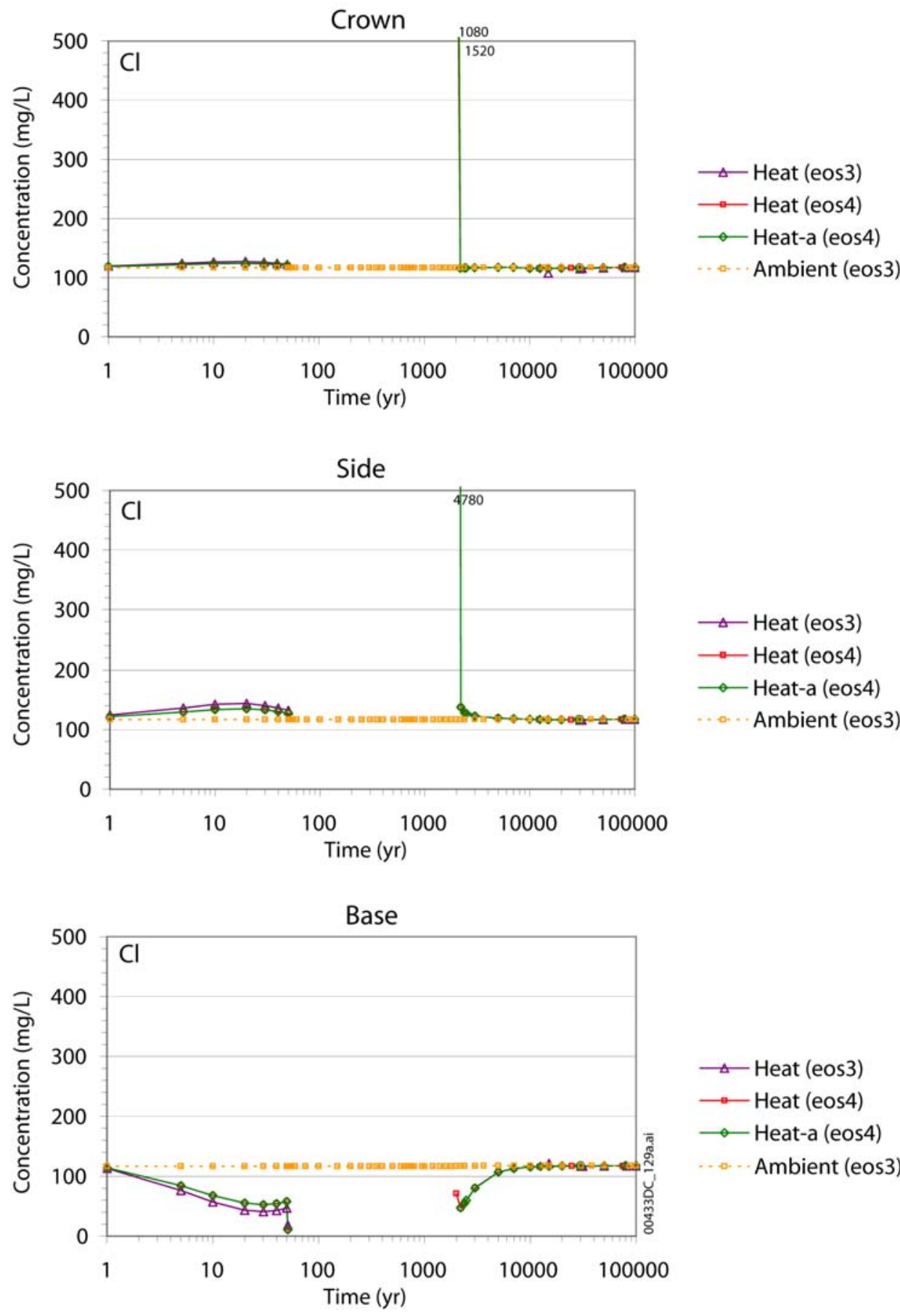

Output DTNs: LB0302DSCPTHCS.002, LB0307DSTTHCR2.002.

NOTE: Simulation labeled "Heat-a" is run with the $\mathrm{CO}_{2}$ diffusion coefficient six times smaller than other simulations (see text).

Figure 6.5-17. THC Seepage Model (Tptpll): Time Profiles of Modeled Total Aqueous Chloride Concentrations in Fracture Water at Three Drift-Wall Locations, under Heating (Heat) and Non-Heating (Ambient) Conditions, Including (eos4) and Excluding (eos3) Water-Vapor-Pressure Lowering 


\section{Fractures}
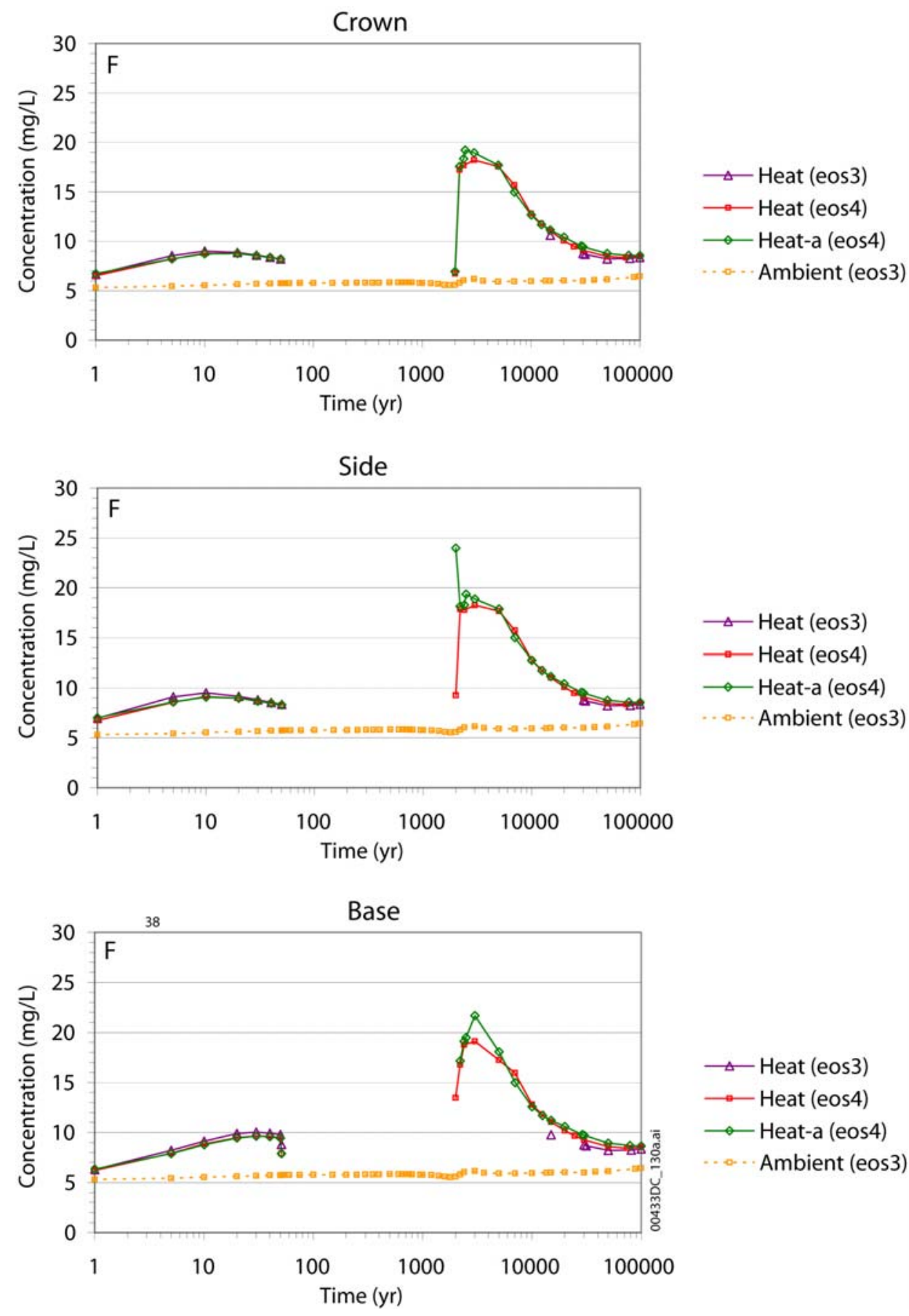

Output DTNs: LB0302DSCPTHCS.002, LB0307DSTTHCR2.002.

NOTE: Simulation labeled "Heat-a" is run with the $\mathrm{CO}_{2}$ diffusion coefficient six times smaller than other simulations (see text).

Figure 6.5-18. THC Seepage Model (Tptpll): Time Profiles of Modeled Total Fluoride Concentrations in Fracture Water at Three Drift-Wall Locations, under Heating (Heat) and Non-Heating (Ambient) Conditions, Including (eos4) and Excluding (eos3) Water-Vapor-Pressure Lowering 

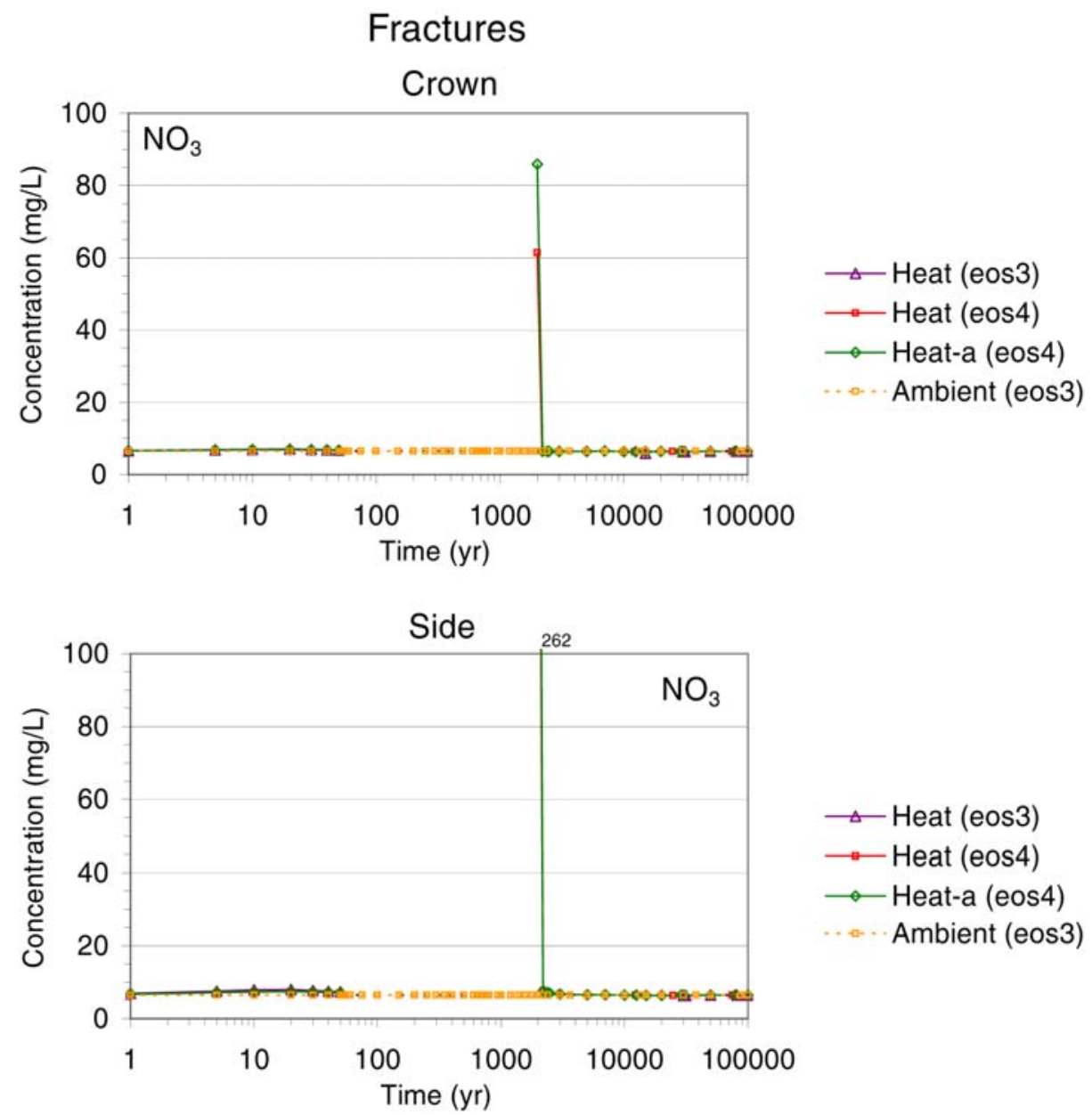

$$
\begin{aligned}
& \rightarrow \text { Heat (eos3) } \\
& \rightarrow-\text { Heat (eos4) } \\
& \therefore \text { Heat-a (eos4) } \\
& \therefore \text { Ambient (eos3) }
\end{aligned}
$$

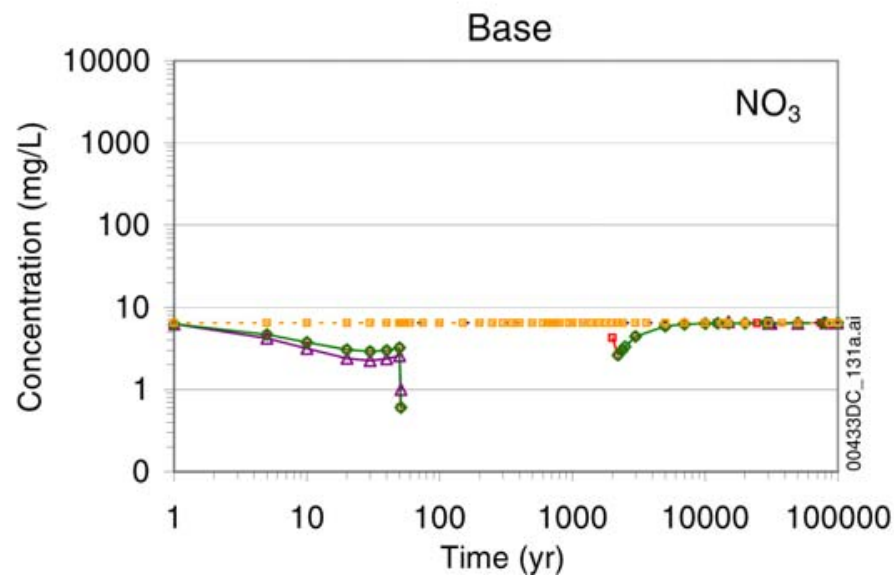

$\triangle$ Heat (eos3)

$\rightarrow$ Heat (eos4)

$\rightarrow$ Heat-a (eos 4$)$

........ Ambient (eos3)

Output DTNs: LB0302DSCPTHCS.002, LB0307DSTTHCR2.002.

NOTE: Simulation labeled "Heat-a" is run with the $\mathrm{CO}_{2}$ diffusion coefficient six times smaller than other simulations (see text).

Figure 6.5-19. THC Seepage Model (Tptpll): Time Profiles of Modeled Total Nitrate Concentrations in Fracture Water at Three Drift-Wall Locations, under Heating (Heat) and Non-Heating (Ambient) Conditions, Including (eos4) and Excluding (eos3) Water-Vapor-Pressure Lowering 

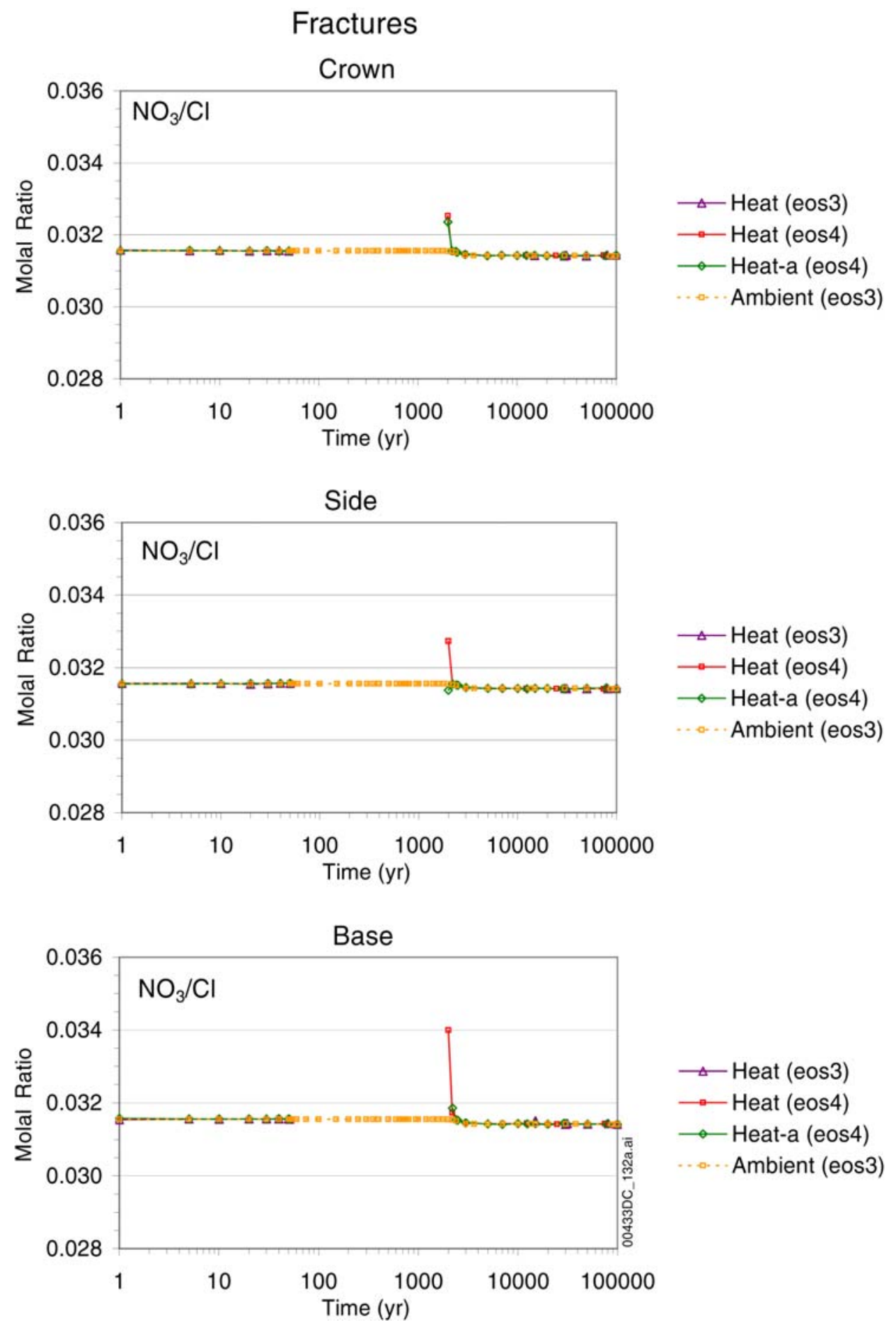

Output DTNs (REV01): LB0302DSCPTHCS.002, LB0307DSTTHCR2.002.

NOTE: Simulation labeled "Heat-a" is run with the $\mathrm{CO}_{2}$ diffusion coefficient six times smaller than other simulations (see text).

Figure 6.5-20. THC Seepage Model (Tptpll): Time Profiles of Modeled Total Nitrate to Chloride Ratio at Three Drift-Wall Locations, under Heating (Heat) and Non-Heating (Ambient) Conditions, Including (eos4) and Excluding (eos3) Water-Vapor-Pressure Lowering 


\subsection{High-Liquid Saturation Zone above Drift Crown}

Predicted concentration profiles at fixed model grid blocks at the crown, side, and base of the drift provide limited information on the chemistry of waters that could seep into drifts. Such profiles do not fully capture the spatial variability of model results around the drift and, more importantly, cannot show water compositions as long as the selected model grid blocks remain dry. To complement results shown in previous sections and to better capture spatial variability, as well as predicted water compositions during the dryout period, concentration time-profiles are also generated for dynamic zones following the expanding, then receding, boiling and condensation fronts around the drift. This selection methodology is presented in Post-Processing Analysis for THC Seepage (BSC 2004 [DIRS 169858]), and examines gridblocks in the host rock that are likely to yield fluids that could seep into the drift, emphasizing water compositions that form when the dryout zone rewets. The selection process down-selects from the full model output, which contains a water composition for every grid block at each time step, to a subset of results corresponding to the water compositions at the boiling zone and the zone of saturation in the host rock. These two locations rarely coincide with the drift wall.

Some of these results are presented here for grid blocks with highest liquid saturation above the drift in fractures. More specifically, data are extracted for model grid blocks located within a 45-degree arc of a line bisecting the drift crown, and for the first six of such grid blocks having the highest liquid saturation in fractures, within radial distance of $25 \mathrm{~m}$ from drift centerline.

Various time profiles are shown below for data extracted in this manner; thus, data for six grid blocks are plotted per point in time for each run. To assess the model sensitivity to initial water compositions and other alternative conceptualizations, time profiles are generated for simulations considering the following:

- The five different input initial water compositions described in Section 6.2.2.1: W0, the composition used so far (HD-PERM), and alternative compositions W4 through W7. These simulations provide results that are used by downstream models.

- Three different infiltration scenarios (using the HD-PERM input water composition): stepwise increase from 6 to $25 \mathrm{~mm} / \mathrm{yr}$, fixed $6 \mathrm{~mm} / \mathrm{yr}$, and fixed $25 \mathrm{~mm} / \mathrm{yr}$ (Table 6.5-3).

- The two different water vapor-pressure models implemented in TOUGHREACT V3.0 (LBNL 2002 [DIRS 161256]) modules EOS4 and EOS3 (using the HD-PERM input water composition), corresponding to with and without vapor-pressure lowering due to capillary pressure.

Time profiles generated in this way capture a spread of concentrations related to (1) the natural variability of input water compositions, (2) alternative model conceptualizations, and (3) for each model run at any given time, the spatial variability of model results for grid blocks of highest liquid saturation above the drift crown. In addition to this spread, fluctuations of computed concentrations with time arising from THC effects (as discussed below) are also captured. 
The distance from drift center, temperature, and liquid saturation in model grid blocks having the highest liquid saturation (above the drift) picked up by the extraction procedure (using CUTCHEM V1.0 (LBNL 2002 [DIRS 161127])) are shown in Figures 6.5-21, 6.5-22, and 6.5-23, respectively (these figures exclude a few points extracted at times around 50 years and located approximately $24 \mathrm{~m}$ away from the drift center). These data provide a context for the chemistry profiles discussed below. For simulated times up to 50 years, all data are from zones directly above, and adjacent to, the drift crown (i.e., at a distance approximately $2.8 \mathrm{~m}$ from drift center) (Figure 6.5.21). From the onset of boiling at approximately 50 years, high-liquidsaturation grid blocks are all from the condensation (reflux) zone above the drift. Later, after the collapse of the boiling front, grid blocks with the highest liquid saturation are located either directly adjacent to the drift crown (e.g., some of the W0 data on Figure 6.5-21) or further away, adjacent to zones of reduced permeability formed by prior mineral deposition at the boiling front. These zones are discussed in Section 6.5.5.3.

After the onset of boiling, starting at approximately 50 years, the temperature in the most highly liquid-saturated grid blocks remains nearly constant (near $96^{\circ} \mathrm{C}$, the boiling point for the modeled elevation), as would be expected in the zone of condensation and reflux (Figure 6.5-22). For most runs, the boiling temperature in these grid blocks is maintained until around 1,000 years. The boiling front is predicted to collapse a few hundred years earlier for the case with the higher constant infiltration rate of $25 \mathrm{~mm} / \mathrm{yr}$ (Figure 6.5-22). This period of time, during which temperatures are maintained at the boiling point of water, is hereafter referred to as the boiling period. Temperature profiles predicted with the various runs are quite similar, except for the shorter boiling period at higher infiltration. The greatest predicted temperature difference between simulations (around $5^{\circ} \mathrm{C}$ ) is also caused by differences in infiltration rate.

For a given run, and at a given time, predicted liquid saturations in the first six grid blocks with highest liquid saturation (above the drift) are fairly uniform (Figure 6.5-23) because these data represent areas of highest liquid saturation in a laterally homogenous model. Consequently, corresponding concentration time-profiles (Figures 6.5-24 through 6.5-37), for each run at any given time, also show less spatial variability than would evaporated waters from grid blocks with much smaller and variable liquid saturations (such as at the boiling front). Therefore, examining the variability of predicted water compositions in zones of highest liquid saturation provides a better means of evaluating the model sensitivity to various input data or model conceptualizations than would examination of predicted water compositions directly at the boiling front. This is the main reason for focusing on zones of highest liquid saturation. However, when evaluating the compositional variability of waters that could seep into a drift during the boiling period (by somehow penetrating the dryout zone), the predicted water composition at the boiling front should also be considered. This variability is assessed in Post-Processing Analysis for THC Seepage (BSC 2004 [DIRS 169858]). 
Predicted profiles of concentration versus time for $\mathrm{CO}_{2}$ gas and aqueous species of interest are shown in Figures 6.5-24 through 6.5-37. Three observations are particularly significant:

(1) In general, these figures indicate that the different input water compositions (i.e., natural variability) produce a larger relative spread in predicted water and gas compositions than the range of infiltration rates considered or the selected water-vapor pressure module.

(2) At any point, the relative spread of predicted concentrations for the various modeled alternatives (at those grid blocks with highest liquid saturation above the drift crown) generally does not exceed an order of magnitude and is often much less (BSC 2004 [DIRS 169858], Section 6.2.4).

(3) Finally, for all simulations shown, the predicted general concentration trends are quite similar.

The modeled $\mathrm{CO}_{2}$ concentrations in zones of condensation and reflux (Figure 6.5-24) are initially higher than at drift wall locations shown previously because heat mobilizes $\mathrm{CO}_{2}$ outward from the drift wall (Section 7.1). However, $\mathrm{CO}_{2}$ concentrations eventually also decrease in the reflux/condensation zone because of continued depletion of aqueous carbonate (Figure 6.5-26) from $\mathrm{CO}_{2}$ exsolution and calcite precipitation (see below). The subsequent trend of rising $\mathrm{CO}_{2}$ concentration (from approximately 600 to 2,000 years) (Figure 6.5-24) was also noted earlier for locations at the drift wall (Figure 6.5-11). Note that during this time period, when the $\mathrm{CO}_{2}$ concentrations are rising (from approximately 600 to 2,000 years), the spread of these concentrations is sharply reduced compared to the spread during other simulated time intervals (Figure 6.5-24a). This appears to be caused by the arrival of percolating water with a significantly higher dissolved $\mathrm{CO}_{2}$ content than the locally decarbonated water. This temporarily higher dissolved $\mathrm{CO}_{2}$ content in percolation water results from prior mobilization of $\mathrm{CO}_{2}$ gas from matrix water into fractures, further up the stratigraphic column. The case with a decrease in $\mathrm{CO}_{2}$ diffusion coefficient (Figure 6.5-24b) shows a similar rise but occurring at a somewhat delayed time, due to the decreased diffusive mobility. The decreasing $\mathrm{pH}$ values from approximately 600 to 2,000 years (Figure 6.5-25) is also consistent with the arrival of more carbonated water from prior $\mathrm{CO}_{2}$ gas mobilization. After approximately 2,000 years, the spread in concentrations increases again as these concentrations become less driven by the mobilization of $\mathrm{CO}_{2}$ and more by water-rock interactions that are more sensitive to the composition of infiltration water (even though all waters are set with the same $\mathrm{CO}_{2}$ partial pressure at the top model boundary). Also, the increase in infiltration rate at 2,000 years exacerbates this effect. The profiles of total aqueous carbonate concentrations (Figure 6.5-26) are consistent with this trend, showing a significant decrease in relative spread when concentrations increase after approximately 600 years until about 2,000 years, then spreading wider again after that time.

After the rise in $\mathrm{CO}_{2}$ concentrations, the simulation using a constant $6 \mathrm{~mm} / \mathrm{yr}$ infiltration rate predicts an earlier decrease in these concentrations than other simulations (all using $25 \mathrm{~mm} / \mathrm{yr}$ in this time period) (Figure 6.5-24b). In the 25-mm/yr cases, $\mathrm{CO}_{2}$ concentrations diminish at later times because more $\mathrm{CO}_{2}$ is mobilized (exsolved from incoming water) prior to the collapse of the boiling front. Note that in the $6-\mathrm{mm} / \mathrm{yr}$ case, $\mathrm{CO}_{2}$ concentrations rise again somewhat after 15,000 years because of a second small pulse of slightly more carbonated water percolating downwards (related to the various degrees of water-rock interaction in the different stratigraphic 
units further above the drift). In all cases, above-ambient $\mathrm{CO}_{2}$ values are maintained for over 10,000 years, driven by the mobilized $\mathrm{CO}_{2}$ exsolved from the incoming water prior to collapse of the boiling front.

The predicted range of $\mathrm{pH}$ values covered by all simulations (Figure 6.5-25) is from approximately 7.2 to 8.4 . This range is fairly small and is similar to the range predicted previously for locations directly adjacent to the drift wall. After long periods of time ( $>10,000$ years), predicted $\mathrm{pH}$ values for runs using the different input water compositions tend to converge towards similar ambient values (in the 8.2 to 8.4 range after 100,000 years). Values of $\mathrm{pH}$ rise toward these ambient values after a decrease (from approximately 600 to 2,000 years) caused by the percolation of more carbonated and, thus, slightly more acidic waters as discussed above. For some of the waters considered, these long-term ambient values are slightly higher than initial values (in the approximate 8 to 8.3 range, Table 6.2-1) because the long-term alteration of rock-forming minerals (Equations 6.5-1 and 6.5-2) tends to drive the $\mathrm{pH}$ up.

The concentration profiles of conservative species, such as chloride (Figure 6.5-27) (and also nitrate in simulations presented here; Figure 6.5-28), are useful in evaluating the degree of dilution and evaporative concentration in the areas for which predicted water compositions are shown. Dilution from condensation initially occurs (within a factor of around 10) after the onset of boiling. However, later in the boiling period, evaporative concentration takes over (also within a factor of around 10, compared to initial values). Comparing the chloride concentration profiles (Figure 6.5-27) with profiles showing the distance from drift center at which these concentrations occur (Figure 6.5-21) helps in distinguishing the following successive stages in the evolution of water composition in the condensation zone:

1. A dilution stage occurs when the dryout zone is expanding, roughly from 50 to around 100 to 150 years. It is caused by steam originating from water boiling in the rock matrix then migrating and condensing into fractures (Section 6.2.1.1).

2. An evaporative concentration stage takes place while the high liquid saturation zone remains essentially stationary. The water in fractures is concentrated by boiling the percolating water, with no or little additional influx of condensation water derived from boiling matrix water. This stage lasts approximately from 150 years to 600 years, but is shorter by several hundred years under the higher infiltration rate (Figure 6.5-27).

3. At 600 years (earlier under higher infiltration rates), a change in the climate state (from ambient to monsoon) causes infiltration rates to increase, resulting in dilution. Concentrations drop slowly until about 2,000 years, when decreasing rates of heat generation, coupled with another climate change (monsoonal to glacial-transition) and a corresponding increase in infiltration, result in the collapse of the boiling zone and rewetting to the drift wall. Concentrations spike slightly during this rewetting phase, as soluble salts redissolve, and the $\mathrm{pH}$ drops. Following the rewetting period, dilution by percolating waters overcomes the effect of evaporative concentration and brings concentrations back to their ambient values over tens of thousands of years.

The effects of these three distinct stages are visible on the predicted concentration trends of most constituents. In the case of chloride, looking at the results of all simulations, concentrations drop 
to as low as around $1 \mathrm{ppm}$ (with Water W6) during the dilution stage and rise to as high as approximately 1,500 ppm (with Water W0) during the evaporative concentration stage (Figure 6.5-27).

The trends of most other aqueous species can be evaluated in terms of the degree of dilution, concentration, and mineral reaction taking place. By dividing aqueous species concentrations by chloride concentrations, the relative degree of mineral dissolution or precipitation can be evaluated. However, the variations of these ratios do not necessarily indicate that reactions are taking place in the grid blocks where the ratios are evaluated. Reactions in the rock matrix could also affect these ratios in fracture water if significant diffusion occurs between fractures and matrix. Reactions above areas being investigated could also affect these ratios. In the present simulations, in zones of highest liquid saturation above the drift crown, predicted increases in $\mathrm{Ca} / \mathrm{Cl}$ in fractures during the dilution stage (after the onset of boiling and steam condensation) (Figure 6.5-30) result from calcite dissolution in fractures. This dissolution is enhanced by the somewhat lower $\mathrm{pH}$ of condensation waters caused by $\mathrm{CO}_{2}$ dissolution (Section 7.1). After this time, when evaporative concentration takes over, $\mathrm{Ca} / \mathrm{Cl}$ ratios decrease through precipitation of calcite and, to a lesser extent, of stellerite. The trends of $\mathrm{Ca} / \mathrm{Cl}$ ratios in logarithmic form (Figure 6.5-30) are similar and somewhat parallel for all simulations, suggesting that the degree of reaction involving calcium minerals is similar in all cases considered.

The $\mathrm{Na} / \mathrm{Cl}$ ratios in fracture water also increase initially during the dilution stage (Figure 6.5-32), but much less than $\mathrm{Ca} / \mathrm{Cl}$ ratios. The increase in this case results from albite dissolution (accompanied by stellerite precipitation, Equations 6.5-1 and 6.5-2), which occurs at a much slower rate than calcite dissolution. After the dilution stage, the $\mathrm{Na} / \mathrm{Cl}$ ratios decrease significantly, even though albite is still dissolving in fractures. The $\mathrm{Na} / \mathrm{Cl}$ decrease in this case appears to result from sodium diffusion into the rock matrix where albite precipitation is taking place (not shown here). This trend is eventually reversed by the continued alteration of albite to stellerite in fractures, which becomes even more pronounced as the evaporative stage ends. Like the $\mathrm{Ca} / \mathrm{Cl}$ ratios, the similar and somewhat parallel trends of $\mathrm{Na} / \mathrm{Cl}$ ratios (in logarithmic form) would suggest that all waters react to a similar degree with sodium phases.

As discussed in Section 6.2.2.1, the ratio of calcium to total aqueous carbonate concentration (expressed here as $\mathrm{Ca} / \mathrm{HCO}_{3}$ ) gives some indication of the likelihood for a water to evolve towards a potentially deleterious calcium chloride brine upon continued evaporation. These brines are more likely to form in initial waters with a $\mathrm{Ca} / \mathrm{HCO}_{3}$ molal ratio greater than 1 . These values are exceeded during the evaporative concentration stage for all considered initial water compositions (Figure 6.5-33). However, Waters W0 and $\mathrm{W} 7$ display $\mathrm{Ca} / \mathrm{HCO}_{3}$ ratios significantly higher than the other waters. Water W4 shows the lowest ratios.

Ratios of nitrate to chloride (Figure 6.5-34) remain essentially constant. This is expected because redox processes are not considered in these simulations, and solid nitrate and chloride phases are formed only upon complete dryout (Section 6.4.5). The re-dissolution of nitrate and chloride salts formed during dryout has a short-lived, hardly noticeable effect in zones with the highest liquid saturations.

The predicted magnesium concentrations (Figure 6.5-35) reflect the effects of the dilution and evaporative concentration stages discussed earlier, but remain significantly depressed below 
ambient values after the boiling period. The magnesium depletion is caused by the precipitation of sepiolite early in the simulations. This depletion is also observed in the simulations of ambient conditions (Section 6.5.5.1) and is not consistent with observed water compositions at Yucca Mountain. One reason may be that sepiolite is either too stable or that it does not belong in the set of selected potential secondary minerals. REV01 simulations (ambient and thermal pulse) without sepiolite in the geochemical system did not predict such magnesium depletion. Another reason for underestimating magnesium concentrations could be the lack of primary magnesium-bearing minerals in simulations (e.g., biotite). These minerals, however, occur in small amounts in the repository host units. Younger calcite at Yucca Mountain has been reported to contain up to around 1 percent (by weight) magnesium (Wilson et al. 2000 [DIRS 154279]). Therefore, taking this into account in simulations would also have an effect on predicted magnesium concentrations. This would contribute more magnesium in solution during calcite dissolution, but could also result in magnesium depletion upon calcite precipitation (under both thermal loading and ambient conditions).

Predicted dissolved silica concentration profiles (Figure 6.5-38) show the same effects of dilution and evaporative concentration as most other species. Profiles of $\mathrm{SiO}_{2} / \mathrm{Cl}$ ratios (not shown here) have the same general shape as the $\mathrm{Ca} / \mathrm{Cl}$ profiles (Figure 6.5-30) and indicate significant silica dissolution during the dilution stage, as would be expected. Later, continued reflux and boiling lead to an increase in concentrations. Predicted concentrations eventually reached values greater than the solubility of amorphous silica (around $350 \mathrm{ppm}$ at $95^{\circ} \mathrm{C}$ ). This is because at this point, the calculated precipitation rate of amorphous silica, although quite fast, cannot keep up with the boiling rate.

Predicted fluoride concentrations (Figure 6.5-37) follow a trend similar to the trend of silica and other aqueous species. The host rock is modeled with a small, ubiquitous amount of primary fluorite. As noted earlier, because the reaction rate of fluorite is fast, waters generally reach saturation with respect to this mineral. During the boiling and refluxing stage, concentrations up to around $40 \mathrm{ppm}$ are predicted, which are much larger than the concentration (approximately $1.4 \mathrm{ppm}$ ) calculated by equilibrating fluorite with the solution, using the maximum calcium concentrations (around 0.02 molal, see Figure 6.5-29) predicted during that time period. In this case also, the precipitation rate of fluorite cannot keep up with the boiling rate. Eventually, concentrations come back to values dictated by equilibrium of ambient waters with fluorite (typically in the 4 to 8 ppm range). 


\section{Location of High-Liquid Saturation Nodes}
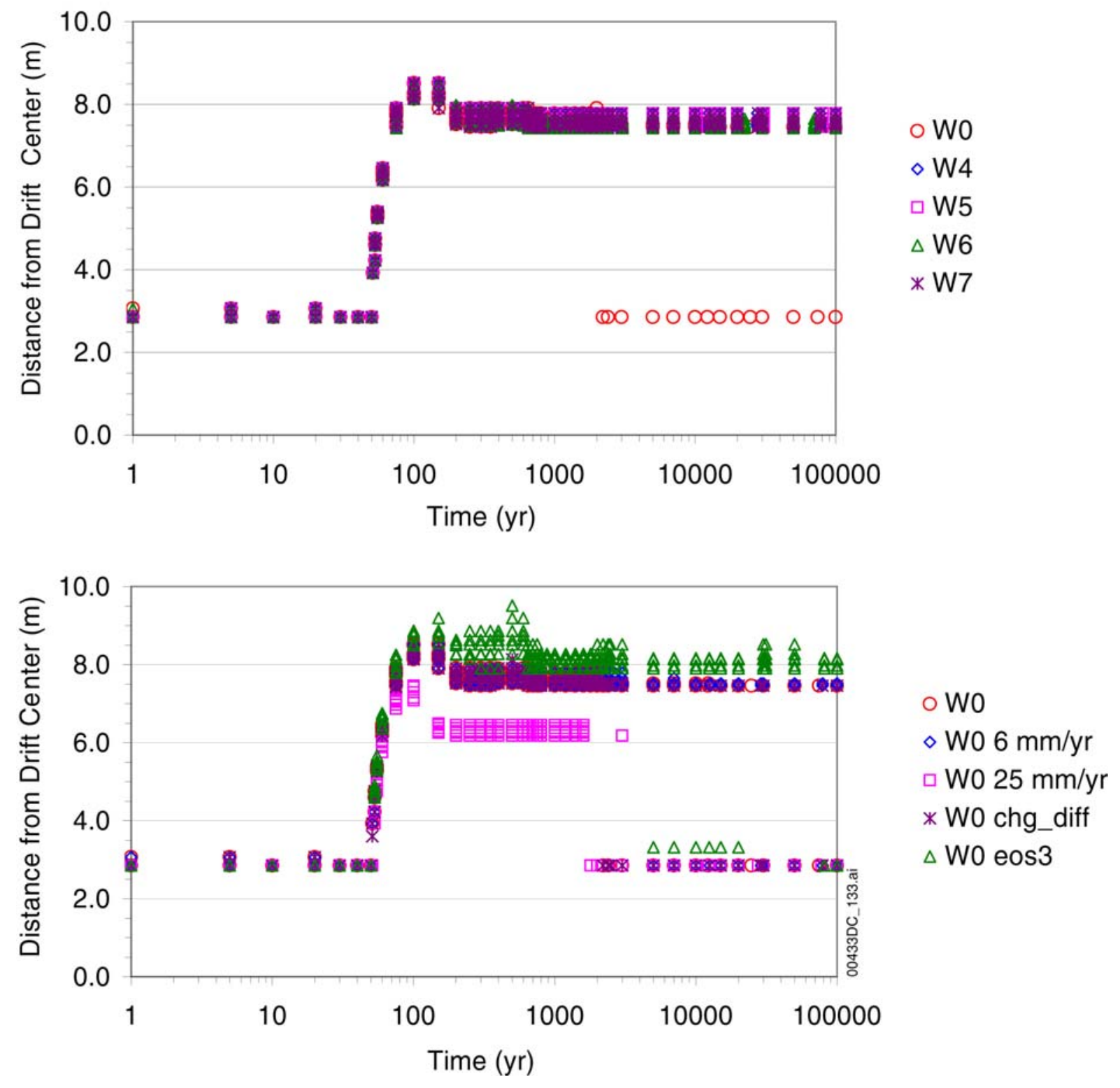

Output DTNs: LB0302DSCPTHCS.002, LB0307DSTTHCR2.002.

NOTE: Grid blocks are those with highest liquid saturation in fractures within a $25-\mathrm{m}$ radius from drift center and a $45^{\circ}$ arc from the drift crown. Data are shown in the top graph for simulations using different initial water compositions (W0 - W7). Except as noted below, all simulations are run using a stepwise-increasing infiltration rate $(6,16$, and $25 \mathrm{~mm} / \mathrm{yr})$ and with vapor pressure lowering. Alternatives using Water W0 are shown in the bottom graph, including simulations without vapor pressure lowering (W0 - eos3), with the smaller $\mathrm{CO}_{2}$ diffusion coefficient (Section 6.5.3), and with fixed 25 and $6 \mathrm{~mm} / \mathrm{yr}$ infiltration rates (W0 $-6 \mathrm{~mm} / \mathrm{yr}$ and $\mathrm{W} 0-25 \mathrm{~mm} / \mathrm{yr}$, respectively).

Figure 6.5-21. THC Seepage Model (Tptpll): Location of Model Grid Blocks for Data Shown on Figures 6.5-22 through 6.5-37, for Each Time When Model Output Is Produced 


\section{Temperature}
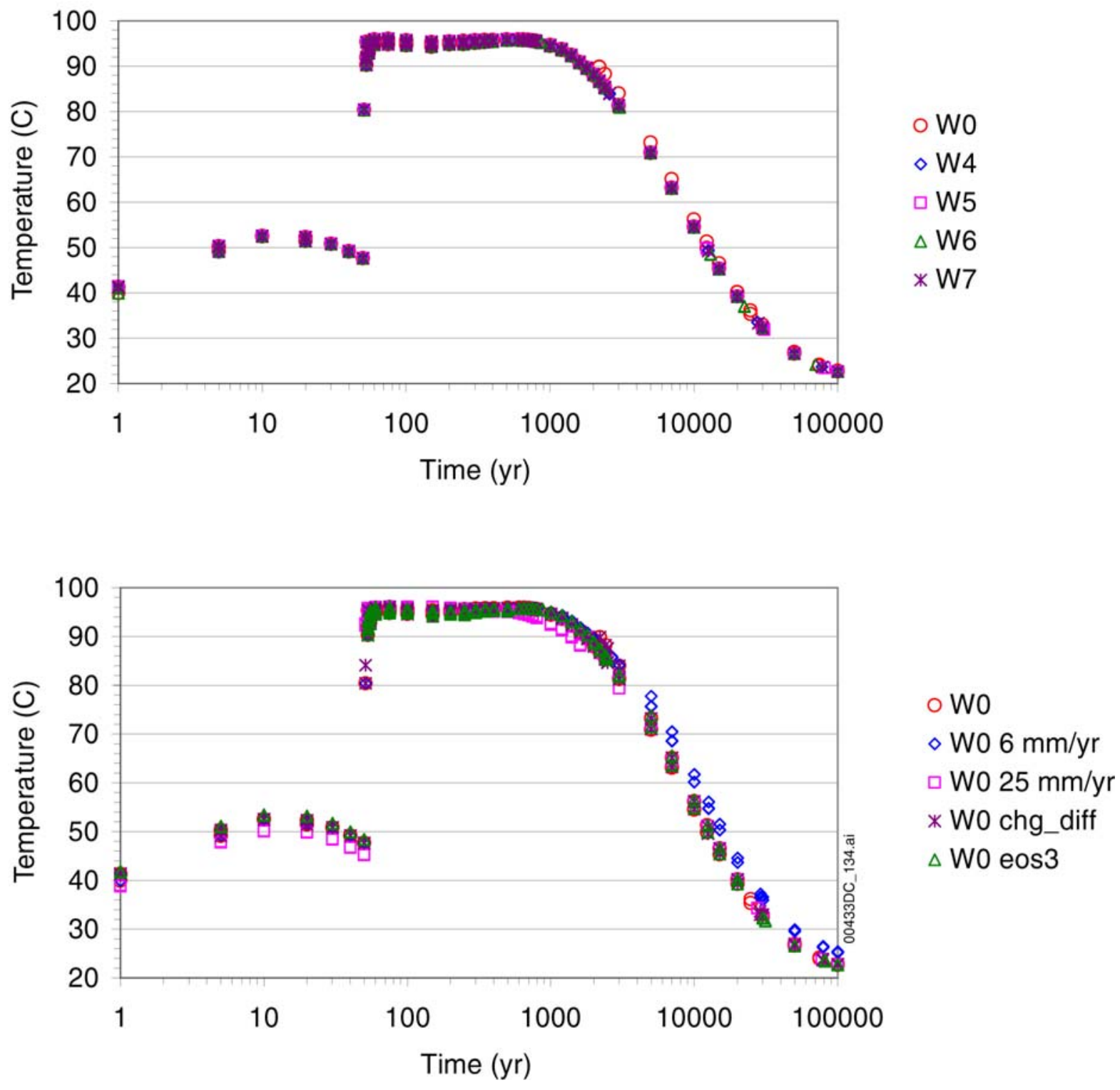

Output DTNs: LB0302DSCPTHCS.002, LB0307DSTTHCR2.002.

NOTE: Grid blocks are those with highest liquid saturation in fractures within a 25-m radius from drift center and a $45^{\circ}$ arc from the drift crown. Data are shown in the top graph for simulations using different initial water compositions (W0 - W7). Except as noted below, all simulations are run using a stepwise-increasing infiltration rate $(6,16$, and $25 \mathrm{~mm} / \mathrm{yr})$ and with vapor pressure lowering. Alternatives using Water W0 are shown in the bottom graph, including simulations without vapor pressure lowering (W0 - eos3), with the smaller $\mathrm{CO}_{2}$ diffusion coefficient (Section 6.5.3), and with fixed 25 and $6 \mathrm{~mm} / \mathrm{yr}$ infiltration rates (WO $-6 \mathrm{~mm} / \mathrm{yr}$ and $\mathrm{W} 0-25 \mathrm{~mm} / \mathrm{yr}$, respectively).

Figure 6.5-22. THC Seepage Model (Tptpll): Time Profiles of Modeled Temperatures in Fracture Water in Areas of Highest Liquid Saturation above the Drift Crown 


\section{Liquid Saturation - Fractures}
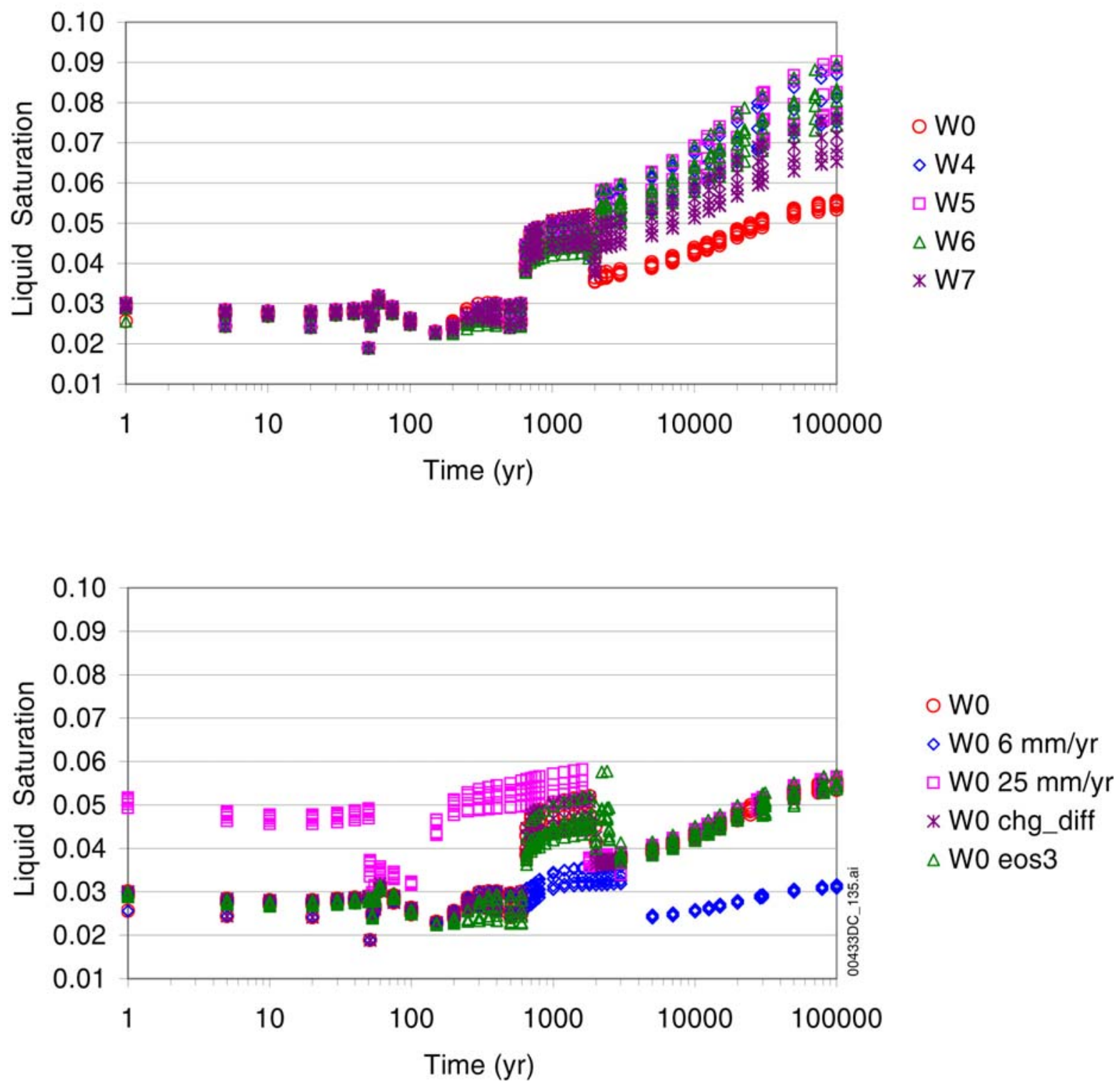

Output DTNs: LB0302DSCPTHCS.002, LB0307DSTTHCR2.002.

NOTE: Grid blocks are those with highest liquid saturation in fractures within a 25-m radius from drift center and a $45^{\circ}$ arc from the drift crown. Data are shown in the top graph for simulations using different initial water compositions (W0 - W7). Except as noted below, all simulations are run using a stepwise-increasing infiltration rate $(6,16$, and $25 \mathrm{~mm} / \mathrm{yr})$ and with vapor pressure lowering. Alternatives using Water $\mathrm{W} 0$ are shown in the bottom graph, including simulations without vapor pressure lowering (W0 - eos3), with the smaller $\mathrm{CO}_{2}$ diffusion coefficient (Section 6.5.3), and with fixed 25 and $6 \mathrm{~mm} / \mathrm{yr}$ infiltration rates (WO $-6 \mathrm{~mm} / \mathrm{yr}$ and $\mathrm{WO}-25 \mathrm{~mm} / \mathrm{yr}$, respectively).

Figure 6.5-23. THC Seepage Model (Tptpll): Time Profiles of Modeled Liquid Saturations in Fracture Water in Areas of Highest Liquid Saturation above the Drift Crown 


\section{$\mathrm{CO}_{2}$ - Fractures}
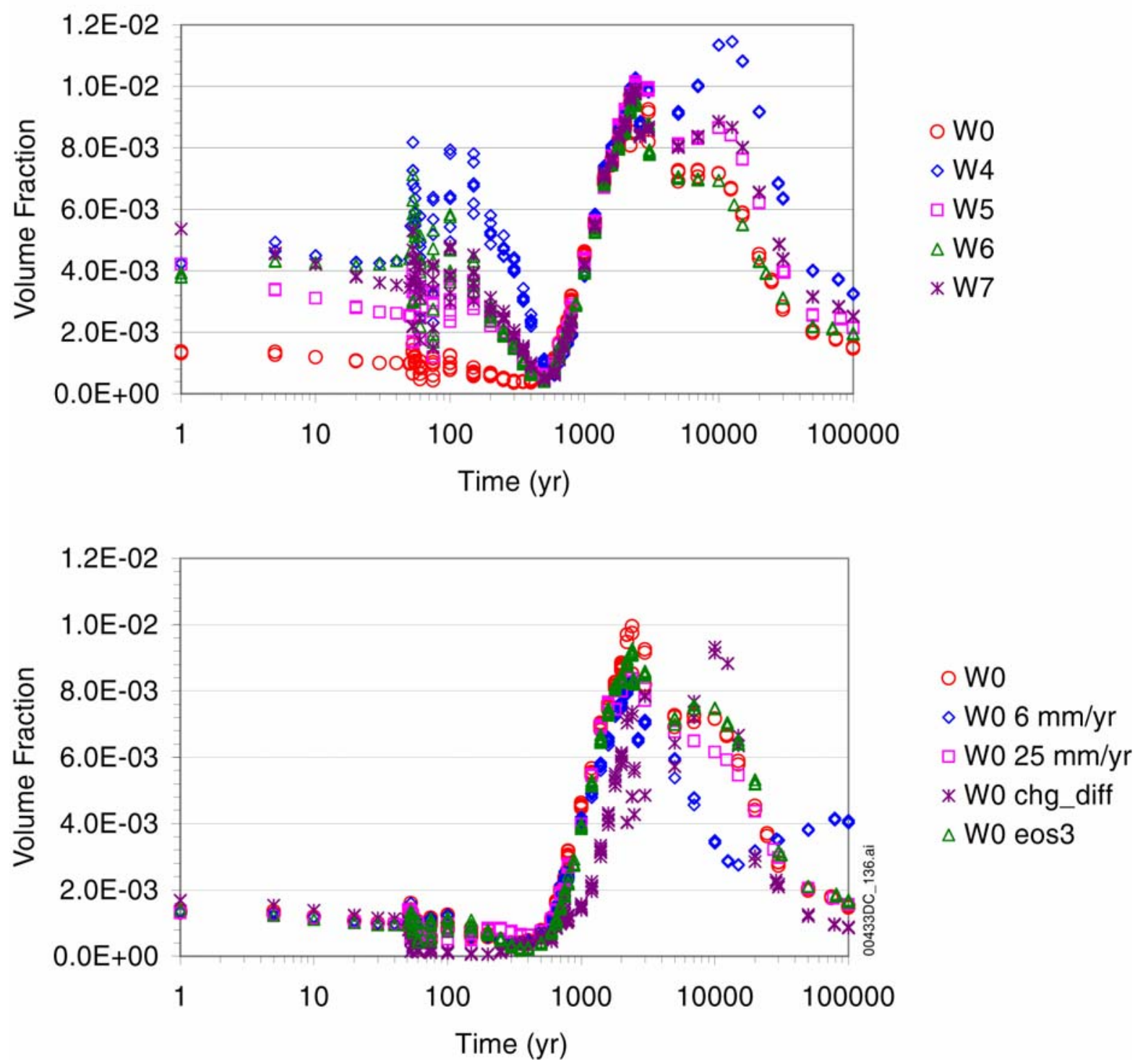

Output DTNs: LB0302DSCPTHCS.002, LB0307DSTTHCR2.002.

NOTE: Grid blocks are those with highest liquid saturation in fractures within a 25-m radius from drift center and a $45^{\circ}$ arc from the drift crown. Data are shown in the top graph for simulations using different initial water compositions (W0 - W7). Except as noted below, all simulations are run using a stepwise-increasing infiltration rate $(6,16$, and $25 \mathrm{~mm} / \mathrm{yr})$ and with vapor pressure lowering. Alternatives using Water W0 are shown in the bottom graph, including simulations without vapor pressure lowering (W0 - eos3), with the smaller $\mathrm{CO}_{2}$ diffusion coefficient (Section 6.5.3), and with fixed 25 and $6 \mathrm{~mm} / \mathrm{yr}$ infiltration rates (WO $-6 \mathrm{~mm} / \mathrm{yr}$ and $\mathrm{W} 0-25 \mathrm{~mm} / \mathrm{yr}$, respectively).

Figure 6.5-24. THC Seepage Model (Tptpll): Time Profiles of Modeled $\mathrm{CO}_{2}$ Gas Concentrations in Fracture Water in Areas of Highest Liquid Saturation above the Drift Crown 


\section{$\mathrm{pH}$ - Fractures}
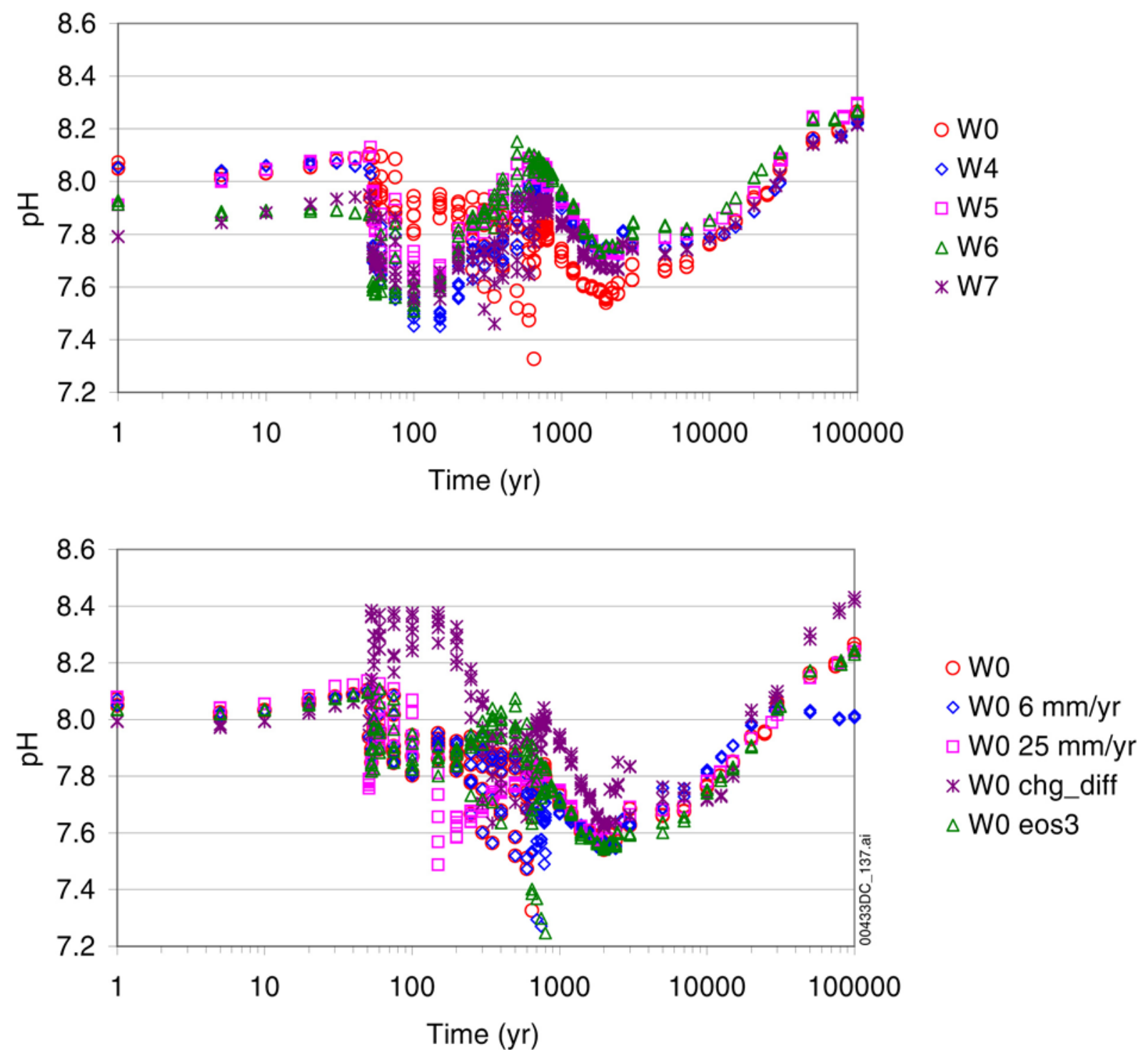

Output DTNs: LB0302DSCPTHCS.002, LB0307DSTTHCR2.002.

NOTE: Grid blocks are those with highest liquid saturation in fractures within a 25-m radius from drift center and a $45^{\circ}$ arc from the drift crown. Data are shown in the top graph for simulations using different initial water compositions (W0 - W7). Except as noted below, all simulations are run using a stepwise-increasing infiltration rate $(6,16$, and $25 \mathrm{~mm} / \mathrm{yr})$ and with vapor pressure lowering. Alternatives using Water $\mathrm{W} 0$ are shown in the bottom graph, including simulations without vapor pressure lowering (W0 - eos 3 ), with the smaller $\mathrm{CO}_{2}$ diffusion coefficient (Section 6.5.3), and with fixed 25 and $6 \mathrm{~mm} / \mathrm{yr}$ infiltration rates (WO $-6 \mathrm{~mm} / \mathrm{yr}$ and $\mathrm{W} 0-25 \mathrm{~mm} / \mathrm{yr}$, respectively).

Figure 6.5-25. THC Seepage Model (Tptpll): Time Profiles of Modeled pH in Fracture Water in Areas of Highest Liquid Saturation above the Drift Crown 


\section{$\mathrm{HCO}_{3}$ - Fractures}
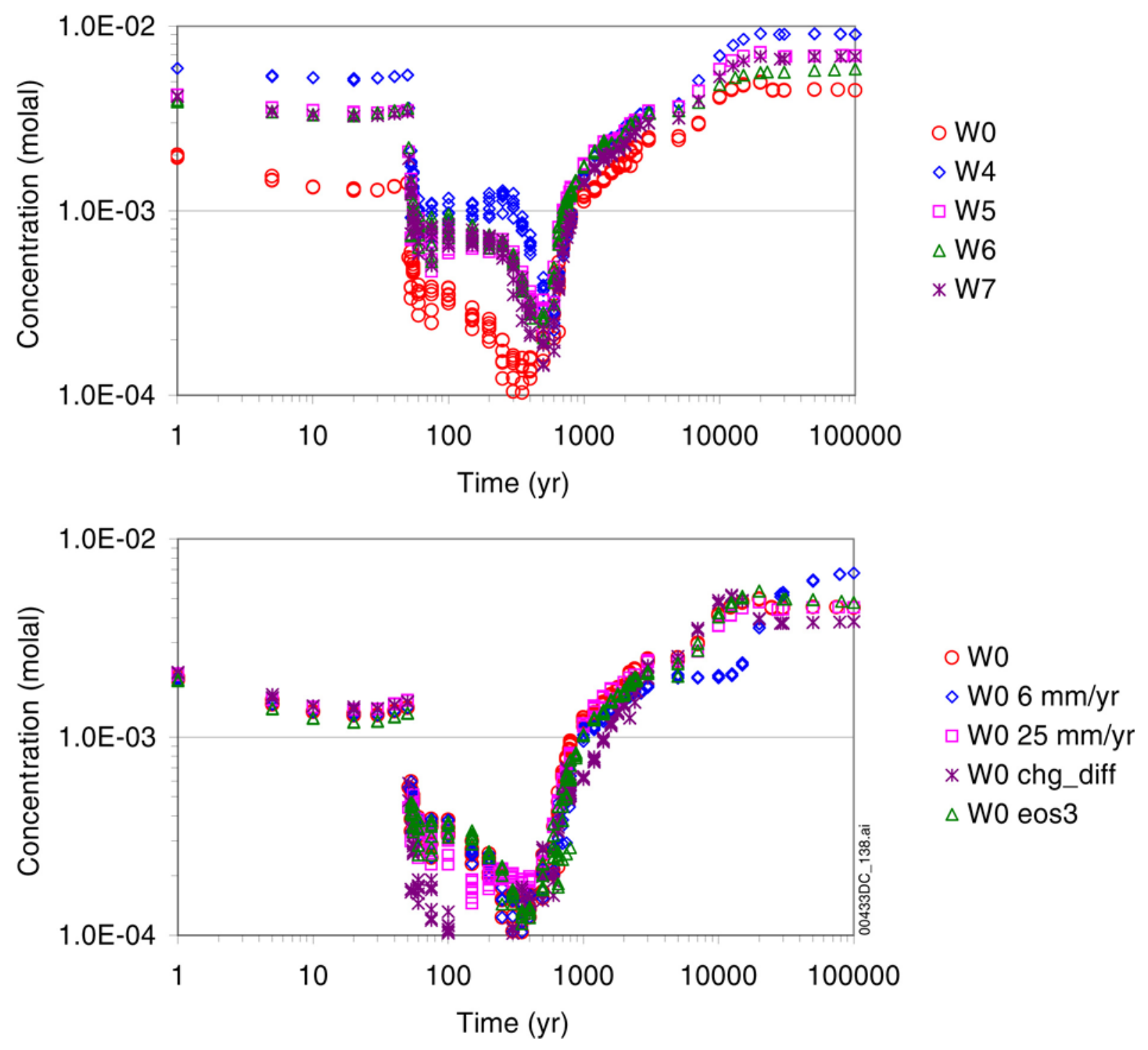

Output DTNs: LB0302DSCPTHCS.002, LB0307DSTTHCR2.002.

NOTE: Grid blocks are those with highest liquid saturation in fractures within a $25-\mathrm{m}$ radius from drift center and a $45^{\circ}$ arc from the drift crown. Data are shown in the top graph for simulations using different initial water compositions (W0 - W7). Except as noted below, all simulations are run using a stepwise-increasing infiltration rate $(6,16$, and $25 \mathrm{~mm} / \mathrm{yr})$ and with vapor pressure lowering. Alternatives using Water W0 are shown in the bottom graph, including simulations without vapor pressure lowering (W0 - eos3), with the smaller $\mathrm{CO}_{2}$ diffusion coefficient (Section 6.5.3), and with fixed 25 and $6 \mathrm{~mm} / \mathrm{yr}$ infiltration rates (W0 $-6 \mathrm{~mm} / \mathrm{yr}$ and $\mathrm{W} 0-25 \mathrm{~mm} / \mathrm{yr}$, respectively).

Figure 6.5-26. THC Seepage Model (Tptpll): Time Profiles of Modeled Total Aqueous Carbonate Concentrations $\left(\right.$ as $\mathrm{HCO}_{3}$ ) in Fracture Water in Areas of Highest Liquid Saturation above the Drift Crown 


\section{$\mathrm{Cl}$ - Fractures}
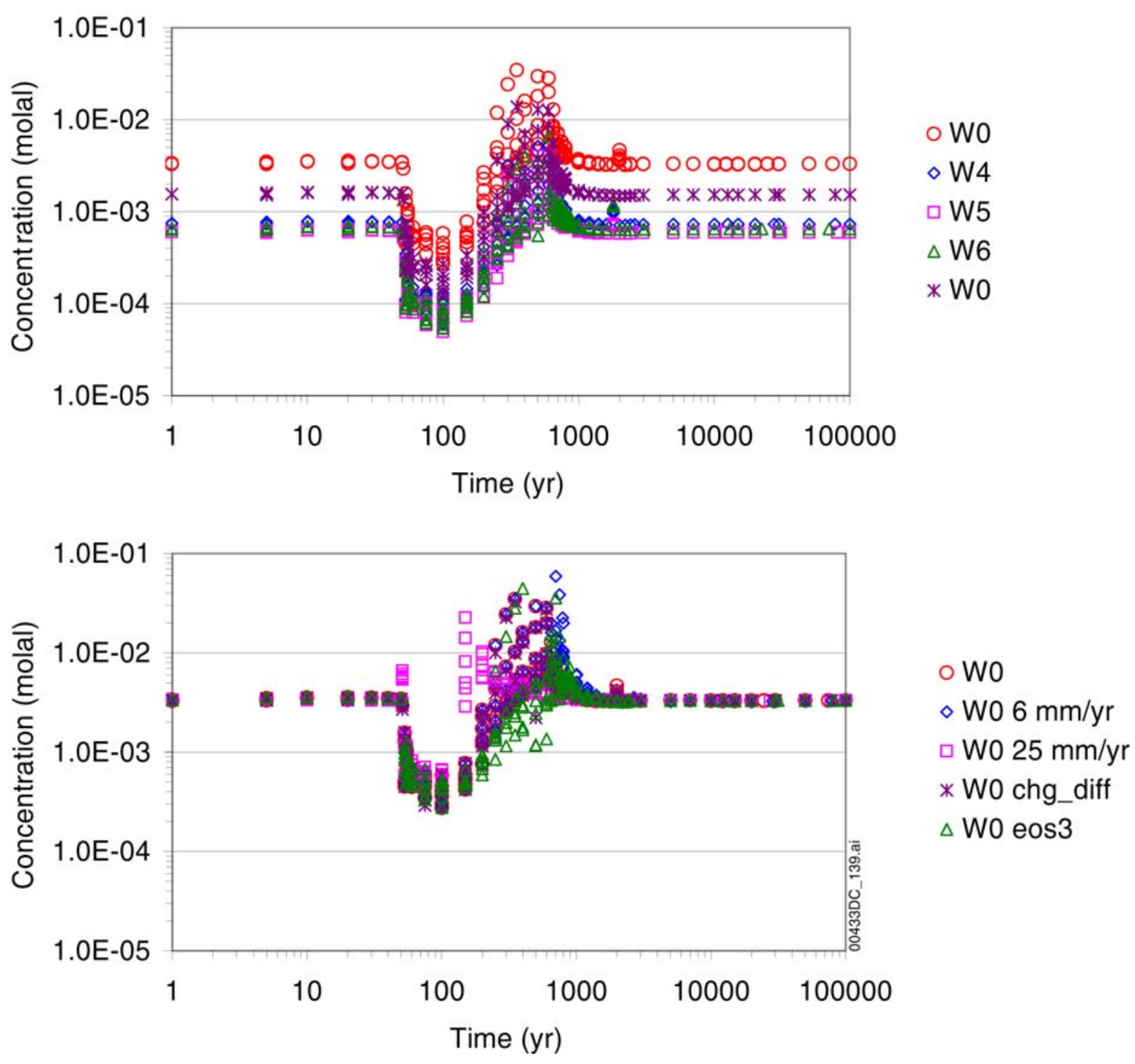

Output DTNs: LB0302DSCPTHCS.002, LB0307DSTTHCR2.002.

NOTE: Grid blocks are those with highest liquid saturation in fractures within a 25-m radius from drift center and a $45^{\circ}$ arc from the drift crown. Data are shown in the top graph for simulations using different initial water compositions (W0 - W7). Except as noted below, all simulations are run using a stepwise-increasing infiltration rate $(6,16$, and $25 \mathrm{~mm} / \mathrm{yr})$ and with vapor pressure lowering. Alternatives using Water W0 are shown in the bottom graph, including simulations without vapor pressure lowering (W0 - eos3), with the smaller $\mathrm{CO}_{2}$ diffusion coefficient (Section 6.5.3), and with fixed 25 and $6 \mathrm{~mm} / \mathrm{yr}$ infiltration rates (W0 $-6 \mathrm{~mm} / \mathrm{yr}$ and $\mathrm{W} 0-25 \mathrm{~mm} / \mathrm{yr}$, respectively).

Figure 6.5-27. THC Seepage Model (Tptpll): Time Profiles of Modeled Total Aqueous Chloride Concentrations in Fracture Water in Areas of Highest Liquid Saturation above the Drift Crown 
$\mathrm{NO}_{3}$ - Fractures
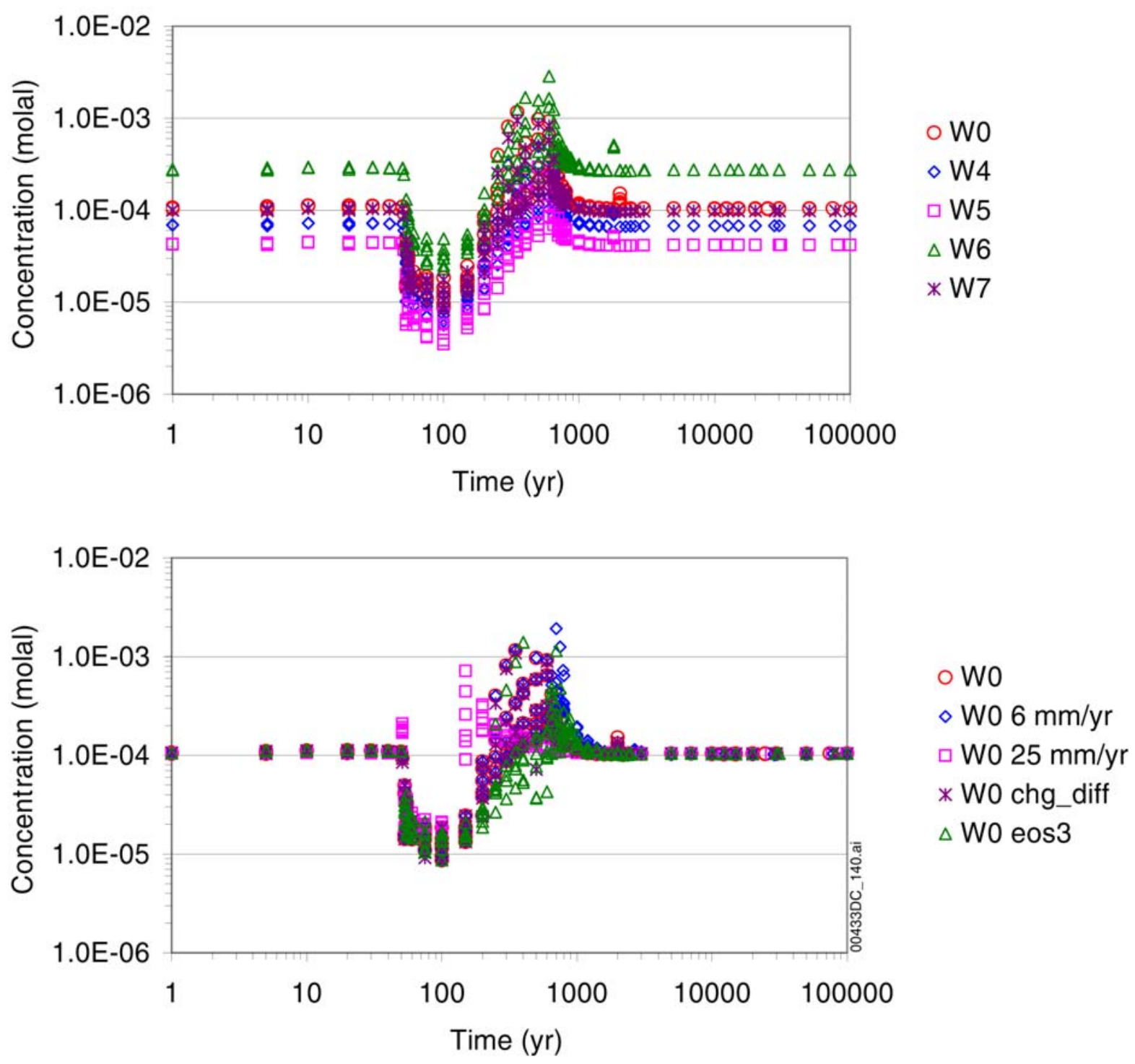

Output DTNs: LB0302DSCPTHCS.002, LB0307DSTTHCR2.002.

NOTE: Grid blocks are those with highest liquid saturation in fractures within a $25-\mathrm{m}$ radius from drift center and a $45^{\circ}$ arc from the drift crown. Data are shown in the top graph for simulations using different initial water compositions (W0 - W7). Except as noted below, all simulations are run using a stepwise-increasing infiltration rate $(6,16$, and $25 \mathrm{~mm} / \mathrm{yr})$ and with vapor pressure lowering. Alternatives using Water WO are shown in the bottom graph, including simulations without vapor pressure lowering (W0 - eos3), with the smaller $\mathrm{CO}_{2}$ diffusion coefficient (Section 6.5.3), and with fixed 25 and $6 \mathrm{~mm} / \mathrm{yr}$ infiltration rates (W0 $-6 \mathrm{~mm} / \mathrm{yr}$ and $\mathrm{W} 0-25 \mathrm{~mm} / \mathrm{yr}$, respectively).

Figure 6.5-28. THC Seepage Model (Tptpll): Time Profiles of Modeled Total Aqueous Nitrate Concentrations in Fracture Water in Areas of Highest Liquid Saturation above the Drift Crown 


\section{$\mathrm{Ca}$ - Fractures}
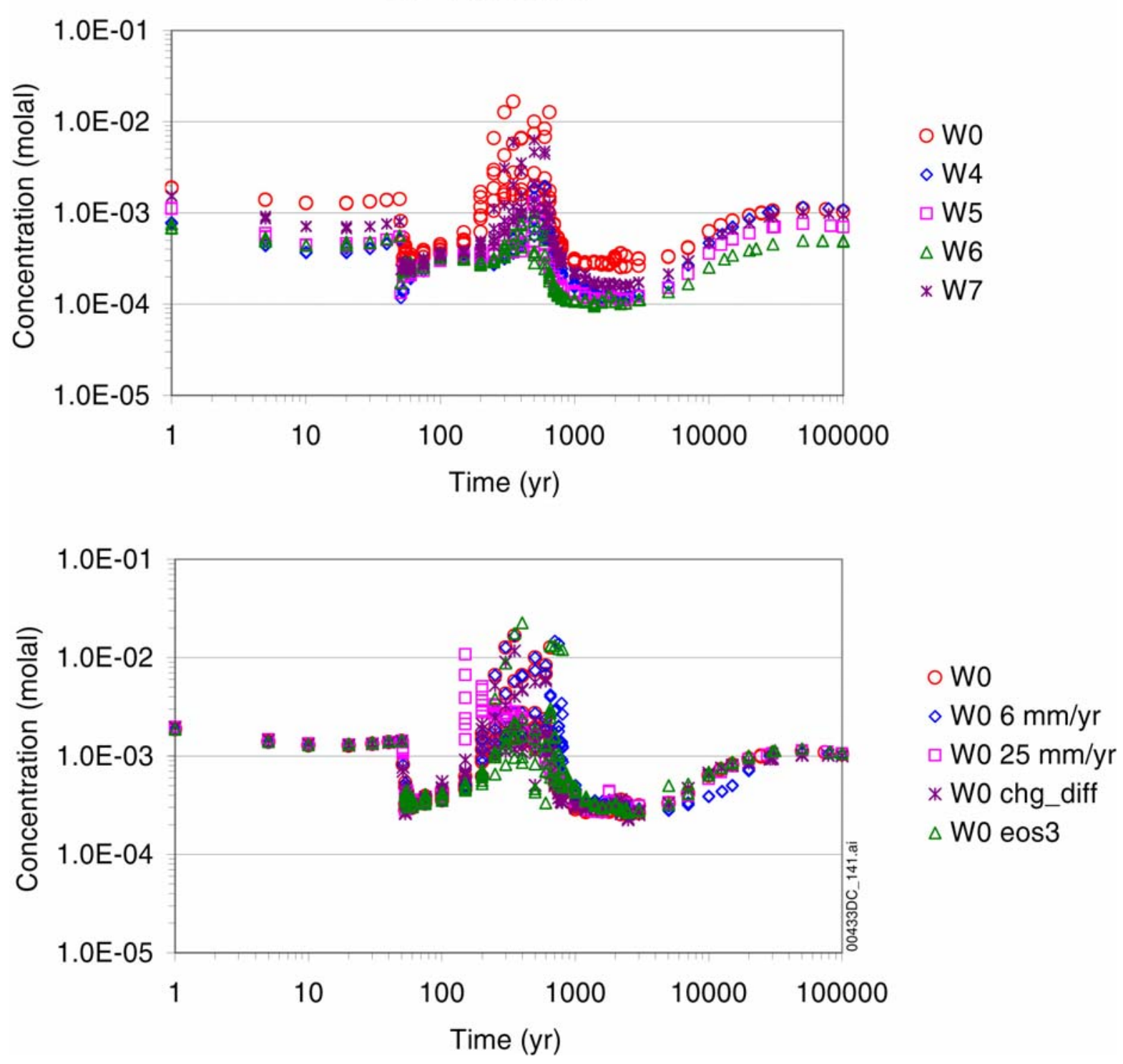

Output DTNs: LB0302DSCPTHCS.002, LB0307DSTTHCR2.002.

NOTE: Grid blocks are those with highest liquid saturation in fractures within a 25-m radius from drift center and a $45^{\circ}$ arc from the drift crown. Data are shown in the top graph for simulations using different initial water compositions (W0 - W7). Except as noted below, all simulations are run using a stepwise-increasing infiltration rate $(6,16$, and $25 \mathrm{~mm} / \mathrm{yr})$ and with vapor pressure lowering. Alternatives using Water W0 are shown in the bottom graph, including simulations without vapor pressure lowering (W0 - eos3), with the smaller $\mathrm{CO}_{2}$ diffusion coefficient (Section 6.5.3), and with fixed 25 and $6 \mathrm{~mm} / \mathrm{yr}$ infiltration rates (W0 $-6 \mathrm{~mm} / \mathrm{yr}$ and $\mathrm{W} 0-25 \mathrm{~mm} / \mathrm{yr}$, respectively).

Figure 6.5-29. THC Seepage Model (Tptpll): Time Profiles of Modeled Total Aqueous Calcium Concentrations in Fracture Water in Areas of Highest Liquid Saturation above the Drift Crown 


\section{$\mathrm{Ca} / \mathrm{Cl}$ - Fractures}
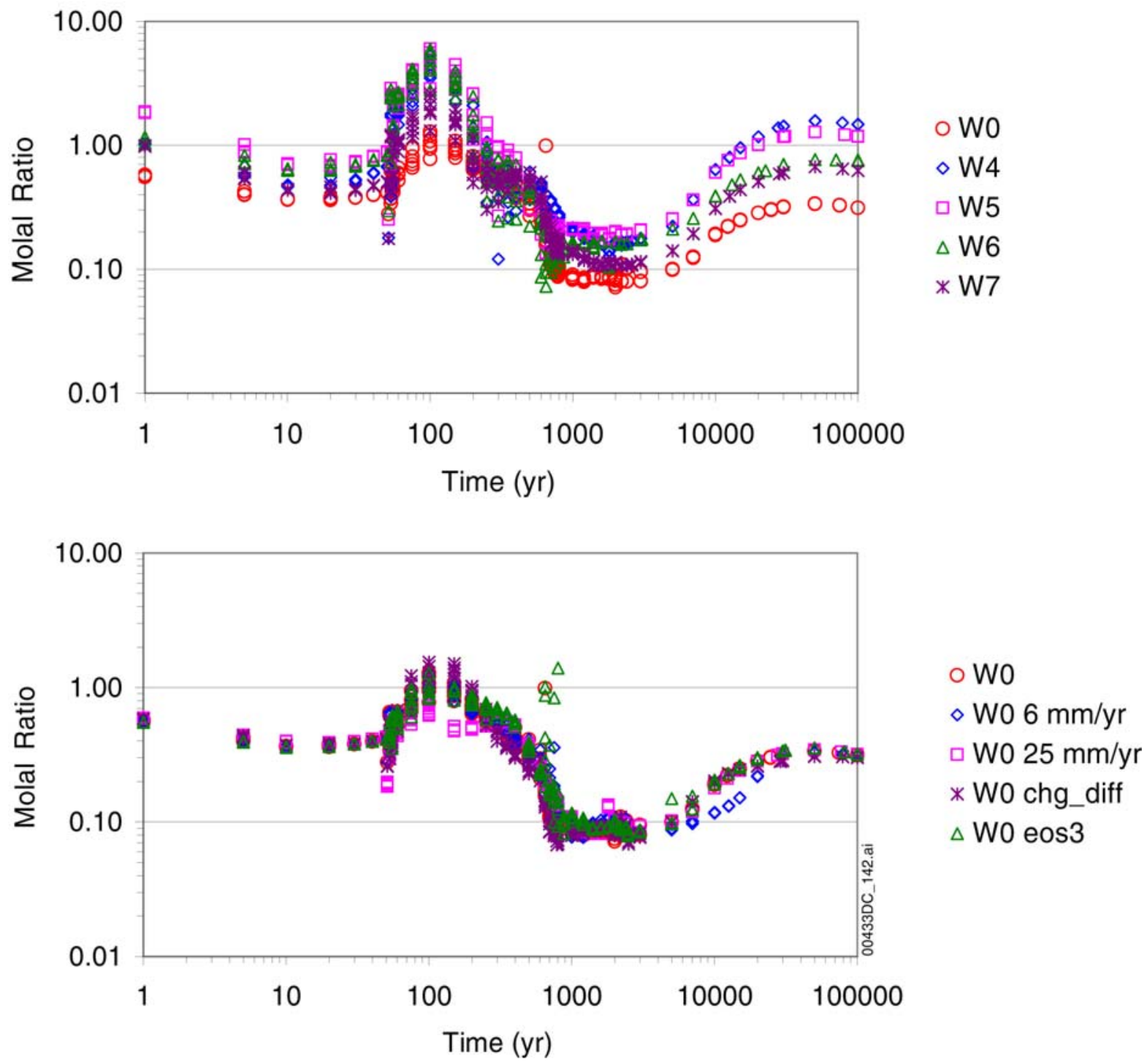

Output DTNs: LB0302DSCPTHCS.002, LB0307DSTTHCR2.002.

NOTE: Grid blocks are those with highest liquid saturation in fractures within a 25-m radius from drift center and a $45^{\circ}$ arc from the drift crown. Data are shown in the top graph for simulations using different initial water compositions (W0 - W7). Except as noted below, all simulations are run using a stepwise-increasing infiltration rate $(6,16$, and $25 \mathrm{~mm} / \mathrm{yr})$ and with vapor pressure lowering. Alternatives using Water $\mathrm{W} 0$ are shown in the bottom graph, including simulations without vapor pressure lowering (W0 - eos 3 ), with the smaller $\mathrm{CO}_{2}$ diffusion coefficient (Section 6.5.3), and with fixed 25 and $6 \mathrm{~mm} / \mathrm{yr}$ infiltration rates (WO $-6 \mathrm{~mm} / \mathrm{yr}$ and $\mathrm{W} 0-25 \mathrm{~mm} / \mathrm{yr}$, respectively).

Figure 6.5-30. THC Seepage Model (Tptpll): Time Profiles of Modeled Total Aqueous Calcium to Chloride Ratios in Fracture Water in Areas of Highest Liquid Saturation above the Drift Crown 

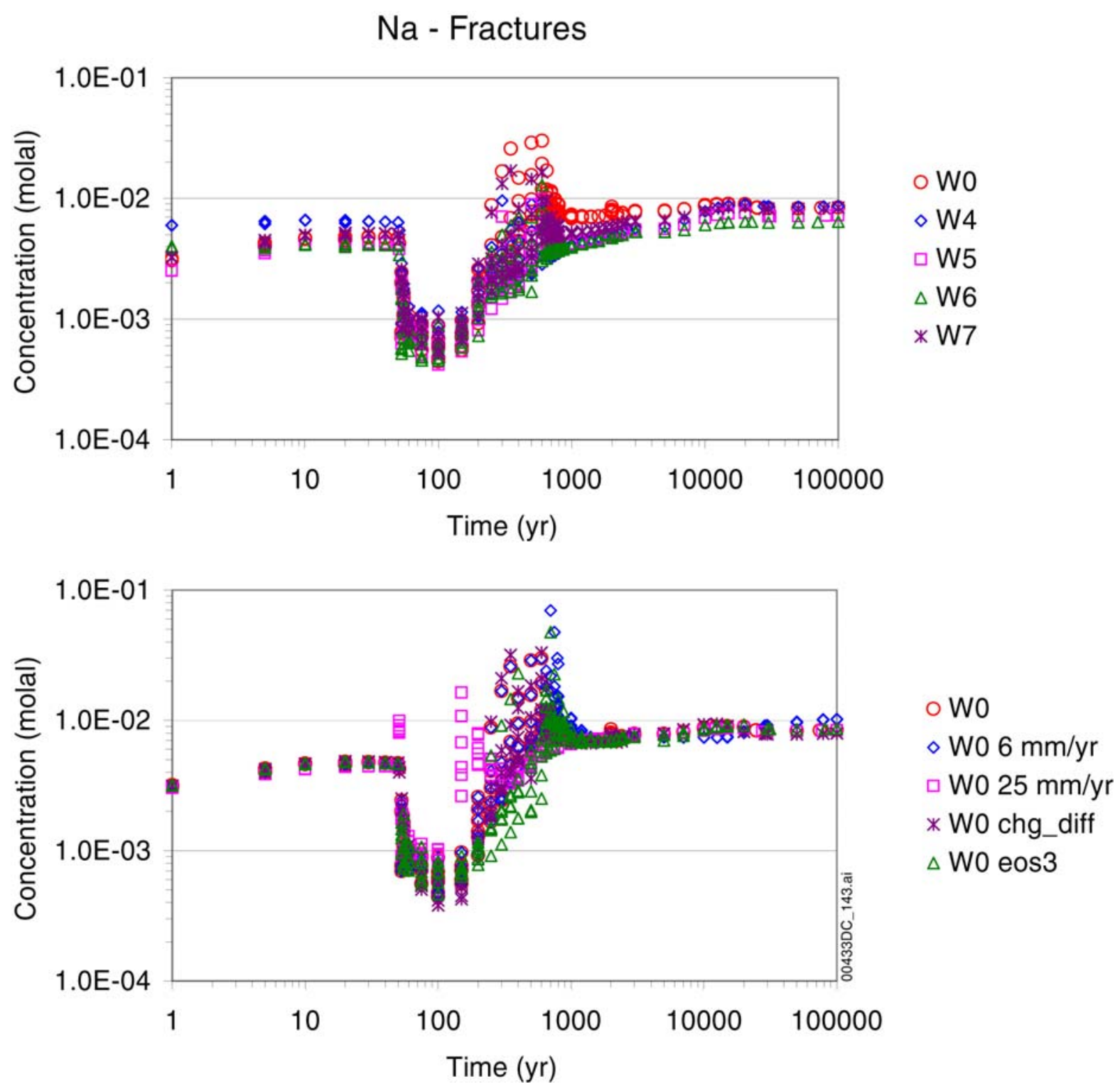

Output DTNs: LB0302DSCPTHCS.002, LB0307DSTTHCR2.002.

NOTE: Grid blocks are those with highest liquid saturation in fractures within a 25-m radius from drift center and a $45^{\circ}$ arc from the drift crown. Data are shown in the top graph for simulations using different initial water compositions (W0 - W7). Except as noted below, all simulations are run using a stepwise-increasing infiltration rate $(6,16$, and $25 \mathrm{~mm} / \mathrm{yr})$ and with vapor pressure lowering. Alternatives using Water W0 are shown in the bottom graph, including simulations without vapor pressure lowering (W0 - eos 3 ), with the smaller $\mathrm{CO}_{2}$ diffusion coefficient (Section 6.5.3), and with fixed 25 and $6 \mathrm{~mm} / \mathrm{yr}$ infiltration rates (W0 $-6 \mathrm{~mm} / \mathrm{yr}$ and $\mathrm{W} 0-25 \mathrm{~mm} / \mathrm{yr}$, respectively).

Figure 6.5-31. THC Seepage Model (Tptpll): Time Profiles of Modeled Total Aqueous Sodium Concentrations in Fracture Water in Areas of Highest Liquid Saturation above the Drift Crown 
$\mathrm{Na} / \mathrm{Cl}$ - Fractures
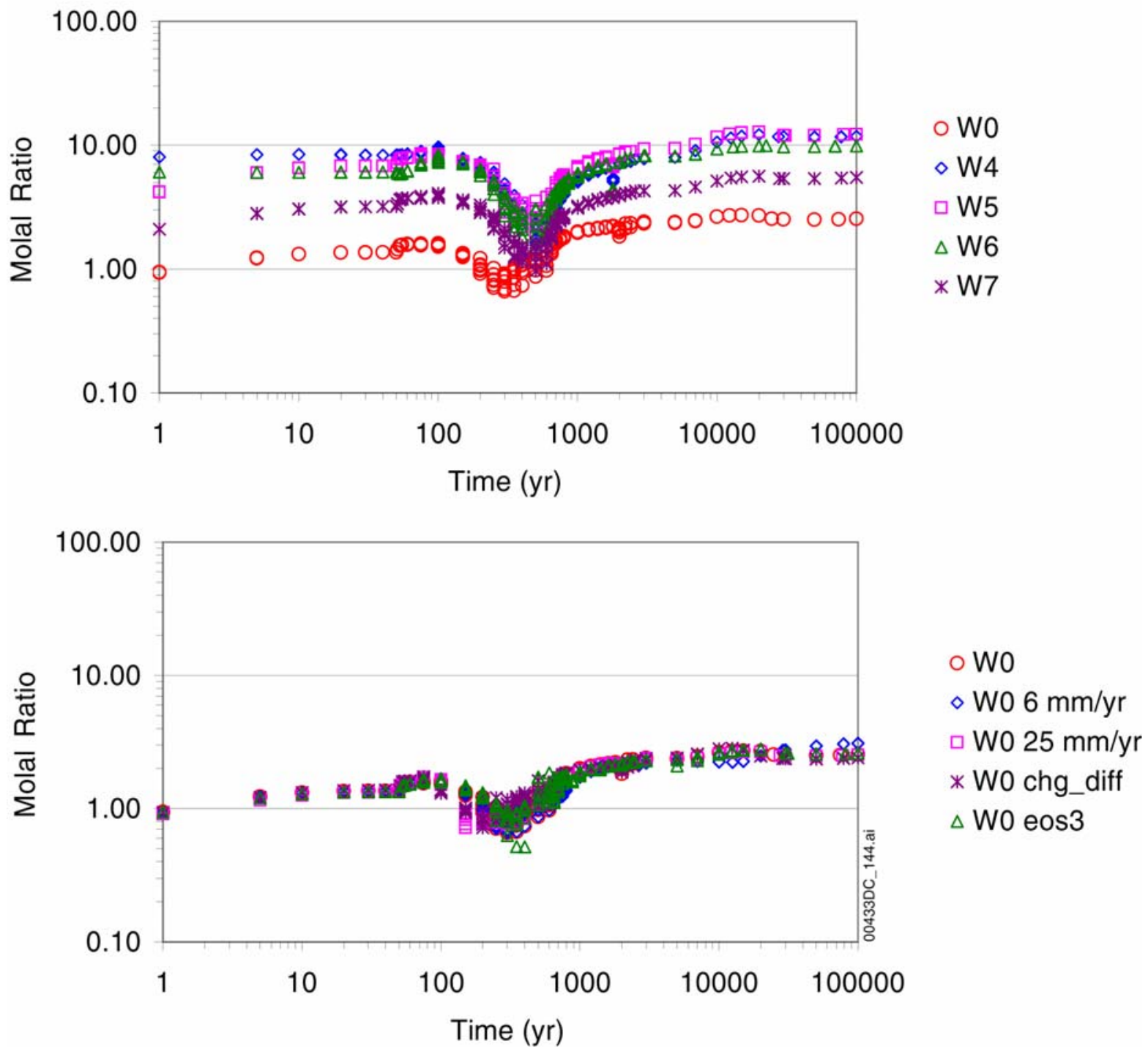

Output DTNs: LB0302DSCPTHCS.002, LB0307DSTTHCR2.002.

NOTE: Grid blocks are those with highest liquid saturation in fractures within a 25-m radius from drift center and a $45^{\circ}$ arc from the drift crown. Data are shown in the top graph for simulations using different initial water compositions (W0 - W7). Except as noted below, all simulations are run using a stepwise-increasing infiltration rate $(6,16$, and $25 \mathrm{~mm} / \mathrm{yr})$ and with vapor pressure lowering. Alternatives using Water WO are shown in the bottom graph, including simulations without vapor pressure lowering (W0 - eos 3 ), with the smaller $\mathrm{CO}_{2}$ diffusion coefficient (Section 6.5.3), and with fixed 25 and $6 \mathrm{~mm} / \mathrm{yr}$ infiltration rates (W0 $-6 \mathrm{~mm} / \mathrm{yr}$ and $\mathrm{W} 0-25 \mathrm{~mm} / \mathrm{yr}$, respectively).

Figure 6.5-32. THC Seepage Model (Tptpll): Time Profiles of Modeled Total Aqueous Sodium to Chloride Ratios in Fracture Water in Areas of Highest Liquid Saturation above the Drift Crown 


\section{$\mathrm{Ca} / \mathrm{HCO}_{3}$ - Fractures}
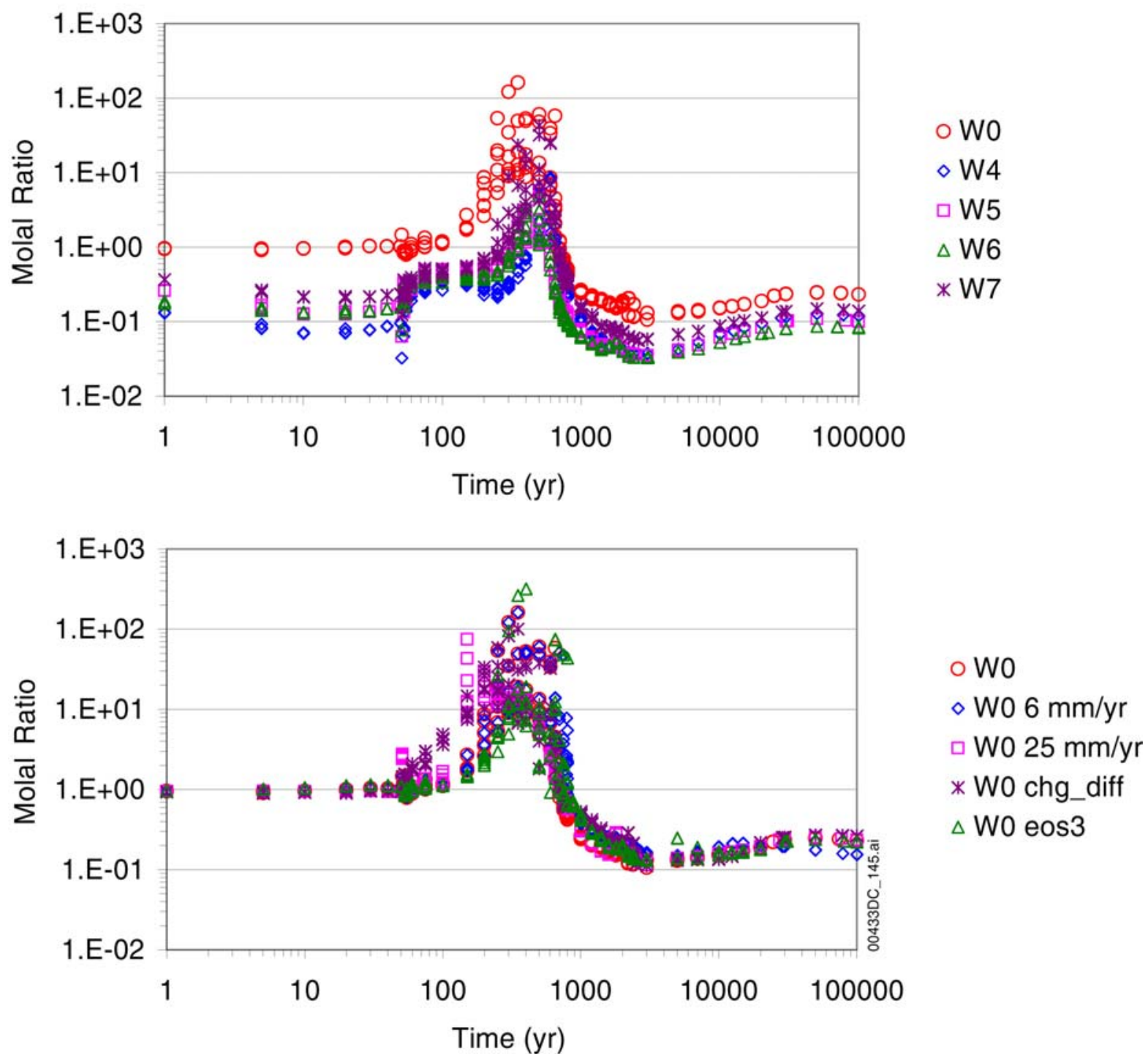

Output DTNs: LB0302DSCPTHCS.002, LB0307DSTTHCR2.002.

NOTE: Grid blocks are those with highest liquid saturation in fractures within a $25-\mathrm{m}$ radius from drift center and a $45^{\circ}$ arc from the drift crown. Data are shown in the top graph for simulations using different initial water compositions (W0 - W7). Except as noted below, all simulations are run using a stepwise-increasing infiltration rate $(6,16$, and $25 \mathrm{~mm} / \mathrm{yr})$ and with vapor pressure lowering. Alternatives using Water WO are shown in the bottom graph, including simulations without vapor pressure lowering (W0 - eos 3 ), with the smaller $\mathrm{CO}_{2}$ diffusion coefficient (Section 6.5.3), and with fixed 25 and $6 \mathrm{~mm} / \mathrm{yr}$ infiltration rates (W0 $-6 \mathrm{~mm} / \mathrm{yr}$ and $\mathrm{W} 0-25 \mathrm{~mm} / \mathrm{yr}$, respectively).

Figure 6.5-33. THC Seepage Model (Tptpll): Time Profiles of Modeled Total Aqueous Calcium to Carbonate Ratios in Fracture Water in Areas of Highest Liquid Saturation above the Drift Crown 

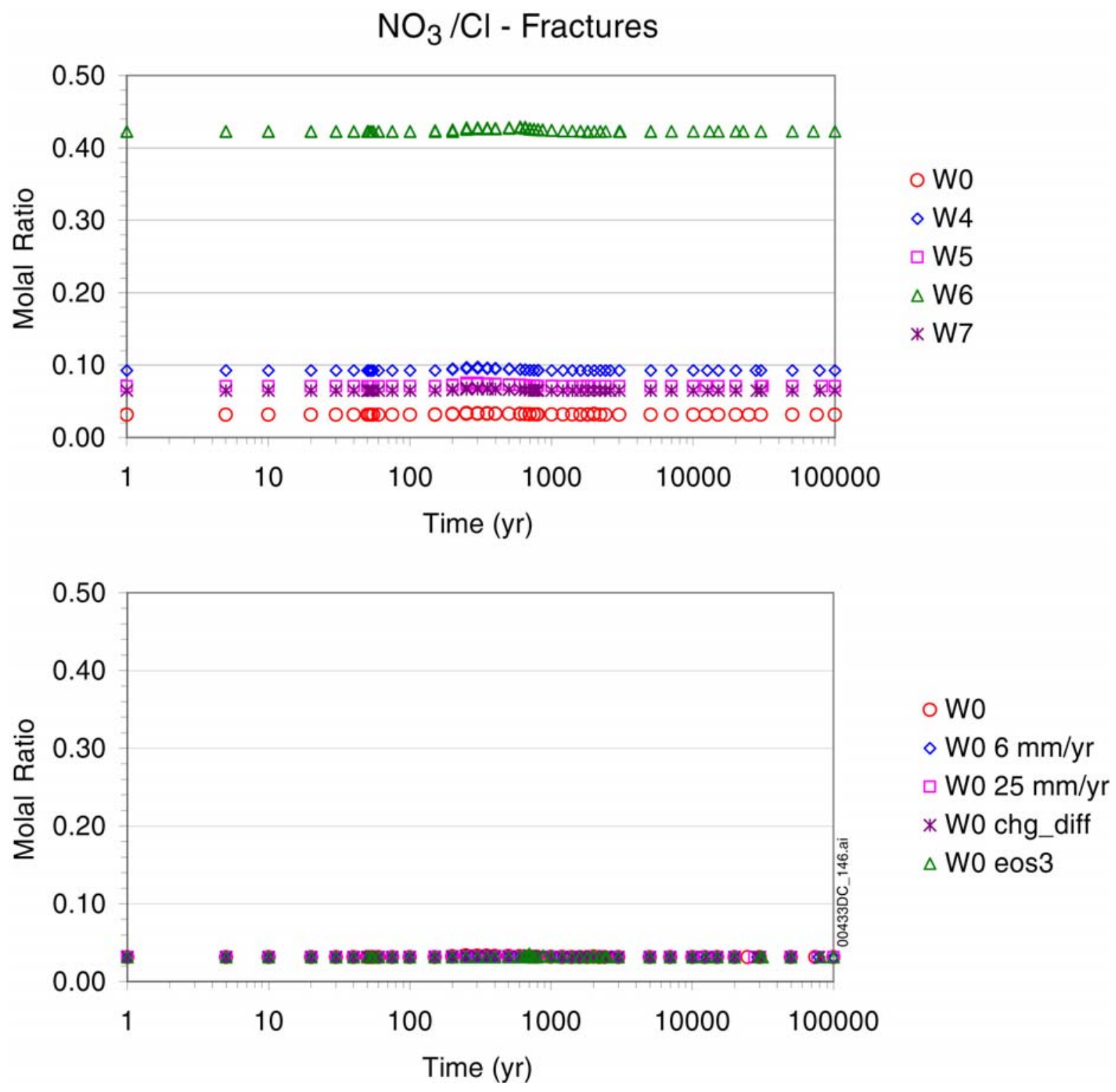

Output DTNs: LB0302DSCPTHCS.002, LB0307DSTTHCR2.002.

NOTE: Grid blocks are those with highest liquid saturation in fractures within a 25-m radius from drift center and a $45^{\circ}$ arc from the drift crown. Data are shown in the top graph for simulations using different initial water compositions (W0 - W7). Except as noted below, all simulations are run using a stepwise-increasing infiltration rate $(6,16$, and $25 \mathrm{~mm} / \mathrm{yr})$ and with vapor pressure lowering. Alternatives using Water W0 are shown in the bottom graph, including simulations without vapor pressure lowering (W0 - eos3), with the smaller $\mathrm{CO}_{2}$ diffusion coefficient (Section 6.5.3), and with fixed 25 and $6 \mathrm{~mm} / \mathrm{yr}$ infiltration rates (WO $-6 \mathrm{~mm} / \mathrm{yr}$ and $\mathrm{W} 0-25 \mathrm{~mm} / \mathrm{yr}$, respectively).

Figure 6.5-34. THC Seepage Model (Tptpll): Time Profiles of Modeled Total Aqueous Nitrate to Chloride Ratios in Fracture Water in Areas of Highest Liquid Saturation above the Drift Crown 


\section{$\mathrm{Mg}$ - Fractures}
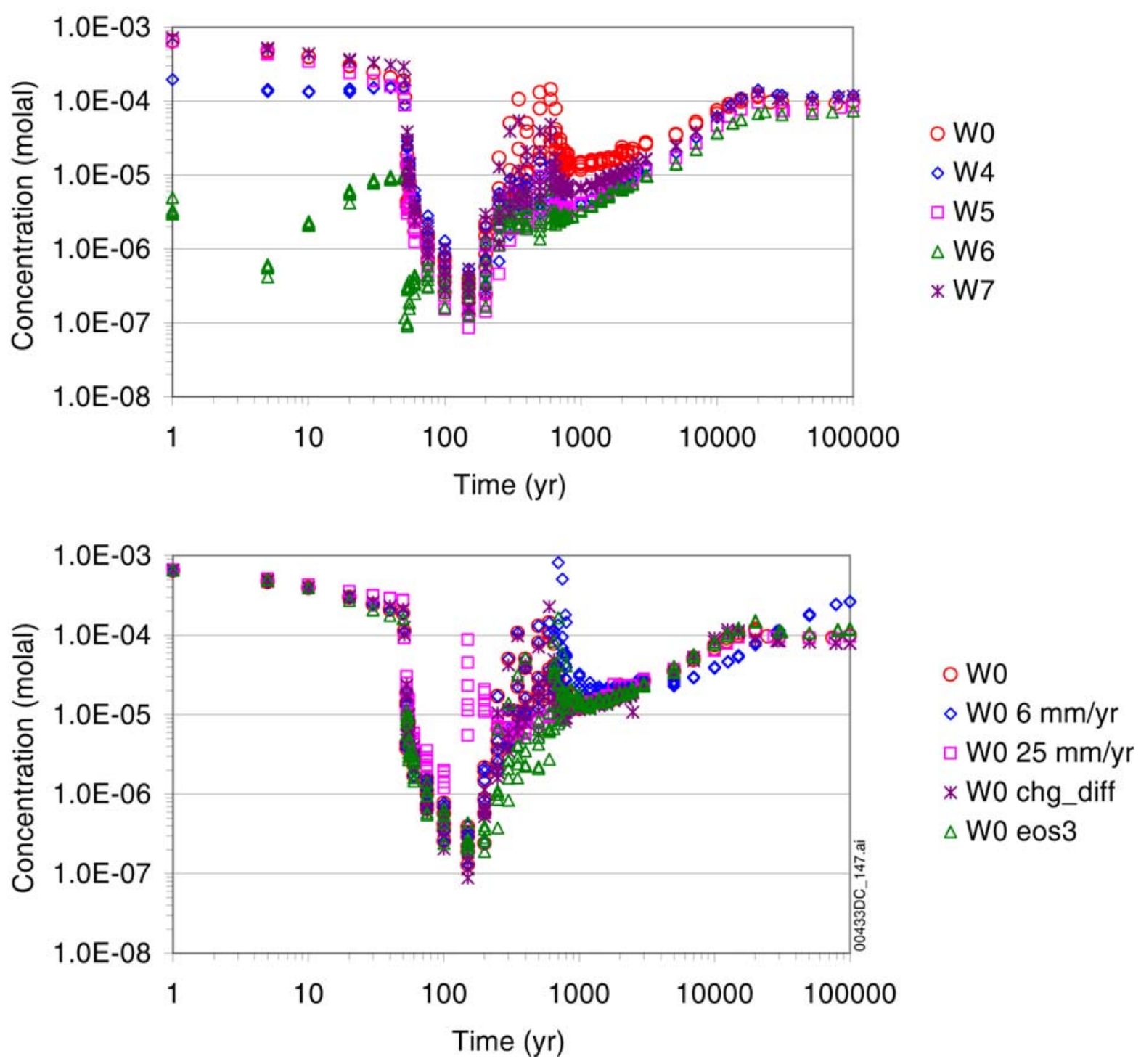

Output DTNs: LB0302DSCPTHCS.002, LB0307DSTTHCR2.002.

NOTE: Grid blocks are those with highest liquid saturation in fractures within a 25-m radius from drift center and a $45^{\circ}$ arc from the drift crown. Data are shown in the top graph for simulations using different initial water compositions (W0 - W7). Except as noted below, all simulations are run using a stepwise-increasing infiltration rate $(6,16$, and $25 \mathrm{~mm} / \mathrm{yr})$ and with vapor pressure lowering. Alternatives using Water $\mathrm{W} 0$ are shown in the bottom graph, including simulations without vapor pressure lowering (W0 - eos 3 ), with the smaller $\mathrm{CO}_{2}$ diffusion coefficient (Section 6.5.3), and with fixed 25 and $6 \mathrm{~mm} / \mathrm{yr}$ infiltration rates (WO $-6 \mathrm{~mm} / \mathrm{yr}$ and $\mathrm{W} 0-25 \mathrm{~mm} / \mathrm{yr}$, respectively).

Figure 6.5-35. THC Seepage Model (Tptpll): Time Profiles of Modeled Total Aqueous Magnesium Concentrations in Fracture Water in Areas of Highest Liquid Saturation above the Drift Crown 


\section{$\mathrm{SiO}_{2}$ - Fractures}
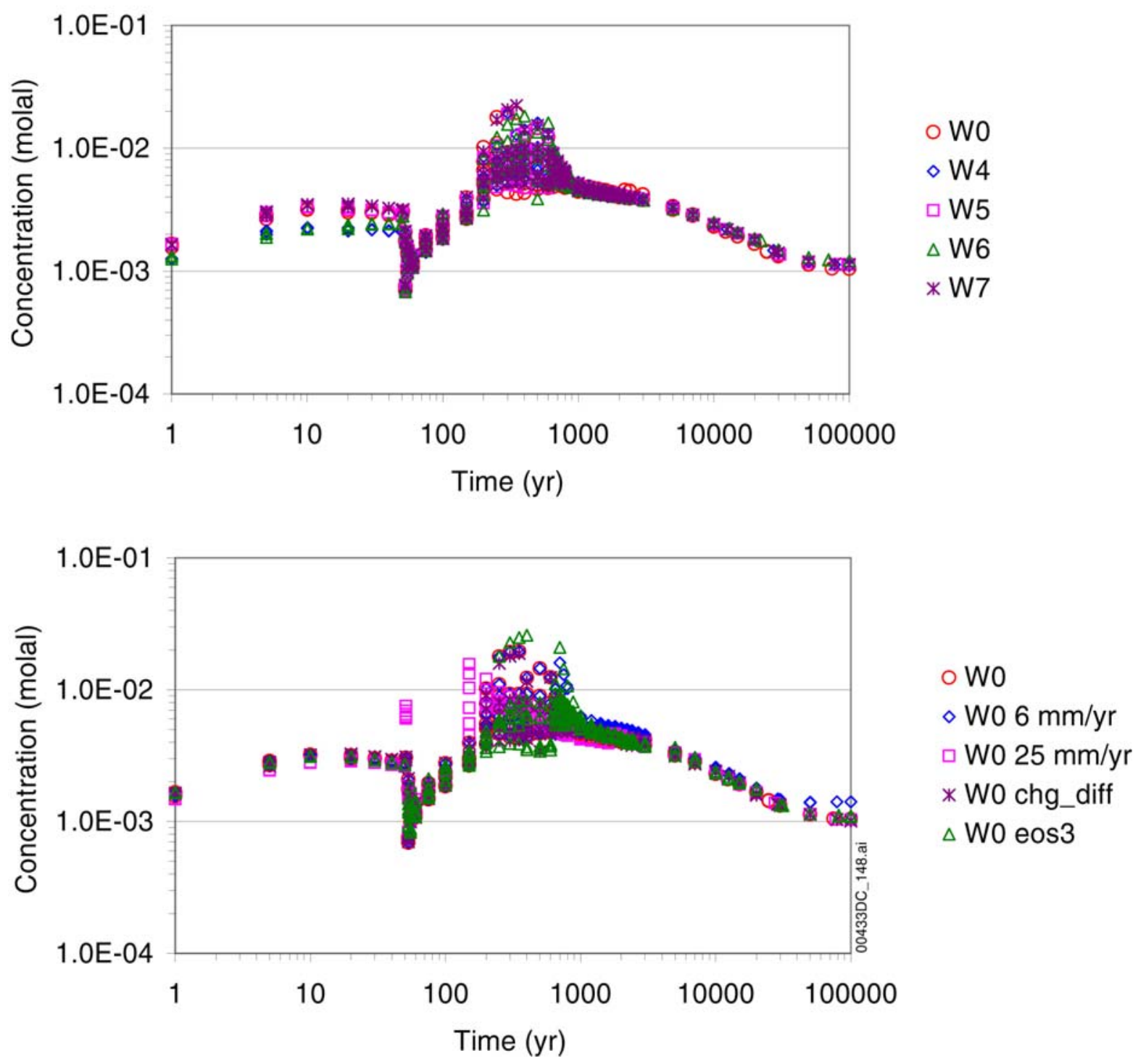

Output DTNs: LB0302DSCPTHCS.002, LB0307DSTTHCR2.002.

NOTE: Grid blocks are those with highest liquid saturation in fractures within a 25-m radius from drift center and a $45^{\circ}$ arc from the drift crown. Data are shown in the top graph for simulations using different initial water compositions (W0 - W7). Except as noted below, all simulations are run using a stepwise-increasing infiltration rate $(6,16$, and $25 \mathrm{~mm} / \mathrm{yr})$ and with vapor pressure lowering. Alternatives using Water WO are shown in the bottom graph, including simulations without vapor pressure lowering (W0 - eos 3 ), with the smaller $\mathrm{CO}_{2}$ diffusion coefficient (Section 6.5.3), and with fixed 25 and $6 \mathrm{~mm} / \mathrm{yr}$ infiltration rates (W0 $-6 \mathrm{~mm} / \mathrm{yr}$ and $\mathrm{W} 0-25 \mathrm{~mm} / \mathrm{yr}$, respectively).

Figure 6.5-36. THC Seepage Model (Tptpll): Time Profiles of Modeled Total Aqueous Silica Concentrations in Fracture Water in Areas of Highest Liquid Saturation above the Drift Crown 


\section{F - Fractures}
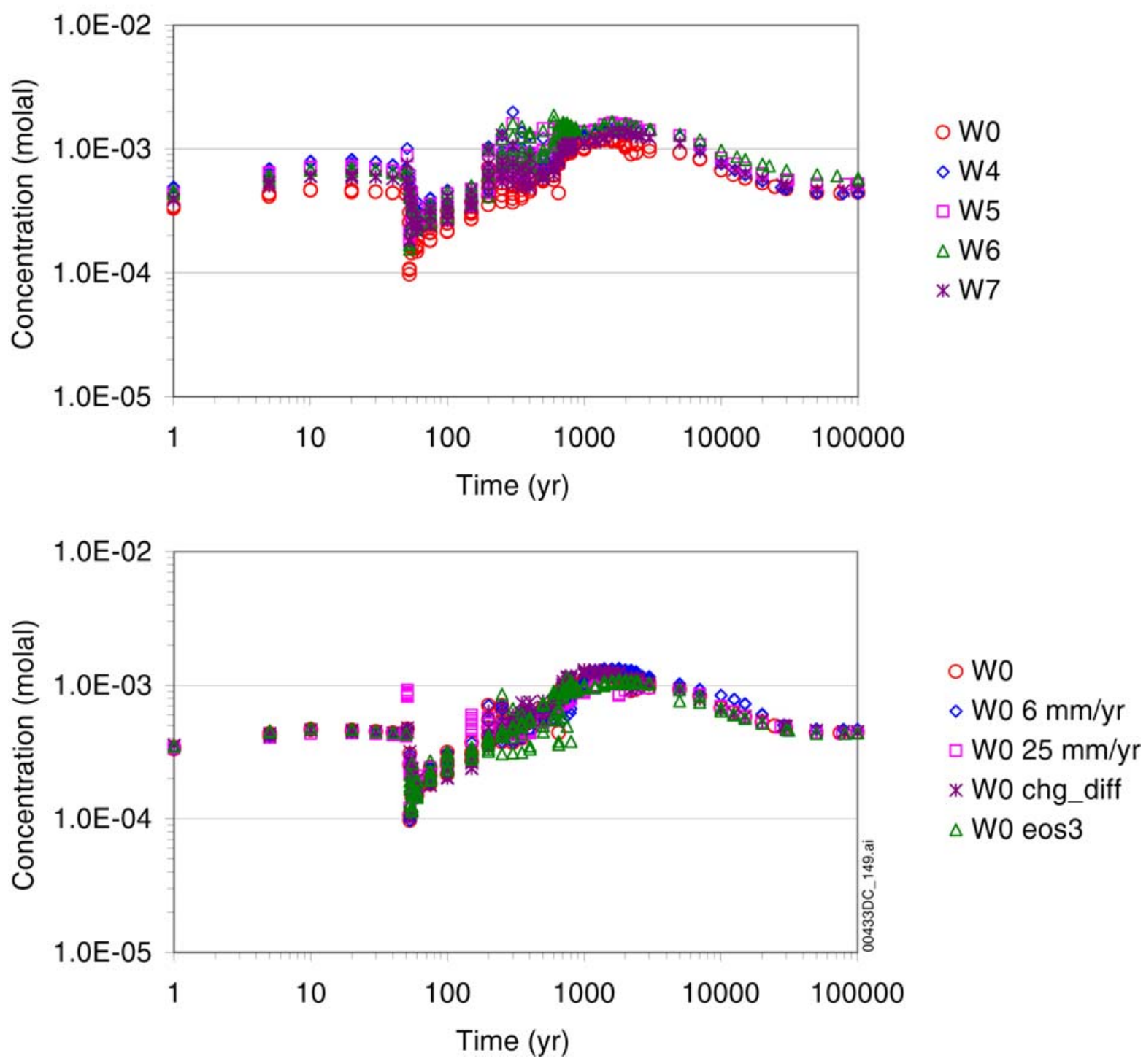

Output DTNs: LB0302DSCPTHCS.002, LB0307DSTTHCR2.002.

NOTE: Grid blocks are those with highest liquid saturation in fractures within a 25-m radius from drift center and a $45^{\circ}$ arc from the drift crown. Data are shown in the top graph for simulations using different initial water compositions (W0 - W7). Except as noted below, all simulations are run using a stepwise-increasing infiltration rate $(6,16$, and $25 \mathrm{~mm} / \mathrm{yr})$ and with vapor pressure lowering. Alternatives using Water W0 are shown in the bottom graph, including simulations without vapor pressure lowering (W0 - eos 3 ), with the smaller $\mathrm{CO}_{2}$ diffusion coefficient (Section 6.5.3), and with fixed 25 and $6 \mathrm{~mm} / \mathrm{yr}$ infiltration rates (W0 $-6 \mathrm{~mm} / \mathrm{yr}$ and $\mathrm{W} 0-25 \mathrm{~mm} / \mathrm{yr}$, respectively).

Figure 6.5-37. THC Seepage Model (Tptpll): Time Profiles of Modeled Total Aqueous Fluoride Concentrations in Fracture Water in Areas of Highest Liquid Saturation above the Drift Crown 


\subsubsection{Mineral Alteration and Porosity/Permeability Changes (Tptpll)}

The predicted effect of water-rock-gas interactions on flow patterns around the drift is much more noticeable in the current model revision than in previous revisions. This is because simulations, using TOUGHREACT V3.0 (LBNL 2002 [DIRS 161256]), make use of a better treatment of mineral precipitation at the boiling front than previously. Also, the fracture porosity used in the current model is approximately half the value that was used in the REV01 simulations.

To provide a baseline for evaluating the effect of mineral precipitation and dissolution on flow, results of a TH simulation are evaluated first. A contour plot of predicted liquid saturations for the simulation (Figure 6.5-38) shows that at 2,400 years, well after the end of the boiling phase, the predicted liquid saturations in the vicinity of the drift reflect the capillary barrier effect of the drift. Ambient water percolation is deflected around the drift (even at much higher infiltration rates than considered here). As a result, liquid saturations in fractures are somewhat increased above the drift crown, relative to ambient values, and significantly decreased below the drift ("shadow" zone).

In contrast, a similar contour map of liquid saturations predicted with Water W0 using a THC simulation (Figure 6.5-39a) shows that after the same simulated time period, a zone of higher liquid saturation has formed 7 to $8 \mathrm{~m}$ above the drift, reflecting partial deflection of flow at this location. This kind of "umbrella" effect results from a thin region of significantly lower permeability (Figure 6.5-39b) created by prior mineral deposition at the boiling front. In this case, the permeability has decreased by a factor of about 10 in this area. As a result, the shadow zone extends somewhat deeper below the drift, and liquid saturations at the drift crown are somewhat reduced, compared to the TH prediction. Similar figures for results using Water W5 as input initial composition show a more pronounced "umbrella" effect (Figure 6.5-40a), with the permeability decreasing by two to three orders of magnitude (Figure 6.5-40b) in the thin region of mineral precipitation. The results using the other waters are very similar. Consequently, the shadow zone below the drift is extended significantly. The time of fracture rewetting around the drift is delayed, and the vertical flux at the drift crown is reduced by up to a factor of 10 compared to the ambient flux without drift opening (Figure 6.5-41a).

Other THC simulations using Water W0 and the two fixed infiltration rates ( 6 and $25 \mathrm{~mm} / \mathrm{yr}$ ), as well as the simulation neglecting water-vapor-pressure lowering, also predict to various degrees an umbrella effect above the drift (Figure 6.5-41b). The effect is most noticeable with the simulation without vapor-pressure lowering, which predicts that the rewetting of fractures at the drift crown is delayed until approximately 20,000 years and around 12,000 years in the matrix. However, in this case, this stronger effect could be unrealistic because some amount of water-vapor-pressure lowering is expected to occur in the natural system. By retaining more water in the matrix, fracture rewetting would be facilitated, because less imbibition of fracture water would occur into the matrix.

The vertical flux predicted at the drift crown at 2,000 years (Figure 6.5-41a or b), without considering THC processes, can be compared with the vertical flux value shown in Drift-Scale Coupled Processes (DST and TH Seepage) Models (BSC 2004 [DIRS 170338], Figure 6.2.3.1-3) for the same time period. Both values are consistent $\left(2.9 \times 10^{-7} \mathrm{~kg} \mathrm{~m}^{-2} \mathrm{~s}^{-1}\right.$, which yields 
approximately $9.5 \mathrm{~mm} / \mathrm{yr}$ using the water density at the corresponding temperature [960 $\mathrm{kg}$ $\left.\left.\mathrm{m}^{-3}\right]\right)$. The flux peak on Figure 6.5-41 (a or b) at 1,400 years $\left(1.07 \times 10^{-6} \mathrm{~kg} \mathrm{~m}^{-2} \mathrm{~s}^{-1}\right)$ corresponds to approximately $35 \mathrm{~mm} / \mathrm{yr}$, consistent with values predicted a few meters above the drift at 1,000 years in Drift-Scale Coupled Processes (DST and TH Seepage) Models (BSC 2004 [DIRS 170338], Figure 6.2.3.1-3). As already mentioned in Sections 6.5.5.1 and 6.5.5.2, these peaks may not be fully resolved. However, these are much smaller than the percolation rate required for seepage to occur $(250 \mathrm{~mm} / \mathrm{yr}$ in Drift-Scale Coupled Processes (DST and TH Seepage) Models [BSC 2004 DIRS 170338], Section 6.2.3.2.3). When THC processes are taken into account, as discussed earlier, percolation rates at the drift crown are even smaller because percolating water is partly diverted by the zone of lower permeability created by mineral precipitation above the drift. However, the model considers homogeneous fracture permeability and, therefore, cannot capture potential flow focusing through this zone of lower permeability. Because this zone is very thin and located several meters above the drift crown (Figure 6.5-40b), the focusing of flow locally through this zone is not anticipated to increase vertical fluxes at the drift crown much beyond what is predicted without considering THC processes.

In all simulations, the permeability decrease results primarily from the precipitation of amorphous silica and, to a lesser extent, calcite (Figures 6.5-42 through 6.5-45). The fracture porosity is predicted to decrease by approximately 4 to 7 percent, depending on the simulation. The maximum porosity decrease is predicted to occur in a thin zone during refluxing at the edge of the dryout zone, before the collapse of this zone around the drift. During that time, salt and gypsum precipitation account for up to around 15 percent of the volume of precipitated minerals (Figure 6.5-44). Gypsum precipitation is noticeable only with Waters W0 and W7, as expected, because these waters initially contain a higher proportion of calcium. Both salts and gypsum quickly redissolve when the fractures rewet. By 2,400 years, with all simulations except that without vapor-pressure lowering, fractures have rewetted, and the amount of precipitated solids (Figure 6.5-45) is predicted to remain essentially unchanged for the remainder of the entire simulated time period. For a long period of time in the simulation without vapor-pressure lowering, any water entering fractures immediately evaporates. This causes further salt deposition until well after 2,400 years, most notably directly above the drift crown (Figure 6.5-42), even though temperatures are well below boiling by this time. Increasing the infiltration rate from a fixed rate of 6 to $25 \mathrm{~mm} / \mathrm{yr}$ does not significantly alter the amount of precipitated solids, but shifts the region of mineral deposition towards the drift by approximately $1 \mathrm{~m}$ (Figure 6.5-43).

Other minerals besides amorphous silica, calcite, gypsum, and salts form or dissolve in small amounts. Some albite dissolution accompanied by stellerite precipitation is predicted to occur in fractures (typically 0.1 percent of the porosity or less). Illite and stellerite are predicted to be the most significant minerals precipitating in the rock matrix, with maximum amounts around 1 percent of the matrix porosity. 


\section{Tptpll Fractures - 2,400 Years (TH)}

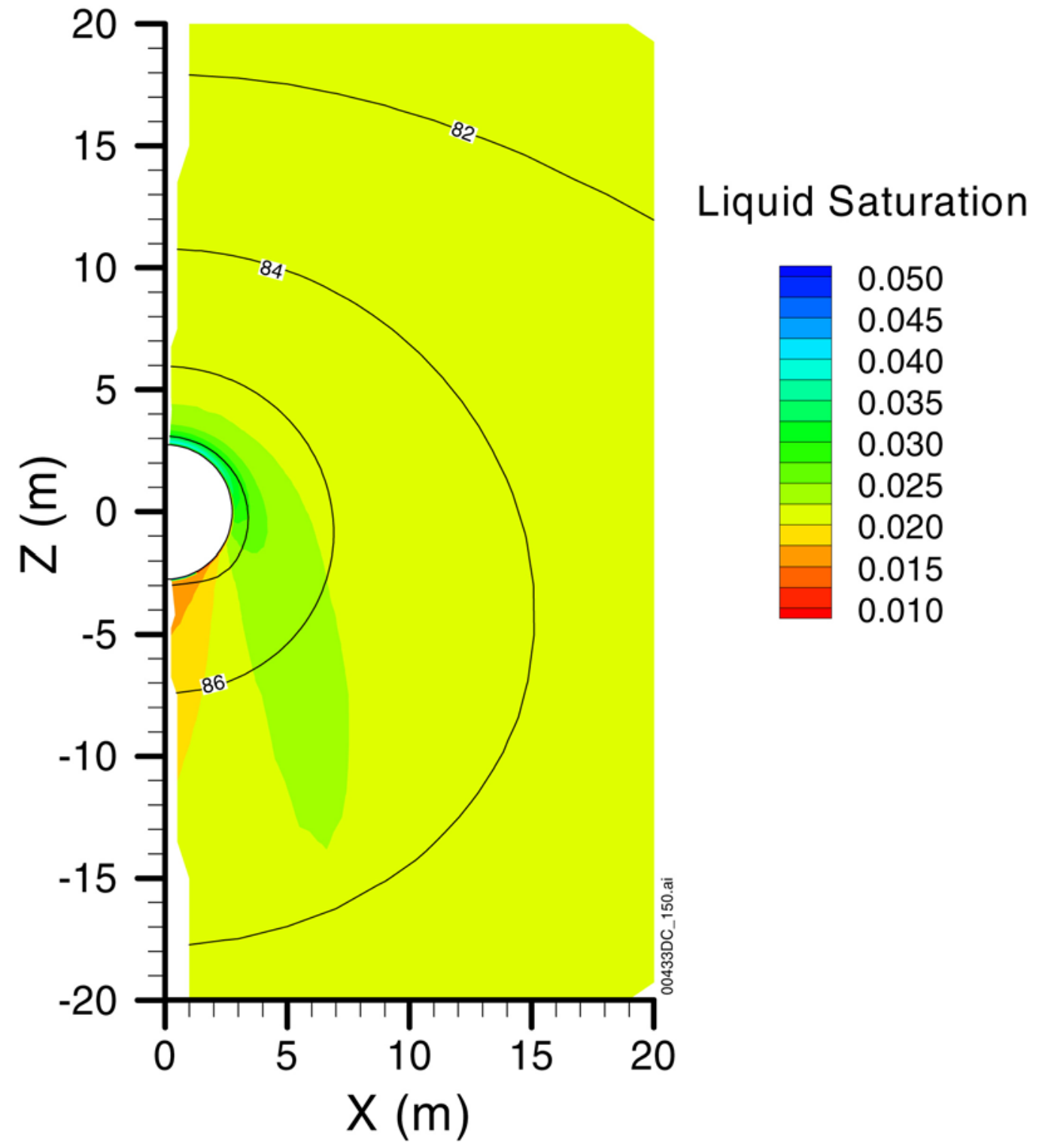

Output DTN: LB0307DSTTHCR2.001.

Figure 6.5-38. TH Simulation (Tptpll): Contour Plot of Modeled Liquid Saturation and Temperature Contours $\left({ }^{\circ} \mathrm{C}\right)$ in Fractures at 2,400 Years (No Chemical Reactions) 
Tptpll Fractures - 2,400 Years (W0)

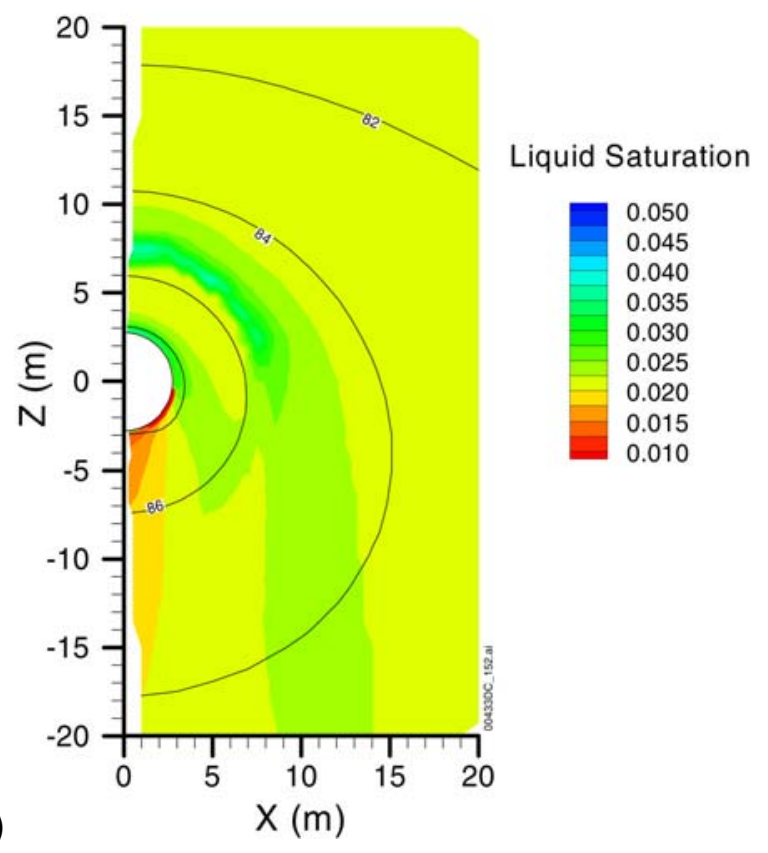

(a)

Tptpll Fractures - 2,400 Years (W0)

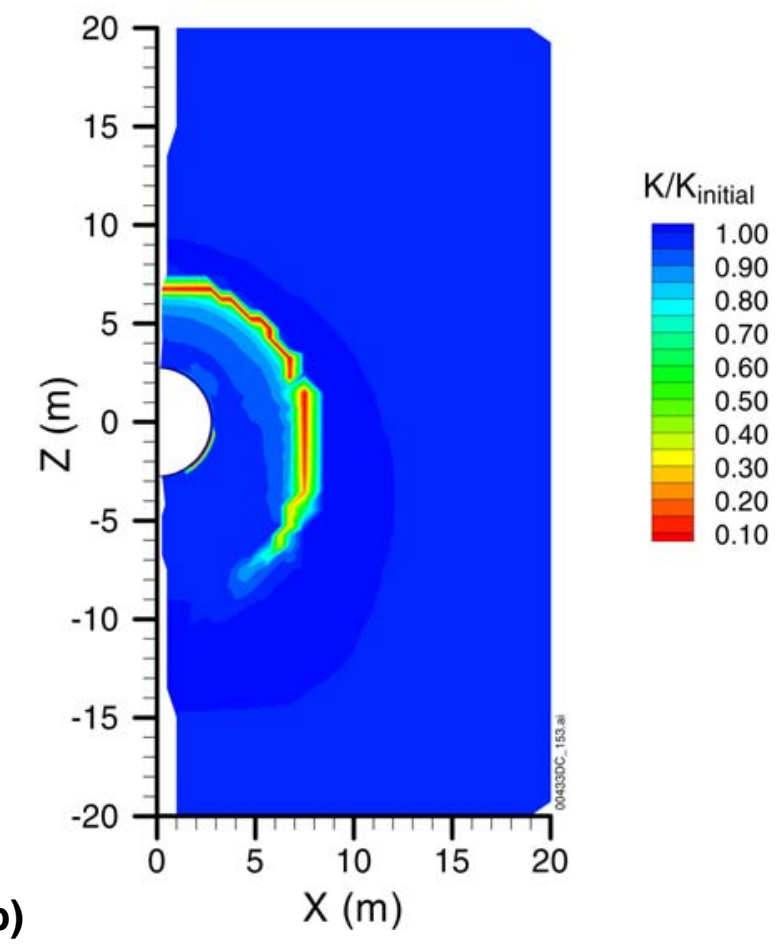

Output DTN: LB0302DSCPTHCS.001.

Figure 6.5-39. THC Simulation (Tptpll - Water W0): Contour Plot of Modeled (a) Liquid Saturation and Temperature Contours $\left({ }^{\circ} \mathrm{C}\right)$ and (b) Permeability Change in Fractures at 2,400 Years 
Tptpll Fractures - 2,400 Years (W5)

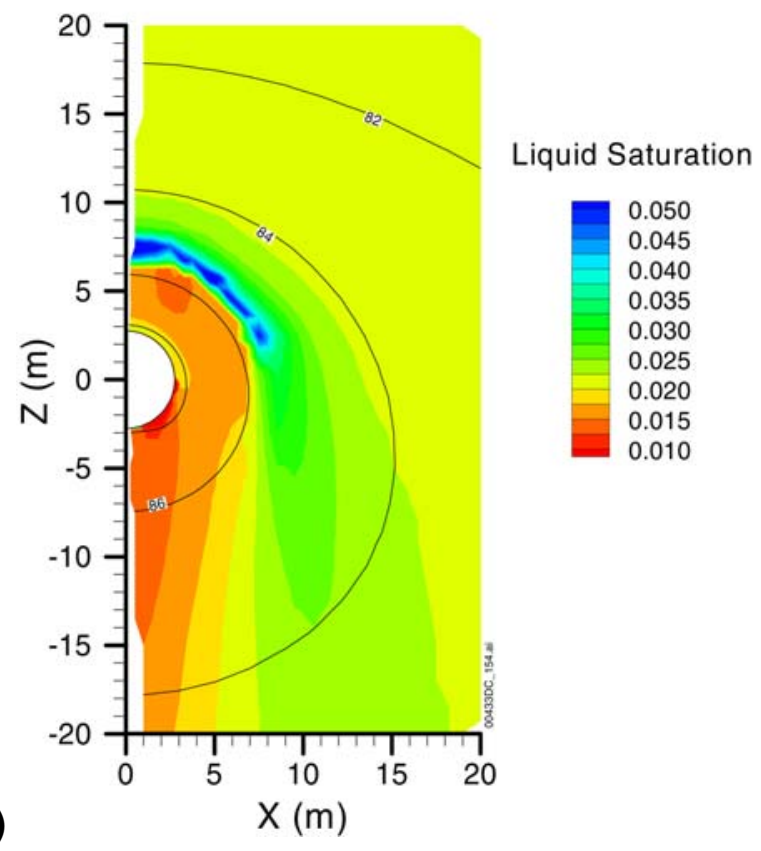

(a)

Tptpll Fractures - 2,400 Years (W5)

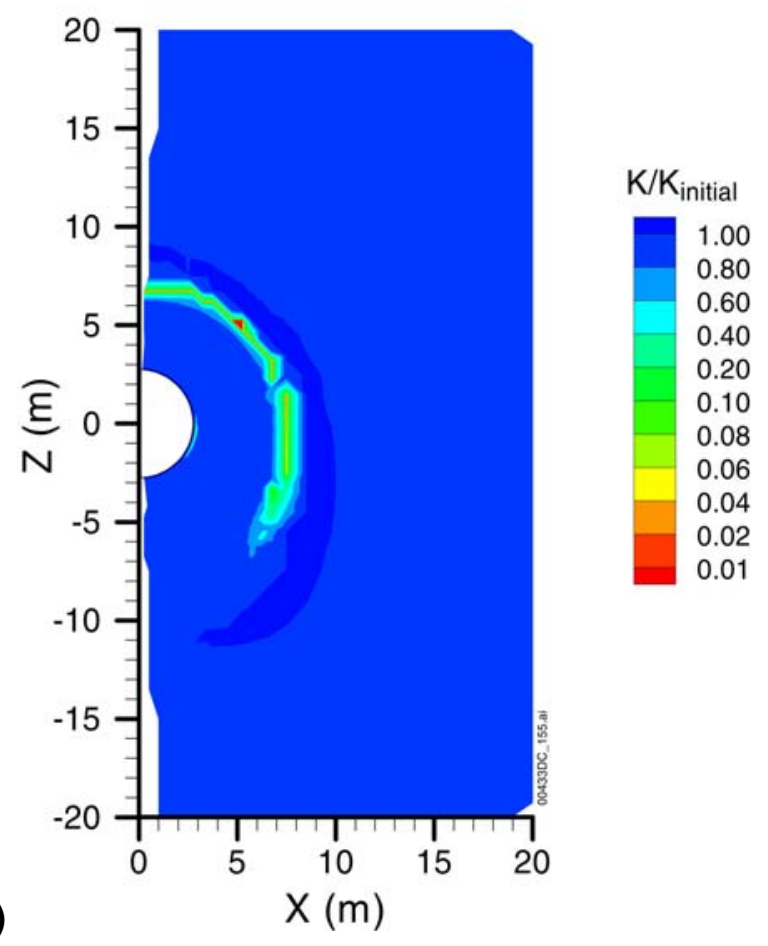

Output DTN: LB0302DSCPTHCS.001.

Figure 6.5-40. THC Simulation (Tptpll - Water W5): Contour Plot of Modeled (a) Liquid Saturation and Temperature Contours $\left({ }^{\circ} \mathrm{C}\right)$ and (b) Permeability Change in Fractures at 2,400 Years 


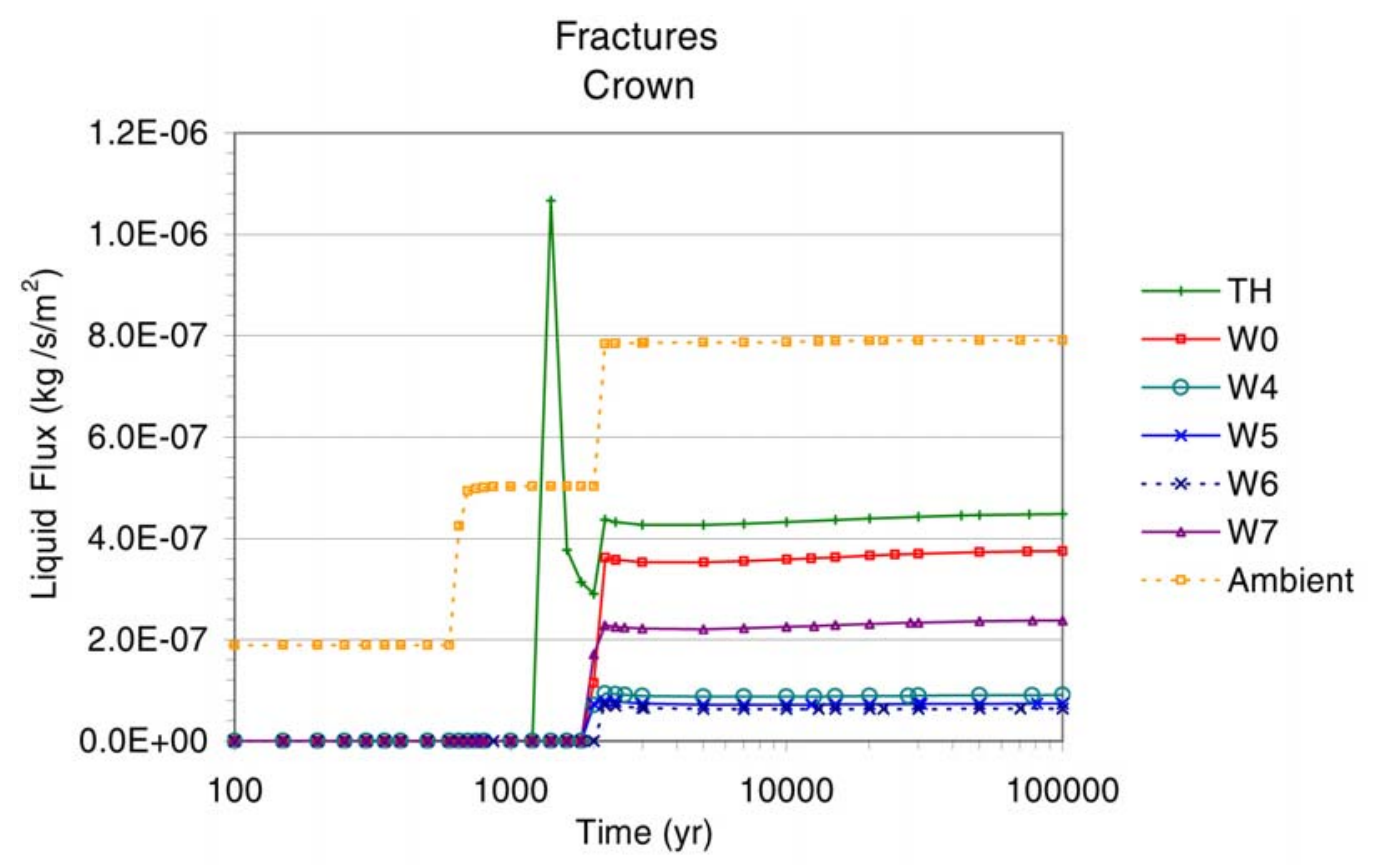

Fractures

Crown

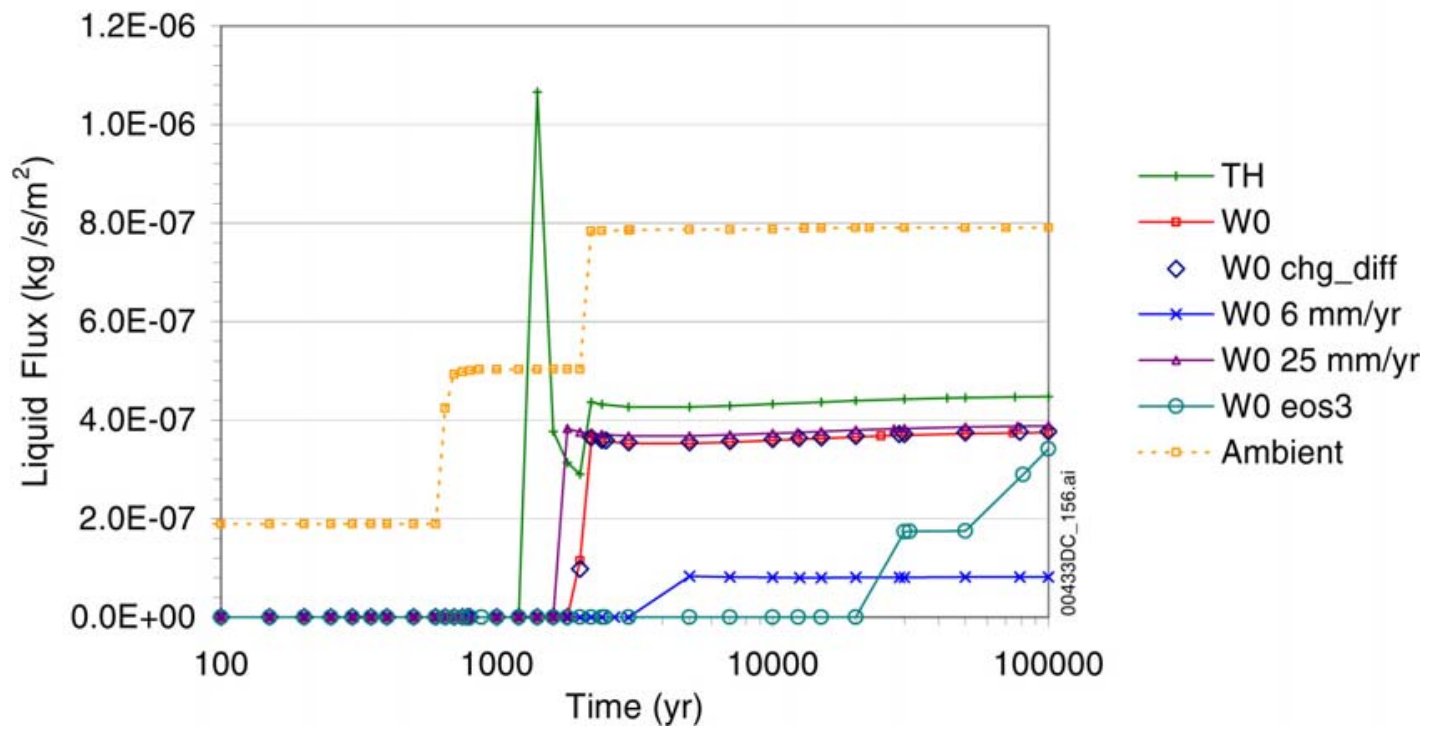

Output DTNs: LB0302DSCPTHCS.002, LB0307DSTTHCR2.002.

NOTE: Except as noted below, simulations consider vapor-pressure lowering and a stepwise-increasing infiltration rate (Table 6.5-2). Results are shown for various thermal loading simulations including: no chemical reactions (TH), five different input water compositions (W0, W4 to W7), no vapor pressure lowering (W0 - eos3), and two fixed infiltration rates (W0 $-6 \mathrm{~mm} / \mathrm{yr}$ and $\mathrm{W} 0-25 \mathrm{~mm} / \mathrm{yr}$ ). Predicted fluxes are also shown for ambient conditions (Ambient) without thermal load or a drift opening.

Figure 6.5-41. TH Simulations and THC Seepage Model (Tptpll): Comparison of Modeled Liquid Flux at the Drift Crown in Fractures at 2,400 Years 

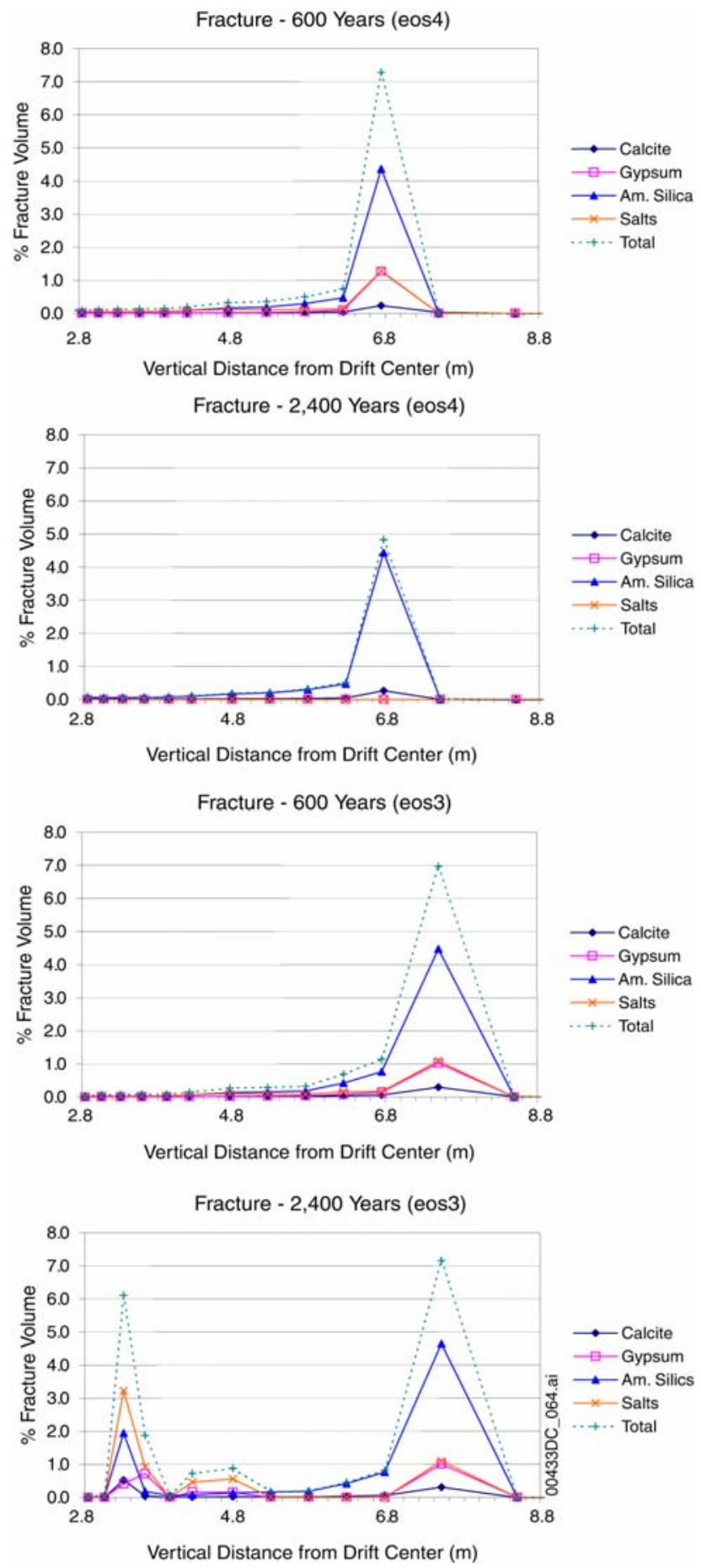

Output DTNs: LB0302DSCPTHCS.001, LB0307DSTTHCR2.001.

NOTE: Profiles are shown for simulated times of 600 and 2,400 years for simulations using Water W0 with vapor-pressure lowering (eos4) and without this effect (eos 3 ). Infiltration rates are increasing from 6 to 16 to $25 \mathrm{~mm} / \mathrm{yr}$ in a stepwise manner (Table 6.5-3).

Figure 6.5-42. THC Seepage Model (Tptpll): Vertical Profile of Predicted Mineral Abundances above the Drift Crown 

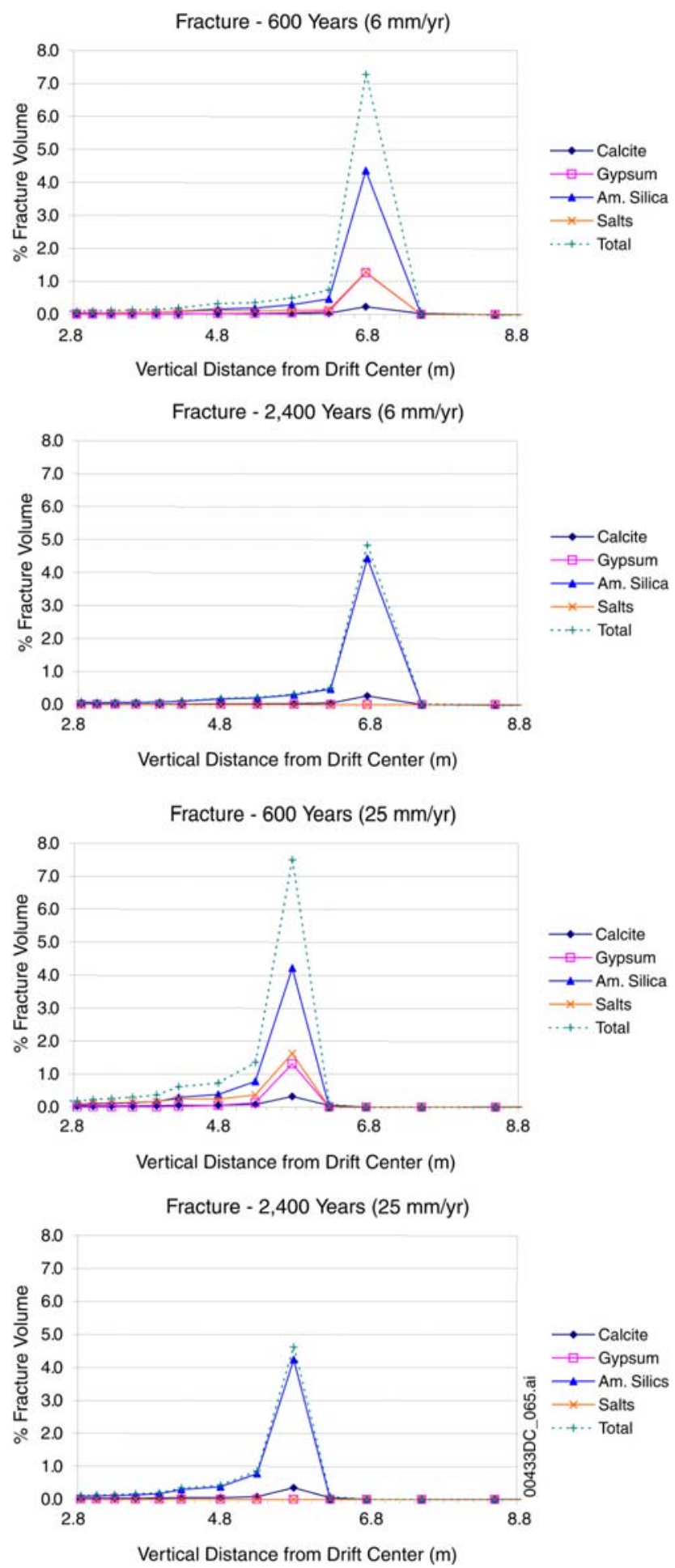

Output DTNs: LB0302DSCPTHCS.001, LB0307DSTTHCR2.001.

NOTE: Profiles are shown for simulated times of 600 and 2,400 years for simulations using Water W0 with vapor-pressure lowering and two different fixed infiltration rates (6 and $25 \mathrm{~mm} / \mathrm{yr})$.

Figure 6.5-43. THC Seepage Model (Tptpll): Vertical Profile of Predicted Mineral Abundances above the Drift Crown 

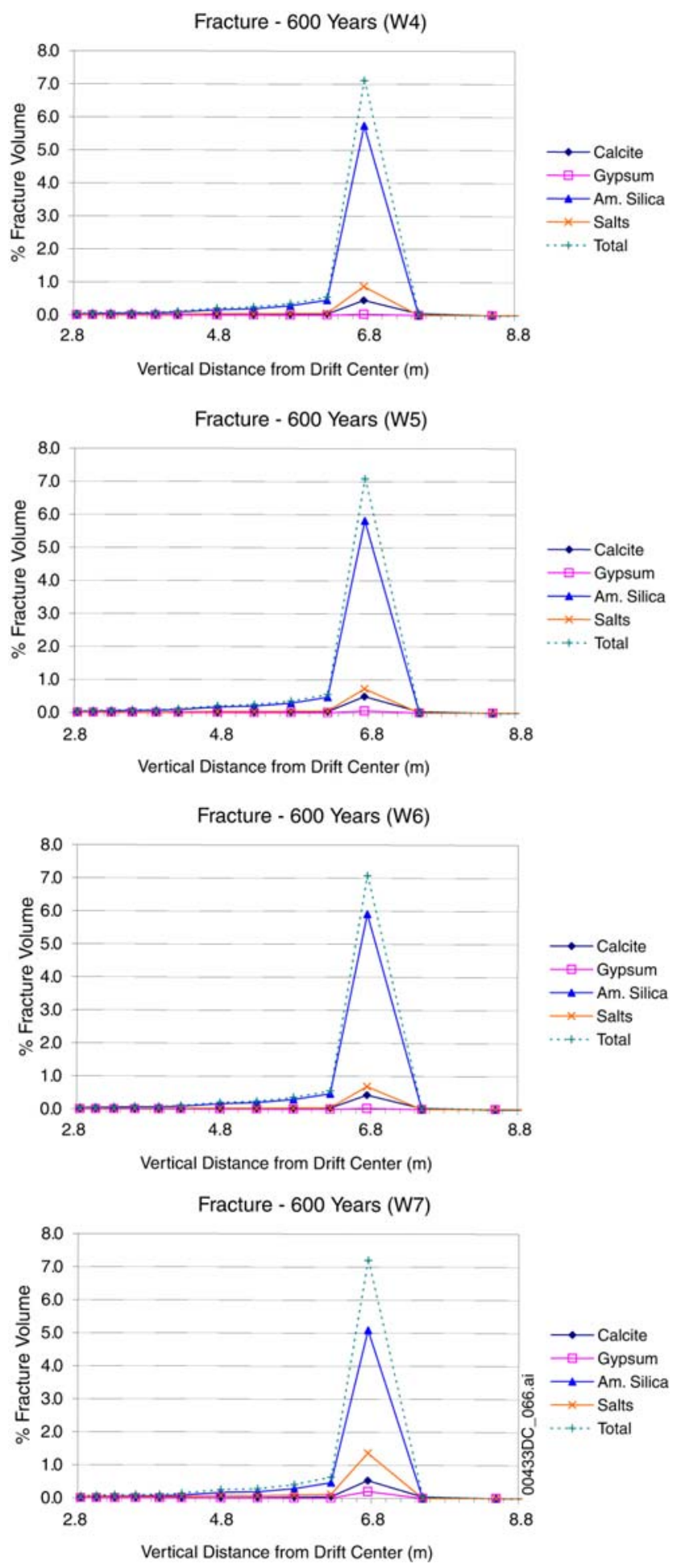

Output DTNs: LB0302DSCPTHCS.001, LB0307DSTTHCR2.001.

NOTE: Profiles are shown for a simulated time of 600 years, for simulations using vapor-pressure lowering and four different input water compositions (W4 to W7).

Figure 6.5-44. THC Seepage Model (Tptpll): Vertical Profile of Predicted Mineral Abundances above the Drift Crown 

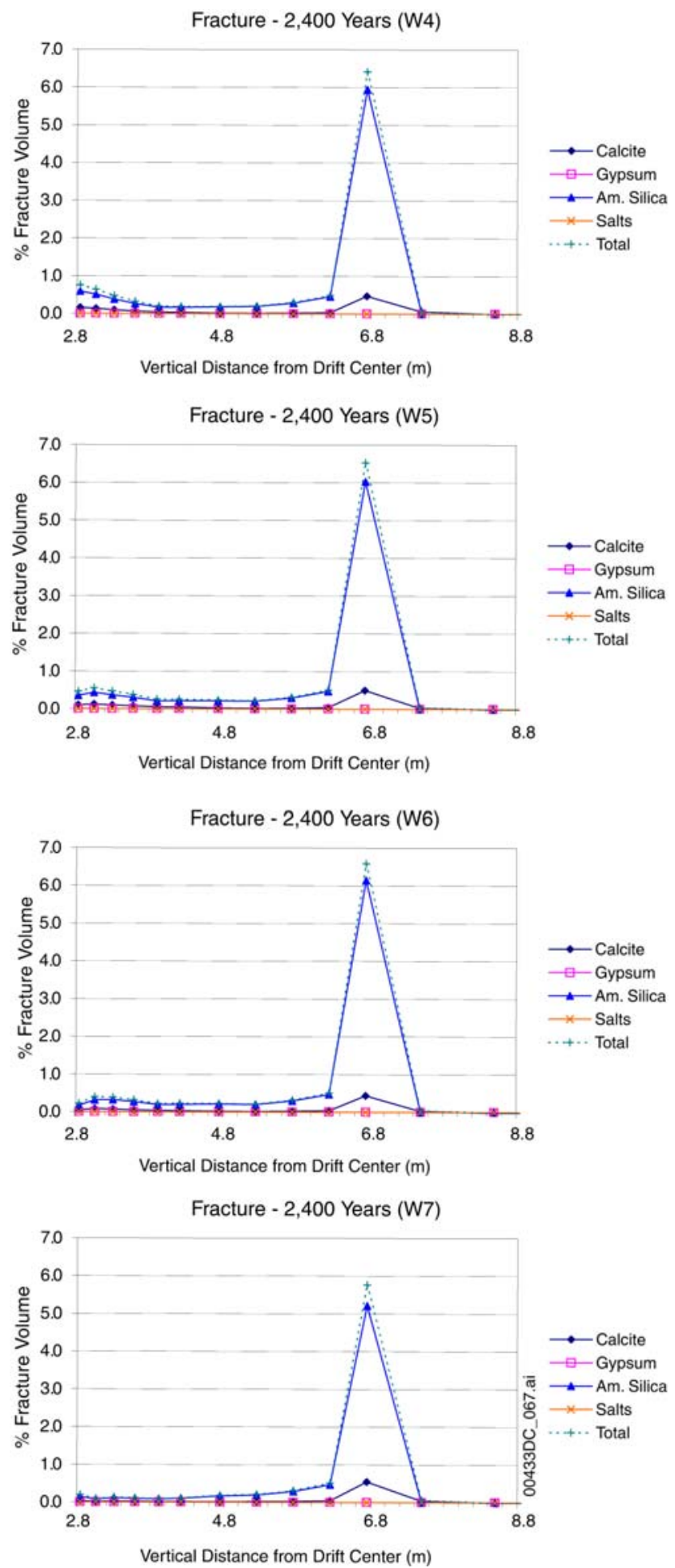

Output DTNs: LB0302DSCPTHCS.001, LB0307DSTTHCR2.001.

NOTE: Profiles are shown for a simulated time of 2,400 years for simulations using vapor-pressure lowering and four different input water compositions (W4 to W7). These profiles remain essentially unchanged for the rest of the simulated time period (100,000 years).

Figure 6.5-45. THC Seepage Model (Tptpll): Vertical Profile of Predicted Mineral Abundances above the Drift Crown 


\subsubsection{Simulations of Ambient Conditions (Thermodynamic Data Sensitivity)}

Results of simulations of ambient conditions are presented below to illustrate the model sensitivity to thermodynamic data and to justify the selection of the thermodynamic data used in this study (Appendix C and Section 4.1.4). These simulations are run with the three thermodynamic data sets discussed in Section 6.4.8: Set 1 representing the data adopted for this study, and Set 2 and Set 3 representing alternatives (mostly data from the YMP database data0.com.R2) that were considered, but not chosen for reasons given below. These simulations are run with the HD-PERM input water composition (Table 6.2-1). For consistency between all runs, the total aluminum concentration of the initial water in runs using all data sets has been recomputed for equilibrium with the illite phase from these alternative thermodynamic data sets.

Predicted ambient water composition trends with the three sets of thermodynamic data are shown in Figures 6.5-46 through 6.5-48. Set 2 leads to the least stable predicted compositions, including unrealistic $\mathrm{pH}$ fluctuations to near 10, very large depletion of calcium and magnesium, and an increase in sodium concentrations to around $500 \mathrm{mg} / \mathrm{L}$ after 100,000 years. On the other hand, the simulation with Set 1 predicts the most stable trends. Using Set 3 (i.e., by incorporating revised zeolite thermodynamic data into Set 2), trend stability improves considerably, but the magnitude of concentration changes over the 100,000-year simulated time period is still quite large for most species. With all three thermodynamic data sets, unrealistic magnesium depletion in water is predicted to occur, primarily on account of sepiolite precipitation. However, the least predicted magnesium depletion occurs when using Set 1 . Note also that simulations using Set 2 and Set 3 predict the total dissolution of calcite initially present in the model (with precipitation of zeolites and clays having calcium). Using Set 1, calcite dissolution is not predicted. For these reasons, Set 1 is deemed a better alternative than either Set 2 or Set 3, because it yields long-term water compositions more consistent with observed data than the other two sets. For these reasons, Set 1 has been adopted for the rest of this study. It should be recalled here that most of these thermodynamic data are from the YMP database data0.com.R2, with changes from this database documented under DTN: LB0307THMBDRTM.001 [DIRS 164434] (and summarized in Section 4.1.4 for major changes).

These simulations illustrate that for any fixed water composition close to equilibrium with a mineral assemblage, a small change in thermodynamic data can reverse the calculated degree of saturation (i.e., from supersaturation to undersaturation and vice versa) of minerals in that water and, thus, reverse the calculated direction of reactions between these phases. In such instances, different water-composition trends can be predicted regardless of the magnitude of reaction rates assumed in the model. In such cases, the reliability of model results can be more affected by thermodynamic data than by kinetic data.

Free energies for minerals such as clays and zeolites may never be known so accurately that adjustments within the (sometimes already small) uncertainty in these values will not be necessary for ambient simulations lasting thousands of years. Whether these adjustments provide values that are better, or not, than the data0.ymp.R2 data depends on the data themselves and their intended use. For clay minerals, because the adjustments have been made to better match measured water compositions at Yucca Mountain, these adjustments may in part compensate for other effects not directly modeled such as more complex solid solutions or ion 
exchange processes. Therefore, the thermodynamic data for clays and zeolites that are used in this model may not be "better" than those in the data0.ymp.R2 database, but are better suited for long-term reactive transport simulations at Yucca Mountain.
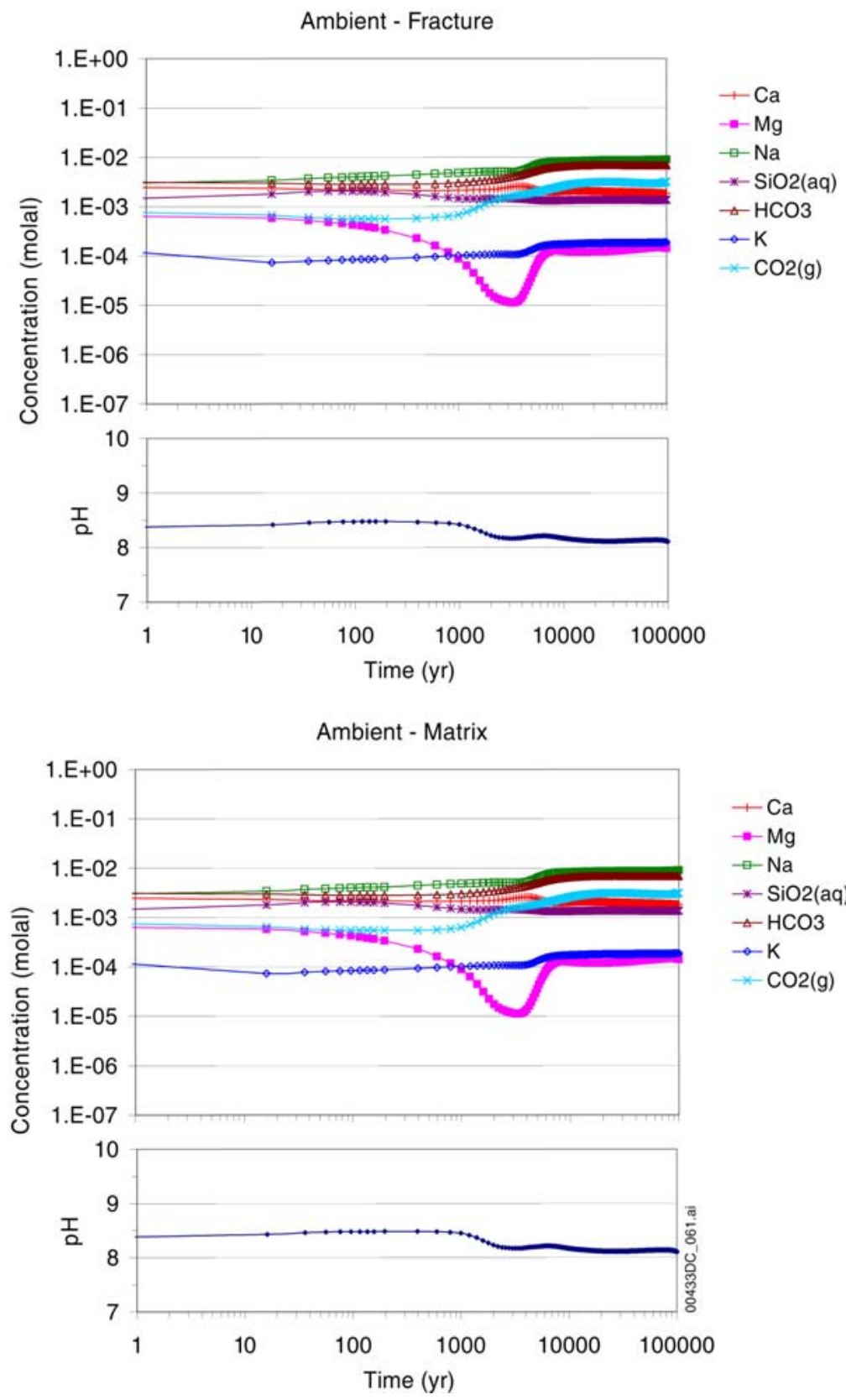

Output DTN: LB0307DSTTHCR2.001.

NOTE: Infiltration is constant at $6 \mathrm{~mm} / \mathrm{yr}$.

Figure 6.5-46. Predicted Water Compositions without Thermal Loading (in the Tptpll Lithostratigraphic Unit at the Repository Location) Using the Thermodynamic Data Adopted for this Study (Data Set 1 - Appendix C) 

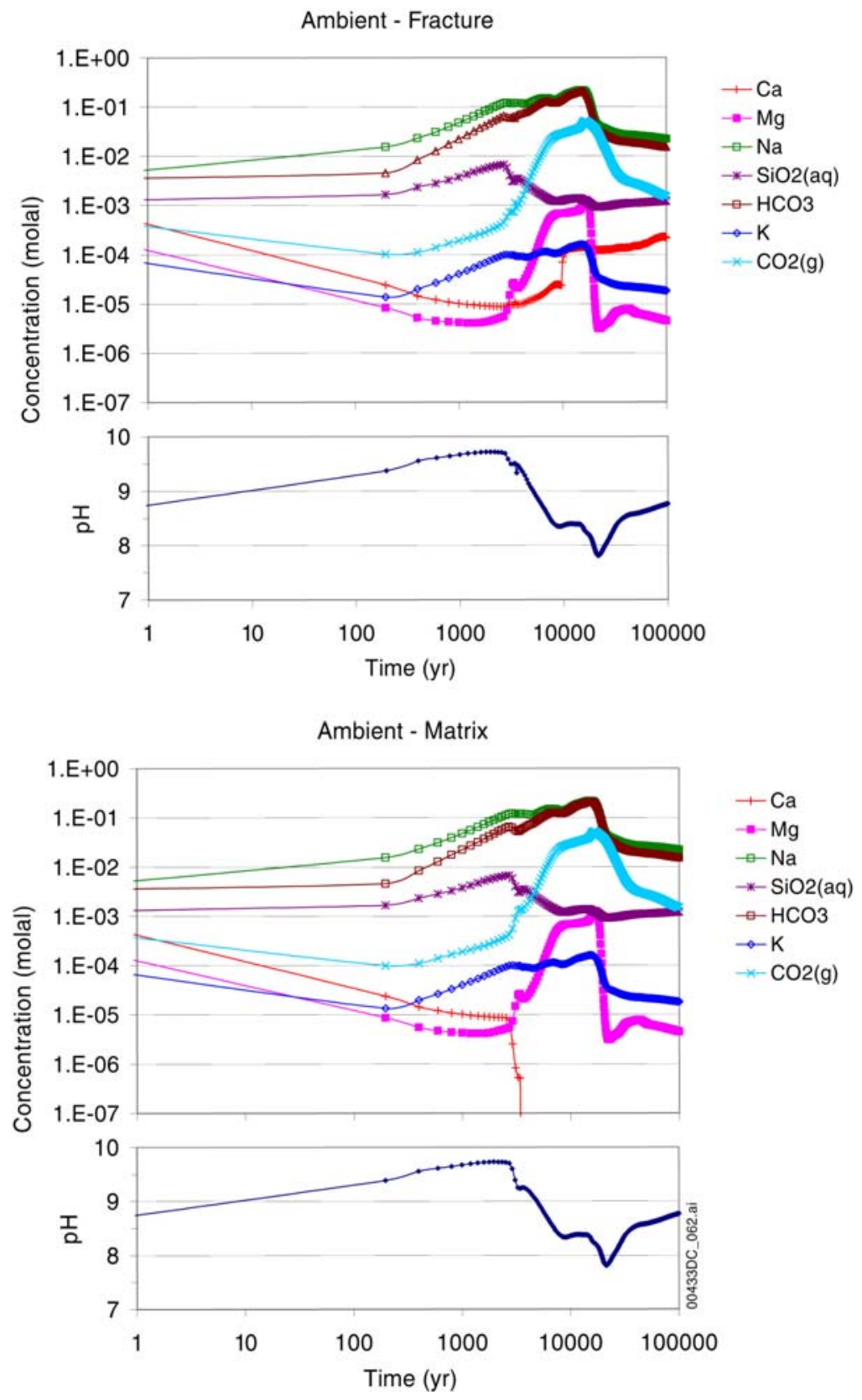

Output DTN: LB0307DSTTHCR2.001.

NOTE: Infiltration is constant at $6 \mathrm{~mm} / \mathrm{yr}$.

Figure 6.5-47. Predicted Water Compositions without Thermal Loading (in the Tptpll Lithostratigraphic Unit at the Repository Location) Using Thermodynamic Data from Data Set 2 (Section 6.4.8) 

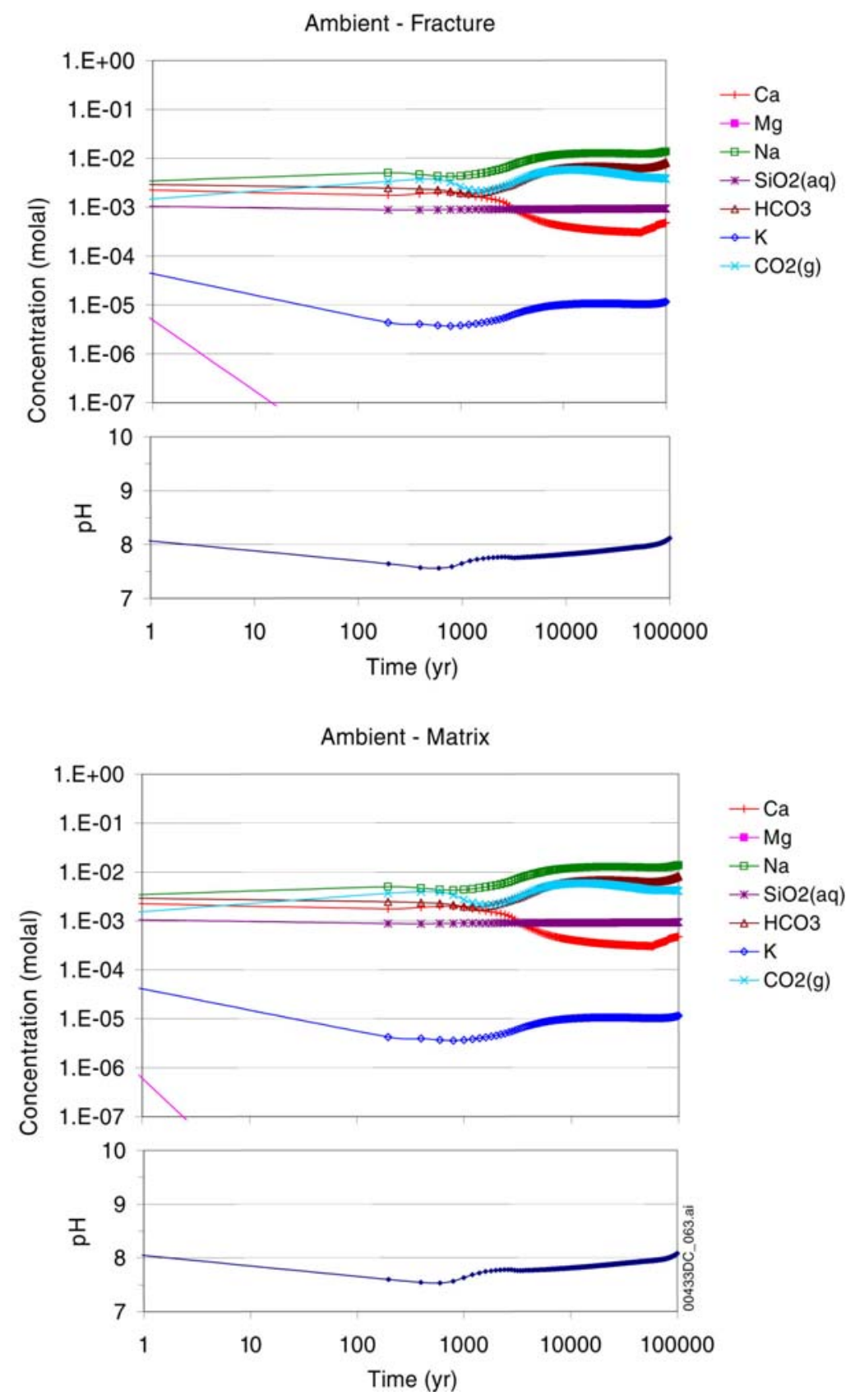

Output DTN: LB0307DSTTHCR2.001.

NOTE: Infiltration is constant at $6 \mathrm{~mm} / \mathrm{yr}$.

Figure 6.5-48. Predicted Water Compositions without Thermal Loading (in the Tptpll Lithostratigraphic Unit at the Repository Location) Using Thermodynamic Data from Data Set 3 (Section 6.4.8) 


\subsubsection{Sensitivity to Revised Matrix Porosity and Thermal Values}

After the simulations presented earlier in this section were run, revised porosity and thermal property data for the various stratigraphic layers in the UZ at Yucca Mountain became available. The potential impact of the new parameter values (DTN: LB0402THRMLPRP.001 [DIRS 168481]) has been evaluated through sensitivity analyses. Simulations th6_1.45kw, thc6_w0, and thc6_w0b (Table 6.5-5) have been rerun using the revised properties but kept all other input data (Section 6.5.3) unchanged. These additional model runs are summarized in Table 6.5-6.

Table 6.5-6. Tptpll THC Model Sensitivity Runs Using Revised Matrix Properties from Table 6.5-7

\begin{tabular}{|c|c|l|l|l|l|}
\hline $\begin{array}{c}\text { Input Water } \\
\text { Composition } \\
\text { (Table 6.2.1) }\end{array}$ & $\begin{array}{c}\text { Thermo. Data } \\
\text { Set } \\
\text { (Section 6.4.8) }\end{array}$ & $\begin{array}{c}\text { Infiltration Case } \\
\text { (Table 6.5-2) }\end{array}$ & $\begin{array}{c}\text { Equation of State } \\
\text { (EOS) Module }\end{array}$ & \multicolumn{1}{|c|}{ Simulation Type } & \multicolumn{1}{c|}{ Run ID } \\
\hline None & None & Mean Infiltration & EOS4 & TH (two-dimensional) & th6_1.45kw_i1 \\
\hline W0 & Set 1 & Mean Infiltration & EOS4 & THC (two-dimensional) & thc6_w0_i1 \\
\hline W0 & Set $1^{\mathrm{b}}$ & Mean Infiltration & EOS4 & THC (two-dimensional) & thc6_w0b \\
\hline
\end{tabular}

a TOUGHREACT V3.0 (LBNL 2002 [DIRS 161256]) flow modules: EOS3 neglects vapor pressure lowering due to capillary pressure; EOS4 takes this effect into account.

${ }^{b} \mathrm{~A} \mathrm{CO}_{2}$ molecular diameter of $2.5 \times 10^{-10} \mathrm{~m}$ (Section 4.1.6) is used for this run instead of the value of $1 \times 10^{-10} \mathrm{~m}$ input in the other THC simulation listed here (Section 6.5.3).

NOTE: Run ID's are used in Output DTNs: LB0404DSTTHCR2.001 and LB0404DSTTHCR2.002; see Appendix G.

The revisions to matrix porosity and thermal properties affected primarily hydrogeologic units other than the repository units (Table 6.5-7). The properties of the repository units are essentially unchanged (shaded data on Table 6.5-7).

The modeling procedure is unchanged from that described in Section 6.5.3. Prior to running the $\mathrm{TH}$ and THC simulations, because of the matrix properties revision, a simulation without heat load, drift, or reactive transport is run until steady-state thermal and hydrologic conditions are achieved. These conditions are then used as the initial thermal and hydrologic state for heat load simulations.

Comparisons of $\mathrm{TH}$ simulations results obtained using revised and original rock matrix properties are shown in Figures 6.5-49 through 6.5-53 (original and new simulations th6_1.45kw and th6_1.45kw_i1, respectively). 


\begin{tabular}{|c|c|c|c|c|c|c|c|c|c|c|}
\hline \multirow{3}{*}{$\begin{array}{c}\text { UZ Model } \\
\text { Layer }\end{array}$} & \multicolumn{2}{|c|}{ Matrix Porosity } & \multirow{2}{*}{\multicolumn{2}{|c|}{$\begin{array}{c}\text { Grain Density } \\
\left(\mathrm{kg} / \mathrm{m}^{3}\right) \\
\end{array}$}} & \multirow{2}{*}{\multicolumn{2}{|c|}{$\begin{array}{c}\text { Heat Capacity } \\
(\mathrm{J} / \mathrm{Kg}-\mathrm{K})\end{array}$}} & \multirow{2}{*}{\multicolumn{2}{|c|}{$\begin{array}{c}\text { Bulk Dry Conductivity } \\
(\mathrm{W} / \mathrm{m}-\mathrm{K})\end{array}$}} & \multirow{2}{*}{\multicolumn{2}{|c|}{$\begin{array}{c}\text { Bulk Wet Conductivity } \\
(\mathrm{W} / \mathrm{m}-\mathrm{K})\end{array}$}} \\
\hline & \multirow[b]{2}{*}{ Revised } & \multirow[b]{2}{*}{ Original } & & & & & & & & \\
\hline & & & Revised & Original & Revised & Original & Revised & Original & Revised & Original \\
\hline tcw11 & 0.119 & 0.118 & 2486 & 2514 & 985.0 & 985.0 & 1.30 & 1.30 & 1.81 & 1.80 \\
\hline tcw12 & 0.119 & 0.118 & 2486 & 2514 & 985.0 & 985.0 & 1.30 & 1.30 & 1.81 & 1.80 \\
\hline tcw13 & 0.211 & 0.0457 & 2385 & 2274 & 1040 & 1040 & 0.572 & 0.670 & 0.909 & 0.794 \\
\hline ptn21 & 0.385 & 0.354 & 2374 & 2288 & 1040 & 1040 & 0.490 & 0.489 & 1.06 & 1.07 \\
\hline ptn22 & 0.385 & 0.354 & 2374 & 2288 & 1040 & 1040 & 0.490 & 0.489 & 1.06 & 1.07 \\
\hline ptn23 & 0.385 & 0.354 & 2374 & 2288 & 1040 & 1040 & 0.490 & 0.489 & 1.06 & 1.07 \\
\hline ptn24 & 0.385 & 0.354 & 2374 & 2288 & 1040 & 1040 & 0.490 & 0.489 & 1.06 & 1.07 \\
\hline ptn25 & 0.385 & 0.354 & 2374 & 2288 & 1040 & 1040 & 0.490 & 0.489 & 1.06 & 1.07 \\
\hline ptn26 & 0.385 & 0.251 & 2374 & 2283 & 1040 & 1040 & 0.490 & 0.537 & 1.06 & 0.957 \\
\hline tsw31 & 0.0775 & 0.0457 & 2441 & 2274 & 1012 & 1040 & 0.900 & 0.670 & 1.11 & 0.794 \\
\hline tsw32 & 0.119 & 0.118 & 2486 & 2514 & 985.0 & 985.0 & 1.30 & 1.30 & 1.81 & 1.80 \\
\hline tsw33 & 0.143 & 0.143 & 2344 & 2358 & 985.0 & 985.0 & 1.16 & 1.16 & 1.68 & 1.68 \\
\hline tsw34 & 0.129 & 0.129 & 2466 & 2466 & 985.0 & 985.0 & 1.42 & 1.42 & 2.07 & 2.07 \\
\hline tsw35 & 0.149 & 0.149 & 2325 & 2325 & 985.0 & 985.0 & 1.28 & 1.28 & 1.89 & 1.89 \\
\hline tsw36 & 0.106 & 0.106 & 2473 & 2473 & 985.0 & 985.0 & 1.49 & 1.49 & 2.13 & 2.13 \\
\hline tsw37 & 0.106 & 0.106 & 2473 & 2473 & 985.0 & 985.0 & 1.54 & 1.49 & 2.20 & 2.13 \\
\hline tsw38 & 0.0360 & 0.046 & 2396 & 2274 & 1040 & 1040 & 0.688 & 0.670 & 0.796 & 0.794 \\
\hline tsw39 & 0.385 & 0.046 & 2374 & 2274 & 1040 & 1040 & 0.490 & 0.670 & 1.06 & 0.794 \\
\hline $\operatorname{ch} 1(v, z)$ & 0.385 & 0.354 & 2374 & 2288 & 1040 & 1040 & 0.490 & 0.489 & 1.06 & 1.07 \\
\hline $\operatorname{ch} 2(\mathrm{v}, \mathrm{z})$ & 0.333 & 0.328 & 2504 & 2256 & 1038 & 1038 & 0.595 & 0.600 & 1.26 & 1.27 \\
\hline $\operatorname{ch} 3(\mathrm{v}, \mathrm{z})$ & 0.333 & 0.328 & 2504 & 2256 & 1038 & 1038 & 0.595 & 0.600 & 1.26 & 1.27 \\
\hline $\operatorname{ch} 4(\mathrm{v}, \mathrm{z})$ & 0.333 & 0.328 & 2504 & 2256 & 1038 & 1038 & 0.595 & 0.600 & 1.26 & 1.27 \\
\hline $\operatorname{ch} 5(\mathrm{v}, \mathrm{z})$ & 0.333 & 0.328 & 2504 & 2256 & 1038 & 1038 & 0.595 & 0.600 & 1.26 & 1.27 \\
\hline $\operatorname{ch} 6(\mathrm{v}, \mathrm{z})$ & 0.333 & 0.328 & 2504 & 2256 & 1038 & 1038 & 0.595 & 0.600 & 1.26 & 1.27 \\
\hline $\mathrm{pp} 4$ & 0.300 & 0.297 & 2557 & 2103 & 1040 & 1040 & 0.569 & 0.538 & 1.13 & 1.11 \\
\hline pp3 & 0.300 & 0.297 & 2557 & 2103 & 1040 & 1040 & 0.569 & 0.538 & 1.13 & 1.11 \\
\hline $\mathrm{pp} 2$ & 0.255 & 0.233 & 2587 & 2385 & 1012 & 1009 & 0.741 & 0.733 & 1.33 & 1.34 \\
\hline pp1 & 0.277 & 0.273 & 2519 & 2038 & 1040 & 1040 & 0.596 & 0.564 & 1.15 & 1.13 \\
\hline bf3 & 0.194 & 0.188 & 2485 & 2106 & 1021 & 1018 & 0.788 & 0.757 & 1.34 & 1.33 \\
\hline bf2 & 0.264 & 0.262 & 2506 & 2012 & 1040 & 1040 & 0.611 & 0.576 & 1.16 & 1.14 \\
\hline
\end{tabular}

NOTES: Revised data are from DTN: LB0402THRMLPRP.001 [DIRS 168481] (rounded to the number of significant digit shown). Original data are from DTN: LB0210THRMLPRP.001[DIRS 160799] (rounded to the number of significant digit shown).

Fracture thermal properties are derived using matrix properties as discussed in Section 6.4.6. Other rock properties data are identical to those listed in Table 6.4-1 for REV02 simulations. The data for repository units are shaded. 
THC model results are compared in Figures 6.5-54 through 6.5-70 (simulations thc6_w0 and thc6_w0 il using original and revised properties, respectively). These figures are directly comparable to Figures 6.5-4 through 6.5-9, and 6.5-21 through 6.5-37. The latter are generated for areas of maximum liquid saturation above the drift as described in Section 6.5.5.3.2.

Temperatures differ by less than one degree between the original and revised simulation results (Figures 6.5-49 and 6.5-55), the revised simulation results showing a slight temperature decrease. Both TH simulations predict the rewetting of fractures at the drift crown at around the same time ( 1400 years) (Figure 6.5-50). At the drift side and base, rewetting of fractures is predicted to occur up to 200 years earlier for the case using the revised properties (Figure 6.5-50). This small difference is not observed with the THC simulations, which predict rewetting to occur around 2000 years at all three drift wall locations in both cases. However, although the maximum time step used in the THC seepage model is 5 years (Section 6.5.3), the time of rewetting is not well resolved in Figure 6.5-50, because the model-result printout interval is 200 years.

In the most liquid saturated regions above the drift, differences in predicted water chemistries and $\mathrm{CO}_{2}$ gas concentrations between the original and revised cases are quite small (Figures 6.5-57 through 6.5-70). These small differences are negligible compared to the spread in model results obtained when using different input water chemistries, infiltration rates, and model conceptualizations (Figures 6.5-21 through 6.5-37). Differences in predicted water compositions at other locations around the drift are presented in Post-Processing Analysis for THC Seepage (BSC 2004 DIRS 169858]) and are also negligible. Therefore, it can be concluded that the matrix porosity and thermal properties revisions discussed here have essentially no effect on predicted water and gas chemistries in the vicinity of the drift. This would be expected given the fact that the thermal properties of the repository units are essentially unchanged between these two cases, yielding nearly identical temperatures around the drift. 

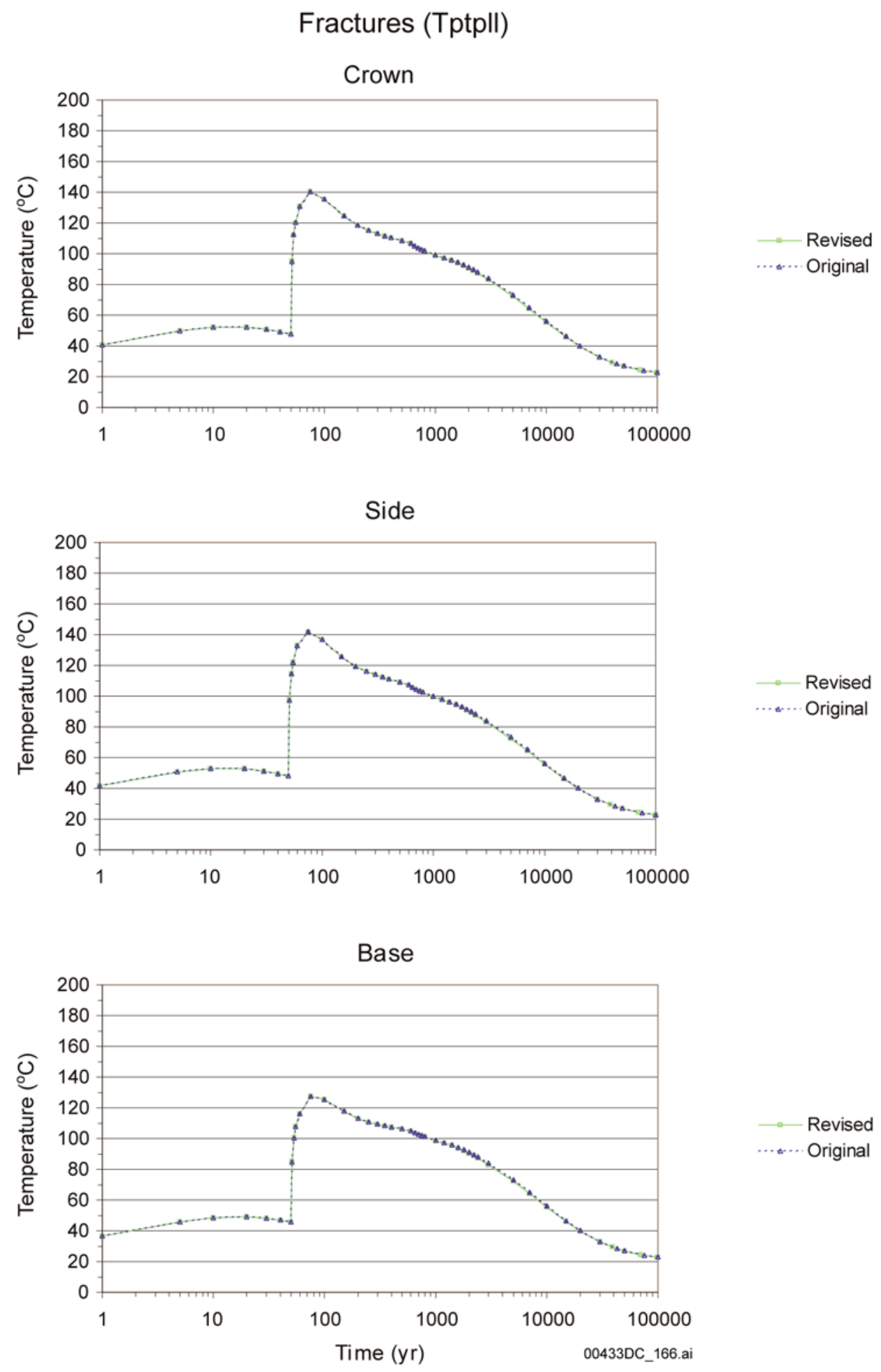

Output DTNs: LB0307DSTTHCR2.002, LB0404DSTTHCR2.002.

Figure 6.5-49. TH Simulation (Revised vs. Original Properties): Time Profiles of Modeled Temperatures in Fractures at Three Drift-Wall Locations 

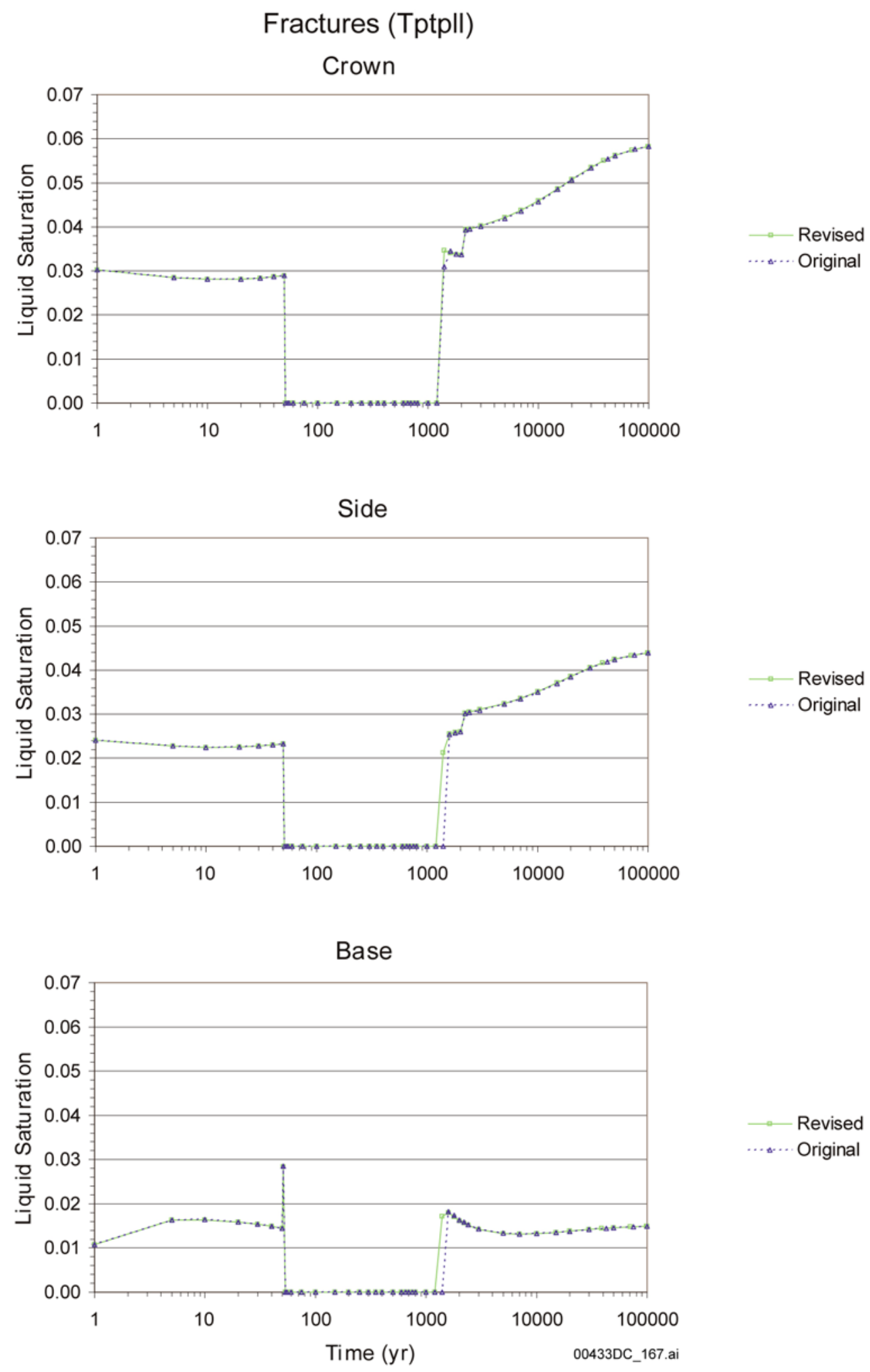

Output DTNs: LB0307DSTTHCR2.002, LB0404DSTTHCR2.002.

Figure 6.5-50. TH Simulation (Revised vs. Original Properties): Time Profiles of Modeled Liquid Saturations in Fractures at Three Drift-Wall Locations 

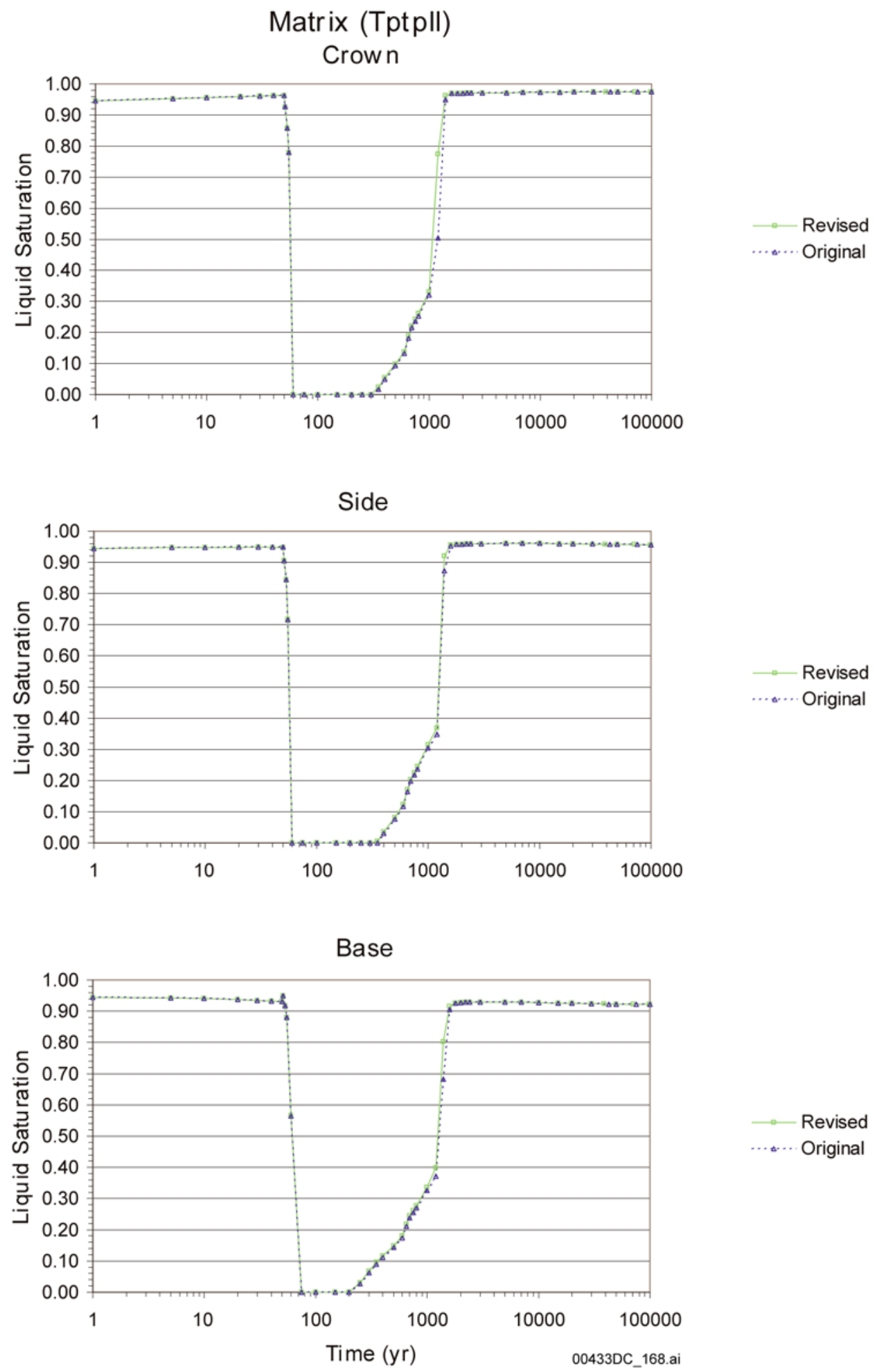

Output DTNs : LB0307DSTTHCR2.002, LB0404DSTTHCR2.002.

Figure 6.5-51. TH Simulation (Revised vs. Original Properties): Time Profiles of Modeled Liquid Saturations in Matrix at Three Drift-Wall Locations 

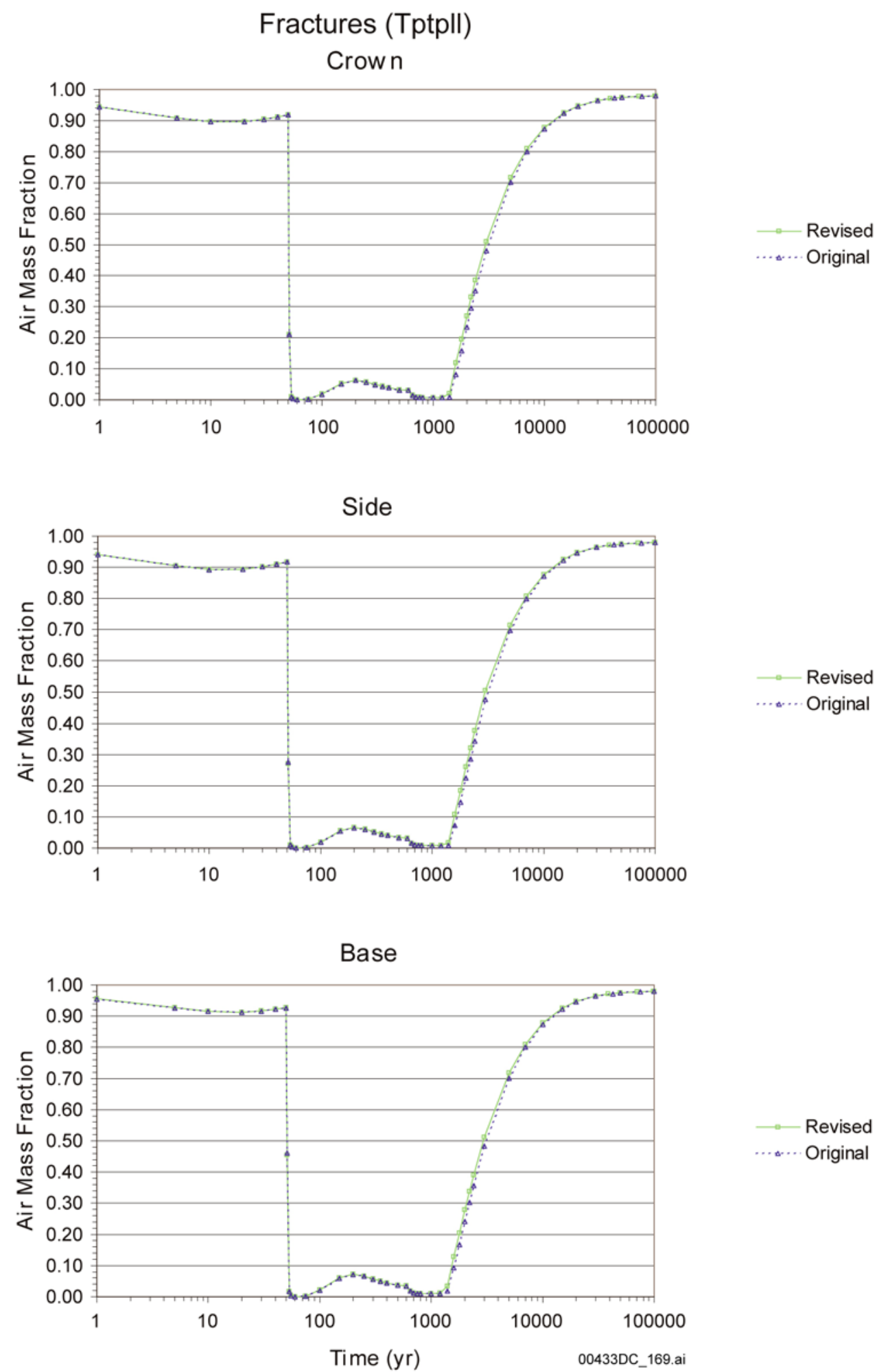

Output DTNs: LB0307DSTTHCR2.002, LB0404DSTTHCR2.002.

Figure 6.5-52. TH Simulation (Revised vs. Original Properties): Time Profiles of Modeled Air Mass Fractions in the Gas Phase in Fractures at Three Drift-Wall Locations 


\section{Fractures (Tptpll) \\ Crown}

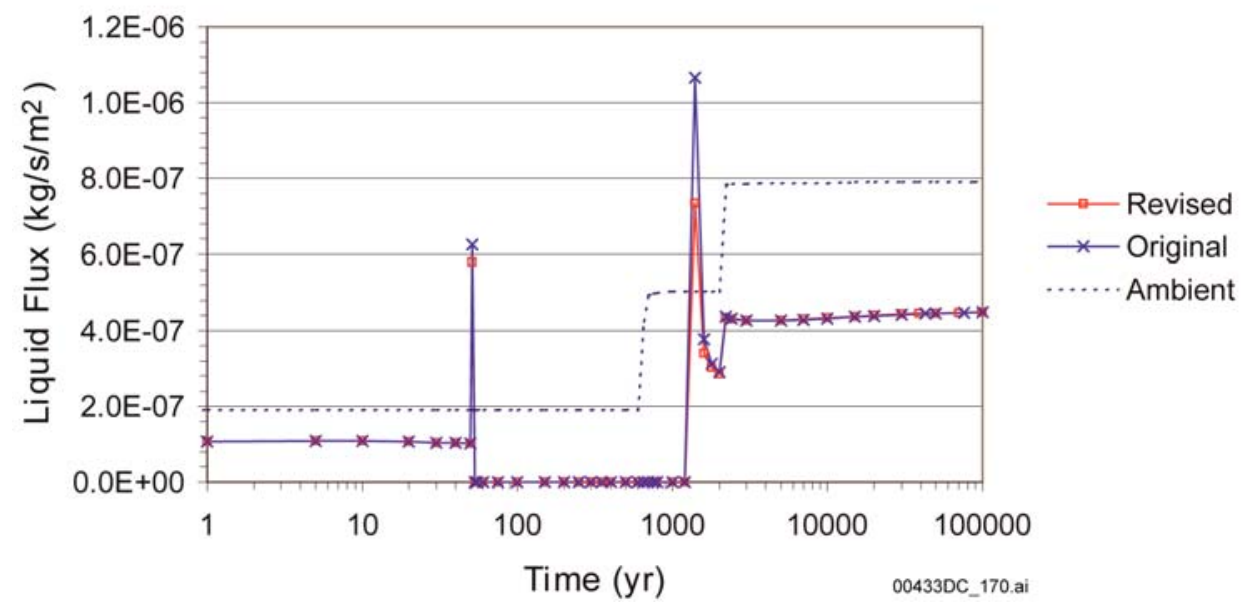

Output DTNs: LB0307DSTTHCR2.002, LB0404DSTTHCR2.002.

NOTE: The peaks at the start and end of the boiling period (at $\sim 50$ and $\sim 1,400$ years, respectively) may not be fully resolved.

Figure 6.5-53. TH Simulation (Revised vs. Original Properties): Time Profiles of Modeled Downward Water Flux at the Drift Crown

\section{HISAT-TOP (Fractures)}

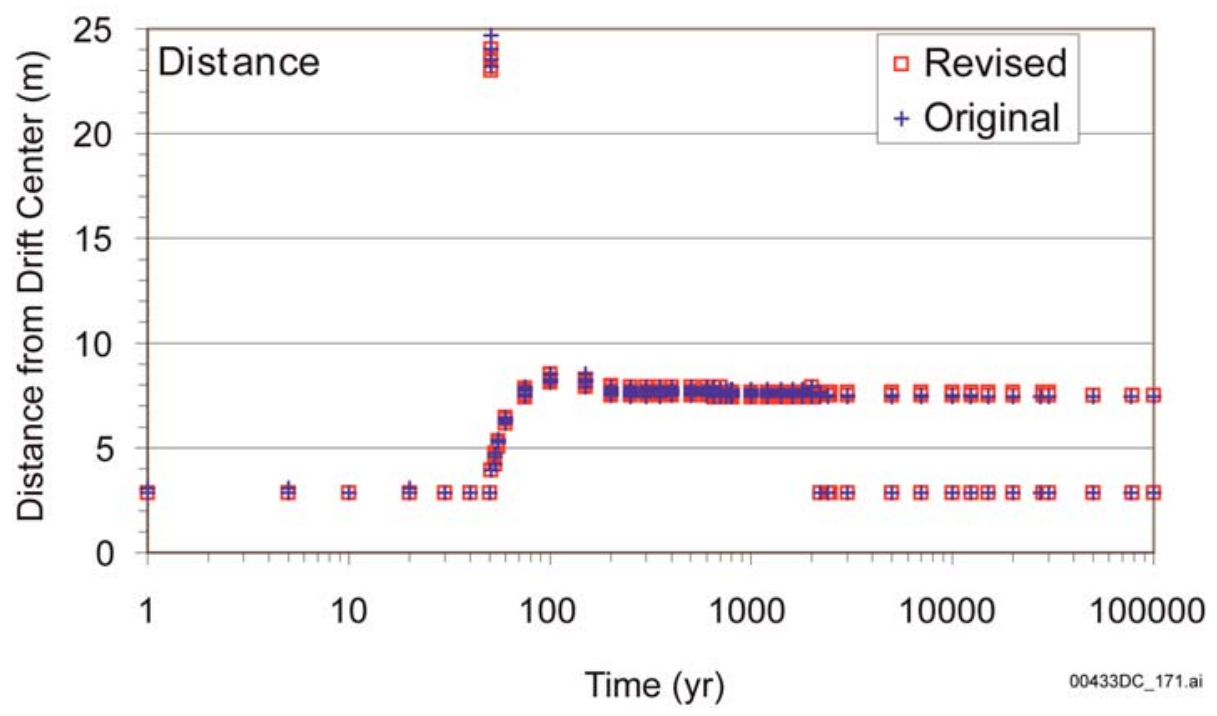

Output DTNs: LB0307DSTTHCR2.002, LB0404DSTTHCR2.002.

NOTE: Grid blocks are those with the highest liquid saturation in fractures within a $25-\mathrm{m}$ radius from drift center and a $45^{\circ}$ arc from the drift crown. Data are shown for simulations using the same initial water composition (W0). Both simulations are run using a stepwise-increasing infiltration rate $(6,16$, and $25 \mathrm{~mm} / \mathrm{yr}$ ) and with vapor pressure lowering.

Figure 6.5-54. THC Simulations (Revised vs. Original Properties): Location of Model Grid Blocks for Data Shown on Figures A-7 through A-22, for Each Time When Model Output Is Produced 
HISAT-TOP (Fractures)

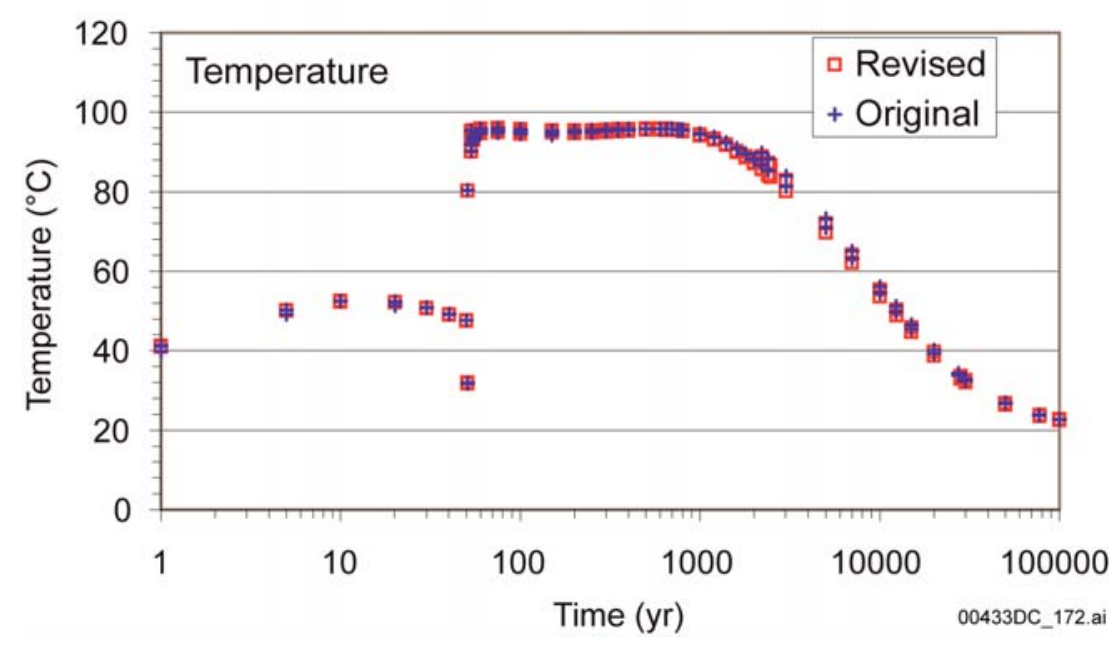

Output DTNs: LB0307DSTTHCR2.002, LB0404DSTTHCR2.002.

NOTE: Grid blocks are those with the highest liquid saturation in fractures within a 25-m radius from drift center and $\mathrm{a} 45^{\circ}$ arc from the drift crown. Data are shown for simulations using the same initial water composition (W0). Both simulations are run using a stepwise-increasing infiltration rate $(6,16$, and $25 \mathrm{~mm} / \mathrm{yr}$ ) and with vapor pressure lowering.

Figure 6.5-55. THC Simulations (Revised vs. Original Properties): Time Profiles of Modeled Temperatures in Fractures in Areas of Highest Liquid Saturation above the Drift Crown

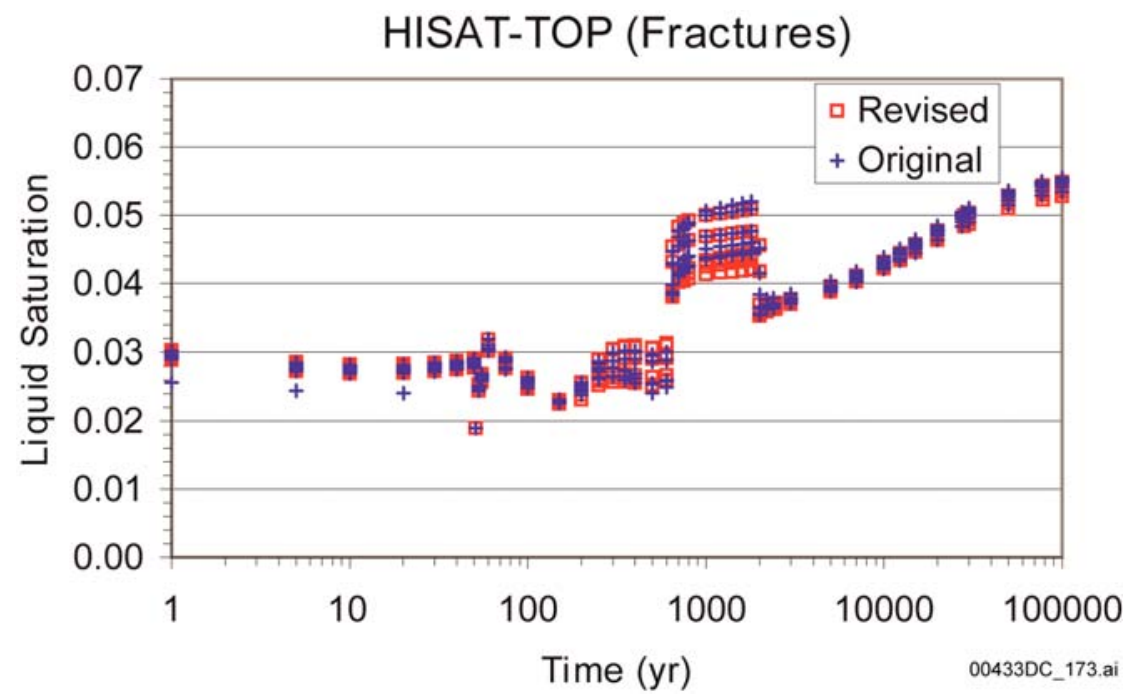

Output DTNs: LB0307DSTTHCR2.002, LB0404DSTTHCR2.002.

NOTE: Grid blocks are those with the highest liquid saturation in fractures within a 25-m radius from drift center and $\mathrm{a} 45^{\circ}$ arc from the drift crown. Data are shown for simulations using the same initial water composition (W0). Both simulations are run using a stepwise-increasing infiltration rate $(6,16$, and $25 \mathrm{~mm} / \mathrm{yr}$ ) and with vapor pressure lowering.

Figure 6.5-56. THC Simulations (Revised vs. Original Properties): Time Profiles of Modeled Liquid Saturations in Fractures in Areas of Highest Liquid Saturation above the Drift Crown 


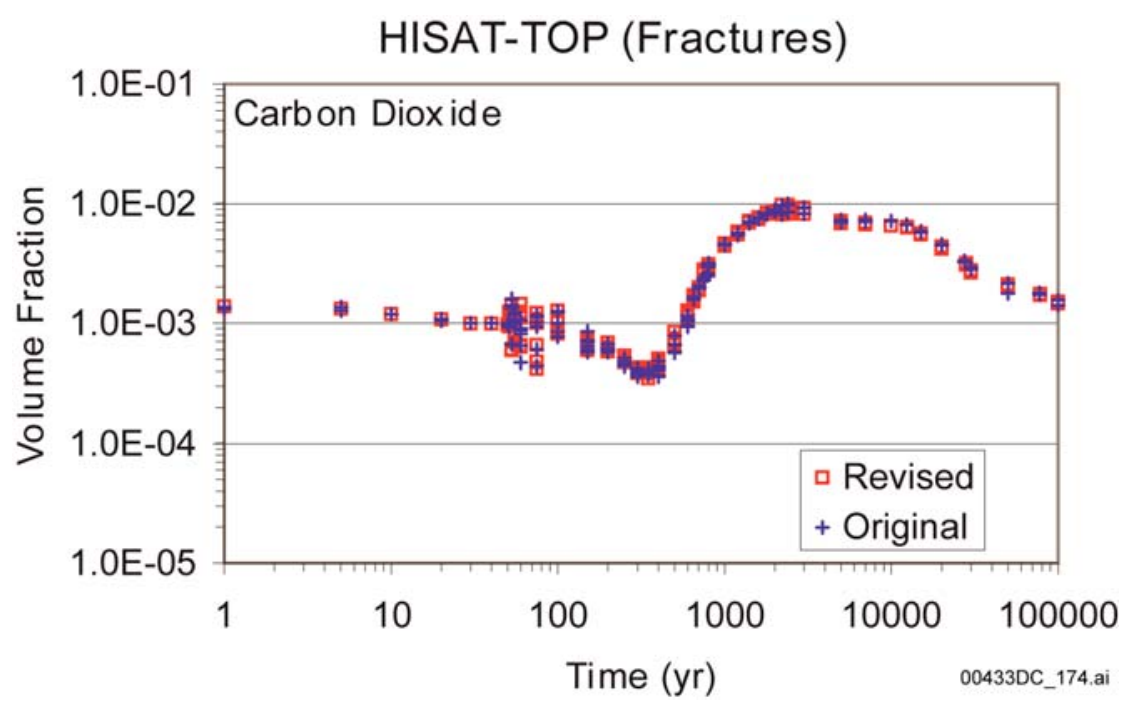

Output DTNs: LB0307DSTTHCR2.002, LB0404DSTTHCR2.002.

NOTE: Grid blocks are those with the highest liquid saturation in fractures within a 25-m radius from drift center and $\mathrm{a} 45^{\circ}$ arc from the drift crown. Data are shown for simulations using the same initial water composition (W0). Both simulations are run using a stepwise-increasing infiltration rate $(6,16$, and $25 \mathrm{~mm} / \mathrm{yr}$ ) and with vapor pressure lowering.

Figure 6.5-57. THC Simulations (Revised vs. Original Properties): Time Profiles of Modeled $\mathrm{CO}_{2}$ Gas Concentrations in Fractures in Areas of Highest Liquid Saturation above the Drift Crown

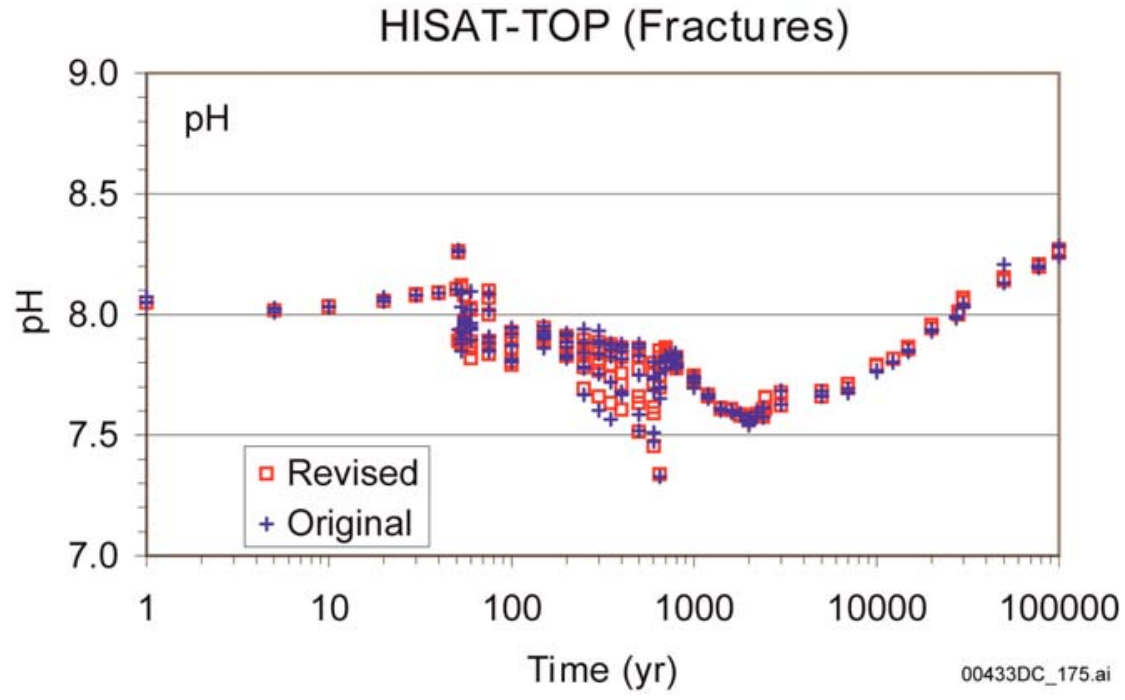

Output DTNs: LB0307DSTTHCR2.002, LB0404DSTTHCR2.002.

NOTE: Grid blocks are those with the highest liquid saturation in fractures within a 25-m radius from drift center and $\mathrm{a} 45^{\circ}$ arc from the drift crown. Data are shown for simulations using the same initial water composition (W0). Both simulations are run using a stepwise-increasing infiltration rate $(6,16$, and $25 \mathrm{~mm} / \mathrm{yr}$ ) and with vapor pressure lowering.

Figure 6.5-58. THC Simulations (Revised vs. Original Properties): Time Profiles of Modeled pH in Fracture Water in Areas of Highest Liquid Saturation above the Drift Crown 


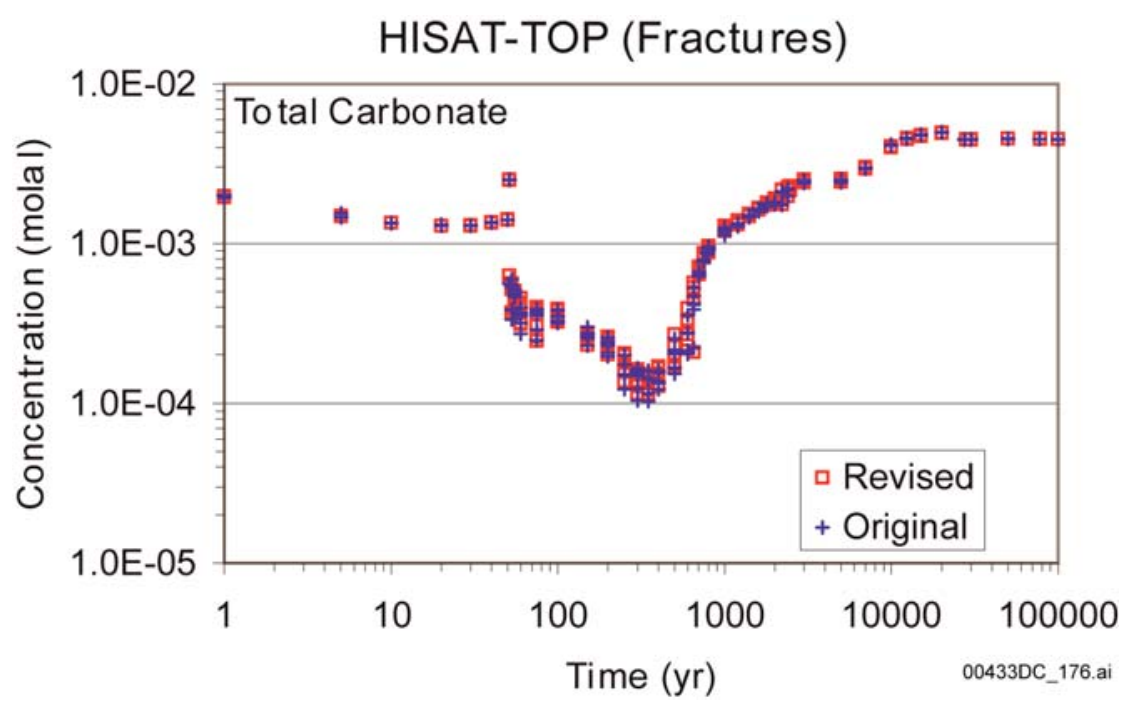

Output DTNs: LB0307DSTTHCR2.002, LB0404DSTTHCR2.002.

NOTE: Grid blocks are those with the highest liquid saturation in fractures within a 25-m radius from drift center and $\mathrm{a} 45^{\circ}$ arc from the drift crown. Data are shown for simulations using the same initial water composition (W0). Both simulations are run using a stepwise-increasing infiltration rate $(6,16$, and $25 \mathrm{~mm} / \mathrm{yr}$ ) and with vapor pressure lowering.

Figure 6.5-59. THC Simulations (Revised vs. Original Properties): Time Profiles of Modeled Total Aqueous Carbonate Concentrations in Fracture Water in Areas of Highest Liquid Saturation above the Drift Crown

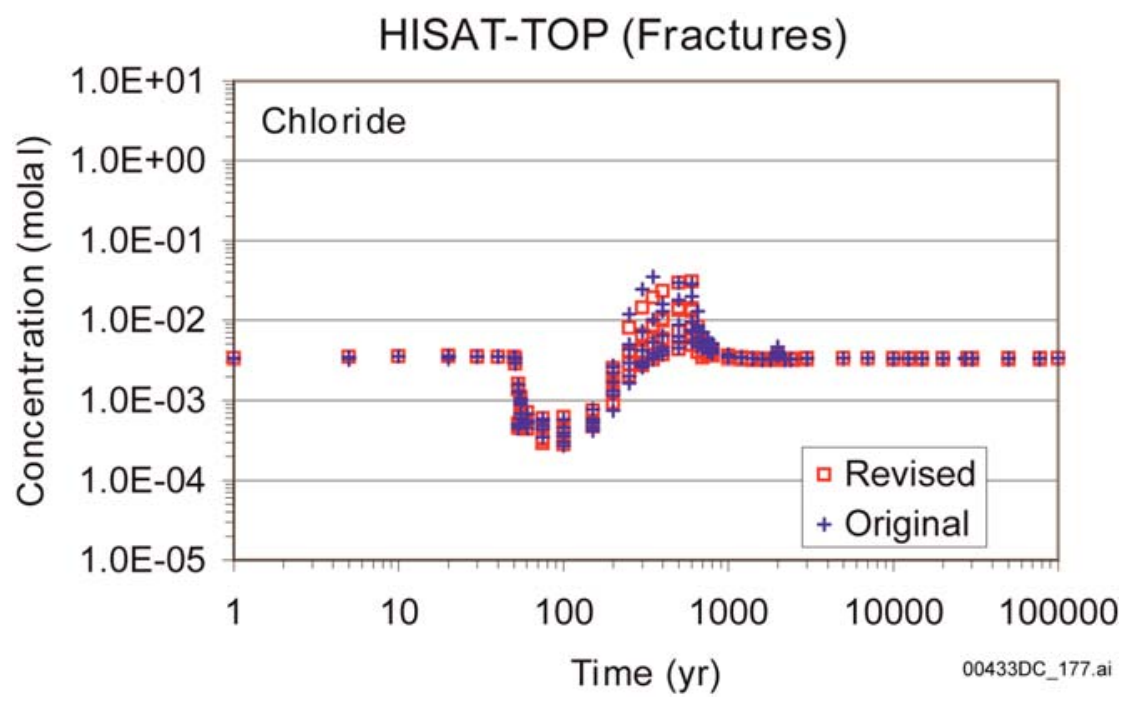

Output DTNs: LB0307DSTTHCR2.002, LB0404DSTTHCR2.002.

NOTE: Grid blocks are those with the highest liquid saturation in fractures within a 25-m radius from drift center and $\mathrm{a} 45^{\circ}$ arc from the drift crown. Data are shown for simulations using the same initial water composition (W0). Both simulations are run using a stepwise-increasing infiltration rate $(6,16$, and $25 \mathrm{~mm} / \mathrm{yr}$ ) and with vapor pressure lowering.

Figure 6.5-60. THC Simulations (Revised vs. Original Properties): Time Profiles of Modeled Total Aqueous Chloride Concentrations in Fracture Water in Areas of Highest Liquid Saturation above the Drift Crown 


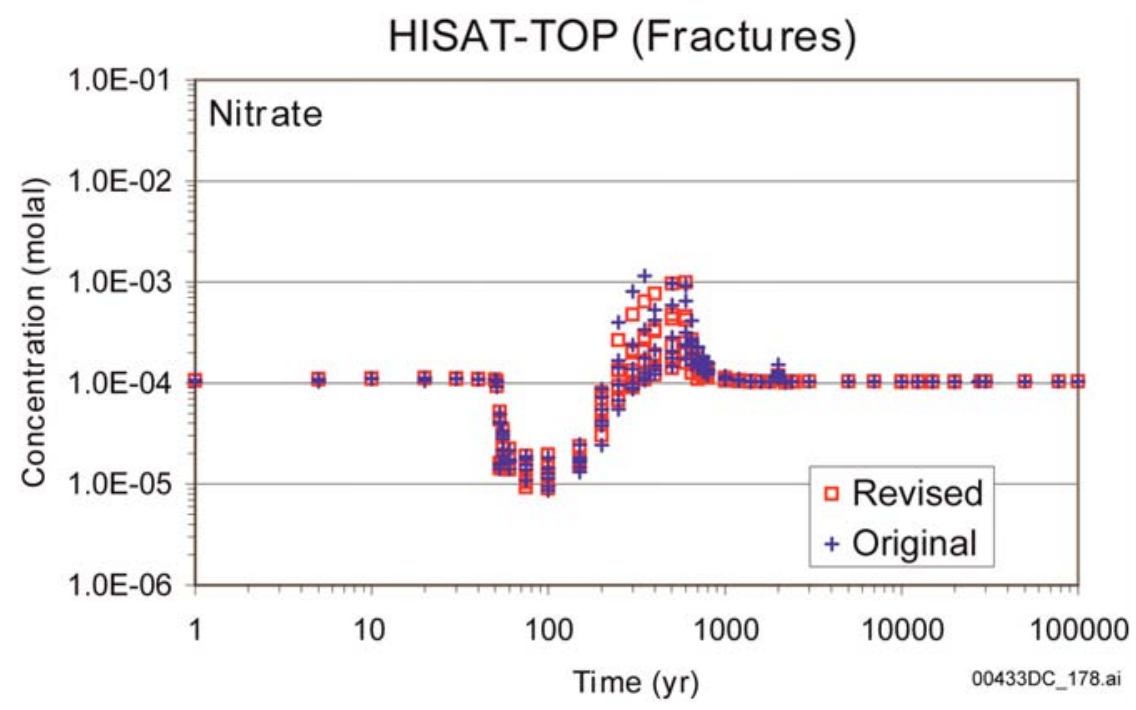

Output DTNs: LB0307DSTTHCR2.002, LB0404DSTTHCR2.002.

NOTE: Grid blocks are those with the highest liquid saturation in fractures within a 25-m radius from drift center and $\mathrm{a} 45^{\circ}$ arc from the drift crown. Data are shown for simulations using the same initial water composition (W0). Both simulations are run using a stepwise-increasing infiltration rate $(6,16$, and $25 \mathrm{~mm} / \mathrm{yr}$ ) and with vapor pressure lowering.

Figure 6.5-61. THC Simulations (Revised vs. Original Properties): Time Profiles of Modeled Total Aqueous Nitrate Concentrations in Fracture Water in Areas of Highest Liquid Saturation above the Drift Crown

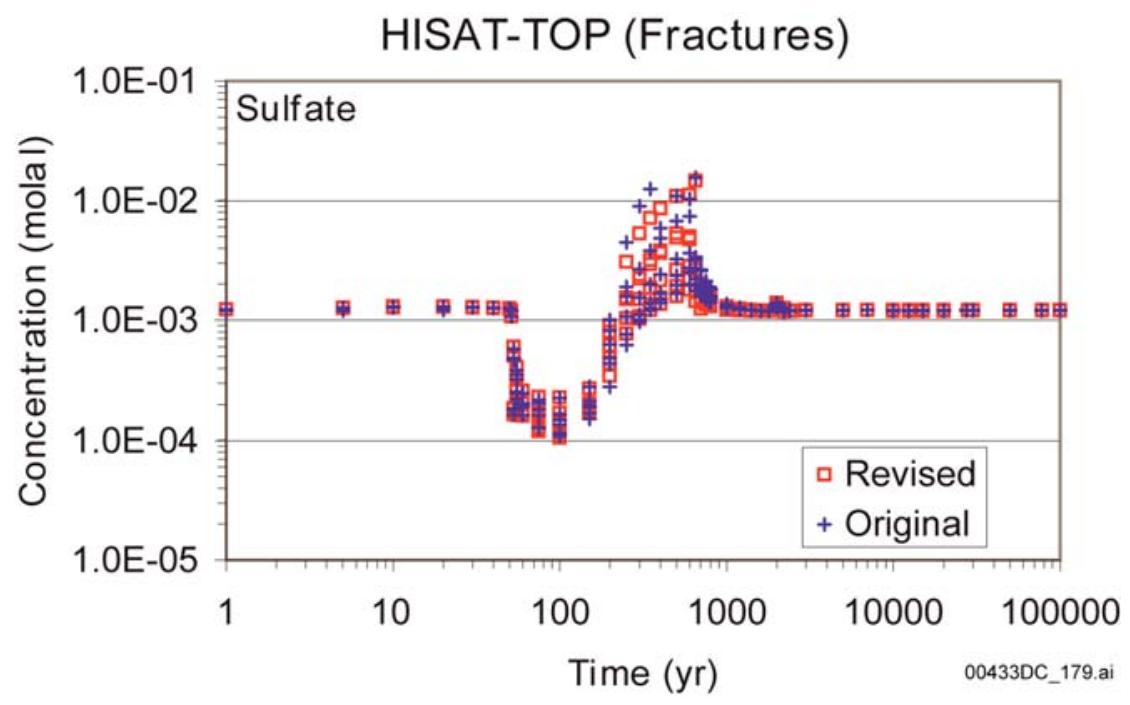

Output DTNs: LB0307DSTTHCR2.002, LB0404DSTTHCR2.002.

NOTE: Grid blocks are those with the highest liquid saturation in fractures within a 25-m radius from drift center and $a 5^{\circ}$ arc from the drift crown. Data are shown for simulations using the same initial water composition (W0). Both simulations are run using a stepwise-increasing infiltration rate $(6,16$, and $25 \mathrm{~mm} / \mathrm{yr}$ ) and with vapor pressure lowering.

Figure 6.5-62. THC Simulations (Revised vs. Original Properties): Time Profiles of Modeled Total Aqueous Sulfate Concentrations in Fracture Water in Areas of Highest Liquid Saturation above the Drift Crown 


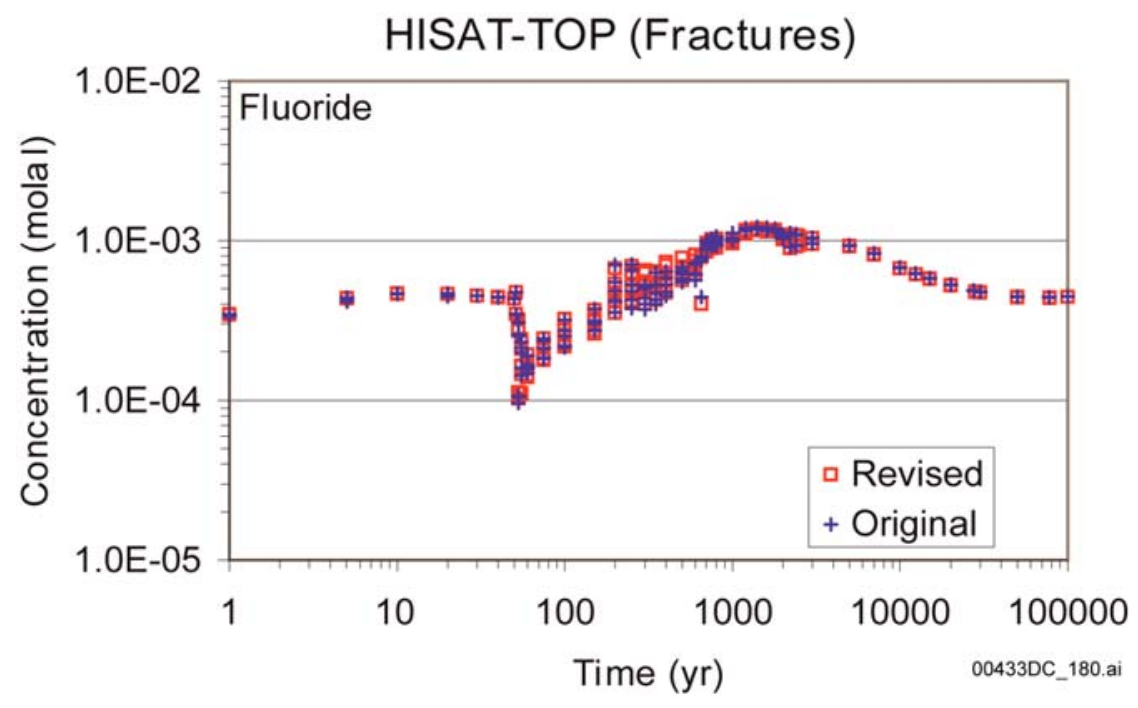

Output DTNs: LB0307DSTTHCR2.002, LB0404DSTTHCR2.002.

NOTE: Grid blocks are those with the highest liquid saturation in fractures within a 25-m radius from drift center and $\mathrm{a} 45^{\circ}$ arc from the drift crown. Data are shown for simulations using the same initial water composition (W0). Both simulations are run using a stepwise-increasing infiltration rate $(6,16$, and $25 \mathrm{~mm} / \mathrm{yr}$ ) and with vapor pressure lowering.

Figure 6.5-63. THC Simulations (Revised vs. Original Properties): Time Profiles of Modeled Total Aqueous Fluoride Concentrations in Fracture Water in Areas of Highest Liquid Saturation above the Drift Crown

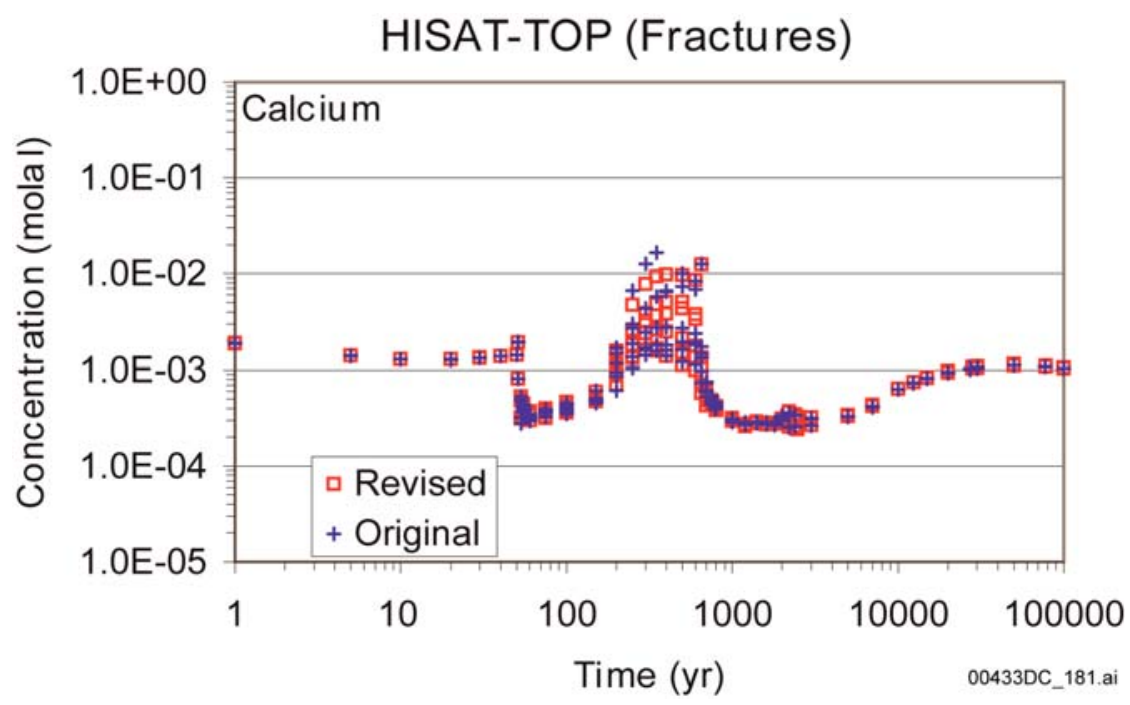

Output DTNs: LB0307DSTTHCR2.002, LB0404DSTTHCR2.002.

NOTE: Grid blocks are those with the highest liquid saturation in fractures within a 25-m radius from drift center and $\mathrm{a} 45^{\circ}$ arc from the drift crown. Data are shown for simulations using the same initial water composition (W0). Both simulations are run using a stepwise-increasing infiltration rate $(6,16$, and $25 \mathrm{~mm} / \mathrm{yr}$ ) and with vapor pressure lowering.

Figure 6.5-64. THC Simulations (Revised vs. Original Properties): Time Profiles of Modeled Total Aqueous Calcium Concentrations in Fracture Water in Areas of Highest Liquid Saturation above the Drift Crown 


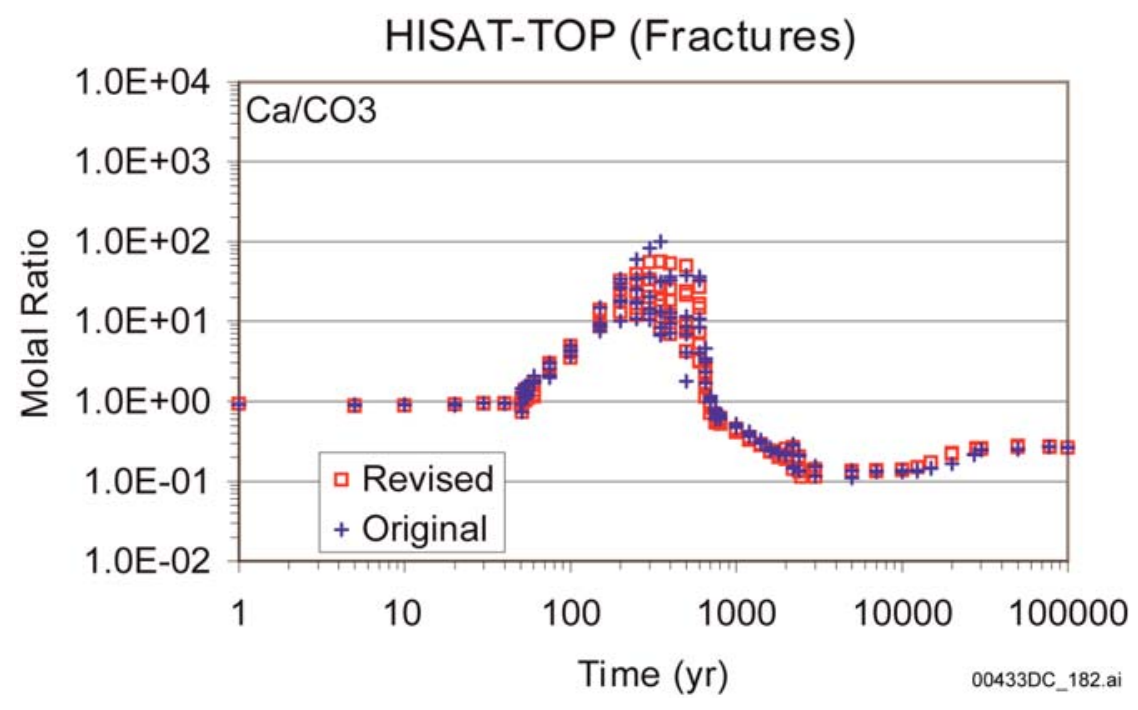

Output DTNs: LB0307DSTTHCR2.002, LB0404DSTTHCR2.002.

NOTE: Grid blocks are those with the highest liquid saturation in fractures within a 25-m radius from drift center and $\mathrm{a} 45^{\circ}$ arc from the drift crown. Data are shown for simulations using the same initial water composition (W0). Both simulations are run using a stepwise-increasing infiltration rate $(6,16$, and $25 \mathrm{~mm} / \mathrm{yr}$ ) and with vapor pressure lowering.

Figure 6.5-65. THC Simulations (Revised vs. Original Properties): Time Profiles of Modeled Total Aqueous Calcium to Carbonate Concentration Ratios in Fracture Water in Areas of Highest Liquid Saturation above the Drift Crown

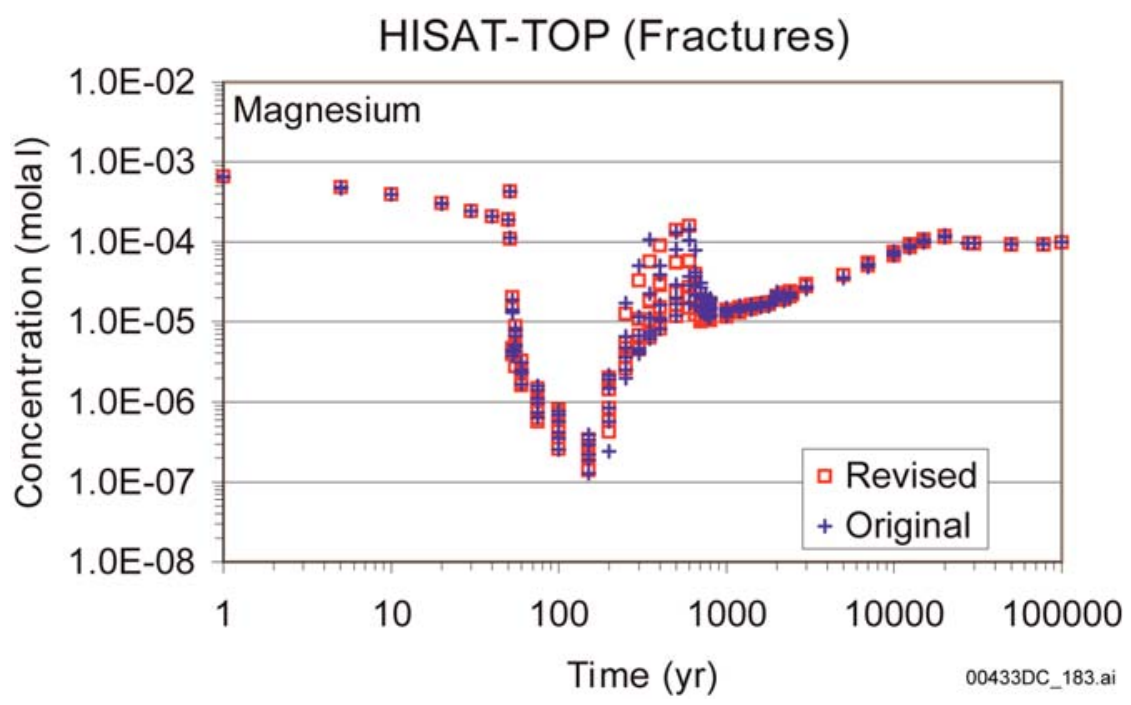

Output DTNs: LB0307DSTTHCR2.002, LB0404DSTTHCR2.002.

NOTE: Grid blocks are those with the highest liquid saturation in fractures within a 25-m radius from drift center and a $45^{\circ}$ arc from the drift crown. Data are shown for simulations using the same initial water composition (W0). Both simulations are run using a stepwise-increasing infiltration rate $(6,16$, and $25 \mathrm{~mm} / \mathrm{yr}$ ) and with vapor pressure lowering.

Figure 6.5-66. THC Simulations (Revised vs. Original Properties): Time Profiles of Modeled Total Aqueous Magnesium Concentrations in Fracture Water in Areas of Highest Liquid Saturation above the Drift Crown 


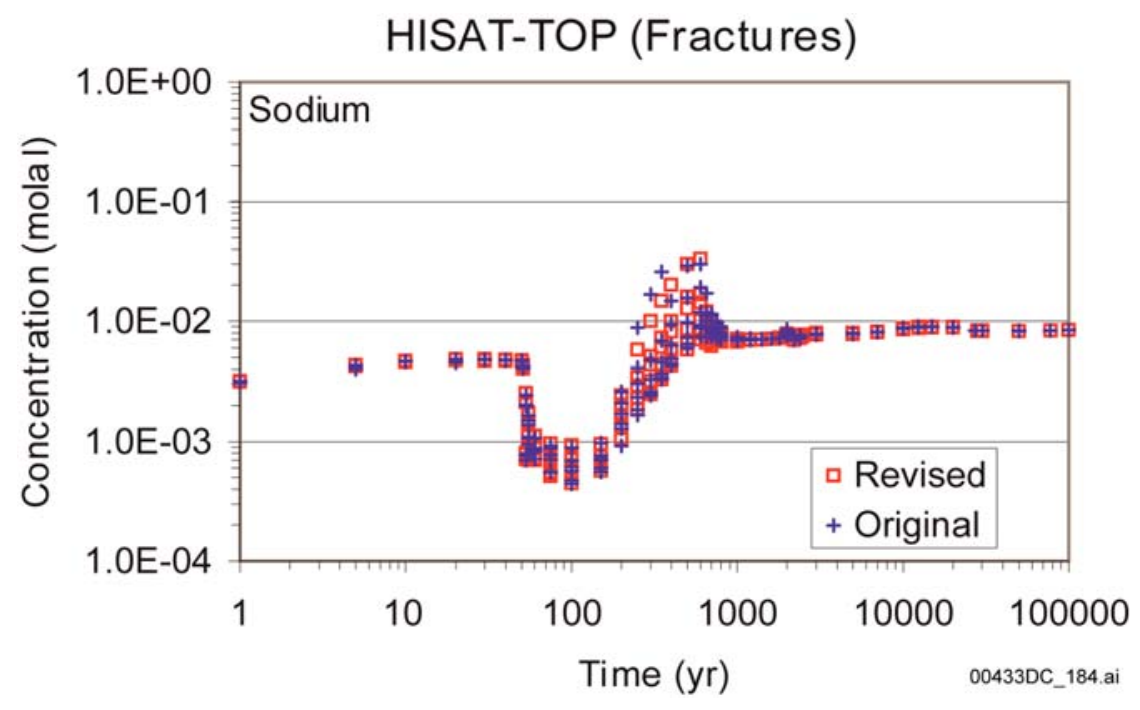

Output DTNs: LB0307DSTTHCR2.002, LB0404DSTTHCR2.002.

NOTE: Grid blocks are those with the highest liquid saturation in fractures within a 25-m radius from drift center and $\mathrm{a} 45^{\circ}$ arc from the drift crown. Data are shown for simulations using the same initial water composition (W0). Both simulations are run using a stepwise-increasing infiltration rate $(6,16$, and $25 \mathrm{~mm} / \mathrm{yr}$ ) and with vapor pressure lowering.

Figure 6.5-67. THC Simulations (Revised vs. Original Properties): Time Profiles of Modeled Total Aqueous Sodium Concentrations in Fracture Water in Areas of Highest Liquid Saturation above the Drift Crown

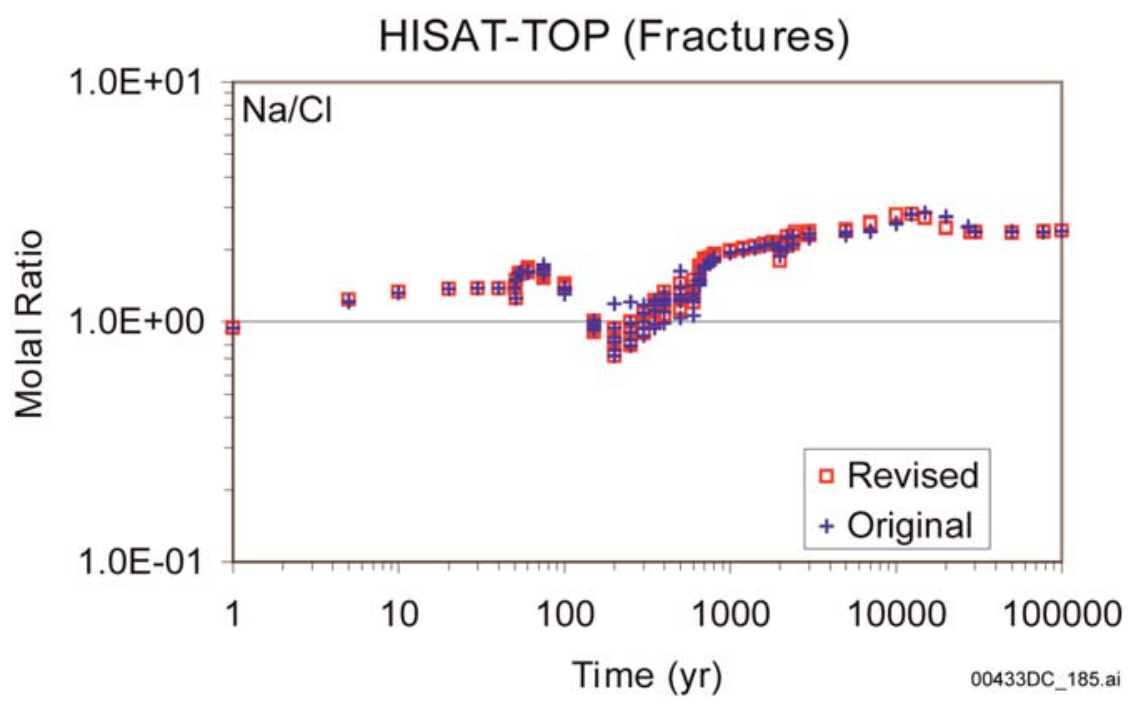

Output DTNs: LB0307DSTTHCR2.002, LB0404DSTTHCR2.002.

NOTE: Grid blocks are those with the highest liquid saturation in fractures within a 25-m radius from drift center and a $45^{\circ}$ arc from the drift crown. Data are shown for simulations using the same initial water composition (W0). Both simulations are run using a stepwise-increasing infiltration rate $(6,16$, and $25 \mathrm{~mm} / \mathrm{yr}$ ) and with vapor pressure lowering.

Figure 6.5-68. THC Simulations (Revised vs. Original Properties): Time Profiles of Modeled Total Aqueous Sodium to Chloride Concentration Ratios in Fracture Water, in Areas of Highest Liquid Saturation above the Drift Crown 


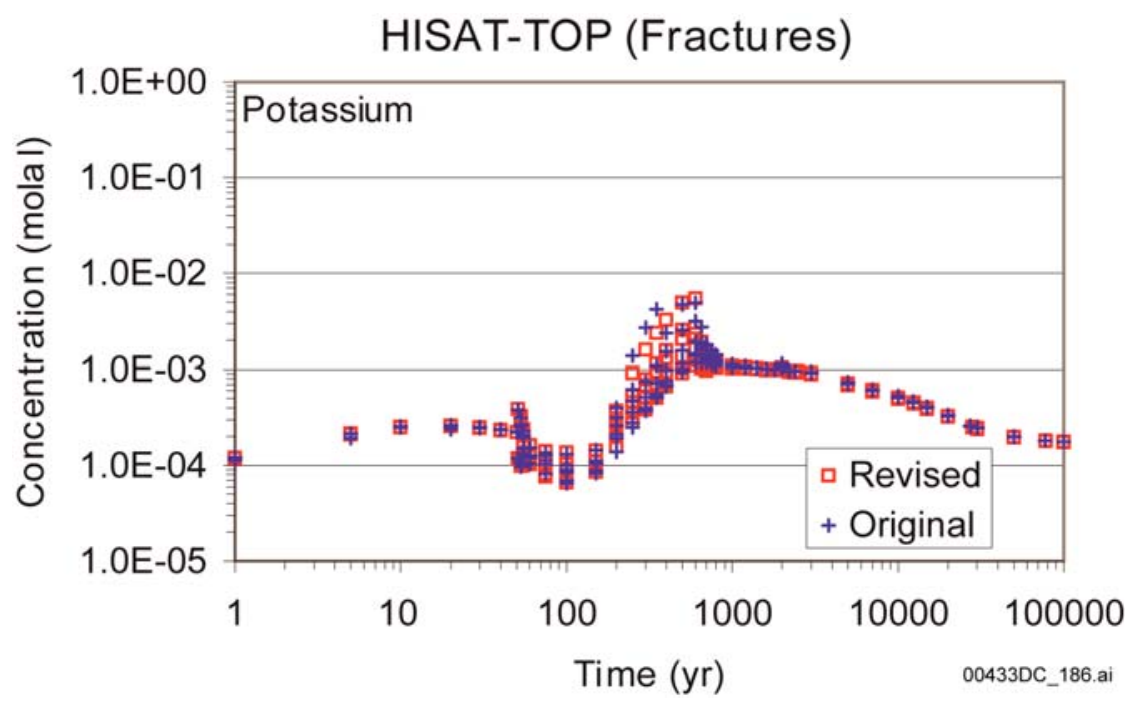

Output DTNs: LB0307DSTTHCR2.002, LB0404DSTTHCR2.002.

NOTE: Grid blocks are those with the highest liquid saturation in fractures within a 25-m radius from drift center and a $45^{\circ}$ arc from the drift crown. Data are shown for simulations using the same initial water composition (W0). Both simulations are run using a stepwise-increasing infiltration rate $(6,16$, and $25 \mathrm{~mm} / \mathrm{yr}$ ) and with vapor pressure lowering.

Figure 6.5-69. THC Simulations (Revised vs. Original Properties): Time Profiles of Modeled Total Aqueous Potassium Concentrations in Fracture Water in Areas of Highest Liquid Saturation above the Drift Crown

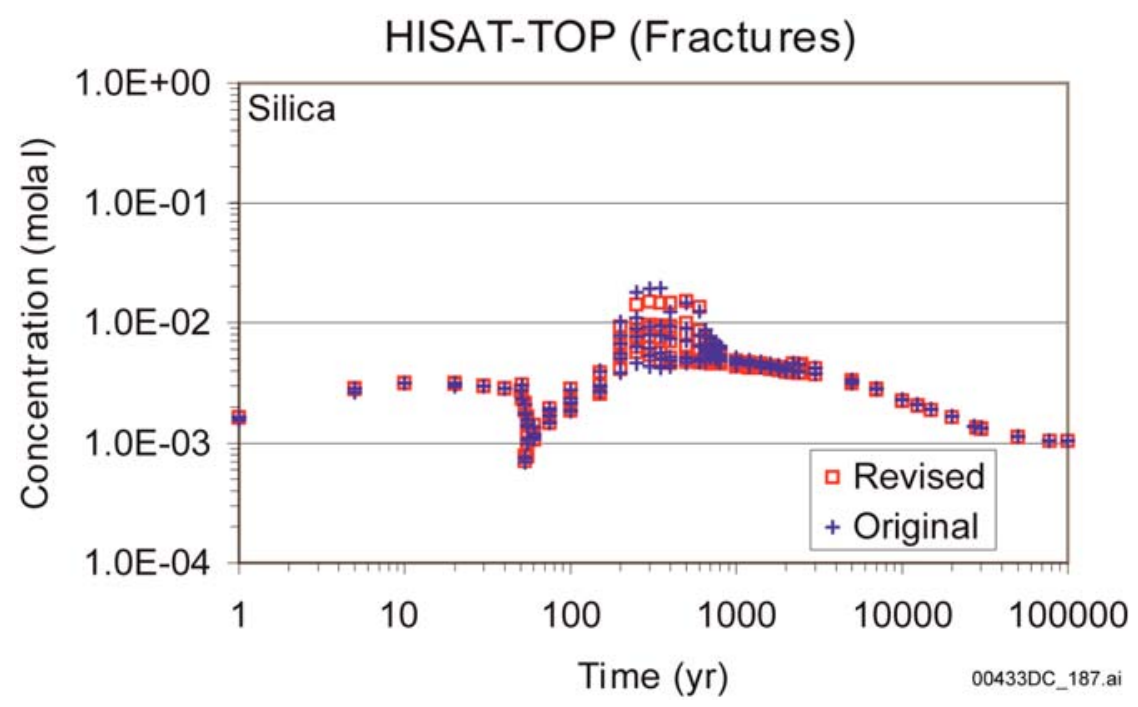

Output DTNs: LB0307DSTTHCR2.002, LB0404DSTTHCR2.002.

NOTE: Grid blocks are those with the highest liquid saturation in fractures within a 25-m radius from drift center and a $45^{\circ}$ arc from the drift crown. Data are shown for simulations using the same initial water composition (W0). Both simulations are run using a stepwise-increasing infiltration rate $(6,16$, and $25 \mathrm{~mm} / \mathrm{yr}$ ) and with vapor pressure lowering.

Figure 6.5-70. THC Simulations (Revised vs. Original Properties): Time Profiles of Modeled Total Aqueous Silica Concentrations in Fracture Water in Areas of Highest Liquid Saturation above the Drift Crown 


\subsection{MODEL UNCERTAINTY}

\subsubsection{Potential Sources of Uncertainty}

The simulations of THC processes include coupling between heat, water, and vapor flow; aqueous and gaseous species transport; kinetic and equilibrium mineral-water reactions; and feedback of mineral precipitation-dissolution on porosity, permeability, and capillary pressure (hydrologic properties) for a dual-permeability (fracture-matrix) system. As such, the THC seepage model takes into account the effects of mineral dissolution and precipitation, carbon dioxide exsolution and transport in the region surrounding emplacement drifts, and resulting changes to porosity, permeability, seepage, and chemical composition of percolating waters. The large number of input parameters, numerical methods implemented in simulating these complex coupled processes, and simplification and approximations pertaining to the physical setup of the model all contribute to uncertainties in the predictions from these models. Uncertainties in model input data that could affect calculated water and gas compositions include:

- Thermodynamic data (equilibrium constants for mineral-water reactions and aqueous species dissociation)

- Kinetic data (rate constants, reactive surface areas, and activation energies)

- Initial compositions of pore water and pore gas

- Initial composition of infiltrating water and gas

- Infiltration rates

- Transport parameters (diffusion coefficients of aqueous species and gases, tortuosity)

- Initial rock mineralogy (model location and stratigraphy)

- Number of geochemical constituents (including the simulations)

- Number and types of potential secondary mineral phases

- Rock thermal, physical, and hydrologic properties (including input data for both watersaturated and unsaturated rock).

Process model uncertainties also may affect the calculated water and gas compositions. These include:

- Formulation of models to simulate fluid flow in dual permeability media (e.g., fracture-matrix interactions; and relative permeability and saturation-capillary pressure models)

- Activity coefficient models

- Kinetic mineral precipitation and dissolution models 
- Inclusion or exclusion of certain specific thermal, hydrologic, or chemical processes (e.g., active fracture model, vapor pressure lowering, mineral solid solutions, redox reactions).

Uncertainties in the setup of the model could also affect the results of the THC seepage model. These include:

- Physical model representation (stratigraphic and geologic extrapolations)

- Representation of the fracture and matrix continua in the model mesh

- Model discretization (in space and time)

- Boundary conditions (e.g., drift open versus closed to fluid flow).

Of these uncertainties, those directly affecting chemical processes would be most likely to have the most effect on predicted water and gas compositions. Such uncertainties, their treatment in the model, and their effect on model results are summarized in Table 6.6-1.

Note that temperature is also a critical parameter affecting modeling results, although it cannot be considered an uncertainty by itself (temperature can generally be predicted to within a few degrees; therefore, it is not included in Table 6.6-1). Temperature directly affects equilibrium constants and reaction rates, the degree of water evaporation and boiling, and the amount of carbon dioxide volatilization from pore water, with direct implications for computed water and gas chemistries. Parameters affecting predicted temperatures could significantly affect computed aqueous and gas species concentrations. However, important changes in design heat load are likely to affect model results more than uncertainties associated with input parameters used to calculate temperatures (e.g., rock thermal conductivity and heat capacity). In this report, only the heat load from the current repository design is considered. This heat load leads to temperatures in the vicinity of emplacement drifts that exceed the boiling point of water for several hundred years if ventilation is not maintained after the 50 -year preclosure period. The increased water-rock-gas interactions resulting from higher temperatures are expected to affect water chemistry and flow to a greater extent than if a lower heat load were considered. However, some of the effects of elevated temperatures, such as dryout and reduced permeabilities caused by mineral precipitation, could have positive aspects with respect to repository performance. 


\begin{tabular}{|c|c|c|c|}
\hline Category & Issue & Treatment & Consequences \\
\hline \multirow[t]{3}{*}{$\begin{array}{l}\text { Conceptual } \\
\text { uncertainties }\end{array}$} & $\begin{array}{l}\text { Geochemical system } \\
\text { considered (minerals, } \\
\text { gases, and aqueous } \\
\text { species) }\end{array}$ & $\begin{array}{l}\text { Treated by including major rock-forming minerals, major } \\
\text { aqueous species, and major gases of interest (CO2, air, } \\
\text { water vapor) in the system, and also minor minerals such } \\
\text { as clays. } \\
\text { Effects of secondary mineral phase precipitation is most } \\
\text { uncertain at higher temperatures. } \\
\text { Uncertainty is limited under ambient conditions if ambient } \\
\text { water concentrations can be reproduced. } \\
\text { Trace minerals and aqueous species are not considered } \\
\text { (not within the current scope for the THC seepage model). } \\
\text { However, results of model validation (Section } 7 \text { ) against } \\
\text { the Drift Scale Test and other experiments suggest that the } \\
\text { geochemical system, as modeled, is constrained enough } \\
\text { to reproduce the experimental data within validation } \\
\text { criteria. Also, the range of incoming waters considered in } \\
\text { the model capture, at least in some part, the range of } \\
\text { uncertainties related to the geochemical system. }\end{array}$ & $\begin{array}{l}\text { Precipitation of secondary phases not currently included in } \\
\text { simulations could affect the predicted composition of } \\
\text { waters around the drift at high temperature. Reactions } \\
\text { involving trace minerals (e.g., other clay minerals or Mg, } \\
\text { Fe, Mn minerals) could affect pH, which in turn could affect } \\
\text { the precipitation/dissolution of other mineral phases and } \\
\text { indirectly affect the concentrations of major species. } \\
\text { The type of mineral precipitating could also affect the } \\
\text { calculated porosity change (i.e., effect of different molar } \\
\text { volume), although this effect would be minimal because } \\
\text { the bulk of the precipitation consists of amorphous silica. } \\
\text { Uncertainties affecting the precipitation of secondary } \\
\text { phases would increase at near dryout conditions; however, } \\
\text { such conditions (i.e., small liquid saturations) are not } \\
\text { conducive to seepage. }\end{array}$ \\
\hline & $\begin{array}{l}\text { Drift wall } \\
\text { conceptualization: } \\
\text { closed vs. open to } \\
\text { advective fluid flow; } \\
\text { also, hydrologic effect } \\
\text { of ventilation is } \\
\text { neglected }\end{array}$ & $\begin{array}{l}\text { Both cases of open and closed drift wall are addressed. } \\
\text { Infiltration rates (even at high rates indicative of future wet } \\
\text { climates) are below seepage thresholds, so there is little } \\
\text { effect of closing the drift wall on water percolation fluxes } \\
\text { around the drift. } \\
\text { Evaporative concentration effects (due to ventilation) are } \\
\text { indirectly taken into account by "downstream" in-drift } \\
\text { evaporation models. }\end{array}$ & $\begin{array}{l}\text { Boundary conditions of pressure and relative humidity in } \\
\text { the drift could affect evaporative concentration effects at } \\
\text { the drift wall, mostly during the preclosure ventilation } \\
\text { period. } \\
\text { In-drift interactions are not considered (this is not a goal of } \\
\text { the THC seepage model). }\end{array}$ \\
\hline & $\begin{array}{l}\text { Precipitation/nucleation } \\
\text { kinetics }\end{array}$ & $\begin{array}{l}\text { Not treated. } \\
\text { This affects minerals such as silica and calcite, which have } \\
\text { fast reaction rates. Implementation of a supersaturation } \\
\text { gap for calcite (as done here) may approximate the } \\
\text { nucleation processes. } \\
\text { Silica precipitation is modeled with a very fast reaction } \\
\text { rate. }\end{array}$ & $\begin{array}{l}\text { In areas where rapid boiling occurs, predicted aqueous } \\
\text { silica concentrations may be overestimated, and silica } \\
\text { precipitation underestimated. However, the water } \\
\text { saturation in these areas is very small, and therefore the } \\
\text { actual amounts of silica are minute. }\end{array}$ \\
\hline
\end{tabular}


Table 6.6-1. Summary of Uncertainties Affecting Chemical Processes in the THC Seepage Model (Continued)

\begin{tabular}{|c|c|c|c|}
\hline Category & Issue & Treatment & Consequences \\
\hline \multirow[t]{5}{*}{$\begin{array}{l}\text { Conceptual } \\
\text { uncertainties } \\
\text { (cont.) }\end{array}$} & $\begin{array}{l}\text { Water chemistry is not } \\
\text { computed below a set } \\
\text { water saturation limit } \\
\left(10^{-5}\right) \text { or above a set } \\
\text { ionic strength limit (4) } \\
\text { (activity coefficient } \\
\text { model limitations) } \\
\end{array}$ & $\begin{array}{l}\text { Salt precipitation in the last remaining water when boiling } \\
\text { or evaporating is taken into account using a simple } \\
\text { approach (Section } 6.4 .5 \text { ). These salts are then available } \\
\text { for dissolution upon rewetting, providing a conceptually } \\
\text { correct (although simplified) representation of actual } \\
\text { processes accompanying dryout and rewetting. }\end{array}$ & $\begin{array}{l}\text { The type and sequence of salts assumed to precipitate } \\
\text { upon dryout affects computed water compositions at the } \\
\text { very early stages of rewetting only. Changes in nitrate- } \\
\text { chloride ratios during rewetting may be an artifact of this } \\
\text { approach. However, during this initial rewetting stage, the } \\
\text { liquid saturation is low and the associated volume of water } \\
\text { is small, immobile, and unlikely to contribute to seepage. }\end{array}$ \\
\hline & $\begin{array}{l}\text { Vapor pressure } \\
\text { lowering due to } \\
\text { capillary pressure }\end{array}$ & $\begin{array}{l}\text { Treated by running simulations with and without vapor } \\
\text { pressure lowering. }\end{array}$ & $\begin{array}{l}\text { No large effect on computed gas and water chemistries. } \\
\text { However, a large effect on the predicted time of rewetting } \\
\text { of fractures and matrix at the drift wall is observed. } \\
\text { Neglecting vapor pressure lowering could increase the } \\
\text { effect of evaporative concentration around the drift, } \\
\text { resulting in higher water salinities, although this is not } \\
\text { observed. }\end{array}$ \\
\hline & $\begin{array}{l}\text { Oxidation-reduction } \\
\text { processes are } \\
\text { neglected }\end{array}$ & $\begin{array}{l}\text { Not treated (considers only oxidized conditions). } \\
\text { Oxidizing conditions prevail in the unsaturated zone at } \\
\text { Yucca Mountain such that the redox species considered in } \\
\text { the THC seepage model (iron and sulfate) occur only in } \\
\text { their oxidized state. }\end{array}$ & $\begin{array}{l}\text { Limited anticipated effect because of the prevailing } \\
\text { oxidized conditions. Likely no effect for iron and sulfate in } \\
\text { the current models. Redox reactions involving microbial } \\
\text { processes and species not presently modeled (nitrates, } \\
\text { phosphates) could have a limited effect on pH. }\end{array}$ \\
\hline & Mineral solid-solutions & $\begin{array}{l}\text { Ideal solid-solution treatment for clays; no treatment for } \\
\text { other minerals. } \\
\text { Compositions of primary solid solution phases, when } \\
\text { known, are directly taken into account by the relative } \\
\text { amounts of individual end-members input into the model. } \\
\text { Individual mineral phases with fixed solid-solution } \\
\text { compositions (determined by analysis) are included in the } \\
\text { simulations (e.g., zeolites). }\end{array}$ & $\begin{array}{l}\text { Limited anticipated effect because solid solutions are } \\
\text { partially treated as described in the adjacent table column. } \\
\text { This primarily affects the composition of precipitating alkali } \\
\text { feldspars (thus affecting predicted Na and K } \\
\text { concentrations). However, these minerals form nearly } \\
\text { pure secondary phases in nature (i.e., as modeled). } \\
\text { Zeolites in the repository host units (mostly stellerite) are } \\
\text { not abundant and not particularly variable in composition. }\end{array}$ \\
\hline & $\begin{array}{l}\text { lon-exchange and } \\
\text { surface complexation }\end{array}$ & $\begin{array}{l}\text { Not explicitly treated. However, precipitation/ dissolution of } \\
\text { mineral solid solutions and pure end-member phases (for } \\
\text { clays and zeolites, respectively), accounts for this to some } \\
\text { degree. } \\
\text { Dominant primary rock minerals in the repository host units } \\
\text { are not strong ion exchangers (for major ions). } \\
\text { THC seepage simulations do not include trace elements } \\
\text { that could be strongly affected by surface complexation. }\end{array}$ & $\begin{array}{l}\text { Limited effect for the current application range of the THC } \\
\text { seepage model. However, a limited shift in the predicted } \\
\text { concentrations of } \mathrm{Na}, \mathrm{K}, \mathrm{Ca} \text {, and } \mathrm{Mg} \text { could still affect } \\
\text { significantly the composition of end-brines upon complete } \\
\text { evaporation. }\end{array}$ \\
\hline
\end{tabular}


Table 6.6-1. Summary of Uncertainties Affecting Chemical Processes in the THC Seepage Model (Continued)

\begin{tabular}{|c|c|c|c|}
\hline Category & Issue & Treatment & Consequences \\
\hline $\begin{array}{l}\text { Conceptual } \\
\text { uncertainties } \\
\text { (cont.) }\end{array}$ & $\begin{array}{l}\text { Capillary pressure } \\
\text { effect on chemical } \\
\text { potentials of reacting } \\
\text { species }\end{array}$ & $\begin{array}{l}\text { Not treated. } \\
\text { It is taken indirectly into account through adjustments of } \\
\text { thermodynamic data such that ambient water compositions } \\
\text { can be reproduced. }\end{array}$ & $\begin{array}{l}\text { Could potentially shift predicted concentrations of some } \\
\text { species. }\end{array}$ \\
\hline \multirow[t]{4}{*}{$\begin{array}{l}\text { Data } \\
\text { uncertainties }\end{array}$} & $\begin{array}{l}\text { Infiltration water and } \\
\text { initial pore-water } \\
\text { composition }\end{array}$ & $\begin{array}{l}\text { Five alternate water analyses are used in REV } 02 \\
\text { simulations, covering fairly well the compositional } \\
\text { variability of pore waters in repository host units. } \\
\text { Uncertainty can be assessed by comparing predictions of } \\
\text { ambient water compositions with measured ambient } \\
\text { pore-water compositions and pore-gas } \mathrm{CO}_{2} \\
\text { concentrations. }\end{array}$ & $\begin{array}{l}\text { Input water compositions affect predicted water } \\
\text { compositions around the drift, and likely more so through } \\
\text { infiltration/transport than through reaction. }\end{array}$ \\
\hline & $\begin{array}{l}\text { Carbon dioxide partial } \\
\text { pressures }\end{array}$ & $\begin{array}{l}\text { Composition of infiltrating water input into the model } \\
\text { essentially dictates the boundary } \mathrm{CO}_{2} \text { pressure; therefore, } \\
\text { the uncertainty in infiltrating water composition overcomes } \\
\text { this uncertainty. However, various infiltrating waters are } \\
\text { assumed to equilibrate at the same boundary } \mathrm{CO}_{2} \\
\text { pressure (around } 3200 \text { ppmv). }\end{array}$ & $\begin{array}{l}\text { A large effect is not expected within the possible range of } \\
\text { observed natural concentrations because the range of } \\
\text { thermally induced } \mathrm{CO}_{2} \text { partial pressures is much larger } \\
\text { than (and thus overwhelms) background concentrations. }\end{array}$ \\
\hline & $\begin{array}{l}\text { Thermodynamic and } \\
\text { kinetic data }\end{array}$ & $\begin{array}{l}\text { Treated partly through sensitivity studies on long-term } \\
\text { behavior of ambient system chemistry, assuming a fixed } \\
\text { infiltration rate and different thermodynamic data for clays } \\
\text { and zeolites (the model is very sensitive to the } \\
\text { thermodynamic data for these minerals). } \\
\text { When possible within the uncertainty of the original data, } \\
\text { treated by revising the data to reproduce observed water } \\
\text { compositions and mineralogical data. } \\
\text { Other uncertainties treated through model validation (Drift } \\
\text { Scale Test and laboratory experiments). }\end{array}$ & $\begin{array}{l}\text { Currently one of the main uncertainties affecting predicted } \\
\text { water compositions around the drift. However, it can be } \\
\text { constrained by adjustments and model validation against } \\
\text { observed data, such that ambient simulations predict } \\
\text { concentrations consistent with observed values. }\end{array}$ \\
\hline & Host rock mineralogy & $\begin{array}{l}\text { Treated by considering alternative drift locations (Tptpmn } \\
\text { versus Tptpll host rock unit). } \\
\text { Bulk chemical composition of the repository host units do } \\
\text { not differ significantly. }\end{array}$ & $\begin{array}{l}\text { No significant effect on the predicted compositions of major } \\
\text { aqueous species. Small amounts of fast reacting minerals } \\
\text { containing elements present in minor quantities in pore } \\
\text { water (e.g., fluorite) can have a large effect on the } \\
\text { predicted concentrations of these minor species (e.g., } \mathrm{F}^{-} \text {) }\end{array}$ \\
\hline
\end{tabular}


Table 6.6-1. Summary of Uncertainties Affecting Chemical Processes in the THC Seepage Model (Continued)

\begin{tabular}{|c|c|c|c|}
\hline Category & Issue & Treatment & Consequences \\
\hline $\begin{array}{l}\text { Data } \\
\text { uncertainties } \\
\text { (cont.) }\end{array}$ & Infiltration rates & Alternative infiltration rate scenarios are used. & $\begin{array}{l}\text { Between } 6 \text { and } 25 \mathrm{~mm} / \mathrm{yr} \text {, there is a small effect on } \\
\text { predicted concentrations at the drift wall. The effect would } \\
\text { be greater under lower rates of infiltration (when reaction } \\
\text { effects start to dominate transport), but such conditions } \\
\text { would be less likely to cause in-drift seepage. } \\
\text { At high-infiltration rates, most conducive to in-drift } \\
\text { seepage, water compositions are more a function of } \\
\text { transport than of reaction with host rock minerals, such that } \\
\text { the uncertainty regarding the composition of the infiltration } \\
\text { water, rather than the rate of mineral dissolution/ } \\
\text { precipitation, becomes more important. }\end{array}$ \\
\hline \multirow[t]{2}{*}{$\begin{array}{l}\text { Parameter } \\
\text { uncertainties }\end{array}$} & Heterogeneity & $\begin{array}{l}\text { Heterogeneous fracture permeability was used in an earlier } \\
\text { (REV01) model, but the current model assumes } \\
\text { homogeneous fracture permeability. } \\
\text { Heterogeneity in matrix properties not treated. } \\
\text { Local heterogeneity in mineralogy not treated; however, } \\
\text { the bulk composition of host rocks is fairly uniform. } \\
\text { Heterogeneity in initial water geochemistry not treated } \\
\text { directly; treated indirectly through testing with alternate } \\
\text { water compositions. }\end{array}$ & $\begin{array}{l}\text { Possible local changes in predicted water compositions } \\
\text { around the drift. However, the bulk composition of waters } \\
\text { around the drift is not expected to be significantly affected, } \\
\text { because the rock chemical composition and mineralogy in } \\
\text { the repository units is fairly homogeneous. Comparison of } \\
\text { REV01 results showed that heterogeneous fracture } \\
\text { permeability had little effect (Section 6.6). }\end{array}$ \\
\hline & $\begin{array}{l}\text { Transport parameters } \\
\text { (effective diffusivity) }\end{array}$ & $\begin{array}{l}\text { The } \mathrm{CO}_{2} \text { diffusion coefficient was changed by a factor of } 6 \\
\text { between REV01 and REV02 analyses (and a factor of } 30 \\
\text { since earlier simulations). } \\
\text { Sensitivity to diffusion coefficient for aqueous species was } \\
\text { not investigated. However, tortuosity was changed from } \\
0.2 \text { to } 0.7 \text { between earlier report revisions (REV00 and } \\
\text { REV01) without noticeable effect. }\end{array}$ & $\begin{array}{l}\mathrm{CO}_{2} \text { diffusion coefficient mainly affects in-drift predicted } \\
\mathrm{CO}_{2} \text { concentrations during dryout. At other times, } \\
\text { predicted } \mathrm{CO}_{2} \text { concentrations are mainly dictated by water } \\
\text { compositions. }\end{array}$ \\
\hline
\end{tabular}




\subsubsection{Evaluation of Model Result Uncertainty}

Model sensitivities to key input parameters are evaluated through use of additional simulations with modified parameter sets/model conditions, and use of developmental model runs with differing input parameters (Section 6.5). Furthermore, confidence in model results is obtained by comparing model results against data from the DST and laboratory experiments (Section 7), and improving the model conceptualization and mathematical formulation (e.g., incorporating vapor pressure lowering due to capillary effects, making the drift wall open to advective and diffusive flow; adding minerals and aqueous species to the geochemical system; Sections 6.2 to 6.4), as necessary, to yield a reasonably good agreement between calculated and measured data (i.e., per LP-SIII.10Q-BSC, 5.3.2(c)(1)).

In this study, the spread in predicted concentrations of aqueous species and $\mathrm{CO}_{2}$ gas (Figures 6.5-11 to 6.5-20 and 6.5-24 to 6.5-37) is related to:

- The natural variability of input water compositions (Sections 6.2.2.1)

- The various investigated model conceptualizations (vapor-pressure model, drift location, stratigraphic columns, open versus closed drift wall) (Table 6-1)

- Ranges of input parameters other than water composition (in this case, infiltration rates and $\mathrm{CO}_{2}$ diffusion coefficients) (Section 6.5.4).

The relative spread caused by the variability of input water compositions (computed as standard deviation) is shown as a function of time in Table 6.6-2. This spread is up to one order of magnitude and in many cases much less. The spread overlaps with, and in most cases is larger than, the spread introduced by use of the different model conceptualizations and ranges of other input data considered (compare Figures 6.5-24a through 6.5-37a to Figures $6.5-24 \mathrm{~b}$ through 6.5-37b). This is quantitatively demonstrated in Post-Processing Analysis for THC Seepage (BSC 2004 [DIRS 169858]).

One model validation criterion for use with the DST THC submodel is that gas and aqueous species concentrations are predicted to within an order of magnitude, resulting in an acceptable range for DST comparisons, of two orders of magnitude. The scatter in model results for the five starting waters, is always much less than this (Table 6.2.2). Nevertheless, the scatter in the starting waters is a more relevant estimate of uncertainty, for several reasons. The model validation criterion used with the DST THC submodel accounts for error in the measured values (due to sampling issues; Section 7.1.7.1), as well as uncertainty in the modeled values, and recognizes that the relatively small scale of the DST makes it sensitive to local heterogeneities in the host rock.

Also, the uncertainties in many of the parameters passed downstream from the THC seepage model are constrained to a relatively narrow range of values by the coupled processes that are validated by the DST THC submodel. For instance, nitrate and chloride behave conservatively in the model, so their concentration in solution is mostly a function of the degree of evaporation and condensation. These are controlled by heat and vapor transfer, processes that are well predicted by the DST THC submodel (Section 7.1.9). The conservative behavior means that the 
spread in the nitrate/chloride ratio closely matches that of the initial solutions (BSC 2004 [DIRS 169858], Figure 6.2-9). Changes in this ratio in any given run occur only during rewetting, when previously precipitated salts redissolve (Figure 6.3-4), and may be a function of the model implementation of salt dissolution/reprecipitation (Section 6.4.5).

Most of the other parameters of importance to downstream models are also constrained to relatively narrow ranges due to the processes validated by the DST THC submodel. Interactions with calcite and aluminosilicates serve to buffer the $\mathrm{pH}$ to a narrow range of values. $\mathrm{CO}_{2}$ diffuses readily and is not strongly affected by local heterogeneities. Its concentration is mostly a function of the temperature, displacement by water vapor due to boiling, and dissolution of calcite in zones of condensate formation and drainage. All of these processes buffer the response of the chemical system to thermal perturbation, tending to reduce the spread in predicted water chemistries, especially over longer time intervals (BSC 2004 [DIRS 169858], Figures 6.2-4 to 6.2-20). The concentrations of reactive aqueous species are buffered to a narrow range of values, while conservative species concentrations are a function of the starting water composition and the degree of evaporation/condensation. Concentration ratios for conservative species are largely those of the starting waters. Thus, the uncertainty in the THC seepage model is adequately captured by the variability in the initial pore water compositions input into the model.

Uncertainties in kinetic and thermodynamic data could affect the standard deviations shown in Table 6.6-2, although the results of model validation against the DST and other laboratory experiments (Section 7), as well as the results of simulations of ambient conditions (Section 6.5.5.4), suggest these data are constrained to the extent that the model results are generally consistent with measured data. The model validation results (Section 7) also provide confidence that some of the other uncertainties listed in Table 6.6-1 do not significantly affect the spread in model results. This could be because model validation results are either not very sensitive to these uncertainties (at least over the period of time covered by the validation simulations) or that the effects of some of these uncertainties cancel out.

Table 6.6-2. Standard Deviations in Water and Gas Compositions Predicted Using Five Different Input Water Compositions (W0, W4, W5, W6, and W7)

\begin{tabular}{|c|c|c|c|c|c|c|c|c|}
\hline Time (yr) & $\mathbf{p H}$ & $\mathbf{C a}$ & $\mathbf{M g}$ & $\mathbf{N a}$ & $\mathbf{C l}$ & $\mathbf{S i O}_{2}(\mathbf{a q})$ & $\mathbf{H C O}_{3}$ & $\mathbf{S O}_{4}$ \\
\hline 0 & 0.11 & 0.11 & 0.52 & 0.18 & 0.29 & 0.08 & 0.14 & 0.37 \\
\hline 1 & 0.10 & 0.17 & 0.90 & 0.13 & 0.29 & 0.05 & 0.16 & 0.37 \\
\hline 53 & 0.14 & 0.15 & 0.82 & 0.25 & 0.37 & 0.20 & 0.22 & 0.44 \\
\hline 100 & 0.13 & 0.04 & 0.23 & 0.11 & 0.31 & 0.06 & 0.16 & 0.39 \\
\hline 200 & 0.09 & 0.23 & 0.38 & 0.16 & 0.40 & 0.14 & 0.23 & 0.46 \\
\hline 300 & 0.10 & 0.40 & 0.35 & 0.26 & 0.46 & 0.19 & 0.30 & 0.51 \\
\hline 400 & 0.11 & 0.35 & 0.38 & 0.24 & 0.40 & 0.16 & 0.22 & 0.44 \\
\hline 500 & 0.15 & 0.41 & 0.49 & 0.29 & 0.44 & 0.17 & 0.13 & 0.51 \\
\hline 600 & 0.17 & 0.42 & 0.47 & 0.26 & 0.40 & 0.16 & 0.13 & 0.45 \\
\hline 700 & 0.10 & 0.24 & 0.34 & 0.15 & 0.31 & 0.06 & 0.10 & 0.38 \\
\hline 801 & 0.10 & 0.20 & 0.28 & 0.12 & 0.30 & 0.04 & 0.07 & 0.37 \\
\hline 1,000 & 0.09 & 0.16 & 0.23 & 0.10 & 0.29 & 0.02 & 0.06 & 0.37 \\
\hline 1,200 & 0.09 & 0.15 & 0.22 & 0.09 & 0.29 & 0.02 & 0.08 & 0.37 \\
\hline 2,000 & 0.08 & 0.18 & 0.19 & 0.08 & 0.32 & 0.01 & 0.07 & 0.38 \\
\hline 2,200 & 0.06 & 0.18 & 0.17 & 0.06 & 0.29 & 0.02 & 0.08 & 0.37 \\
\hline 2,400 & 0.06 & 0.18 & 0.17 & 0.06 & 0.29 & 0.02 & 0.07 & 0.37 \\
\hline
\end{tabular}


Table 6.6-2. Standard Deviations in Water and Gas Compositions Predicted Using Five Different Input Water Compositions (W0, W4, W5, W6, and W7) (Continued)

\begin{tabular}{|c|c|c|c|c|c|c|c|c|}
\hline Time (yr) & $\mathrm{K}$ & $\mathbf{F}$ & $\mathrm{NO}_{3}$ & $\mathrm{CO}_{2 \text { (gas) }}$ & $\mathrm{Ca} / \mathrm{HCO}_{3}$ & $\mathrm{NO}_{3} / \mathrm{Cl}$ & $\mathrm{Na} / \mathrm{Cl}$ & $\mathrm{Ca} / \mathrm{Cl}$ \\
\hline 5,000 & 0.05 & 0.14 & 0.14 & 0.06 & 0.29 & 0.01 & 0.07 & 0.37 \\
\hline 10,000 & 0.03 & 0.14 & 0.10 & 0.06 & 0.29 & 0.01 & 0.08 & 0.37 \\
\hline 20,000 & 0.04 & 0.14 & 0.11 & 0.06 & 0.29 & 0.01 & 0.09 & 0.37 \\
\hline 100,000 & 0.03 & 0.13 & 0.08 & 0.05 & 0.29 & 0.02 & 0.10 & 0.37 \\
\hline Time (yr) & K & $F$ & $\mathrm{NO}_{3}$ & $\mathrm{CO}_{2 \text { (gas) }}$ & $\mathrm{Ca} / \mathrm{HCO}_{3}$ & $\mathrm{NO}_{3} / \mathrm{Cl}$ & $\mathrm{Na} / \mathrm{Cl}$ & $\mathrm{Ca} / \mathrm{Cl}$ \\
\hline 0 & 0.06 & 0.30 & 0.27 & 0.23 & 0.19 & 0.38 & 0.36 & 0.24 \\
\hline 1 & 0.12 & 0.06 & 0.27 & 0.21 & 0.30 & 0.38 & 0.34 & 0.17 \\
\hline 53 & 0.24 & 0.25 & 0.35 & 0.32 & 0.33 & 0.38 & 0.27 & 0.31 \\
\hline 100 & 0.11 & 0.08 & 0.30 & 0.29 & 0.19 & 0.38 & 0.29 & 0.27 \\
\hline 200 & 0.16 & 0.12 & 0.33 & 0.32 & 0.45 & 0.38 & 0.32 & 0.21 \\
\hline 300 & 0.27 & 0.18 & 0.42 & 0.34 & 0.68 & 0.37 & 0.28 & 0.19 \\
\hline 400 & 0.24 & 0.13 & 0.40 & 0.25 & 0.53 & 0.37 & 0.19 & 0.12 \\
\hline 500 & 0.29 & 0.12 & 0.39 & 0.13 & 0.51 & 0.37 & 0.17 & 0.11 \\
\hline 600 & 0.27 & 0.13 & 0.41 & 0.08 & 0.54 & 0.38 & 0.16 & 0.17 \\
\hline 700 & 0.16 & 0.08 & 0.29 & 0.07 & 0.33 & 0.38 & 0.17 & 0.16 \\
\hline 801 & 0.12 & 0.07 & 0.28 & 0.07 & 0.27 & 0.38 & 0.18 & 0.14 \\
\hline 1,000 & 0.10 & 0.05 & 0.27 & 0.03 & 0.22 & 0.38 & 0.20 & 0.15 \\
\hline 1,200 & 0.09 & 0.04 & 0.27 & 0.01 & 0.23 & 0.38 & 0.21 & 0.15 \\
\hline 2,000 & 0.08 & 0.07 & 0.28 & 0.01 & 0.25 & 0.38 & 0.23 & 0.15 \\
\hline 2,200 & 0.07 & 0.07 & 0.27 & 0.03 & 0.26 & 0.38 & 0.23 & 0.12 \\
\hline 2,400 & 0.07 & 0.07 & 0.27 & 0.02 & 0.25 & 0.38 & 0.23 & 0.12 \\
\hline 5,000 & 0.07 & 0.06 & 0.27 & 0.04 & 0.21 & 0.38 & 0.23 & 0.15 \\
\hline 10,000 & 0.06 & 0.05 & 0.27 & 0.08 & 0.17 & 0.38 & 0.25 & 0.20 \\
\hline 20,000 & 0.06 & 0.06 & 0.27 & 0.12 & 0.15 & 0.38 & 0.26 & 0.22 \\
\hline 100,000 & 0.05 & 0.05 & 0.27 & 0.11 & 0.15 & 0.38 & 0.26 & 0.24 \\
\hline
\end{tabular}

Output DTN: LB0307DSTTHCR2.002.

NOTE: Standard deviations are computed using data depicted in Figures 6.5-25 (top) through 6.5-37 (top) (zones of highest liquid saturation above the drift) and represent:

- For $\mathrm{pH}$, standard deviation of $\mathrm{pH}$ values in $(+) \mathrm{pH}$ units.

- For other data, standard deviation of logarithmic values: i.e., (+) change in log10 values of concentrations and concentration ratios around the mean of log 10 values (thus, a value of 0.5 corresponds to a total spread of one order of magnitude). 


\section{INTENTIONALLY LEFT BLANK}




\section{VALIDATION}

This section describes models and data used to validate the THC seepage model and input for the THC seepage model. Validation of the model is accomplished through comparison of simulation results to data collected from the Drift Scale Test (DST) and to laboratory experiments that explore various specific aspects of the model. The DST THC submodel is derived from the THC seepage model, relying on the same conceptual model, modeling the same coupled processes in the same manner, and using many of the same input data (i.e., intrinsic physical, hydrologic, thermodynamic, and kinetic parameters). Because the DST THC submodel is a special case of the THC seepage model, evaluation of the DST THC submodel serves to validate the THC seepage model.

The DST THC submodel and comparison of model simulation results to measured data are presented in Section 7.1. The validation of the THC models by comparison of DST THC submodel results with chemical data for water and gas samples is subject to a variety of uncertainties. These uncertainties are discussed in detail throughout Section 7, but can be summarized as follows. First, TH processes can lead to spatial differences in the chemistry of water and gases by a few orders of magnitude (Section 7.1.10.2) over very small increments in temperature as a result of boiling and mineral-water reactions. In contrast, temperature exhibits much less spatial variation because it is controlled mainly by conduction in the rock matrix. Second, strong differences in aqueous species concentrations that develop in fractures and the adjacent matrix can be maintained owing to the slow rates of diffusion of aqueous species between them (Section 7.1.11.3). Third, changes that the samples undergo during their extraction from the rock (e.g., cooling, degassing, condensation) have the potential for shifting the aqueous species compositions. Some measured quantities, such as $\mathrm{pH}$, are sensitive to liquid-gas interactions such that shifts in water composition can be orders of magnitude. Sources of data used for model validation are shown in Table 7-1. The approach to model validation acknowledges these uncertainties in the evaluation of model-data comparisons, in establishing and applying the validation criteria, and in the description of uncertainty that is provided for downstream use of THC seepage model results.

Methods and criteria for validating the THC seepage model through the DST THC submodel are described in Section 7.1.7; the validation results are described in the rest of Section 7.1. For Level II validation, Section 2.2.2.2 of Technical Work Plan for: Near-Field Environment and Transport: Coupled Processes (Mountain-Scale TH/THC/THM, Drift-Scale THC Seepage, and Post-Processing Analysis for THC Seepage) Report Integration (BSC 2005 [DIRS 172761]) specifies the following steps for "Confidence Building During Model Development." The development of the model should be documented in accordance with the requirements of Section 5.3.2(b) of LP-SIII.10Q-BSC. The development of the THC seepage model has been conducted according to these criteria in order to establish the scientific basis for the model, as follows:

1. Selection of input parameters and/or input data, and a discussion of how the selection process builds confidence in the model [LP-SIII.10Q-BSC, 5.3.2(b) (1) and LP-2.29Q-BSC, Attachment 3 Level I (a)].

The inputs to the THC seepage model have been obtained from controlled sources (see Table 4.1-1, Section 4.1), or, if older data, have been evaluated and justified for 
intended use (Section 4.1) in this report. Selection and development of input and design parameters is described in detail in Sections 4.1, 6.2, 6.4.8, 6.5, and Appendix C. Model assumptions have been described in Section 5. Detailed discussion about model concepts can be found in Section 6.2.

2. Description of calibration activities, and/or initial boundary condition runs, and/or run convergences, simulation conditions set up to span the range of intended use and avoid inconsistent outputs, and a discussion of how the activity or activities build confidence in the model. Inclusion of a discussion of impacts of any non-convergence runs [(LP-SIII.10Q-BSC, 5.3.2(b)(2) and LP-2.29Q-BSC, Attachment 3 Level I (e)].

Detailed discussion of initial and boundary conditions for the THC seepage model can be found in Section 4.1 (initial model inputs); Section 6.2.2.1 (pore water compositions); Section 6.4.3 (mineral reactive surface areas); and Section 6.5.2 and Section 6.5.3 (boundary conditions and initial inputs). Calibration of the model to ambient pore water compositions is described in Sections 6.4.8 and 6.5.5.4. Section 6.5 provides detailed discussion of various model results (i.e., those of convergence runs). Discussion about issues with non-convergence runs can be found in Section 6.4.8. Additional information regarding convergence issues can be found in the file "chdump.dat" described in Appendix G.

3. Discussion of the impacts of uncertainties to the model results including how the model results represent the range of possible outcomes consistent with important uncertainties [( LP-SIII.10Q-BSC, 5.3.2(b)(3) and LP-2.29Q-BSC, Attachment 3 Level 1 (d) and (f)].

Discussion of model uncertainties and sensitivity analyses are provided in Section 6.6. A summary discussion on uncertainties and their impact is given in Section 8.4.

4. Formulation of defensible assumptions and simplifications [LP-2.29Q-BSC,
[Len Attachment 3 Level I (b)].

Comprehensive discussions of assumptions and simplifications are provided in Section 5 and Section 6.4.6, respectively.

5. Consistency with physical principles, such as conservation of mass, energy, and momentum [LP-2.29Q-BSC, Attachment 3 Level I (c)].

Consistency with physical principles is demonstrated by the conceptual and mathematical formulation in Sections 6.2 and 6.4, and the selection and use of the TOUGHREACT V.3.0 code (LBNL 2002 [DIRS 161256]) in Section 3.

For confidence building after model development, Section 2.2.2.2, "Confidence Building After Model Development" of the technical work plan (BSC 2005 [DIRS 172761]) imposes the following requirements for model validation to support the scientific basis:

1. LP-SIII.10Q-BSC, Section 5.3.2(c)(1), Method 1: Corroboration of results from a derivative simulation, closely similar to the THC Seepage Model but adapted to the DST, with data acquired from the DST. 
Comparison of model results with experimental data is the main method of validation for the THC seepage model. Section 7.1 explains the respective validation and modeling activities in great detail, and discusses explicitly how the criteria for this validation method, as defined in Section 2.2.2.2 of the TWP (BSC 2005 [DIRS 172761]), have been met.

2. LP-SIII.10Q-BSC, Section 5.3.2(d), Technical review through publication in a refereed professional journal.

Additional confidence is obtained through technical review by publication in a refereed professional journal (BSC 2005 [DIRS 172761]). Since the following articles on the subject have already been published, additional confidence has been obtained:

- "Fluid Flow and Reactive Transport Around Potential Nuclear Waste Emplacement Tunnels at Yucca Mountain, Nevada." Journal of Contaminant Hydrology (Spycher et al. 2003 [DIRS 162121]).

- "Experimental and Numerical Simulation of Dissolution and Precipitation: Implications for Fracture Sealing at Yucca Mountain, Nevada." Journal of Contaminant Hydrology (Dobson et al. 2003 [DIRS 165949]).

In addition to use of the DST THC submodel, confidence in the THC seepage model is provided by model-data comparisons from laboratory-scale experiments. Two such experiments have been modeled: a plug-flow reactor to evaluate tuff dissolution (Section 7.2) and a fracture sealing experiment (Section 7.3). Comparisons between the experimentally measured and simulated results using TOUGHREACT are used to test conceptual models that were developed for the THC seepage model and the DST THC submodels. These simulations were performed using previous revisions of TOUGHREACT software and using previous versions of the thermodynamic database. Thus, they do not directly validate the current THC model, but provide added confidence in the conceptual model and modeling approach that are implemented by TOUGHREACT, the basis of the THC seepage model. A brief summary of each of these model-data comparison studies is provided here. The simulations are discussed in detail in a previous revision of this report (BSC 2004 [DIRS 168848], Sections 7.2 and 7.3). 
Table 7-1. Sources of Data Used for Model Validation or Corroboration

\begin{tabular}{|c|c|}
\hline DTNs & Description \\
\hline \multicolumn{2}{|l|}{ Mineralogical Data (DST) } \\
\hline LA0201SL831225.001 [DIRS 158426] & Sidewall core sample mineralogical analyses \\
\hline \multicolumn{2}{|l|}{ Analytical Water and Gas Chemistry Data } \\
\hline LB0102CO2DST98.001 [DIRS 159306] & $\mathrm{CO}_{2}$ gas analyses (1st, 2nd, 3rd, and 7th Qtr.) \\
\hline LB990630123142.003 [DIRS 111476] & 4th, 5th, and 6th Qtr. DST $\mathrm{CO}_{2}$ data \\
\hline LB000121123142.003 [DIRS 146451] & DST $\mathrm{CO}_{2}$ data $(8 / 99$ to $11 / 99)$ \\
\hline LB0011CO2DST08.001 [DIRS 153460] & DST $\mathrm{CO}_{2}$ data $(11 / 99$ to $8 / 2000)$ \\
\hline CRWMS M\&O 2001 [DIRS 153814] & DST $\mathrm{CO}_{2}$ data $(7 / 98)$ \\
\hline LB0208ISODSTHP.001 [DIRS 161638] & DST $\mathrm{CO}_{2}$ and isotopic data (combined) \\
\hline MO0005PORWATER.000 [DIRS 150930] & $\begin{array}{l}\text { Analyses of pore waters from Alcove } 5 \text { core samples in the ESF (HD- } \\
\text { PERM-2 and HD-PERM-3 samples) }\end{array}$ \\
\hline LL990702804244.100 [DIRS 144922] & Aqueous chemistry of water sampled from the DST (6/4/98 to $3 / 30 / 99)$ \\
\hline LL001100931031.008 [DIRS 153288] & $\begin{array}{l}\text { Aqueous chemistry of water sampled from the DST (collected } 10 / 27 / 99 \\
\text { to } 1 / 25 / 00 \text { ) }\end{array}$ \\
\hline MO0207AL5WATER.001 [DIRS 159300] & DST Field measurements \\
\hline SN0203F3903102.001 [DIRS 159133] & DST Field measurements \\
\hline LL020405123142.019 [DIRS 159307] & DST Aqueous chemistry \\
\hline LL020302223142.015 [DIRS 159134] & DST Aqueous chemistry \\
\hline LL001200231031.009 [DIRS 153616] & $\begin{array}{l}\text { Aqueous chemistry of water sampled from the DST (8/9/99 and } \\
8 / 10 / 99)\end{array}$ \\
\hline MO0101SEPFDDST.000 [DIRS 153711] & Field $\mathrm{pH}$ of water sampled from DST on $5 / 23 / 00$ and $6 / 29 / 00$ \\
\hline
\end{tabular}

\subsection{THE DRIFT SCALE TEST THC SUBMODEL}

The DST is the second underground thermal test to be carried out in the Exploratory Studies Facility (ESF) at Yucca Mountain, Nevada. The purpose of the test is to evaluate the coupled thermal, hydrologic, chemical, and mechanical processes that take place in unsaturated fractured tuff over a range of temperatures (approximately $25^{\circ} \mathrm{C}$ to $200^{\circ} \mathrm{C}$ ). Details regarding the DST layout, borehole orientations, operation of the test, and measurements performed (as well as their uncertainties) are discussed in Section 6.3 of Thermal Testing Measurements Report (BSC 2004 [DIRS 169900]) and in Drift-Scale Test As-Built Report (CRWMS M\&O 1998 [DIRS 111115]). Information on these aspects of the DST is not repeated in this report unless directly related to the geochemical data collected and used for model validation.

In brief, the DST consists of an approximately 50-m-long drift that is $5 \mathrm{~m}$ in diameter. Nine electrical floor canister heaters were placed in this drift (the Heated Drift) to simulate nuclearwaste-bearing containers. Electrical heaters were also placed in a series of horizontal boreholes (wing heaters) drilled perpendicular outward from the central axis of the Heated Drift. These heaters were emplaced to simulate the effect of adjacent emplacement drifts. The DST heaters were activated on December 3, 1997, with a planned period of four years of heating, followed by four years of cooling. After just over four years, the heaters were switched off on January 14, 2002, and since that time the test area has been slowly cooling.

This section describes the DST THC submodel, discusses simulations of THC processes during the DST, and presents comparisons to geochemical measurements performed on gas, water, and mineral samples collected from the DST. The DST THC submodel is a forward numerical model used to gain insight into THC processes taking place during heating of the unsaturated 
devitrified tuffs. The DST THC submodel provides important support for application of the drift-scale THC seepage model to repository simulations. The drift-scale THC conceptual models are described in Sections 6.1 to 6.4. The DST THC submodel is compared with, but not calibrated to, geochemical data collected from the DST. This is important because calibration, if relied upon heavily in model development, could limit the use of the model for representing THC processes over repository time scales. The drift-scale hydrologic and thermal properties used in the DST THC submodel are based on systematic evaluation of hydrologic data from the overall unsaturated zone at Yucca Mountain (BSC 2004 [DIRS 169857]); the property values are not calibrated directly to DST results, but are best estimates for application to the site scale. Accordingly, more differences are observed in model-data comparisons, but use of the DST THC submodel in model validation better represents the other host rock units. Some modifications have been made to the thermodynamic database for the THC seepage model and the DST THC submodel, to capture aspects of the ambient-system pore-water chemistry (discussed in Section 4.1.4). The only other adjustments specific to the DST have been made to the connectivity of the Heated Drift to the Access Drift, to better represent heat losses through the intervening bulkhead.

Processes and data collected primarily during the heating phase of the DST are discussed in this report. The simulation results are compared to data from the full four-year heating phase (for data that are available) as a part of the model validation.

\subsubsection{Modeling Approach}

The modeling approach involves the creation of a numerical grid and the selection or development of thermal, hydrologic, mineralogical, aqueous, and gaseous species geochemical input data. It also involves the selection of appropriate thermal and hydrologic models, as well as chemical, thermodynamic, and kinetic data and models. The approach and input data are described as follows in Sections 7.1.2 to 7.1.5.

\subsubsection{Drift Scale Test Two-Dimensional Numerical Grid}

The two-dimensional dual-permeability numerical grid for the DST represents a vertical cross section through the Heated Drift at a distance approximately $30 \mathrm{~m}$ from the bulkhead, separating the Heated Drift from the Access Drift (Figure 7.1-1).

The mesh used in the current simulations (Figures 7.1-2 and 7.1-3) has been modified slightly from that used in earlier revisions of the DST THC submodel. The earlier mesh consisted of 4,485 grid blocks, including fracture and matrix (DTN: LB0101DSTTHGRD.001 [DIRS 153687]). The top boundary is approximately $99 \mathrm{~m}$ above the drift center, with the bottom boundary at approximately $157 \mathrm{~m}$ below the center. Connections between the interior of the Heated Drift and the Heater Test Alcove included grid blocks designed to act as a bulkhead and as insulating material. Within the drift, heat is applied directly to the drift wall instead of explicitly representing the electric heaters and calculating the heat transfer across the air mass inside the drift. The DST includes a plane of linear wing heaters on each side of the drift that have been given small grid blocks in the model. Small grid blocks are also employed adjacent to the wing heaters and drift wall to capture the strong gradients in temperature and liquid saturation in these regions. Radial mesh blocks in the drift interior are replaced near the drift base by Cartesian grid blocks to represent the concrete invert. Incorporation of the concrete invert is unique to the DST THC submodel; it is not part of the model grid for the THC seepage 
model. Also, in the DST THC submodel, the concrete is only incorporated with respect to thermal and hydrologic properties - no cement phases are present in the geochemical system used.

For the current simulations (Figures 7.1-2 and 7.1-3), grid blocks representing the insulation and bulkhead have been removed, and the Heated Drift grid block is connected directly to the Heater Test Alcove grid block. The connection area and distance have been adjusted so that heat loss from the drift resulted in roughly similar crown temperatures to the maximum observed values. This is done to simulate heat and mass losses through the bulkhead, instead of reducing power by a set factor, as was done in earlier revisions of this model. In the approximate location of the observation drift, the grid block volumes are increased to a large value to represent connection to the atmosphere (Figure 7.1-2). Grid blocks that were removed previously (to represent a no-flux boundary for the observation drift) have been added and connected to adjacent grid blocks. The distances from the drift center grid block and the connecting elements have been modified to represent the true distance, so that heat could be applied to the drift center and not to the elements at the drift walls.

\subsubsection{Heater Power}

The DST THC submodel employs a nine-month initial period at ambient temperature, corresponding approximately to the time that was required to set up the test. The wing heaters are split into inner and outer zones, with more power applied to the outer zone to approximate the presence of an adjacent parallel drift. In the drift, heat is applied solely to the drift-center grid block, which is connected to all surrounding grid blocks. The positions of grid blocks representing heaters are shown in Figure 7.1-3.

The heating schedule is based on step-wise averages of the 10-day incremented power data (DTN: MO0208RESTRDST.002 [DIRS 161129]). The sources for this 10-day incremented power data are given in Table 7.1-1. Intentional power reductions are directly accounted for in the power data, using accurate time information gathered from the DTNs listed in Table 7.1-1. 


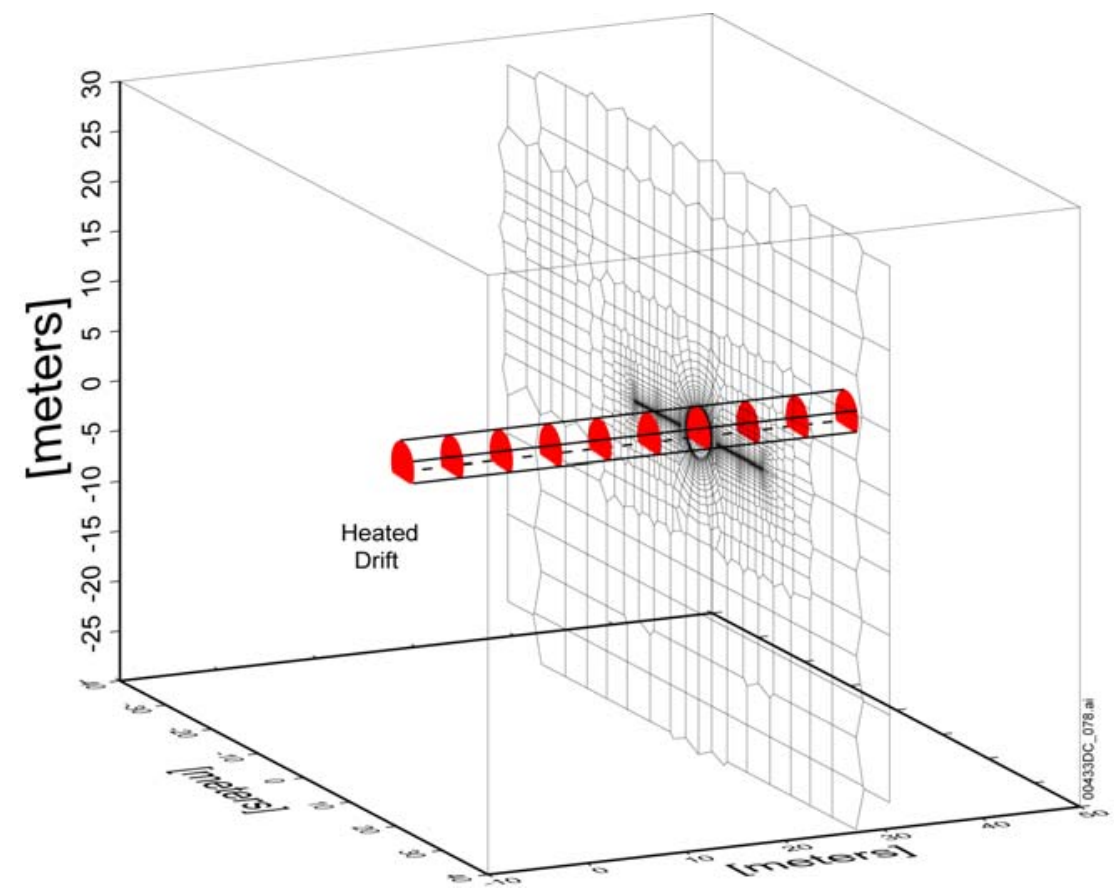

Output DTN: LB0307DSTTHCR2.001.

NOTE: Mesh extends in all directions from area shown.

Figure 7.1-1. Three-Dimensional Schematic Diagram of the DST Showing Perspective View of Numerical Mesh for DST THC Submodel Simulations

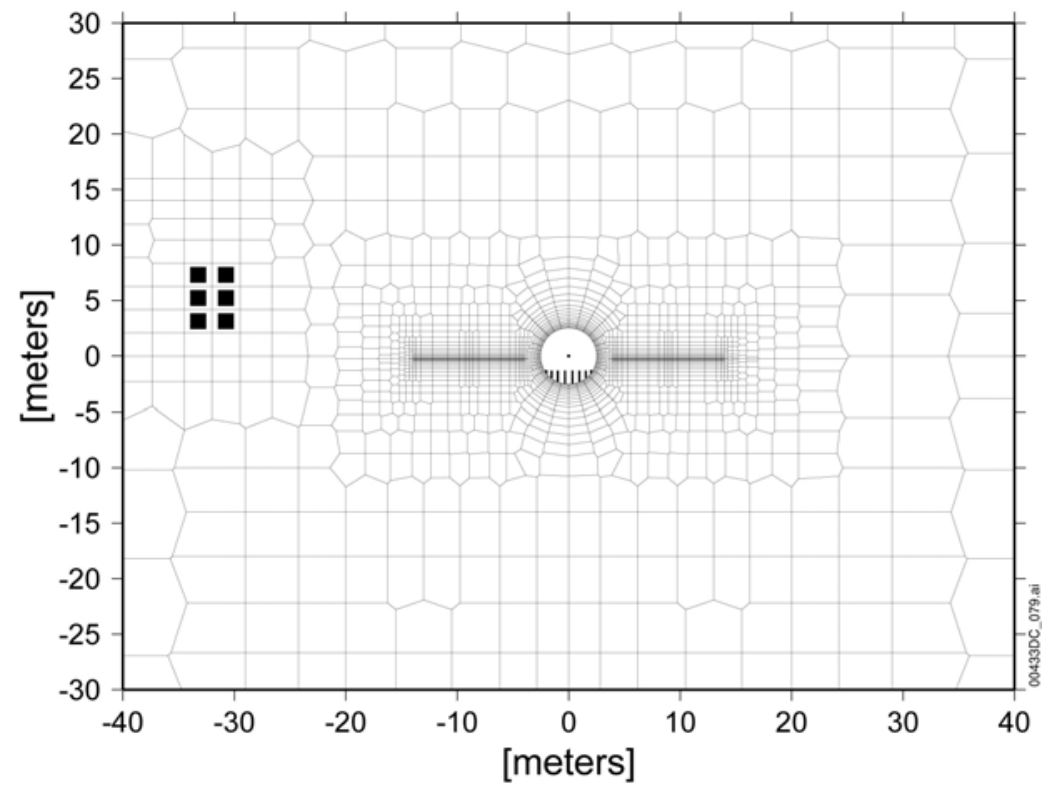

Output DTN: LB0307DSTTHCR2.001.

NOTE: The Observation Drift is shown as black squares. Mesh extends outside the area shown (see text). The Heated Drift is a circular region at the center.

Figure 7.1-2. Numerical Mesh for DST THC Submodel Simulations 


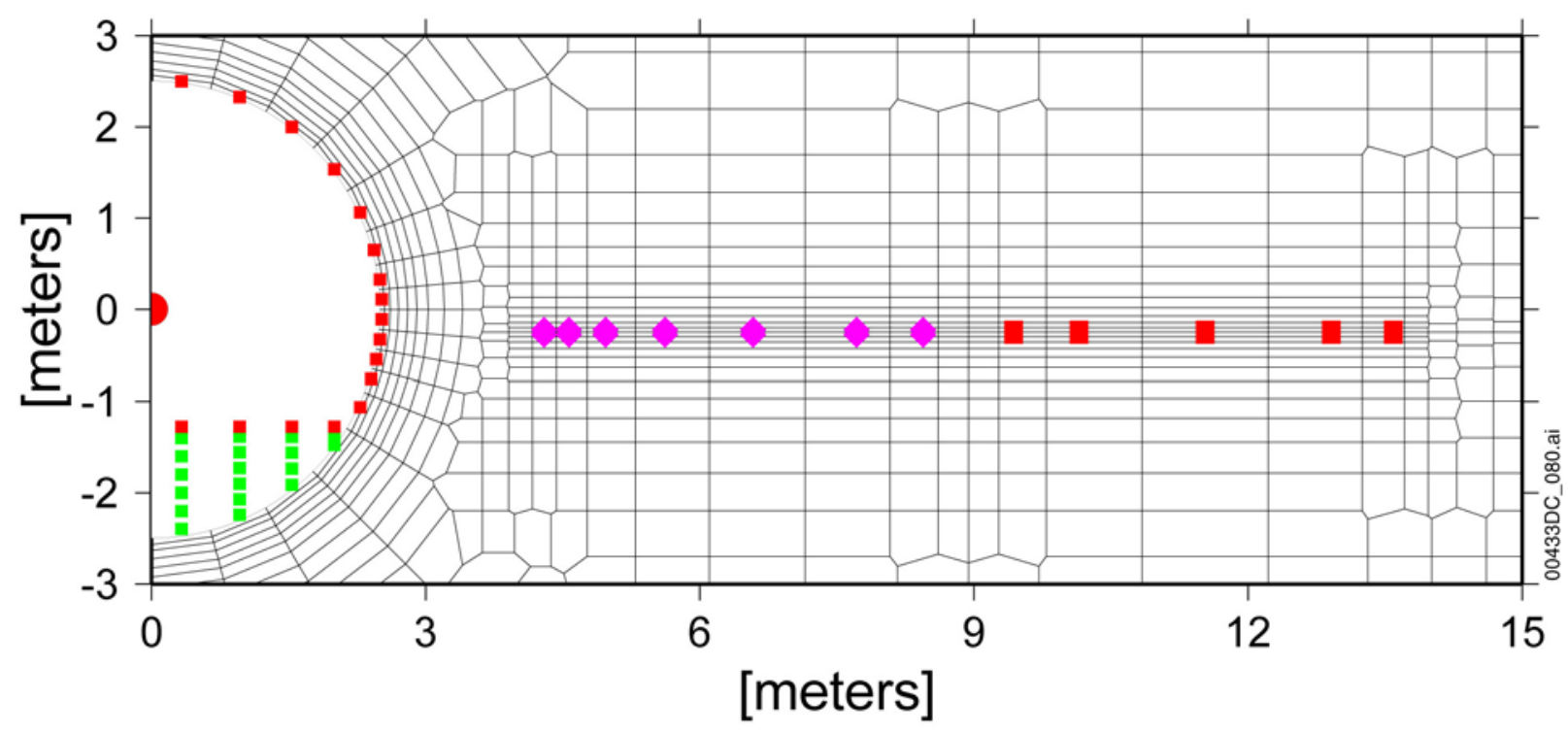

Output DTN: LB0307DSTTHCR2.001.

NOTE: Inner (violet diamonds closer to drift) and outer wing heater (large red squares) grid block coordinates. Heat is applied to grid block marked at drift center. Small red squares in the drift represent locations where heat was applied in the REV01 model. Green squares indicate grid block locations for the concrete invert.

Figure 7.1-3. Enlarged View of the Numerical Grid Showing the Locations of Grid Blocks Representing the Heated Drift, Wing Heaters, and Concrete Invert

Table 7.1-1. Input DTNs Used for Estimating Times/Dates of Power Reductions and Outages for DST THC Submodel Simulations

\begin{tabular}{|l|c|}
\hline \multicolumn{1}{|c|}{ Power Data Sources (DTNs) } & Dates \\
\hline MO0208RESTRDST.002 [DIRS 161129] & Heating Phase (10-day increments) \\
\hline MO9807DSTSET01.000 [DIRS 113644] & $11 / 7 / 97$ to $5 / 3 / 98$ \\
\hline MO9810DSTSET02.000 [DIRS 113662] & $6 / 1 / 98$ to $8 / 31 / 98$ \\
\hline MO9906DSTSET03.000 [DIRS 113673] & $9 / 1 / 98$ to $5 / 31 / 99$ \\
\hline MO0001SEPDSTPC.000 [DIRS 153836] & $6 / 1 / 99$ to $10 / 31 / 99$ \\
\hline MO0007SEPDSTPC.001 [DIRS 153707] & $11 / 1 / 99$ to $5 / 31 / 00$ \\
\hline MO0012SEPDSTPC.002 [DIRS 153708] & $6 / 1 / 00$ to $11 / 30 / 00$ \\
\hline MO0107SEPDSTPC.003 [DIRS 158321] & $12 / 1 / 00$ to $5 / 31 / 01$ \\
\hline MO0202SEPDSTTV.001 [DIRS 158320] & $6 / 1 / 01$ to $1 / 14 / 02$ \\
\hline
\end{tabular}

The DTNs in Table 7.1-1 are also used to estimate the length of the longer (approximately greater than 1/2 day) temporary power outages. Table 7.1-2 gives the step-wise averaged power data implemented in the DST THC submodel simulations. Each time in Table 7.1-2 represents the initiation of a specific period of heating or power loss that continues until the succeeding time. The simulations are run for the full period of heating plus a four-year period of cooling (shown by hypothetical end time at the base of Table 7.1-2). 
Table 7.1-2. Step-Wise Averaged Power Data for the DST THC Simulations

\begin{tabular}{|c|c|c|c|c|c|c|}
\hline Date & Time (s) & $\begin{array}{c}\text { Time } \\
\text { (days) }\end{array}$ & $\begin{array}{c}\text { Canister } \\
\text { Power (watts) }\end{array}$ & $\begin{array}{c}\text { WH (inner) } \\
\text { Power (watts) }\end{array}$ & $\begin{array}{c}\text { WH (outer) } \\
\text { Power (watts) }\end{array}$ & Comments \\
\hline $3 / 5 / 97$ & $0.00000 \mathrm{E}+00$ & 0.00 & 0.0000 & 0.0000 & 0.0000 & pre-test \\
\hline $12 / 3 / 97$ & $2.35872 \mathrm{E}+07$ & 273.00 & 1091.3740 & 1232.4007 & 1626.7690 & heaters turned on \\
\hline $3 / 15 / 98$ & $3.24000 \mathrm{E}+07$ & 375.00 & 1091.3740 & 0.0000 & 0.0000 & outage - right rib \\
\hline $3 / 16 / 98$ & $3.25080 \mathrm{E}+07$ & 376.25 & 1091.3740 & 1232.4007 & 1626.7690 & \\
\hline $4 / 12 / 98$ & $3.48192 \mathrm{E}+07$ & 403.00 & 1077.9972 & 1198.5773 & 1582.1220 & \\
\hline $8 / 10 / 98$ & $4.51872 E+07$ & 523.00 & 1119.6842 & 1201.8035 & 1586.3807 & \\
\hline 1/27/99 & $5.98752 \mathrm{E}+07$ & 693.00 & 0.0000 & 0.0000 & 0.0000 & power outage \\
\hline 1/27/99 & $5.99400 \mathrm{E}+07$ & 693.75 & 1123.5789 & 1204.4465 & 1589.8693 & \\
\hline 2/16/99 & $6.16032 \mathrm{E}+07$ & 713.00 & 1102.5965 & 1189.0805 & 1569.5862 & \\
\hline $5 / 27 / 99$ & $7.02432 \mathrm{E}+07$ & 813.00 & 0.0000 & 0.0000 & 0.0000 & power outage \\
\hline $5 / 27 / 99$ & $7.03080 \mathrm{E}+07$ & 813.75 & 1102.5965 & 1189.0805 & 1569.5862 & \\
\hline $5 / 29 / 99$ & $7.04160 \mathrm{E}+07$ & 815.00 & 0.0000 & 0.0000 & 0.0000 & power outage \\
\hline $5 / 30 / 99$ & $7.04808 \mathrm{E}+07$ & 815.75 & 1087.8653 & 1155.5245 & 1525.2923 & \\
\hline 6/18/99 & $7.21440 \mathrm{E}+07$ & 835.00 & 0.0000 & 0.0000 & 0.0000 & power outage \\
\hline 6/19/99 & $7.22088 \mathrm{E}+07$ & 835.75 & 1087.8653 & 1155.5245 & 1525.2923 & \\
\hline $7 / 9 / 99$ & 7.39584E+07 & 856.00 & 0.0000 & 0.0000 & 0.0000 & power outage \\
\hline $7 / 15 / 99$ & $7.44768 \mathrm{E}+07$ & 862.00 & 1087.8653 & 1155.5245 & 1525.2923 & \\
\hline 8/27/99 & $7.81920 \mathrm{E}+07$ & 905.00 & 0.0000 & 0.0000 & 0.0000 & power outage \\
\hline $8 / 29 / 99$ & $7.83216 \mathrm{E}+07$ & 906.50 & 1087.8653 & 1155.5245 & 1525.2923 & \\
\hline $11 / 22 / 99$ & $8.57088 \mathrm{E}+07$ & 992.00 & 1087.8653 & 0.0000 & 0.0000 & outage - right rib \\
\hline $11 / 24 / 99$ & $8.58816 \mathrm{E}+07$ & 994.00 & 1087.8653 & 1155.5245 & 1525.2923 & \\
\hline $2 / 11 / 00$ & $9.27072 \mathrm{E}+07$ & 1073.00 & 0.0000 & 0.0000 & 0.0000 & power outage \\
\hline $2 / 11 / 00$ & $9.27720 \mathrm{E}+07$ & 1073.75 & 1078.8421 & 1184.6642 & 1563.7568 & \\
\hline $3 / 2 / 00$ & $9.44352 \mathrm{E}+07$ & 1093.00 & 1029.1930 & 1115.3660 & 1472.2831 & power reduction \\
\hline $3 / 12 / 00$ & $9.52992 \mathrm{E}+07$ & 1103.00 & 0.0000 & 0.0000 & 0.0000 & power loss \\
\hline $3 / 13 / 00$ & $9.54072 \mathrm{E}+07$ & 1104.25 & 1029.1930 & 1115.3660 & 1472.2831 & \\
\hline $5 / 2 / 00$ & $9.97056 \mathrm{E}+07$ & 1154.00 & 964.5263 & 1040.2813 & 1373.1713 & power reduction \\
\hline $8 / 15 / 00$ & $1.08778 \mathrm{E}+08$ & 1259.00 & 917.3463 & 978.7397 & 1291.9364 & power reduction \\
\hline $1 / 20 / 01$ & $1.22429 \mathrm{E}+08$ & 1417.00 & 0.0000 & 0.0000 & 0.0000 & power outage \\
\hline $1 / 21 / 01$ & $1.22515 E+08$ & 1418.00 & 917.3463 & 978.7397 & 1291.9364 & \\
\hline $5 / 1 / 01$ & $1.31155 \mathrm{E}+08$ & 1518.00 & 875.5711 & 925.4672 & 1221.6168 & power reduction \\
\hline $7 / 1 / 01$ & $1.36426 \mathrm{E}+08$ & 1579.00 & 0.0000 & 0.0000 & 0.0000 & power outage \\
\hline $7 / 1 / 01$ & $1.36490 \mathrm{E}+08$ & 1579.75 & 875.5711 & 925.4672 & 1221.6168 & \\
\hline $8 / 22 / 01$ & $1.40918 \mathrm{E}+08$ & 1631.00 & 826.8171 & 875.8317 & 1156.0979 & power reduction \\
\hline $1 / 14 / 02$ & $1.53446 \mathrm{E}+08$ & 1776.00 & 0.0000 & 0.0000 & 0.0000 & heaters turned off \\
\hline $1 / 14 / 06$ & $2.79677 \mathrm{E}+08$ & 3237.00 & 0.0000 & 0.0000 & 0.0000 & cooling period end \\
\hline
\end{tabular}

NOTE: Input DTNs for power data are listed in Table 7.1-1. Each time represents the initiation of a particular period of heating (or power loss) that continues until the next time in the table. Data are for a two-dimensional vertical slice. 


\subsubsection{Hydrologic and Geochemical Input Data}

Sources of hydrologic and geochemical input data are listed in Table 4.1-1. Other details regarding the use or modifications to these data are given in Sections 7.1.5 and 7.1.6.

Thermodynamic data are described in Section 4.1.4 and presented in Appendix C. Kinetic data are given in Table 4.1-3. The mineral volume fractions reflect the mineralogical assemblage used in the current Tptpll THC seepage model (Appendix A). Mineral reactive surface areas are given in Appendix B.

\subsubsection{Initial and Boundary Conditions: Hydrologic and Thermal}

Hydrologic and thermal initial and boundary conditions are derived from the UZ flow model (BSC 2004 [DIRS 169861], Table 6.1-2). Hydrologic and thermal properties are from the output of separate studies (BSC 2004 [DIRS 169854]; BSC 2004 [DIRS 169857]; BSC 2004 [DIRS 170033]) that are consistent with the UZ flow model. Models and data for the ambient geochemistry of the UZ at Yucca Mountain (i.e., Cl, Sr, calcite) support the infiltration rates used as boundary conditions for the UZ flow and transport model (Sonnenthal and Bodvarsson 1999 [DIRS 117127], p. 107; Liu et al. 2003 [DIRS 162470]; and Xu et al. 2003 [DIRS 162124]). The nature and extent of this foundation work is substantially the same for the DST THC submodel and the THC seepage model used for repository prediction, and supports confidence that the THC seepage model uses representative values for hydrologic and thermal properties, initial conditions, and boundary conditions. Further details of the initial and boundary conditions are described below.

Steady-state liquid saturations, temperatures, and pressures are obtained for these simulations using the updated drift-scale thermal-hydrologic property set (DTN: LB0208UZDSCPMI.002 [DIRS 161243]). These hydrologic properties are listed in Table 6.4-1. Modifications have been made to the fracture medium void fraction (usually set to 0.99 or 1.0 ) to be consistent with the fracture porosities (DTN: LB0210THRMLPRP.001 [DIRS 160799]). This modification has approximately the same effect as changing the relative volumes of the fracture and matrix grid blocks (the usual procedure for implementing fracture porosity).

The top and bottom boundaries are set to constant temperature, pressure, and liquid saturation, based on steady-state values obtained from simulations of a one-dimensional column extending from the land surface to the water table. The top boundary of the two-dimensional model extends $150 \mathrm{~m}$ above and below the drift center, but does not reach either the land surface or the water table. Under these conditions, the percolation flux at the top boundary is approximately $0.5 \mathrm{~mm} / \mathrm{yr}$. This value is consistent with predicted net infiltration rates for the region of the DST, which generally range from 0 to $1 \mathrm{~mm} / \mathrm{yr}$ (DTN: GS000308311221.005 [DIRS 147613]; BSC 2004 [DIRS 170007], Figure 6-26). The bottom boundary condition is open to gas and to liquid flow. The side boundaries of the domain are located $81.5 \mathrm{~m}$ away from the drift center on each side (outside of the test influence area) and are no-flux for mass and heat. The air pressure and temperature in the observation drift are set to constant values and, therefore, do not reflect temporal fluctuations in barometric pressure or tunnel air temperatures. The heated drift wall is open to advection and conduction of heat and mass (e.g., air, water vapor, and $\mathrm{CO}_{2}$ ). 


\subsubsection{Initial and Boundary Conditions: Geochemical}

Initial and boundary geochemical conditions are set using qualified data, based on pore water and mineralogical analyses and taken from the TDMS. Pore water data have been selected, over successive revisions of the model, from a relatively large set of measured data (Section 6.2.2.1), which provides confidence that the selected compositions represent the range of host rock conditions. Additional discussion of the available pore water data is provided in Section 4.1.5. The approach used to set the initial and boundary conditions is described in the following paragraphs.

Initial geochemical data used in the simulations are given in Appendices A through $\mathrm{C}$ (sources in Tables 4.1-1). All aqueous and gaseous species concentrations in the rock are initially set to a uniform value (Section 6.2.2.1). The Heater Alcove and Observation Drift $\mathrm{CO}_{2}$ concentrations are fixed to approximately that of the atmosphere. The Heated Drift $\mathrm{CO}_{2}$ concentration is initially set to the same value as that in the Observation Drift, but is allowed to exchange $\mathrm{CO}_{2}$ with the Heater Test Alcove and with the surrounding rock. The simulations are performed with the geochemical system presented in Table 6.2-2.

Both the top and bottom boundary conditions are open to gas and aqueous species transport. The top and bottom boundaries are also set so that no mineral reactions take place (and, therefore, no changes in aqueous species concentrations occur as a result of mineral-water reactions). Their volumes are set to extremely large values so they act, essentially, as constant concentration boundaries. The side boundaries are no-flux for gas and aqueous-species transport.

\subsubsection{Model Validation Methods, Criteria, and Limitations}

In the following sections, data and predictions are reviewed to demonstrate that the criteria specified in the TWP (BCS 2005 [DIRS 172761]) have been met for the DST THC submodel. Because the THC seepage model uses the same conceptualization and mathematical treatment of THC coupled processes as the DST THC submodel, including the same thermodynamic and kinetic data, DST model validation effectively validates the THC seepage model. Additional validation of the THC modeling approach is presented in Sections 7.2 and 7.3 where results of laboratory plug-flow and fracture boiling experiments are compared to simulations.

The THC seepage model is validated and the necessary confidence is achieved by Method 1 listed in LP-SIII.10Q-BSC, Section 5.3.2(c)(1), Corroboration with Experimental Data. Additional confidence in the model is provided by Technical Review through Publication in a Refereed Technical Journal, as per LP-SIII.10Q-BSC, 5.3.2(d). These validation methods provide the most confidence in the conceptual and numerical models and their outputs.

\subsubsection{Validation Method 1-Corroboration with Experimental Data}

Data from the DST used for comparison consist of analyses of water and gas samples from borehole intervals between packers and observations of mineral precipitation in boreholes. Intervals have been selected for comparison based upon the availability of a long, continuous sample record and the absence of confounding factors, such as the sampling interval being too long to compare with a particular grid block or pair of grid blocks, or boreholes being near either 
end of the DST and affected by three-dimensional transport (see below). The locations of the hydrology boreholes, sampling intervals, and temperature sensors are shown in Figure 7.1-4.

Differences between the DST THC submodel predictions and DST measurements are important. There are several reasons (listed below) why individual measured data may lie outside the predictions, and yet support use of the DST THC submodel for validation. It is important that these considerations are kept in mind when reviewing the model comparisons to measured data (in the following discussion, the term model refers to the DST THC submodel).

1. The continuum model does not simulate individual fractures, which may intersect boreholes near sampling points, their aperture and frequency resulting in different flow rates and temperatures; thus, affecting the chemistry of the gas and water samples in that interval.

2. All samples were taken from long borehole intervals (approximately 8 to $10 \mathrm{~m}$ long), which cross regions of large gradients in gas species concentrations (up to a few orders of magnitude) and exhibit temperature variations of tens of degrees Celsius. The sampling boreholes may alter composition of the incoming gas and liquid phase compositions from fractures.

3. The model does not consider all deviations from planned operation of the DST. These deviations include the exact time periods of power losses, variations in heat loss through the bulkhead, changes in pressure from forced ventilation, the effect of the many DST boreholes, and barometric pressure fluctuation. Changes predicted to occur at a particular time in the model may be shifted in the DST data by several months or more.

4. Gas and water samples are affected by condensation of water vapor as the sample cools in the collection tubes from the borehole interval to the sample containers. This results in dilution by distillation of water vapor, and changes to $\mathrm{CO}_{2}$ concentrations. The $\mathrm{pH}$ of the water may drop as distillate formed in the sampling apparatus is mixed with water from the sampled borehole.

The greatest effects from these mechanisms on the magnitude of differences in model-data comparisons may be expressed when the boiling front in the rock is proximal to the measurement location. The magnitude of such differences may be compared to the difference between relatively dilute condensate in fractures, and evaporatively concentrated waters closer to the boiling front. 


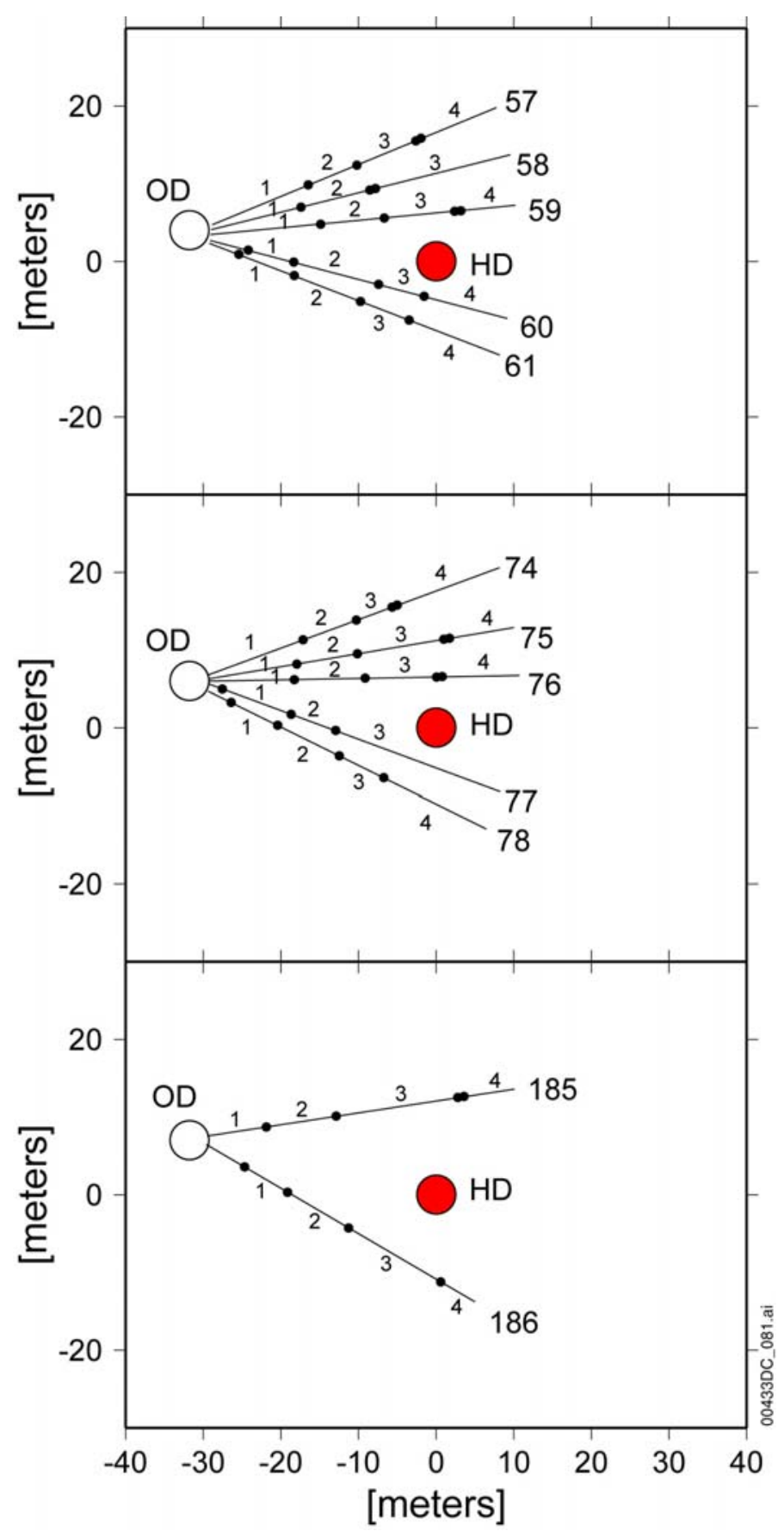

Coordinates from DTN: MO0002ABBLSLDS.000 [DIRS 147304].

NOTE: Borehole intervals are designated as 1, 2, 3, and 4 moving away from the Observation Drift (open circle designated "OD"). Temperature sensors (not labeled) are shown as the small closed circles, and are designated similarly to the intervals (i.e., sensor 60-4 is the 4th sensor from the Observation Drift). $\mathrm{OD}=$ Observation Drift; $\mathrm{HD}=$ Heated Drift.

Figure 7.1-4. Locations of Hydrology Boreholes, Sampling Intervals (Numbered) and Temperature Sensors 
Given these considerations, the following criteria are adopted for validation using model-data comparisons for the DST:

- Predicted temporal trends in the concentrations of aqueous and gaseous chemical species, and spatial distribution of precipitated mineral phases, should be similar to field measurements. Significant differences are explained qualitatively in terms of the physical and chemical processes. The THC modeling approach uses average properties and simulates average response; local or short-term variability in the measured data is associated with effects that are not included in the model.

- Observed concentrations of gas and aqueous species, once adjusted for sample degassing and water vapor loss, match predicted concentrations to within an order of magnitude (up or down). This range is justified for several reasons. First, natural variability within the repository horizon pore waters is as much as five-fold for any given chemical species. Second, TH (boiling and condensation) and THC processes (mineral-water-gas reactions) can lead to changes in the chemistry of water and gases by one or more orders of magnitude (Section 7.1.10.2) in response to small changes in temperature (e.g., around the boiling temperature of water). Third, differences in aqueous species concentrations in the rock may develop over distances of tens of centimeters or less, because diffusion rates of aqueous species in the rock matrix are limited (Section 7.1.11.3). Fourth, changes that the samples undergo during their extraction from the rock (e.g., cooling, degassing, condensation) have the potential for shifting aqueous species concentrations.

Consistent with these potential contributions to uncertainty, the validation criterion of one order-of-magnitude in concentration (or a $\mathrm{pH}$ unit, up or down) is smaller than the potential range, and is appropriate for predicted compositions for fracture and matrix waters over the time period of the DST.

As stated above, the THC seepage model approach uses average properties and simulates averaged responses, and does not predict small-scale or short-term events such as the spike in $\mathrm{CO}_{2}$ after 48 months in borehole 75 of the DST (Section 7.1.10). Furthermore, experimental measurements of $\mathrm{CO}_{2}$ and $\mathrm{pH}$ are directly impacted by sampling methodology, including changes in temperature and pressure, and sample degassing. Accordingly, validation of a given parameter may be done indirectly through examination of correlated parameters (e.g., $\mathrm{pH}$, which is associated with significant data uncertainty, can be validated by comparing $\mathrm{CO}_{2}$ gas concentrations).

\subsubsection{Publication in a Refereed Technical Journal}

As described by LP-SIII.10Q-BSC, Section 5.3.2(d), technical review through publication in a refereed technical journal provides additional confidence in the THC seepage model. Essentially the same THC seepage model has been published in Journal of Contaminant Hydrology (Spycher et al. 2003 [DIRS 162121]). A second article in Journal of Contaminant Hydrology (Dobson et al. 2003 [DIRS 165949]) does not directly address the THC seepage model, but evaluates fracture sealing due to mineral precipitation for a Yucca Mountain tuff, and provides added confidence in the conceptual model implemented by TOUGHREACT. 


\subsubsection{THC Simulations}

In the following sections, DST THC submodel simulations are described. Only the current simulation results are shown, sometimes with a brief discussion of any differences observed from previous revisions of this report.

Key elements of the DST THC submodel include:

1. A revised numerical mesh, to account for heat input at the drift center and heat and mass transfer across the Heated Drift and Observation Drift walls (Section 7.1.2)

2. More accurate estimates of heater power over time (Section 7.1.3)

3. Use of the same updated inputs as the current THC seepage model, including:

- Calibrated thermal-hydrologic properties data set (Table 6.4-1)

- Thermodynamic data (Appendix C)

- Kinetic data (Section 4.1.3 and Table 4.1-3)

- Geochemical system (Section 6.2.2.2 and Table 6.2-2), including aqueous species and primary and secondary mineral phases

4. Consistent with the current THC seepage model, use of an improved method for mineral precipitation at the boiling front that is implemented in TOUGHREACT V3.0 (LBNL 2002 [DIRS 161256]). This includes the addition of various salt minerals as potential precipitating phases (or as phases formed during flow into dry blocks; see Section 6.4.5).

Three THC simulations and two TH simulations have been performed for this report using TOUGHREACT V3.0 (LBNL 2002 [DIRS 161256]):

1. Extended Case Geochemical System (Table 6.2-2), EOS3 (no vapor pressure lowering due to capillary effects), higher $\mathrm{CO}_{2}$ diffusion coefficient (value used in most THC seepage model simulations) [simulation dstrev2_thc7]

2. Extended Case, EOS4 (vapor pressure lowering due to capillary effects implemented), lower $\mathrm{CO}_{2}$ diffusion coefficient (used in THC seepage model sensitivity analysis) [simulation dstrev2_thc8]

3. Extended Case, EOS3, lower $\mathrm{CO}_{2}$ diffusion coefficient [simulation dstrev2 thc9]

4. EOS3 TH simulation [simulation dstrev2_th12]

5. EOS4 TH simulation [simulation dstrev2_th13]. 
In all DST THC submodel simulations, HD-PERM water (W0, Table 6.2-1) was used as the starting water, as this water was recovered from borehole core from Alcove 5, near the DST. The extended-case geochemical system is used for all DST THC simulations because the THC seepage model considers only this geochemical system. Results from the "high" diffusion coefficient Simulation 1 are not shown because validation should be based on parameter values within the range expected. All input and output data files for the DST THC simulations are given in Appendix G.

The following Sections 7.1.9 through 7.1.14 present the model results, representative data from the DST, and the model-data comparisons that support validation of the THC seepage model. Section 7.1.9 describes the prediction of thermal-hydrologic conditions, which is covered in more detail by Drift-Scale Coupled Processes (DST and TH Seepage) Models (BSC 2004 [DIRS 170338], Section 7.4). Section 7.1.10 presents the model-data comparisons for gas-phase $\mathrm{CO}_{2}$, an important variable that controls carbonate chemistry and directly affects the chemical environment in the emplacement drifts. Section 7.1.11 describes model-data comparisons for aqueous species, which were analyzed in samples of fracture water collected in DST boreholes. Section 7.1.12 describes mineralogical changes predicted by the DST THC submodel, with comparison to the available analysis of minerals formed during the test. Section 7.1.13 describes the predicted changes in fracture and matrix porosity, and the implication for bulk permeability, with discussion of the observed indications of permeability change in the DST. Finally, Section 7.1.14 presents representative ${ }^{14} \mathrm{C}$ isotopic analysis of gas samples, and interprets the evolution of ${ }^{14} \mathrm{CO}_{2}$ during the heating phase in terms of the operant chemical processes in the DST THC submodel.

\subsubsection{Simulation Results: Thermal and Hydrologic Evolution}

The main driving force for changes in the hydrologic and chemical behavior of the system is the thermal load applied to the system. The resulting changes in temperature, liquid saturation, and gas-phase composition lead to changes in the chemistry of water and gas, as well as mineral dissolution and precipitation. A more complete discussion of thermal-hydrologic processes is presented in Drift-Scale Coupled Processes (DST and TH Seepage) Models (BSC 2004 [DIRS 170338]). Key aspects of the thermal-hydrologic behavior of the DST that drive the chemical evolution of the system are discussed briefly in this section.

The simulation results for the TH evolution of the DST, as well as all other simulation results shown in this section, are based on Simulation 2 above, performed using the EOS4 module in TOUGHREACT V3.0 (LBNL 2002 [DIRS 161256]). TH (and chemical) results are nearly identical to those not using the vapor-pressure-lowering (EOS3) in Simulation 3, and the latter are therefore not shown. Outputs from all simulations are, however, included in the data submittal to the TDMS. The relatively minor difference in the results is largely related to the implementation of revised capillary pressure curves in the hydrologic parameter set. The property set has a maximum capillary pressure of $10^{8} \mathrm{~Pa}$, which results in a relatively small change in the saturation-temperature history in the rock as it is heated. Low matrix permeabilities in the model parameter set lead to higher matrix pore pressure, thus delaying boiling more substantially than the capillary-pressure-lowering effect. In addition, coupled effects of mineral precipitation/dissolution on flow did not significantly affect the $\mathrm{TH}$ evolution of the DST. 
The modeled temperatures in the drift reflect the heat input at the drift center (at the approximate location of the electrical canister heater) and subsequent heat transfer to the drift wall (Figure 7.1-5). Differences in temperature between the drift center and drift wall (Figure 7.1-5) near the top (drift crown) are approximately $20^{\circ} \mathrm{C}$, similar to the differences observed between electrical canister temperatures and drift-crown temperature measurements (DTN: MO0007SEPDSTPC.001 [DIRS 153707]). Sharp temperature drops are the result of power losses, heater failures, and/or intentional power reductions.

Drift-wall temperatures predicted by the two-dimensional model eventually exceed the maximum measured values by about $20^{\circ} \mathrm{C}$. However, predicted temperatures in the rock are typically closer to measured values (Figure 7.1-6). There are several reasons for the elevated temperature in the drift. First, the two-dimensional cross section can only approximate the exchange of heat through the rock along the axis of the DST. Second, heat lost through the bulkhead by a combination of advection and diffusion is uncertain and is approximated using a bulkhead correction that is essentially one-dimensional. Therefore, this model is most applicable to areas near the center of the test - away from both the bulkhead and away from the distal end of the Heated Drift. For application to repository simulation, the THC seepage model is used similarly, to predict the composition of waters in the host rock that could potentially seep into drifts.

Other factors that control the temperature response of the drift wall include thermal properties (conductivity, heat capacity) of the rock and the representation of heat transfer processes in the drift (i.e., the approximate treatment of thermal radiation and convection). However, comparison of temperatures measured in the rock, with simulated temperatures, provides an effective test of validity for treatment of heat transfer to the rock. Confidence in the approach used is supported by the close agreement with measured temperatures (Figure 7.1-6).

The modeled distributions of fracture and matrix liquid saturation (with temperature contours overlain) are shown in Figures 7.1-7a to d. The plots correspond to one and four years from the initiation of the heating phase. The extent of the dryout zone increases over the heating period and is larger in the fractures than in the matrix. A wider spatial interval between the $90^{\circ} \mathrm{C}$ and $100^{\circ} \mathrm{C}$ isotherms indicates the presence of an isothermal boiling/condensation (heat pipe) zone, which is especially well developed above the wing heaters. An extensive drainage zone extending several tens of meters in the fractures below the heaters contrasts with a very narrow high-saturation zone above the heaters, where water is continuously diverted around the heated zone. The narrow band of increased fracture saturation above the heaters is characterized by temperatures of about $90^{\circ} \mathrm{C}$ to $95^{\circ} \mathrm{C}$. Typically, water was collected from hydrology boreholes when this heat-pipe zone intersected the borehole intervals (Figure 7.1-4) (BSC 2004 [DIRS 170338], Section 7.4.3). During the DST, saturation changes in the rock were monitored using ground-penetrating radar (GPR) and electrical resistance tomography (ERT) (BSC 2004 [DIRS 170338], Section 7.4.1). The spatial distribution of the observed changes in matrix saturation are similar to model results as discussed further in Drift-Scale Coupled Processes (DST and TH Seepage) Models (BSC 2004 [DIRS 170338], Section 7.4.3.2). 


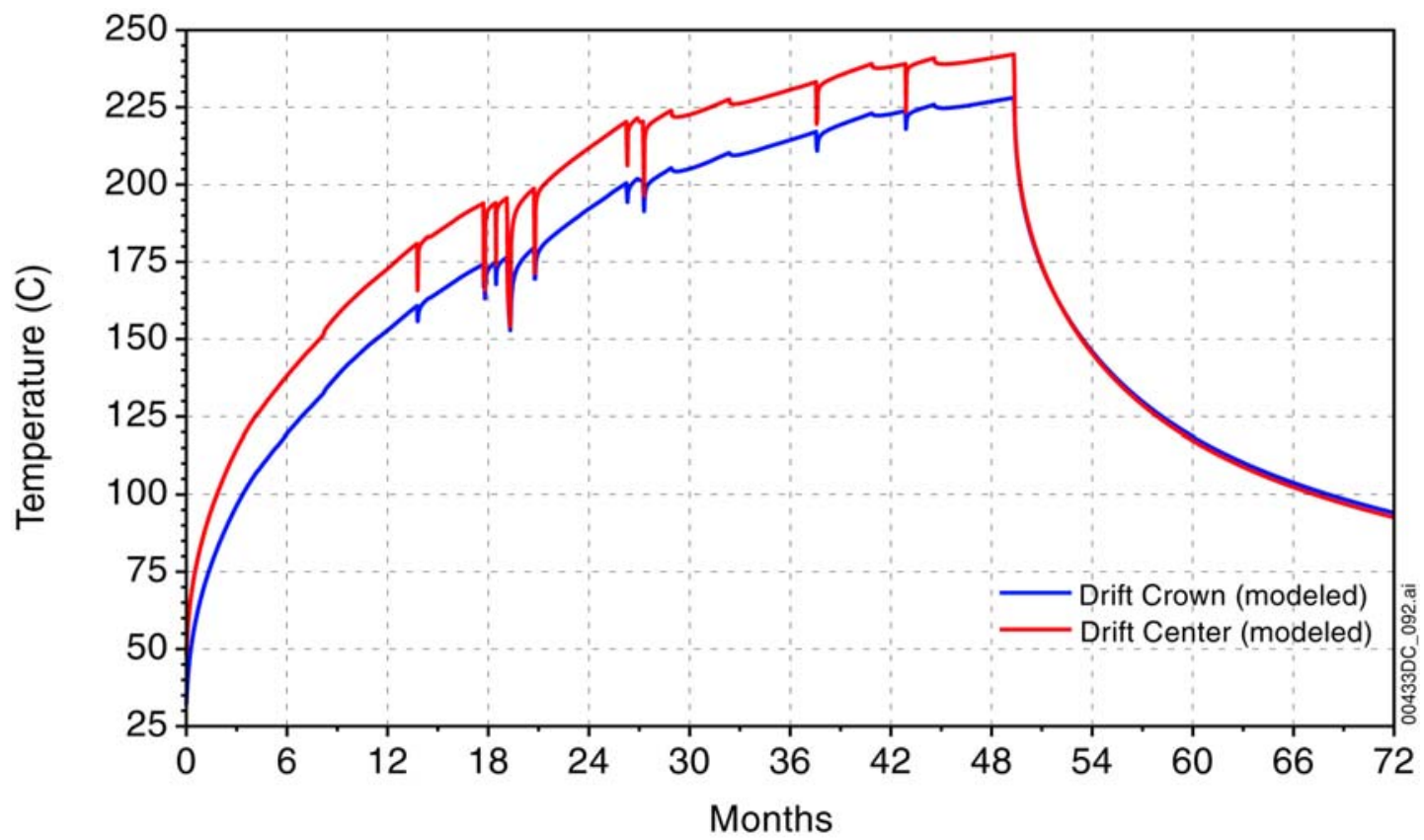

Output DTN: LB0307DSTTHCR2.001.

Figure 7.1-5. Drift Center and Drift Crown Modeled Temperatures over the First Six Years of the DST

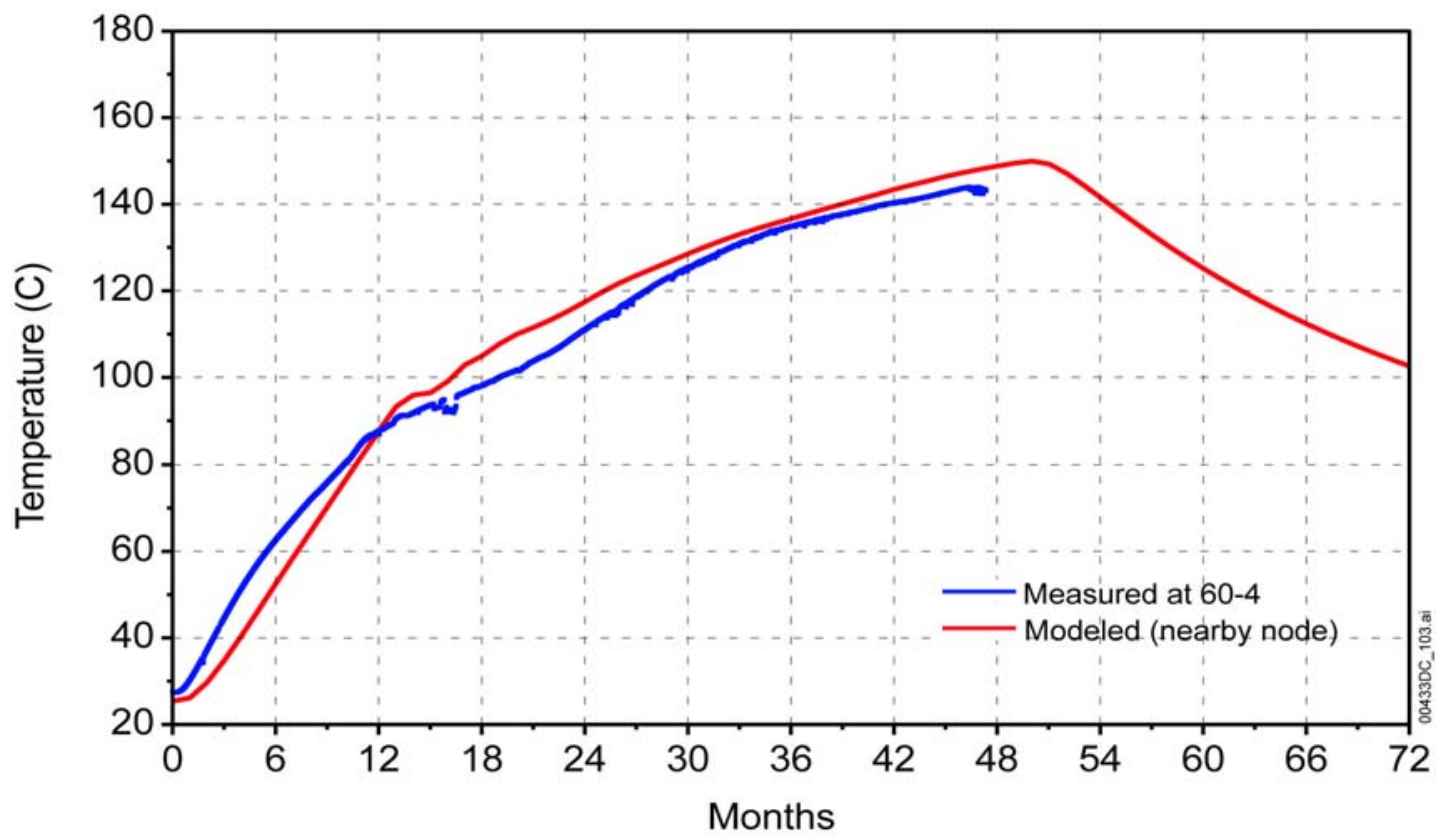

Output DTN: LB0307DSTTHCR2.001 (modeled values).

NOTE: Modeled temperatures are for a nearby grid node. Location of temperature sensor is indicated on Figure 7.1-4. See Table 7.1-1 for DTNs for measured temperatures.

Figure 7.1-6. Comparison of Modeled and Measured Temperatures over Time for the Sensor Located at Hydrology Borehole Packer 60-4 
(a)

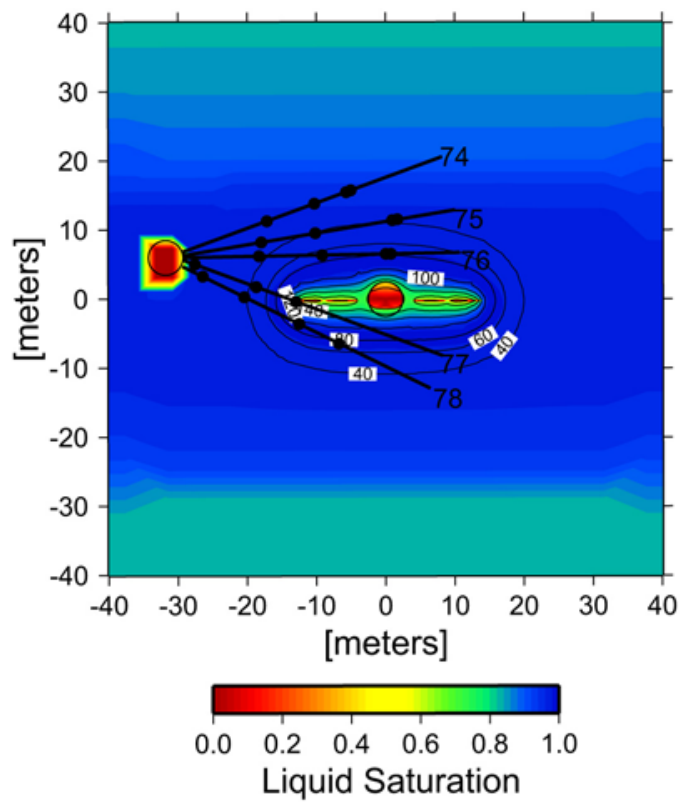

(b)

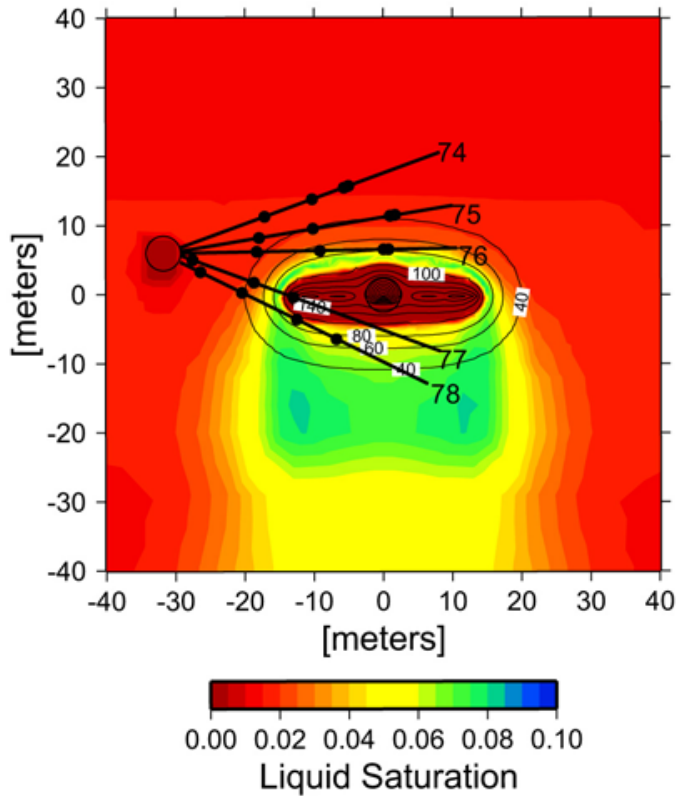

(c)

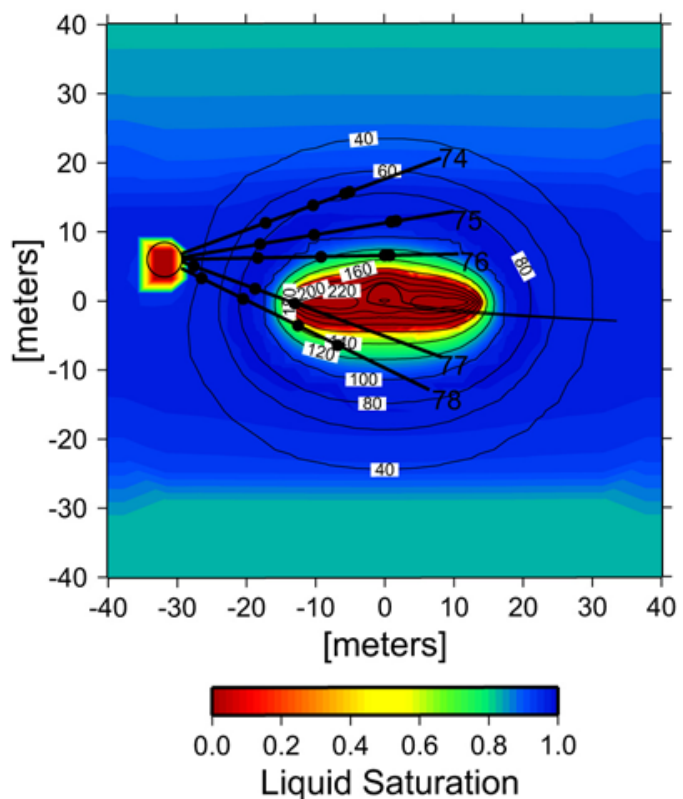

(d)

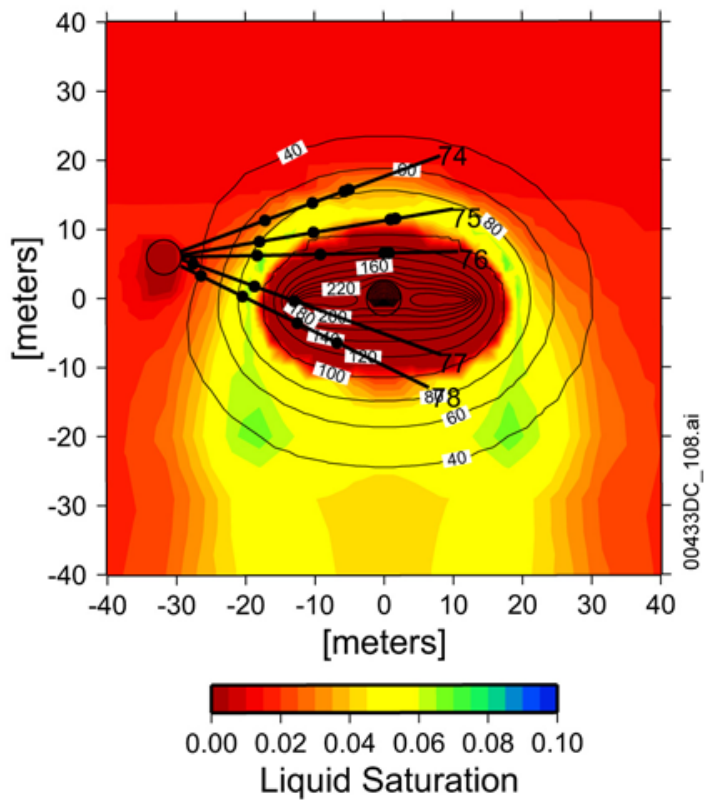

Output DTN: LB0307DSTTHCR2.001.

NOTE: $\quad$ Borehole intervals where water samples were collected are shown in Figure 7.1-7.

Figure 7.1-7. Liquid Saturation (Colors) and Temperature (Contour Lines) in the DST (Base Case) at One Year (Matrix - a, Fracture - b) and at Four Years (Matrix - c, Fracture - d) 


\subsubsection{Gas-Phase $\mathrm{CO}_{2}$ Evolution: Measured Compositions and Simulation Results}

The evolution of $\mathrm{CO}_{2}$ concentrations in the gas phase is discussed in this section. Simulation results are compared to concentrations measured in gas samples taken from boreholes during the entire heating phase of the DST. The concentration of $\mathrm{CO}_{2}$ in the gas phase is a function of temperature, pressure, aqueous-phase chemistry, mineral-water reactions, and advective and diffusive transport. From a model validation standpoint, the strong effect of $\mathrm{CO}_{2}$ partial pressure on water $\mathrm{pH}$ and the final brine composition formed upon evaporation make the analysis of $\mathrm{CO}_{2}$ distributions in the DST important. Numerous measurements of $\mathrm{CO}_{2}$ concentrations in gas collected from the DST have been made as a function of space and time, and therefore a more complete comparison of the model results to $\mathrm{CO}_{2}$ data can be made than to the relatively fewer number of water-chemistry measurements. $\mathrm{CO}_{2}$ concentrations in gases collected from the DST also provide a qualitative measure of the influence of atmospheric gas on the system, because of the relatively low and constant value in the atmosphere $(\approx 400 \mathrm{ppmv})$. Isotopic compositions of $\mathrm{CO}_{2}$ (discussed in Section 7.1.14) yield insight into the sources of $\mathrm{CO}_{2}$.

\subsubsection{Gas Sampling and $\mathrm{CO}_{2}$ Measurements}

Gas sampling, analytical methods, and compositional data are discussed in Thermal Testing Measurements Report (BSC 2004 [DIRS 169900], Section 6.3.4.2). Gas samples were taken from several meter-long borehole intervals that spanned a wide range of temperatures as a result of their orientation relative to the heaters. As part of the sampling procedure, the gas samples had much of their water vapor removed before analyses were performed, and therefore measured $\mathrm{CO}_{2}$ concentrations are for the noncondensable gas fraction. The noncondensable gas fraction is very high ( $>95$ percent) at the ambient temperature of about $25^{\circ} \mathrm{C}$, but may drop to extremely low values $\left(<1\right.$ percent) under boiling conditions. Hence, reported $\mathrm{CO}_{2}$ concentrations at temperatures close to boiling are much higher than if the measurements were made on a "complete" gas composition (air $+\mathrm{CO}_{2}+\mathrm{H}_{2} \mathrm{O}$ ). This effect must be considered when comparing model results to measured values.

An example of the distributions of measured $\mathrm{CO}_{2}$ concentrations (DTNs listed in Table 7-1) after one year and after 15 months of heating is shown in Figure 7.1-8. Comparison of the 15-month to the one-year data shows that in nearly all of the boreholes, the $\mathrm{CO}_{2}$ concentrations are higher at 15 months, owing to heating of pore water and exsolution of $\mathrm{CO}_{2}$ into the gas phase. Areas that have maintained $\mathrm{CO}_{2}$ concentrations close to the ambient value in the "rock" of around 1,000 ppmv (log volume fraction $=-3$ ) can be seen near the observation drift. However, very close to the Observation Drift, some of the values are lower, suggesting that mixing with atmospheric gas may have taken place. 

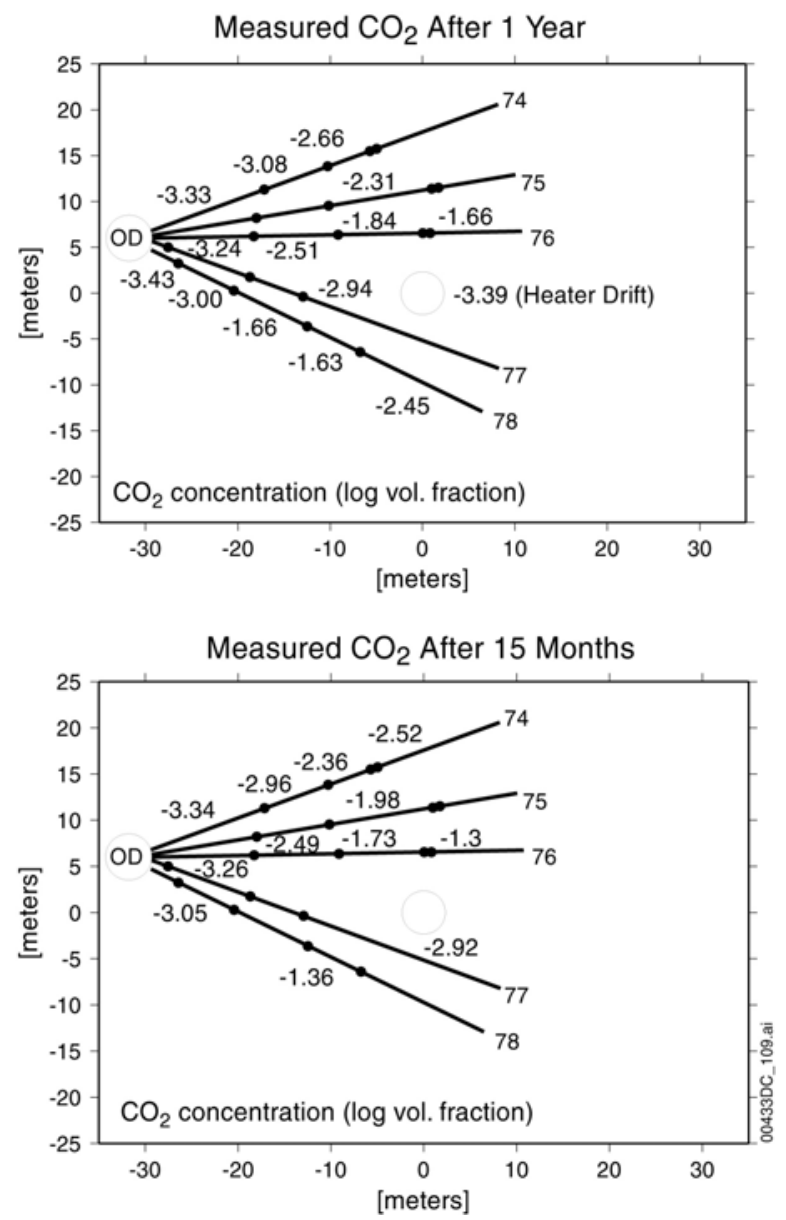

Source: DTN: LB990630123142.003 [DIRS 111476].

NOTE: Concentrations refer to intervals between pairs of points.

Figure 7.1-8. Measured Concentrations of $\mathrm{CO}_{2}$ (log vol. fraction) in Gas Phase around the DST at 1 Year and at 15 Months

\subsubsection{Modeled Spatial Distribution of $\mathrm{CO}_{2}$}

Model results are presented for the extended system (described in Table 6.2-2). Modeled distributions of $\mathrm{CO}_{2}$ concentrations (log ppmv) in fractures are shown at yearly intervals during the heating phase (Figure 7.1-9) and during the cooling phase (Figure 7.1-10). Over the heating phase of four years, a region of highly elevated $\mathrm{CO}_{2}$ concentrations, centered approximately at the $60^{\circ} \mathrm{C}$ isotherm, is seen to move gradually outward from the heaters. Outside this region, $\mathrm{CO}_{2}$ concentrations gradually decrease to the ambient value in equilibrium with pore water (approximately 1,000 ppmv). Maximum $\mathrm{CO}_{2}$ concentrations of around 50,000 ppmv are located above and below the wing heaters and Heated Drift. Towards the heaters, $\mathrm{CO}_{2}$ concentrations drop off more sharply with increasing temperature, decreasing to values below $10 \mathrm{ppmv}$. This sharp decline takes place as a result of the $\mathrm{CO}_{2}$ degassed during heating of the pore water, its transport outward, and displacement of air and $\mathrm{CO}_{2}$ by steam generated during boiling. 
(a)

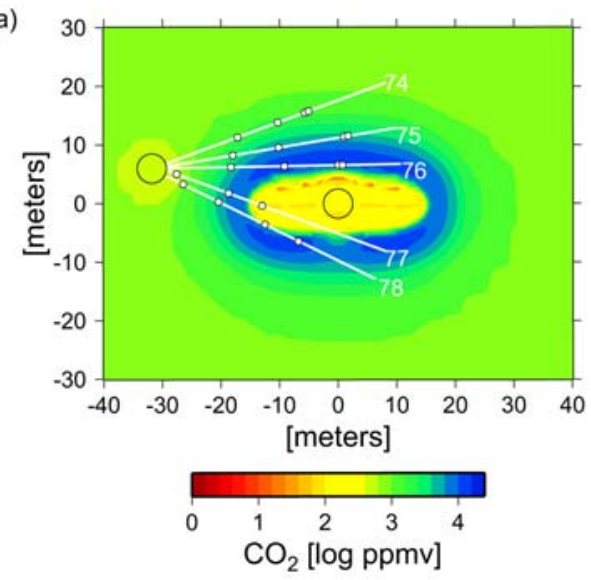

(b)

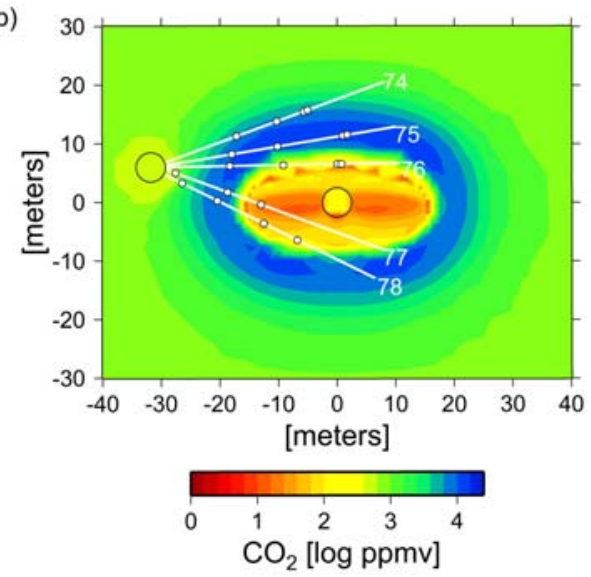

(c)

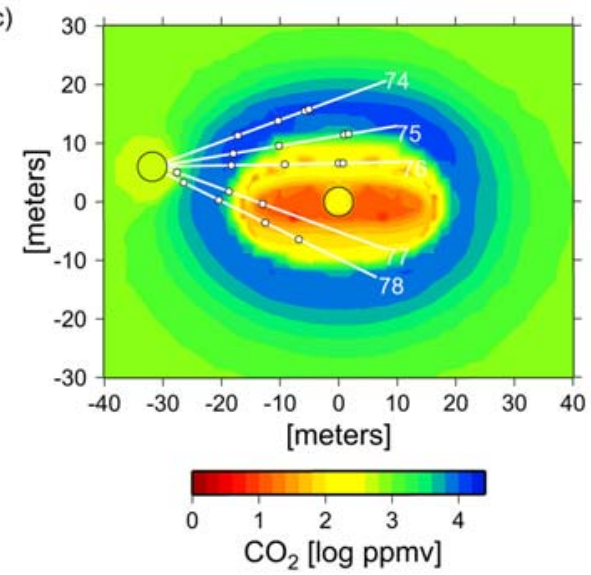

(d)

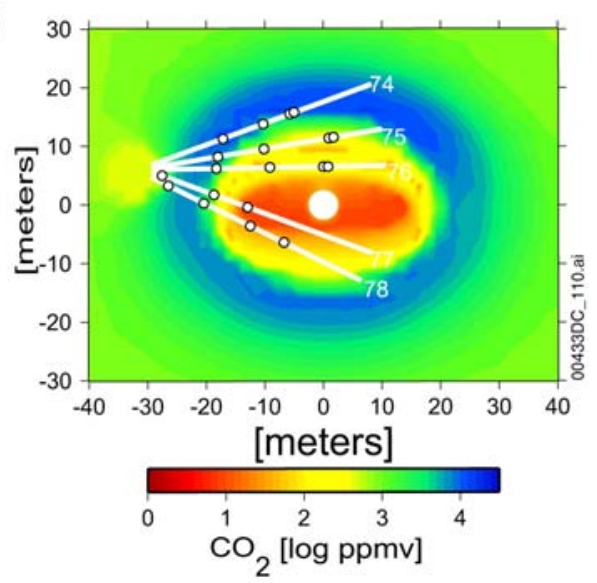

Output DTN: LB0307DSTTHCR2.001.

NOTE: $\quad$ Compare to calculated values in Figure 7.1-8.

Figure 7.1-9. Modeled Gas Phase $\mathrm{CO}_{2}$ Concentrations (Log ppmv) in Fractures during the Heating Phase of the DST at 1, 2, 3, and 4 Years

The zone of maximum $\mathrm{CO}_{2}$ concentrations also transects the hydrology borehole intervals as it migrates outwards, with some intervals registering a two order-of-magnitude variation between them.

The effect of the atmospheric $\mathrm{CO}_{2}$ concentration of the gas in the Observation Drift on its surroundings is evident up to about $10 \mathrm{~m}$ from the drift wall. However, effects on the fracture gas composition are relatively minor beyond about $5 \mathrm{~m}$ from the drift wall. Carbon dioxide concentrations in the Heated Drift stay close to the atmospheric value, owing to transport (advection and diffusion) between the Heater Test Alcove (set to atmospheric $\mathrm{CO}_{2}$ ) and the Heated Drift.

The modeled cooling phase of the DST (Figure 7.1-10) is characterized by a gradual re-equilibration of $\mathrm{CO}_{2}$ concentrations throughout the DST area, via cooling, gas-phase diffusion, and flow of gas and water. Exchange of atmospheric gas among the Heated Drift, Heater Test Alcove, and rock around the Heated Drift is clearly evident. 
(a)

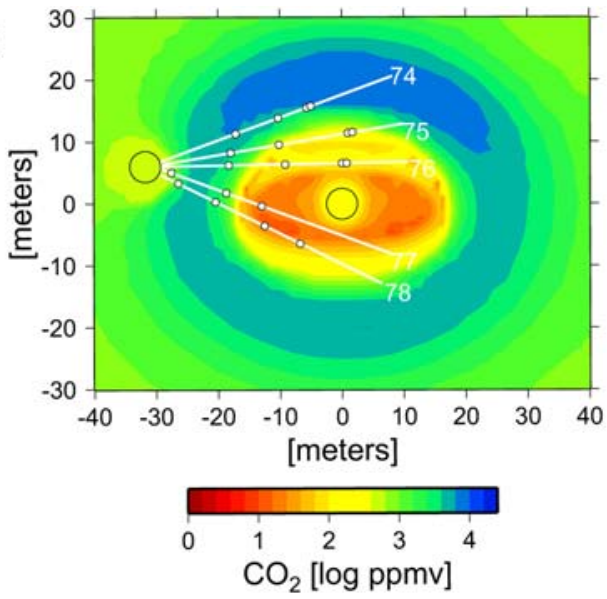

(b)

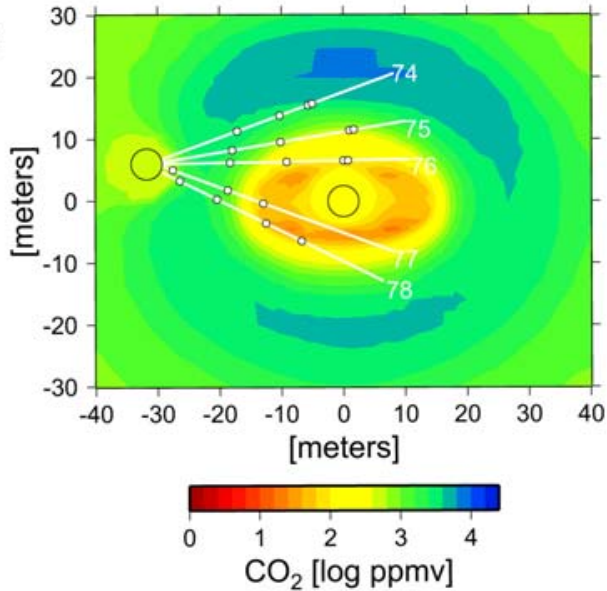

(c)

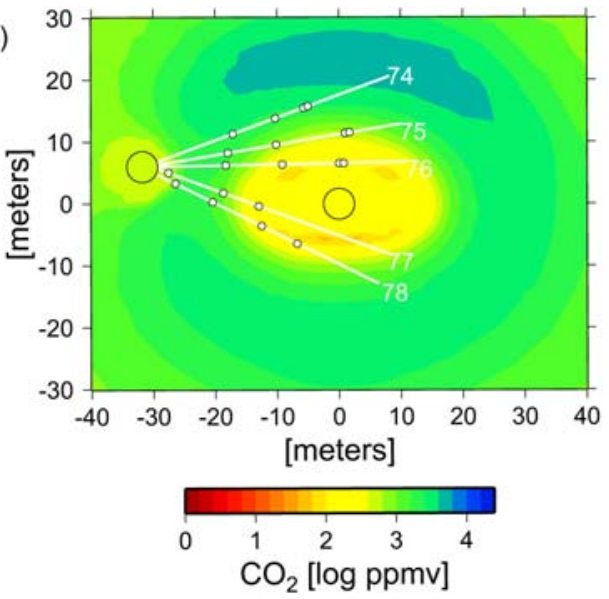

(d)

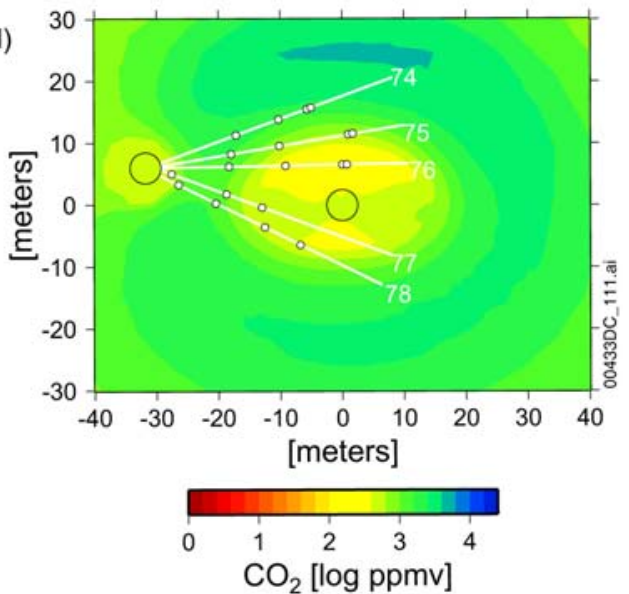

Output DTN: LB0307DSTTHCR2.001.

Figure 7.1-10. Modeled Gas Phase $\mathrm{CO}_{2}$ Concentrations (Log ppmv) in Fractures during the Cooling Phase of the DST at $5,6,7$, and 8 Years

\subsubsection{Modeled and Measured $\mathrm{CO}_{2}$ Concentrations over Time}

Validation of the DST THC submodel for the prediction of the temporal evolution of $\mathrm{CO}_{2}$ concentrations is performed by comparison of measured values from intervals repeatedly sampled from February 1998 through January 2002 (DTNs listed in Table 7-1) to model results. The locations of the grid block central coordinates relative to the gas collected in borehole intervals from which the gas samples were taken are illustrated in Figure 7.1-11. Because the measured concentrations come from borehole intervals that are several meters long, and not from a specific location, model data are chosen from the grid block closest to the center of the interval. If a grid block is not centered on the borehole, a grid block closest to the center is chosen on the outer (cooler) side of the borehole. Grid blocks on the cooler side should compare more closely to the measured data because the two-dimensional model, having no heat loss in the rock perpendicular to the drift, produces temperatures that are somewhat higher than the measured temperatures after approximately the first year of heating. However, measured temperatures may be higher prior to that time (refer back to the temperature comparison in Figure 7.1-6). 


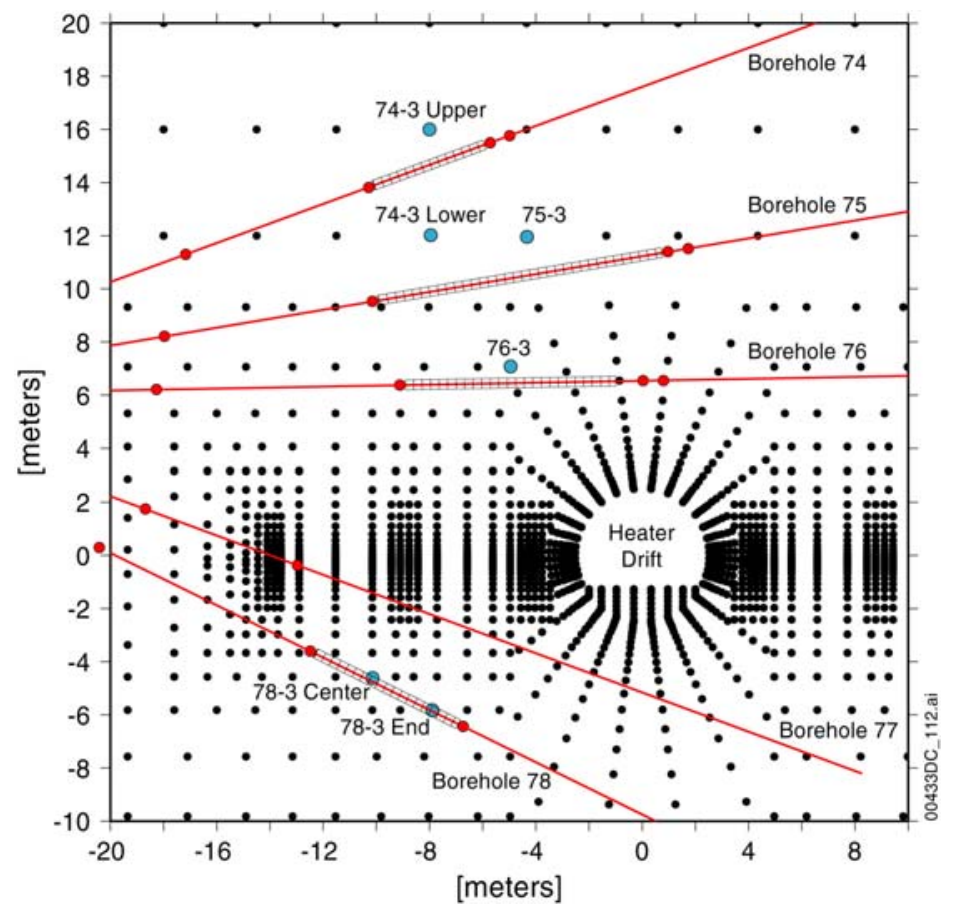

Source: DTN: LB991200DSTTHC.002 [DIRS 142162].

NOTE: Borehole intervals from which gas samples were taken are shown in the hachured regions.

Figure 7.1-11. Close-Up of DST Grid, Showing Nodes Used to Extract Model Data for Comparison to Concentrations Measured in Gas Samples

Figure 7.1-12 shows measured $\mathrm{CO}_{2}$ concentrations that have been corrected for the effect of water-vapor condensation during sample collection. More details regarding the effect and the process involved in the correction procedure are given following the discussion of results in this section. Measured and modeled data are presented up to the end of the heating phase of the DST (including a few measurements performed about 1 month into the cooling phase). In the hottest interval (76-3), the concentrations remained low from 2 years after heating was initiated until after the cooling phase had begun. Except for one sample that may have been predominantly water vapor, similar but delayed behavior took place in 75-3. Modeled compositions shown for 74-3 are given as an average of the values from the "upper" and "lower" grid blocks shown in Figure 7.1-11.

The measured values in Figure 7.1-12 have been corrected for water extraction from the gas during collection. $\mathrm{CO}_{2}$ concentrations have been corrected for the approximate amount of water removed during chilling of the gas sample from the temperature of the sampling interval to $25^{\circ} \mathrm{C}$. The method assumes that the gas is vapor-saturated, removes the appropriate amount of water vapor to the amount at saturation at $25^{\circ} \mathrm{C}$, and adds some of the $\mathrm{CO}_{2}$ into solution (the condensate) as $\mathrm{HCO}_{3}{ }^{-}$, based on the equilibrium partitioning of $\mathrm{CO}_{2}$ into $\mathrm{H}_{2} \mathrm{O}$. The actual temperature of the chiller was $4^{\circ} \mathrm{C}$; however, the efficiency of the unit was such that not all water was taken out when the gas was at boiling temperatures (BSC 2004 [DIRS 169900], Section 6.3.4.2.5). Therefore, for consistency, the chill temperature was set to $25^{\circ} \mathrm{C}$ for all samples. Because the difference in water vapor content between $25^{\circ} \mathrm{C}$ and $4^{\circ} \mathrm{C}$ is small, this 
approximation is valid. For samples with temperatures below approximately $60^{\circ} \mathrm{C}$, the correction is very small; however, at temperatures near boiling, the correction may be close to an order of magnitude (Section 7.1.10.1). The corrections are documented by Wang (2003 [DIRS 161665], Notebook SN-LBNL-SCI-112-V2, pp. 60 to 63).

The effect of the correction on the measured $\mathrm{CO}_{2}$ concentrations is a gradual (but increasing) reduction up to the boiling temperature, where the sharp "second" spike in the uncorrected data largely disappears. It is clear that the correction to the measured concentrations substantially improves the comparison to the modeled data at higher temperatures. Figure 7.1-13 shows an example of the effect of the correction on the $\mathrm{CO}_{2}$ concentrations for borehole interval 75-3.

Trends in modeled $\mathrm{CO}_{2}$ concentrations are clearly followed for all borehole intervals evaluated. Deviations in concentrations for certain samples can be attributed to the factors discussed in Section 7.1.7.1. The comparison of simulated and measured (corrected) $\mathrm{CO}_{2}$ concentrations are generally within a factor of 2 , and in most cases within an order of magnitude, except for low concentration, high-temperature samples, where the correction due to condensation of water vapor is large. The "second" peak in the data at 48 months is not consistent with any process predicted to occur in the rock and is associated with near-boiling sampling conditions when only a tiny fraction of the gas is noncondensable and the potential error in the correction for water vapor extraction is relatively large. Accordingly, the validation criteria discussed in Section 7.1.7 are met.

\subsubsection{Aqueous Species Evolution}

\subsubsection{Chemistry of Waters Sampled During the Drift Scale Test}

Water samples were collected from several hydrology boreholes during the heating phase of the DST. Collection dates, volumes, and field measurements (e.g., pH) for all water samples are presented in Thermal Testing Measurements Report (BSC 2004 [DIRS 169900], Table 6.3.4.1-1). Cation and anion analyses of the water samples are given in Table 6.3.4.1-2 (DTN: LL020709923142.023 [DIRS 161677]) of the same report. The latter table lists all samples that were analyzed, regardless of their origin. In particular, many samples were collected from borehole intervals above boiling temperatures and were clearly derived from water vapor that condensed in the tubing leading out of the interval. In most cases, such samples are clearly recognizable from the water samples pumped directly out of boreholes (and in contact with rock), based on (1) their significantly lower $\mathrm{pH}$ (most below $\mathrm{pH} 5$ ) relative to water samples that accumulated inside the boreholes (nearly all above $\mathrm{pH} 6$ ), (2) their extremely low anion and cation content (total dissolved solids around $10 \mathrm{ppm}$ or less), and (3) very low total Si concentrations (most much less than $10 \mathrm{mg} / \mathrm{L}$ ) compared to water samples having total $\mathrm{Si}$ concentrations mostly greater than $40 \mathrm{mg} / \mathrm{L}$. 
(a)

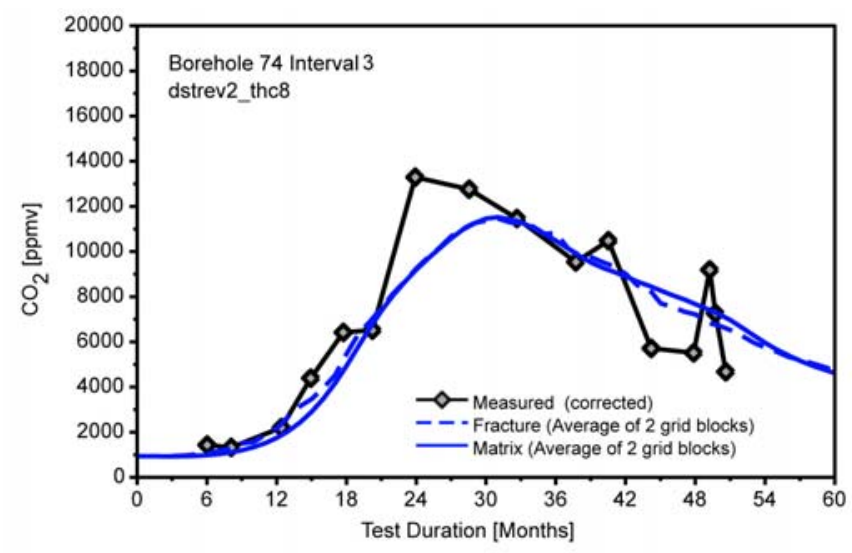

(b)

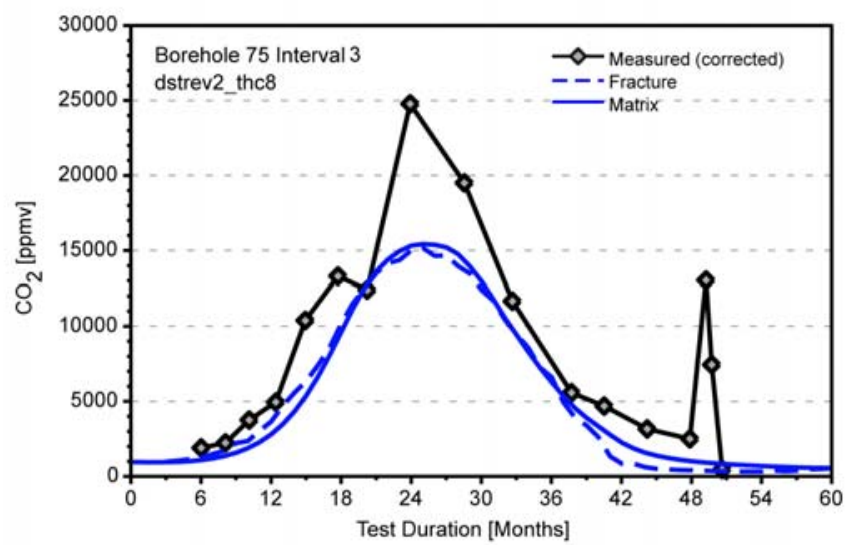

(c)

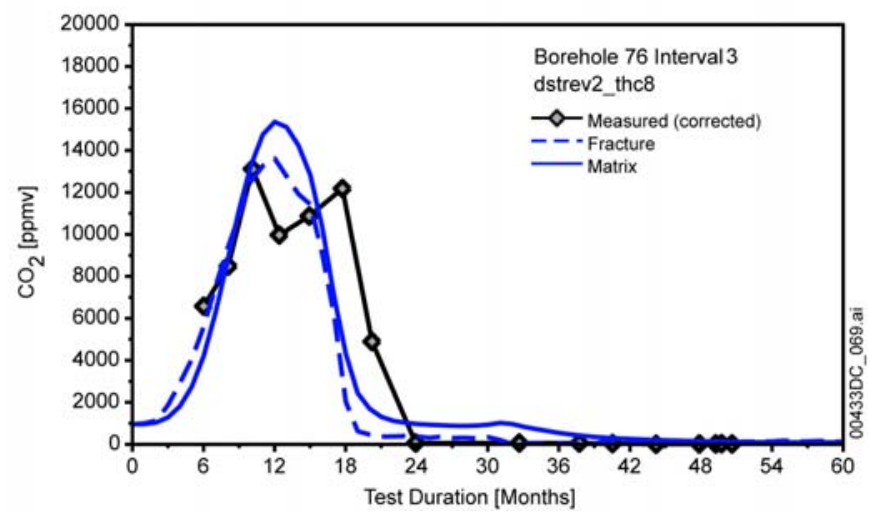

Source: DTN: LB0208ISODSTHP.001 [DIRS 161638] (measured $\mathrm{CO}_{2}$ uncorrected). Output DTN: LB0307DSTTHCR2.001 (modeled).

Figure 7.1-12. Comparison of Modeled $\mathrm{CO}_{2}$ Concentrations in Fractures to Measured (Corrected) Concentrations in Boreholes: (a) Borehole Interval 74-3 (Average of Bounding Grid Blocks); (b) Borehole Interval 75-3; (c) Borehole Interval 76-3 


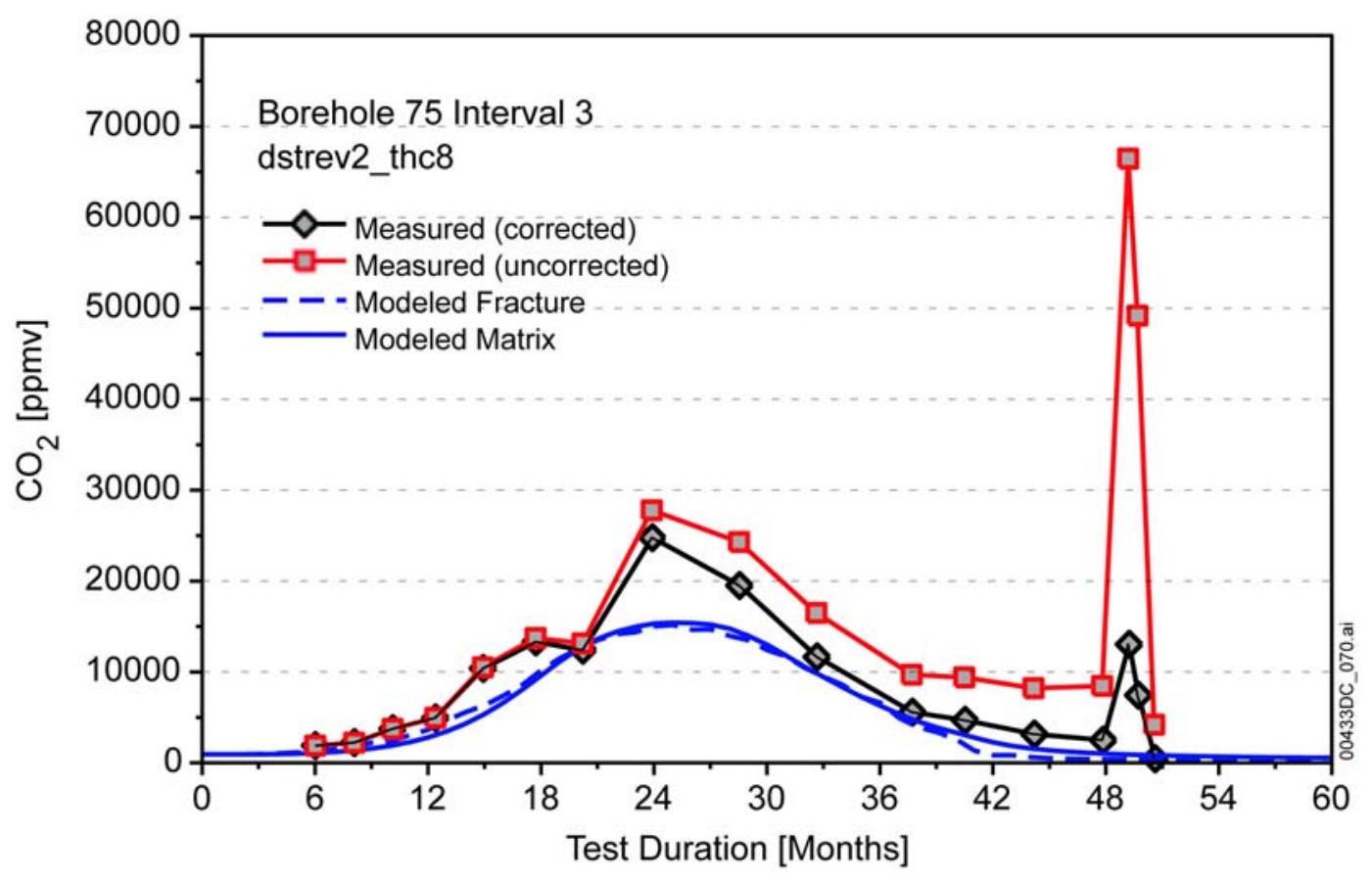

Source: DTN: LB0208ISODSTHP.001 [DIRS 161638] (measured $\mathrm{CO}_{2}$ uncorrected). Output DTN: LB0307DSTTHCR2.001 (modeled).

NOTE: See text for discussion of the outliers at 48 months.

Figure 7.1-13. Comparison of Measured and Corrected Concentrations for Borehole Interval 75-3 and the Model Simulation Results

Specific exceptions to these criteria are those samples collected from intervals at high temperatures $\left(>140^{\circ} \mathrm{C}\right)$ that have relatively low $\mathrm{pH}$ values $(<\mathrm{pH} 4)$, elevated $\mathrm{F}^{-}$concentrations $(>10 \mathrm{mg} / \mathrm{L})$, and relatively high total $\mathrm{Si}$ values, but contain few other measurable constituents. Experimental studies confirmed the hypothesis that the breakdown of fluoroelastomer packer materials at elevated temperatures was responsible for the unusual water compositions that formed as high-temperature vapor condensed in tubing and was collected as water (BSC 2004 [DIRS 169900], Table 6.3.4.1-1). In addition, some waters may have been affected by degradation of neoprene packers in sub-boiling zones, such as the high $\mathrm{Cl}$ water collected from borehole 59, interval 4 (Williams 2003 [DIRS 163765]).

Chemical analyses of water samples that, based upon the compositional criteria discussed above, were wholly or mostly derived from water that had resided in a borehole (rather than formed during condensation of water vapor in the collection tube) are given in Table 7.1-3. The intervals where these waters were collected are shown as the blue shaded zones in Figure 7.1-14. The water samples collected during the test were obtained from zones that were hotter than the temperatures given for the samples because the samples cooled substantially as they were pumped out of the rock through the sample collection tubing and into the sample containers. Also listed in Table 7.1-3 are the compositions of pore waters that had been ultracentrifuged out of the rock matrix from a dry-drilled borehole near the DST (HD-PERM designations). 


\section{INTENTIONALLY LEFT BLANK}


Table 7.1-3. Measured Concentrations in Tptpmn Pore Water from Alcove 5 and Chemistry of Water Samples from Hydrology Boreholes

\begin{tabular}{|c|c|c|c|c|c|c|c|c|c|c|c|c|c|}
\hline $\begin{array}{l}\text { SMF No. (SPCO...) } \\
\text { Collection Date } \\
\text { Collection Time } \\
\text { Sample ID }\end{array}$ & $\begin{array}{c}1002488 \\
\text { Pre-Heating } \\
\text { PERM-1 }^{\mathrm{c}}\end{array}$ & $\begin{array}{c}1002586 \\
\text { Pre-Heating } \\
\text { PERM-2 }^{\mathrm{c}}\end{array}$ & $\begin{array}{c}1002525 \\
\text { Pre-Heating } \\
\text { PERM-3 }^{\mathrm{c}}\end{array}$ & $\begin{array}{c}05279699 \\
06 / 04 / 98 \\
\text { BH 60-2 }\end{array}$ & $\begin{array}{c}05279689 \\
06 / 04 / 98 \\
\\
\text { BH 60-2 }\end{array}$ & $\begin{array}{l}0527915^{\mathrm{a}} \\
08 / 12 / 98 \\
\\
\text { BH 60-2 }\end{array}$ & $\begin{array}{l}0527977^{\mathrm{a}} \\
06 / 04 / 98 \\
\\
\text { BH 60-3 }\end{array}$ & $\begin{array}{l}0527916^{\mathrm{a}} \\
08 / 12 / 98 \\
\\
\text { BH 60-3 }\end{array}$ & $\begin{array}{l}0541804^{a} \\
11 / 12 / 98 \\
\\
\text { BH 60-3 }\end{array}$ & $\begin{array}{c}1541804^{a, b} \\
11 / 12 / 98 \\
\text { BH 60-3 }\end{array}$ & $\begin{array}{c}05043968 \\
01 / 26 / 99 \\
\\
\text { BH 60-3 }\end{array}$ & $\begin{array}{c}0529637-\# 1^{a} \\
03 / 30 / 99 \\
9: 50 \text { AM } \\
\text { BH 60-3 }\end{array}$ & $\begin{array}{c}0529637-\# 2^{\mathrm{a}} \\
03 / 30 / 99 \\
9: 55 \text { AM } \\
\text { BH 60-3 }\end{array}$ \\
\hline $\begin{array}{l}\text { Field } \mathrm{pH}^{\mathrm{d}} \\
\text { Metals / Cations }\end{array}$ & 7.79 & 8.32 & 8.31 & 7.5 & na & 6.9 & 7.7 & 6.8 & 6.92 & 6.92 & 7.4 & 8.0 & na \\
\hline $\mathrm{Na}(\mathrm{mg} / \mathrm{L})$ & 60.5 & 61.0 & 61.5 & 20.0 & na & 20.4 & 24.0 & 17.2 & 10.1 & 20.3 & 19.1 & 11.2 & 11.0 \\
\hline $\mathrm{Si}(\mathrm{mg} / \mathrm{L})$ & 37 & 31 & 35 & 56 & na & 51.8 & 41 & 43.5 & 60.0 & 53.8 & 65.0 & 62.8 & 59.8 \\
\hline $\mathrm{Ca}(\mathrm{mg} / \mathrm{L})$ & 98.17 & 106.17 & 96.67 & 20 & na & 19.9 & 25 & 18.7 & 15.3 & 13.9 & 5.93 & 2.06 & 2.27 \\
\hline $\mathrm{K}(\mathrm{mg} / \mathrm{L})$ & 6.0 & 7.0 & 9.0 & 6.0 & na & 5.4 & 4.5 & 4.5 & 8.7 & 7.8 & 4.1 & 2.4 & 2.4 \\
\hline$M g(\mathrm{mg} / \mathrm{L})$ & 25.65 & 16.55 & 17.35 & 2.9 & na & 1.21 & 5.7 & 4.0 & 3.35 & 3.00 & 1.17 & 0.27 & 0.26 \\
\hline $\mathrm{Al}(\mathrm{mg} / \mathrm{L})$ & $<0.06$ & $<0.06$ & $<0.06$ & 0.12 & na & $<0.06$ & $0.017^{\mathrm{e}}$ & $0.003^{\mathrm{e}}$ & $0.033^{\mathrm{e}}$ & $0.033^{\mathrm{e}}$ & $<0.06$ & $0.36,0.27^{\mathrm{e}}$ & $0.36,0.27^{\mathrm{e}}$ \\
\hline$B(\mathrm{mg} / \mathrm{L})$ & 3.05 & 2.75 & 2.75 & 1.2 & na & 1.84 & 0.92 & 1.14 & 1.58 & 1.41 & 1.75 & 2.10 & 2.11 \\
\hline $\mathrm{S}(\mathrm{mg} / \mathrm{L})$ & 42.25 & 38.6 & 38.65 & 5.5 & na & 4.5 & 9.2 & 5.2 & 11.6 & 10.5 & 6.4 & 1.83 & 1.82 \\
\hline $\mathrm{Fe}(\mathrm{mg} / \mathrm{L})$ & $<0.02$ & $<0.02$ & $<0.02$ & 0.04 & na & 0.02 & $<0.02$ & 0.12 & 0.02 & $<0.02$ & $<0.02$ & $<0.02$ & $<0.02$ \\
\hline $\mathrm{Li}(\mathrm{mg} / \mathrm{L})$ & 0.1 & 0.45 & 0.05 & 0.07 & na & 0.03 & 0.07 & 0.040 & 0.040 & 0.040 & 0.02 & 0.02 & $<0.01$ \\
\hline $\mathrm{Sr}(\mathrm{mg} / \mathrm{L})$ & 1.4 & 1 & 1.05 & 0.18 & na & 0.11 & 0.34 & 2.21 & 0.22 & 0.20 & 0.09 & 0.02 & 0.02 \\
\hline \multicolumn{14}{|l|}{ Anions } \\
\hline $\mathrm{HCO}_{3}(\mathrm{mg} / \mathrm{L})^{\mathrm{f}}$ & & & & na & na & na & na & na & na & na & 41 & 25.0 & na \\
\hline$F(\mathrm{mg} / \mathrm{L})$ & 0.36 & 0.96 & 0.76 & na & 1.00 & 0.71 & 0.82 & 0.43 & 0.49 & 0.50 & 1.27 & 1.02 & 0.97 \\
\hline $\mathrm{Cl}(\mathrm{mg} / \mathrm{L})$ & 122.73 & 109.93 & 123.13 & na & 10 & 6.14 & 16 & 5.52 & 19.5 & 19.6 & 10.3 & 4.15 & 3.92 \\
\hline $\operatorname{Br}(\mathrm{mg} / \mathrm{L})$ & 0.6 & 0.76 & 1.2 & na & 0.84 & 0.05 & 0.73 & 0.21 & 0.6 & 0.51 & 0.15 & $<0.04$ & $<0.04$ \\
\hline $\mathrm{SO}_{4}(\mathrm{mg} / \mathrm{L})$ & 124.18 & 111.38 & 119.78 & na & 17 & 4.88 & 30 & 8.81 & 30.6 & 30.8 & 13.5 & 3.83 & 3.75 \\
\hline $\mathrm{PO}_{4}(\mathrm{mg} / \mathrm{L})$ & $<0.07$ & $<0.07$ & $<0.07$ & na & $<0.07$ & 0.25 & $<0.07$ & 0.16 & $<0.2$ & $<0.2$ & $<0.05$ & $<0.05$ & $<0.05$ \\
\hline $\mathrm{NO}_{2}(\mathrm{mg} / \mathrm{L})$ & $<0.04$ & $<0.04$ & $<0.04$ & na & $<0.01$ & $<0.04$ & $<0.01$ & $<0.04$ & $<.10$ & $<.10$ & $<.03$ & $<0.03$ & $<0.03$ \\
\hline $\mathrm{NO}_{3}(\mathrm{mg} / \mathrm{L})$ & 21.72 & 2.52 & 10.40 & na & 3.00 & 0.46 & 3.6 & 0.60 & 3.38 & 3.17 & 2.56 & 0.92 & 0.84 \\
\hline
\end{tabular}


Table 7.1-3. Measured Concentrations in Tptpmn Pore Water from Alcove 5 and Chemistry of Water Samples from Hydrology Boreholes (Continued)

\begin{tabular}{|c|c|c|c|c|c|c|c|c|c|c|c|c|c|}
\hline $\begin{array}{l}\text { SMF No. (SPC0...) } \\
\text { Collection Date } \\
\text { Collection Time } \\
\text { Sample ID }\end{array}$ & $\begin{array}{c}0551159^{\mathrm{a}} \\
08 / 09 / 99 \\
\end{array}$ & $\begin{array}{c}0551160^{\mathrm{a}} \\
08 / 09 / 99 \\
\\
\end{array}$ & $\begin{array}{l}0557029^{a} \\
10 / 27 / 99 \\
\\
\\
\text { BH 59-2 }\end{array}$ & $\begin{array}{l}0557032 \\
10 / 27 / 99 \\
\\
H \text { 59-2 }\end{array}$ & $\begin{array}{l}0557033^{\mathrm{a}} \\
10 / 27 / 99 \\
\\
\text { B 59-2 }\end{array}$ & $\begin{array}{l}0557080 \\
11 / 30 / 99 \\
\\
H+59-2\end{array}$ & $\begin{array}{l}0557081 \\
11 / 30 / 99 \\
\\
H \text { 59-2 }\end{array}$ & $\begin{array}{l}0557083 \\
11 / 30 / 99\end{array}$ & $\begin{array}{l}0557022 \\
01 / 25 / 00 \\
\\
\text { BH 59-2 }\end{array}$ & $\begin{array}{l}0550671 \\
01 / 25 / 00 \\
\\
H \text { 59-2 }\end{array}$ & $\begin{array}{l}0550673 \\
01 / 25 / 00 \\
\\
\text { BH 59-2 }\end{array}$ & $\begin{array}{l}0550681 \\
05 / 23 / 00 \\
\\
H \text { 59-2 }\end{array}$ & $\begin{array}{l}0550682 \\
05 / 23 / 00 \\
\\
\text { BH 59-2 }\end{array}$ \\
\hline $\begin{array}{l}\text { Field } \mathrm{pH}^{\mathrm{d}} \\
\text { Metals / Cations }\end{array}$ & na & na & na & 5.93 & 6.08 & 6.86 & 7.24 & na & 7.07 & 6.68 & na & 6.96 & 6.96 \\
\hline $\mathrm{Na}(\mathrm{mg} / \mathrm{L})$ & 30 & 24 & na & 9.2 & 9.2 & 6.6 & 7.7 & na & 8.1 & 6.6 & na & 17 & 18 \\
\hline $\mathrm{Si}(\mathrm{mg} / \mathrm{L})$ & 78 & 81 & na & 44.5 & 44.9 & 38.0 & 39.9 & na & 42.8 & 41.7 & na & 59.4 & 59.2 \\
\hline $\mathrm{Ca}(\mathrm{mg} / \mathrm{L})$ & 47 & 39 & na & 7.53 & 7.47 & 4.33 & 5.63 & na & 7.54 & 2.89 & na & 4.7 & 4.4 \\
\hline $\mathrm{K}(\mathrm{mg} / \mathrm{L})$ & 8 & 6 & na & 3.4 & 3.6 & 2.6 & 3.0 & na & 3.6 & 2.8 & na & 4.3 & 4.4 \\
\hline$M g(\mathrm{mg} / \mathrm{L})$ & 13 & 11 & na & 1.81 & 1.72 & 1.02 & 1.38 & na & 1.78 & 0.72 & na & 1.1 & 1.1 \\
\hline $\mathrm{Al}(\mathrm{mg} / \mathrm{L})$ & $<0.2$ & $<0.2$ & na & $0.033^{\mathrm{g}}$ & $0.033^{9}$ & 0.030 & 0.030 & na & $<0.05$ & 0.043 & na & $<0.053$ & $<0.053$ \\
\hline$B(\mathrm{mg} / \mathrm{L})$ & 0.8 & 0.6 & na & 0.27 & 0.21 & 0.14 & 0.17 & na & 0.29 & 0.21 & na & na & na \\
\hline $\mathrm{S}(\mathrm{mg} / \mathrm{L})$ & 22 & 17 & na & 2.52 & 2.50 & 0.76 & 1.33 & na & 6.44 & 0.65 & na & na & na \\
\hline $\mathrm{Fe}(\mathrm{mg} / \mathrm{L})$ & 0.41 & 0.32 & na & 0.20 & 0.19 & 0.09 & 0.14 & na & 0.07 & $<0.02$ & na & $<0.038$ & $<0.038$ \\
\hline $\mathrm{Li}(\mathrm{mg} / \mathrm{L})$ & $<4$ & $<4$ & na & 0.16 & 0.01 & 0.01 & 0.01 & na & $<0.01$ & $<0.01$ & na & 0.021 & 0.022 \\
\hline $\mathrm{Sr}(\mathrm{mg} / \mathrm{L})$ & 0.54 & 0.45 & na & 0.11 & 0.08 & 0.06 & 0.08 & na & 0.091 & 0.036 & na & $<0.013$ & $<0.013$ \\
\hline \multicolumn{14}{|l|}{ Anions } \\
\hline $\mathrm{HCO}_{3}(\mathrm{mg} / \mathrm{L})^{f}$ & na & na & 23.5 & na & 23.5 & na & na & 22.3 & na & na & 22.8 & 31.4 & 31.4 \\
\hline$F(\mathrm{mg} / \mathrm{L})$ & 0.725 & 0.575 & 0.27 & na & 0.27 & na & na & 0.35 & na & na & 0.73 & 0.58 & 0.55 \\
\hline $\mathrm{Cl}(\mathrm{mg} / \mathrm{L})$ & 88.3 & 71.0 & 9.5 & na & 9.1 & na & na & 5.0 & na & na & 3.8 & 10.15 & 10.6 \\
\hline $\mathrm{Br}(\mathrm{mg} / \mathrm{L})$ & 0.515 & 0.46 & 0.61 & na & 0.58 & na & na & $<0.03$ & na & na & $<0.1$ & $<0.1$ & 0.38 \\
\hline $\mathrm{SO}_{4}(\mathrm{mg} / \mathrm{L})$ & 64.2 & 53.5 & 6.2 & na & 6.3 & na & na & 2.8 & na & na & 1.8 & 2.9 & 3.18 \\
\hline $\mathrm{PO}_{4}(\mathrm{mg} / \mathrm{L})$ & $<0.02$ & $<0.02$ & $<0.02$ & na & $<0.02$ & na & na & $<0.02$ & na & na & 0.62 & $<0.2$ & $<0.2$ \\
\hline $\mathrm{NO}_{2}(\mathrm{mg} / \mathrm{L})$ & $<0.007$ & $<0.007$ & $<0.007$ & na & $<0.007$ & na & na & $<0.007$ & na & na & $<0.05$ & $<0.06$ & $<0.06$ \\
\hline $\mathrm{NO}_{3}(\mathrm{mg} / \mathrm{L})$ & 3.79 & 2.83 & 1.32 & na & 1.40 & na & na & $<0.02$ & na & na & 0.77 & 0.56 & 0.54 \\
\hline
\end{tabular}


Table 7.1-3. Measured Concentrations in Tptpmn Pore Water from Alcove 5 and Chemistry of Water Samples from Hydrology Boreholes (Continued)

\begin{tabular}{|c|c|c|c|c|c|c|c|c|c|c|c|c|c|}
\hline $\begin{array}{l}\text { SMF No. (SPC0...) } \\
\text { Collection Date } \\
\text { Collection Time }\end{array}$ & $\begin{array}{l}0550684 \\
05 / 23 / 00\end{array}$ & $\begin{array}{l}0550693 \\
06 / 29 / 00\end{array}$ & $\begin{array}{l}0550694 \\
06 / 29 / 00\end{array}$ & $\begin{array}{l}0550691 \\
06 / 29 / 00\end{array}$ & $\begin{array}{l}0550689 \\
06 / 29 / 00\end{array}$ & $\begin{array}{l}0550690 \\
06 / 29 / 00\end{array}$ & $\begin{array}{l}0530398 \\
01 / 23 / 01\end{array}$ & $\begin{array}{c}0557036^{\mathrm{a}} \\
10 / 27 / 99\end{array}$ & $\begin{array}{c}0557038^{\mathrm{a}} \\
10 / 27 / 99\end{array}$ & $\begin{array}{l}0552575 \\
11 / 30 / 99\end{array}$ & $\begin{array}{l}0557043 \\
11 / 30 / 99\end{array}$ & $\begin{array}{l}0541803^{\mathrm{a}} \\
11 / 12 / 98\end{array}$ & $\begin{array}{r}0541803^{\mathrm{a}, \mathrm{h}} \\
11 / 12 / 98\end{array}$ \\
\hline Sample ID & BH 59-2 & BH 59-2 & BH 59-2 & BH 59-2 & BH 59-2 & BH 59-2 & BH 59-2 & BH 59-3 & BH 59-3 & BH 59-3 & BH 59-3 & BH 59-4 & BH 59-4 \\
\hline $\begin{array}{l}\text { Field } \mathrm{pH}^{\mathrm{d}} \\
\text { Metals / Cations }\end{array}$ & 6.95 & 6.99 to 7.08 & 6.99 to 7.08 & 7.00 & na & na & na & na & 6.64 & 7.47 & na & 6.63 & 6.63 \\
\hline $\mathrm{Na}(\mathrm{mg} / \mathrm{L})$ & 17 & 16 & 15 & $<4.8$ & na & na & 29 & na & 19.3 & 15.6 & na & 22.6 & 135 \\
\hline $\mathrm{Si}(\mathrm{mg} / \mathrm{L})$ & 59.3 & 62.7 & 57.5 & 36.3 & na & na & 84.5 & na & 84.2 & 92.5 & na & 33.5 & 44.2 \\
\hline $\mathrm{Ca}(\mathrm{mg} / \mathrm{L})$ & 4.5 & 4.3 & 3.8 & 2.0 & na & na & 7.8 & na & 13.2 & 2.86 & na & 476 & 450 \\
\hline $\mathrm{K}(\mathrm{mg} / \mathrm{L})$ & 4.4 & 4.7 & 4.2 & 2.5 & na & na & 5.8 & na & 5.6 & 3.9 & na & 29.5 & 37.8 \\
\hline$M g(\mathrm{mg} / \mathrm{L})$ & 1.1 & 1.1 & 1.0 & 0.54 & na & na & 1.8 & na & 1.49 & 0.29 & na & 64.1 & 83.9 \\
\hline $\mathrm{Al}(\mathrm{mg} / \mathrm{L})$ & $<0.053$ & $<0.053$ & $<0.053$ & $<0.11$ & na & na & $<0.053$ & na & 0.040 & 0.071 & na & $0.01^{\mathrm{e}}$ & $<0.06$ \\
\hline B (mg/L) & na & na & na & na & na & na & na & na & 0.86 & 1.06 & na & 4.47 & 4.13 \\
\hline $\mathrm{S}(\mathrm{mg} / \mathrm{L})$ & na & na & na & na & na & na & na & na & 14.48 & 3.25 & na & 50.7 & 64.8 \\
\hline $\mathrm{Fe}(\mathrm{mg} / \mathrm{L})$ & $<0.038$ & $<0.038$ & $<0.038$ & $<0.076$ & na & na & $<0.038$ & na & $<0.02$ & $<0.02$ & na & $<0.02$ & $<0.02$ \\
\hline $\mathrm{Li}(\mathrm{mg} / \mathrm{L})$ & 0.021 & 0.019 & 0.018 & 0.010 & na & na & 0.033 & na & 0.02 & 0.02 & na & 0.21 & 0.20 \\
\hline $\mathrm{Sr}(\mathrm{mg} / \mathrm{L})$ & $<0.013$ & $<0.013$ & $<0.013$ & $<0.026$ & na & na & $<0.013$ & na & 0.13 & 0.03 & na & 4.02 & 3.71 \\
\hline \multicolumn{14}{|l|}{ Anions } \\
\hline $\mathrm{HCO}_{3}(\mathrm{mg} / \mathrm{L})^{f}$ & 31.4 & na & na & na & 29.4 & 29.4 & na & 12.4 & 12.4 & na & 20.7 & na & na \\
\hline$F(\mathrm{mg} / \mathrm{L})$ & 0.49 & na & na & na & 0.18 & 0.15 & 0.78 & 0.64 & 0.73 & na & 1.3 & 0.8 & 4.3 \\
\hline $\mathrm{Cl}(\mathrm{mg} / \mathrm{L})$ & 10.15 & na & na & na & 0.90 & 0.32 & 25.20 & 12.9 & 12.9 & na & 8.8 & 1,130 & 1,250 \\
\hline $\mathrm{Br}(\mathrm{mg} / \mathrm{L})$ & $<0.1$ & na & na & na & 0.62 & 0.48 & $<0.1$ & 0.89 & 0.51 & na & $<0.03$ & 1.13 & $<0.07$ \\
\hline $\mathrm{SO}_{4}(\mathrm{mg} / \mathrm{L})$ & 3.1 & na & na & na & 0.5 & 0.42 & 9.5 & 40.7 & 40.3 & na & 8.2 & 226 & 213 \\
\hline $\mathrm{PO}_{4}(\mathrm{mg} / \mathrm{L})$ & $<0.2$ & na & na & na & $<0.2$ & $<0.2$ & $<0.2$ & $<0.04$ & $<0.04$ & na & $<0.02$ & $<5$ & $<0.2$ \\
\hline $\mathrm{NO}_{2}(\mathrm{mg} / \mathrm{L})$ & $<0.06$ & na & na & na & $<0.06$ & $<0.06$ & $<0.06$ & $<0.01$ & $<0.01$ & na & $<0.007$ & $<3$ & $<10$ \\
\hline $\mathrm{NO}_{3}(\mathrm{mg} / \mathrm{L})$ & 0.71 & na & na & na & 0.65 & 0.48 & 0.99 & 3.06 & 3.05 & na & 2.4 & 3.12 & 7.81 \\
\hline
\end{tabular}


Table 7.1-3. Measured Concentrations in Tptpmn Pore Water from Alcove 5 and Chemistry of Water Samples from Hydrology Boreholes (Continued)

\begin{tabular}{|c|c|c|c|c|c|c|c|c|c|c|c|c|c|}
\hline $\begin{array}{l}\text { SMF No. (SPC0...) } \\
\text { Collection Date } \\
\text { Collection Time } \\
\text { Sample ID } \\
\end{array}$ & $\begin{array}{l}0504397^{\mathrm{a}} \\
01 / 26 / 99 \\
\\
\text { BH 59-4 } \\
\end{array}$ & $\begin{array}{l}0551169^{a} \\
08 / 10 / 99 \\
\\
\text { BH 61-3 } \\
\end{array}$ & $\begin{array}{l}0559464 \\
04 / 17 / 01 \\
\\
\text { BH 76-2 } \\
\end{array}$ & $\begin{array}{l}0559458 \\
04 / 17 / 01 \\
\\
\text { BH 76-2 } \\
\end{array}$ & $\begin{array}{l}0559456 \\
04 / 17 / 01 \\
\\
\text { BH 76-2 } \\
\end{array}$ & $\begin{array}{l}1016082 \\
01 / 07 / 02 \\
\\
\text { BH 76-2 } \\
\end{array}$ & $\begin{array}{c}0557040^{\mathrm{a}} \\
10 / 27 / 99 \\
\\
\text { BH 76-3 } \\
\end{array}$ & $\begin{array}{l}0552578 \\
11 / 30 / 99 \\
\\
\text { BH 76-3 } \\
\end{array}$ & $\begin{array}{l}0552579 \\
11 / 30 / 99 \\
\\
\text { BH 76-3 } \\
\end{array}$ & $\begin{array}{l}0550697 \\
05 / 23 / 00 \\
\\
\text { BH 76-3 } \\
\end{array}$ & $\begin{array}{l}0541805^{a} \\
11 / 12 / 98 \\
\\
\text { BH 186-3 } \\
\end{array}$ & $\begin{array}{c}0541805^{\mathrm{a}, \mathrm{b}} \\
11 / 12 / 98 \\
\\
\text { BH 186-3 } \\
\end{array}$ & $\begin{array}{l}0527961^{a} \\
01 / 26 / 99 \\
\\
\text { BH 186-3 } \\
\end{array}$ \\
\hline $\begin{array}{l}\text { Field } \mathrm{pH}^{\mathrm{d}} \\
\text { Metals / Cations }\end{array}$ & na & na & 7.68 & 8.22 & 8.29 & 7.8 & 6.14 to 6.46 & 6.94 & na & 6.92 to 6.96 & 6.83 & 6.83 & 7.2 \\
\hline $\mathrm{Na}(\mathrm{mg} / \mathrm{L})$ & 219 & 19 & 9 & 9 & 9 & na & 64.5 & 28.2 & na & 29 & 105 & 17.0 & 25.9 \\
\hline $\mathrm{Si}(\mathrm{mg} / \mathrm{L})$ & 12.0 & 67 & 42.6 & 44.1 & 45.6 & na & 133.4 & 92.8 & na & 96.0 & 16.0 & 27.2 & 49.3 \\
\hline $\mathrm{Ca}(\mathrm{mg} / \mathrm{L})$ & 429 & 14 & 1.3 & 1.1 & 1.3 & na & 59.5 & 22.3 & na & 7.1 & 11.5 & 20.2 & 2.92 \\
\hline $\mathrm{K}(\mathrm{mg} / \mathrm{L})$ & 29.7 & 5 & 1.6 & 1.6 & 1.9 & na & 13.4 & 7.4 & na & 6.5 & 3.5 & 3.9 & 5.9 \\
\hline$M g(m g / L)$ & 164 & 3.2 & 0.27 & 0.22 & 0.23 & na & 13.8 & 4.71 & na & 1.4 & 5.1 & 5.68 & 6.32 \\
\hline $\mathrm{Al}(\mathrm{mg} / \mathrm{L})$ & $0.086^{e}$ & $<0.2$ & 0.42 & 0.43 & 0.45 & na & 0.010 & 0.031 & na & $<0.053$ & $<0.003^{\mathrm{e}}$ & $<0.003^{\mathrm{e}}$ & $<0.06$ \\
\hline B (mg/L) & 6.68 & 1.5 & na & na & na & na & 2.38 & 0.81 & na & na & 0.51 & 0.58 & 0.84 \\
\hline $\mathrm{S}(\mathrm{mg} / \mathrm{L})$ & 109 & 3.1 & na & na & na & na & 34.55 & 9.46 & na & na & 8.47 & 9.42 & 7.9 \\
\hline $\mathrm{Fe}(\mathrm{mg} / \mathrm{L})$ & $<0.02$ & 1.2 & 0.40 & 0.40 & 0.39 & na & $<0.02$ & 0.10 & na & $<0.038$ & 0.02 & $<0.02$ & 0.09 \\
\hline $\mathrm{Li}(\mathrm{mg} / \mathrm{L})$ & 0.33 & $<4$ & 0.0098 & 0.010 & 0.0076 & na & 0.13 & 0.04 & na & 0.045 & 0.05 & 0.05 & 0.05 \\
\hline $\mathrm{Sr}(\mathrm{mg} / \mathrm{L})$ & 5.84 & 0.14 & $<0.013$ & $<0.013$ & $<0.013$ & na & 0.78 & 0.26 & na & $<0.013$ & 0.30 & 0.34 & 0.37 \\
\hline \multicolumn{14}{|l|}{ Anions } \\
\hline $\mathrm{HCO}_{3}(\mathrm{mg} / \mathrm{L})^{f}$ & na & na & na & na & na & $<5$ & na & na & 82.3 & na & na & na & 116 \\
\hline$F(\mathrm{mg} / \mathrm{L})$ & 0.51 & 0.835 & na & 0.38 & 0.47 & 0.4 & 1.11 & na & 1.3 & 0.76 & 0.56 & 0.62 & 1.20 \\
\hline $\mathrm{Cl}(\mathrm{mg} / \mathrm{L})$ & 1,160 & 24.1 & na & 1.9 & 1.71 & 2.75 & 81.9 & na & 19 & 14.5 & 18.7 & 18.6 & 23.3 \\
\hline $\mathrm{Br}(\mathrm{mg} / \mathrm{L})$ & 1.51 & 0.35 & na & $<0.1$ & $<0.1$ & $<0.2$ & 0.97 & na & $<0.03$ & $<0.1$ & 0.67 & 0.60 & 0.32 \\
\hline $\mathrm{SO}_{4}(\mathrm{mg} / \mathrm{L})$ & 240 & 9.13 & na & 0.89 & 0.85 & 1.02 & 94.6 & na & 26.0 & 4.98 & 26.3 & 26.2 & 21 \\
\hline $\mathrm{PO}_{4}(\mathrm{mg} / \mathrm{L})$ & $<0.5$ & $<0.02$ & na & $<0.2$ & $<0.2$ & $<0.3$ & $<0.02$ & na & $<0.02$ & $<0.2$ & $<0.2$ & $<0.2$ & $<0.1$ \\
\hline $\mathrm{NO}_{2}(\mathrm{mg} / \mathrm{L})$ & $<.3$ & $<0.007$ & na & $<0.06$ & $<0.06$ & $<0.2$ & $<0.007$ & na & $<0.007$ & $<0.06$ & $<.1$ & $<.1$ & $<0.05$ \\
\hline $\mathrm{NO}_{3}(\mathrm{mg} / \mathrm{L})$ & 11.6 & 0.825 & na & $<0.09$ & $<0.09$ & $<0.2$ & 6.42 & na & 2.5 & 1.47 & 7.47 & 7.27 & 6.73 \\
\hline
\end{tabular}

Analytical results are corroborating data (as defined in Section 3.6 of AP-SIII.3Q) and non-qualified. See Table 7-1 for Source DTNs.

6 Sample filtered in the field and laboratory (LLNL) prior to analyses.

d Pore water samples (baseline): sample ultracentrifuged from borehole core.

e Low detection limit analysis - sample filtered to $0.10 \mathrm{~mm}$ and acidified.

$\mathrm{HCO}_{3}^{-}$- field measurement.

Sample ID SPC0057028 submitted for low detection for Al analysis.

NOTE: $\quad$ na $=$ not available; $<=$ not detected (less than "practical reporting limit"). Field chemistry of samples for high fluoride study (11/8/01 to 12/5/01) are reported in BSC 2004 [DIRS 169900], Table 6.3.4.5-1. 


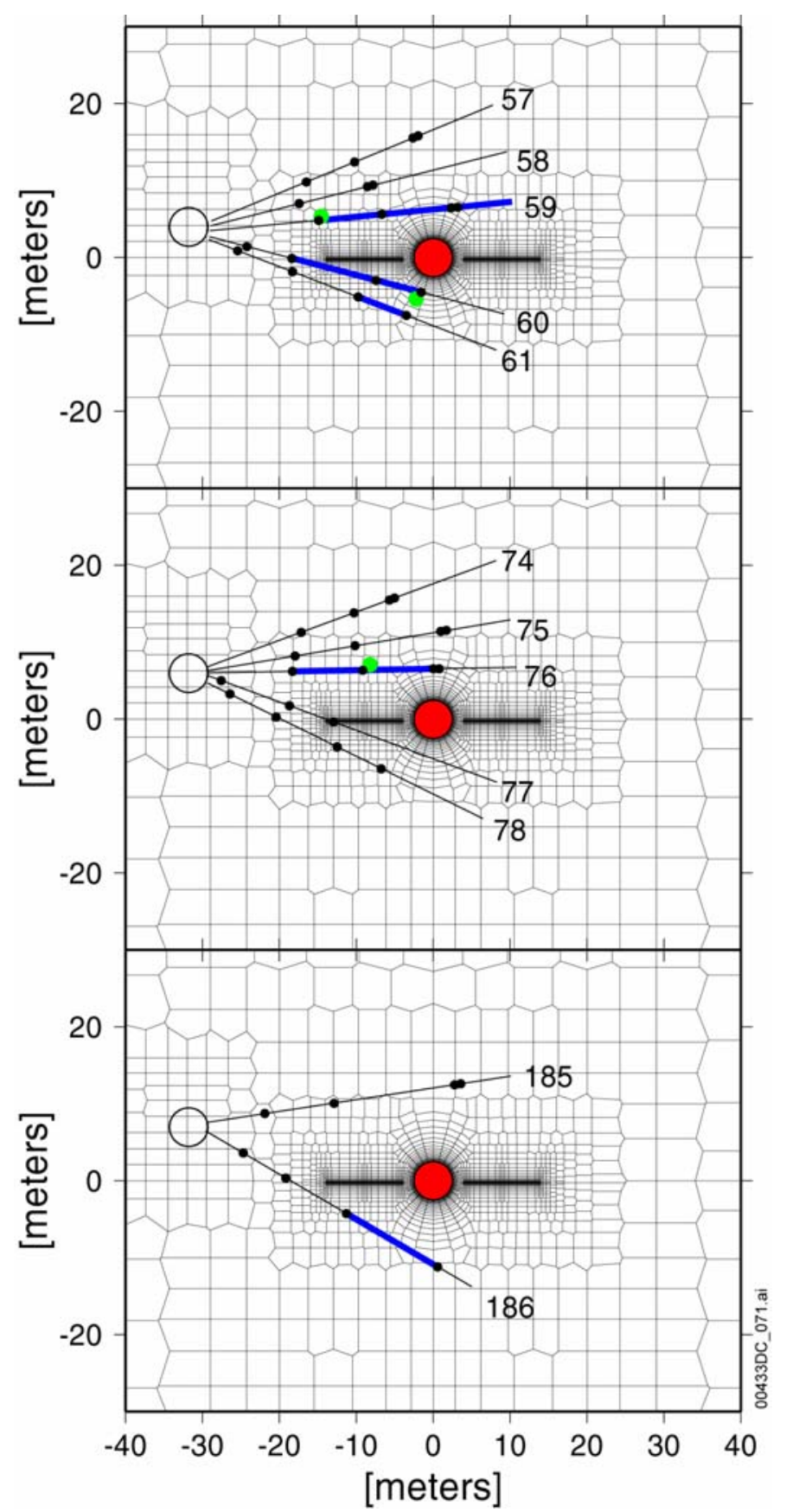

DTNs: LB0307DSTTHCR2.001 (mesh-Output-DTN), MO0002ABBLSLDS.000 [DIRS 147304] (sensors and boreholes).

Source: BSC 2004 [DIRS 169900], Table 6.3.4.1-1 - water collection locations.

NOTE: Only those waters having the distinct criteria discussed in this section are considered to have been liquid in the borehole. Locations where comparisons are made to measured compositions are shown as green circles. The Heater Drift is shown in red.

Figure 7.1-14 Zones Where Water Was Collected from Hydrology Boreholes Superimposed (Thick Shading in Blue) on the Model Grid 
Some of the processes that could explain the water chemistry of samples collected in the hydrology boreholes include mixing of pure condensate water with fracture pore waters, equilibration of condensate waters with matrix pore waters via molecular diffusion, reaction of condensate waters with fracture-lining minerals, and mineral precipitation. Waters that were collected from the hydrology boreholes at elevated temperatures are generally more dilute (lower $\mathrm{Cl}^{-}$and $\mathrm{SO}_{4}{ }^{2-}$ ) and lower in $\mathrm{pH}$ than the initial pore water. Aqueous silica concentrations are similar to or much higher than in the pore water, indicating that these waters are not simple mixtures of pore water and pure condensate water. Some clear trends in water chemistry of the condensate waters over time are increases in $\mathrm{pH}$ and $\mathrm{SiO}_{2}$ (aq) concentration and a drop in $\mathrm{Ca}^{2+}$. The higher silica concentration in the waters collected at later times in several boreholes (and at higher temperatures), relative to chloride and the initial pore-water silica concentration, is consistent with dissolution of a silicate phase, rather than with increased concentration via boiling. Concentrations of $\mathrm{K}^{+}, \mathrm{Mg}^{2+}$, and $\mathrm{Na}^{+}$are also higher than what would be expected by dilution of original pore water (as evidenced by the low chloride concentrations). Therefore, the silicate phases that dissolved must have been some combination of silica polymorphs (i.e., opal, cristobalite, tridymite, and quartz) and feldspar, clays, or zeolites, rather than just a pure silica phase. Many of the waters show a drop in $\mathrm{Ca}^{2+}$ over time, consistent with calcite precipitation as the water was heated further and underwent $\mathrm{CO}_{2}$ degassing.

These water samples are considered to be representative of fracture waters produced by THC processes in the region around the DST. However, the borehole intervals from which the waters were collected are approximately 8 to $10 \mathrm{~m}$ in length and at times have temperatures several tens of degrees different at each end (Section 7.1.7). Therefore, vapor flow from the hot end to the cool end of an interval, accompanied by condensation and reaction with the rock lining the borehole, could account for some of the water found in the boreholes. Because the borehole surface mineralogy is not identical to the fracture surface mineralogy, the water chemistry in the borehole may have some differences from the chemistry of water in the fractures. Yet, because the rock surface in the borehole was freshly drilled, it may be more reactive with respect to silicate mineral reactions; hence, potentially producing higher concentrations of species making up the silicate mineral phases. The fresh mineral surfaces in the borehole could, therefore, result in dissolution rates greater than that in the fractures even though the surface area of the smooth borehole is likely to be less than that of the irregular fracture surface.

Further discussion of water chemistry in the DST and comparisons to simulation results is given in Section 7.1.11.2. Model results are compared to a more complete data set from these intervals and also to borehole interval 76-3, which is above the heaters in an array closer to the area where the maximum drift crown temperature is reached $(30 \mathrm{~m}$ from the bulkhead). Waters were collected from other borehole intervals, but on only one or two occasions, and are therefore of limited value for validation. However, they do provide additional information on the range of potential water compositions.

\subsubsection{Evolution in the pH of Waters from the DST}

In this section, simulations of the evolution of $\mathrm{pH}$ in space and time are shown, followed by comparisons of $\mathrm{pH}$ measurements of waters collected from boreholes and model results at specific locations. The $\mathrm{pH}$ of waters in the rock is a function of the coupled thermal, chemical, and transport processes taking place in the fractures and matrix as the system undergoes heating. 
The water chemistry can also be affected near rock interfaces, such as at the drift wall. Here, exchange of atmospheric air with gas in the rock takes place via advective transport and diffusion, or by simple degassing of water owing to barometric pressure changes.

The modeled spatial distribution of $\mathrm{pH}$ in fracture water at various times during the heating phase is shown in Figure 7.1-15. The times correspond approximately to the dates when water was sampled from hydrology borehole intervals, which are also highlighted. Based on the compositions of ambient pore water ultracentrifuged from the rock in the DST block, the pH of waters in the region of the DST likely started out between approximately 7.8 and 8.3 (Table 7.1-3). The initial $\mathrm{pH}$ of the water used in the DST THC submodel simulation is approximately 8.3. The most obvious effect of heating is a reduction in $\mathrm{pH}$ to about 7.2 in the condensate region, corresponding approximately to the increases in $\mathrm{CO}_{2}$ concentrations shown in Figure 7.1-12. As with the $\mathrm{CO}_{2}$ concentrations, the low $\mathrm{pH}$ zone increases in size and moves outward with time. Close to the dryout zone, the $\mathrm{pH}$ of the water increases, owing to boiling, degassing, and outward transport of the $\mathrm{CO}_{2}$. Another important factor affecting the $\mathrm{pH}$ is the reaction rates of certain minerals, such as feldspars, that upon dissolution consume $\mathrm{H}^{+}$, resulting in a rise in $\mathrm{pH}$.

There is greater uncertainty in measured $\mathrm{pH}$ values than in other compositional parameters. The $\mathrm{pH}$ is temperature-sensitive, and the measured values are for partially cooled samples. For example, over the temperature range from $60^{\circ} \mathrm{C}$ to ambient $\left(25^{\circ} \mathrm{C}\right)$ the dissociation constant for water changes by approximately one order of magnitude (lowering the $\mathrm{pH}$ at higher temperature; Garrels and Christ 1965 [DIRS 144877], Table 2.8). In addition, some $\mathrm{CO}_{2}$ degassing and exchange with the ambient drift atmosphere occurred during sampling. Finally, as discussed in Section 7.1.11.1, some samples were contaminated by acid vapor released from degradation of the fluoroelastomer and chloroelastomer packer materials. Because of these factors, model-data comparisons for $\mathrm{pH}$ are presented here but as supporting information only and not as part of the planned validation strategy. Confidence in the predicted $\mathrm{pH}$ values is based on superior fits between the predicted and measured $\mathrm{HCO}_{3}{ }^{-}$, temperature, and $\mathrm{Pco}_{2}$ data, as these parameters are among the dominant controls on $\mathrm{pH}$.

Model-data comparisons for fracture water $\mathrm{pH}$ are shown for borehole intervals 60-3, 59-2, and 76-3 in Figure 7.1-16. The measured and simulated $\mathrm{pH}$ values generally fall within circumneutral $\mathrm{pH}$ range of approximately 6 to 8 . At all three sampling locations, an initial decrease in $\mathrm{pH}$ was followed by an increase and the model results show similar trends at comparable times. Note the changes in the time-axis between Figures 7.1-16a, b, and c. 
(a)

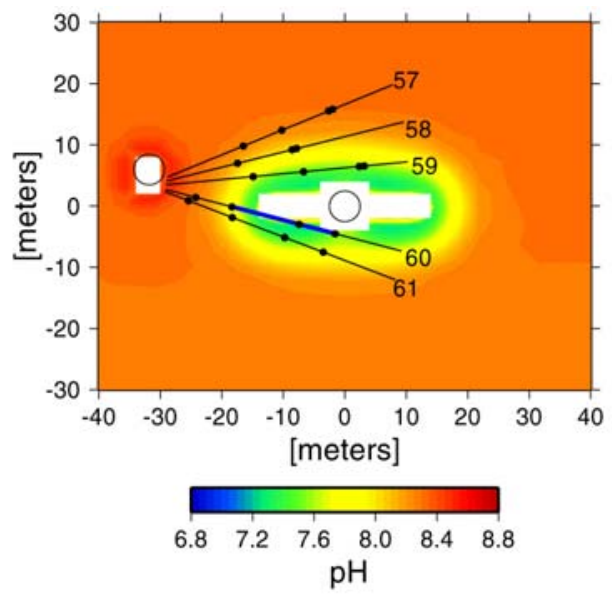

(b)

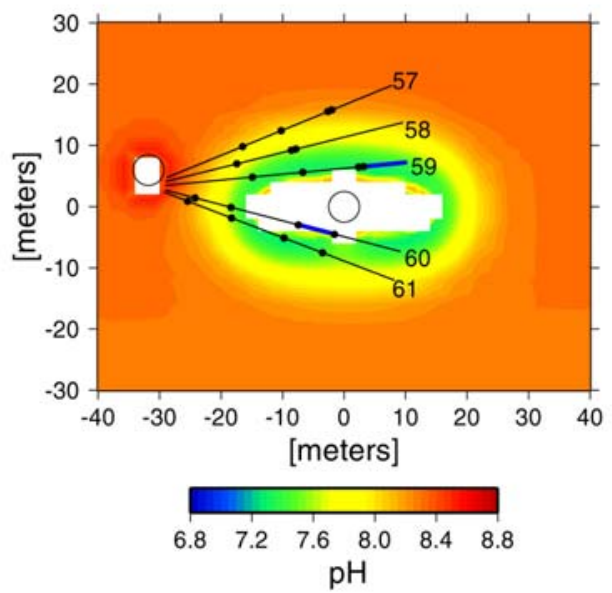

(c)

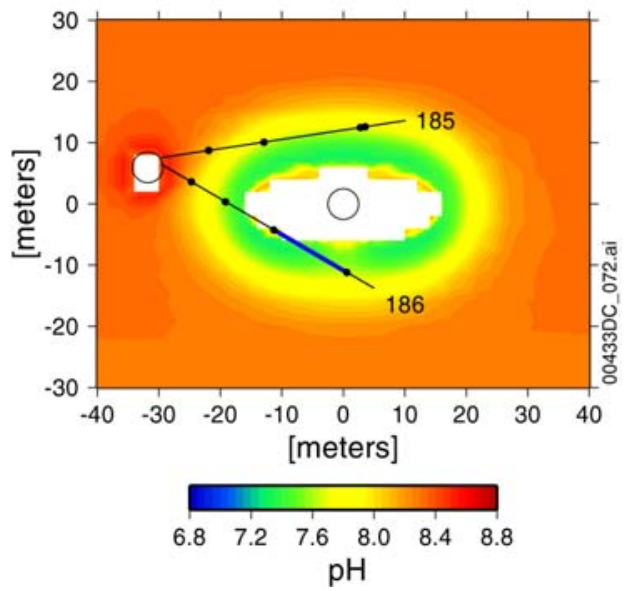

Output DTN: LB0307DSTTHCR2.001 (modeled).

Source: BSC 2004 [DIRS 169900], Table 6.3.4.1-1, water collection locations.

NOTE: The intervals where water was sampled are more thickly shaded (in blue). Areas of zero liquid saturation are blanked out in white.

Figure 7.1-15. Modeled Distribution of $\mathrm{pH}$ in Fractures at Various Times When Water Was Sampled from Hydrology Borehole Intervals: (a) 6 Months, (b) 11 Months, and (c) 14 Months 
(a)

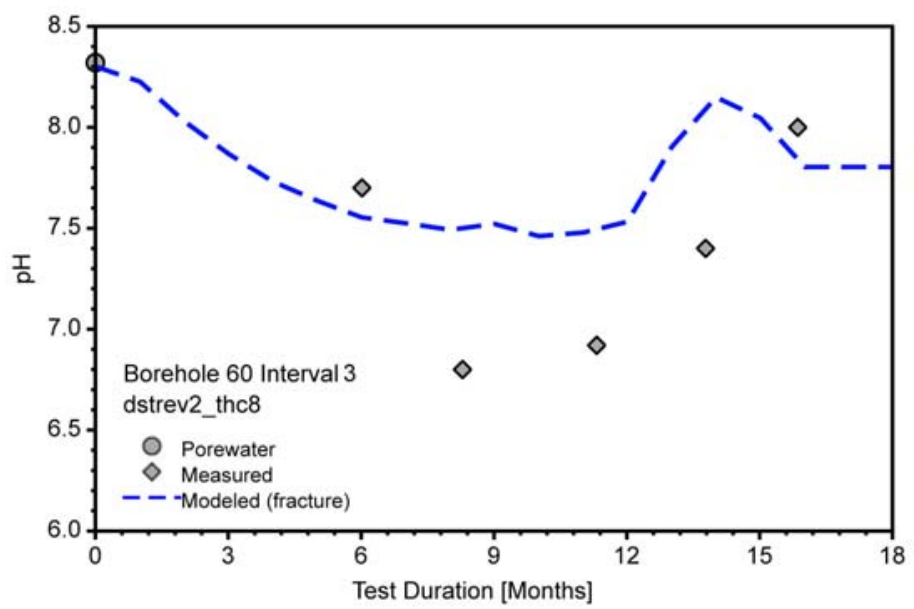

(b)

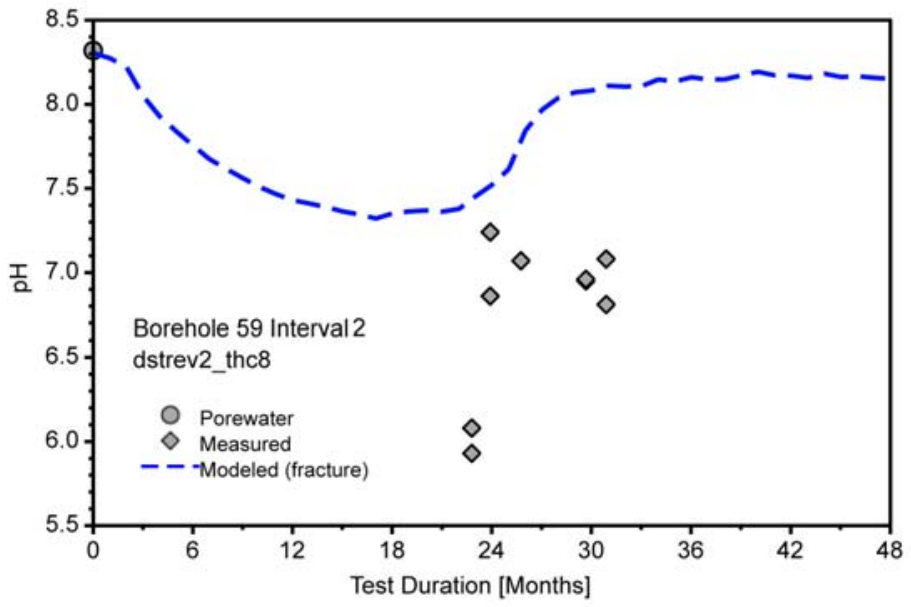

(c)

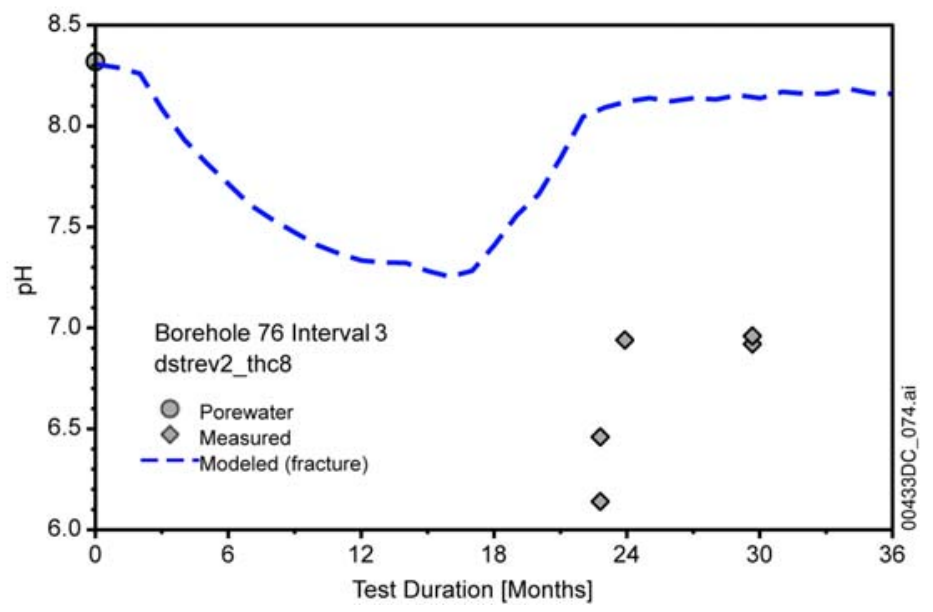

Source: DTN: LL020709923142.023 [DIRS 161677] (measured).

Output DTN: LB0307DSTTHCR2.001 (modeled).

NOTE: The ambient pore-water $\mathrm{pH}$ is approximately 8.3. The measured $\mathrm{pH}$ values are selected from Table 7.1-3, as representative for model-data comparison.

Figure 7.1-16. Comparison of Measured $\mathrm{pH}$ in Water Samples Collected from Borehole Intervals (a) $60-3$, (b) 59-2, and (c) 76-3 to the Modeled Fracture Water pH at Representative Model Grid Blocks 


\subsubsection{Evolution of Anion and Cation Concentrations}

The effects of dilution through condensation of pure water vapor, increases in concentration caused by boiling, and fracture-matrix interaction can be assessed by examining the variation in conservative species such as chloride $\left(\mathrm{Cl}^{-}\right)$and sulfate $\left(\mathrm{SO}_{4}{ }^{2-}\right)$. These species are conservative because chloride and sulfate-bearing minerals, such as halite and gypsum (or anhydrite), are not present in the rock initially and precipitate under more saline conditions, expected only at the final drying stages of the dilute waters observed in the rock at Yucca Mountain.

The modeled spatial variations in $\mathrm{Cl}^{-}$concentrations in fracture and matrix are plotted in Figure 7.1-17, at times of 1 year and 4 years during the heating phase. The main effect is a marked decrease in $\mathrm{Cl}^{-}$concentrations within fractures in the condensation and drainage zones. In the matrix, there is significant dilution in the condensation zones and significant increases in concentration near the edge of the dryout zone.

The predicted trends in fracture-water $\mathrm{Cl}^{-}$and $\mathrm{SO}_{4}{ }^{2-}$ concentrations from the simulation (Figures 7.1-18 and 7.1-19) are generally corroborated by the measurements, in particular the strong dilution trend from the initial pore water concentration. Model-data agreement could have been improved by changes in hydrologic properties to enhance water vapor transport out of the matrix and formation of dilute condensate in the fractures. However, site-average properties are judged to be more representative for application of the THC seepage model for the reasons discussed in Section 7.1.7.1. The reduction in vapor transport out of the matrix led to lower liquid saturations in the fractures and a weaker dilution effect on the ambient fracture pore water. Despite these differences, the trends are to more dilute compositions compared to the pore water, and most measured concentrations are within an order of magnitude of the modeled values. Therefore, the DST THC submodel meets the model validation requirements for chloride and sulfate concentrations.

$\mathrm{Na}^{+}$concentrations in the simulation (Figure 7.1-20) are elevated with respect to the measured concentrations in the 60-3 and 59-2 boreholes, but are closer to the measured values in borehole interval 76-3. The shape of the modeled $\mathrm{Na}^{+}$curve shows an increase with temperature prior to the main condensation pulse. This increase clearly results from the higher reactivity of albite, which also leads to increases in $\mathrm{pH}$ and a reduction in the partial pressure of $\mathrm{CO}_{2}$. In the actual rock, it is likely that albite had undergone preferential weathering over several million years of infiltration and is coated by later-formed clays, silica polymorphs, and Ca-rich zeolites.

Calcium is more sensitive to water-rock interaction than most other species because of the fast reaction rate of calcite, its lower solubility with increasing temperature, and the common occurrence of calcite in fractures. Other potential sources of $\mathrm{Ca}^{2+}$ in the rock include Ca-rich zeolites, such as stellerite, that are abundant in fractures.

$\mathrm{Ca}^{2+}$ concentrations in the simulation (Figures 7.1-21a, b, and c) are slightly elevated with respect to measured concentrations in the 60-3 and 59-2 boreholes, but are close to the measured values in all the boreholes. The shape of the simulated $\mathrm{Ca}^{2+}$ history curve for $60-3$ does not exhibit as early an initial dilution-induced drop in concentration. Instead, the reduction occurs later, when the strong condensation pulse is encountered and increasing temperature results in calcite precipitation. The $\mathrm{Ca}^{2+}$ concentration increases as boiling proceeds and the remaining 
water is evaporated. The model results capture the trend in the $\mathrm{Ca}^{2+}$ concentrations and are, in most cases, within one order of magnitude of the measured values. Therefore, the validation criteria for $\mathrm{Ca}^{2+}$ in the DST THC submodel have been met.

(a)

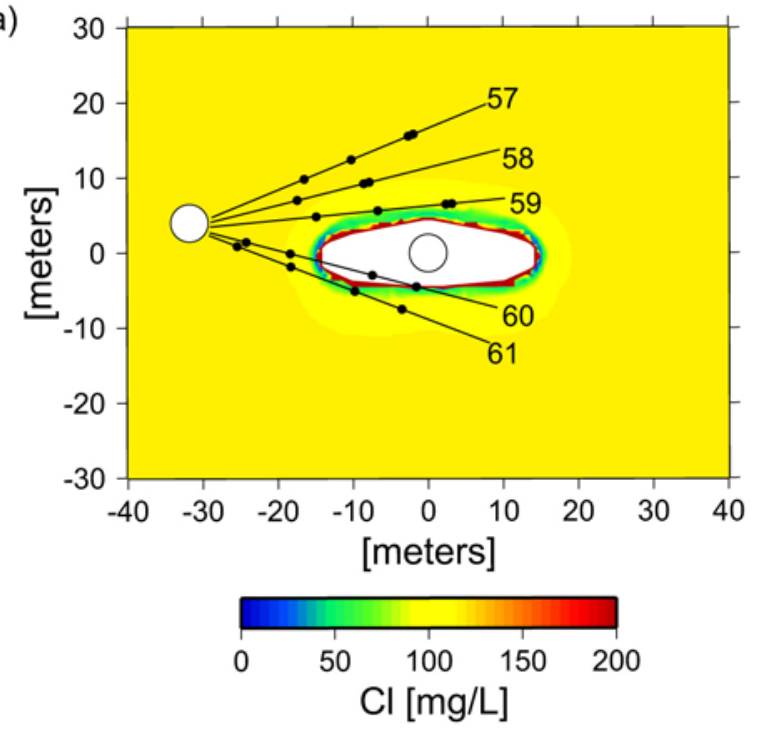

(b)
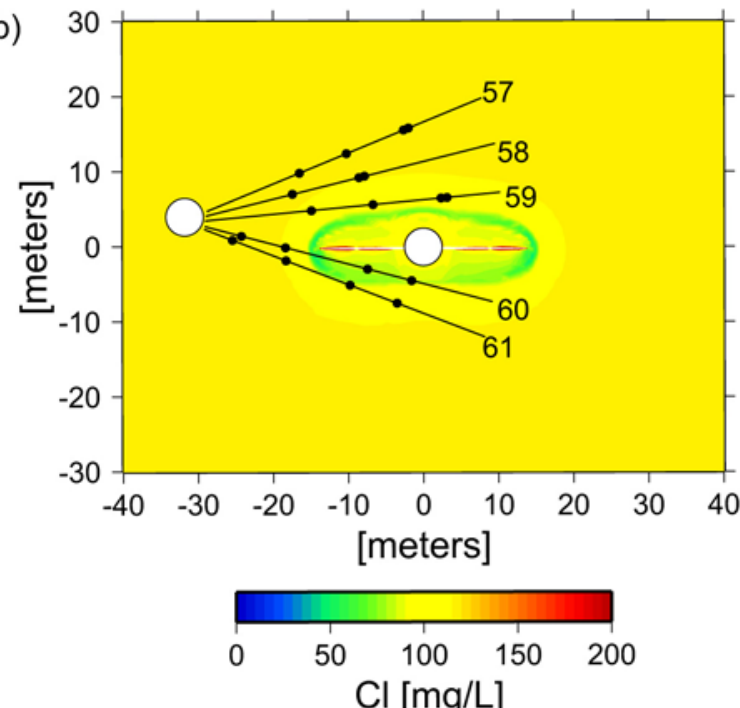

(c)
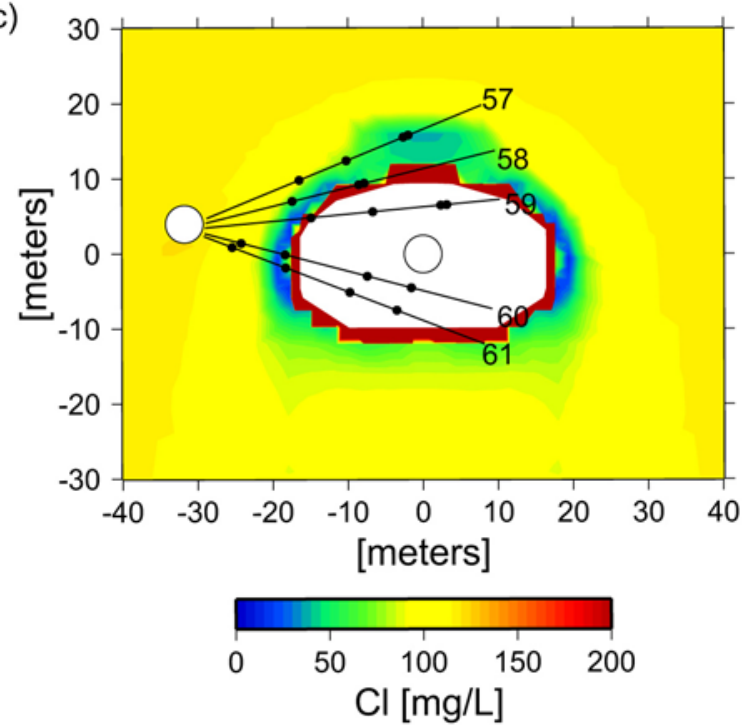

(d)

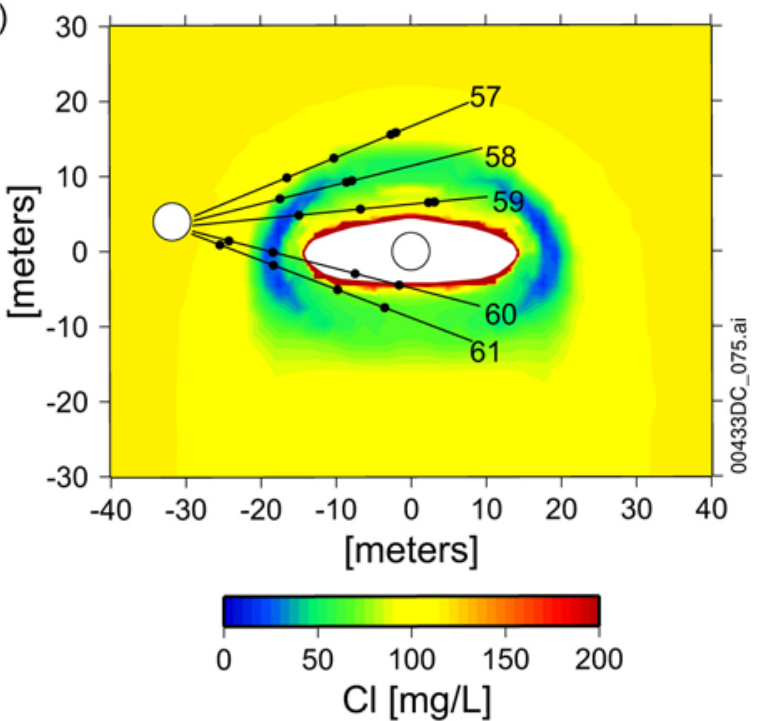

Output DTN: LB0307DSTTHCR2.001.

NOTE: $\quad$ Areas of zero liquid saturation are blanked out in white.

Figure 7.1-17. Modeled Distribution of $\mathrm{Cl}^{-}$in Fractures and Matrix at One and Four Years during the Heating Phase of the DST: Fracture-4 Years, and (d) Matrix - 4 Years 
(a)

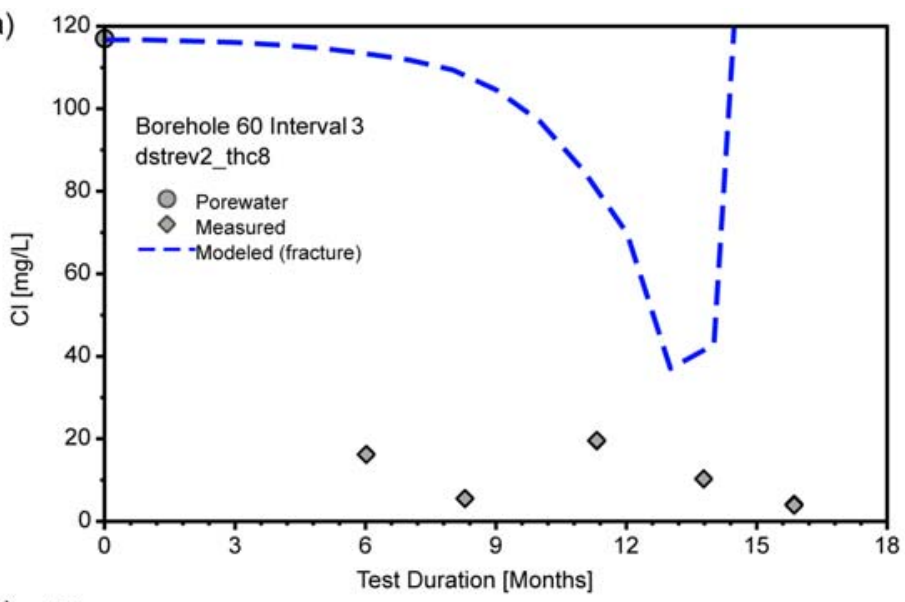

(b)
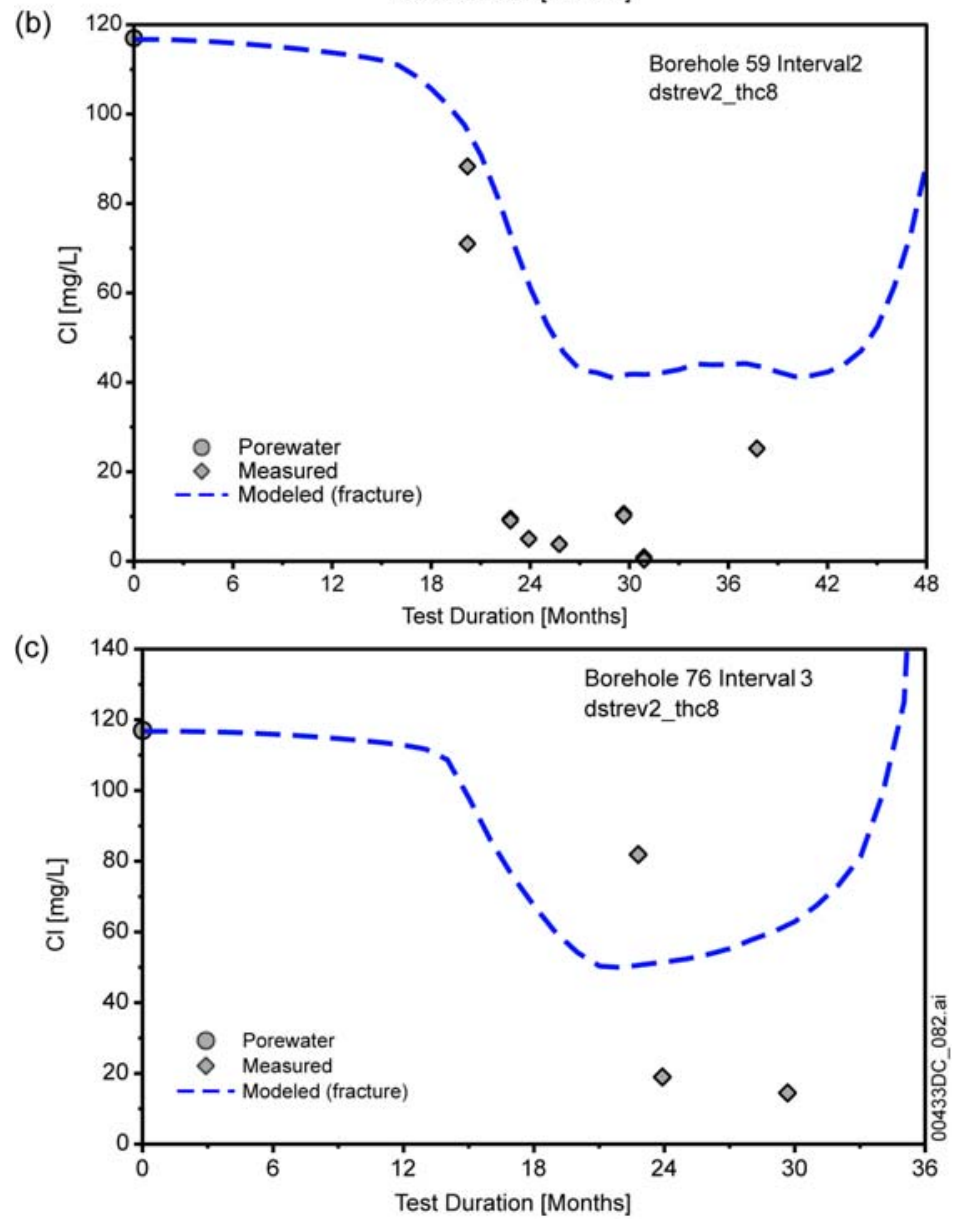

Source: DTN: LL020709923142.023 [DIRS 161677] (measured).

Output DTN: LB0307DSTTHCR2.001 (modeled).

Figure 7.1-18. $\mathrm{Cl}^{-}$Concentrations (mg/L) in Water Samples Collected from Borehole Intervals (a) 60-3, (b) 59-2, and (c) 76-3 Compared to the Modeled Fracture Water $\mathrm{Cl}^{-}$ 

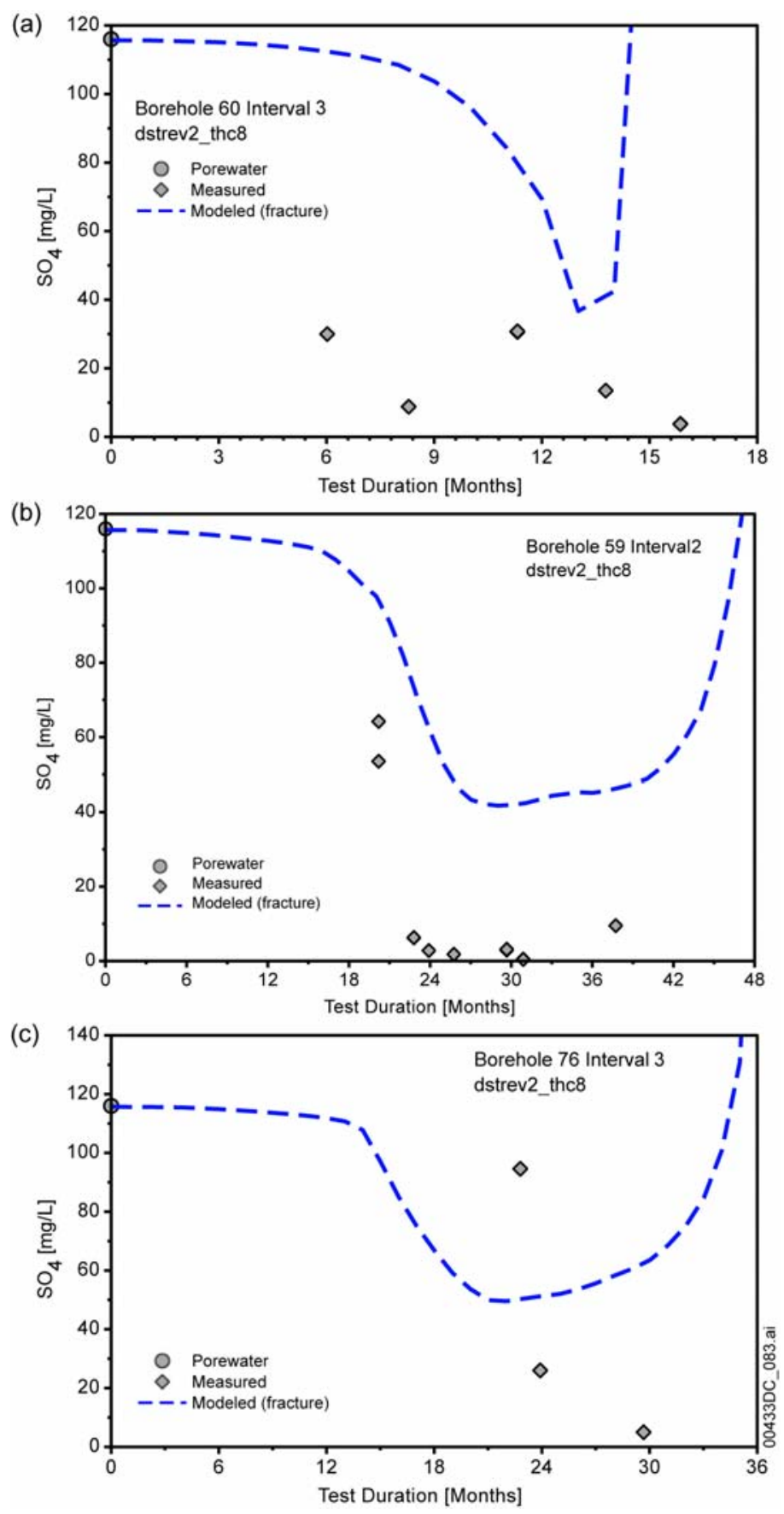

Source: DTN: LL020709923142.023 [DIRS 161677] (measured).

Output DTN: LB0307DSTTHCR2.001 (modeled).

Figure 7.1-19. $\mathrm{SO}_{4}{ }^{2-}$ Concentrations $(\mathrm{mg} / \mathrm{L})$ in Water Samples Collected from Borehole Intervals (a) 60-3, (b) 59-2, and (c) 76-3 Compared to the Modeled Fracture Water $\mathrm{SO}_{4}{ }^{2-}$ 
(a)

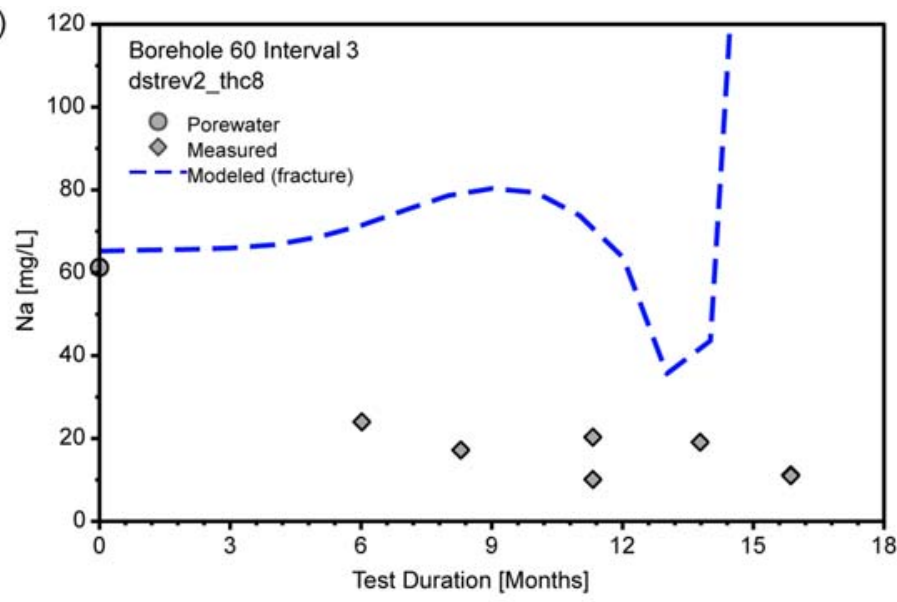

(b)

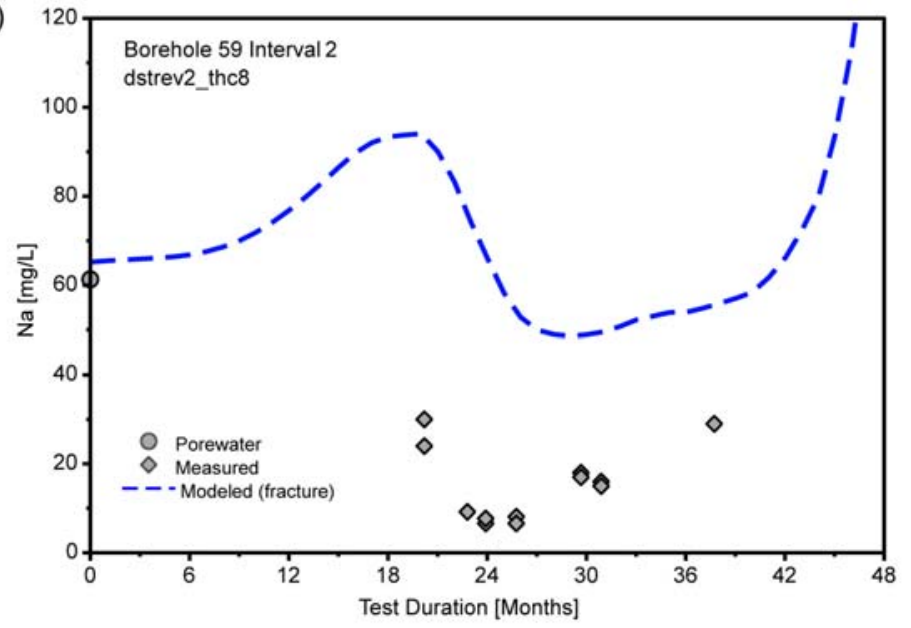

(c)

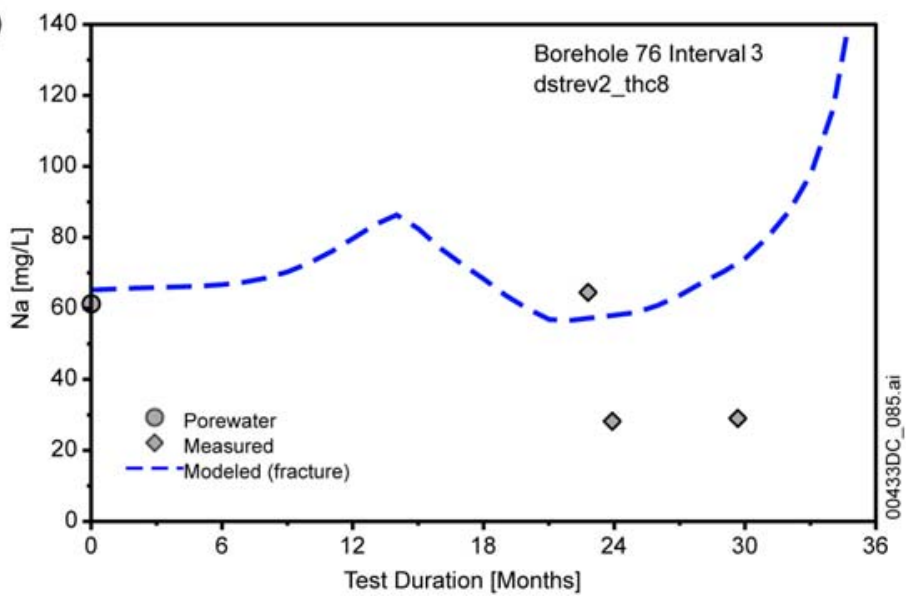

Source: DTN: LL020709923142.023 [DIRS 161677] (measured).

Output DTN: LB0307DSTTHCR2.001 (modeled).

Figure 7.1-20. $\mathrm{Na}^{+}$Concentrations (mg/L) in Water Samples Collected from Borehole Intervals (a) 60-3, (b) 59-2, and (c) 76-3 the Modeled $\mathrm{Na}^{+}$Concentrations in Fractures 

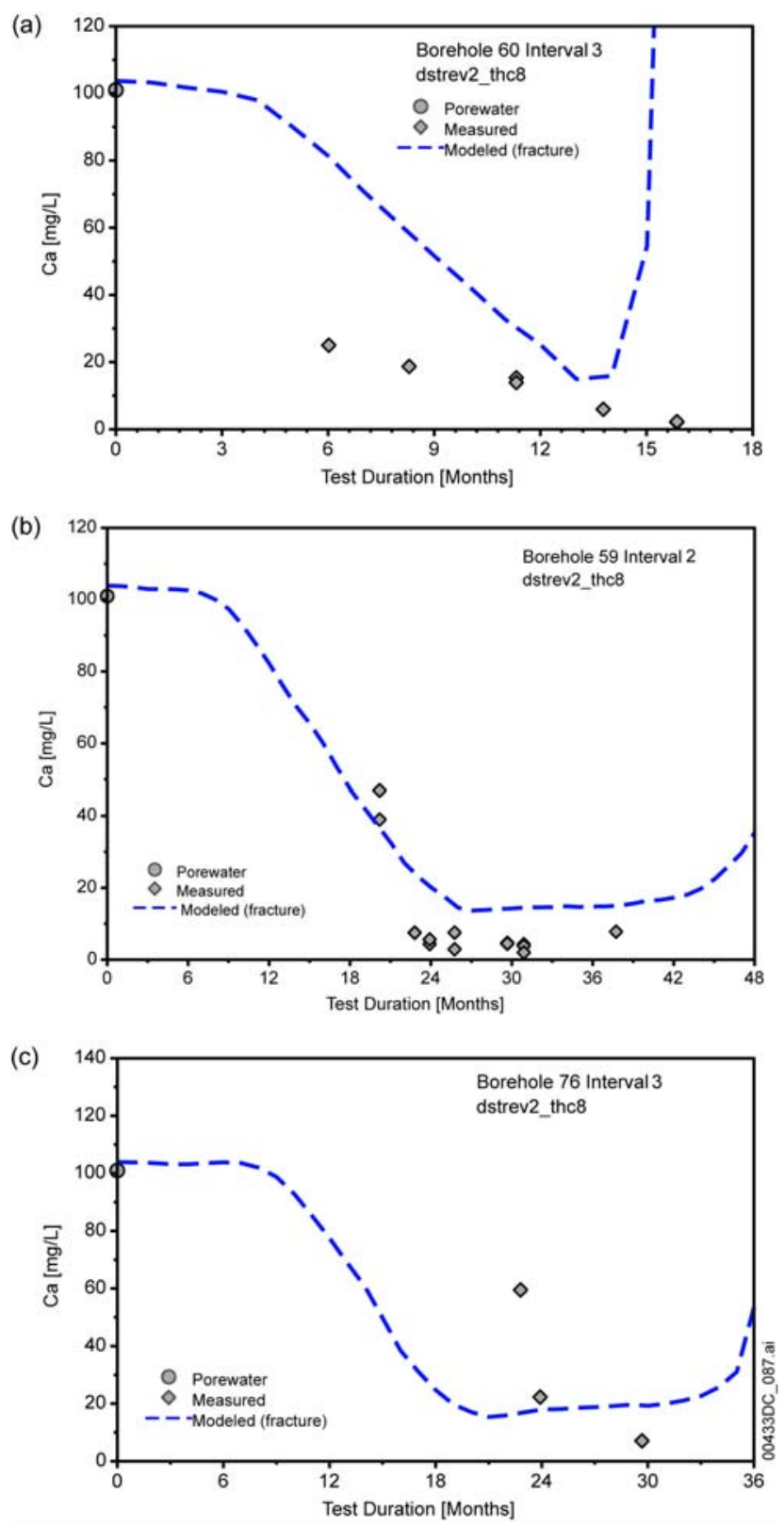

Source: DTN: LL020709923142.023 [DIRS 161677] (measured).

Output DTN: LB0307DSTTHCR2.001 (modeled).

Figure 7.1-21. $\mathrm{Ca}^{2+}$ Concentrations (mg/L) in Water Samples Collected from Borehole Intervals (a) 60-3, (b) 59-2, and (c) 76-3 Compared to the Modeled $\mathrm{Ca}^{2+}$ in Fracture Water 
The modeled silica concentrations in fracture waters (Figures 7.1-22a, b, and c) capture the strong increases observed in the measured compositions, especially those seen in the borehole intervals overlying the heaters (59-2 and 76-3). In 76-3, the first water sample collected had a silica concentration of over $280 \mathrm{mg} / \mathrm{L}$, compared to about $180 \mathrm{mg} / \mathrm{L}$ in the model simulation. The two waters collected later had silica concentration around $200 \mathrm{mg} / \mathrm{L}$, which is closer to the model results. Except for two samples in 60-3, for which the model predicts an earlier rise in concentration, simulated $\mathrm{SiO}_{2}$ values are within an order of magnitude of the observed ones, and therefore the model results meet the validation requirements.

The modeled concentrations of $\mathrm{K}^{+}$(Figures 7.1-23a, b, and c), like those of $\mathrm{Na}^{+}$, increase to values somewhat higher than the measured concentrations. However, trends between modeled and measured data are similar, suggesting that a reduction in the K-feldspar reactivity and an increase in the dilution effect would result in a closer match to the measured concentrations. The modifications to hydrologic and thermodynamic (and/or kinetic) data required for such reduction in reactivity would be consistent with the shifts needed for both the conservative species, such as $\mathrm{Cl}^{-}$and $\mathrm{SO}_{4}{ }^{2-}$, as well as for $\mathrm{Na}^{+}$. The lower matrix permeability used in the model induces slower transfer of pore water to enter into the fractures, and results in lower dilution of the conservative species.

The fact that $\mathrm{Na}^{+}$and $\mathrm{K}^{+}$show similar trends over time is consistent with their predominance in either an alkali feldspar solid-solution phase, such as sanidine, and/or as closely intergrown exsolved phases from a precursor solid-solution alkali feldspar mineral. All model results meet the validation requirements (trend to higher concentrations than in the initial pore water and within an order-of magnitude).

Fewer bicarbonate $\left(\mathrm{HCO}_{3}{ }^{-}\right)$concentrations were measured in the borehole waters because of difficulties making the measurements in the field. Available data are plotted in Figure 7.1-24, along with the-modeled concentrations. Although the few measured values do not allow trends to be defined, model $\mathrm{HCO}_{3}{ }^{-}$concentrations compare well to the measured concentrations. Therefore, the model results for $\mathrm{HCO}_{3}{ }^{-}$meet the model validation criteria. 
(a)

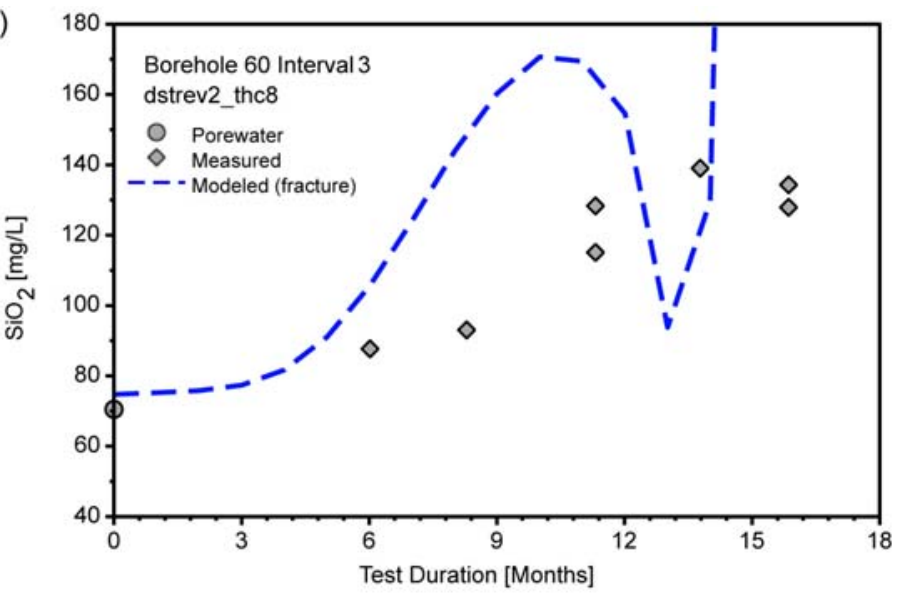

(b)

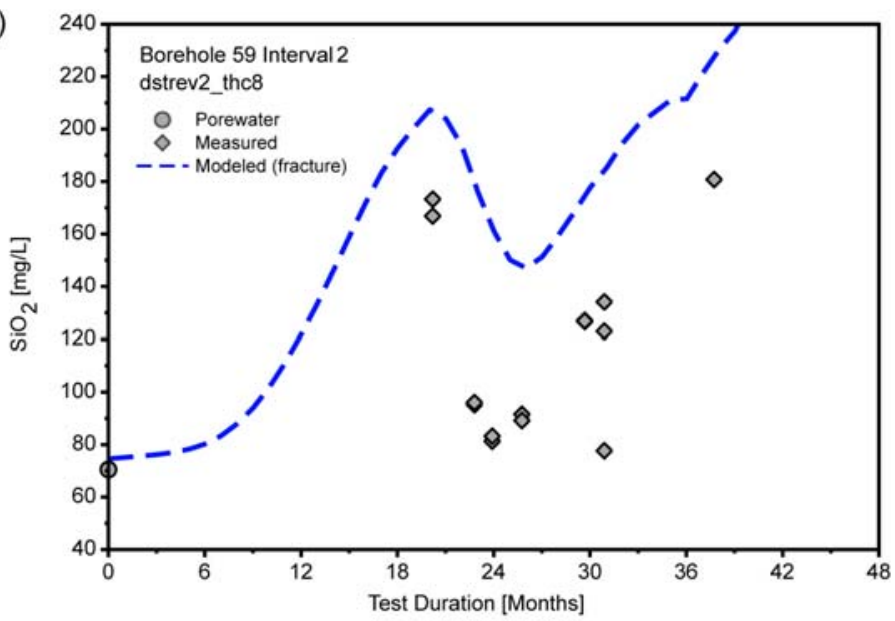

(c)

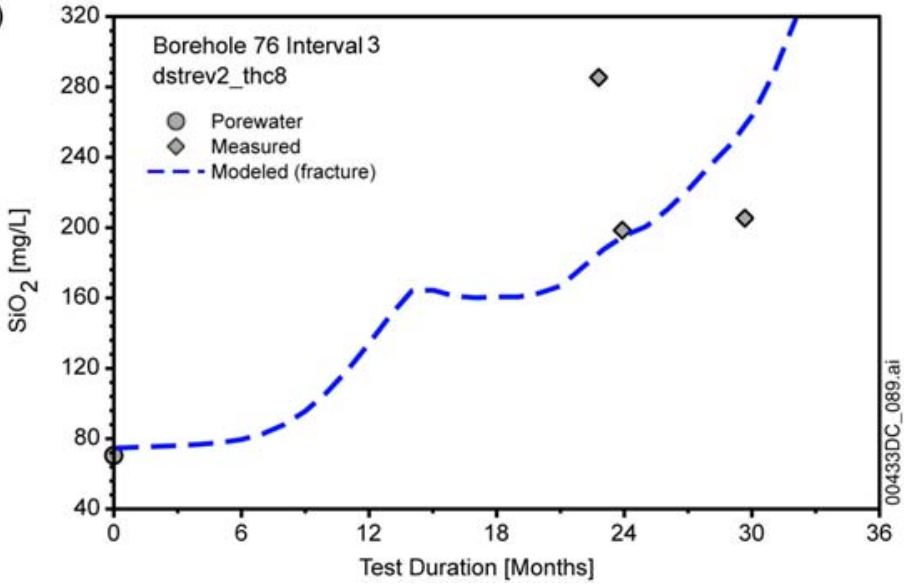

Source: DTN: LL020709923142.023 [DIRS 161677] (measured).

Output DTN: LB0307DSTTHCR2.001 (modeled).

Figure 7.1-22. $\mathrm{SiO}_{2(\mathrm{aq})}$ Concentrations $(\mathrm{mg} / \mathrm{L})$ in Water Samples Collected from Borehole Intervals (a) $60-3$, (b) $59-2$, and (c) 76-3 Compared to Modeled Fracture Water $\mathrm{SiO}_{2 \text { (aq) }}$ Concentrations 

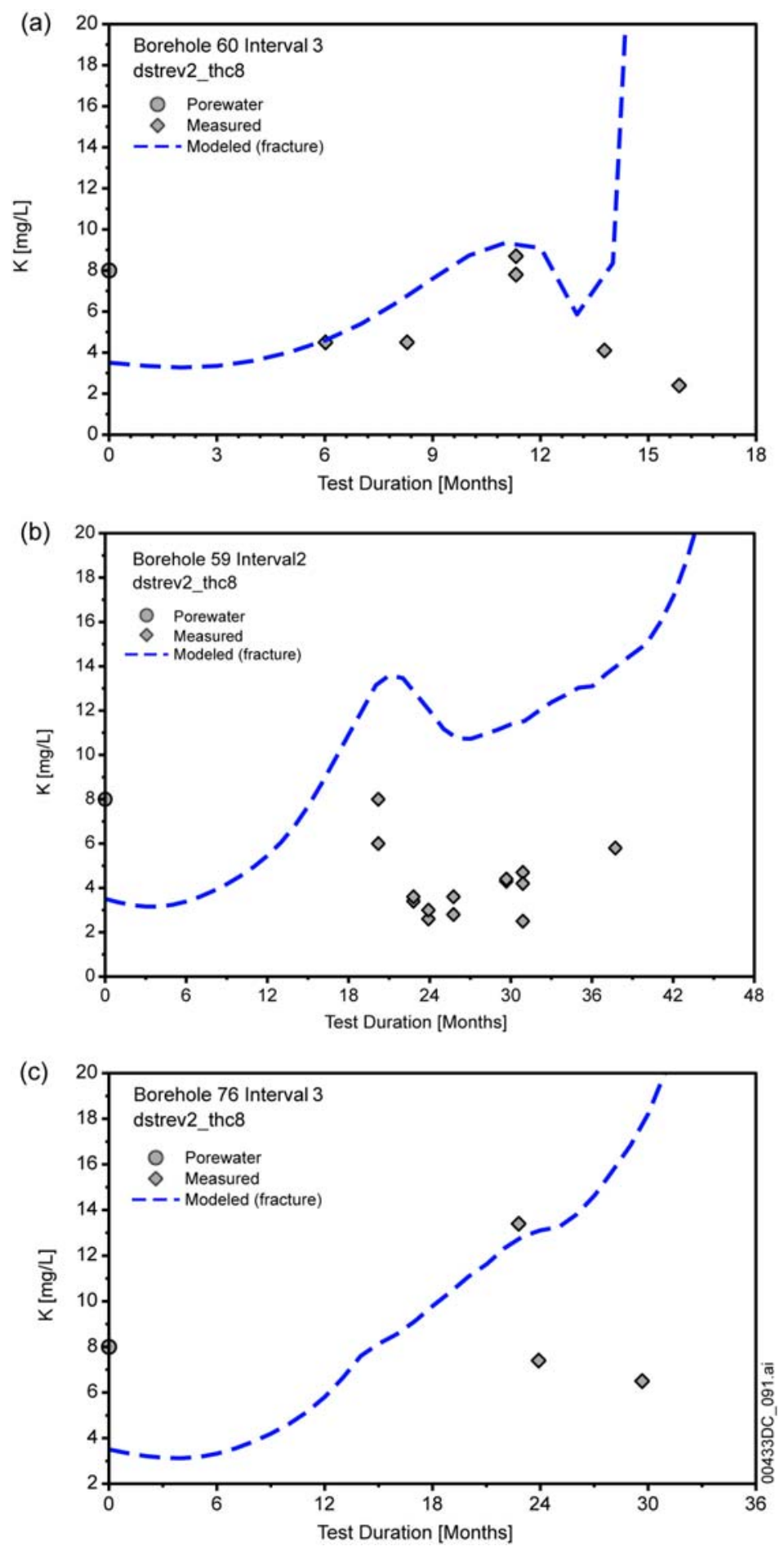

Source: DTN: LL020709923142.023 [DIRS 161677] (measured). Output DTN: LB0307DSTTHCR2.001 (modeled).

Figure 7.1-23. $\mathrm{K}^{+}$Concentrations (mg/L) in Water Samples Collected from Borehole Intervals (a) 60-3, (b) 59-2, and (c) 76-3 Compared to Modeled Fracture Water $\mathrm{K}^{+}$Concentrations 
(a)

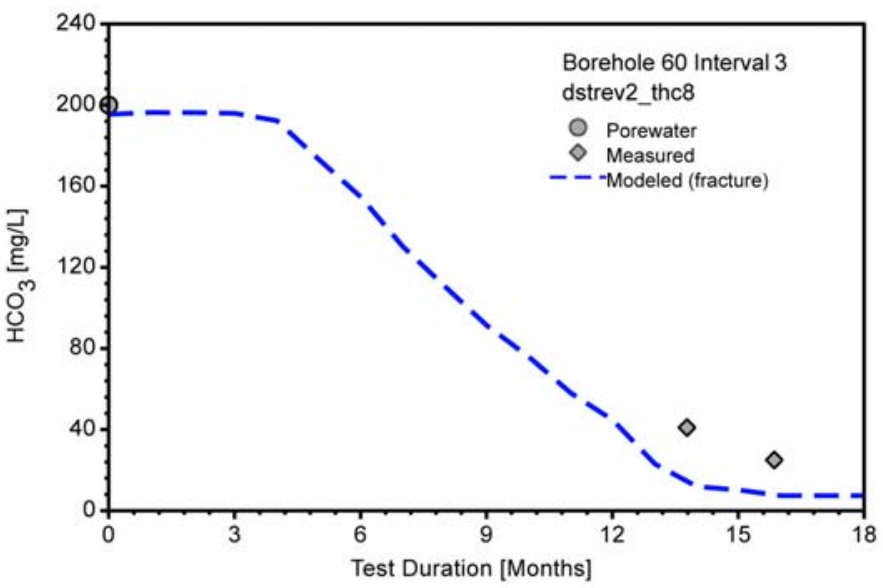

(b)

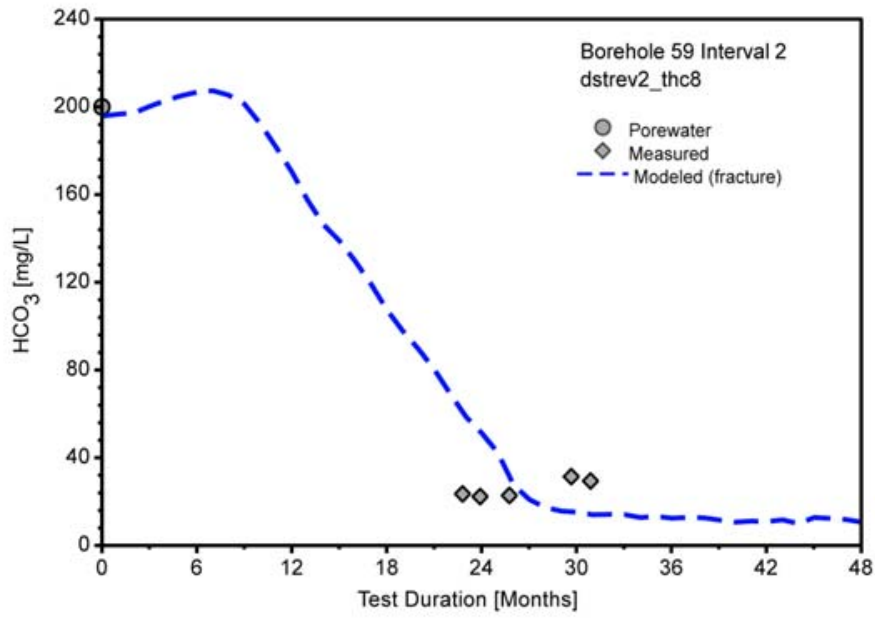

(c)

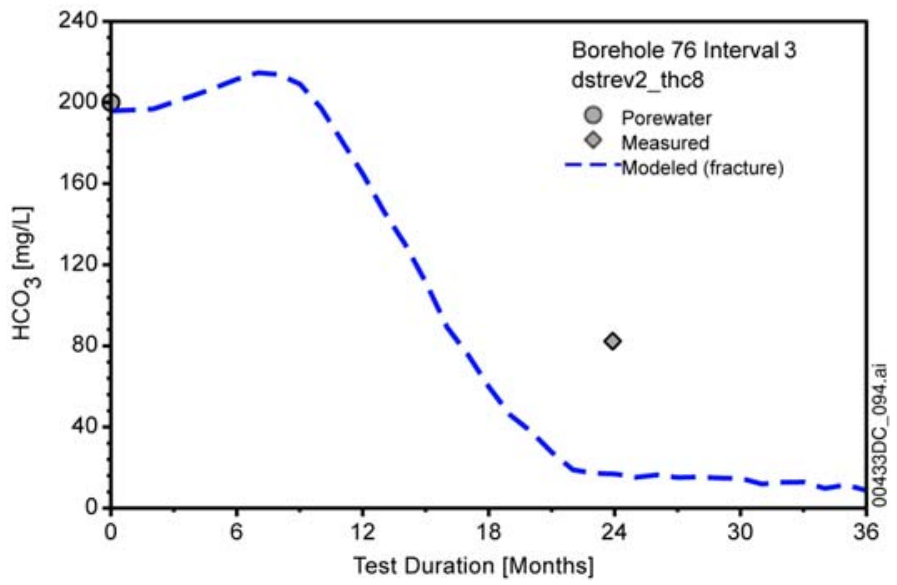

Source: DTN: LL020709923142.023 [DIRS 161677] (measured).

Output DTN: LB0307DSTTHCR2.001 (modeled).

Figure 7.1-24. $\mathrm{HCO}_{3}^{-}$Concentrations $(\mathrm{mg} / \mathrm{L})$ in Water Samples Collected from Borehole Intervals (a) 60-3, (b) 59-2, and (c) 76-3 Compared to the Modeled Fracture Water $\mathrm{HCO}_{3}{ }^{-}$ Concentrations 
Modeled concentrations of some additional aqueous species $\left(\mathrm{Mg}^{2+}, \mathrm{NO}_{3}{ }^{-}\right.$, and $\left.\mathrm{F}^{-}\right)$in the simulation are compared to measured compositions from 59-2, 60-3, and 76-3 in Figures 7.1-25 through 7.1-27. Measured $\mathrm{Mg}^{2+}$ concentrations (Figure 7.1-25) show initial concentrations closer to the pore-water value of about $17 \mathrm{mg} / \mathrm{L}$, and then a considerable drop in all the borehole intervals. Modeled $\mathrm{Mg}^{2+}$ concentrations show a similar pattern and are close to the measured concentrations. The sharp drop in the modeled concentrations is related to a combination of dilution from condensate and the precipitation of sepiolite (a Mg-rich sheet silicate). It is not clear whether precipitation of a Mg-rich phase takes place in the boiling zone in the rock, because the extent of dilution of $\mathrm{Mg}^{2+}$ is roughly similar to that observed for the conservative species, such as $\mathrm{Cl}^{-}$. Some $\mathrm{Mg}^{2+}$ is likely incorporated into calcite that is precipitated as the condensate water above the heaters drains down and boils, although this may have a minimal effect on $\mathrm{Mg}^{2+}$ concentrations. The thermodynamic model for calcite does not include $\mathrm{Mg}^{2+}$, and therefore another $\mathrm{Mg}$-bearing phase (i.e., sepiolite) must take up some of the $\mathrm{Mg}^{2+}$. Most samples fall within an order of magnitude of the model results, thus meeting the validation requirements.

Nitrate $\left(\mathrm{NO}_{3}^{-}\right)$is included in the list of modeled species for the simulations, owing to its importance for the evolution of final salt compositions in potential seepage waters. Nitrate is highly soluble, and there are no nitrate minerals initially present in the tuff. The pore water has somewhat more variable nitrate concentrations compared to $\mathrm{Cl}^{-}$and $\mathrm{SO}_{4}{ }^{2-}$. The greater variability in pore-water concentrations may be a result of biologically mediated nitrogen reduction, possibly after sample collection. Measured and modeled nitrate concentrations are shown in Figure 7.1-26. Concentrations measured in waters collected from the hydrology boreholes are almost all lower than those from the pore water, showing a similar pattern as $\mathrm{Cl}^{-}$ and $\mathrm{SO}_{4}{ }^{2-}$. This finding suggests that over the time scale of the experiment, nitrate acts as a conservative species and may not have been affected significantly by biological activity in the rock. The modeled concentrations capture the measured pattern of nitrate concentrations quite well, although the dilution effect is not as strong. This effect is similar to that seen for most other weakly reactive or nonreactive species. Model validation requirements for $\mathrm{NO}_{3}{ }^{-}$have been met, both in terms of the trend and range of values.

Fluorite has been added to the initial mineral assemblage for the simulations. Fluorite is observed sporadically in the Yucca Mountain tuffs, and observed fluoride concentrations in pore water samples reflect the presence of this mineral. Most pore waters from the repository level are near saturation with respect to fluorite (around 4 to $5 \mathrm{mg} / \mathrm{L}$; see Table 6.2-1). Therefore, in the THC seepage model, fluorite is assumed to be present in the rock mass, and fluoride concentration is limited by fluoride precipitation/dissolution. Fluoride is included in the THC seepage model because it may contribute to uniform corrosion of the titanium drip shield (BSC 2004 [DIRS 169845], Section 6.5.7).

However, fluoride concentrations were lower in the water samples recovered from the DST. Concentrations in the initial pore waters from the DST block (HD-PERM, Table 7.1-3) were found to be less than $1 \mathrm{mg} / \mathrm{L}$, much lower than the equilibrium solubility of fluorite (around 4 to $5 \mathrm{mg} / \mathrm{L}$ at ambient temperatures). In addition, almost all waters from the hydrology boreholes in the DST have measured fluoride concentrations of around $1 \mathrm{mg} / \mathrm{L}$ or less, with only one sample at about $4 \mathrm{mg} / \mathrm{L}$. The measured values are shown in Figure 7.1-27 for borehole intervals 59-2, $60-3$, and 76-3, compared to the model results. The modeled fluoride concentrations quickly 
increase from the initial concentration of less than $1 \mathrm{mg} / \mathrm{L}$ (HD-PERM, shown as PERM-1, PERM-2, and PERM-3 in Table 7.1-3) to several $\mathrm{mg} / \mathrm{L}$, eventually attaining much higher values as increasing temperatures result in much higher fluorite solubility (the rapid initial increase is not shown in Figure 7.1-27). The increase is also related to the fast dissolution rate of fluorite.

The model results do not capture the trend in the fluoride concentrations because the assumption that fluorite is present in the rock and controls fluoride concentrations in solution through dissolution/precipitation (made to be consistent with the THC seepage model), while generally true for repository-level units, is not true for pore waters in the region of the DST. However, as stated in the TWP (BSC 2005 [DIRS 172761], Section 2.2.2.4.2), because this deviation can be readily explained in terms of simple physical and chemical processes, these data do not invalidate the DST THC submodel.

Model results for aqueous $\mathrm{Fe}$ and $\mathrm{Al}$ concentrations are not compared to DST measured values in this report. There are several reasons for this. First, measured concentrations for these elements are sparse. Data for Fe and $\mathrm{Al}$ were either not measured or below the detection limit for more than half of the water samples listed in Table 7.1-3. Also, the water samples were only filtered through 0.45 micron filters. These are not sufficient to exclude colloidal particles, which could significantly contribute to the reported concentrations of a few tens of nanograms per milliliter. For these reasons, the potential errors in the measured $\mathrm{Fe}$ and $\mathrm{Al}$ values are large.

For iron, most of the reported values exceed by several orders of magnitude the calculated solubility of crystalline $\mathrm{Fe}(\mathrm{III})$ mineral phases, and even amorphous $\mathrm{Fe}(\mathrm{OH})_{3}$, at the measured $\mathrm{pH}$ values (Langmuir 1997 [DIRS 100051], Figures 7.10 and 7.11). Because iron oxides precipitate rapidly and readily, this also suggests that the iron analyses are not reliable.

THC DST seepage submodel predictions for Fe are also several orders of magnitude lower than the measured values. Iron was added to the THC seepage model to provide initial $\mathrm{Fe}$ concentrations for downstream users, and only one iron-bearing mineral, hematite, is included in the model. Because of the large amounts of ferrous materials in the drift, downstream models perform their own calculations of Fe concentrations, and make no use of the Fe values from the THC seepage model (BSC 2004 [169860], Section 6.6.3). Since Fe values from this report are not used by downstream models, and measured concentrations from the DST are sparse and probably unreliable, THC Fe concentrations have not been validated and are presented for information only.

The values for dissolved Al that were measured in DST waters are much higher than expected from the model. As stated earlier, this is probably an artifact of not filtering the solutions appropriately to remove colloidal $\mathrm{Al}$ and thus miscounting colloidal aluminum mass as "dissolved". Large overestimates in Al concentrations due of inclusion of colloidal material are extensively documented throughout the literature. Although the Al concentrations reported in THC seepage model output files have little direct affect on downstream models, as concentrations are very low and do not affect the predicted major element concentrations of evolving brines presented in Engineered Barrier System: Physical and Chemical Environment (BSC 2004 [DIRS 169860]), the predicted Al values have a significant impact within the THC model, which may propagate indirectly to downstream models. Although Al concentrations are very small, they contribute to the predicted ion activity product $(Q)$ for aluminosilicate minerals, 
which affects mineral dissolution/precipitation rates through the $Q / K$ relationship described in Section 6.4.2. If modeled $\mathrm{Al}$ concentrations were too low, this would lead to lower $\mathrm{Q}$ values for aluminosilicate mineral dissolution reactions (corresponding to farther-from-equilibrium conditions), which would translate into higher mineral dissolution rates (and lower aluminosilicate precipitation rates in the converse). This would affect other dissolved components released from the aluminosilicates such as $\mathrm{Ca}^{+2}, \mathrm{~K}^{+}, \mathrm{Na}^{+}$, and silica, and could lead to higher than expected dissolved concentrations of these components. This effect would in fact be magnified for the cation components because the Al has a larger stoichiometric coefficient that multiplies its effect on the rates. For this reason, it is important to validate the Al concentrations predicted by the THC seepage model.

Because $\mathrm{Al}$ concentrations measured in the DST are likely to be in error, it is not possible to directly validate the $\mathrm{Al}$ concentrations predicted by the THC model. Predicted major element concentrations $\left(\mathrm{Na}, \mathrm{K}, \mathrm{Ca}, \mathrm{SiO}_{2}\right)$ are corroborated by DST results, providing supporting evidence that aluminosilicate mineral dissolution and precipitation, and hence aluminum concentrations, are being accurately modeled. However, $\mathrm{pH}$ is already assessed as a dependent variable, and because it is involved in all mineral dissolution/precipitation reactions, it is not possible to argue that $\mathrm{Al}$ concentrations must be accurate simply because the cation concentrations are matched adequately.

The plug flow reactor experiment, described in Section 7.2 and in greater detail in Revision 2 of the THC model (BSC 2004 [DIRS 168848], Section 7.2), provides similar supporting data. The effect of water-rock interactions was greater in the plug-flow reactor experiment relative to the DST, and good matches between the measured and predicted values for the major components in the water, including $\mathrm{Na}, \mathrm{K}, \mathrm{Ca}$, and $\mathrm{SiO}_{2}$ ( $\mathrm{Al}$ concentrations were below detection limits) also support the general approach used by the THC Seepage model. However, it must be noted that the plug-flow reactor modeling was performed with earlier versions of the model and the thermodynamic database.

The THC DST seepage submodel results do not capture the measured aluminum concentrations because the measured values are very small and have large uncertainties. However, matches in major element concentrations for the DST and plug flow reactor provide support that mineral dissolution and precipitation are being handled in a reasonable manner, and, as stated in the TWP (BSC 2005 [DIRS 172761], Section 2.2.2.4.2), because the deviation in measured and predicted Al concentrations can be readily explained in terms of simple physical and chemical processes, these data do not invalidate the DST THC submodel.

\subsubsection{Mineralogical Changes}

As the last few sections have documented, marked changes have taken place in the water and gas chemistry in the DST, owing to thermal-hydrologic processes as well as mineral-water-gas reactions. The total amount of minerals precipitated or dissolved, though, may be exceedingly small, even though the effect on the water composition is quite strong. The strong effect on the water composition is related to the water-rock ratio, which is very low in the unsaturated low-porosity fractured tuff. The system is also characterized by an exceedingly low percolation flux of only a few millimeters per year or less and, therefore, the ambient water has a long residence time. This section documents the predicted changes in mineralogy over the heating 
phase of the DST and compares the results to a few measurements made from in situ sidewall core samples obtained from above-boiling zones. Since the last revision of this report, a series of small core samples was analyzed for evidence of mineral alteration during the heating phase of the DST. The first set of samples was obtained in November 2000 by sidewall coring of fractures in "chemistry" boreholes 53 and 54, which were originally designed for water sampling. However, the SEAMIST pad system employed in those boreholes failed to provide uncontaminated water samples owing to the engineering materials in the boreholes and the unknown compositions of the pads. The collection and analyses of the rock samples are documented in Thermal Testing Measurements Report (BSC 2004 [DIRS 169900], Section 6.3.4.3). Chemical analyses, identification, and description of mineral alteration products for a few of the samples are given in DTN: LA0201SL831225.001 [DIRS 158426]. These data represent observations and analyses from two locations taken about $1 \mathrm{~m}$ apart in an above-boiling region above the heaters.

Calcite, amorphous silica, and a calcium sulfate phase (tentatively identified as gypsum) are the only phases in these samples identified so far as products of the processes taking place during the DST (DTN: LA0201SL831225.001 [DIRS 158426]). Amorphous silica was common in both samples, whereas calcite and gypsum were only described from the sample further into the above-boiling zone (the other sample was from the outer edge). Although anhydrite is thermodynamically more stable than gypsum under the conditions of the DST, gypsum was observed in analyses of borehole surfaces from the Single Heater Test (DTN: LA0009SL831151.001 [DIRS 153485]). On the basis of this identification, the calcium sulfate phase observed in the DST sidewall core samples was considered to be gypsum (BSC 2004 [DIRS 169900], Section 6.3.4.3).

From these descriptions, amorphous silica was the dominant phase precipitated during boiling, with much lesser amounts of calcite and gypsum. Amorphous silica appears as glassy coatings covering larger areas of the surface, commonly in the form of thin curled sheets and fine tubules. Calcite typically is found as scattered, small late-stage mounds, with gypsum as very late-formed scattered crystals on top of other phases. Although calcite is not a major phase in the tuffs at Yucca Mountain, its rapid reaction rate, strong effect on $\mathrm{pH}$, and ubiquitous presence in fracture coatings make it an important mineral phase. The actual percentage of mineral precipitates in the fracture system could not be determined from this type of localized analysis. Some of the silica coatings were approximately 10 to $20 \mu \mathrm{m}$ thick, with discrete gypsum crystals up to $80 \mu \mathrm{m}$ long. Given a uniform 10- $\mu$ m-thick layer of mineral precipitates on one side of all fractures, with a hypothetical range in fracture aperture of 100 to $1,000 \mu \mathrm{m}$, the proportion of fracture volume filled would range from 1 to 10 percent. Because many of the coatings are much less than $10 \mu \mathrm{m}$ thick and do not cover all areas of every fracture, the volume filled is likely to be less than 1 percent. 
(a)

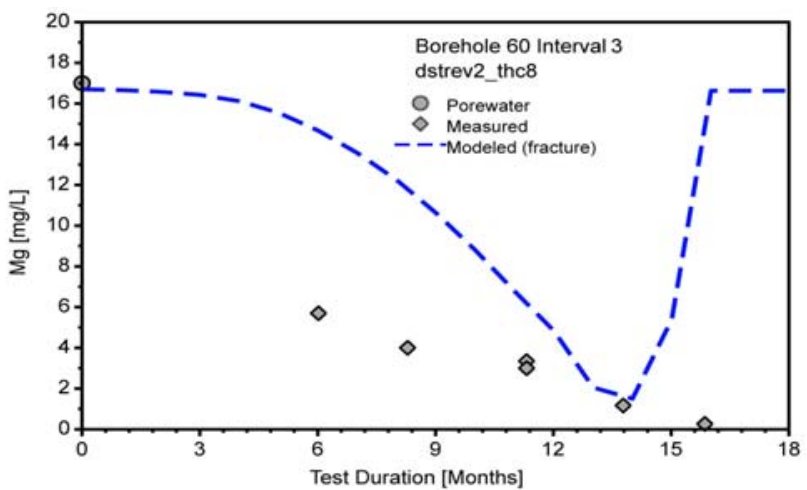

(b)

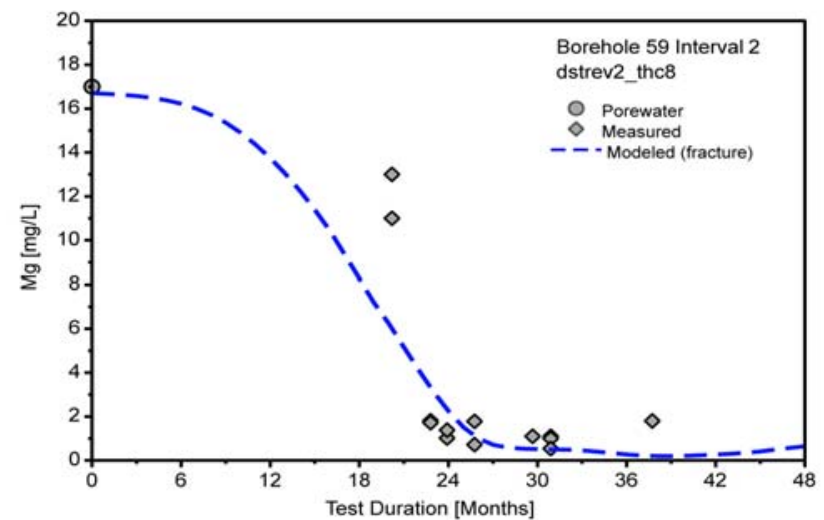

(c)

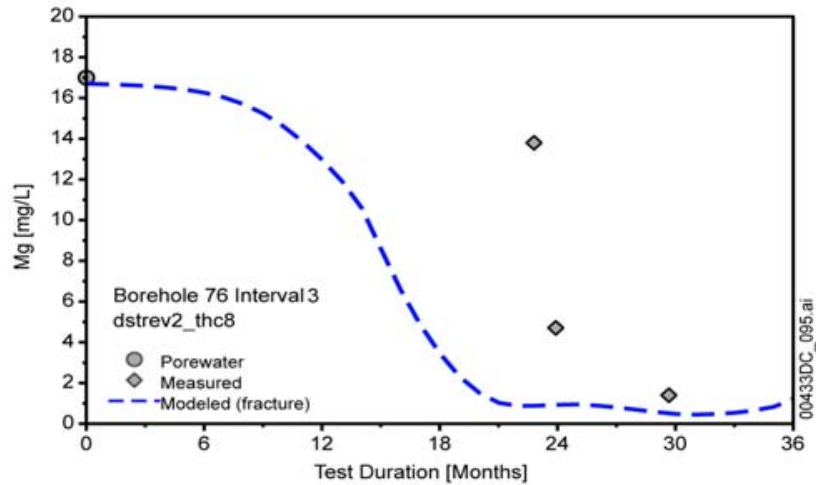

Source: DTN: LL020709923142.023 [DIRS 161677] (measured).

Output DTN: LB0307DSTTHCR2.001 (modeled).

Figure 7.1-25. $\mathrm{Mg}^{2+}$ Concentrations (mg/L) in Water Samples Collected from Borehole Intervals (a) 60-3, (b) 59-2, and (c) 76-3 Compared to the Modeled Fracture Water $\mathrm{Mg}^{2+}$ Concentrations 
(a)

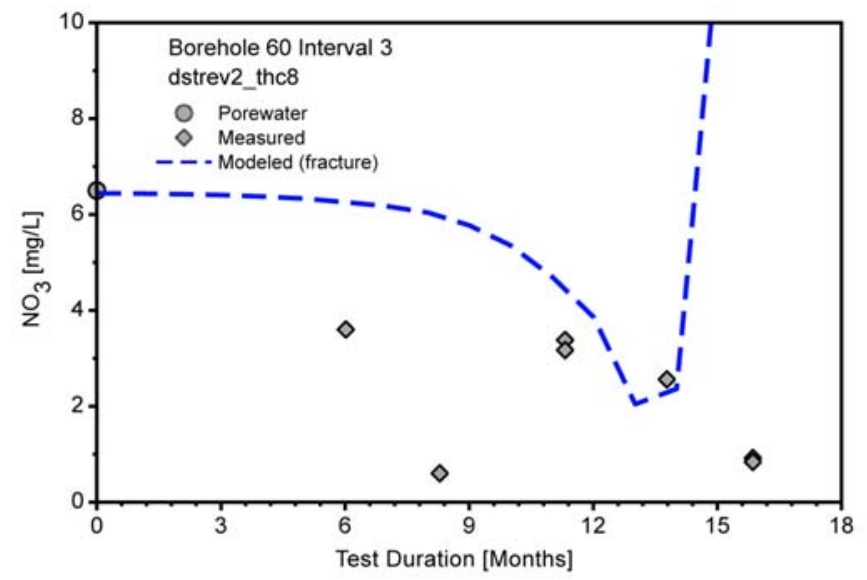

(b)

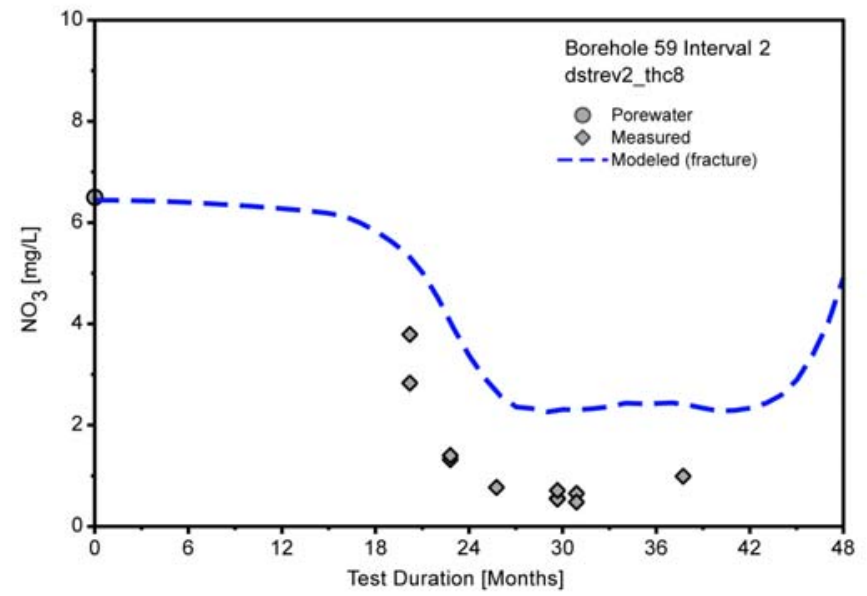

(c)

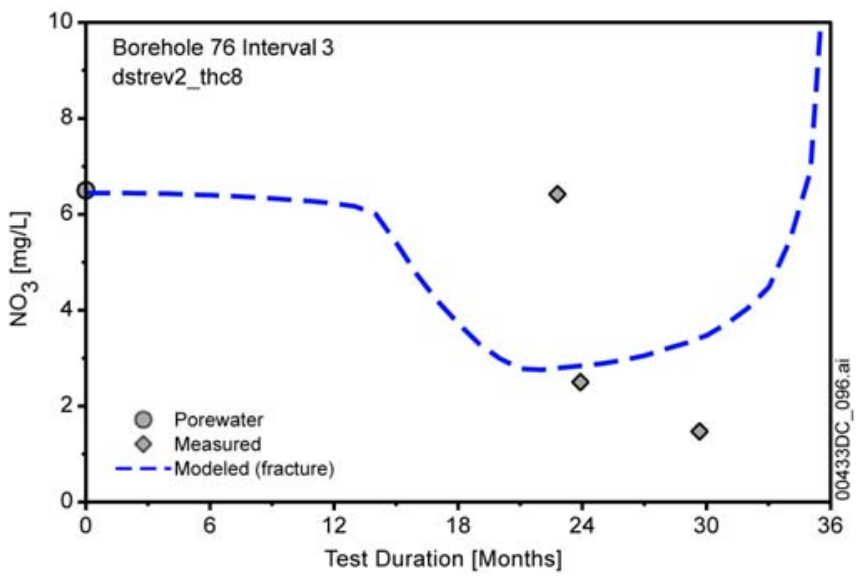

Source: DTN: LL020709923142.023 [DIRS 161677] (measured).

Output DTN: LB0307DSTTHCR2.001 (modeled).

Figure 7.1-26. $\quad \mathrm{NO}_{3}{ }^{-}$Concentrations (mg/L) in Water Samples Collected from Borehole Intervals (a) 60-3, (b) 59-2, and (c) 76-3 Compared to the Modeled Fracture Water $\mathrm{NO}_{3}{ }^{-}$Concentrations 
(a)

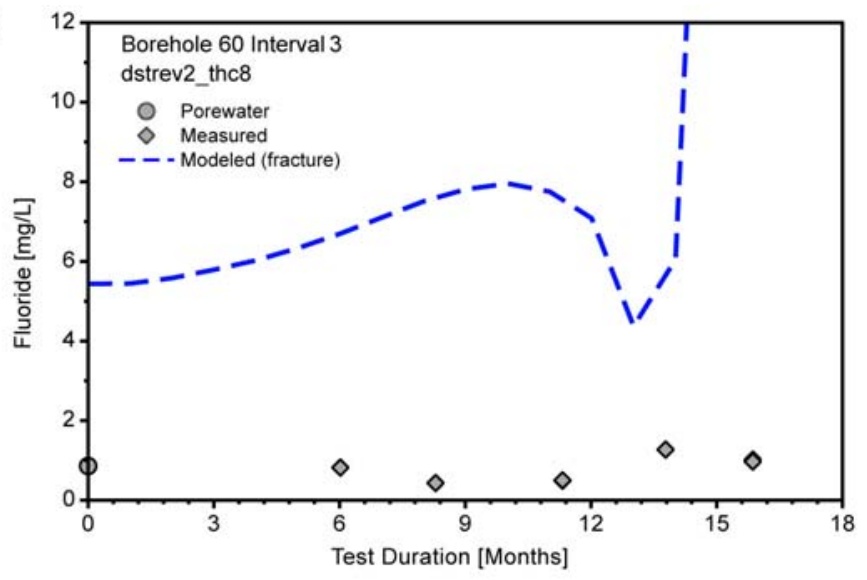

(b)

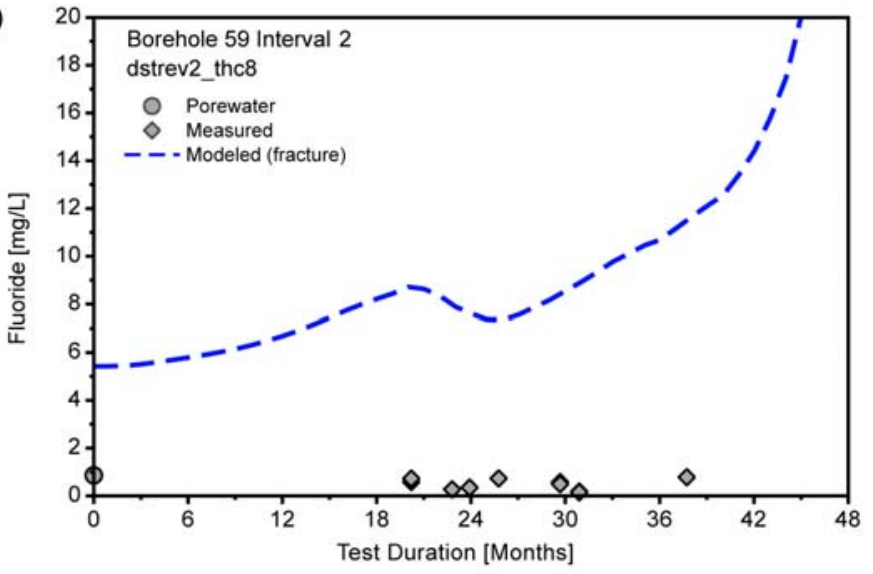

(c)

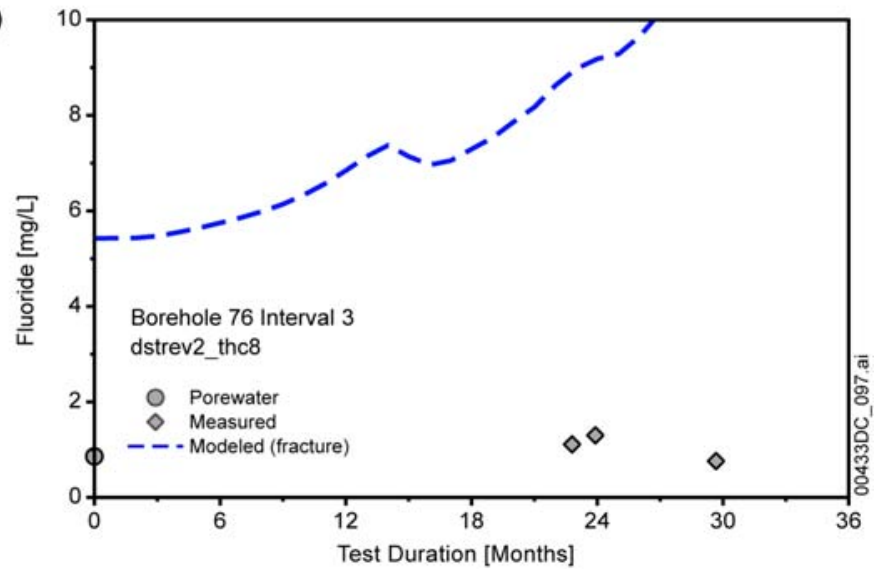

Source: DTN: LL020709923142.023 [DIRS 161677] (measured).

Output DTN: LB0307DSTTHCR2.001 (modeled).

Figure 7.1-27. $\mathrm{F}^{-}$Concentrations $(\mathrm{mg} / \mathrm{L})$ in Water Samples Collected from Borehole Intervals (a) 60-3, (b) 59-2, and (c) 76-3 Compared to the Modeled Fracture Water $\mathrm{F}^{-}$Concentrations 
Figures 7.1-28 through 7.1-30 show the modeled distributions of calcite, amorphous silica, and gypsum in the DST at the time the samples were collected. The location of borehole 54 is plotted, as well as the sites where the mineral was observed in a sidewall core sample. The modeled distributions of other, much more minor phases are not shown, because it is not possible yet to validate their abundances.

The modeled distribution of calcite in the simulation (Figure 7.1-28) shows a precipitation zone for this mineral above the heaters. The overall calcite abundance in this precipitation zone is larger than that observed in previous revisions of the DST THC submodel (Section 6.3) and is primarily a result of an improved mass-conservation formulation for mineral precipitation at the boiling front that is implemented in TOUGHREACT V3.0 (LBNL 2002 [DIRS 161256]). Another less important factor is the somewhat lower fracture porosity in the hydrologic property set. The location of modeled calcite precipitation matches the location of observed calcite in the sidewall core sample.

Like calcite, the modeled distribution of amorphous silica in the current DST simulation (Figure 7.1-29) shows the presence of a precipitation zone above the heaters. This amorphous silica precipitation is mainly due to the combined effect of the higher aqueous silica concentrations in the simulated water compositions for the current DST THC submodel, which are much closer to measured values (Figure 7.1-22), and the improved mass conservation formulation in TOUGHREACT V3.0 (LBNL 2002 [DIRS 161256]). The maximum amount of amorphous silica precipitated is about 0.4 percent after three years and less than about 1 percent for the entire duration of the DST. There is also an excellent correspondence in the region of modeled amorphous silica precipitation and the observed amorphous silica in the sidewall core samples from borehole 54. Although the observations of mineral coatings on a few samples cannot be used to judge the total amount of mineral precipitated, the small volumes precipitated in the model are consistent with the generally thin coatings observed.

Precipitation of gypsum is localized to the zones where modeled sulfate concentrations become very high as a result of boiling (Figure 7.1-30). The observed location of gypsum in the sidewall core sample is consistent with the model results that show this sample to be just within the edge of the modeled zone of precipitation.

The sidewall core sample observations of significantly greater amorphous silica precipitation compared to calcite and gypsum, with the latter phases occurring in roughly equivalent amounts, are also consistent with the DST THC submodel results. Although the maximum amount of amorphous silica precipitated is about an order of magnitude greater than calcite, there are not enough samples to determine the spatial distribution of these phases and whether areas exist where the relative proportions differ. Given that the three observed mineral phases are in the locations predicted by the model simulations, the validation criteria have been met. 


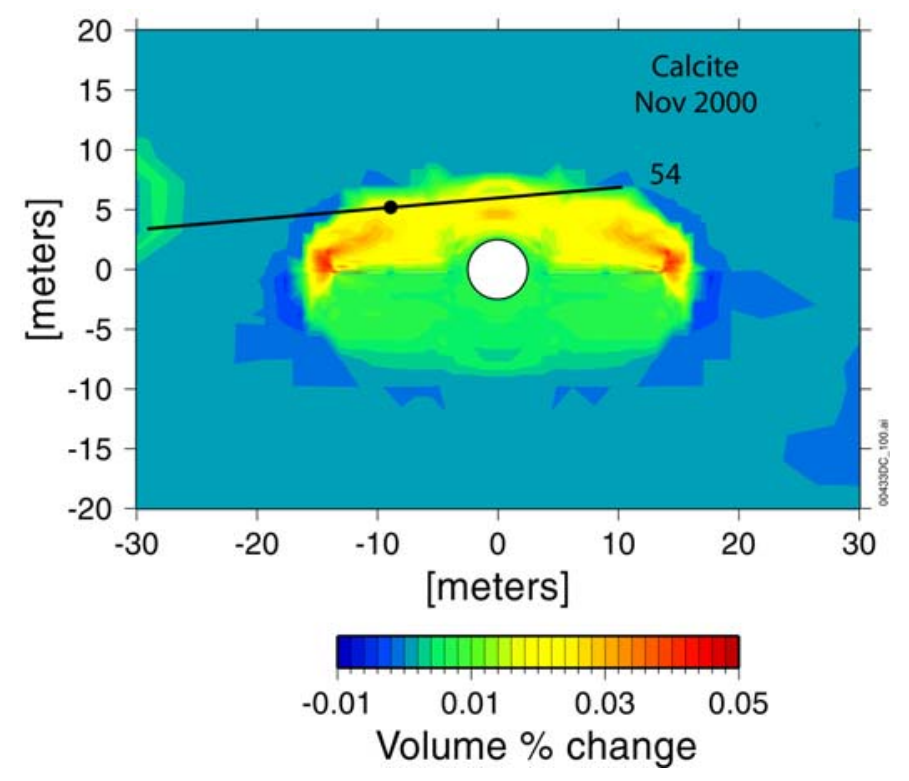

Source: DTN: LA0201SL831225.001 [DIRS 158426] (measured).

Output DTN: LB0307DSTTHCR2.001 (modeled).

NOTE: Chemistry borehole 54 is shown with location of observed calcite (filled circle) formed during DST.

Figure 7.1-28. Modeled Volume Percent Change in Calcite in Fractures as of November 2000 (35 Months of Heating)

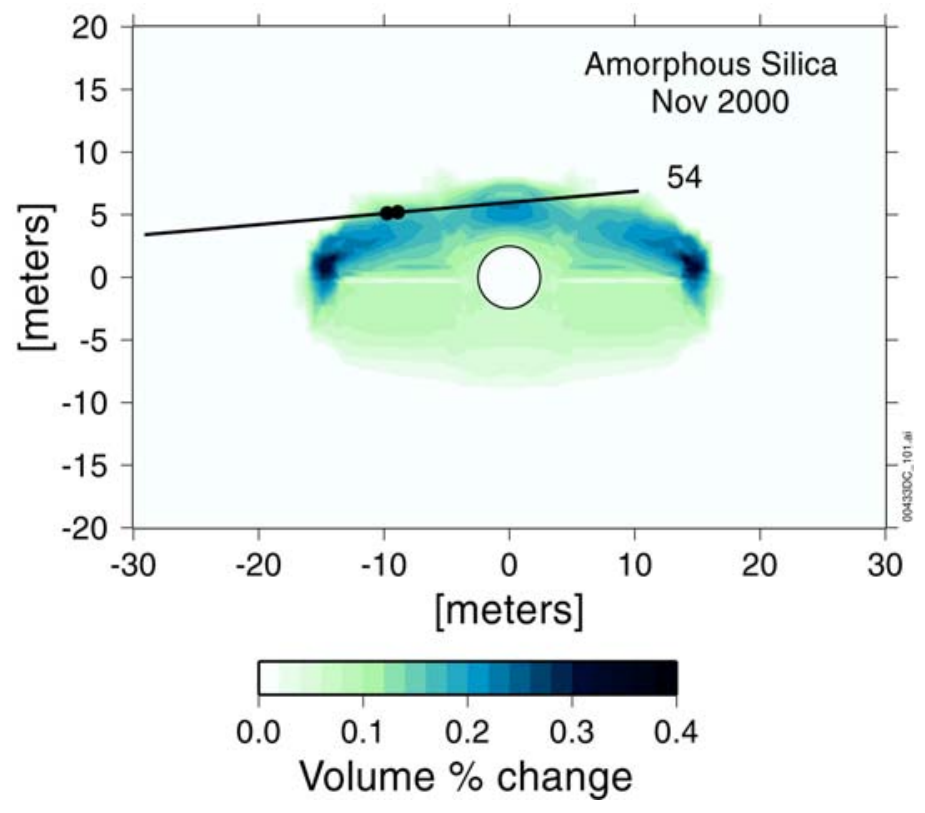

Source: DTN: LA0201SL831225.001 [DIRS 158426] (measured).

Output DTN: LB0307DSTTHCR2.001 (modeled).

NOTE: Chemistry borehole 54 is shown with location of observed amorphous silica (filled circle) formed during DST.

Figure 7.1-29. Modeled Volume Percent Amorphous Silica in Fractures as of November 2000 (35 Months of Heating) 


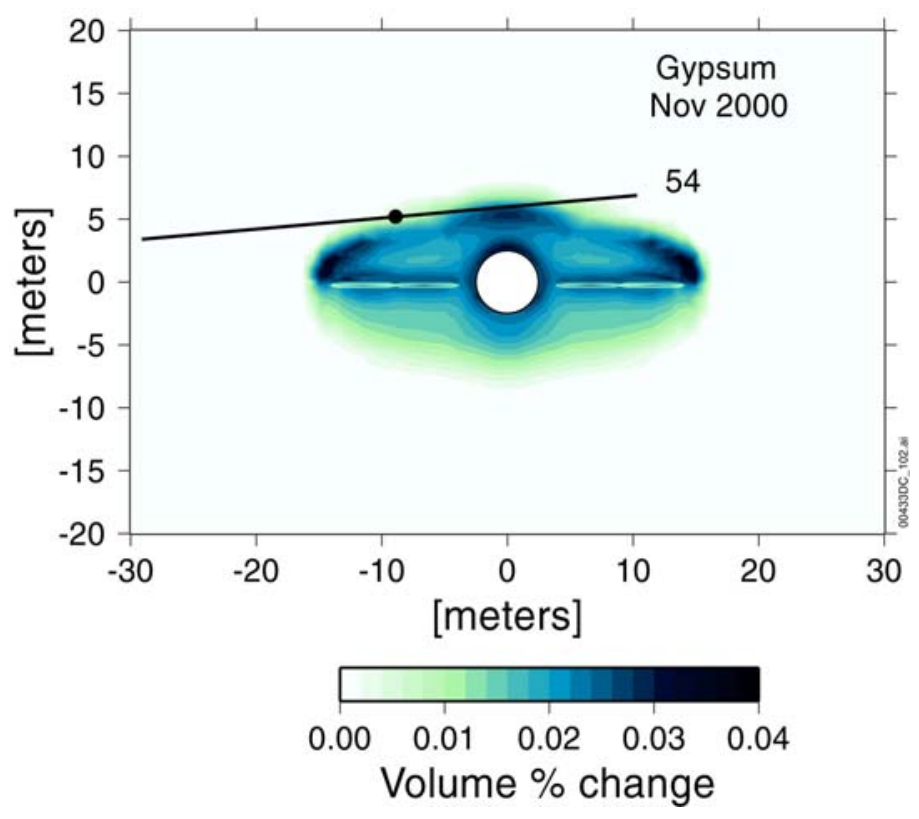

Source: DTN: LA0201SL831225.001 [DIRS 158426] (measured).

Output DTN: LB0307DSTTHCR2.001 (modeled).

NOTE: Chemistry borehole 54 is shown with location of observed gypsum (filled circle) formed during DST.

Figure 7.1-30. Modeled Volume Percent Gypsum in Fractures as of November 2000 (35 Months of Heating)

\subsubsection{Porosity and Permeability Changes}

The predicted amorphous silica abundances are about an order of magnitude greater in the current DST THC simulations than in the earlier simulations (Section 6.3). Consequently, fracture porosity changes are expected to be about one order of magnitude higher. Figure 7.1-31 shows the change in fracture porosity after four years of heating in the DST. The areas above the Heated Drift and near the edges of the wing heaters show the greatest reduction in fracture porosity, reaching somewhat less than -0.8 percent. Areas of slight fracture porosity increases in the model results can be found in the outer condensation zones, but are not evident in the contour plot. 


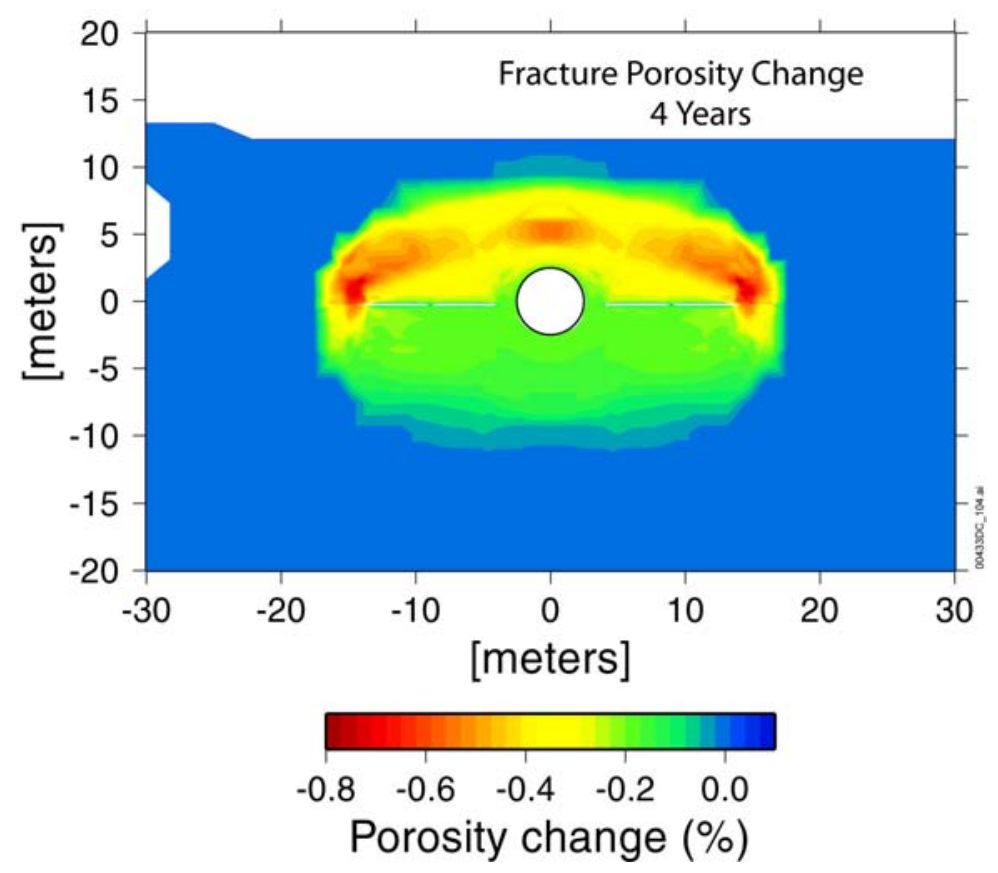

Output DTN: LB0307DSTTHCR2.001.

NOTE: Negative values indicate a net porosity reduction resulting from mineral precipitation, and positive values indicate a net porosity increase resulting from mineral dissolution.

Figure 7.1-31. Change in Fracture Porosity after Four Years of Heating

As discussed in the preceding section, several factors are responsible for the modeled increased mineral volume changes in fractures. The increase in aqueous silica concentrations from the addition of opal as a starting mineral phase, changes in the thermodynamic data, a reduction of the initial fracture porosity to 0.0085 from 0.01 , and the improved-mass balance formulation at the boiling front in TOUGHREACT V3.0 (LBNL 2002 [DIRS 161256]) are all contributing factors.

Changes in matrix porosity after four years of heating are shown in Figure 7.1-32. Reductions in matrix porosity are limited solely to the dryout zone where mineral precipitation accompanied boiling of the in situ pore water. Increases in matrix porosity are actually greater than the reductions and are evident throughout the condensation zones, where imbibition of dilute water led to mineral dissolution. Areas of strong fracture drainage around the outer edges of the heated zone apparently led to the highest level of matrix imbibition and mineral dissolution in the matrix. The porosity increase in the matrix is, however, approximately two orders of magnitude less than the porosity decrease in the fractures.

Fracture permeability changes resulting from mineral precipitation and dissolution are tied to changes in porosity and more directly to fracture aperture changes. Changes in fracture porosity of less than 1 percent of the original value would have a correspondingly small effect on fracture permeability. These results are consistent with the observations of minimal changes in air permeability during the DST, which have been attributed predominantly to water saturation changes (mostly in the condensation zones, where mineral precipitation is negligible) (BSC 2004 [DIRS 169900], p. 6.3-15). 
Thermal-hydrologic-mechanical (THM) coupled processes have also been evaluated using data from the DST, and are also predicted to cause changes in the repository host rock permeability (BSC 2004 [DIRS 169864], Section 6.9). Thermal stress tends to close fractures oriented radially to the opening, and open fractures oriented tangentially. For the same simulation conditions (equivalent thermal-hydrology), the effects from the THM simulations are centered closer to the drift openings than the THC effects.

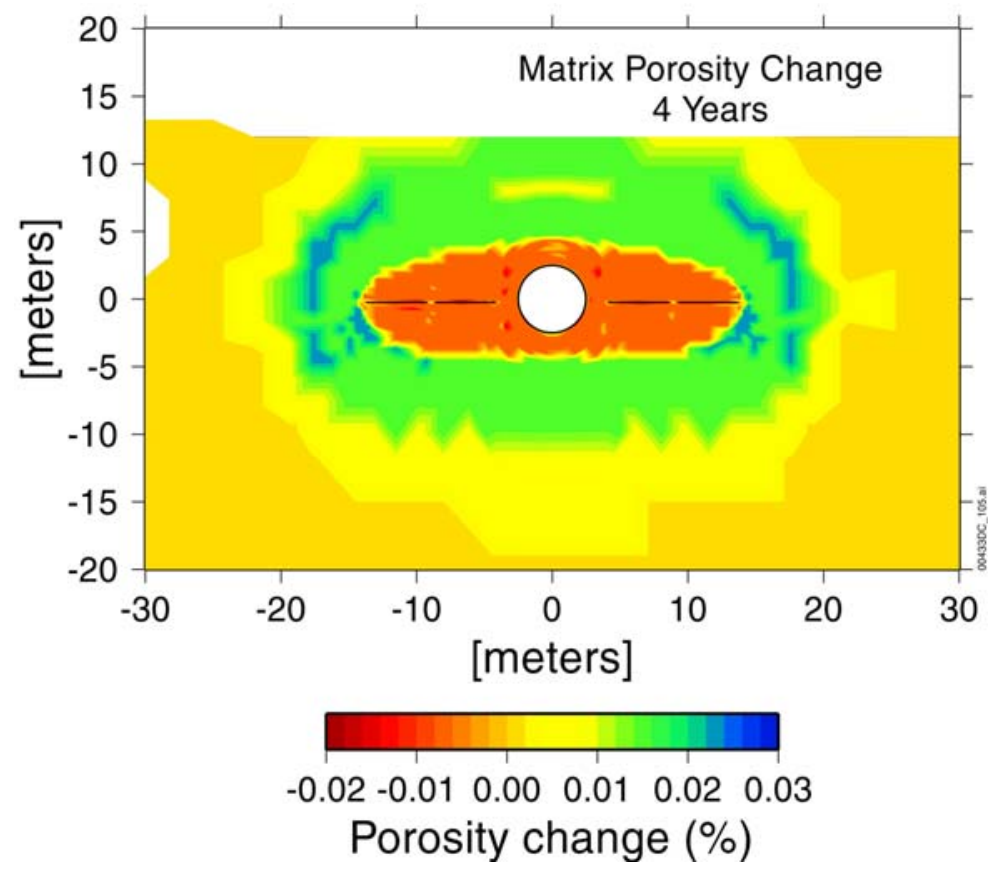

Output DTN: LB0307DSTTHCR2.001.

NOTE: Negative values indicate a net porosity reduction resulting from mineral precipitation, and positive values indicate a net porosity increase resulting from mineral dissolution.

Figure 7.1-32. Change in Matrix Porosity after Four Years of Heating

\subsubsection{Isotopic Compositions of Gases and Water: Model Corroboration Using ${ }^{14} \mathrm{C}$ in $\mathrm{CO}_{2}$}

Gas-phase $\mathrm{CO}_{2}$ concentrations and stable isotopic ratios $\left(\delta^{13} \mathrm{C}, \delta^{18} \mathrm{O}, \delta \mathrm{D}\right.$, and $\left.{ }^{14} \mathrm{C}\right)$ were measured from gases pumped from hydrology boreholes (BSC 2004 [DIRS 169900], Table 6.3.4.2-1). For the gas-phase compositions, direct comparisons of model results have been made only to $\mathrm{CO}_{2}$ concentrations. Isotopic ratios of carbon $\left(\delta^{13} \mathrm{C}\right)$, oxygen $\left(\delta^{18} \mathrm{O}\right)$, and hydrogen $(\delta \mathrm{D})$ are sensitive to fractionation effects between the liquid and gas phases as well as to diffusive fractionation, owing to the differing masses of the isotopes. Thus, they are useful in interrogating thermal-hydrologic transport processes. These fractionation effects are pronounced at lower temperatures, such that the relatively minor extent of water-rock interaction is strongly masked; thus, they are less useful for directly investigating mineral alteration during the DST.

Relative to the stable carbon isotopes $\left({ }^{12} \mathrm{C}\right.$ and $\left.{ }^{13} \mathrm{C}\right)$, carbon- $14\left({ }^{14} \mathrm{C}\right)$ abundances are minimally affected by fractionation because their activities vary over a large range, owing to the geologically short time for the radioactive decay of this species $\left(\mathrm{t}_{1 / 2} \approx 5,000\right.$ years). The virtual lack of ${ }^{14} \mathrm{C}$ in carbonate minerals at Yucca Mountain (because these materials are predominantly 
tens of thousands to millions of years old) allows for a sensitive indicator of the dissolution of calcite. Fortuitously, ${ }^{14} \mathrm{C}$ activities in the gas phase in the rock, at approximately the level of the Tptpmn unit, are close to 0.5 (fraction modern carbon) for several measurements done in different areas (BSC 2002 [DIRS 160247], Table 20 [p. I-39], Figure 44 [p. II-46]). The convention "fraction modern carbon" refers to the activity of ${ }^{14} \mathrm{C}$ prior to atmospheric testing of nuclear weapons. Thus, the present-day activity of atmospheric ${ }^{14} \mathrm{C}$ is somewhat greater than one, because of the addition of ${ }^{14} \mathrm{C}$ through weapons testing. In the subsurface at Yucca Mountain, therefore, any addition of atmospheric $\mathrm{CO}_{2}$ to the rock gas will drive its ${ }^{14} \mathrm{C}$ activity from about 0.5 towards 1.0 , whereas dissolution of calcite will drive the activity to close to zero.

Measured ${ }^{14} \mathrm{C}$ activities in $\mathrm{CO}_{2}$ from several hydrology borehole intervals (BH74-3, BH75-3, BH76-3, and BH78-3) are shown in Figure 7.1-33 over much of the heating phase of the DST. Unfortunately, an initial, unperturbed gas sample was not analyzed; however, the earliest samples collected had ratios around 0.4. All of the zones show a significant drop-off over time to values below 0.2 and several to around 0.1 or less. By projecting the trajectories of these early slopes back to time zero, the zones appear to converge to an initial activity close to 0.5 . Note that all of the samples analyzed from rock gas (over 40 measurements) had activities below 0.5. Two measurements of gas from the Heated Drift (taken after about 12 and 44 months) were also analyzed and show nearly identical values of about 0.98 , which is almost entirely atmospheric in composition. Thus, it is clear that the gas in the Heated Drift is exchanging freely with the atmosphere, even though the pore water in the rock is generating abundant $\mathrm{CO}_{2}$ with low ${ }^{14} \mathrm{C}$ activities.

It can be concluded from these data that little atmospheric $\mathrm{CO}_{2}$ has affected the $\mathrm{CO}_{2}$ in the rock gas. Although atmospheric gas has undoubtedly been introduced into the system through gas-permeability testing and drilling, the relatively low $\mathrm{CO}_{2}$ concentration in atmospheric air $(\approx 400 \mathrm{ppmv})$ compared to the ambient rock gas $(\approx 1,000 \mathrm{ppmv})$ and to the large concentrations generated during heating $\left(>10,000\right.$ ppmv) make contamination by atmospheric $\mathrm{CO}_{2}$ difficult.

The strong drop-off of ${ }^{14} \mathrm{C}$ in the gas over time is caused primarily by the dissolution of calcite having little or no ${ }^{14} \mathrm{C}$. The pore water could also be heterogeneous with respect to ${ }^{14} \mathrm{C}$, the interior of the matrix blocks having "older" water than the exterior. The latter explanation, though, is implausible, owing to the rapid diffusivity of $\mathrm{CO}_{2}$ in the gas phase in the unsaturated matrix and the rapid equilibration of $\mathrm{CO}_{2}$ with bicarbonate in the aqueous phase. Furthermore, this possibility is not supported by the gradual return in all of the measured borehole intervals to higher ${ }^{14} \mathrm{C}$ activities. Finally, ${ }^{14} \mathrm{C}$ activities as low as 0.08 have not been observed in the gas phase in the UZ at Yucca Mountain and would imply isolated water with ages over 15,000 years. 


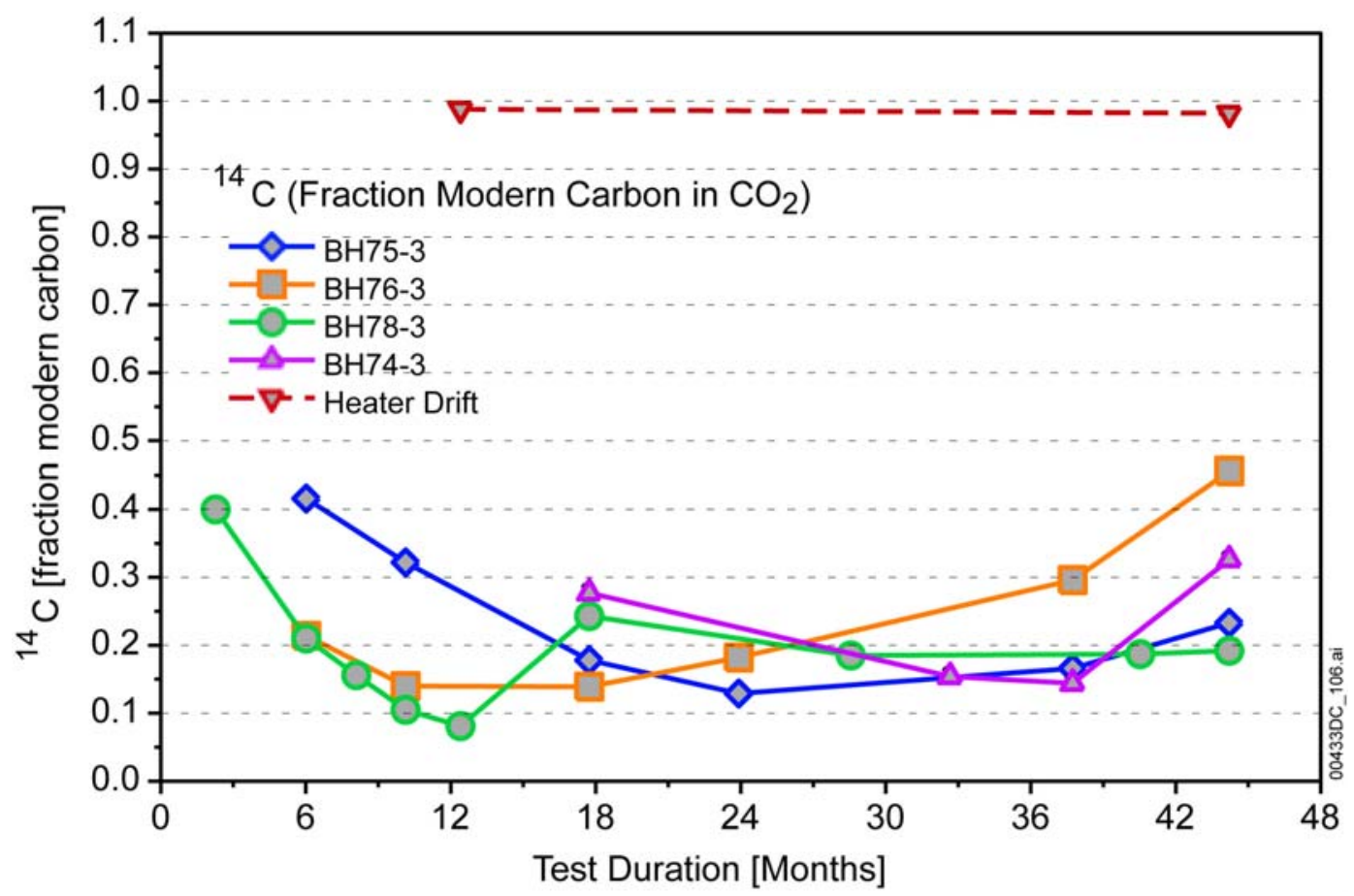

Source: BSC 2004 [DIRS 169900], Table 6.3.4.2-1.

NOTE: Two samples collected from the Heater Drift were also analyzed.

Figure 7.1-33. Measured Activities of ${ }^{14} \mathrm{C}$ (Expressed as a Fraction of Modern Carbon) in $\mathrm{CO}_{2}$ from Gas Collected in Several Hydrology Boreholes over Most of the Heating Phase of the DST

Another aspect to the trend in ${ }^{14} \mathrm{C}$ activities can be found by examining their relation to the $\mathrm{CO}_{2}$ in the gas phase. The abundance of ${ }^{14} \mathrm{C}$ in the gas is governed by the equilibrium between $\mathrm{HCO}_{3}{ }^{-}$in the water and $\mathrm{CO}_{2}$ in the gas phase. Under closed conditions, the gas should be in equilibrium with the water. This is assumed in modeling the $\mathrm{CO}_{2}$ concentrations in the DST, where there is excellent correspondence between modeled and measured values. The overall trend in ${ }^{14} \mathrm{C}$ activities seen in Figure 7.1-33 is inversely related to the changes in $\mathrm{CO}_{2}$ concentrations observed in these intervals. The timing of the peak in $\mathrm{CO}_{2}$ concentration and the low in ${ }^{14} \mathrm{C}$ activity is also very close (Figure 7.1-12). A comparison of measured $\mathrm{CO}_{2}$ (corrected for water-vapor removal) and ${ }^{14} \mathrm{C}$ is shown for three borehole intervals in Figure 7.1-34. It is apparent that at the highest $\mathrm{CO}_{2}$ concentrations reached in each zone, the ${ }^{14} \mathrm{C}$ activities are also among the lowest. 


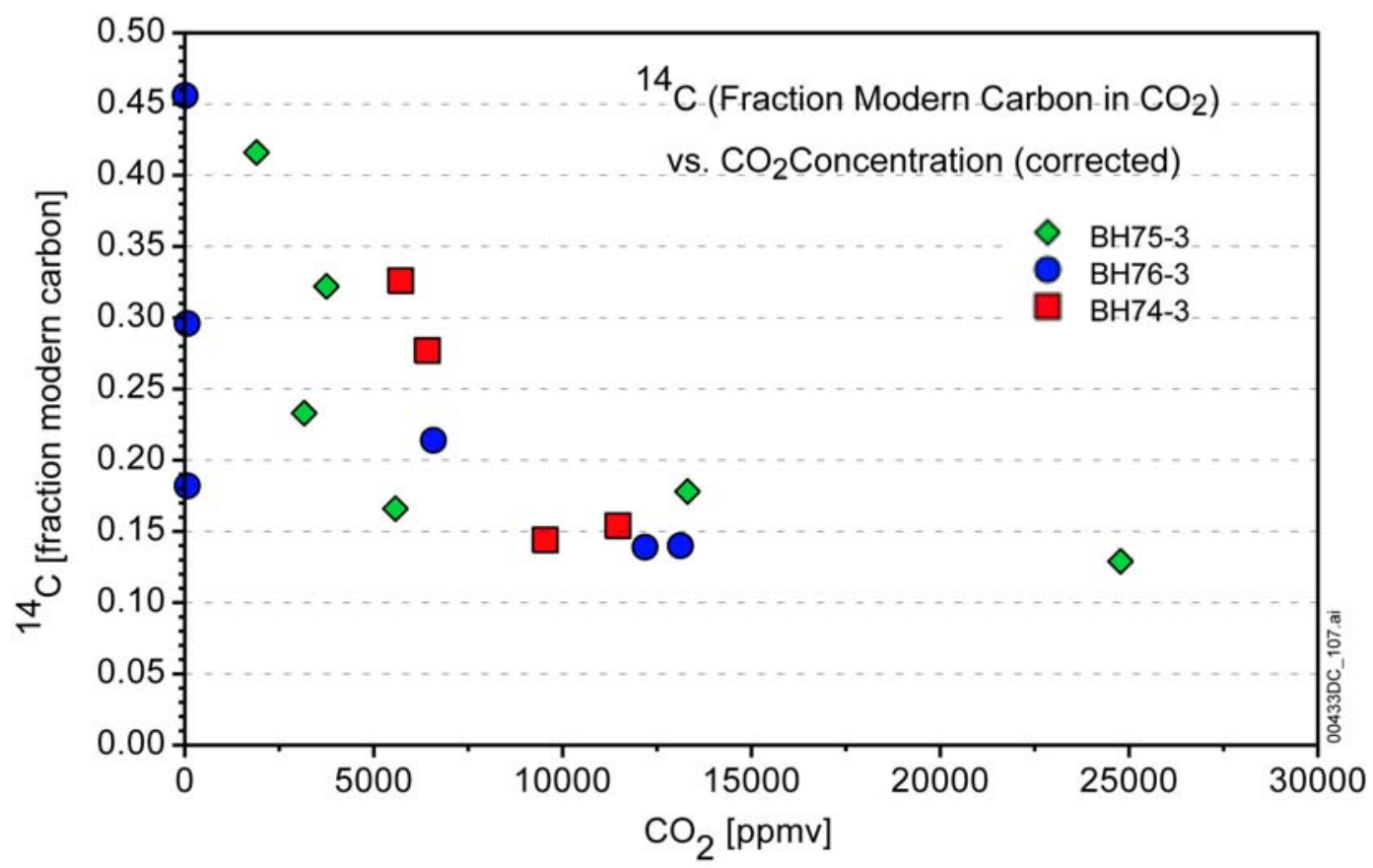

Source: BSC 2004 [DIRS 169900], Table 6.3.4.2-1.

Figure 7.1-34. Measured Activities of ${ }^{14} \mathrm{C}$ (Expressed as a Fraction of Modern Carbon) Compared to Measured $\mathrm{CO}_{2}$ (Corrected for Water Vapor Removal) from Gas Collected in Some Hydrology Boreholes over Most of the Heating Phase of the DST

The peak in $\mathrm{CO}_{2}$ concentrations observed in the model results, and in the measured values, takes place at temperatures of close to $60^{\circ} \mathrm{C}$, well below boiling and prior to the dilution of the gas phase by significant quantities of water vapor. This temperature region is characterized by some vapor condensation (Figure 7.1-7), a lowering of $\mathrm{pH}$ (Figure 7.1-15), and calcite dissolution (Figure 7.1-28) in the model simulations. Therefore, the trend to low ${ }^{14} \mathrm{C}$ activities in the areas where calcite is predicted to dissolve is consistent with the model results and with the aqueousand gas-phase chemical data that have been used to validate the model.

\subsubsection{Summary of Model-Data Comparisons Using the Drift Scale Test}

The foregoing discussion in Sections 7.1.9 through 7.1.14 has described the corroboration of the THC seepage model, through the DST THC submodel, using experimental data. The validation approach described in Section 7.1.7.1 is completed through comparison with thermal-hydrologic data (Section 7.1.9), gas-phase $\mathrm{CO}_{2}$ concentration data (Section 7.1.10), measured aqueous composition of sampled fracture waters (Section 7.1.11), and sampled mineralogical data (Section 7.1.12). Consideration is also given to fracture and matrix porosity changes, and changes in bulk permeability, and the corroborative indications from the DST (Section 7.1.13). Also, data for the ${ }^{14} \mathrm{C}$ isotopic composition of the gas phase are interpreted to corroborate the simulation of reactions involving $\mathrm{CO}_{2}$. The DST is the largest, most comprehensive test of its kind ever performed, and the results provide extensive corroboration of the THC seepage model approach and predictive capability. Where model-data comparisons exhibit differences, the magnitude is incorporated in a general assessment of uncertainty that is propagated to TSPA-LA (Section 6.6). 


\subsection{SIMULATION OF THE PLUG-FLOW REACTOR EXPERIMENT}

Comparisons between a laboratory-scale tuff dissolution experiment and simulated results using TOUGHREACT have been used to test geochemical models that were developed for the THC seepage model and the DST THC submodel. These simulations were performed with previous revisions of TOUGHREACT, using older thermodynamic databases, and do not directly address validation of the current THC model. However, a brief summary is provided here because these simulations do provide added confidence in the conceptual model that is the basis of the THC seepage model. The simulations are discussed in detail in a previous revision of this report (BSC 2004 [DIRS 168848], Section 7.2).

The experiment was a plug-flow reactor experiment using crushed tuff from the Tptpmn lithostratigraphic unit, and was performed under isothermal elevated temperature conditions $\left(94^{\circ} \mathrm{C}\right)$ with well-constrained initial water and rock compositions. Measured water compositions of samples obtained during the duration of the experiment allowed the evaluation of kinetically controlled reactions (e.g., mineral dissolution and precipitation) with time. A series of isothermal one-dimensional TOUGHREACT V2.2 (LBNL 1999 [DIRS 153219]) and V2.3 (LBNL 2001 [DIRS 153101]) simulations were performed to model this dissolution. Measured and predicted effluent concentrations were compared to evaluate the conceptual models developed for the THC seepage model.

Although some simulations exhibited closer matches than others, depending on the estimated mineral surface areas and the thermodynamic database used, predicted concentrations for the major aqueous species in the effluent generally matched the measured values well, usually within a factor of 3, and always within an order of magnitude. Measured $\mathrm{pH}$ values were not modeled well. The discrepancy in $\mathrm{pH}$ can be attributed to the exposure of the plug-flow effluent to air and the subsequent cooling and degassing of the outflow solution before analysis. The outflow $\mathrm{pH}$ values matched the simulated results closely after they had been corrected for these processes.

Two important conclusions can be derived from the tuff dissolution experiment and simulations, even though they do not serve to directly validate the current THC seepage model:

- A good match was obtained between the water compositions for the observed and simulated plug-flow experiment, providing additional confidence in the THC seepage model conceptualization.

- Differences between the modeled and measured values in $\mathrm{pH}$ result from cooling and degassing of the experimental samples after exiting the tuff dissolution column. This illustrates the potential for fluid-chemistry changes during sample collection for the DST experiment, and supports the conclusion (Section 7.1.11.2) that the poor fits between the measured DST $\mathrm{pH}$ values and those predicted by the DST THC submodel are due to cooling, condensation, and degassing during sample collection. 


\subsection{SIMULATION OF THE FRACTURE SEALING EXPERIMENT}

A laboratory-scale fracture-sealing experiment has also been simulated using TOUGHREACT. As with the plug-reactor experiment, these simulations were performed with previous versions of TOUGHREACT, using older thermodynamic databases. Thus, they do not directly address validation of the current THC model, but provide added confidence in the conceptual model basis and parameterization. The simulations are discussed in detail in the previous revision of this report (BSC 2004 [DIRS 168848], Section 7.3) and are summarized here.

The fracture sealing experiment was designed to emulate and evaluate the effects of condensate reflux through a fracture network and into a boiling environment. Two saw-cut blocks of welded rhyolite ash-flow tuff (from unit Tptpmn in Alcove 6 of the ESF), were separated by gold shims to create a vertical planar fracture. The outer surfaces of the blocks were sealed and the temperature gradient of $80^{\circ} \mathrm{C}$ at the top and $130^{\circ} \mathrm{C}$ at the bottom was established with heaters. Effluent from the plug-flow reactor (Section 7.2) was directed into the top of the fracture and vapor was removed from the bottom. Fracture sealing occurred after five days. After cooling, the fracture was opened and examined to determine the location and nature of secondary mineral formation. The precipitate (identified as mainly amorphous silica from SEM X-ray analyses and visual and petrographic examination) was deposited almost exclusively in zones where the temperature had exceeded $100^{\circ} \mathrm{C}$.

TOUGHREACT V2.4 (LBNL 2001 [DIRS 160880]) simulations were performed to model fracture sealing, using a mesh configuration with dimensions (in one dimension) identical to those of the tuff fracture experiment. The initial rock mineralogy was considered to be the same as that used in the plug-flow experiment. Different simulations were run for a period of 5.8 days, with amorphous silica controlled by either equilibrium or kinetic conditions.

The simulation results indicated the formation of a nearly isothermal two-phase region with an overlying water column below and a vapor zone below. The precipitation of amorphous silica at the base of the two-phase zone accounted for all of the porosity and permeability reduction in the fracture system. The base of the boiling zone (and region of silica precipitation) shifted downward over time due to a gradual pressure buildup, caused by the reduction of the fracture aperture at the top of the fracture system. The thickness and location of the silica precipitation zone were different in the kinetic and equilibrium simulations. The simulations conducted using equilibrium precipitation and dissolution for amorphous silica showed the effects of both precipitation and dissolution, as the trailing (upper) edge of the silica front underwent dissolution with time. In the kinetic simulations, almost no dissolution of precipitated amorphous silica occurred, resulting in a thicker band of silica that occluded less of the fracture aperture. Significant permeability reductions occurred within five days after initiation of fluid flow for both the experiment and simulations. The presence of silica precipitate throughout the boiling zone in the experimental fracture system suggests that the kinetic simulation, which retains early-formed precipitate, is a more appropriate match to the experimental results.

These simulations provide confidence in the geochemical model developed for the THC seepage model and the DST THC submodel presented in this report. Both of the simulations accurately predicted the distribution and type of secondary mineral precipitation. Amorphous silica was the dominant secondary mineral phase and simulated amorphous silica precipitation was restricted to 
the lower portion of the two-phase zone at temperatures of around $105^{\circ} \mathrm{C}$ to $109^{\circ} \mathrm{C}$, consistent with the observed pattern of mineralization along the fracture surface in the experiment. The predicted total fracture-porosity-reduction values resulting from silica precipitation in the equilibrium and kinetic simulations were 2.2 and 3.9 percent, respectively, comparable to the estimated values of 0.9 to 3.6 percent for the experiment. The experimentally determined distribution of silica precipitation was predicted more accurately by the simulation assuming kinetic control of silica precipitation, providing support for the use of this approach in the THC seepage model and the DST THC submodel.

\subsection{VALIDATION SUMMARY}

The THC seepage model has been validated by applying acceptance criteria based on an evaluation of the model's relative importance to the potential performance of the repository system. All validation requirements defined in the TWP (BSC 2005 [DIRS 172761], Section 2.2.2) have been fulfilled, including corroboration of model results with experimental data and additional confidence building by publication in a refereed professional journal (Section 7). Activities requirements for confidence building during model development have also been satisfied. The model development activities and post-development validation activities described establish the scientific bases for the drift-scale THC seepage model. Based on this, the drift-scale THC seepage model is considered to be sufficiently accurate and adequate for the intended purpose and to the level of confidence required by the model's relative importance to the potential performance of the repository system. No future validation activities are required for the drift-scale THC seepage model. 


\section{INTENTIONALLY LEFT BLANK}




\section{CONCLUSIONS}

This report documents the THC seepage model (Sections 4 and 6), the Drift Scale Test (DST) THC submodel (Section 7.1), and experimental studies to validate various aspects of the models (Sections 7.2 and 7.3). The models describe coupled THC processes at the drift scale to assess (1) the chemistry of water and gas potentially entering drifts and (2) changes in permeability and flow around drifts. The THC seepage model is used primarily to predict the composition of waters and gases around and potentially seeping into waste emplacement drifts and the effect of water-rock interaction on flow. Key findings of this model are summarized in Figure 8-1. The DST THC submodel is used primarily to validate the THC seepage model.

The underlying conceptual and mathematical models (Sections 6.1 to 6.4) provide the basis for modeling the thermal and hydrologic effects of the relevant mineral-water-gas reactions and transport processes in the host rock for 100,000 years, a time period sufficient to capture the entire duration of the thermal pulse and the return to ambient conditions. Confirmatory actions include evaluating the sensitivity of the models to different input parameters and conceptualizations. Validation (Section 7) is accomplished through comparison of simulation results to data collected from the DST and to laboratory experiments that explore various specific aspects of the modeling approach. Additional confidence building is also accomplished through publication in refereed journals (Spycher et al. 2003 [DIRS 162121]; Dobson et al. 2003 [DIRS 165949]). Model results have been submitted to the Technical Data Management System (TDMS) as output under DTNs listed in Sections 9.4 and 8.5, and Appendix G of this report. Applicable acceptance criteria from the YMRP addressed by this report are discussed in Section 4.2 with pointers referring to sections of this report where these criteria are addressed. The barrier capabilities of the natural system, including host rocks and the capillary barrier effects of drift openings, are considered throughout this report (Sections 6.5.2 and 6.5.5.1). Potential barrier effects from mineral precipitation during the thermal period are also considered (Section 6.5.5.3).

\subsection{MODELED COUPLED PROCESSES AND UNCERTAINTY}

Simulations of THC processes include coupling among heat, water, and vapor flow; aqueous and gaseous species transport; kinetic and equilibrium mineral-water reactions; and feedback of mineral precipitation-dissolution on porosity, permeability, and capillary pressure for a dual-permeability (fracture-matrix) system. Treatment of $\mathrm{CO}_{2}$ included gas-water equilibration, gas species diffusion, and advection. Data are incorporated from the calibrated thermal-hydrologic property sets, the three-dimensional mineralogical model, the unsaturated zone flow and transport model, thermal test geochemical data (fracture and matrix mineralogy, aqueous geochemistry, and gas chemistry), thermodynamic data (minerals, gases, and aqueous species), kinetic data for mineral-water reactions, and transport (diffusion coefficient) data (Section 4.1). The THC seepage model and the DST THC submodel include a wide range of major and minor aqueous species and minerals (primary and potential secondary phases). The following primary aqueous species are considered: $\mathrm{H}^{+}, \mathrm{Ca}^{2+}, \mathrm{Mg}^{2+}, \mathrm{Na}^{+}, \mathrm{K}^{+}, \mathrm{SiO}_{2(\mathrm{aq})}, \mathrm{AlO}_{2}^{-}$, $\mathrm{HFeO}_{2(\mathrm{aq})}, \mathrm{SO}_{4}{ }^{2-}, \mathrm{HCO}_{3}{ }^{-}, \mathrm{Cl}^{-}, \mathrm{NO}_{3}^{-}$, and $\mathrm{F}^{-}$. Minerals include several silica phases ( $\alpha$-cristobalite, quartz, tridymite, amorphous silica, and opal-CT), calcite, feldspars, smectites, illite, kaolinite, sepiolite, zeolites, fluorite, hematite, goethite, gypsum, and volcanic (rhyolitic) glass. In addition to the calibration of the hydrologic properties, some thermodynamic and 
kinetic data have been revised (within their ranges of uncertainty) to yield model results for the ambient system that are consistent with measured pore water compositions over long simulation times.

Many sources of uncertainty exist in modeling coupled THC processes (Section 6.6), because of the number of parameters needed to describe the natural system as described in Sections 4, 6, and 7. Model validation provides a better test of whether the system can be described sufficiently well for the intended purposes of the model. Validation is accomplished through analyses of the DST, supplemented by analyses of laboratory plug-flow reactor experiments, and fracture sealing experiments performed under temperatures, pressures, and chemical compositions corresponding to the range expected for the repository thermal loading conditions and drift design. As summarized further in this section, results of DST THC simulations captured the important changes in $\mathrm{pH}$, aqueous species concentrations, gas-phase $\mathrm{CO}_{2}$ concentrations, and mineral deposition at specific locations over time. This provides confidence in the modeling capability to predict trends of spatial and temporal variations in water and gas chemistry around emplacement drifts. Although the duration of the DST heating phase is approximately four years, the DST results exhibit the same processes known to control water chemistry, gas compositions, and permeability over longer time periods.

Several sensitivity analyses have been performed in the development of the present version, and previous versions, of this report. The results of these analyses contribute significantly to confidence that the important uncertainties have been addressed in the THC seepage model implementation for TSPA-LA. These sensitivity analyses address the following major issues:

1. Different repository host-rock geologic units (Tptpmn and Tptpll)

2. Alternative geochemical systems (base case and extended case, additional minerals and chemical components)

3. Alternative thermodynamic data sets (different equilibrium constants for key minerals)

4. Different treatments of mineral-water reactions (different kinetic rate constants and reactive surface areas; equilibrium vs. kinetic reactions)

5. Spatial heterogeneity in fracture permeability

6. Different infiltration rates and effects of climate change

7. Alternative water vapor pressure models

8. Alternative initial water compositions

9. Different effective $\mathrm{CO}_{2}$ diffusivities

10. Alternative drift-wall conceptualizations (open vs. closed to liquid flow).

These THC seepage model simulations covered a wide range of the most important uncertainties, and the range of results obtained is represented by the principal source of uncertainty, which is the natural variability in input water composition. In the spread of simulation results corresponding to the range of input water composition, the uncertainties in predicted 
concentrations of aqueous species and of $\mathrm{CO}_{2}$ gas are estimated to approximately one order of magnitude, or less (Section 6.6.2).

\subsection{THC SEEPAGE MODEL RESULTS}

The THC seepage model is designed to represent waste package heating over time, changes in heat load caused by ventilation, the effective heat transfer within the drift, and THC processes in the unsaturated zone around waste emplacement drifts. Simulations considered an initial heat load of $1.45 \mathrm{~kW} / \mathrm{m}$, including a preclosure period of 50 years using a ventilation efficiency of 86.3 percent. Model results predict the chemistry of matrix and fracture water at various locations around a drift, the times of rewetting around the drifts, and the net fluxes of water and gas near and across the drift wall for a period of 100,000 years.

The scope of this report includes essentially one design heat load, resulting in temperatures near emplacement drifts that exceed the boiling point of water for approximately 1,500 years after repository closure. Temperature is an important parameter because it affects the extent of water-rock-gas interaction taking place around proposed emplacement drifts.

The predicted extent of the dryout zone and the time of rewetting vary with different infiltration rates and water-vapor pressure models considered in this report. Depending on the modeled scenario, the maximum extent of the dryout zone in fractures is predicted to be between $6 \mathrm{~m}$ and $10 \mathrm{~m}$ above drift center, and the predicted time of fracture rewetting at the drift crown varied between 1,200 and 2,000 years in most cases. In one case neglecting the effect of vapor-pressure lowering caused by capillary suction, rewetting is predicted to occur much later (i.e., between 12,000 and 20,000 years). 
General Findings: Potential seepage waters (i.e., water in fractures having higher liquid saturation) are relatively dilute and in the near-neutral to moderately alkaline $\mathrm{pH}$ range of 7 to 9 . Elevated concentrations of aqueous species in the 1,000-10,000 ppm range are predicted for a short period at the onset of rewetting, in regions exhibiting very low liquid fluxes. General trends of gas phase $\mathrm{CO}_{2}$ and aqueous species concentrations do not differ significantly for any of the scenarios considered, with maximum gas phase $\mathrm{CO}_{2}$ concentrations $<12,000$ ppmv. Gas phase $\mathrm{CO}_{2}$

concentrations around the drift are higher than ambient values during the period when the boiling front is receding. The uncertainty in predicted major cation and anion concentrations and gas phase $\mathrm{CO}_{2}$ concentration is estimated to be about an order of magnitude or less.

\section{Effect of host rock and stratigraphic} column: Minor effect on predicted trends in major cations and anions. The initial relative spread in concentrations between models is maintained though time. Higher $\mathrm{T}$ in Tptpll ( $\sim 15 \%$ higher $\left.\mathrm{T}_{\text {max }}\right)$ leads to slightly greater evaporative concentration. Addition of fluorite to host rock results in elevated F concentrations ( 20-40 ppm). Minerals precipitated in the Tptpmn and Tptpll models are similar. Greater fracture porosity reduction in the Tptpll by several $\%$ and increased water diversion are not related to differences in the host rock. (REV01)

\section{Sensitivity to input pore water} compositions: Trends in composition through time are similar for all waters. Some waters lead to more mineral precipitation than others ( 5 to $7 \%$ reduction in fracture porosity). The relative spread in model results is generally smaller than the relative spread of input water compositions, and larger than the spread related to infiltration rate.

The heterogeneous case was run using REV01 hydrological properties and with TOUGHREACT V2.3 [DIRS 153101]. The use of REV02 properties and TOUGHREACT V3.0 [DIRS 161256] resulted in greater reductions in porosity and permeability for the homogeneous permeability case, which would also be expected for the heterogeneous case.

Figure 8-1. Key Findings of the THC Seepage Model

Sensitivity to infiltration rates: In the 6$25 \mathrm{~mm} / \mathrm{yr}$ range, the effect of infiltration rate on water composition is less than that of differing input water chemistry. The zone of reduced porosity migrates closer to the drift at higher infiltration rates, but the maximum porosity reduction remains similar.

Effect of fracture permeability heterogeneity: Insignificant effect on predicted fracture water compositions at a large scale $(>10 \mathrm{~m})$. At a small scale $(\sim 1 \mathrm{~m})$, flow focusing and heterogeneous liquid saturations yield differences in concentrations resulting from changes in dilution/evaporation and effective mineral surface areas. Reductions in porosity $(\sim 5 \%)$ and permeability $(25 \%)$ are greater than for the homogeneous permeability case ${ }^{1}$

Effect of model revisions from REV01 to REV02: Enhanced mineral precipitation at the boiling front results in a reduction in fracture permeability of 1 to 2 orders-of-magnitude. Region of reduced permeability above the drift results in increased water diversion.

Other sensitivities: Vapor pressure lowering minimal effect on long-term water compositions, but results in a much shorter dryout period. Open drift wall $-\mathrm{CO}_{2}$ concentrations in the drift rise above ambient levels at an earlier time. Higher $\mathrm{CO}_{2}$ effective diffusivity - increased $\mathrm{CO}_{2}$ concentrations in drift during the dryout period. 
In all of the model cases, including the five THC runs developed for TSPA-LA using representative input water compositions, relatively dilute and near-neutral to moderately alkaline water compositions are predicted in fractures around drifts, with circumneutral $\mathrm{pH}$ values and gas-phase $\mathrm{CO}_{2}$ concentrations less than 12,000 ppmv. General trends of $\mathrm{CO}_{2}$ gas and aqueous species concentrations around the drifts do not differ significantly for any of the cases. The simulations also exhibit increased $\mathrm{CO}_{2}$ gas concentration around the drifts during rewetting, relative to ambient values. Elevated concentrations of aqueous species relative to background values are predicted to occur temporarily at the time of rewetting in fractures, though at low liquid saturations.

Similar trends in water and gas compositions are predicted for modeled cases with heat loading in the Tptpmn and in the Tptpll geologic units. At any point in time, the spread in predicted water compositions above the drift, including alternative model cases and the five THC runs developed for TSPA-LA using representative input water compositions, is generally one order of magnitude or less (Section 6.6.2). This spread is potentially significant for chemical species for which small variations in initial concentration could shift the brine type that forms on evaporative concentration. Recognizing this possibility, simulations prepared to support TSPA-LA use a range of input water compositions to yield predicted seepage waters that evolve toward a representative range of possible end-brine types (Section 6.2.2.1).

In general, when modeling a geochemical system without aluminum silicate minerals and glass, development of the THC seepage model through multiple revisions of this report has shown that predicted $\mathrm{pH}$ values are somewhat lower and $\mathrm{CO}_{2}$ concentrations higher than in simulations that include these phases. Therefore, the incorporation of mineral-water reactions involving clays and zeolite minerals is potentially important. Aqueous sodium concentrations are predicted to increase by a factor of approximately four in 100,000 years (from the dissolution of mostly albite and glass), which is greater than the typical concentrations in the natural system. In this respect, simulations including aluminosilicate minerals could provide an upper limit on effects of water-rock-gas interactions around waste emplacement drifts.

The predicted magnitude of fracture porosity change caused by water-rock interaction around waste emplacement drifts depends on the initial fracture porosity (with the largest relative change for the smallest porosity), and results in large part from mineral precipitation directly at the boiling front above the drift opening. Simulations carried out for the THC seepage model (Section 6.5) use a more representative treatment of mineral precipitation at the boiling front than earlier versions. Accordingly, the THC seepage model simulations predict a significant effect of water-gas-rock interactions on flow patterns around the drift. This zone has a fracture permeability that is one to two orders of magnitude lower than in the surrounding rock fractures, deflecting some of the percolating water around the drift and significantly extending the shadow zone below the drift. Because the silica solubility decreases with declining temperature, the amorphous silica precipitated in fractures does not dissolve significantly into percolating water over 100,000 years.

Sensitivity studies documented previously are discussed in this report. Steady-state (ambient temperature), $\mathrm{TH}$, and $\mathrm{THC}$ simulations have been performed using three heterogeneous fracture permeability field realizations. Heterogeneity in fracture permeability can have various effects on thermohydrology, including flow focusing and irregularities in the isotherms and liquid 
saturations. Areas of highest initial liquid saturation, also having lower permeability and generally residing above the drift, tend to show the greatest reduction in fracture permeability as a result of mineral precipitation. The effect of this localized permeability reduction tends to cause some additional flow focusing, but the permeability changes (up to 25 percent) are much less than the initial range in permeability. Spatial differences in water chemistry are not affected significantly by permeability heterogeneities, and because of the strong control of the mineral assemblage on water chemistry (and not the mineral proportions), this would also be expected to be the case if the properties used in the current THC seepage model are used.

\subsection{DST THC SUBMODEL RESULTS (VALIDATION)}

Validation of the modeling approach and parameters used in the THC seepage model is accomplished using a derivative submodel adapted for direct comparison to observations of gas composition, water chemistry, and mineral deposition in the Drift Scale Test (DST). The DST THC submodel has been developed for this purpose, and is used for sensitivity studies in addition to direct comparisons of model output to measured data.

Comparisons between observed and modeled aqueous $\mathrm{pH}$ and $\mathrm{CO}_{2}$ concentrations in the gas phase indicate that a limited set of aqueous species, minerals (calcite, silica phases, fluorite, and gypsum), and gases $\left(\mathrm{H}_{2} \mathrm{O}\right.$, air, and $\left.\mathrm{CO}_{2}\right)$ (base case) could describe the general evolution of DST waters with respect to $\mathrm{pH}, \mathrm{CO}_{2}$, and conservative anions. A more complete geochemical system (extended case), including a wide range of aluminosilicates (such as feldspars, clays and zeolites), yielded modeled aqueous silica concentrations closer to those observed, plus information on additional species (i.e., $\mathrm{Mg}^{2+}, \mathrm{Al}^{3+}$, and $\mathrm{Fe}^{3+}$ ). However, predicted $\mathrm{pH}$ values for the extended system are slightly higher than those observed, and gas-phase $\mathrm{CO}_{2}$ concentrations are slightly lower than the measured values.

In particular, simulation results compared to measured gas-phase $\mathrm{CO}_{2}$ concentrations and the chemistry of waters collected from hydrology boreholes indicate that the model captures the general trend in concentrations in the borehole intervals where comparisons have been made. Predicted locations and relative abundances of secondary minerals are consistent with in situ sidewall core samples retrieved from zones that had undergone boiling. The most important mineral phase is amorphous silica followed by significantly lesser amounts of calcite and gypsum. Analyses of ${ }^{14} \mathrm{C}$ concentrations in $\mathrm{CO}_{2}$ also corroborate the model results because of their sensitivity to calcite dissolution and drift air contamination.

The evidence based on field and laboratory measurements demonstrates that model validation criteria have been met for $\mathrm{CO}_{2}$ concentrations in gas, for several aqueous species concentrations, and for mineral precipitation in fractures. Although some disagreements between modeled and measured values exist, they could be attributed to sampling interferences or to the selection of a phase (e.g., fluorite) in the mineral assemblage (because minor amounts of fluorite are known to exist in the Tptpll unit). These differences serve to quantify the sensitivity of the model to the associated input parameters. Some heterogeneities in the measured data could not be matched by the model results, which is not unexpected for simulation of such an extensive field test. The results achieved provide confidence in the modeling approach and the use of average properties for the purpose of the THC seepage model, which is to represent the chemical composition of 
water that could potentially seep into emplacement drifts, and the composition of the gas phase in the drifts.

Confidence in various aspects of the modeling approach and input data used in the THC seepage model is also based on a comparison of modeled and measured water compositions from a laboratory plug-flow dissolution experiment using volcanic tuff from the Tptpmn unit at Yucca Mountain. The model simulations captured the magnitude and change in aqueous species concentrations measured during this experiment at elevated temperatures, and thus the validation criteria were met. A fracture sealing laboratory experiment has also been simulated, with the location and amounts of amorphous silica precipitated closely comparable to that observed, also supporting validation.

Although not required for the planned validation strategy, the THC responses of the Yucca Mountain Drift Scale Test have been independently analyzed by the participants of the DECOVALEX III project, an international research project to develop coupled models and their validation against experiments. The outcome of the analyses by the DECOVALEX participants, generally corroborative of the contents of this report, has been presented in the GeoProc 2003 conference held in Stockholm, Sweden, and will be published in a special issue of the International Journal of Rock Mechanics.

Based on the results presented in Section 7 and summarized here, the drift scale THC seepage model is considered to be sufficiently accurate and adequate for the intended purpose and to the level of confidence required by the model's relative importance to the performance of the repository system.

\subsection{UNCERTAINTIES AND RESTRICTIONS FOR DOWNSTREAM USE}

Section 1.3 states the general model limitations. Potential uncertainties affecting model results are discussed in a qualitative manner in Section 6.6.1, and addressed more quantitatively in Section 6.6.2. Various alternative conceptualizations and ranges of input data are considered (summarized in Section 8.1; see also Table 6-1). In addition, confidence in the model results is obtained by comparing model results to experimental data from the DST (Section 7.1; summarized in Section 8.3) and other laboratory experiments (Sections 7.2 and 7.3). Much of the spread in the output compositions from the THC seepage model simulations is caused by the natural variability of input water compositions. This spread is up to approximately one order of magnitude and in many cases less (Section 6.6.2). The input data and model conceptualizations considered in this study all yield similar trends in modeled aqueous species and gas-phase $\mathrm{CO}_{2}$ concentrations over time.

\subsection{DATA TRACKING NUMBERS FOR DATA GENERATED IN THIS REPORT}

Table 8.5-1 lists the DTNs for data generated in this report, which included the following:

- DTNs containing THC seepage model simulations that provide feeds to downstream models and indirectly to TSPA-LA

- DTNs documenting model validation test cases discussed in Section 7 of this document. 
The files contained in each DTN are described in detail in Appendix G.

Table 8.5-1. Drift-Scale THC Seepage Model Output DTNs

\begin{tabular}{|c|c|c|}
\hline Data Tracking Number & Location In Text & Description of TSPA Parameters \\
\hline \multicolumn{3}{|c|}{ THC Seepage Model Output DTNs } \\
\hline LB0302DSCPTHCS.001 & Section 6.4 & THC Seepage Model Simulations. \\
\hline LB0302DSCPTHCS.002 & Section 6.4 & $\begin{array}{l}\text { THC Seepage Model Data Summary. This DTN } \\
\text { provides direct feeds to downstream models that } \\
\text { eventually feed TSPA-LA calculations. These feeds } \\
\text { are in the form of spatially and temporally abstracted } \\
\text { water and gas chemical compositions. }\end{array}$ \\
\hline LB0404DSTTHCR2.001 & Section 6.5 .5 .5 & $\begin{array}{l}\text { THC Seepage Model Simulations. Rerun of } \\
\text { simulations using revised porosity and thermal property } \\
\text { data. }\end{array}$ \\
\hline LB0404DSTTHCR2.002 & Section 6.5 .5 .5 & $\begin{array}{l}\text { THC Seepage Model Simulations. Rerun of } \\
\text { simulations using revised porosity and thermal property } \\
\text { data. }\end{array}$ \\
\hline \multicolumn{3}{|c|}{ Output DTNs for Model Validation Simulations } \\
\hline LB0307DSTTHCR2.001 & Section 7.1 & DST THC Submodel: Simulations. \\
\hline LB0307DSTTHCR2.002 & Section 7.1 & DST THC Submodel: Data Summary. \\
\hline
\end{tabular}




\section{INPUTS AND REFERENCES}

The following is a list of the references cited in this document. Column 2 represents the unique six digit numerical identifier (DIRS number), which is placed in the text following the reference callout (e.g., BSC 2005 [DIRS 172761]). The purpose of these numbers is to assist the reader in locating a specific reference. In the reference list below, sources are sorted alphabetically by author. Multiple sources by the same author are sorted by date and, if the date is the same, alphabetically by title.

\subsection{DOCUMENTS CITED}

Arnórsson, S. and Stefánsson, A. 1999. "Assessment of Feldspar Solubility

153329

Constants in Water in the Range $0^{\circ}$ to $350^{\circ} \mathrm{C}$ at Vapor Saturation Pressures."

American Journal of Science, 299, (3), 173-209. New Haven, Connecticut: Yale University, Kline Geology Laboratory. TIC: 249258.

Barnes, H.L. 1971. "Investigations in Hydrothermal Sulfide Systems." Chapter 160181 12 of Research Techniques for High Pressure and High Temperature. Ulmer, G.C., ed. New York, New York: Springer-Verlag. TIC: 235147.

Bear, J. 1988. Dynamics of Fluids in Porous Media. New York, New York: Dover Publications. TIC: 217568.

Bird, R.B.; Stewart, W.E.; and Lightfoot, E.N. 1960. Transport Phenomena. New York, New York: John Wiley \& Sons. TIC: 208957.

Blum, A.E. and Stillings, L.L. 1995. "Feldspar Dissolution Kinetics." Chapter 7 126590 of Chemical Weathering Rates of Silicate Minerals. White, A.F. and Brantley, S.L., eds. Reviews in Mineralogy Volume 31. Washington, D.C.: Mineralogical Society of America. TIC: 222496.

Brady, P.V. and Walther, J.V. 1989. "Controls on Silicate Dissolution Rates in 110748 Neutral and Basic pH Solutions at $25^{\circ} \mathrm{C}$." Geochimica et Cosmochimica Acta, 53, 2823-2830. New York, New York: Pergamon Press. TIC: 235216.

Bruno, J.; Stumm, W.; Wersin, P.; and Brandberg, F. 1992. "On the Influence of 160189 Carbonate in Mineral Dissolution: I. The Thermodynamics and Kinetics of Hematite Dissolution in Bicarbonate Solutions at T $=25^{\circ} \mathrm{C}$." Geochimica et Cosmochimica Acta, 56, (3), 1139-1147. New York, New York: Pergamon Press. TIC: 253396.

BSC (Bechtel SAIC Company) 2001. FY 01 Supplemental Science and Performance Analyses, Volume 1: Scientific Bases and Analyses. TDR-MGR-MD-000007 REV 00 ICN 01. Las Vegas, Nevada: Bechtel SAIC Company. ACC: MOL.20010801.0404; MOL.20010712.0062;

MOL.20010815.0001. 
BSC 2001. Multiscale Thermohydrologic Model. ANL-EBS-MD-000049

158204

REV 00 ICN 02. Las Vegas, Nevada: Bechtel SAIC Company.

ACC: MOL.20020123.0279.

BSC 2001. Repository Multiple Waste Package Thermal Calculation.

156276

CAL-WIS-TH-000010 REV 00. Las Vegas, Nevada: Bechtel SAIC Company.

ACC: MOL.20010814.0330.

BSC 2002. Analysis of Geochemical Data for the Unsaturated Zone.

160247

ANL-NBS-HS-000017 REV 00 ICN 02. Las Vegas, Nevada: Bechtel SAIC

Company. ACC: MOL.20020314.0051.

BSC 2002. Invert Effective Thermal Conductivity Calculation.

159906

000-00C-WIS0-00100-000-00A. Las Vegas, Nevada: Bechtel SAIC Company.

ACC: MOL.20020828.0178.

BSC 2002. Repository Design, Repository/PA IED Subsurface Facilities

159527

Plan Sht. 1 of 5, Sht. 2 of 5, Sht. 3 of 5, Sht. 4 of 5, and Sht. 5 of 5.

DWG-MGR-MD-000003 REV A. Las Vegas, Nevada: Bechtel SAIC Company.

ACC: MOL.20020601.0194.

BSC 2002. Users Manual (UM) for TOUGHREACT V3.0. 10396-UM-3.0-00.

Las Vegas, Nevada: Bechtel SAIC Company. ACC: MOL.20030411.0090.

BSC 2002. Ventilation Model. ANL-EBS-MD-000030 REV 01 ICN 01. Las

Vegas, Nevada: Bechtel SAIC Company. ACC: MOL.20021106.0055.

BSC 2003. Advection Versus Diffusion in the Invert. ANL-EBS-MD-000063

170881

REV 00. Las Vegas, Nevada: Bechtel SAIC Company.

ACC: DOC.20040217.0004.

BSC 2003. Repository Design Project, Repository/PA IED Emplacement Drift

162444 Committed Materials. 800-IED-EBS0-00301-000-00A. Las Vegas, Nevada:

Bechtel SAIC Company. ACC: ENG.20030311.0022.

BSC 2004. Abstraction of Drift-Scale Coupled Processes. MDL-NBS-HS-000018

169617

REV 00 Errata 002. Las Vegas, Nevada: Bechtel SAIC Company.

ACC: DOC.20031223.0004; DOC.20040223.0003; DOC.20040512.0001.

BSC 2004. Abstraction of Drift Seepage. MDL-NBS-HS-000019 REV 01. Las

169131

Vegas, Nevada: Bechtel SAIC Company. ACC: DOC.20041103.0003.

BSC 2004. Calibrated Properties Model. MDL-NBS-HS-000003 REV 02. Las

169857

Vegas, Nevada: Bechtel SAIC Company. ACC: DOC.20041006.0004. 
BSC 2004. D\&E / PA/C IED Emplacement Drift Configuration and Environment. 800-IED-MGR0-00201-000-00B. Las Vegas, Nevada: Bechtel SAIC Company. ACC: ENG.20040326.0001.

BSC 2004. D\&E / PA/C IED Interlocking Drip Shield and Emplacement Pallet. 169220 800-IED-WIS0-00401-000-00D. Las Vegas, Nevada: Bechtel SAIC Company. ACC: ENG.20040503.0018.

BSC 2004. D\&E / PA/C IED Typical Waste Package Components Assembly. 169480 800-IED-WIS0-00201-000-00E. Las Vegas, Nevada: Bechtel SAIC Company. ACC: ENG.20040517.0007.

BSC 2004. D\&E / PA/C IED Typical Waste Package Components Assembly. 167369 800-IED-WIS0-00204-000-00B. Las Vegas, Nevada: Bechtel SAIC Company. ACC: ENG.20040202.0012.

BSC 2004. D\&E / PA/C IED Typical Waste Package Components Assembly. 800-IED-WIS0-00205-000-00D. Las Vegas, Nevada: Bechtel SAIC Company. ACC: ENG.20040518.0001.

BSC 2004. Design and Engineering, Drip Shield Plate - 1. 168283 000-M00-SSE0-00601-000-00A. Las Vegas, Nevada: Bechtel SAIC Company. ACC: ENG.20040310.0027.

BSC 2004. Development of Numerical Grids for UZ Flow and Transport 169855 Modeling. ANL-NBS-HS-000015 REV 02. Las Vegas, Nevada: Bechtel SAIC Company. ACC: DOC.20040901.0001.

BSC 2004. Drift Scale THM Model. MDL-NBS-HS-000017 REV 01. Las Vegas, Nevada: Bechtel SAIC Company. ACC: DOC.20041012.0001.

BSC 2004. Drift-Scale Coupled Processes (DST and TH Seepage) Models. 170338 MDL-NBS-HS-000015 REV 01. Las Vegas, Nevada: Bechtel SAIC Company. ACC: DOC.20040930.0003.

BSC 2004. Drift-Scale Coupled Processes (DST and THC Seepage) Models. 168848 MDL-NBS-HS-000001 REV 02 Errata 002. Las Vegas, Nevada: Bechtel SAIC Company. ACC: DOC.20030804.0004; DOC.20040219.0002;

DOC.20040405.0005.

BSC 2004. Engineered Barrier System: Physical and Chemical Environment. 169860 ANL-EBS-MD-000033 REV 03. Las Vegas, Nevada: Bechtel SAIC Company. ACC: DOC.20041201.0001.

BSC 2004. General Corrosion and Localized Corrosion of the Drip Shield. ANL-EBS-MD-000004 REV 02. Las Vegas, Nevada: Bechtel SAIC Company. ACC: DOC.20040921.0002. 
BSC 2004. Geologic Framework Model (GFM2000). MDL-NBS-GS-000002

REV 02. Las Vegas, Nevada: Bechtel SAIC Company.

ACC: DOC.20040827.0008.

BSC 2004. In-Drift Precipitates/Salts Model. ANL-EBS-MD-000045 REV 02.

Las Vegas, Nevada: Bechtel SAIC Company. ACC: 20041111.0002.

BSC 2004. Mountain-Scale Coupled Processes (TH/THC/THM) Models. 169866 MDL-NBS-HS-000007 REV 02. Las Vegas, Nevada: Bechtel SAIC Company. ACC: DOC.20041108.0001.

BSC 2004. Multiscale Thermohydrologic Model. ANL-EBS-MD-000049

REV 02. Las Vegas, Nevada: Bechtel SAIC Company.

ACC: DOC.20041014.0008.

BSC 2004. Post-Processing Analysis for THC Seepage. ANL-NBS-HS-000045

ACC: DOC.20040929.0002.

BSC 2004. Repository Subsurface Emplacement Drifts Steel Invert Structure Sect.

\& Committed Materials. 800-SS0-SSE0-00102-000-00B. Las Vegas, Nevada:

Bechtel SAIC Company. ACC: ENG.20040520.0005.

BSC 2004. Simulation of Net Infiltration for Present-Day and Potential Future Company. ACC: DOC.20041109.0004.

BSC 2004. Thermal Conductivity of Non-Repository Lithostratigraphic Layers. MDL-NBS-GS-000006 REV 01. Las Vegas, Nevada: Bechtel SAIC Company. ACC: DOC.20041022.0004.

BSC 2004. Thermal Conductivity of the Potential Repository Horizon.

MDL-NBS-GS-000005 REV 01. Las Vegas, Nevada: Bechtel SAIC Company. ACC: DOC.20040928.0006.

BSC 2004. Thermal Testing Measurements Report. TDR-MGR-HS-000002

REV 00. Las Vegas, Nevada: Bechtel SAIC Company. ACC:

DOC.20040928.0005.

BSC 2004. UZ Flow Models and Submodels. MDL-NBS-HS-000006, REV 02. Las Vegas, Nevada: Bechtel SAIC Company. ACC: DOC.20041101.0004.

BSC 2004. Ventilation Model and Analysis Report. ANL-EBS-MD-000030

REV 04. Las Vegas, Nevada: Bechtel SAIC Company.

ACC: DOC.20041025.0002. 
BSC 2005. Technical Work Plan for: Near-Field Environment and Transport:

Coupled Processes (Mountain-Scale TH/THC/THM, Drift-Scale THC Seepage, and Post-Processing Analysis for THC Seepage) Report Integration.

TWP-MGR-PA-000017 REV 01 ICN 02. Las Vegas, Nevada: Bechtel SAIC Company. ACC: DOC.20050211.0001

Buscheck, T.A. and Nitao, J.J. 1993. "Repository-Heat-Driven Hydrothermal Flow at Yucca Mountain, Part I: Modeling and Analysis." Nuclear Technology, 104, (3), 418-448. La Grange Park, Illinois: American Nuclear Society.

TIC: 224039.

Canori, G.F. and Leitner, M.M. 2003. Project Requirements Document. 166275 TER-MGR-MD-000001 REV 02. Las Vegas, Nevada: Bechtel SAIC Company. ACC: DOC.20031222.0006.

Carlos, B.A.; Chipera, S.J.; Bish, D.L.; and Craven, S.J. 1993. "Fracture-Lining Manganese Oxide Minerals in Silicic Tuff, Yucca Mountain, Nevada, U.S.A." Chemical Geology, 107, 47-69. Amsterdam, The Netherlands: Elsevier.

TIC: 208629.

Carroll, S.; Mroczek, E.; Alai, M.; and Ebert, M. 1998. "Amorphous Silica Precipitation $\left(60\right.$ to $\left.120^{\circ} \mathrm{C}\right)$ : Comparison of Laboratory and Field Rates." 124275 Geochimica et Cosmochimica Acta, 62, (8), 1379-1396. New York, New York: Elsevier. TIC: 243029.

Carroll, S.A. and Walther, J.V. 1990. "Kaolinite Dissolution at $25^{\circ}, 60^{\circ}$, and 160681 $80^{\circ} \mathrm{C}$." American Journal of Science, 290, (7), 797-810. New Haven, Connecticut: Yale University, Kline Geology Laboratory. TIC: 253554.

CRWMS (Civilian Radioactive Waste Management System) M\&O (Management and Operating Contractor) 1998. Drift Scale Test As-Built Report. BAB000000-01717-5700-00003 REV 01. Las Vegas, Nevada: CRWMS M\&O. ACC: MOL.19990107.0223.

CRWMS M\&O 2000. Tabulated In-Drift Geometric and Thermal Properties Used in Drift-Scale Models for TSPA-SR. CAL-EBS-HS-000002 REV 00. Las Vegas, Nevada: CRWMS M\&O. ACC: MOL.20020212.0257.

CRWMS M\&O 2001. Drift-Scale Coupled Processes (DST and THC Seepage) 154426 Models. MDL-NBS-HS-000001 REV 01. Las Vegas, Nevada: CRWMS M\&O. ACC: MOL.20010314.0003.

CRWMS M\&O 2001. Updated CO2 Analysis of Gas Samples Collected from the 153814 Drift Scale Test. Input Transmittal 00423.T. Las Vegas, Nevada: CRWMS M\&O. ACC: MOL.20010202.0170. 
de Marsily, G. 1986. Quantitative Hydrogeology: Groundwater Hydrology for

Dobson, P.F.; Kneafsey, T.J.; Sonnenthal, E.L.; Spycher, N.; and Apps, J.A. 2003.

"Experimental and Numerical Simulation of Dissolution and Precipitation:

Implications for Fracture Sealing at Yucca Mountain, Nevada." Journal of Contaminant Hydrology, 62-63, 459-476. New York, New York: Elsevier. TIC: 254205.

Doughty, C. 1999. "Investigation of Conceptual and Numerical Approaches for Evaluating Moisture, Gas, Chemical, and Heat Transport in Fractured Unsaturated Rock." Journal of Contaminant Hydrology, 38, (1-3), 69-106. New York, New York: Elsevier. TIC: 244160.

Drever, J.I. 1997. The Geochemistry of Natural Waters, Surface and Groundwater 140067 Environments. 3rd Edition. Upper Saddle River, New Jersey: Prentice Hall. TIC: 246732.

Ehrlich, R.; Etris, E.L.; Brumfield, D.; Yuan, L.P.; and Crabtree, S.J. 1991. "Petrography and Reservoir Physics III: Physical Models for Permeability and Formation Factor.” AAPG Bulletin, 75, (10), 1579-1592. Tulsa, Oklahoma: American Association of Petroleum Geologists. TIC: 246294.

Fridriksson, T.; Neuhoff, P.S.; Arnórsson, S.; and Bird, D.K. 2001. "Geological 160460 Constraints on the Thermodynamic Properties of the Stilbite-Stellerite Solid Solution in Low-Grade Metabasalts." Geochimica et Cosmochimica Acta, 65, (21), 3993-4008. New York, New York: Elsevier. TIC: 253460.

Garrels, R.M. and Christ, C.L. 1990. Solutions, Minerals, and Equilibria. Boston, Massachusetts: Jones and Barlett Publishers. TIC: 223483.

Gunnarsson, I. and Arnórsson, S. 2000. "Amorphous Silica Solubility and the Thermodynamic Properties of $\mathrm{H}_{4} \mathrm{SiO}_{4}$ in the Range of $0^{\circ}$ to $350^{\circ} \mathrm{C}$ at $\mathrm{P}_{\text {sat. }}$." Geochimica et Cosmochimica Acta, 64, (13), 2295-2307. New York, New York: Elsevier. TIC: 250506.

Helgeson, H.C.; Kirkham, D.H.; and Flowers, G.C. 1981. "Theoretical Prediction 106024 of the Thermodynamic Behavior of Aqueous Electrolytes at High Pressures and Temperatures: IV. Calculation of Activity Coefficients, Osmotic Coefficients, and Apparent Molal and Standard and Relative Partial Molal Properties to $600^{\circ} \mathrm{C}$ and 5 kb." American Journal of Science, 281, (10), 1249-1516. New Haven, Connecticut: Yale University, Kline Geology Laboratory. TIC: 238264.

Hellmann, R. 1994. "The Albite-Water System: Part I. The Kinetics of Dissolution as Function of $\mathrm{pH}$ at 100,200 and $300^{\circ} \mathrm{C}$." Geochimica et Cosmochimica Acta, 58, (2), 595-611. New York, New York: Elsevier. TIC: 235348. 
Hersman, L.; Lloyd, T.; and Sposito, G. 1995. "Siderophore-Promoted

Dissolution of Hematite." Geochimica et Cosmochimica Acta, 59, (16), 3327-3330. Tarrytown, New York: Elsevier. TIC: 234034.

Inskeep, W.P. and Bloom, P.R. 1985. "An Evaluation of Rate Equations for

Calcite Precipitation Kinetics at pCO2 Less than 0.01 atm and $\mathrm{pH}$ Greater than 8." Geochimica et Cosmochimica Acta, 49, 2165-2180. New York, New York:

Pergamon Press. TIC: 241125.

Jeschke, A.A.; Vosbeck, K.; and Dreybrodt, W. 2001. "Surface Controlled 161694 Dissolution Rates of Gypsum in Aqueous Solutions Exhibit Nonlinear Dissolution Kinetics." Geochimica et Cosmochimica Acta, 65, (1), 27-34. New York, New York: Elsevier. TIC: 253857.

Knauss, K.G. and Wolery, T.J. 1986. "Dependence of Albite Dissolution Kinetics on $\mathrm{pH}$ and Time at $25^{\circ} \mathrm{C}$ and $70^{\circ} \mathrm{C}$." Geochimica et Cosmochimica Acta, 50, (11), 2481-2497. Elmsford, New York: Pergamon Journals. TIC: 221756.

Knauss, K.G. and Wolery, T.J. 1989. "Muscovite Dissolution Kinetics as a Function of $\mathrm{pH}$ and Time at $70^{\circ} \mathrm{C}$." Geochimica et Cosmochimica Acta, 53, 1493-1501. Elmsford, New York: Pergamon Press. TIC: 236215.

Kneafsey, T.J. and Pruess, K. 1998. "Laboratory Experiments on Heat-Driven Two-Phase Flows in Natural and Artificial Rock Fractures." Water Resources Research, 34, (12), 3349-3367. Washington, D.C.: American Geophysical Union. TIC: 247468.

Knowles-Van Cappellan, V.; Van Cappellan, P.; and Tiller, C. 1997. "Probing the Charge of Reactive Sites at the Mineral-Water Interface: Effect of Ionic Strength on Crystal Growth Kinetics of Fluorite." Geochimica et Cosmochimica Acta, 61, (9), 1871-1877. New York, New York: Pergamon Press. TIC: 246450.

Kulik, D.A. and Aja, S.U. 1997. "The Hydrothermal Stability of Illite: Implications of Empirical Correlations and Gibbs Energy Minimization." Proceedings of the Fifth International Symposium on Hydrothermal Reactions, Gatlinburg, Tennessee, July 20-24, 1997. Palmer, D.A. and Wesolowski, D.J., eds. Pages 288-292. Oak Ridge, Tennessee: Oak Ridge National Laboratory. TIC: 247217.

Langmuir, D. 1997. Aqueous Environmental Geochemistry. Upper Saddle River, 100051 New Jersey: Prentice Hall. TIC: 237107.

Lasaga, A.C. 1998. Kinetic Theory in the Earth Sciences. Princeton, New Jersey: 117091 Princeton University Press. TIC: 246279. 
Levy, S.S.; Fabryka-Martin, J.T.; Dixon, P.R.; Liu, B.; Turin, H.J.; and Wolfsberg,

A.V. 1997. "Chlorine-36 Investigations of Groundwater Infiltration in the

Exploratory Studies Facility at Yucca Mountain, Nevada." Scientific Basis for

Nuclear Waste Management XX, Symposium held December 2-6, 1996, Boston,

Massachusetts. Gray, W.J. and Triay, I.R., eds. 465, 901-908. Pittsburgh,

Pennsylvania: Materials Research Society. TIC: 238884.

Lichtner, P.C. and Seth, M.S. 1996. User's Manual for MULTIFLO:

151989

Part II-MULTIFLO 1.0 and GEM 1.0 Multicomponent-Multiphase Reactive

Transport Model. CNWRA 96-010. San Antonio, Texas: Center for Nuclear

Waste Regulatory Analyses. TIC: 248807.

Lide, D.R., ed. 1993. CRC Handbook of Chemistry and Physics. 74th Edition.

Boca Raton, Florida: CRC Press. TIC: 209252.

Liu, H-H.; Haukwa, C.B.; Ahlers, C.F.; Bodvarsson, G.S.; Flint, A.L.; and

Guertal, W.B. 2003. "Modeling Flow and Transport in Unsaturated Fractured

Rock: An Evaluation of the Continuum Approach." Journal of Contaminant

Hydrology, 62-63, 173-188. New York, New York: Elsevier. TIC: 254205.

Liu, H.H.; Doughty, C.; and Bodvarsson, G.S. 1998. "An Active Fracture Model for Unsaturated Flow and Transport in Fractured Rocks." Water Resources

Research, 34, (10), 2633-2646. Washington, D.C.: American Geophysical Union.

TIC: 243012.

Mazer, J.J.; Bates, J.K.; Bradley, J.P.; Bradley, C.R.; and Stevenson, C.M. 1992.

"Alteration of Tektite to Form Weathering Products." Nature, 357, 573-576.

London, England: Macmillan Magazines. TIC: 246479.

Murphy, W.M.; Pabalan, R.T.; Prikryl, J.D.; and Goulet, C.J. 1996. "Reaction

Kinetics and Thermodynamics of Aqueous Dissolution and Growth of Analcime and Na-Clinoptilolite at $25^{\circ} \mathrm{C}$." American Journal of Science, 296, 128-186. New Haven, Connecticut: Yale University, Kline Geology Laboratory. TIC: 235949.

NRC (U.S. Nuclear Regulatory Commission) 2003. Yucca Mountain Review Plan, Final Report. NUREG-1804, Rev. 2. Washington, D.C.: U.S. Nuclear Regulatory Commission, Office of Nuclear Material Safety and Safeguards.

TIC: 254568.

Penman, H.L. 1940. "Gas and Vapor Movement in Soils I. The Diffusion of Vapours Through Porous Solids." Journal of Agricultural Science, 30, 437-462. Cambridge, England: The University Press. TIC: 236561.

Peterman, Z.E. and Cloke, P.L. 2002. "Geochemistry of Rock Units at the Potential Repository Level, Yucca Mountain, Nevada (includes Erratum)." Applied Geochemistry, 17, (6, 7), 683-698, 955-958. New York, New York: Pergamon. TIC: $252516 ; 252517$. 
Pokrovskii, V.A. and Helgeson, H.C. 1995. "Thermodynamic Properties of

Aqueous Species and the Solubilities of Minerals at High Pressures and

Temperatures: The System $\mathrm{Al}_{2} \mathrm{O}_{3}-\mathrm{H}_{2} \mathrm{O}-\mathrm{NaCl}$." American Journal of Science, 295, 1255-1342. New Haven, Connecticut: Yale University, Kline Geology

Laboratory. TIC: 236803.

Pruess, K. 1997. "On Vaporizing Water Flow in Hot Sub-Vertical Rock

Fractures." Transport in Porous Media, 28, (3), 335-372. Boston, Massachusetts:

Kluwer Academic Publishers. TIC: 238922.

Pruess, K.; Tsang, Y.W.; and Wang, J.S.Y. 1984. Numerical Studies of Fluid and

144801

Heat Flow Near High-Level Nuclear Waste Packages Emplaced in Partially

Saturated Fractured Tuff. LBL-18552. Berkeley, California: Lawrence Berkeley Laboratory. TIC: 211033.

Pruess, K.; Wang, J.S.Y.; and Tsang, Y.W. 1990. "On Thermohydrologic

100818

Conditions Near High-Level Nuclear Wastes Emplaced in Partially Saturated

Fractured Tuff, 1. Simulation Studies with Explicit Consideration of Fracture Effects." Water Resources Research, 26, (6), 1235-1248. Washington, D.C.: American Geophysical Union. TIC: 221923.

Ragnarsdottir, K.V. 1993. "Dissolution Kinetics of Heulandite at pH 2-12 and $25^{\circ}$ C." Geochimica et Cosmochimica Acta, 57, (11), 2439-2449. New York, New York: Pergamon Press. TIC: 243920.

Reed, M.H. 1982. "Calculation of Multicomponent Chemical Equilibria and Reaction Processes in Systems Involving Minerals, Gases and an Aqueous Phase." Geochimica et Cosmochimica Acta, 46, (4), 513-528. New York, New York: Pergamon Press. TIC: 224159.

Renders, P.J.N.; Gammons, C.H.; and Barnes, H.L. 1995. "Precipitation and 107088 Dissolution Rate Constants for Cristobalite from 150 to $300^{\circ} \mathrm{C}$." Geochimica et Cosmochimica Acta, 59, 77-85. New York, New York: Elsevier. TIC: 226987.

Rimstidt, J.D. 1997. "Quartz Solubility at Low Temperatures." Geochimica et 101709 Cosmochimica Acta, 61, (13), 2553-2558. New York, New York: Pergamon Press. TIC: 239020.

Rimstidt, J.D. and Barnes, H.L. 1980. "The Kinetics of Silica-Water Reactions." 101708 Geochimica et Cosmochimica Acta, 44, 1683-1699. New York, New York: Pergamon Press. TIC: 219975.

Robie, R.A.; Hemingway, B.S.; and Fisher, J.R. 1979. Thermodynamic Properties of Minerals and Related Substances at 298.15 K and 1 Bar (10 ${ }^{5}$ Pascals) Pressure and at Higher Temperatures. U.S. Geological Survey Bulletin 1452. Washington, D.C.: U.S. Government Printing Office. TIC: 230505. 
Rosenberg, N.D.; Gdowski, G.E.; and Knauss, K.G. 2001. "Evaporative Chemical

Savage, D.; Cave, M.R.; Haigh, D.; Milodowski, A.E.; and Young, M.E. 1993.

160198

"The Reaction Kinetics of Laumontite Under Hydrothermal Conditions."

European Journal of Mineralogy, 5, (3), 523-535. Stuttgart, Germany: E.

Schweizerbart'sche Verlagsbuchhandlung. TIC: 253021.

Sawyer, D.A.; Fleck, R.J.; Lanphere, M.A.; Warren, R.G.; Broxton, D.E.; and

100075

Hudson, M.R. 1994. "Episodic Caldera Volcanism in the Miocene Southwestern

Nevada Volcanic Field: Revised Stratigraphic Framework, ${ }^{40} \mathrm{Ar} /{ }^{39} \mathrm{Ar}$

Geochronology, and Implications for Magmatism and Extension." Geological

Society of America Bulletin, 106, (10), 1304-1318. Boulder, Colorado: Geological

Society of America. TIC: 222523.

Slider, H.C. 1976. Practical Petroleum Reservoir Engineering Methods, An

128146

Energy Conservation Science. Tulsa, Oklahoma: Petroleum Publishing

Company. TIC: 247798.

Sonnenthal, E. 2000. First Exploratory Study Facility Thermal Test. Scientific

Notebook YMP-LBNL-YWT-ELS-1. ACC: MOL.20000907.0251;

MOL.20000411.0792; MOL.19991109.0319.

Sonnenthal, E.L. and Bodvarsson, G.S. 1999. "Constraints on the Hydrology of the Unsaturated Zone at Yucca Mountain, NV from Three-Dimensional Models of Chloride and Strontium Geochemistry." Journal of Contaminant Hydrology, 38, (1-3), 107-156. New York, New York: Elsevier. TIC: 244160.

Spycher, N. 2001. Drift Scale Modeling (YMP-LBNL-DSM-NS-1). Scientific Notebook SN-LBNL-SCI-141-V1. ACC: MOL.20011017.0003.

Spycher, N.F.; Sonnenthal, E.L.; and Apps, J.A. 2003. "Fluid Flow and Reactive

Transport Around Potential Nuclear Waste Emplacement Tunnels at Yucca

Mountain, Nevada." Journal of Contaminant Hydrology, 62-63, 653-673. New

York, New York: Elsevier. TIC: 254205.

Steefel, C.I. and Lasaga, A.C. 1994. "A Coupled Model for Transport of Multiple

101480

Chemical Species and Kinetic Precipitation/Dissolution Reactions with

Application to Reactive Flow in Single Phase Hydrothermal Systems." American

Journal of Science, 294, (5), 529-592. New Haven, Connecticut: Yale University, Kline Geology Laboratory. TIC: 235372.

Steefel, C.I. and Lichtner, P.C. 1998. "Multicomponent Reactive Transport in Discrete Fractures: I. Controls on Reaction Front Geometry." Journal of Hydrology, 209, 186-199. New York, New York: Elsevier. TIC: 247524. 
Steefel, C.I. and Yabusaki, S.B. 1996. OS3D/GIMRT Software for Modeling

Multicomponent-Multidimensional Reactive Transport User Manual \&

Programmer's Guide. PNL-11166. Richland, Washington: Pacific Northwest

Laboratory. TIC: 240572.

Stefánsson, A. and Arnórsson, S. 2000. "Feldspar Saturation State in Natural

Waters." Geochimica et Cosmochimica Acta, 64, (15), 2567-2584. New York,

New York: Elsevier. TIC: 249336.

Svensson, U. and Dreybrodt, W. 1992. "Dissolution Kinetics of Natural Calcite

127978

Minerals in CO2-Water Systems Approaching Calcite Equilibrium." Chemical

Geology, 100, 129-145. Amsterdam, The Netherlands: Elsevier. TIC: 246497.

Tester, J.W.; Worley, G.W.; Robison, B.A.; Grigsby, C.O.; and Feerer, J.L. 1994.

"Correlating Quartz Dissolution Kinetics in Pure Water from $25^{\circ}$ to $625^{\circ} \mathrm{C}$."

Geochimica et Cosmochimica Acta, 58, (11), 2407-2420. New York, New York:

Elsevier. TIC: 236776.

Tsang, Y.W. and Birkholzer, J.T. 1999. "Predictions and Observations of the

Thermal-Hydrologic Conditions in the Single Heater Test." Journal of

Contaminant Hydrology, 38, (1-3), 385-425. New York, New York: Elsevier.

TIC: 244160.

Vaniman, D.T.; Chipera, S.J.; Bish, D.L.; Carey, J.W.; and Levy, S.S. 2001.

157427

"Quantification of Unsaturated-Zone Alteration and Cation Exchange in Zeolitized Tuffs at Yucca Mountain, Nevada, USA." Geochimica et Cosmochimica Acta, 65, (20), 3409-3433. New York, New York: Elsevier. TIC: 251574.

Wang, J.S. 2003. "Scientific Notebooks Referenced in Model Report N0120/U0110, Drift-Scale Coupled Processes (DST and THC Seepage) Models MDL-NBS-HS-000001 REV 02." Interoffice correspondence from J.S. Wang (BSC) to File, June 6, 2003, with attachments. ACC: MOL.20030611.0079.

White, A.F. and Brantley, S.L., eds. 1995. Chemical Weathering Rates of Silicate 154492 Minerals. Reviews in Mineralogy Volume 31. Washington, D.C.: Mineralogical Society of America. TIC: 222496.

Williams, N.H. 2003. "Contract No. DE-AC28-01RW1210 - Transmittal of 163765 White Paper, Effects of Neoprene on Water in the Drift Scale Test." Letter from N.H. Williams (BSC) to J.D. Ziegler (DOE/ORD), February 4, 2003, 0129035843, with enclosure. ACC: MOL.20030206.0211.

Wilson, N.S.F.; Cline, J.S.; and Lundberg, S.A.W. 2000. "Paragenesis and 154279 Chemical Composition of Secondary Mineralization at Yucca Mountain, Nevada." Abstracts with Programs - Geological Society of America, 32, (7), A-260.

Boulder, Colorado: Geological Society of America. TIC: 249113. 
Wu, Y.S.; Ritcey, A.C.; and Bodvarsson, G.S. 1999. "A Modeling Study of Perched Water Phenomena in the Unsaturated Zone at Yucca Mountain." Journal of Contaminant Hydrology, 38, (1-3), 157-184. New York, New York: Elsevier. TIC: 244160.

$\mathrm{Xu}, \mathrm{T}$. and Pruess, K. 1998. Coupled Modeling of Non-Isothermal Multi-Phase Flow, Solute Transport and Reactive Chemistry in Porous and Fractured Media: 1. Model Development and Validation. LBNL-42050. Berkeley, California: Lawrence Berkeley National Laboratory. TIC: 243735.

Xu, T. and Pruess, K. 2001. "Modeling Multiphase Non-Isothermal Fluid Flow and Reactive Geochemical Transport in Variably Saturated Fractured Rocks: 1. Methodology." American Journal of Science, 301, 16-33. New Haven, Connecticut: Yale University, Kline Geology Laboratory. TIC: 251482.

Xu, T.; Pruess, K.; and Brimhall, G. 1998. An Improved Equilibrium-Kinetics Speciation Algorithm for Redox Reactions in Variably Saturated Subsurface Flow Systems. LBNL-41789. Berkeley, California: Lawrence Berkeley National Laboratory. TIC: 240019.

Xu, T.; Sonnenthal, E.; and Bodvarsson, G. 2003. "A Reaction-Transport Model for Calcite Precipitation and Evaluation of Infiltration Fluxes in Unsaturated Fractured Rock." Journal of Contaminant Hydrology, 64, (1-2), 113-127. New York, New York: Elsevier. TIC: 254008.

Xu, T.; Sonnenthal, E.; Spycher, N.; Pruess, K.; Brimhall, G.; and Apps, J. 2001. 161864 "Modeling Multiphase Non-Isothermal Fluid Flow and Reactive Geochemical Transport in Variably Saturated Fractured Rocks: 2. Applications to Supergene Copper Enrichment and Hydrothermal Flows." American Journal of Science, 301, (1), 34-59. New Haven, Connecticut: Yale University, Kline Geology Laboratory. TIC: 253949.

Yang, I.C.; Rattray, G.W.; and Yu, P. 1996. Interpretation of Chemical and Isotopic Data from Boreholes in the Unsaturated Zone at Yucca Mountain, Nevada. Water-Resources Investigations Report 96-4058. Denver, Colorado: U.S. Geological Survey. ACC: MOL.19980528.0216.

Yokoyama, T. and Banfield, J. F. 2002. "Direct Determination of the Rates of Rhyolite Dissolution and Clay Formation Over 52,000 Years and Comparison with Laboratory Measurements." Geochimica et Cosmochimica Acta, 66, (15), 2665-2681. New York, New York: Pergamon. TIC: 256435. 


\subsection{CODES, STANDARDS, REGULATIONS, AND PROCEDURES}

10 CFR 63. Energy: Disposal of High-Level Radioactive Wastes in a Geologic

Repository at Yucca Mountain, Nevada. Readily available.

AP-2.22Q, Rev. 1, ICN 1. Classification Analyses and Maintenance of the Q-List. Washington, D.C.: U.S. Department of Energy, Office of Civilian Radioactive Waste Management. ACC: DOC.20040714.0002.

AP-SIII.3Q, Rev. 2, ICN 1. Submittal and Incorporation of Data to the Technical Data Management System. Washington, D.C.: U.S. Department of Energy, Office of Civilian Radioactive Waste Management. ACC: MOL.20040226.0001.

AP-SV.1Q, Rev. 1, ICN 2. Control of the Electronic Management of Information. Washington, D.C.: U.S. Department of Energy, Office of Civilian Radioactive Waste Management. ACC: DOC.20050119.0004.

LP-2.29Q-BSC, Rev 0, ICN 0. Planning for Science Activities. Washington, D.C.: U.S. Department of Energy, Office of Civilian Radioactive Waste Management. ACC: DOC.20050114.0001.

LP-SI.11Q-BSC, Rev. 0, ICN 1. Software Management. Washington, D.C.: U.S. Department of Energy, Office of Civilian Radioactive Waste Management. ACC: DOC.20041005.0008.

LP-SIII.2Q-BSC, Rev. 0, ICN 0. Qualification of Unqualified Data. Washington, D.C.: U.S. Department of Energy, Office of Civilian Radioactive Waste Management. ACC: DOC.20050119.0002.

LP-SIII.10Q-BSC, Rev. 0, ICN 0. Models. Washington, D.C.: U.S. Department of Energy, Office of Civilian Radioactive Waste Management.

ACC: DOC.20050203.0009.

YMP-LBNL-QIP-SV.0, Rev. 2, Mod. 1. Management of YMP-LBNL Electronic Data. Berkeley, California: Lawrence Berkeley National Laboratory.

ACC: MOL.20020717.0319.

\subsection{SOURCE DATA, LISTED BY DATA TRACKING NUMBER}

GS000308311221.005. Net Infiltration Modeling Results for 3 Climate Scenarios 147613 for FY99. Submittal date: 03/01/2000.

GS000483351030.003. Thermal Properties Measured 12/01/99 to 12/02/99 Using 152932 the Thermolink Soil Multimeter and Thermal Properties Sensor on Selected Potential Candidate Backfill Materials Used in the Engineered Barrier System. Submittal date: 11/09/2000. 
GS020408312272.003. Collection and Analysis of Pore Water Samples for the

Period from April 2001 to February 2002. Submittal date: 04/24/2002.

GS020808312272.004. Analysis of Water-Quality Samples for the Period from

166569 July 1999 to July 2002. Submittal date: 09/18/2002.

GS030408312272.002. Analysis of Water-Quality Samples for the Period from

165226

July 2002 to November 2002. Submittal date: 05/07/2003.

GS031008312272.008. Analysis of Pore Water and Miscellaneous Water Samples

for the Period from December 2002 to July 2003. Submittal date: 11/13/2003.

LA0009SL831151.001. Fracture Mineralogy of the ESF Single Heater Test

153485

Block, Alcove 5. Submittal date: 09/28/2000.

LA0201SL831225.001. Chemical, Textural, and Mineralogical Characteristics of

158426

Sidewall Samples from the Drift Scale Test. Submittal date: 01/10/2002.

LA9908JC831321.001. Mineralogic Model "MM3.0” Version 3.0. Submittal date: $08 / 16 / 1999$.

LA9912SL831151.001. Fracture Mineralogy of Drill Core ESF-HD-TEMP-2.

Submittal date: 01/05/2000.

LA9912SL831151.002. Percent Coverage by Fracture-Coating Minerals in Core

146449

ESF-HD-TEMP-2. Submittal date: 01/05/2000.

LB000121123142.003. Isotope Data for CO2 Gas Samples Collected From the Hydrology Holes of the ESF Drift Scale Test for the Period August 9, 1999 through November 30, 1999. Submittal date: 01/21/2000.

LB0011CO2DST08.001. Isotope Data for CO2 from Gas Samples Collected from 153460 Hydrology Holes in Drift-Scale Test. Submittal date: 12/09/2000.

LB0011DSTTHCR1.002. Model Input and Output Files, Excel Spreadsheets and 161282 Resultant Figures which are Presented in AMR U0110/N0120, "Drift-Scale Coupled Processes (DST and THC Seepage) Models REV 01." Submittal date: $12 / 19 / 2000$.

LB0101DSTTHCR1.002. Attachment II - Mineral Initial Volume Fractions for TPTPLL THC Model for AMR N0120/U0110 REV01, "Drift-Scale Coupled Processes (Drift-Scale Test and THC Seepage) Models." Submittal date: 01/26/2001. 
LB0101DSTTHCR1.004. Attachment IV - Mineral Reactive Surface Areas:

161279

TPTPLL THC Model for AMR N0120/U0110 REV01, "Drift-Scale Coupled Processes (Drift-Scale Test and THC Seepage) Models." Submittal date:

01/26/2001.

LB0101DSTTHGRD.001. 2D Finite Element Mesh Used for DST THC Model

Simulations (Input to AMR N0120/U0110 REV. 01). Submittal date: 01/05/2001.

LB0102CO2DST98.001. Concentration Data for CO2 from Gas Samples

159306

Collected from Hydrology Holes in Drift-scale Test. Submittal date: 02/28/2001.

LB0205REVUZPRP.001. Fracture Properties for UZ Model Layers Developed

159525

from Field Data. Submittal date: 05/14/2002.

LB0207REVUZPRP.002. Matrix Properties for UZ Model Layers Developed

from Field and Laboratory Data. Submittal date: 07/15/2002.

LB0208ISODSTHP.001. Isotope Data and CO2 Analysis for the Heating Phase of the DST. Submittal date: 08/09/2002.

161638

LB0208UZDSCPMI.002. Drift-Scale Calibrated Property Sets: Mean Infiltration

161243

Data Summary. Submittal date: 08/26/2002.

LB0210THRMLPRP.001. Thermal Properties of UZ Model Layers: Data

160799

Summary. Submittal date: 10/25/2002.

LB03023DKMGRID.001. UZ 3-D Site Scale Model Grids. Submittal date:

162354

02/26/2003.

LB0307KNTDBRTM.001. Kinetic Database for Reactive Transport Modeling.

164433

Submittal date: 07/22/2003.

LB0307THMDBRTM.001. Thermodynamic Database for Reactive Transport Modeling. Submittal date: 07/22/2003.

164434

LB0402THRMLPRP.001. Thermal Properties of UZ Model Layers: Data 168481 Summary. Submittal date: 02/20/2004.

LB990501233129.004. 3-D UZ Model Calibration Grids for AMR U0000, 111475 "Development of Numerical Grids of UZ Flow and Transport Modeling". Submittal date: 09/24/1999.

LB990601233124.001. Seepage Data Feed to UZ Drift-Scale Flow Model for TSPA-SR. Submittal date: 06/18/1999.

105888

LB990630123142.003. Fourth, Fifth, and Sixth Quarters TDIF Submission for the 111476

Drift Scale Test, September 1998 to May 1999. Submittal date: 06/30/1999. 
LB990701233129.002. 3-D Model Calibration Grid for Calculation of Flow

125604 Fields Using \#3 Perched Water Conceptual Model (Non-Perched Water Model) for AMR U0050, "UZ Flow Models and Submodels." Submittal date: 03/11/2000.

LB991200DSTTHC.002. Model Input and Output Files, Excel Spreadsheets and 142162 Resultant Figures Which are Presented in AMR N0120/U0110, "Drift-Scale Coupled Processes (Drift-Scale Test and THC Seepage) Models." Submittal date: 03/11/2000.

LL000114004242.090. TSPA-SR Mean Calculations. Submittal date: $01 / 28 / 2000$.

LL001100931031.008. Aqueous Chemistry of Water Sampled from Boreholes of 153288 the Drift Scale Test (DST). Submittal date: 11/10/2000.

LL001200231031.009. Aqueous Chemistry of Water Sampled from Boreholes of 153616 the Drift Scale Test (DST). Submittal date: 12/04/2000.

LL020302223142.015. Aqueous Geochemistry of DST Samples Collected from HYD Boreholes. Submittal date: 03/07/2002.

LL020405123142.019. Aqueous Geochemistry of Condensed Fluids Collected During Studies of Introduced Materials. Submittal date: 05/22/2002.

LL020709923142.023. Aqueous Geochemistry of Borehole Waters Collected in the Heating Phase of the DST. Submittal date: 07/26/2002.

LL990702804244.100. Borehole and Pore Water Data. Submittal date: 07/13/1999.

MO0001SEPDSTPC.000. Drift Scale Test (DST) Temperature, Power, Current, 153836 and Voltage Data for June 1, 1999 through October 31, 1999. Submittal date: 01/12/2000.

MO0002ABBLSLDS.000. As-Built Borehole Locations and Sensor Locations for 147304 the Drift Scale Test Given in Local (DST) Coordinates. Submittal date: 02/01/2000.

MO0003RIB00071.000. Physical and Chemical Characteristics of Alloy 22. 148850 Submittal date: 03/13/2000.

MO0005PORWATER.000. Perm-Sample Pore Water Data. Submittal date: 150930 05/04/2000. 
MO0007SEPDSTPC.001. Drift Scale Test (DST) Temperature, Power, Current, 153707 and Voltage Data for November 1, 1999 through May 31, 2000. Submittal date: $07 / 13 / 2000$.

MO0012SEPDSTPC.002. Drift Scale Test (DST) Temperature, Power, Current, 153708 and Voltage Data for June 1, 2000 through November 30, 2000. Submittal date: $12 / 19 / 2000$.

MO0101SEPFDDST.000. Field Measured Data of Water Samples from the Drift Scale Test. Submittal date: 01/03/2001.

MO0107SEPDSTPC.003. Drift Scale Test (DST) Temperature, Power, Current, and Voltage Data for December 1, 2000 through May 31, 2001. Submittal date: 07/06/2001.

MO0202SEPDSTTV.001. Drift Scale Test (DST) Temperature, Power, Current, 158320 and Voltage Data for June 1, 2001 through January 14, 2002. Submittal date: 02/28/2002.

MO0207AL5WATER.001. Water Sampling in Alcove 5 (Results from 2/4/1997 159300 through 4/20/1999). Submittal date: 07/11/2002.

MO0208RESTRDST.002. Restructured Drift Scale Test (DST) Heating Phase Power and Temperature Data. Submittal date: 08/06/2002.

MO0302SPATHDYN.000. Thermodynamic Data Input Files - Data0.YMP.R2. Submittal date: 02/05/2003.

MO0407SEPFEPLA.000. LA FEP List. Submittal date: 07/20/2004.

170760

MO9807DSTSET01.000. Drift Scale Test (DST) Temperature, Power, Current, 113644 Voltage Data for November 7, 1997 through May 31, 1998. Submittal date: 07/09/1998.

MO9810DSTSET02.000. Drift Scale Test (DST) Temperature, Power, Current, Voltage Data for June 1 through August 31, 1998. Submittal date: 10/09/1998.

MO9906DSTSET03.000. Drift Scale Test (DST) Temperature, Power, Current, and Voltage Data for September 1, 1998 through May 31, 1999. Submittal date: 06/08/1999.

SN0002T0872799.009. Effective Thermal Conductivity Parameter for the No 153364 Backfill Case Implemented in the Drift-Scale Models used in TSPA-SR. Submittal date: $02 / 10 / 2000$.

SN0203F3903102.001. Drift Scale Test Water Sampling (with Results from 159133 4/17/2001 through 1/14/2002). Submittal date: 03/29/2002. 
SN9908T0872799.004. Tabulated In-Drift Geometric and Thermal Properties

108437 Used in Drift-Scale Models for TSPA-SR (Total System Performance Assessment-Site Recommendation). Submittal date: 08/30/1999

\subsection{OUTPUT DATA, LISTED BY DATA TRACKING NUMBER}

LB0302DSCPTHCS.001. Drift-Scale Coupled Processes (THC Seepage) Model: Simulations. Submittal date: 02/11/2003.

LB0302DSCPTHCS.002. Drift-Scale Coupled Processes (THC Seepage) Model: Data Summary. Submittal date: 02/11/2003.

LB0307DSTTHCR2.001. Drift-Scale Coupled Processes (DST Seepage) Model: Simulations. Submittal date: 07/24/2003.

LB0307DSTTHCR2.002. Drift-Scale Coupled Processes (DST Seepage) Model: Data Summary. Submittal date: 07/24/2003.

LB0404DSTTHCR2.001. Tptpll THC Model - Simulation Input and Output Files. Submittal date: $04 / 02 / 2004$.

LB0404DSTTHCR2.002. Tptpll THC Model - Summary Spreadsheets of THC Seepage Models Output Data. Submittal date: 04/02/2004.

\subsection{SOFTWARE CODES}

LBNL (Lawrence Berkeley National Laboratory) 09/22/2000. Software Routine 153091 Report: merggrid2.f. V1.0. SUN w/Unix OS. 10314-1.0-00.

LBNL 2000. Software Routine Report: mk_circ2. V1.0. SUN w/Unix OS.

153092 10312-1.0-00.

LBNL 2000. Software Routine: mk_incon. V1.0. SUN w/Unix OS.

152901 10350-1.0-00.

LBNL 2000. Software Routine: regress. V1.0. PC w/Windows OS. 152900 10321-1.0-00.

LBNL 2000. Software Routine: switch. V1.0. PC w/Windows OS.

152899 10322-1.0-00.

LBNL 2000. Software Routine Report: sav1d_dst2d.f. V1.0. SUN w/Unix OS. 153083 10381-1.0-00.

LBNL 1999. Software Code: AMESH. V1.0. Sun, DEC O.S. 5.5.1, V4.0. 147561 10045-1.0-00. 
LBNL 1999. Software Code: SOLVEQ/CHILLER. V1.0. PC w/Windows OS. 10057-1.0-00.

LBNL 1999. Software Code: SUPCRT92. V1.0. PC w/Windows OS and MAC 153218 w/MAC OS. 10058-1.0-00.

LBNL 1999. Software Code: TOUGHREACT. V2.2. DEC and SUN w/Unix 153219 OS. 10154-2.2-00.

LBNL 2000. Software Code: TOUGH2. V.1.4. Sun Ultra Sparc, SUN O.S. 5.5.1, and DEC/ALPHA, OSF 2 V4.0, OSF1 V5.1. 10007-1.4-01.

LBNL 2000. Software Routine Report: 2kgridv1a.for. V1.0. PC, DOS 153067 Emulation. 10382-1.0-00.

LBNL 2000. Software Routine Report: assign.f. V1.0. SUN, SUN O.S. 5.5.1. 153090 10315-1.0-00.

LBNL 2000. Software Routine Report: exclude.f. V1.0. SUN, SUN O.S. 5.5.1. 10316-1.0-00.

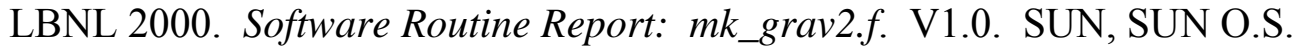

LBNL 2000. Software Routine: mk_rect2. V1.0. SUN w/Unix OS. 10313-1.0-00.

LBNL 2000. Software Routine Report: mrgdrift.f. V1.0. SUN, SUN O.S. 5.5.1. 10380-1.0-00.

LBNL 2001. Software Code: TOUGHREACT. V2.3. SUN and DEC w/Unix 153101 OS. 10396-2.3-00.

LBNL 2001. Software Code: TOUGHREACT. V2.4. SunOS 5.5.1, Dec Alpha 160880 TRU64 Unix \& OS1 V4.0. 10396-2.4-00.

LBNL 2002. Software Code: CUTCHEM. V1.0. DEC ALPHA/OSF1 V5.1, PC /WINDOWS 2000/NT 4.0/98. 10898-1.0-00.

LBNL 2002. Software Code: DBCONV. V1.0. PC/Windows 98/NT; 
LBNL 2002. Software Code: THERMOCHK. V1.1. PC/Windows 98/NT 4.0;

DEC-Alpha/OSF1 V5.1; SunOS 5.5.1. 10895-1.1-00.

LBNL 2002. Software Code: TOUGHREACT. V3.0. DEC ALPHA/OSF1 V5.1,

161256

DEC ALPHA/OSF1 V5.0, Sun UltraSparc/SUN OS 5.5.1, PC/Linux Redhat 7.2.

10396-3.0-00.

LBNL 2003. Software Code: TOUGH2. V1.6. PC/MS-DOS Windows 98, Sun 161491 UltraSparc/Sun OS 5.5.1, DEC-Alpha OSF1 V4.0. 10007-1.6-01. 
APPENDIX A

MINERAL INITIAL VOLUME FRACTIONS 


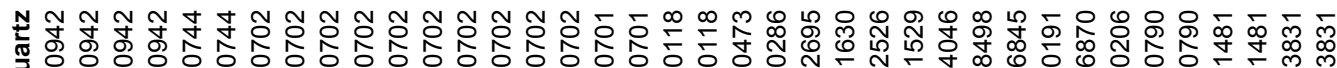

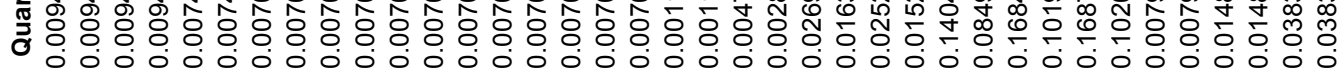

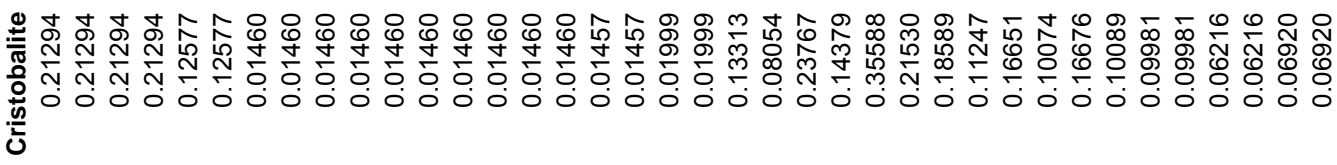

년

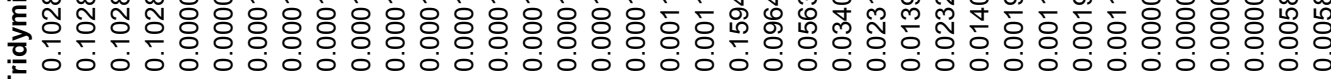

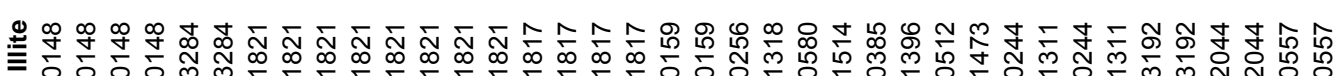

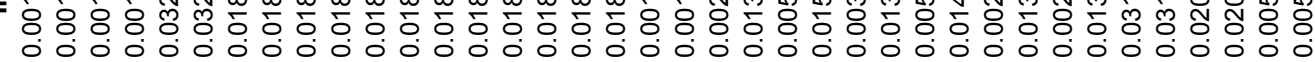

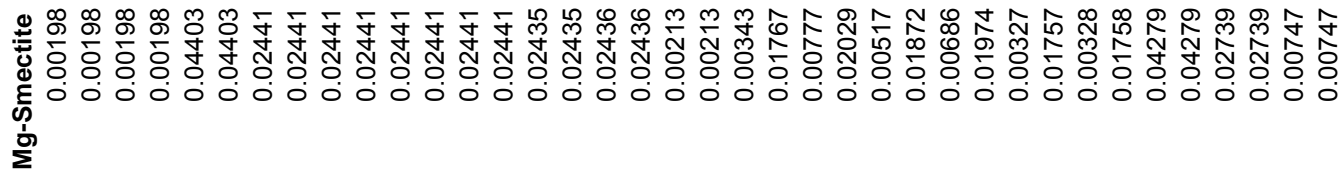

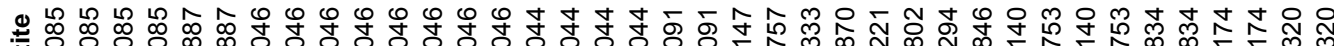

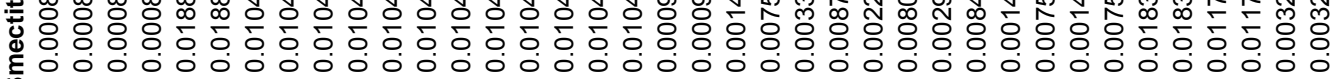

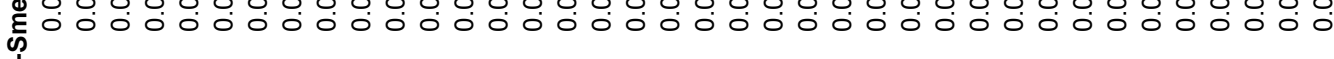
要

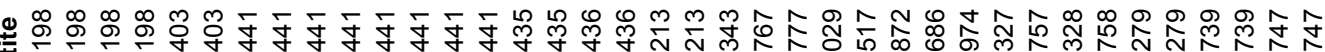

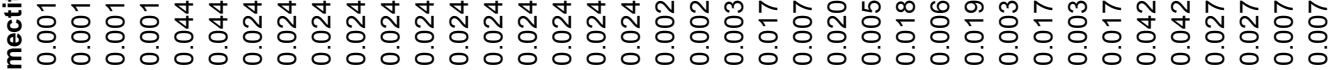
के రั

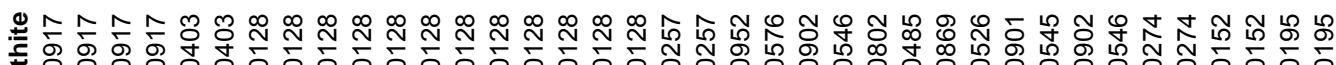

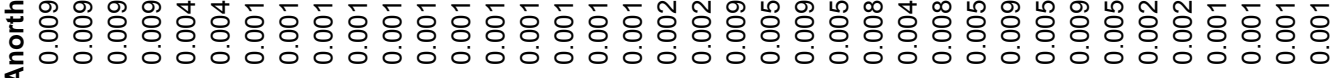

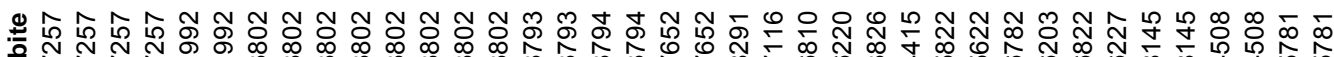

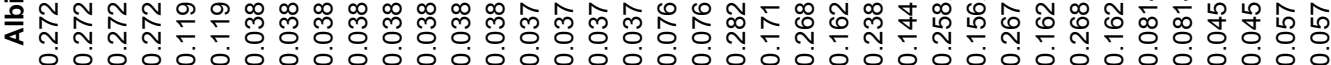

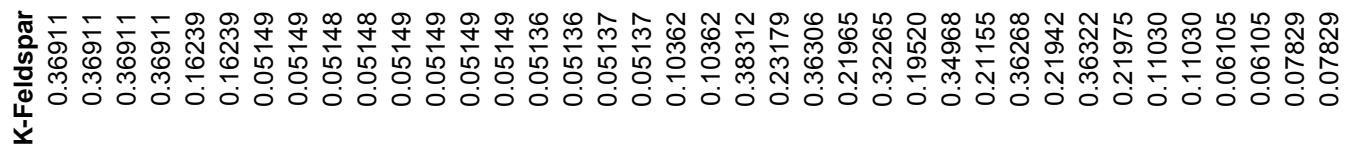
突

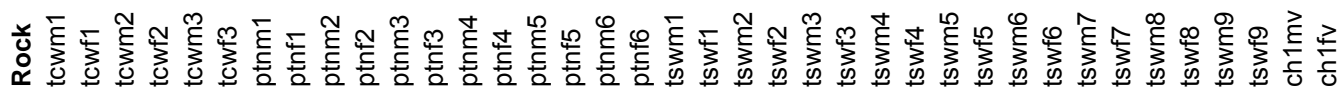




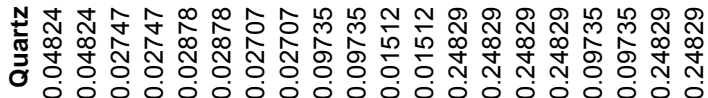

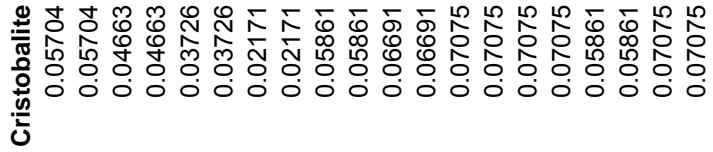

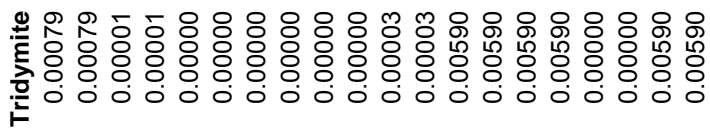

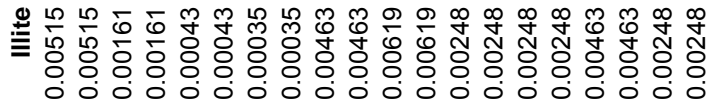

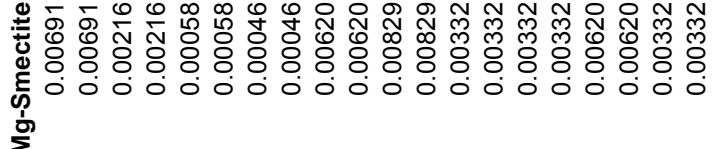

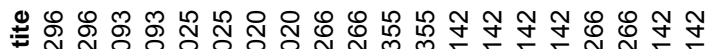

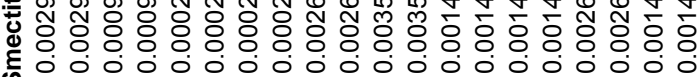
究

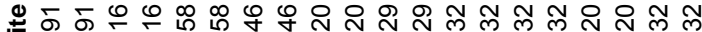
¿ ठึ

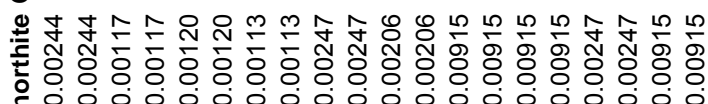

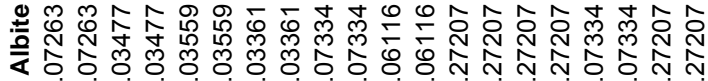

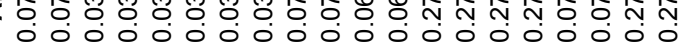

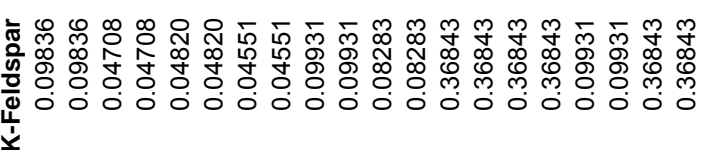

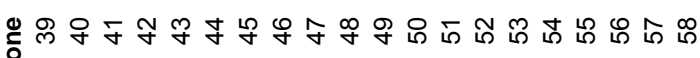
กั

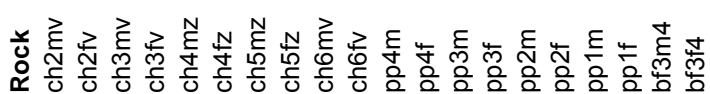




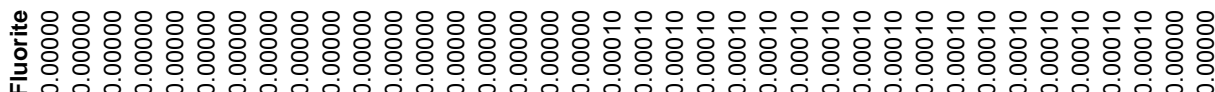

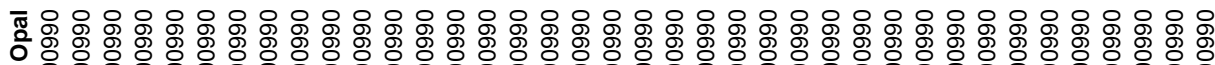
แุด

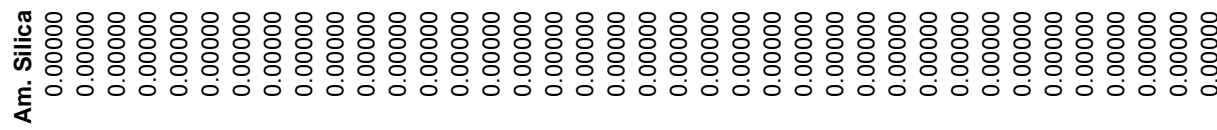

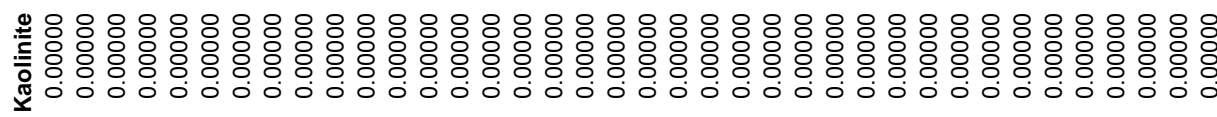

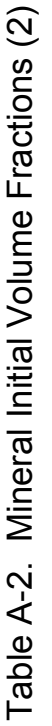

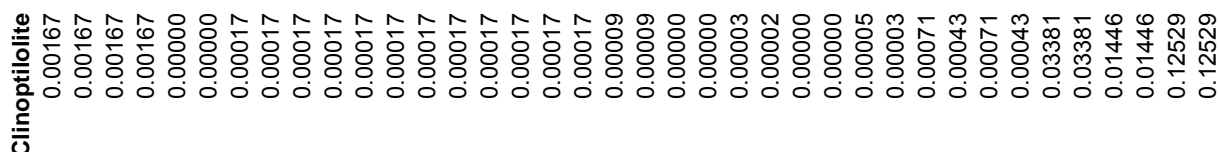

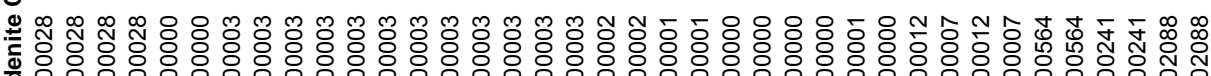

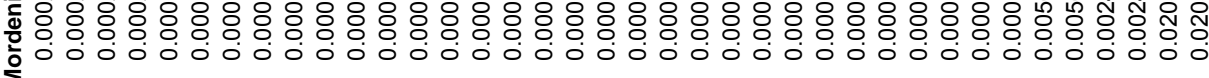

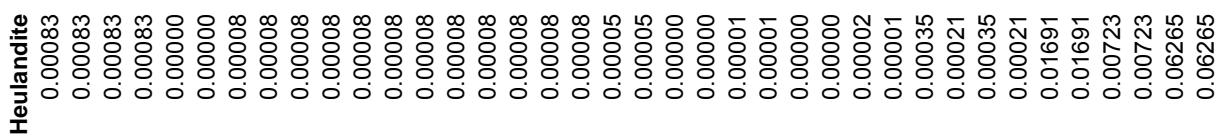

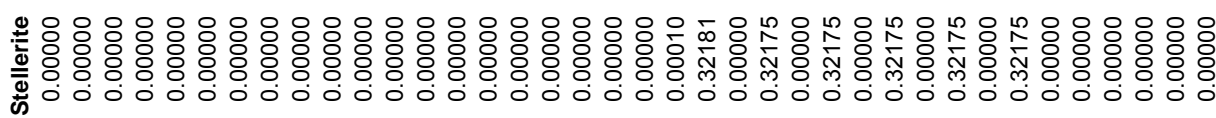

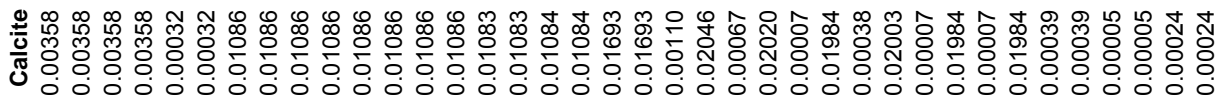

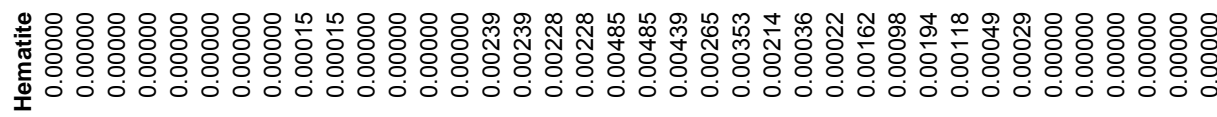
Mg

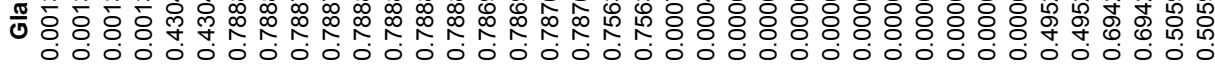

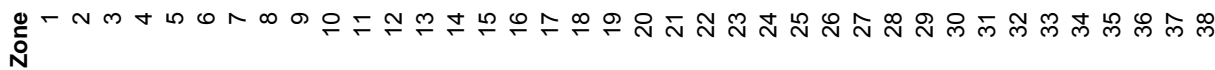

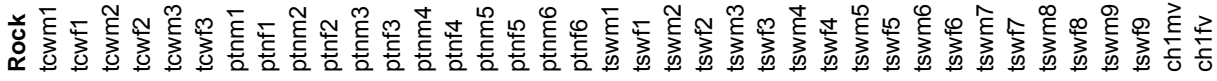




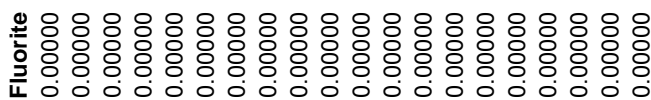

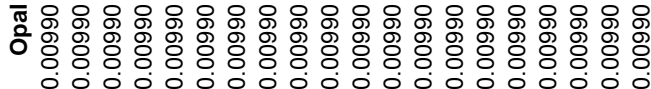

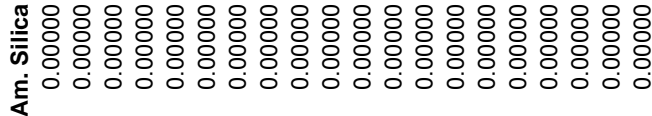

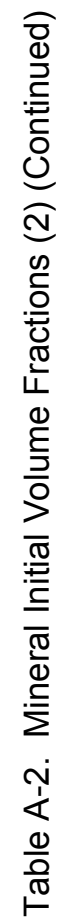

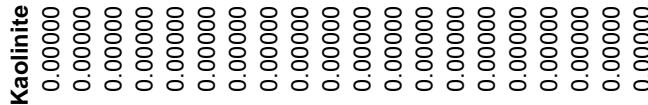

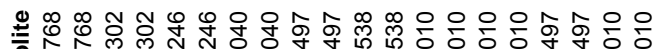

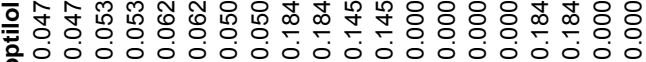
ù

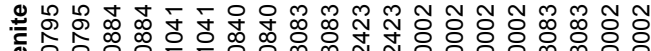

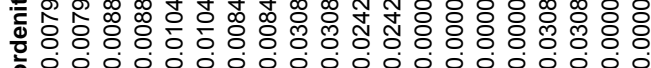
के

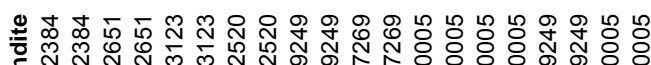

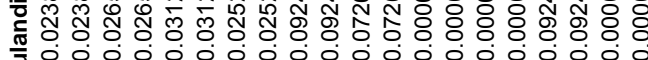
宁

능 ㅇㅇㅇㅇㅇㅇㅇㅇㅇㅇㅇㅇㅇㅇㅇㅇㅇㅇㅇㅇㅇㅇㅇㅇㅇㅇㅇㅇㅇㅇㅇㅇㅇ

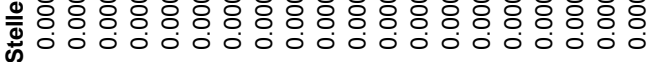

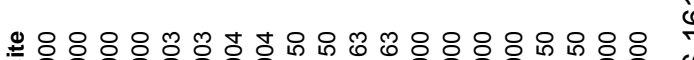

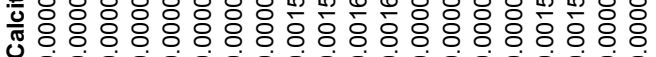

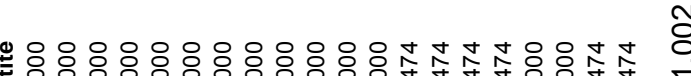

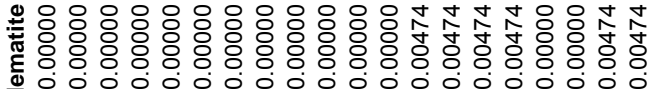

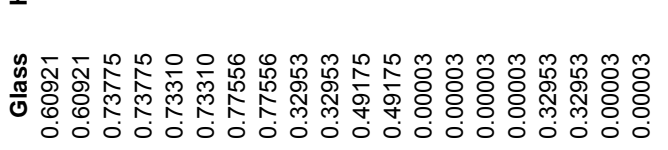

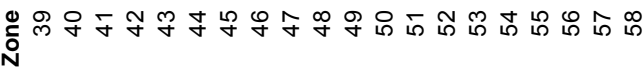

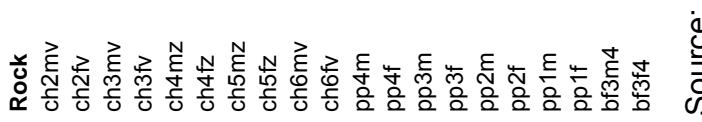


APPENDIX B

MINERAL REACTIVE SURFACE AREAS 


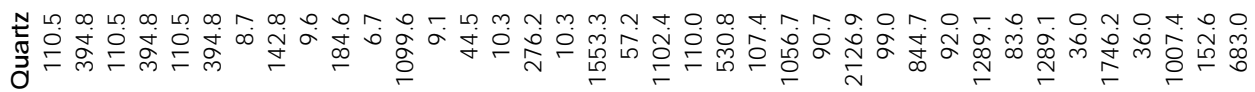

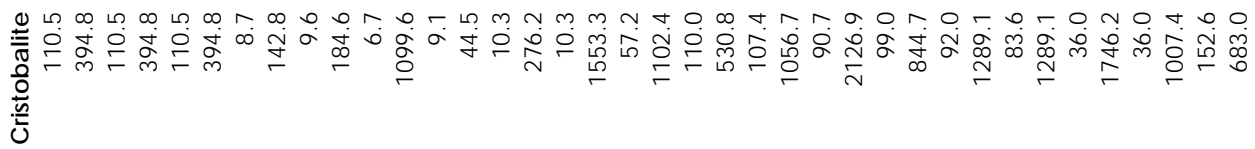

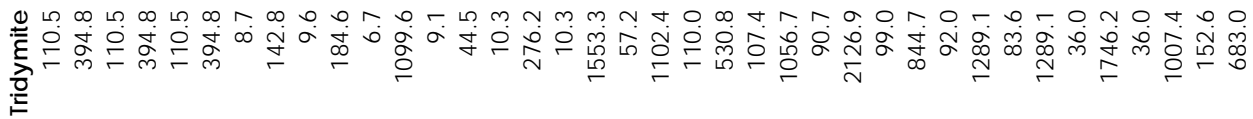

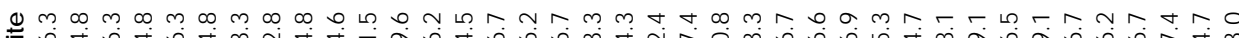

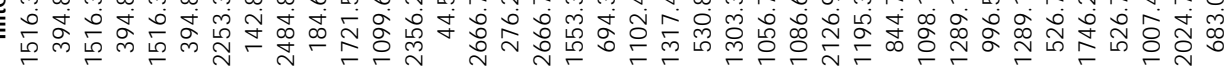

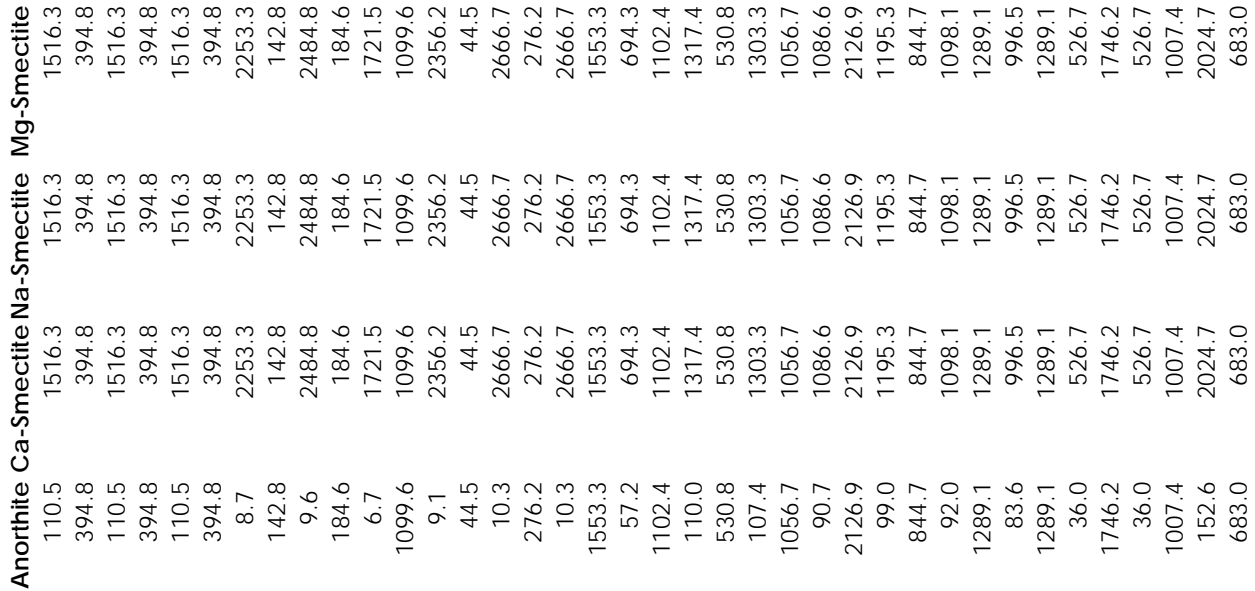

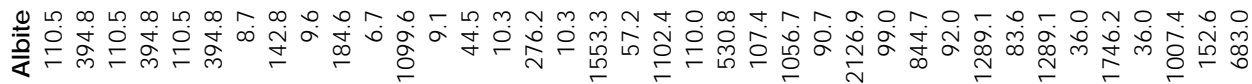

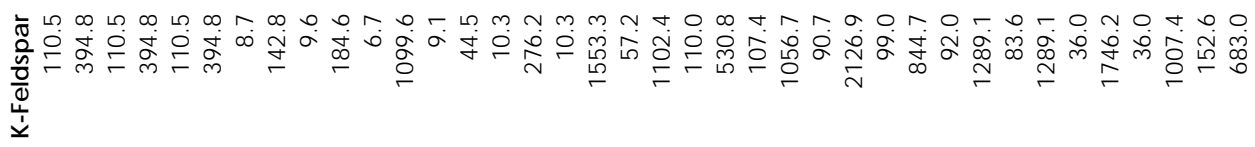

过

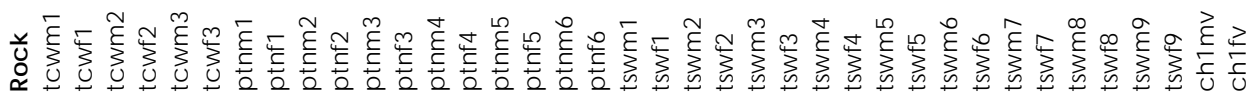




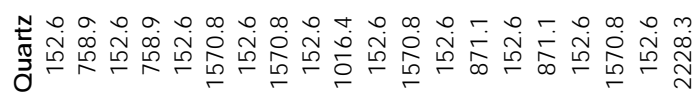

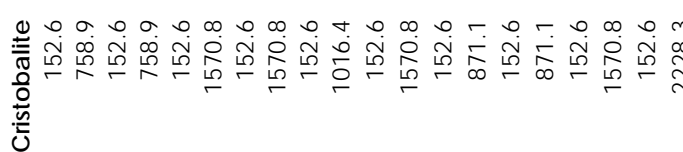

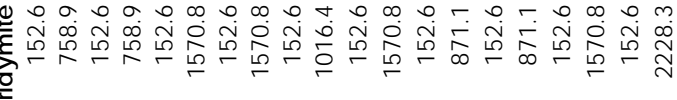

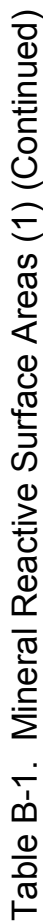

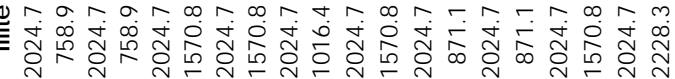

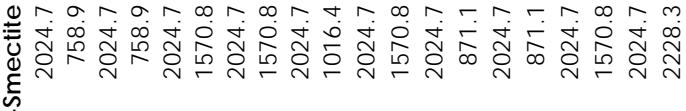

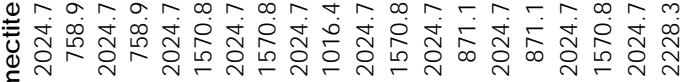

离

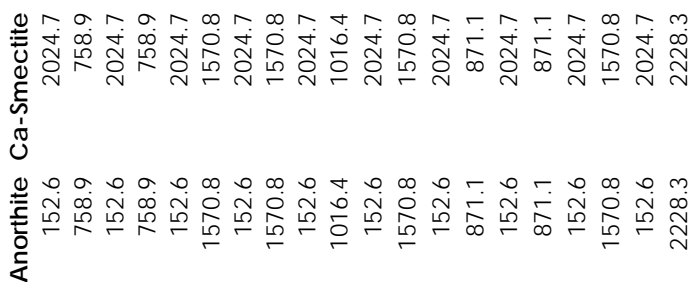

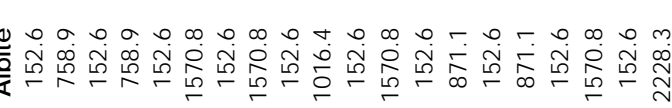

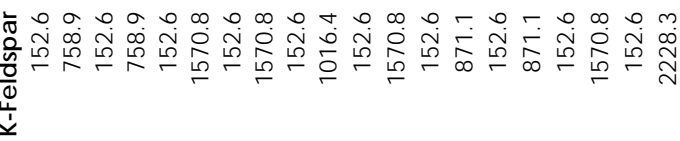

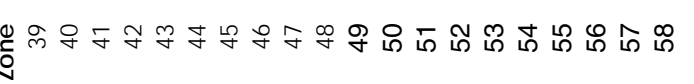

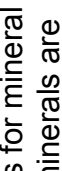

号

ऽ

幽苞

匘

ำ

$\overline{4}$

든

肴

范

흔

है

원

产离

क

๘

ํㅡㅁ

$\checkmark$ क

욜

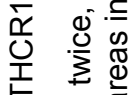

5 क व

ल

응 는

ป

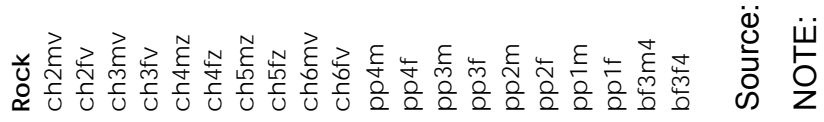




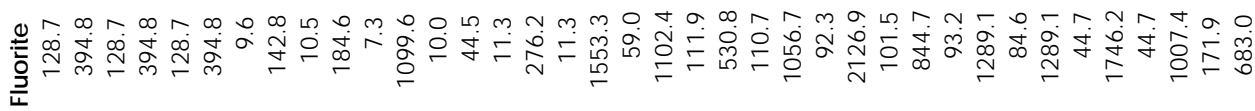

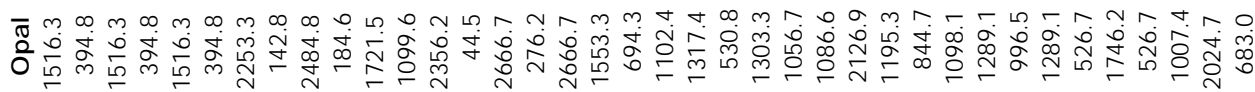

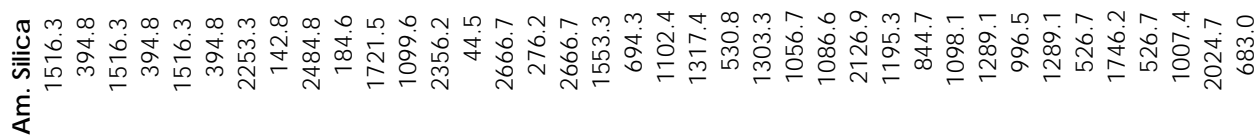

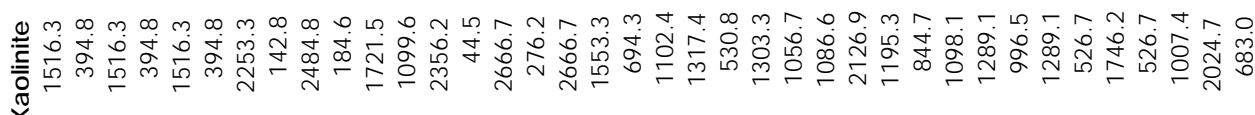

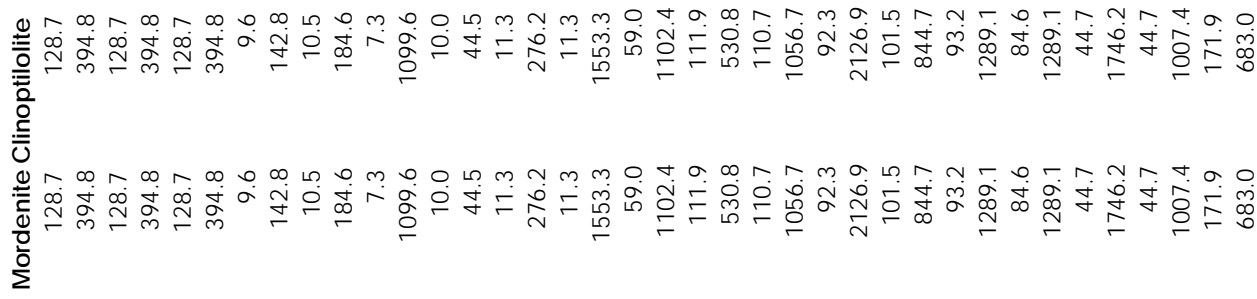

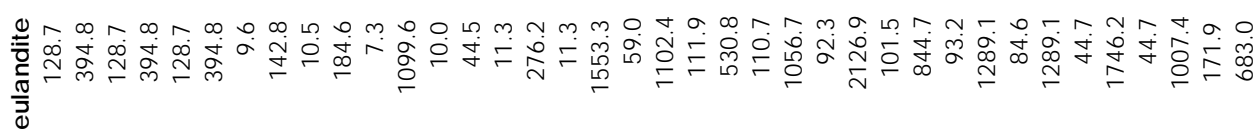

M $n$ -

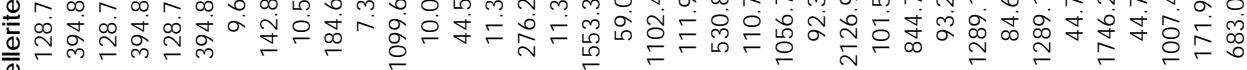

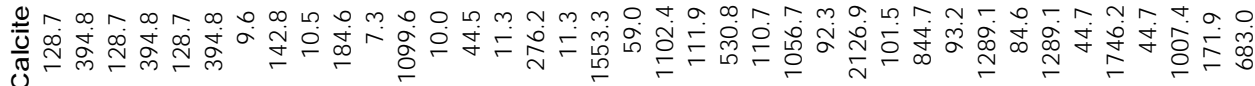

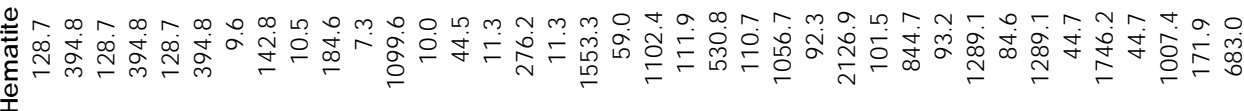

Иิ ก

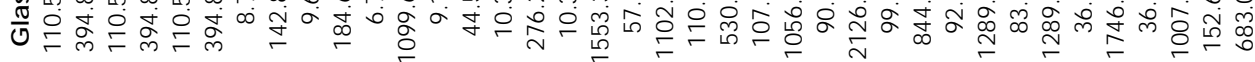

옥

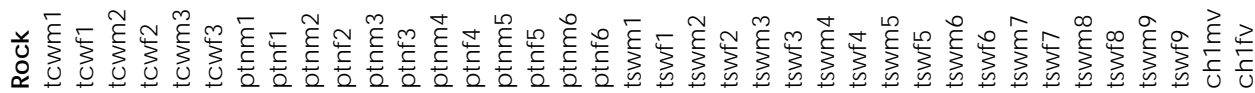




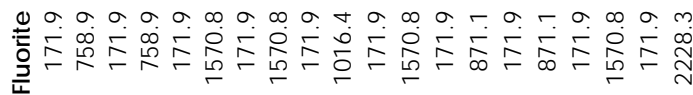

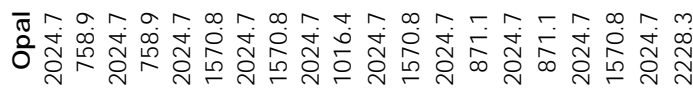

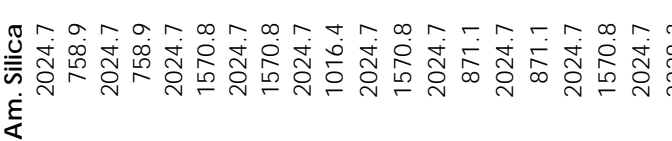

.

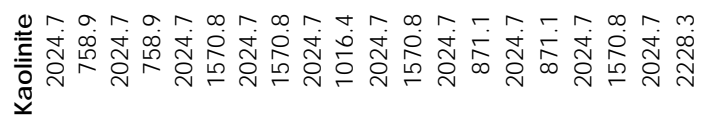

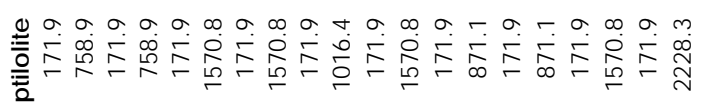

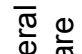

$\frac{\bar{\varepsilon}}{\frac{\pi}{6}}$

$\stackrel{\oplus}{=}$

苞

过

曾

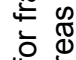

$\varliminf_{+\infty}^{\infty}$

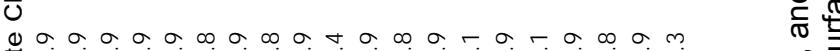

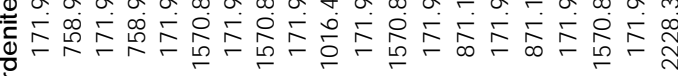

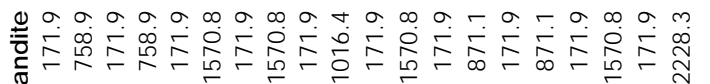

Е $\stackrel{0}{=}$

垔

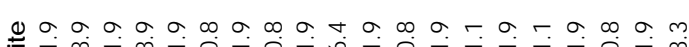

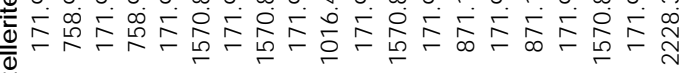

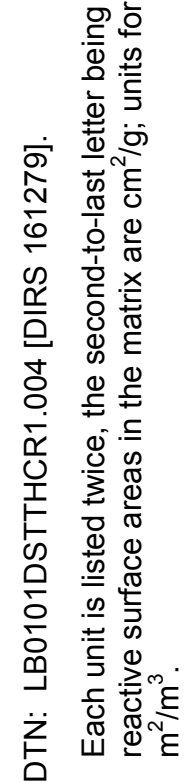

ง

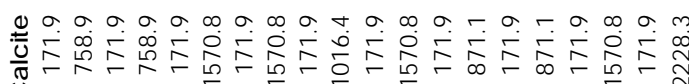

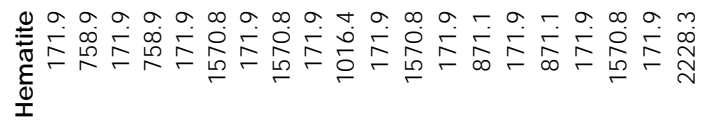

ด

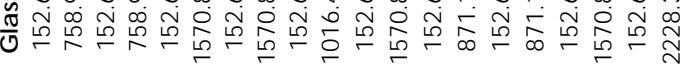

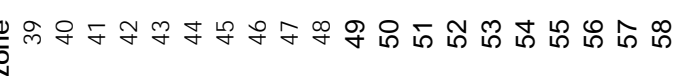

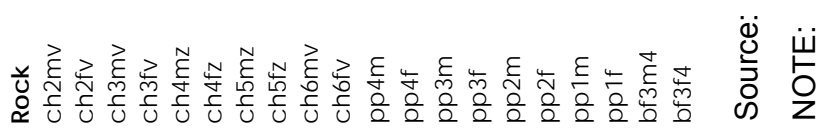




\section{APPENDIX C}

THERMODYNAMIC DATABASE 
Table C-1. Thermodynamic Database: Minerals (DTN: LB0307THMDBRTM.001 [DIRS 164434])

\begin{tabular}{|c|c|c|c|c|c|c|c|c|c|c|c|}
\hline \multirow[b]{2}{*}{ Mineral } & \multirow[b]{2}{*}{$\begin{array}{c}\text { Molecular } \\
\text { Weight } \\
\text { (g/mol) }\end{array}$} & \multirow[b]{2}{*}{$\begin{array}{c}\text { Molar } \\
\text { Volume } \\
\left(\mathrm{cm}^{3} / \mathrm{mol}\right)\end{array}$} & \multirow[b]{2}{*}{ Reaction Stoichiometry $^{\mathrm{a}}$} & \multicolumn{8}{|c|}{$\log (K)$} \\
\hline & & & & $0\left({ }^{\circ} \mathrm{C}\right)$ & $25\left({ }^{\circ} \mathrm{C}\right)$ & $60\left({ }^{\circ} \mathrm{C}\right)$ & $100\left({ }^{\circ} \mathrm{C}\right)$ & $150\left({ }^{\circ} \mathrm{C}\right)$ & $200\left({ }^{\circ} \mathrm{C}\right)$ & $250\left({ }^{\circ} \mathrm{C}\right)$ & $300\left({ }^{\circ} \mathrm{C}\right)$ \\
\hline albite-low & 262.223 & 100.070 & (1)alo2-, (1)na+, (3)sio2(aq) & -21.697 & -20.179 & -18.365 & -16.686 & -15.096 & -13.987 & -13.293 & -12.963 \\
\hline anorthite & 278.207 & 100.790 & (2)alo2-, (1)ca+2, (2)sio2(aq) & -21.229 & -20.484 & -19.640 & -18.960 & -18.514 & -18.485 & -18.839 & -19.547 \\
\hline calcite & 100.087 & 36.934 & $(1) \mathrm{ca}+2,(-1) \mathrm{h}+,(1) \mathrm{hco}-$ & 2.226 & 1.849 & 1.333 & 0.774 & 0.100 & -0.584 & -1.326 & -2.215 \\
\hline clinopt/10 & 277.660 & 126.410 & $\begin{array}{l}(2.6) \mathrm{h} 2 \mathrm{o},(0.68) \text { alo2-, }(0.28) \mathrm{ca}+2 \\
(0.08) \mathrm{k}+,(0.04) \mathrm{na}+,(2.92) \text { sio2 }(\mathrm{aq})\end{array}$ & -20.216 & -18.475 & -16.703 & -15.136 & -13.577 & -12.339 & -11.395 & -10.816 \\
\hline clpt/10-r02 & 277.660 & 126.410 & $\begin{array}{l}(2.6) \mathrm{h} 2 \mathrm{o},(0.68) \text { alo2-, }(0.28) \mathrm{ca}+2 \\
(0.08) \mathrm{k}+,(0.04) \mathrm{na}+,(2.92) \text { sio2 }(\mathrm{aq})\end{array}$ & -17.760 & -16.020 & -14.250 & -12.680 & -11.120 & -9.880 & -8.940 & -8.360 \\
\hline cristoba-a & 60.084 & 25.740 & (1)sio2(aq) & -3.542 & -3.192 & -2.867 & -2.589 & -2.306 & -2.071 & -1.877 & -1.742 \\
\hline fluorite & 78.075 & 24.542 & $(1) \mathrm{ca}+2,(2) \mathrm{f}-$ & -10.310 & -10.037 & -9.907 & -9.967 & -10.265 & -10.784 & -11.555 & -12.703 \\
\hline gypsum & 172.172 & 74.690 & (2)h2o, (1)ca+2, (1)so4-2 & -4.533 & -4.482 & -4.609 & -4.904 & -5.410 & -6.058 & -6.874 & -7.971 \\
\hline halite & 58.442 & 27.015 & (1)na+, (1)cl- & 1.492 & 1.586 & 1.618 & 1.578 & 1.450 & 1.242 & 0.936 & 0.468 \\
\hline hematite & 159.688 & 30.274 & $(-1) h 2 o,(2) h f e o 2(a q)$ & -26.438 & -23.927 & -21.486 & -19.661 & -18.293 & -17.573 & -17.272 & -17.248 \\
\hline heuland/10 & 279.347 & 126.640 & $\begin{array}{l}(2.6) \mathrm{h} 2 \mathrm{o},(0.8) \mathrm{alo} 2-,(0.33) \mathrm{ca}+2 \\
(0.04) \mathrm{k}+,(0.1) \mathrm{na}+,(2.8) \mathrm{sio} 2(\mathrm{aq})\end{array}$ & -21.097 & -19.348 & -17.565 & -15.992 & -14.437 & -13.217 & -12.306 & -11.779 \\
\hline heul/10-r02 & 279.347 & 126.640 & $\begin{array}{l}(2.6) \mathrm{h} 2 \mathrm{o},(0.8) \mathrm{alo} 2-,(0.33) \mathrm{ca}+2, \\
(0.04) \mathrm{k}+,(0.1) \mathrm{na}+,(2.8) \mathrm{sio} 2(\mathrm{aq})\end{array}$ & -18.620 & -16.870 & -15.090 & -13.510 & -11.960 & -10.740 & -9.830 & -9.300 \\
\hline illite & 378.963 & 135.080 & $\begin{array}{c}(0.44) \mathrm{h} 2 \mathrm{o},(2.06) \text { alo2- } \\
(1.12) \mathrm{h}+,(0.5) \mathrm{k}+,(0.22) \mathrm{mg}+2 \\
(3.72) \text { sio2 }(\mathrm{aq})\end{array}$ & -45.566 & -42.016 & -38.333 & -35.129 & -32.064 & -29.760 & -28.120 & -27.254 \\
\hline kaolinite & 258.160 & 99.520 & (1)h2o, (2)alo2-, (2)h+, (2)sio2(aq) & -43.234 & -39.917 & -36.348 & -33.216 & -30.252 & -28.074 & -26.558 & -25.754 \\
\hline microcline-b & 278.332 & 108.741 & (1)alo2-, (1)k+, (3)sio2(aq) & -23.770 & -21.820 & -19.530 & -17.440 & -15.470 & -14.080 & -13.170 & -12.670 \\
\hline morden/10 & 269.631 & 127.350 & $\begin{array}{c}(2.2) \mathrm{h} 2 \mathrm{o},(0.6) \mathrm{alo} 2-,(0.15) \mathrm{ca}+2 \\
(0.09) \mathrm{k}+,(0.21) \mathrm{na}+,(3) \mathrm{sio} 2(\mathrm{aq})\end{array}$ & -19.244 & -17.542 & -15.820 & -14.298 & -12.776 & -11.558 & -10.617 & -10.021 \\
\hline mord/10-r02 & 269.631 & 127.350 & $\begin{array}{l}(2.2) \mathrm{h} 2 \mathrm{o},(0.6) \mathrm{alo} 2-,(0.15) \mathrm{ca}+2 \\
(0.09) \mathrm{k}+,(0.21) \mathrm{na}+,(3) \text { sio2 }(\mathrm{aq})\end{array}$ & -16.950 & -15.250 & -13.530 & -12.010 & -10.480 & -9.270 & -8.330 & -7.730 \\
\hline opal-proxy & 60.084 & 29.000 & (1)sio2(aq) & -3.501 & -3.005 & -2.627 & -2.358 & -2.118 & -1.926 & -1.765 & -1.632 \\
\hline quartz & 60.084 & 22.688 & (1)sio2(aq) & -4.153 & -3.743 & -3.348 & -3.006 & -2.661 & -2.376 & -2.142 & -1.976 \\
\hline sepiolite & 323.913 & 142.830 & $(-4) \mathrm{h}+,(5.5) \mathrm{h} 2 \mathrm{o},(2) \mathrm{mg}+2,(3) \operatorname{sio} 2(\mathrm{aq})$ & 17.631 & 15.992 & 13.961 & 12.164 & 10.536 & 9.352 & 8.397 & 7.457 \\
\hline sio2(amor.) & 60.084 & 29.000 & (1)sio2(aq) & -2.954 & -2.670 & -2.422 & -2.213 & -1.998 & -1.815 & -1.663 & -1.562 \\
\hline
\end{tabular}


Table C-1. Thermodynamic Database: Minerals (DTN: LB0307THMDBRTM.001 [DIRS 164434]) (Continued)

\begin{tabular}{|c|c|c|c|c|c|c|c|c|c|c|c|}
\hline \multirow[b]{2}{*}{ Mineral } & \multirow[b]{2}{*}{$\begin{array}{c}\text { Molecular } \\
\text { Weight } \\
\text { (g/mol) }\end{array}$} & \multirow[b]{2}{*}{$\begin{array}{c}\text { Molar } \\
\text { Volume } \\
\left(\mathrm{cm}^{3} / \mathrm{mol}\right)\end{array}$} & \multirow[b]{2}{*}{ Reaction Stoichiometry $^{\mathrm{a}}$} & \multicolumn{8}{|c|}{$\log (K)$} \\
\hline & & & & $0\left({ }^{\circ} \mathrm{C}\right)$ & $25\left({ }^{\circ} \mathrm{C}\right)$ & $60\left({ }^{\circ} \mathrm{C}\right)$ & $100\left({ }^{\circ} \mathrm{C}\right)$ & $150\left({ }^{\circ} \mathrm{C}\right)$ & $200\left({ }^{\circ} \mathrm{C}\right)$ & $250\left({ }^{\circ} \mathrm{C}\right)$ & $300\left({ }^{\circ} \mathrm{C}\right)$ \\
\hline smect-ca-cal & 365.394 & 132.510 & $\begin{array}{l}(0.52) \mathrm{h} 2 \mathrm{o},(1.77) \mathrm{alo} 2-,(0.145) \mathrm{ca}+2 \\
(0.96) \mathrm{h}+,(0.26) \mathrm{mg}+2,(3.97) \text { sio2(aq) }\end{array}$ & -40.190 & -36.970 & -33.660 & -30.790 & -28.010 & -25.900 & -24.370 & -23.550 \\
\hline smect-na-cal & 366.250 & 132.510 & $\begin{array}{c}(0.52) \mathrm{h} 2 \mathrm{o},(1.77) \text { alo2-, }(0.96) \mathrm{h}+ \\
(0.26) \mathrm{mg}+2,(0.29) \mathrm{na}+,(3.97) \mathrm{sio} 2(\mathrm{aq})\end{array}$ & -40.290 & -36.980 & -33.560 & -30.560 & -27.660 & -25.440 & -23.820 & -22.900 \\
\hline smect-mg-cal & 363.107 & 132.510 & $\begin{array}{l}\text { (0.52)h2o, (1.77)alo2-, }(0.96) \mathrm{h}+ \\
(0.405) \mathrm{mg}+2,(3.97) \mathrm{sio} 2(\mathrm{aq}) \\
\end{array}$ & -40.240 & -37.060 & -33.790 & -30.950 & -28.200 & -26.110 & -24.600 & -23.790 \\
\hline steller/10 & 281.733 & 133.1 & $\begin{array}{c}(2.8) \mathrm{h} 2 \mathrm{o},(0.79) \mathrm{alo}- \\
(0.39) \mathrm{ca}+2,(0.01) \mathrm{na}+,(2.81) \text { sio2(aq) }\end{array}$ & -21.144 & -19.432 & -17.691 & -16.156 & -14.636 & -13.444 & -12.553 & -12.041 \\
\hline stell/10-r02 & 281.733 & 133.1 & $\begin{array}{c}(2.8) \mathrm{h} 2 \mathrm{o},(0.79) \mathrm{alo} 2- \\
(0.39) \mathrm{ca}+2,(0.01) \text { na }+,(2.81) \operatorname{sio} 2(\mathrm{aq}) \\
\end{array}$ & -18.37 & -16.88 & -15.4 & -14.12 & -12.86 & -11.89 & -11.2 & -10.87 \\
\hline sylvite & 74.551 & 37.524 & $(1) \mathrm{k}+,(1) \mathrm{cl}-$ & 0.525 & 0.846 & 1.122 & 1.285 & 1.330 & 1.238 & 1.013 & 0.604 \\
\hline tridymite & 60.084 & 26.586 & $(1) \operatorname{sio} 2(a q)$ & -3.946 & -3.572 & -3.193 & -2.834 & -2.413 & -1.995 & -1.587 & -1.203 \\
\hline hydglassfe3 & 48.466 & 20.536 & $\begin{array}{c}(-0.0006) \mathrm{h}+,(0.5981) \mathrm{sio} 2(\mathrm{aq}) \\
(0.1180) \mathrm{alo}-,(0.0556) \mathrm{na}+ \\
(0.0594) \mathrm{k}+,(0.016) \mathrm{ca}+2 \\
(0.0002) \mathrm{mg}+2,(0.0055) \mathrm{hfeo} 2(\mathrm{aq}) \\
(0.0783) \mathrm{h} 2 \mathrm{o} \\
\end{array}$ & 1.646 & 1.462 & 1.209 & 0.978 & 0.759 & 0.584 & 0.415 & 0.211 \\
\hline mgso4 & 120.369 & 45.250 & $(1) \mathrm{mg}+2,(1) \mathrm{so} 4-2$ & 6.237 & 4.882 & 3.1 & 1.263 & -0.811 & -2.748 & -4.677 & -6.787 \\
\hline nano3 & 84.995 & 50.000 & (1)na+, (1)no3- & -0.811 & -0.206 & 0.403 & 0.88 & 1.275 & 1.518 & 1.651 & 1.665 \\
\hline $\begin{array}{c}\mathrm{k} 2 \mathrm{so} 4 \\
\text { (arcanite) }\end{array}$ & 174.260 & 65.500 & (2)k, (1)so4-2 & -2.273 & -1.801 & -1.469 & -1.365 & -1.488 & -1.826 & -2.365 & -3.19 \\
\hline $\begin{array}{c}\text { na2so4 } \\
\text { (thenardite) }\end{array}$ & 142.043 & 53.330 & (2)na+, (1)so4-2 & -0.35 & -0.309 & -0.438 & -0.705 & -1.15 & -1.716 & -2.473 & -3.548 \\
\hline $\operatorname{co} 2(\mathrm{~g})$ & 44.01 & $2.50 \mathrm{E}-10$ & $(-1) \mathrm{h} 2 \mathrm{o},(1) \mathrm{h}+,(1) \mathrm{hco3-}$ & -7.677 & -7.814 & -8.053 & -8.357 & -8.769 & -9.217 & -9.720 & -10.339 \\
\hline
\end{tabular}

${ }^{a}$ Negative numbers in parentheses indicate the species is on the left side of equation.

NOTES: Mineral names or abbreviations above are those used in the database and may not exactly match names used in the text of the report. Names ending by /10 indicate the stoichiometry, molecular weight, molar volume, and $\log (\mathrm{K})$ values for those minerals were divided by 10 compared to original data. Glass phases glass 1 and glass were used with the extended-case and base-case geochemical systems, respectively. 
Table C-2. Thermodynamic Database: Aqueous Species

\begin{tabular}{|c|c|c|c|c|c|c|c|c|c|c|c|c|}
\hline $\begin{array}{l}\text { Aqueous } \\
\text { Species }\end{array}$ & $\begin{array}{c}\text { Molecular } \\
\text { Weight } \\
\text { (g/mol) }\end{array}$ & $\mathbf{r}_{\mathrm{ej}}$ & Charge & Reaction Stoichiometry & $0\left({ }^{\circ} \mathrm{C}\right)$ & $25\left({ }^{\circ} \mathrm{C}\right)$ & $60\left({ }^{\circ} \mathrm{C}\right)$ & $100\left({ }^{\circ} \mathrm{C}\right)$ & $150\left({ }^{\circ} \mathrm{C}\right)$ & $200\left({ }^{\circ} \mathrm{C}\right)$ & $250\left({ }^{\circ} \mathrm{C}\right)$ & $300\left({ }^{\circ} \mathrm{C}\right)$ \\
\hline $\mathrm{Al}+3$ & 26.982 & 3.33 & 3 & $(-2) \mathrm{h} 2 \mathrm{o},(1)$ alo2-, (4)h+ & -25.795 & -22.883 & -19.571 & -16.582 & -13.676 & -11.409 & -9.598 & -8.167 \\
\hline $\mathrm{Al}(\mathrm{OH}) 2+$ & 60.996 & 2.31 & 1 & (1)alo2-, (2)h+ & -13.655 & -12.289 & -10.825 & -9.600 & -8.530 & -7.823 & -7.396 & -7.238 \\
\hline $\mathrm{AlOH}+2$ & 43.989 & 2.8 & 2 & $(-1) \mathrm{h} 2 \mathrm{o},(1)$ alo2-, (3)h+ & -20.068 & -17.926 & -15.567 & -13.519 & -11.625 & -10.242 & -9.232 & -8.547 \\
\hline $\mathrm{CO} 2(\mathrm{aq})$ & 44.010 & 0 & 0 & $(-1) \mathrm{h} 2 \mathrm{o},(1) \mathrm{h}+,(1) \mathrm{hco} 3-$ & -6.580 & -6.345 & -6.268 & -6.388 & -6.724 & -7.197 & -7.787 & -8.528 \\
\hline $\mathrm{CO} 3-2$ & 60.009 & 2.81 & -2 & $(-1) \mathrm{h}+,(1) \mathrm{hco} 3-$ & 10.624 & 10.329 & 10.130 & 10.084 & 10.200 & 10.465 & 10.871 & 11.464 \\
\hline $\mathrm{CaCO} 3(\mathrm{aq})$ & 100.087 & 0 & 0 & $(1) \mathrm{ca}+2,(-1) \mathrm{h}+,(1) \mathrm{hco}-$ & 7.505 & 7.002 & 6.455 & 5.975 & 5.492 & 5.057 & 4.589 & 3.978 \\
\hline $\mathrm{CaCl}+$ & 75.531 & 2.31 & 1 & (1)ca+2, (1)cl- & 0.356 & 0.293 & 0.094 & -0.215 & -0.682 & -1.227 & -1.870 & -2.677 \\
\hline $\mathrm{CaCl} 2(\mathrm{aq})$ & 110.983 & 0 & 0 & $(1) \mathrm{ca}+2,(2) \mathrm{cl}-$ & 0.456 & 0.644 & 0.634 & 0.400 & -0.118 & -0.844 & -1.802 & -3.116 \\
\hline $\mathrm{CaF}+$ & 59.076 & 2.31 & 1 & $(1) \mathrm{ca}+2,(1) \mathrm{f}-$ & -0.655 & -0.682 & -0.862 & -1.171 & -1.650 & -2.217 & -2.888 & -3.728 \\
\hline $\mathrm{CaHCO} 3+$ & 101.095 & 2.31 & 1 & (1)ca+2, (1)hco3- & -1.094 & -1.047 & -1.158 & -1.413 & -1.848 & -2.383 & -3.027 & -3.840 \\
\hline $\mathrm{CaHSiO} 3+$ & 117.170 & 2.31 & 1 & $(-1) \mathrm{h}+,(1) \mathrm{ca}+2,(1) \mathrm{h} 2 \mathrm{o},(1) \operatorname{sio} 2(\mathrm{aq})$ & 8.778 & 8.575 & 8.115 & 7.596 & 7.043 & 6.588 & 6.200 & 5.837 \\
\hline $\mathrm{CaOH}+$ & 57.085 & 2.31 & 1 & $(-1) \mathrm{h}+,(1) \mathrm{ca}+2,(1) \mathrm{h} 2 \mathrm{o}$ & 14.085 & 12.833 & 11.416 & 10.142 & 8.903 & 7.928 & 7.126 & 6.434 \\
\hline CaSO4(aq) & 136.142 & 0 & 0 & (1)ca+2, (1)so4-2 & -2.071 & -2.111 & -2.265 & -2.511 & -2.910 & -3.433 & -4.144 & -5.188 \\
\hline $\mathrm{Fe}+3$ & 55.845 & 3.46 & 3 & $(3) \mathrm{h}+,(1) \mathrm{hfeo} 2(\mathrm{aq}),(-2) \mathrm{h} 2 \mathrm{o}$ & -14.305 & -12.018 & -9.602 & -7.594 & -5.807 & -4.521 & -3.530 & -2.696 \\
\hline $\mathrm{FeCl}+2$ & 91.298 & 2.8 & 2 & $(1) \mathrm{cl}-,(3) \mathrm{h}+,(-2) \mathrm{h} 2 \mathrm{o},(1) \mathrm{hfeo} 2$ & -15.770 & -13.498 & -11.217 & -9.449 & -8.047 & -7.230 & -6.813 & -6.721 \\
\hline $\mathrm{FeF}+2$ & 74.843 & 2.8 & 2 & $(1) \mathrm{f}-,(3) \mathrm{h}+,(-2) \mathrm{h} 2 \mathrm{o},(1) \mathrm{hfeo}(\mathrm{aq})$ & -20.032 & -18.018 & -16.038 & -14.546 & -13.418 & -12.827 & -12.608 & -12.697 \\
\hline FeF2+ & 93.842 & 2.31 & 1 & $(2) f-,(3) h+,(-2) h 2 o,(1) h f e o 2(a q)$ & -22.323 & -20.368 & -18.459 & -17.037 & -16.011 & -15.569 & -15.590 & -16.086 \\
\hline $\mathrm{FeO}+$ & 71.844 & 2.31 & 1 & $(1) \mathrm{h}+,(-1) \mathrm{h} 2 \mathrm{o},(1) \mathrm{hfeo} 2(\mathrm{aq})$ & -7.324 & -6.368 & -5.372 & -4.561 & -3.865 & -3.393 & -3.060 & -2.807 \\
\hline FeO2- & 87.844 & 1.81 & -1 & $(-1) \mathrm{h}+,(1) \mathrm{hfeo} 2(\mathrm{aq})$ & 10.231 & 9.602 & 8.839 & 8.111 & 7.381 & 6.822 & 6.430 & 6.249 \\
\hline $\mathrm{FeOH}+2$ & 72.852 & 2.8 & 2 & $(2) \mathrm{h}+,(-1) \mathrm{h} 2 \mathrm{o},(1) \mathrm{hfeo} 2(\mathrm{aq})$ & -11.409 & -9.813 & -8.174 & -6.853 & -5.727 & -4.964 & -4.415 & -3.979 \\
\hline FeSO4+ & 151.909 & 2.31 & 1 & (1)so4-2, (3)h+, (-2)h2o, (1)hfeo2(aq) & -15.846 & -13.946 & -12.089 & -10.700 & -9.681 & -9.213 & -9.179 & -9.602 \\
\hline $\mathrm{HAIO} 2$ & 59.988 & 0 & 0 & (1)alo2-, (1)h+ & -7.080 & -6.450 & -5.846 & -5.409 & -5.119 & -5.035 & -5.120 & -5.384 \\
\hline $\mathrm{HF}$ & 20.006 & 0 & 0 & (1)f-, (1)h+ & -2.985 & -3.168 & -3.474 & -3.848 & -4.338 & -4.859 & -5.437 & -6.135 \\
\hline HF2- & 39.005 & 1.81 & -1 & $(1) \mathrm{h}+,(2) \mathrm{f}-$ & -2.238 & -2.551 & -2.960 & -3.385 & -3.880 & -4.374 & -4.915 & -5.578 \\
\hline $\mathrm{HNO} 3(\mathrm{aq})$ & 63.013 & 0 & 0 & (1)h+, (1)no3- & 1.540 & 1.303 & 0.952 & 0.556 & 0.074 & -0.412 & -0.936 & -1.579 \\
\hline HSiO3- & 77.092 & 1.81 & -1 & $(-1) \mathrm{h}+,(1) \mathrm{h} 2 \mathrm{o},(1) \operatorname{sio} 2(\mathrm{aq})$ & 9.811 & 9.585 & 9.241 & 8.960 & 8.802 & 8.833 & 9.035 & 9.433 \\
\hline $\mathrm{KCl}(\mathrm{aq})$ & 74.551 & 0 & 0 & $(1) \mathrm{cl}-,(1) \mathrm{k}+$ & 2.840 & 2.536 & 2.141 & 1.731 & 1.255 & 0.785 & 0.278 & -0.344 \\
\hline KHSO4(aq) & 136.170 & 0 & 0 & $(1) \mathrm{h}+,(1) \mathrm{k}+,(1) \mathrm{so} 4-2$ & 2.039 & 1.495 & 0.595 & -0.476 & -1.817 & -3.172 & -4.601 & -6.242 \\
\hline $\mathrm{KOH}(\mathrm{aq})$ & 56.106 & 0 & 0 & $(-1) \mathrm{h}+,(1) \mathrm{h} 2 \mathrm{o},(1) \mathrm{k}+$ & 15.498 & 14.439 & 13.314 & 12.378 & 11.552 & 10.978 & 10.570 & 10.267 \\
\hline KSO4- & 135.162 & 1.81 & -1 & $(1) \mathrm{k}+,(1) \mathrm{so} 4-2$ & -0.886 & -0.880 & -0.991 & -1.195 & -1.521 & -1.921 & -2.419 & -3.090 \\
\hline $\mathrm{MgCO} 3(\mathrm{aq})$ & 84.314 & 0 & 0 & $(-1) \mathrm{h}+,(1) \mathrm{hco3}-,(1) \mathrm{mg}+2$ & 7.742 & 7.350 & 6.929 & 6.574 & 6.228 & 5.911 & 5.543 & 5.019 \\
\hline $\mathrm{MgCl}+$ & 59.758 & 2.31 & 1 & $(1) \mathrm{cl}-,(1) \mathrm{mg}+2$ & 0.097 & 0.135 & 0.041 & -0.173 & -0.537 & -0.992 & -1.550 & -2.276 \\
\hline $\mathrm{MgF}+$ & 43.303 & 2.31 & 1 & $(1) \mathrm{f}-,(1) \mathrm{mg}+2$ & -1.387 & -1.352 & -1.478 & -1.739 & -2.169 & -2.691 & -3.321 & -4.125 \\
\hline $\mathrm{MgHCO} 3+$ & 85.322 & 2.31 & 1 & (1)hco3-, (1)mg+2 & -1.077 & -1.036 & -1.160 & -1.423 & -1.852 & -2.369 & -2.984 & -3.758 \\
\hline $\mathrm{MgHSiO} 3+$ & 101.397 & 2.31 & 1 & $(-1) \mathrm{h}+,(1) \mathrm{h} 2 \mathrm{o},(1) \mathrm{mg}+2,(1) \mathrm{sio} 2(\mathrm{aq})$ & 8.454 & 8.325 & 7.943 & 7.501 & 7.036 & 6.666 & 6.358 & 6.072 \\
\hline
\end{tabular}


Table C-2. Thermodynamic Database: Aqueous Species (Continued)

\begin{tabular}{|c|c|c|c|c|c|c|c|c|c|c|c|c|}
\hline $\begin{array}{c}\text { Aqueous } \\
\text { Species }\end{array}$ & $\begin{array}{c}\text { Molecular } \\
\text { Weight } \\
\text { (g/mol) }\end{array}$ & $r_{e j}$ & Charge & Reaction Stoichiometry & $0\left({ }^{\circ} \mathrm{C}\right)$ & $25\left({ }^{\circ} \mathrm{C}\right)$ & $60\left({ }^{\circ} \mathrm{C}\right)$ & $100\left({ }^{\circ} \mathrm{C}\right)$ & $150\left({ }^{\circ} \mathrm{C}\right)$ & $200\left({ }^{\circ} \mathrm{C}\right)$ & $250\left({ }^{\circ} \mathrm{C}\right)$ & $300\left({ }^{\circ} \mathrm{C}\right)$ \\
\hline $\mathrm{MgOH}+$ & 41.312 & 2.31 & 1 & $(-1) \mathrm{h}+,(1) \mathrm{h} 2 \mathrm{o},(1) \mathrm{mg}+2$ & 12.674 & 11.683 & 10.502 & 9.399 & 8.291 & 7.392 & 6.634 & 5.967 \\
\hline $\mathrm{MgSO} 4(\mathrm{aq})$ & 120.369 & 0 & 0 & $(1) \mathrm{mg}+2,(1) \mathrm{so} 4-2$ & -2.184 & -2.230 & -2.393 & -2.641 & -3.031 & -3.539 & -4.236 & -5.271 \\
\hline $\mathrm{NaCO} 3-$ & 82.999 & 1.81 & -1 & $(-1) \mathrm{h}+,(1) \mathrm{hco3}-$, (1)na+ & 9.725 & 9.815 & 9.917 & 10.012 & 10.104 & 10.177 & 10.236 & 10.285 \\
\hline $\mathrm{NaCl}(\mathrm{aq})$ & 58.442 & 0 & 0 & (1)cl-, (1)na+ & 0.829 & 0.777 & 0.651 & 0.473 & 0.214 & -0.093 & -0.478 & -1.013 \\
\hline $\mathrm{NaF}(\mathrm{aq})$ & 41.988 & 0 & 0 & (1)f-, (1)na+ & 1.082 & 0.998 & 0.833 & 0.623 & 0.338 & 0.010 & -0.397 & -0.957 \\
\hline $\mathrm{NaHCO} 3(\mathrm{aq})$ & 84.007 & 0 & 0 & (1)hco3-, (1)na+ & -0.398 & -0.154 & 0.075 & 0.244 & 0.358 & 0.374 & 0.277 & 0.004 \\
\hline $\mathrm{NaHSiO3(aq)}$ & 100.081 & 0 & 0 & $(-1) h+,(1) h 2 o,(1) n a+,(1) \operatorname{sio} 2(a q)$ & 7.603 & 7.754 & 7.780 & 7.795 & 7.873 & 8.014 & 8.190 & 8.365 \\
\hline $\mathrm{NaOH}(\mathrm{aq})$ & 39.997 & 0 & 0 & $(-1) \mathrm{h}+,(1) \mathrm{h} 2 \mathrm{o},(1) \mathrm{na}+$ & 15.132 & 14.205 & 13.210 & 12.377 & 11.642 & 11.130 & 10.762 & 10.480 \\
\hline NaSO4- & 119.053 & 1.81 & -1 & (1)na+, (1)so4-2 & -0.677 & -0.700 & -0.842 & -1.063 & -1.389 & -1.772 & -2.242 & -2.873 \\
\hline $\mathrm{OH}-$ & 17.007 & 1.4 & -1 & $(-1) h+,(1) h 2 o$ & 14.940 & 13.995 & 13.027 & 12.255 & 11.631 & 11.284 & 11.168 & 11.300 \\
\hline SiF6-2 & 142.076 & 3 & -2 & $(-2) h 2 o,(1) \operatorname{sio} 2(a q),(4) h+,(6) f-$ & -27.654 & -26.275 & -25.220 & -24.654 & -24.534 & -24.919 & -25.819 & -27.436 \\
\hline
\end{tabular}

Source: DTN: LB0307THMDBRTM.001 [DIRS 164434].

Table C-3. Primary Aqueous Basis Species

P

\begin{tabular}{|c|c|c|c|}
\hline $\begin{array}{c}\text { Primary } \\
\text { Aqueous } \\
\text { Species }\end{array}$ & $\begin{array}{c}\text { Molecular } \\
\text { Weight } \\
\text { (g/mol) }\end{array}$ & $\mathbf{r}_{\mathrm{ej}}$ & Charge \\
\hline $\mathrm{H} 2 \mathrm{O}$ & 18.015 & 0.00 & 0 \\
\hline $\mathrm{AlO2}-$ & 58.980 & 1.81 & -1 \\
\hline $\mathrm{Ca}+2$ & 40.078 & 2.87 & 2 \\
\hline $\mathrm{Cl}-$ & 35.453 & 1.81 & -1 \\
\hline $\mathrm{F}-$ & 18.998 & 1.33 & -1 \\
\hline $\mathrm{H}+$ & 1.008 & 3.08 & 1 \\
\hline $\mathrm{HCO} 3-$ & 61.017 & 2.10 & -1 \\
\hline $\mathrm{HFeO} 2(\mathrm{aq})$ & 88.852 & 0.00 & 0 \\
\hline $\mathrm{K}+$ & 39.098 & 2.27 & 1 \\
\hline $\mathrm{Mg}+2$ & 24.305 & 2.54 & 2 \\
\hline $\mathrm{Na}+$ & 22.990 & 1.91 & 1 \\
\hline $\mathrm{NO} 3-$ & 62.005 & 2.81 & -1 \\
\hline $\mathrm{SiO} 2(\mathrm{aq})$ & 60.084 & 0.00 & 0 \\
\hline $\mathrm{SO} 4-2$ & 96.064 & 3.15 & -2 \\
\hline
\end{tabular}

Source: DTN: LB0307THMDBRTM.001 [DIRS 164434]. 
APPENDIX D

WASTE PACKAGE AVERAGE HEAT TRANSFER 
Table D-1. Waste Package Average Heat Transfer

\begin{tabular}{|c|c|c|}
\hline $\begin{array}{c}\text { Time } \\
\text { (years) }\end{array}$ & $\begin{array}{c}\text { Total Heat } \\
\text { (no ventilation) } \\
\text { (W/meter) }\end{array}$ & $\begin{array}{c}\text { Model Heat Load } \\
\text { (W/meter) }\end{array}$ \\
\hline 0 & 1450.000 & 198.650 \\
\hline 1 & 1400.000 & 191.800 \\
\hline 2 & 1360.000 & 186.320 \\
\hline 3 & 1320.000 & 180.840 \\
\hline 4 & 1290.000 & 176.730 \\
\hline 5 & 1260.000 & 172.620 \\
\hline 6 & 1230.000 & 168.510 \\
\hline 7 & 1210.000 & 165.770 \\
\hline 8 & 1180.000 & 161.660 \\
\hline 9 & 1160.000 & 158.920 \\
\hline 10 & 1140.000 & 156.180 \\
\hline 11 & 1110.000 & 152.070 \\
\hline 12 & 1090.000 & 149.330 \\
\hline 13 & 1070.000 & 146.590 \\
\hline 14 & 1050.000 & 143.850 \\
\hline 15 & 1030.000 & 141.110 \\
\hline 16 & 1010.000 & 138.370 \\
\hline 17 & 995.000 & 136.315 \\
\hline 18 & 978.000 & 133.986 \\
\hline 19 & 961.000 & 131.657 \\
\hline 20 & 946.000 & 129.602 \\
\hline 21 & 929.000 & 127.273 \\
\hline 22 & 912.000 & 124.944 \\
\hline 23 & 897.000 & 122.889 \\
\hline 24 & 882.000 & 120.834 \\
\hline 25 & 868.000 & 118.916 \\
\hline 26 & 854.000 & 116.998 \\
\hline 27 & 840.000 & 115.080 \\
\hline 28 & 826.000 & 113.162 \\
\hline 29 & 813.000 & 111.381 \\
\hline 30 & 801.000 & 109.737 \\
\hline 31 & 787.000 & 107.819 \\
\hline 32 & 775.000 & 106.175 \\
\hline 33 & 762.000 & 104.394 \\
\hline 34 & 751.000 & 102.887 \\
\hline 35 & 740.000 & 101.380 \\
\hline 36 & 728.000 & 99.736 \\
\hline 37 & 716.000 & 98.092 \\
\hline 38 & 706.000 & 96.722 \\
\hline 39 & 695.000 & 95.215 \\
\hline 40 & 685.000 & 93.845 \\
\hline 41 & 675.000 & 92.475 \\
\hline
\end{tabular}


Table D-1. Waste Package Average Heat Transfer (Continued)

\begin{tabular}{|c|c|c|}
\hline $\begin{array}{l}\text { Time } \\
\text { (years) }\end{array}$ & $\begin{array}{c}\text { Total Heat } \\
\text { (no ventilation) } \\
\text { (W/meter) }\end{array}$ & $\begin{array}{c}\text { Model Heat Load } \\
\text { (W/meter) }\end{array}$ \\
\hline 42 & 665.000 & 91.105 \\
\hline 43 & 655.000 & 89.735 \\
\hline 44 & 646.000 & 88.502 \\
\hline 45 & 636.000 & 87.132 \\
\hline 46 & 627.000 & 85.899 \\
\hline 47 & 618.000 & 84.666 \\
\hline 48 & 609.000 & 83.433 \\
\hline 49 & 601.000 & 82.337 \\
\hline 50 & 593.000 & 81.241 \\
\hline 50.001 & 593.000 & 593.000 \\
\hline 51 & 585.000 & 585.000 \\
\hline 52 & 577.000 & 577.000 \\
\hline 53 & 569.000 & 569.000 \\
\hline 54 & 561.000 & 561.000 \\
\hline 55 & 554.000 & 554.000 \\
\hline 56 & 547.000 & 547.000 \\
\hline 57 & 539.000 & 539.000 \\
\hline 58 & 532.000 & 532.000 \\
\hline 59 & 526.000 & 526.000 \\
\hline 60 & 519.000 & 519.000 \\
\hline 61 & 512.000 & 512.000 \\
\hline 62 & 506.000 & 506.000 \\
\hline 63 & 500.000 & 500.000 \\
\hline 64 & 494.000 & 494.000 \\
\hline 65 & 488.000 & 488.000 \\
\hline 66 & 482.000 & 482.000 \\
\hline 67 & 476.000 & 476.000 \\
\hline 68 & 470.000 & 470.000 \\
\hline 69 & 465.000 & 465.000 \\
\hline 70 & 460.000 & 460.000 \\
\hline 71 & 454.000 & 454.000 \\
\hline 72 & 449.000 & 449.000 \\
\hline 73 & 444.000 & 444.000 \\
\hline 74 & 439.000 & 439.000 \\
\hline 75 & 434.000 & 434.000 \\
\hline 76 & 430.000 & 430.000 \\
\hline 77 & 425.000 & 425.000 \\
\hline 78 & 420.000 & 420.000 \\
\hline 79 & 416.000 & 416.000 \\
\hline 80 & 412.000 & 412.000 \\
\hline 81 & 407.000 & 407.000 \\
\hline
\end{tabular}


Table D-1. Waste Package Average Heat Transfer (Continued)

\begin{tabular}{|c|c|c|}
\hline $\begin{array}{c}\text { Time } \\
\text { (years) }\end{array}$ & $\begin{array}{c}\text { Total Heat } \\
\text { (no ventilation) } \\
\text { (W/meter) }\end{array}$ & $\begin{array}{c}\text { Model Heat Load } \\
\text { (W/meter) }\end{array}$ \\
\hline 82 & 403.000 & 403.000 \\
\hline 83 & 399.000 & 399.000 \\
\hline 84 & 395.000 & 395.000 \\
\hline 85 & 391.000 & 391.000 \\
\hline 86 & 387.000 & 387.000 \\
\hline 87 & 383.000 & 383.000 \\
\hline 88 & 379.000 & 379.000 \\
\hline 89 & 376.000 & 376.000 \\
\hline 90 & 372.000 & 372.000 \\
\hline 91 & 369.000 & 369.000 \\
\hline 92 & 365.000 & 365.000 \\
\hline 93 & 362.000 & 362.000 \\
\hline 94 & 359.000 & 359.000 \\
\hline 95 & 355.000 & 355.000 \\
\hline 96 & 352.000 & 352.000 \\
\hline 97 & 349.000 & 349.000 \\
\hline 98 & 346.000 & 346.000 \\
\hline 99 & 343.000 & 343.000 \\
\hline 100 & 340.000 & 340.000 \\
\hline 110 & 315.000 & 315.000 \\
\hline 120 & 294.000 & 294.000 \\
\hline 140 & 259.000 & 259.000 \\
\hline 150 & 245.000 & 245.000 \\
\hline 160 & 235.000 & 235.000 \\
\hline 170 & 225.000 & 225.000 \\
\hline 180 & 216.000 & 216.000 \\
\hline 190 & 208.000 & 208.000 \\
\hline 200 & 201.000 & 201.000 \\
\hline 250 & 176.000 & 176.000 \\
\hline 300 & 159.000 & 159.000 \\
\hline 350 & 145.000 & 145.000 \\
\hline 400 & 134.000 & 134.000 \\
\hline 450 & 125.000 & 125.000 \\
\hline 500 & 117.000 & 117.000 \\
\hline 550 & 110.000 & 110.000 \\
\hline 600 & 103.000 & 103.000 \\
\hline 650 & 97.300 & 97.300 \\
\hline 700 & 92.100 & 92.100 \\
\hline 750 & 87.200 & 87.200 \\
\hline 800 & 82.800 & 82.800 \\
\hline 850 & 78.800 & 78.800 \\
\hline 900 & 75.000 & 75.000 \\
\hline
\end{tabular}


Table D-1. Waste Package Average Heat Transfer (Continued)

\begin{tabular}{|c|c|c|}
\hline $\begin{array}{c}\text { Time } \\
\text { (years) }\end{array}$ & $\begin{array}{c}\text { Total Heat } \\
\text { (no ventilation) } \\
\text { (W/meter) }\end{array}$ & $\begin{array}{c}\text { Model Heat Load } \\
\text { (W/meter) }\end{array}$ \\
\hline 950 & 71.600 & 71.600 \\
\hline 1000 & 68.400 & 68.400 \\
\hline 1500 & 47.300 & 47.300 \\
\hline 2000 & 37.200 & 37.200 \\
\hline 2500 & 32.100 & 32.100 \\
\hline 3000 & 29.300 & 29.300 \\
\hline 3500 & 27.500 & 27.500 \\
\hline 4000 & 26.200 & 26.200 \\
\hline 4500 & 25.200 & 25.200 \\
\hline 5000 & 24.200 & 24.200 \\
\hline 5500 & 23.400 & 23.400 \\
\hline 6000 & 22.600 & 22.600 \\
\hline 6500 & 21.800 & 21.800 \\
\hline 7000 & 21.100 & 21.100 \\
\hline 7500 & 20.500 & 20.500 \\
\hline 8000 & 19.800 & 19.800 \\
\hline 8500 & 19.200 & 19.200 \\
\hline 9000 & 18.600 & 18.600 \\
\hline 9500 & 18.000 & 18.000 \\
\hline 10000 & 17.500 & 17.500 \\
\hline 15000 & 13.200 & 13.200 \\
\hline 20000 & 10.200 & 10.200 \\
\hline 25000 & 8.210 & 8.210 \\
\hline 30000 & 6.760 & 6.760 \\
\hline 35000 & 5.680 & 5.680 \\
\hline 40000 & 4.850 & 4.850 \\
\hline 45000 & 4.190 & 4.190 \\
\hline 50000 & 3.680 & 3.680 \\
\hline 55000 & 3.250 & 3.250 \\
\hline 60000 & 2.880 & 2.880 \\
\hline 65000 & 2.580 & 2.580 \\
\hline 70000 & 2.330 & 2.330 \\
\hline 75000 & 2.110 & 2.110 \\
\hline 80000 & 1.910 & 1.910 \\
\hline 85000 & 1.750 & 1.750 \\
\hline 90000 & 1.640 & 1.640 \\
\hline 95000 & 1.520 & 1.520 \\
\hline 100000 & 1.400 & 1.400 \\
\hline
\end{tabular}

Source: BSC 2002 [DIRS 159527], Sheet 5 of 5 (Section 4.1.7).

NOTE: Point at 50.001 years was interpolated between original data points at 50 and 55 years. From 0 to 50 years: Model Heat Load $=$ Total Heat $\times$ (1-0.863) [86.3\% heat removal]. 
APPENDIX E

EFFECTIVE THERMAL CONDUCTIVITY FOR IN-DRIFT OPEN SPACES 
Table E-1. Effective Thermal Conductivity for In-Drift Open Spaces during Preclosure

\begin{tabular}{|c|c|c|}
\hline (sec) & (year) & Factor \\
\hline $3.15360 \mathrm{E}+03$ & 0.0 & 0.395 \\
\hline $3.15360 \mathrm{E}+07$ & 1.0 & 0.777 \\
\hline $4.73040 \mathrm{E}+07$ & 1.5 & 0.825 \\
\hline $6.30720 \mathrm{E}+07$ & 2 & 0.856 \\
\hline $9.46080 \mathrm{E}+07$ & 3 & 0.898 \\
\hline $1.26144 \mathrm{E}+08$ & 4 & 0.921 \\
\hline $1.57680 \mathrm{E}+08$ & 5 & 0.939 \\
\hline $1.89216 \mathrm{E}+08$ & 6 & 0.955 \\
\hline $2.20752 \mathrm{E}+08$ & 7 & 0.966 \\
\hline $2.52288 \mathrm{E}+08$ & 8 & 0.975 \\
\hline $2.83824 \mathrm{E}+08$ & 9 & 0.982 \\
\hline $3.15360 \mathrm{E}+08$ & 10 & 0.988 \\
\hline $3.46896 \mathrm{E}+08$ & 11 & 0.993 \\
\hline 3.78432E+08 & 12 & 0.997 \\
\hline $4.73040 \mathrm{E}+08$ & 15 & 1 \\
\hline $6.30720 \mathrm{E}+08$ & 20 & 0.993 \\
\hline $7.88400 \mathrm{E}+08$ & 25 & 0.977 \\
\hline 8.19936E+08 & 26 & 0.974 \\
\hline $8.51472 \mathrm{E}+08$ & 27 & 0.97 \\
\hline $9.46080 \mathrm{E}+08$ & 30 & 0.958 \\
\hline 1.10376E+09 & 35 & 0.936 \\
\hline $1.26144 \mathrm{E}+09$ & 40 & 0.915 \\
\hline $1.57680 \mathrm{E}+09$ & 50 & 0.879 \\
\hline
\end{tabular}

Source: DTN: SN0002T0872799.009 [DIRS 153364], file "tough2-input_noBF.txt" in zip file "effKth_noBF.zip."

NOTES: Kthermal is calculated as Max. Kthermal $\times$ Factor.

Maximum Kthermal $(\mathrm{W} / \mathrm{m}-\mathrm{K})=10.568$. 
Table E-2. Effective Thermal Conductivity for In-Drift Open Spaces during Postclosure (No Backfill)

\begin{tabular}{|c|c|c|c|}
\hline \multicolumn{2}{|c|}{ Time } & \multicolumn{2}{|c|}{ Factor } \\
\hline (sec) & (year) & Inner & Outer \\
\hline $1.57680 \mathrm{E}+09$ & 50 & 0.879 & 0.879 \\
\hline $1.608336 \mathrm{E}+09$ & 51 & 0.844 & 0.829 \\
\hline $1.639872 \mathrm{E}+09$ & 52 & 0.892 & 0.878 \\
\hline $1.734480 \mathrm{E}+09$ & 55 & 0.951 & 0.944 \\
\hline $1.892160 \mathrm{E}+09$ & 60 & 0.988 & 0.986 \\
\hline $2.049840 \mathrm{E}+09$ & 65 & 1 & 1 \\
\hline $2.207520 \mathrm{E}+09$ & 70 & 0.995 & 0.998 \\
\hline $2.365200 \mathrm{E}+09$ & 75 & 0.985 & 0.99 \\
\hline $2.396736 \mathrm{E}+09$ & 76 & 0.983 & 0.988 \\
\hline $2.428272 \mathrm{E}+09$ & 77 & 0.981 & 0.986 \\
\hline $2.522880 \mathrm{E}+09$ & 80 & 0.973 & 0.98 \\
\hline $2.838240 \mathrm{E}+09$ & 90 & 0.954 & 0.963 \\
\hline $3.153600 \mathrm{E}+09$ & 100 & 0.932 & 0.943 \\
\hline $3.185136 \mathrm{E}+09$ & 101 & 0.929 & 0.941 \\
\hline $3.311280 E+09$ & 105 & 0.918 & 0.929 \\
\hline $3.468960 \mathrm{E}+09$ & 110 & 0.905 & 0.917 \\
\hline $3.784320 \mathrm{E}+09$ & 120 & 0.882 & 0.896 \\
\hline $4.099680 \mathrm{E}+09$ & 130 & 0.872 & 0.886 \\
\hline $4.415040 \mathrm{E}+09$ & 140 & 0.864 & 0.879 \\
\hline $5.045760 \mathrm{E}+09$ & 160 & 0.852 & 0.869 \\
\hline $5.676480 \mathrm{E}+09$ & 180 & 0.839 & 0.857 \\
\hline $6.307200 \mathrm{E}+09$ & 200 & 0.83 & 0.849 \\
\hline $6.937920 \mathrm{E}+09$ & 220 & 0.818 & 0.838 \\
\hline $7.884000 \mathrm{E}+09$ & 250 & 0.798 & 0.818 \\
\hline $9.460800 \mathrm{E}+09$ & 300 & 0.763 & 0.784 \\
\hline 1.103760E+10 & 350 & 0.736 & 0.758 \\
\hline $1.261440 \mathrm{E}+10$ & 400 & 0.707 & 0.729 \\
\hline $1.419120 \mathrm{E}+10$ & 450 & 0.689 & 0.711 \\
\hline $1.576800 \mathrm{E}+10$ & 500 & 0.677 & 0.7 \\
\hline $1.734480 \mathrm{E}+10$ & 550 & 0.672 & 0.694 \\
\hline $1.892160 \mathrm{E}+10$ & 600 & 0.667 & 0.69 \\
\hline $2.207520 \mathrm{E}+10$ & 700 & 0.656 & 0.68 \\
\hline $2.522880 \mathrm{E}+10$ & 800 & 0.646 & 0.67 \\
\hline $2.838240 \mathrm{E}+10$ & 900 & 0.637 & 0.661 \\
\hline $3.153600 \mathrm{E}+10$ & 1000 & 0.627 & 0.651 \\
\hline $3.468960 \mathrm{E}+10$ & 1100 & 0.619 & 0.643 \\
\hline $3.784320 \mathrm{E}+10$ & 1200 & 0.611 & 0.635 \\
\hline
\end{tabular}


Table E-2. Effective Thermal Conductivity for In-Drift Open Spaces during Postclosure (No Backfill) (Continued)

\begin{tabular}{|c|c|c|c|}
\hline \multicolumn{2}{|c|}{ Time } & \multicolumn{2}{|c|}{ Factor } \\
\hline (sec) & (year) & Inner & Outer \\
\hline 4.099680E+10 & 1300 & 0.602 & 0.626 \\
\hline 4.415040E+10 & 1400 & 0.592 & 0.616 \\
\hline $4.730400 E+10$ & 1500 & 0.582 & 0.605 \\
\hline $5.045760 \mathrm{E}+10$ & 1600 & 0.574 & 0.597 \\
\hline $5.676480 \mathrm{E}+10$ & 1800 & 0.559 & 0.583 \\
\hline $6.307200 E+10$ & 2000 & 0.543 & 0.566 \\
\hline $6.937920 \mathrm{E}+10$ & 2200 & 0.533 & 0.555 \\
\hline $7.884000 \mathrm{E}+10$ & 2500 & 0.519 & 0.541 \\
\hline $9.460800 \mathrm{E}+10$ & 3000 & 0.503 & 0.523 \\
\hline $1.103760 \mathrm{E}+11$ & 3500 & 0.491 & 0.51 \\
\hline $1.261440 \mathrm{E}+11$ & 4000 & 0.48 & 0.499 \\
\hline $1.419120 \mathrm{E}+11$ & 4500 & 0.472 & 0.491 \\
\hline $1.576800 E+11$ & 5000 & 0.465 & 0.484 \\
\hline $1.892160 \mathrm{E}+11$ & 6000 & 0.453 & 0.471 \\
\hline $2.207520 \mathrm{E}+11$ & 7000 & 0.444 & 0.461 \\
\hline $2.522880 \mathrm{E}+11$ & 8000 & 0.436 & 0.452 \\
\hline $3.153600 \mathrm{E}+11$ & 10000 & 0.422 & 0.438 \\
\hline $4.730400 E+11$ & 15000 & 0.395 & 0.411 \\
\hline $6.307200 E+11$ & 20000 & 0.378 & 0.393 \\
\hline $9.460800 \mathrm{E}+11$ & 30000 & 0.354 & 0.367 \\
\hline $1.261440 \mathrm{E}+12$ & 40000 & 0.341 & 0.354 \\
\hline $1.576800 \mathrm{E}+12$ & 50000 & 0.333 & 0.346 \\
\hline 1.892160E+12 & 60000 & 0.326 & 0.339 \\
\hline $2.522880 \mathrm{E}+12$ & 80000 & 0.318 & 0.33 \\
\hline $3.153600 E+12$ & 100000 & 0.314 & 0.325 \\
\hline
\end{tabular}

Source: DTN: SN0002T0872799.009 [DIRS 153364], file "tough2-input_noBF.txt" in zip file "effKth_noBF.zip."

NOTES: Kthermal is calculated as Max. Kthermal $\times$ Factor.

Maximum Kthermal $(\mathrm{W} / \mathrm{m}-\mathrm{K})$ Inner=2.298, Outer=14.407. 


\section{INTENTIONALLY LEFT BLANK}




\section{APPENDIX F}

PARAMETERS FOR FRACTURE PERMEABILITY MODIFICATION 
Table F-1. Parameters for Fracture Permeability Modification

\begin{tabular}{|c|c|c|}
\hline Rock Unit & a-parameter & b-parameter \\
\hline tcw11 & $1.5385 \mathrm{E}-02$ & 1.0870 \\
\hline tcw12 & 1.2696E-03 & 0.5236 \\
\hline tcw13 & 3.4483E-03 & 0.3584 \\
\hline ptn21 & $9.2000 \mathrm{E}-03$ & 1.4925 \\
\hline ptn22 & 7.0922E-03 & 2.1739 \\
\hline ptn23 & $1.2000 \mathrm{E}-03$ & 1.7544 \\
\hline ptn24 & 2.9412E-02 & 2.1739 \\
\hline ptn25 & 5.0459E-03 & 1.9231 \\
\hline ptn26 & 8.7079E-04 & 1.0309 \\
\hline tsw31 & $1.2953 \mathrm{E}-03$ & 0.4608 \\
\hline tsw32 & 2.5857E-03 & 0.8929 \\
\hline tsw33 & 1.3063E-03 & 1.2346 \\
\hline tsw34 & 6.2777E-04 & 0.2315 \\
\hline tsw35 & 9.9174E-04 & 0.3165 \\
\hline tsw3[67] & $1.0561 \mathrm{E}-03$ & 0.2488 \\
\hline tsw38 & 8.2459E-04 & 0.2294 \\
\hline tsw39 & 1.4576E-03 & 1.0417 \\
\hline $\operatorname{ch} 1 Z e$ & 1.4545E-03 & 25.0000 \\
\hline ch1VI & 2.0333E-03 & 10.0000 \\
\hline $\operatorname{ch}[23456] \mathrm{VI}$ & 1.7907E-03 & 7.1429 \\
\hline $\operatorname{ch}[2345] \mathrm{Ze}$ & 8.6047E-04 & 7.1429 \\
\hline ch6 & $1.4545 \mathrm{E}-03$ & 25.0000 \\
\hline pp4 & 8.6047E-04 & 7.1429 \\
\hline pp3 & $1.5902 \mathrm{E}-03$ & 5.0000 \\
\hline pp2 & 1.5902E-03 & 5.0000 \\
\hline pp1 & 8.6047E-04 & 7.1429 \\
\hline bf3 & $1.5902 \mathrm{E}-03$ & 5.0000 \\
\hline bf2 & 8.6047E-04 & 7.1429 \\
\hline tr3 & $1.5902 \mathrm{E}-03$ & 5.0000 \\
\hline $\operatorname{tr} 2$ & 8.6047E-04 & 7.1429 \\
\hline
\end{tabular}

NOTE: $\quad$ The calculation and use of the $a$ and $b$ parameters are presented in Section 6.4.4.2.

Parameter a (bg) is calculated using Equation 6.4-20. Parameter $b$ is the inverse of the fracture frequency (derived from DTN: LB0205REVUZPRP.001 [DIRS 159525]). 
INTENTIONALLY LEFT BLANK 
APPENDIX G

LIST OF MODEL INPUT AND OUTPUT FILES 


\section{G.1 INPUT AND OUTPUT FILES}

The following types of files were submitted for REV02 of this report to the TDMS under DTN: LB0307DSTTHCR2.001 and LB0302DSCPTHCS.001. They represent the current output THC seepage model; this revision of the report (REV04), does not produce new outputs.

1. Input and output files of simulations with the reactive transport code TOUGHREACT V3.0 (LBNL 2002 [DIRS 161256]). For each simulation, these files were concatenated into one file using the Unix tar utility, then compressed using the Unix gzip utility. Resulting concatenated/compressed files have the extension .tar.gz.

2. Summary Excel spreadsheets of seepage model output data at locations adjacent to the drift wall (crown, side, and base).

3. Spreadsheets containing calculations have been included as part of several DTNs in order to document the embedded calculations and supplement the Scientific Notebooks. Readme.doc files in each output DTN contain a general description of the spreadsheets contained therein. Spreadsheets are annotated with descriptions of the calculations performed, commonly on a separate "notes" worksheet. The calculations can be observed by clicking on the spreadsheet cells or selecting the "Tools $\backslash$ Options $\backslash$ View $\backslash$ Formulas" option in Excel. In addition, the cell references in the equations show all cells used as input to the calculation executed in the spreadsheet. The formulae in the submitted spreadsheets use the standard functions of MS Excel 97.

DST THC Submodel Input and Output File Folders (Simulations in Section 7.1.8.2)

(DTN: LB0307DSTTHCR2.001)

dstrev2 th12

dstrev2 th13

dstrev2 the 7

dstrev2 thc 8

dstrev2_thc9

More complete descriptions can be found in Section 7.1.

Tptpll THC Seepage Model Input and Output File Folders (Simulations listed in Table 6.5-4)

(DTN: LB0307DSTTHCR2.001)

th6_1.45kw (_, a, _b, _c)

thc $\overline{6}_{-}$w0e3 (_,, a, $\left., \bar{b} 2,{ }_{-}, \mathrm{b}, \mathrm{bb}, \mathrm{c}_{-}, \mathrm{d}\right)$

thc6_w0a (b, c c, d $)$

thc6_w0b (_,_a, _b, _bb, cc, d)

thc25_w0 (_, a, _b, _c, _d)

thc6_w0_q

thc6_w0_q1

thc6 w0amb

the6 w0amb1

thc6_w4amb1

the6_w5amb1 
thc6_w6amb1

(DTN: LB0404DSTTHCR2.001)

th6 $1.45 \mathrm{kw}$ il (, , a, _b, _c)

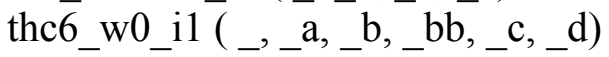

thc6_w0b_il (_, a, _b, _bb, _c, _d)

(DTN: LB0302DSCPTHCS.001)

thc6_w0 (_,_a,_b, _bb,_c, d)

thc6_w4 (_, a, _b, _bb, _c, _d)

thc6_w5 (_, _a, _b, _bb, _c, _d)

thc6_w6 (_, a, _b, _bb, c, _d)

thc6_w7 (_, a, _b, _bb, _c, d)

\section{G.2 CONTENTS OF .tar.gz FILES}

Note: Some file names are lowercase in TOUGHREACT V3.0 (LBNL 2002 [DIRS 161256]) and uppercase in earlier versions.

flow.inp Rock thermal and hydrologic properties, run flags, and other specifications (input)

flow.out Thermal and hydrologic results (gas/liquid saturation, T, P, air mass fraction, etc.) (output)

GENER Infiltration rates, heat load, and effective thermal conductivity (input)

INCON Initial thermal and hydrologic conditions ( $\mathrm{T}, \mathrm{P}$, liquid saturation, etc.) (input)

MESH Input numerical mesh (input)

SAVE Thermal and hydrologic conditions ( $\mathrm{T}, \mathrm{P}$, liquid saturation, etc.) to use for

TABLE Miscellaneous output data

VERS Miscellaneous output data

LINEQ Miscellaneous output data

CHEMICAL.INP Water chemistry, mineralogy, and $\mathrm{CO}_{2}$ partial pressure data (input)

CHEMICAL.OUT Echo of data read in CHEMICAL.INP

SOLUTE.INP

SOLUTE.OUT

Run flags and other data relating to reactive transport (input)

thermk1.01.dat

TEC_CONC.DAT Calculated concentrations of aqueous species (moles/liter) at each grid node (two records for each node - first record for fractures and second record for matrix) (output)

TEC_MIN.DAT Calculated volume fraction change for minerals at each grid node (two records for each node - first record for fractures and second record for matrix) (output)

TEC_GAS.DAT Calculated $\mathrm{CO}_{2}$ volume fraction at each grid node (two records for each node - first record for fractures and second record for matrix) (output)

TIME.DAT Chemical data at selected grid nodes (output) 
chdump.dat Chemical speciation of initial water (output) and nodes with convergence problems

inchem Chemistry data at all grid nodes to use for restarting a run (input)

savechem Chemistry data at all grid nodes to use for restarting a run (output, same format as INCHEM file)

ITER.DAT Iteration information (output) runlog.dat (run_log.dat) Miscellaneous run-time information. Note: mass balances may not be printed out correctly in this file for runs that have been restarted (i.e., starting at times different than zero).

mbalance.out Mass balance information for chemical species Note: mass balances may not be accurate for runs that have been restarted (i.e., starting at times different than zero). Also, mass balances do not reflect mass loss by transport into large boundary grid blocks.

GASOBS.DAT optional tabular flow output for individual grid blocks

\section{G.3 SUMMARY SPREADSHEETS OF THC SEEPAGE MODELS OUTPUT DATA (ALSO USED FOR PLOTTING TIME PROFILES AND TABULATING STANDARD DEVIATION)}

The data in these files were extracted from output files FLOW.OUT, TEC_CONC.DAT, TEC_MIN.DAT, and TEC_GAS.DAT for each simulation and submitted to the TDMS under DTNs: LB0302DSCPTHCS.002 and LB0307DSTTHCR2.002.

Tptpll THC Model (TOUGHREACT V3.0 (LBNL 2002 [DIRS 161256]))

(extended-case only, simulations details listed in Table 6.5-4)

(DTN: LB0302DSCPTHCS.002)

the6 w0 r.xls

thc6_w0_drift_r.xls

the6_w4_r.xls

the6_w4_drift_r.xls

the6_w5_r.xls

the6_w5_drift_r.xls

the6 w6 r.xls

the6_w6_drift_r.xls

the6_w7_r.xls

thc6_w7_drift_r.xls
THC, Water W0, 6/16/25 mm/yr (track wet nodes)

THC, Water W0, 6/16/25 mm/yr (drift wall only)

THC, Water W4, 6/16/25 mm/yr (track wet nodes)

THC, Water W4, 6/16/25 mm/yr (drift wall only)

THC, Water W5, 6/16/25 mm/yr (track wet nodes)

THC, Water W5, 6/16/25 mm/yr (drift wall only)

THC, Water W6, 6/16/25 mm/yr (track wet nodes)

THC, Water W6, 6/16/25 mm/yr (drift wall only)

THC, Water W7, 6/16/25 mm/yr (track wet nodes)

THC, Water W7, 6/16/25 mm/yr (drift wall only)

(DTN: LB0307DSTTHCR2.002)

th6_1.45kw.xls

the 25 _w0.xls

thc25_w0 drift.xls

the6 w0e3.xls

the6 w0e3 drift.xls

the6_w0b.xis

thc6_w0b_drift.xls

the6_w0a.xls
$\mathrm{TH}, 6 / 16 / 25 \mathrm{~mm} / \mathrm{yr}$

THC, Water W0, $25 \mathrm{~mm} / \mathrm{yr}$ (track wet nodes)

THC, Water W0, $25 \mathrm{~mm} / \mathrm{yr}$ (drift wall only)

THC, Water W0, 6/16/25 mm/yr, EOS3 (track wet nodes)

THC, Water W0, 6/16/25 mm/yr, EOS3 (drift wall only)

THC, Water W0, 6/16/25 mm/yr, $\mathrm{D}_{\mathrm{CO} 2}$ change (track wet nodes)

THC, Water W0, $6 / 16 / 25 \mathrm{~mm} / \mathrm{yr}, \mathrm{D}_{\mathrm{CO} 2}$ change (drift wall only)

THC, Water W0, $6 \mathrm{~mm} / \mathrm{yr}$ (track wet nodes) 
thc6_w0a_drift.xls the6_w0_amb1.xls wo_4_5_6_7.xls

hisat_top-w04567.xls
THC, Water W0, $6 \mathrm{~mm} / \mathrm{yr}$ (drift wall only) THC, Water W0, no heat load, $6 / 16 / 25 \mathrm{~mm} / \mathrm{yr}$ (drift wall only) THC, Water W0, W4, W5, W6, and W7, 6/15/25 mm/yr, track wet nodes (concentrations of data from files listed above under DTN: LB0302DSCPTHCS.002)

Filtered data from w0-4-5-6-7.xls, used to tabulate standard deviations in Table 6.9-2

(DTN: LB0404DSTTHCR2.002)

th6_1.45kw_i1.xls

thc $\overline{6}$ w0 il.xls thc6_w0_drift_i1.xls thc6_w0 ${ }_{-}$i1 $1 . \overline{x l s}$ thc6_w0b_drift_i1.xls
TH, 6/16/25 mm/yr (drift wall only) THC, Water W0, 6/16/25 mm/yr (track wet nodes) THC, Water W0, 6/16/25 mm/yr (drift wall only) THC, Water W0, 6/16/25 mm/yr, DCO2 change (track wet nodes) THC, Water W0, 6/16/25 mm/yr, DCO2 change (drift wall only) 


\begin{abstract}
APPENDIX H
QUALIFICATION OF MINERAL DISSOLUTION/PRECIPITATION KINETICS DATA (MINERAL DISSOLUTION RATE CONSTANTS AND ACTIVATION ENERGIES) IN DTN: LB0307KNTDBRTM.001 [DIRS 164433] FOR USE IN THC COUPLED PROCESS MODELING
\end{abstract}


This appendix documents the qualification of mineral dissolution rate constants $\left(k_{+}\right)$and activation energies $\left(E_{a}\right)$ in DTN: LB0307KNTDBRTM.001 [DIRS 164433], and serves as the data qualification report for that DTN. This data qualification effort has been carried out as described in the Data Qualification Plan that is included in the records package for this report. A facsimile of the Data Qualification Plan is included in Section H.17 of this appendix.

\section{H.1 EVALUATION CRITERIA}

The data being qualified are the mineral dissolution rate constants $\left(k_{+}\right)$and activation energies $\left(E_{a}\right)$ given in DTN: LB0307KNTDBRTM.001 [DIRS 164433], which is provided in Table H.3-1 for convenience. A subset of these values is used in this report, as listed in Table 4.1-3 of this document. All of these values are unqualified data. The qualification of unqualified data must be done in accordance with LP-SIII.2Q-BSC, Qualification of Unqualified Data. This procedure lists five methods for qualification, summarized (and in some cases abridged) as follows:

Criterion 1-Equivalent QA Program. The Equivalent QA Program approach may be used for the qualification of unqualified data when the acquisition, development, or processing of data can be demonstrated to be functionally equivalent (i.e., similar in scope and implementation) to the general process requirements of the QARD. The employed practices or procedures must demonstrate industry acceptable scientific, engineering, or administrative practices or processes with appropriate documentation as defined in this procedure.

Criterion 2-Corroborating Data. The Corroborating Data approach may be used when data comparisons can be shown to substantiate or confirm parameter values. The corroborating data qualification process may include comparisons of unqualified data to unqualified data, as well as unqualified data to qualified data with appropriate compliance documentation as defined in this procedure.

Criterion 3-Confirmatory Testing. The Confirmatory Testing approach may be used when previous test results are non-verifiable as a result of questionable testing methodology or a lack of applicable documentation. Consideration must be given to confirmatory testing resource and schedule requirements, to ensure confirmatory testing is a viable qualification option within the project's funding and time constraints. Confirmatory test results must demonstrate direct correlation to previous test results; however, data extrapolation is acceptable within the limits defined in the compliance documentation defined in this procedure.

Criterion 4-Peer Review. Peer reviews may be initiated per AP-2.12Q. The Qualification Team will evaluate the data acquisition and development approach. The team will also summarize and evaluate the assumptions, calculations, extrapolations, alternative interpretations, methodology, acceptance criteria, and conclusions in data being qualified, as applicable. The team will compile supporting records and present the team's evaluation and supporting records package to a Peer Review Panel convened in accordance with AP-2.12Q. The 
Peer Review Panel will review the evaluation and supporting documentation, assess the adequacy of the data being qualified, and document their conclusions in a report in accordance with AP-2.12Q. Under this method, the Qualification Team's evaluation and the peer review Panel Report will be the documentation of the qualification process.

Criterion 5-Technical Assessment. The Technical Assessment approach may be used when it is determined that an independent evaluation of the data by a subject matter expert is needed to raise the confidence of the data to a proper level for the intended use. Either of the following conditions could require use of the Technical Assessment approach:

a) The confidence in the data is in question because data collection procedures are unavailable for review, or the procedures are not adequate.

b) Documentation or proof of proper data acquisition is unavailable for review.

The mineral dissolution rate constants $\left(k_{+}\right)$and activation energies $\left(E_{a}\right)$ presented in Table H.1-3 are a composite of experimental-based values for some minerals, along with estimated values for other minerals. Different criteria will apply to experimental and estimated values.

Mineral dissolution rate measurements are made at relatively few laboratories, and require experienced personnel to make reliable measurements. The following criterion is given in LP-SIII.2Q-BSC:

Consideration must be given to confirmatory testing resources and schedule requirements to ensure confirmatory testing is a viable qualification option within the project's funding and time constraints.

Given the project's resources and schedule requirements, the use of Criterion 3, Confirmatory Testing, is not a viable option for qualification of the mineral dissolution rate constants and activation energies database, and it will not be used as a data qualification method in this report.

The experimental mineral dissolution rate constants and activation energies in this report are taken from papers published in peer-reviewed journals, and therefore they have already undergone a peer review by several experts in this field of study. However, peer review comments for journal papers are not available to the general public, nor are the names of the reviewers. Likewise, the responses of the authors and the changes that were made to resolve issues raised in the peer reviews are not available. Therefore, the level of documentation for the journal peer reviews is not adequate for the present needs, although such reviews do guarantee that most of the obvious quality-affecting issues will have been resolved prior to publication of these journal papers. Given the project's resources and schedule requirements, the use of Criterion 4, Peer Review, within the guidelines of LP-SIII.2Q-BSC, is not a viable option for qualification of the mineral dissolution rate constants and activation energies database, and it will not be used here.

Four of the referenced studies were done with YMP support, and one was done with NRC support; these studies are those reported by Carroll et al. (1998 [DIRS 124275]), Murphy et al. 
(1996 [DIRS 142167]), Ragnarsdóttir (1993 [DIRS 126601]), and Renders et al. (1995 [DIRS 107088]). Although these studies were performed using well-documented experimental methods, and the resulting information is presented in these reports with sufficient detail to assess their reliability, neither these nor the other published experimental studies yielding mineral dissolution rate constants and activation energies were performed under a formal YMP QA program. Thus, Criterion 1, Equivalent QA Program, will not be used here.

The Data Qualification for the mineral dissolution rate constants $\left(k_{+}\right)$and activation energies $\left(E_{a}\right)$ will be done by use of Criterion 5, Technical Assessment, and/or by Criterion 2, Corroborating Data, when corroborating studies are available to allow for comparison of independently measured rate constants and activation energies. However, the assessed table of mineral dissolution rate constants and activation energies is a composite of experimental-based values along with estimated values for systems either lacking such data or with incomplete data.

\section{H.2 SOME GENERAL CONSIDERATIONS}

The selected experimental mineral dissolution rate constants and activation energies are based on measurements using well-characterized mineral samples with adequately described experimental methods. However, the tabulated dissolution rate constants depend inversely on the estimated surface area of the mineral grains used for the experiments. The usual method of determining mineral surface areas is by using gas absorption measured with the BET (Brunauer, Emmet, Teller) static volume method. This type of surface-area measurement is made using a nonreacting gas, generally nitrogen, krypton, or argon. BET measurements using different gases do not yield the same estimated surface areas. For example, Ragnarsdóttir (1993 [DIRS 126601], p. 2441]) determined the surface area of a crushed sample of heulandite as being $1715 \pm 11 \mathrm{~cm}^{2} \mathrm{~g}^{-1}$ using krypton BET measurements, and $4176 \pm 2435 \mathrm{~cm}^{2} \mathrm{~g}^{-1}$ using nitrogen BET measurements. Surface-area measurements using the inert gases are generally considered to be more reliable than those using nitrogen gas. However, because three different gases were used among the various mineral dissolution studies cited above, any comparison of numerical mineral dissolution and precipitation rate constants needs to consider the uncertainties resulting from the surface-area measurements.

With the exception of a few simple minerals such as quartz and hematite, most natural minerals show significant variations in the composition of samples collected at different locations and even of different samples taken from the same deposit. For example, Murphy et al. (1996 [DIRS 142167, pp. 133, 139, and 129]) cited the chemical composition of a clinoptilolite from Lake Tecopa, Inyo County, California, as being

$$
\left(\mathrm{Na}_{0.56} \mathrm{~K}_{0.98} \mathrm{Ca}_{1.50} \mathrm{Mg}_{1.23}\right)\left(\mathrm{Al}_{6.7} \mathrm{Fe}_{0.3}\right) \mathrm{Si}_{29} \mathrm{O}_{72} \cdot 22 \mathrm{H}_{2} \mathrm{O}
$$

and another one from Malheur County, Oregon as being

$$
\left(\mathrm{Na}_{0.954} \mathrm{~K}_{0.543}\right)\left(\mathrm{Ca}_{0.761} \mathrm{Mg}_{0.124} \mathrm{Ba}_{0.062} \mathrm{Sr}_{0.036} \mathrm{Mn}_{0.0 .002}\right)\left(\mathrm{Al}_{3.450} \mathrm{Fe}_{0.017} \mathrm{Si}_{14.553}\right) \mathrm{O}_{36} \cdot 10.922 \mathrm{H}_{2} \mathrm{O} \text {. }
$$

They also reported analysis results for a Na-clinoptilolite from Death Valley Junction, California, yielding a composition of

$$
\left(\mathrm{Na}_{1.804} \mathrm{~K}_{0.123} \mathrm{Ca}_{0.003} \mathrm{Mg}_{0.035}\right)\left(\mathrm{Al}_{1.947} \mathrm{Fe}_{0.044}\right)\left(\mathrm{Si}_{10.002} \mathrm{Ti}_{0.004}\right) \mathrm{O}_{24} \cdot 7.43 \mathrm{H}_{2} \mathrm{O} \text {. }
$$


They gave the formula of the idealized (pure) Na-clinoptilolite as being

$$
\mathrm{Na}_{2} \mathrm{Al}_{2} \mathrm{Si}_{10} \mathrm{O}_{24} \cdot 8 \mathrm{H}_{2} \mathrm{O} \text {. }
$$

These different formulae are based on use of different-sized structural formula units, and can be compared on an equivalent basis by normalizing them to the same number of (nonwater) oxygens. However, even without this normalization, it is apparent from these few sample compositions that clinoptilolite and most other natural minerals show significant variations in chemical composition for samples collected at different locations.

\section{H.3 SUMMARY OF EXPERIMENTAL MINERAL DISSOLUTION RATE CONSTANTS AND ACTIVATION ENERGIES}

The information in DTN: LB0307KNTDBRTM.001 [DIRS 164433] is repeated in Table H.3-1, along with the qualification method(s) used for each quantity. The listed values of the mineral dissolution rate constants are for the temperature $298.15 \mathrm{~K}$ and neutral to near-neutral $\mathrm{pHs}$. The corresponding data for muscovite have also been added to this table because they are the source for estimated values of the dissolution rate constants and activation energies for several other clay minerals.

The tabulated experimental rate constants at $298.15 \mathrm{~K}\left(25^{\circ} \mathrm{C}\right)$ are given to the same number of significant figures as reported in the source documents (i.e., generally to two or three significant figures). However, because of the uncertainties introduced by the surface-area determinations, and because of the natural variation in chemical composition of most minerals, the listed values of the experimental rate constants at $298.15 \mathrm{~K}$ should be considered uncertain by approximately a factor of 10 when applied to mineral samples from different locations having significantly different chemical compositions. 


\begin{tabular}{|c|c|c|c|c|c|c|c|c|}
\hline MINERAL & $\begin{array}{l}\mathrm{k}_{++-}\left(\mathrm{mol} \mathrm{m}^{-1} \mathrm{~m}^{-2}\right)^{(\mathrm{a})} \\
\text { at } 298.15 \mathrm{~K}\end{array}$ & $\begin{array}{c}E_{a} \\
(\mathrm{~kJ} / \mathrm{mol})^{(\mathrm{b})}\end{array}$ & $m^{(c)}$ & $n^{(c)}$ & $\begin{array}{l}\text { Formula Used to } \\
\text { Calculate Rate } \\
\text { Constant }{ }^{(d)}\end{array}$ & Comment ${ }^{(\mathrm{e})}$ & Reference & $\begin{array}{l}\text { Qualification } \\
\text { Method(s) })^{(f)}\end{array}$ \\
\hline $\begin{array}{c}\alpha \text {-Cristobalite } \\
\mathrm{SiO}_{2}\end{array}$ & $3.45 \times 10^{-13}$ & $68.9( \pm 11)$ & 1 & 1 & $\begin{array}{c}\operatorname{lnk}_{+}=(-0.9)-E_{a} / \\
(R \cdot T(K))\end{array}$ & $\begin{array}{l}\text { Dissolution, no } \\
\text { precipitation }\end{array}$ & $\begin{array}{l}\text { Renders et al. } 1995 \text { [DIRS } \\
\text { 107088], pp. } 77,81\end{array}$ & C \\
\hline $\begin{array}{l}\text { Quartz } \\
\mathrm{SiO}_{2}\end{array}$ & $4.52 \times 10^{-14}$ & $90.1( \pm 2.5)$ & 1 & 1 & $\begin{array}{c}\mathrm{k}_{\mathrm{f}, \text { geom. }}=(276 \pm \\
\text { 193) } \exp \left[-\mathrm{E}_{\mathrm{a}} / \mathrm{R}\right. \\
\mathrm{T}(\mathrm{K})]^{(\mathrm{g})}\end{array}$ & $\begin{array}{l}\text { Dissolution, no } \\
\text { precipitation }\end{array}$ & $\begin{array}{c}\text { Tester et al. } 1994 \text { [DIRS } \\
\text { 101732], p. } 2415\end{array}$ & C \\
\hline $\begin{array}{l}\text { Tridymite } \\
\mathrm{SiO}_{2}\end{array}$ & $3.45 \times 10^{-13}$ & $68.9( \pm 11)$ & 1 & 1 & & $\begin{array}{l}\text { Dissolution rate } \\
\text { constant set to } \alpha- \\
\text { cristobalite, no } \\
\text { precipitation }\end{array}$ & NA & $\mathrm{E}$ \\
\hline \multirow[t]{2}{*}{$\begin{array}{c}\text { Amorphous silica } \\
\mathrm{SiO}_{2}\end{array}$} & $7.32 \times 10^{-13}$ & $60.9-64.9$ & 1 & 1 & $\begin{array}{c}\log _{+}=-0.369+ \\
\left(-7.890 \cdot 10^{-4} \cdot\right. \\
T(K))+(-3438 / \\
T(K))\end{array}$ & Dissolution & $\begin{array}{c}\text { Rimstidt and Barnes } 1980 \\
\text { [DIRS 101708], pp. 1683, } \\
1690\end{array}$ & $C$ \\
\hline & $1.0 \times 10^{-10( \pm 0.06)}$ & $50( \pm 3)$ & $\begin{array}{l}4.4^{(\mathrm{h})} \\
( \pm 0.3)\end{array}$ & 1 & & Precipitation & $\begin{array}{l}\text { Carroll et al. } 1998 \text { [DIRS } \\
\text { 124275], pp. } 1379,1389\end{array}$ & C \\
\hline $\begin{array}{l}\text { Opal-proxy } \\
\mathrm{SiO}_{2}\end{array}$ & $7.32 \times 10^{-13}$ & $60.9-64.9$ & 1 & 1 & & $\begin{array}{c}\text { Dissolution rate } \\
\text { constant and } E_{a} \\
\text { set to amorphous } \\
\text { silica, no } \\
\text { precipitation }\end{array}$ & NA & $C$ \\
\hline $\begin{array}{c}\text { Microcline }=\text { K-spar } \\
\mathrm{KAISi}_{3} \mathrm{O}_{8}\end{array}$ & $\begin{array}{l}1.78 \times 10^{-13} \\
\mathrm{pH} \sim 5-8\end{array}$ & $\begin{array}{c}36 \\
(35-37)\end{array}$ & 1 & 1 & & Reversible & 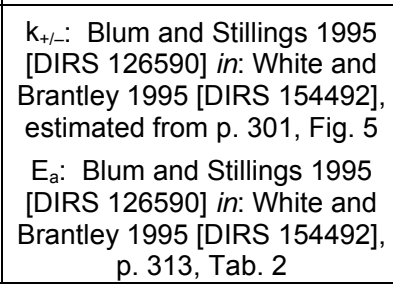 & C \\
\hline $\begin{array}{l}\text { Albite-low } \\
\mathrm{NaAlSi}_{3} \mathrm{O}_{8}\end{array}$ & $\begin{array}{c}7.08 \times 10^{-13} \\
\mathrm{pH} 5-8\end{array}$ & 67.7 & 1 & 1 & & Reversible & \begin{tabular}{|c|c}
$\mathrm{k}_{+/-}:$Blum and Stillings 1995 \\
[DIRS 126590] in: White \\
and Brantley 1995 [DIRS \\
154492], p. 315, Tab. 3 \\
$\mathrm{E}_{\mathrm{a}}:$ Blum and Stillings 1995 \\
[DIRS 126590] in: White \\
and Brantley 1995 [DIRS \\
154492], p. 313, Tab. 2 \\
and p. 317, Fig. 10
\end{tabular} & C \\
\hline
\end{tabular}




\begin{tabular}{|c|c|c|c|c|c|c|c|c|}
\hline MINERAL & $\begin{array}{l}\mathrm{k}_{++/}\left(\mathrm{mol}^{-1} \mathrm{~m}^{-2}\right. \\
\mathrm{s}^{(\mathrm{a})} \\
\text { at } 298.15 \mathrm{~K}\end{array}$ & $\begin{array}{c}E_{\mathrm{a}} \\
(\mathrm{kJ} / \mathrm{mol})^{(\mathrm{b})}\end{array}$ & $\mathrm{m}^{(\mathrm{c})}$ & $n^{(c)}$ & $\begin{array}{l}\text { Formula Used to } \\
\text { Calculate Rate } \\
\text { Constant }\end{array}$ & Comment $^{(e)}$ & Reference & 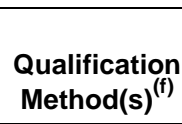 \\
\hline $\begin{array}{l}\text { Anorthite } \\
\mathrm{CaAl}_{2} \mathrm{Si}_{2} \mathrm{O}_{8}\end{array}$ & $\begin{array}{l}3.16 \times 10^{-12} \\
\mathrm{pH} \sim 5-8\end{array}$ & $\begin{array}{l}67.7 \\
\text { (set to } \\
\text { albite) }\end{array}$ & 1 & 1 & & $\begin{array}{l}\text { Dissolution, no } \\
\text { precipitation }\end{array}$ & $\begin{array}{c}\text { Brady and Walther } 1989 \\
\text { [DIRS 110748], } \\
\text { estimated from p. 2825, } \\
\text { Fig. } 4\end{array}$ & $C, E$ \\
\hline $\begin{array}{c}\text { Muscovite formula } \\
\mathrm{K}_{1.84} \mathrm{Na}_{0.16}\left(\mathrm{Al}_{3.75} \mathrm{Fe}_{0.22} \mathrm{Mg}_{0.12}\right. \\
\mathrm{Ti}_{0.02}\left[\left[\mathrm{Si}_{6.06} \mathrm{Al}_{1.92} \mathrm{O}_{20}\right](\mathrm{OH})_{4}\right.\end{array}$ & $1.0 \times 10^{-14}$ & & & & & & $\begin{array}{l}\text { Knauss and Wolery } 1989 \\
\text { [DIRS 124300], p. } 1500\end{array}$ & $E$ \\
\hline $\begin{array}{c}\text { Illite } \\
\mathrm{K}_{0.5}\left(\mathrm{Mg}_{0.22} \mathrm{Al}_{1.78}\right) \\
\left(\mathrm{Si}_{3.72} \mathrm{Al}_{0.28}\right) \mathrm{O}_{10}(\mathrm{OH})_{2}\end{array}$ & $2.0 \times 10^{-14}$ & 58.6 & 1 & 1 & & $\begin{array}{l}\text { Reversible, rate } \\
\text { constant } \\
\text { assumed to be } \\
\text { equal to } \\
\text { muscovite } \\
\text { (corrected for } \\
\text { stoichiometry) }\end{array}$ & NA & $\mathrm{T}, \mathrm{E}$ \\
\hline $\begin{array}{c}\text { Smectite-Ca } \\
\mathrm{Ca}_{0.145}\left(\mathrm{Mg}_{0.26} \mathrm{Al}_{1.74}\right) \\
\left(\mathrm{Si}_{3.97} \mathrm{Al}_{0.03}\right) \mathrm{O}_{10}(\mathrm{OH})_{2}\end{array}$ & $2.0 \times 10^{-14}$ & $\begin{array}{c}58.6 \\
\text { (set to illite) }\end{array}$ & 1 & 1 & & $\begin{array}{l}\text { Reversible, rate } \\
\text { constant set to } \\
\text { illite }\end{array}$ & NA & $E$ \\
\hline $\begin{array}{c}\text { Smectite-Mg } \\
\left(\mathrm{Mg}_{0.405} \mathrm{Al}_{1.74}\right)\left(\mathrm{Si}_{3.97} \mathrm{Al}_{0.03}\right) \\
\mathrm{O}_{10}(\mathrm{OH})_{2}\end{array}$ & $2.0 \times 10^{-14}$ & $\begin{array}{c}58.6 \\
\text { (set to illite) }\end{array}$ & 1 & 1 & & $\begin{array}{l}\text { Reversible, rate } \\
\text { constant set to } \\
\text { illite }\end{array}$ & NA & $E$ \\
\hline $\begin{array}{c}\text { Smectite-Na } \\
\mathrm{Na}_{0.29}\left(\mathrm{Mg}_{0.26} \mathrm{Al}_{1.74}\right) \\
\left(\mathrm{Si}_{3.97} \mathrm{Al}_{0.03}\right) \mathrm{O}_{10}(\mathrm{OH})_{2}\end{array}$ & $2.0 \times 10^{-14}$ & $\begin{array}{c}58.6 \\
\text { (set to illite) }\end{array}$ & 1 & 1 & & $\begin{array}{l}\text { Reversible, rate } \\
\text { constant set to } \\
\text { illite }\end{array}$ & NA & E \\
\hline $\begin{array}{c}\text { Sepiolite } \\
\mathrm{Mg}_{2} \mathrm{Si}_{3} \mathrm{O}_{7.5} \mathrm{OH} \cdot 3 \mathrm{H}_{2} \mathrm{O}\end{array}$ & $2.67 \times 10^{-14}$ & $\begin{array}{c}58.6 \\
\text { (set to illite) }\end{array}$ & 1 & 1 & & $\begin{array}{c}\text { Reversible, rate } \\
\text { constant based on } \\
\text { muscovite rate } \\
\text { constant } \\
\end{array}$ & NA & $E$ \\
\hline $\begin{array}{c}\text { Kaolinite } \\
\mathrm{Al}_{2} \mathrm{Si}_{2} \mathrm{O}_{5}(\mathrm{OH})_{4}\end{array}$ & $\begin{array}{c}\sim 1.0 \times 10^{-13} \\
\text { pH } 5-8\end{array}$ & $\begin{array}{c}7.1( \pm 2.5) \\
\mathrm{pH}=7\end{array}$ & 1 & 1 & & Reversible & 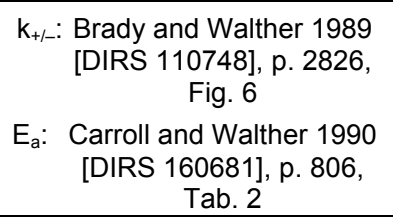 & $C$ \\
\hline $\begin{array}{c}\text { Heulandite } \\
\mathrm{Ca}_{0.33} \mathrm{~K}_{0.04} \mathrm{Na}_{0.1} \\
\left(\mathrm{Al}_{0.8} \mathrm{Si}_{2.8} \mathrm{O}_{7.2}\right) \cdot 2.6 \mathrm{H}_{2} \mathrm{O}\end{array}$ & $\begin{array}{c}5.66 \times 10^{-13} \\
\mathrm{pH}=7.2\end{array}$ & $\begin{array}{c}58.0 \\
\text { (set to } \\
\text { laumontite) }\end{array}$ & 1 & 1 & & $\begin{array}{l}\text { Reversible (rate } \\
\text { based on silica } \\
\text { release) }\end{array}$ & $\begin{array}{l}\mathrm{k}_{+/=}: \text {Ragnarsdóttir (1993 } \\
\text { [DIRS 126601], p. 2439) } \\
\mathrm{E}_{\mathrm{a}}: \text { Savage et al. (1993 } \\
\text { [DIRS 160198], p. 533) }\end{array}$ & $\mathrm{T}, \mathrm{E}$ \\
\hline
\end{tabular}


Table H.3-1. Mineral Dissolution/Precipitation Reaction Rate Constants $\left(k_{+-}\right)$and Activation Energies $\left(E_{a}\right)$ to Be Qualified (Continued)

\begin{tabular}{|c|c|c|c|c|c|c|c|c|}
\hline MINERAL & $\begin{array}{l}\mathrm{K}_{++-}\left(\mathrm{mol} \mathrm{m}^{-2}\right. \\
\left.\mathrm{s}^{-1}\right)^{(\mathrm{a})} \\
\text { at } 298.15 \mathrm{~K}\end{array}$ & $\underset{(\mathrm{kJ} / \mathrm{mol})^{(\mathrm{b})}}{\mathrm{E}_{\mathrm{a}}}$ & $m^{(c)}$ & $n^{(c)}$ & $\begin{array}{l}\text { Formula Used to } \\
\text { Calculate Rate } \\
\text { Constant }^{(d)}\end{array}$ & Comment $^{(\mathrm{e})}$ & Reference & $\begin{array}{l}\text { Qualification } \\
\text { Method(s) })^{(f)}\end{array}$ \\
\hline $\begin{array}{c}\text { Clinoptilolite } \\
\mathrm{Ca}_{0.28} \mathrm{~K}_{0.08} \mathrm{Na}_{0.04} \\
\left(\mathrm{Al}_{0.68} \mathrm{Si}_{2.92} \mathrm{O}_{7.2}\right) \cdot 2.6 \mathrm{H}_{2} \mathrm{O}\end{array}$ & $\begin{array}{c}2.37 \times 10^{-13} \\
\mathrm{pH}=9\end{array}$ & $\begin{array}{c}58.0 \\
\text { (set to } \\
\text { laumontite) }\end{array}$ & 1 & 1 & & Reversible & $\begin{array}{c}\mathrm{k}_{+/=}: \text {Murphy et al. } 1996 \text { [DIRS } \\
\text { 142167], p. } 160\end{array}$ & $\mathrm{~T}, \mathrm{E}$ \\
\hline $\begin{array}{c}\text { Stellerite } \\
\mathrm{Ca}_{0.39} \mathrm{Na}_{0.01}\left(\mathrm{Al}_{0.79} \mathrm{Si}_{2.81} \mathrm{O}_{7.2}\right) \\
\cdot 2.8 \mathrm{H}_{2} \mathrm{O} \\
\end{array}$ & $5.66 \times 10^{-13}$ & $\begin{array}{c}58.0 \\
\text { (set to } \\
\text { laumontite) } \\
\end{array}$ & 1 & 1 & & $\begin{array}{l}\text { Reversible, rate } \\
\text { constant set to } \\
\text { heulandite }\end{array}$ & NA & $E$ \\
\hline $\begin{array}{c}\text { Mordenite } \\
\mathrm{Ca}_{0.15} \mathrm{Na}_{0.21} \mathrm{~K}_{0.09}\left(\mathrm{Al}_{0.6} \mathrm{Si}_{3} \mathrm{O}_{7.2}\right) \\
\cdot 2.2 \mathrm{H}_{2} \mathrm{O}\end{array}$ & $5.66 \times 10^{-13}$ & $\begin{array}{c}58.0 \\
\text { (set to } \\
\text { laumontite) } \\
\end{array}$ & 1 & 1 & & $\begin{array}{c}\text { Reversible, rate } \\
\text { constant set to } \\
\text { heulandite }\end{array}$ & NA & $E$ \\
\hline $\begin{array}{l}\text { Calcite } \\
\mathrm{CaCO}_{3}\end{array}$ & $1.60 \times 10^{-6(\mathrm{i})}$ & $48.1( \pm 3.8)$ & 1 & 1 & & $\begin{array}{c}\text { Reversible } \\
\text { (synthetic calcite) }\end{array}$ & $\begin{array}{c}\mathrm{k}_{+/-}: \text {Svensson and Dreybrodt } \\
1992 \text { [DIRS 127978], } \\
\text { p. } 129 \\
\mathrm{E}_{\mathrm{a}}: \text { Inskeep and Bloom } 1985 \\
\text { [DIRS 128129], p. } 2165\end{array}$ & $T$ \\
\hline $\begin{array}{c}\text { Gypsum } \\
\mathrm{CaSO}_{4} \cdot 2 \mathrm{H}_{2} \mathrm{O}\end{array}$ & equilibrium & NA & NA & NA & & NA & & N.A. \\
\hline $\begin{array}{l}\text { Fluorite } \\
\mathrm{CaF}_{2}\end{array}$ & $1.22 \times 10^{-7(j)}$ & 0.0 & 1 & 2 & & Reversible & $\begin{array}{c}\mathrm{k}_{+/-}: \text {Knowles-Van Cappellan } \\
\text { et al. 1997 [DIRS } \\
124306 \text { ], p. } 1873 \\
\end{array}$ & N.Q. \\
\hline $\begin{array}{l}\text { Hematite } \\
\mathrm{Fe}_{2} \mathrm{O}_{3}\end{array}$ & $7.32 \times 10^{-13}$ & $\begin{array}{l}60.9-64.9 \\
\text { (set to } \\
\text { amorphous } \\
\text { silica) }\end{array}$ & & & & $\begin{array}{l}\text { Reversible, rate } \\
\text { constant set to } \\
\text { amorphous silica }\end{array}$ & NA & $?$ \\
\hline $\begin{array}{c}\text { Glass (vitrophyre; } \\
\text { hydglassfe3) }\end{array}$ & $7.72 \times 10^{-15(\mathrm{k})}$ & 91.0 & 1 & 1 & & $\begin{array}{l}\text { Dissolution, no } \\
\text { precipitation }\end{array}$ & $\begin{array}{c}\mathrm{k}_{+/-}: \text {Mazer et al. } 1992 \text { [DIRS } \\
\text { 124354], p. } 574\end{array}$ & $T$ \\
\hline
\end{tabular}

(a) $\mathrm{k}_{+/ .}$: dissolution/precipitation rate constants at $298.15 \mathrm{~K}$; some values may slightly differ from source values due to unit conversions.

(b) $E_{a}$ : Activation energy; some values may differ slightly from source values due to unit conversions.

(c) Exponents $\mathrm{m}$ and $\mathrm{n}$ in Equation 6 (Section 6.4-8).

(d) Formulas are given only for instances where rates were calculated from data in cited references. No formulas are given if the rate was taken directly from the cited references.

(e) "no precipitation" means precipitation of this mineral is not allowed; "reversible" indicates that the absolute values of the precipitation rate constant are equal to the dissolution rate constant.

(f) For the qualification methods, "C" denotes data qualified by Criterion 2 (Corroborating Data), "T" denotes data qualified by Criterion 5 (Technical Assessment), "NA" denotes not applicable (which is used when the dissolution reaction is rapid enough the equilibrium may be assumed), "E" denotes an estimated value that is usually based on using qualified data for a chemically related mineral, and "NQ" means not qualified. If different methods are used to qualify and $k_{+/-}$and $E_{a}$, then the first entry refers to $k_{+/-}$and the second to $E_{a}$. 
(g) The \pm error limits represent fits to a $95 \%$ confidence level; the overall logk error using a geometric area basis was estimated by the authors to be \pm 0.63 .

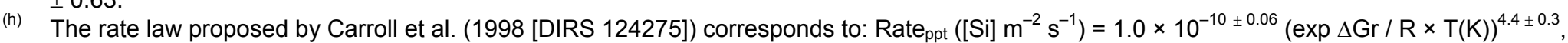
temperature dependence is accounted for in the rate law.

(i) $\mathrm{R}_{E M P}=\alpha\left(1-\mathrm{C} / \mathrm{C}_{\mathrm{s}}\right) ; \alpha$ denotes the rate constant, $\mathrm{C}$ the $\mathrm{Ca}^{2+}$ conc. in solution and $\mathrm{C}_{\mathrm{s}}$ the equil. conc. of $\mathrm{Ca}^{2+}$ with respect to calcite.

(i) $\mathrm{k}_{0}$ calculated from linear growth rate of Knowles-Van Cappellan et al. (1997 [DIRS 124306], p. 1873); for details of calculations, see Scientific Notebook YMP-LBNL-YWT-ELS-1 (Sonnenthal 2000 [DIRS 154870], p. 44).

(k) Recalculated rate constant based on diffusion-limited model of Mazer et al. (1992 [DIRS 124354], p. 574); for details of calculations, read text and/or see Scientific Notebook YMP-LBNL-YWT-ELS-1 (Sonnenthal 2000 [DIRS 154870], p. 43). 


\section{H.4 SILICA PHASES $\alpha$-CRISTOBALITE, QUARTZ, AMORPHOUS SILICA, TRIDYMITE, AND OPAL-PROXY}

To derive reaction rates for quartz and amorphous silica, Rimstidt and Barnes (1980 [DIRS 101708]) performed closed-system dissolution and precipitation experiments at temperatures between $18^{\circ} \mathrm{C}$ and $305^{\circ} \mathrm{C}$, using distilled water and Barnes-type rocking autoclaves (Barnes 1971 [DIRS 160181]), as well as a system for circulating hydrothermal fluids, and they compiled their results along with data reported by other investigators. Measurements by Rimstidt and Barnes, and the other studies cited by them, were made with a variety of different silica samples: quartz sand, fused silica powder, silica gel, porous leached glass, and quartz powder with disturbed surfaces. According to the assessed results of Rimstidt and Barnes (1980 [DIRS 101708], Table 4), which includes not only their data, but also data from numerous other studies, the activation energies for dissolution of the silica polymorphs are: for quartz, $E_{a}=67.4$ to $76.6 \mathrm{~kJ} \mathrm{~mol}^{-1}$; for $\alpha$-cristobalite, $E_{a}=68.7 \mathrm{~kJ} \mathrm{~mol}^{-1}$; for $\beta$-cristobalite, $E_{a}=65.0 \mathrm{~kJ} \mathrm{~mol}^{-1}$; and for amorphous silica, $E_{a}=60.9$ to $64.9 \mathrm{~kJ} \mathrm{~mol}^{-1}$. These values are nearly the same, indicating that the rate-limiting step for these reactions is the breaking of strong Si-O bonds. Figure 4 of Rimstidt and Barnes is an Arrhenius plot for precipitation of silica polymorphs ( $\log k_{-}$as a function of the inverse of the temperature). This plot indicates that values of $k_{-}$for precipitation of the various silica polymorphs coincide within experimental error, which is expected because the same activated complex in solution should control the precipitation rates, with the least-squares value being $E_{a}=49.8 \mathrm{~kJ} \mathrm{~mol}^{-1}$. The dissolution rate constant of amorphous silica, $7.32 \times 10^{-13} \mathrm{~mol} \mathrm{~m}^{-2} \mathrm{~s}^{-1}$, was taken from these authors and that of opal-proxy set to the same value. More recently, Carroll et al. (1998 [DIRS 124275], p. 1386 and Table 3) report $E_{a}=61 \pm$ $1 \mathrm{~kJ} \mathrm{~mol}^{-1}$ for precipitation from slightly acidic solutions $(\mathrm{pH}=3$ to 7$)$, and $E_{a}=50 \mathrm{~kJ} \mathrm{~mol}^{-1}$ for precipitation from near-neutral solutions $(\mathrm{pH}=7$ to 8$)$.

More recent data on quartz dissolution kinetics have been provided by Tester et al. (1994 [DIRS 101732], p. 2410). The dissolution experiments of these authors spanned temperatures from $23^{\circ} \mathrm{C}$ to $255^{\circ} \mathrm{C}$, and were conducted using five different apparatuses. The results of these experiments, combined with data from 10 previous investigations ranging up to $625^{\circ} \mathrm{C}$, including those of Rimstidt and Barnes (1980 [DIRS 101708, p. 2407]), revealed a dissolution-rate variation of eleven orders of magnitude over the studied temperature range (e.g., from $4 \times 10^{-14}$ to $1 \times 10^{-3} \mathrm{~mol} \mathrm{~m}^{-2} \mathrm{~s}^{-1}$ ). The selected values in Table H.3-1 for the dissolution rate constant of quartz at $25^{\circ} \mathrm{C}$ on a geometric surface area basis $\left(k_{+}=4.52 \times 10^{-14} \mathrm{~mol} \mathrm{~m}^{-2} \mathrm{~s}^{-1}\right.$ and $E_{a}=90.1 \pm 2.5 \mathrm{~kJ} \mathrm{~mol}^{-1}$ ) were calculated from Tester et al.'s Equation 17a (1994 [DIRS 101732], p. 2415), and are based on an analysis of a combined set of consistent data from numerous independent studies.

In the course of reviewing the selected values in Table H.3-1, it was discovered that the accepted value of $k_{+}=4.52 \times 10^{-14} \mathrm{~mol} \mathrm{~m}^{-2} \mathrm{~s}^{-1}$ for quartz was based on use of the surface area determined by the "geometric area basis" by Tester et al. (1994 [DIRS 101732], p. 2415). The "geometric area basis" calculation is based on the approximation that the mineral particles have the same surface area as perfectly smooth spheres of similar size. Because mineral grains have irregular surfaces, the "geometric area basis" calculation significantly underestimates the true surface area. The authors also reported the surface area for one sample determined by BET 
measurements, and the value is about a factor of seven larger than the "geometric area basis" value. The more appropriate choices based on the BET surface area measurements are:

$$
k_{+}=1.04 \times 10^{-14} \mathrm{~mol} \mathrm{~m}^{-2} \mathrm{~s}^{-1}
$$

and

$$
E_{a}=87.7 \pm 4.7 \mathrm{~kJ} \mathrm{~mol}^{-1}
$$

calculated using Tester et al.'s Equation 17b (1994 [DIRS 101732], p. 2415). The two values of $E_{a}$ agree to well within their experimental uncertainties, but the values of $k_{+}$differ by a factor of 4 .

Experimentally based dissolution and precipitation rates for $\alpha$-cristobalite were determined by Renders et al. (1995 [DIRS 107088]). These closed-system experiments were conducted at high temperatures $\left(145^{\circ} \mathrm{C}\right.$ to $\left.301^{\circ} \mathrm{C}\right)$, and at water-saturation pressures. The determined activation energy for the precipitation of cristobalite, $E_{a}=52.9 \pm 10 \mathrm{~kJ} \mathrm{~mol}^{-1}$, was found to be, within the uncertainties, equal to those for quartz and amorphous silica determined by Rimstidt and Barnes (1980 [DIRS 101708], Table 4), $E_{a}=49.8 \mathrm{~kJ} \mathrm{~mol}^{-1}$. They also determined $E_{a}=68.9 \pm 11 \mathrm{~kJ} \mathrm{~mol}^{-1}$ for dissolution of synthetic $\alpha$-cristobalite. The dissolution rate constant of $\alpha$-cristobalite and tridymite (set to $\alpha$-cristobalite) at $25^{\circ} \mathrm{C}, k_{+}=3.45 \times 10^{-13} \mathrm{~mol} \mathrm{~m}^{-2} \mathrm{~s}^{-1}$, was calculated from Renders et al. (1995 [DIRS 107088], p. 77), using an equation given in their abstract (assuming the value $\mathrm{R}=8.314 \mathrm{~J} \mathrm{~K}^{-1} \mathrm{~mol}^{-1}$ ), and it is an extrapolated value obtained from higher-temperature data.

To investigate the effect of $\mathrm{pH}$, temperature, and aqueous silica concentration on the precipitation rates of amorphous silica, Carroll et al. (1998 [DIRS 124275], p. 1380 and Figure 3) performed laboratory and field experiments in the temperature range between $80^{\circ} \mathrm{C}$ and $150^{\circ} \mathrm{C}$, and the $\mathrm{pH}$ values between 3.0 and 8.7. Fluidized bed reactors (FBRs) and quartz sand were used in the field experiments, whereas laboratory rates were derived from experiments on silica gel. The starting materials were either dissolved in buffer solutions or geothermal waters until amorphous silica saturation was achieved. Results of the experiments reveal that, in the absence of impurities and in solutions supersaturated with respect to amorphous silica by a factor $<1.3$, precipitation rates have a first-order dependence, whereas in chemically complex field solutions, the precipitation mechanism changes from elementary reaction control to surface defect/surface nucleation control reflected by a nonlinear rate law. The overall activation energy was determined to be $E_{a}=50 \pm 3 \mathrm{~kJ} \mathrm{~mol}^{-1}$ (Carroll et al. 1998 [DIRS 124275], p. 1389). Carroll et al. (1998 [DIRS 124275], p. 1387 and Table 3) also reported $E_{a}=50 \mathrm{~kJ} \mathrm{~mol}^{-1}$ for precipitation from near-neutral solutions $(\mathrm{pH}=7$ to 8$)$, which is in good agreement with the value of $E_{a}=49.8 \mathrm{~kJ} \mathrm{~mol}^{-1}$ reported by Rimstidt and Barnes (1980 [DIRS 101708], Table 4).

There are several determinations of the activation energy for precipitation of various silica polymorphs at near-neutral $\mathrm{pHs}$ that are in very good agreement:

$$
\begin{aligned}
& E_{a}=49.8 \mathrm{~kJ} \mathrm{~mol}^{-1} \text { from Rimstidt and Barnes (1980 [DIRS 101708], Table 4), } \\
& E_{a}=52.9 \pm 10 \mathrm{~kJ} \mathrm{~mol}^{-1} \text { from Renders et al. (1995 [DIRS 107088], pp. 77, 81), and } \\
& E_{a}=50 \mathrm{~kJ} \mathrm{~mol}^{-1} \text { from Carroll et al. (1998 [DIRS 124275], Table 3). }
\end{aligned}
$$


Because of the three independent studies yielding results that corroborate each other, the selected value of $E_{a}=50 \mathrm{~kJ} \mathrm{~mol}^{-1}$ can be accepted with confidence. The selected values of $E_{a}$ for dissolution of the various polymorphs of silica (excluding quartz), in Table H.3-1, fall in a narrow range of $E_{a}=60.9$ to $68.7 \mathrm{~kJ} \mathrm{~mol}^{-1}$, and are based mainly on the measurements of Rimstidt and Barnes (1980 [DIRS 101708], Table 4), along with assessed results from numerous literature studies, and are supplemented for $\alpha$-cristobalite by results from the more recent study of Renders et al. (1995 [DIRS 107088], pp. 77, 81). Assessed values of $k_{+}$and $k_{-}$for the phases are taken from the same studies of Rimstidt and Barnes (1980 [DIRS 101708], Table 4 and Table 3) and Renders et al. (1995 [DIRS 107088], pp. 77, 81). These values are based on many independent studies yielding results that corroborate each other, and the assessed results can be accepted with confidence.

The selected values in Table H.3-1 for the dissolution rate constant of quartz at $25^{\circ} \mathrm{C}$ are $k_{+}=4.52 \times 10^{-14} \mathrm{~mol} \mathrm{~m}^{-2} \mathrm{~s}^{-1}$ and $E_{a}=90.1 \pm 2.5 \mathrm{~kJ} \mathrm{~mol}^{-1}$, which were calculated from Tester et al.'s Equation 17a (1994 [DIRS 101732], p. 2415) and are based on consistent data from numerous studies. However, as noted earlier in this section, these values are also based on use of the surface area determined by the "geometric area basis" by Tester et al. (1994 [DIRS 101732], p. 2415), which significantly underestimates the surface area of mineral grains. The more appropriate choices based on the BET surface area measurements are $k_{+}=1.04 \times 10^{-14} \mathrm{~mol} \mathrm{~m}^{-2} \mathrm{~s}^{-1}$ and $E_{a}=87.7 \pm 4.7 \mathrm{~kJ} \mathrm{~mol}^{-1}$, and were calculated from Tester et al.'s Equation $17 \mathrm{~b}$ (1994 [DIRS 101732], p. 2415). The two values of $E_{a}$ agree to well within their experimental uncertainties, with some of the difference being due to using dissolution rate constants for a wider temperature range for evaluation of the "geometric area basis" value. Given the uncertainties of these two $E_{a}$ values, the differences are not experimentally meaningful. Although the values of $k_{+}$differ by about a factor of 4 at $25^{\circ} \mathrm{C}$, both values agree within the scatter of the literature values used by Tester et al. (1994 [DIRS 101732]) in their evaluation, as indicated by Figures 8 and 9 of that study.

\section{H.5 ALBITE}

Various experimental determinations of the dissolution rate constant for low-albite $\mathrm{NaAlSi}_{3} \mathrm{O}_{8}$ have been compiled and summarized by Blum and Stillings (1995 [DIRS 126590], Table 3), and these studies cover the $\mathrm{pH}$ range from around 1 to over 12 and a temperature range of 5 to $300^{\circ} \mathrm{C}$. Figure 4 of that report shows the variation of $\log k_{+}$with $\mathrm{pH}$ at $25^{\circ} \mathrm{C}$. Experimental data from nine separate studies are plotted, and the data from eight of these studies are consistent within about $\pm 0.5 \mathrm{log}$ unit of a smooth curve through these data. The values of $\log k_{+}$are essentially independent of $\mathrm{pH}$ for the range $\mathrm{pH}=5$ to 8 , yielding $k_{+} \approx 10^{-16.15} \mathrm{~mol} \mathrm{~cm}^{-2} \mathrm{~s}^{-1}=7.08$ $\times 10^{-13} \mathrm{~mol} \mathrm{~m}^{-2} \mathrm{~s}^{-1}$ for this region. Precipitation of albite is assumed to occur at the same rate. The activation energies for albite dissolution under neutral $\mathrm{pH}$ conditions have been determined by various authors, e.g., Knauss and Wolery (1986 [DIRS 160184], pp. 2481 to 2497); Hellmann (1994 [DIRS 160183], Table 6). Based on these compiled data, Blum and Stillings (1995 [DIRS 126590], Table 2) calculated an apparent activation energy of $67.7 \mathrm{~kJ} \mathrm{~mol}^{-1}$, which was accepted and used in the THC simulations. It should be noted that the activation energy, $E_{a}=68.8 \pm 4.5 \mathrm{~kJ} \mathrm{~mol}^{-1}$, determined by Hellmann (1994 [DIRS 160183], Table 6) is very close to this value, whereas those values determined by two of the other authors are lower, ranging 
between 51 and $54 \mathrm{~kJ} \mathrm{~mol}^{-1}$. Because of the numerous independent studies yielding results that corroborate each other, the assessed results in Table H.3-1 can be accepted with confidence.

\section{H.6 K-FELDSPARS}

Various experimental determinations of the dissolution rate constant for various K-feldspars have been compiled and summarized by Blum and Stillings (1995 [DIRS 126590], Table 4), and these studies cover the $\mathrm{pH}$ range from around 1 to over 12 and temperature range of 5 to $200^{\circ} \mathrm{C}$. Figure 5 of that report shows the variation of $\log k_{+}$with $\mathrm{pH}$ at $25^{\circ} \mathrm{C}$. Experimental data from six separate studies are plotted, involving data measured for feldspars from different locations, and they are consistent within about $\pm 0.5 \mathrm{log}$ unit of a smooth curve through these data. The values of $\log k_{+}$are essentially independent of $\mathrm{pH}$ for the range $\mathrm{pH}=5$ to 11 , yielding $k_{+} \approx 10^{-16.75}$ mol $\mathrm{cm}^{-2} \mathrm{~s}^{-1}$, which is equivalent to $k_{+}=1.78 \times 10^{-13} \mathrm{~mol} \mathrm{~m}^{-2} \mathrm{~s}^{-1}$ for this $\mathrm{pH}$ region. The activation energy for $\mathrm{K}$-feldspar dissolution in neutral $\mathrm{pH}$ environments is given by Blum and Stillings (1995 [DIRS 126590], Table 2) as ranging between 35 and $38 \mathrm{~kJ} \mathrm{~mol}^{-1}$ for neutral $\mathrm{pH}$. In the THC simulations an average activation energy value of $E_{a}=36 \mathrm{~kJ} \mathrm{~mol}^{-1}$ was used. The dissolution rate constant is assumed to be the same as that for precipitation. Because of the six independent studies yielding results that corroborate each other, the assessed results in Table H.3-1 can be accepted with confidence. Results for the feldspars microcline and sanidine essentially coincide on Figure 5 of Blum and Stillings (1995 [DIRS 126590]) and therefore the dissolution rate constants of microcline $\mathrm{KAlSi}_{3} \mathrm{O}_{8}$ and all other $\mathrm{K}$-feldspar phases were assumed to be the same.

\section{H.7 ANORTHITE}

The dissolution rate constants for anorthite, $\mathrm{CaAl}_{2} \mathrm{Si}_{2} \mathrm{O}_{8}$, are discussed by Brady and Walther (1989 [DIRS 110748], pp. 2823 to 2830) and Blum and Stillings (1995 [DIRS 126590], pp. 292 to 342). The rate constant in the neutral $\mathrm{pH}$ region was estimated from Brady and Walther's Figure 4, which is a plot of $\log k_{+}$against $\mathrm{pH}$. The values of $\log k_{+}$are essentially independent of $\mathrm{pH}$ for the range $\mathrm{pH}=5$ to 7 , yielding $k_{+} \approx 10^{-15.5} \mathrm{~mol} \mathrm{~cm} \mathrm{c}^{-1}$, which is equivalent to $k_{+}=3.16$ $\times 10^{-12} \mathrm{~mol} \mathrm{~m}^{-2} \mathrm{~s}^{-1}$ at $25^{\circ} \mathrm{C}$ for this $\mathrm{pH}$ region. This value is based on data from three concordant studies. Because the three independent studies yield results that corroborate each other, the assessed results in Table H.3-1 can be accepted with confidence. The only value of the activation energy for anorthite dissolution in the neutral $\mathrm{pH}$ range that was located is listed by Blum and Stillings (1995 [DIRS 126590], Table 2) as $E_{a}=107 \mathrm{~kJ} \mathrm{~mol}^{-1}$. Blum and Stillings (1995 [DIRS 126590], Table 2) also list values from dissolution measurements at acidic pHs, and these values range from $E_{a}=18.4$ to $80.7 \mathrm{~kJ} \mathrm{~mol}^{-1}$. This value of $E_{a}=107 \mathrm{~kJ} \mathrm{~mol}^{-1}$ for neutral solutions is much larger than those reported for chemically related minerals albite and K-feldspars, which is unlikely, and its value was estimated as being the same as for the chemically similar low albite, $E_{a}=67.7 \mathrm{~kJ} \mathrm{~mol}^{-1}$ (Blum and Stillings 1995 [DIRS 126590], Table 2).

\section{H.8 MUSCOVITE, ILLITE, SMECTITE, SEPIOLITE (CLAY MINERALS)}

Knauss and Wolery (1989 [DIRS 124300], pp. 1493 to 1501) measured the dissolution rates of electronic grade ruby mica muscovite as a function of $\mathrm{pH}$ and at $70^{\circ} \mathrm{C}$. They performed 11 experiments spanning the $\mathrm{pH}$ range of 1.4 to 11.8 at roughly equal intervals of $\mathrm{pH}$. The 
50-day dissolution experiments were conducted in a single-pass, flow-through apparatus (open-system) using muscovite grains of $100 \mu \mathrm{m}$ size and dilute buffer solutions. The mica grains were ultrasonically cleaned to remove finer particles. The composition of their mica, as determined from 20 analyses using an electron microprobe, was $\mathrm{K}_{1.84} \mathrm{Na}_{0.16}\left(\mathrm{Al}_{3.75} \mathrm{Fe}_{0.22} \mathrm{Mg}_{0.12} \mathrm{Ti}_{0.02}\right)\left(\mathrm{Si}_{6.06} \mathrm{Al}_{1.92} \mathrm{O}_{20}\right)(\mathrm{OH})_{4}$. To determine dissolution rates under far from equilibrium conditions, the ionic strengths of the reacting solutions were very low $\left(3.0 \times 10^{-4}\right.$ to $\left.0.13 \mathrm{~mol} \mathrm{~kg}^{-1}\right)$ and solutions were undersaturated with respect to muscovite or any other possible secondary phase. The concentrations of silicon and aluminum released during dissolution were determined using inductively coupled plasma emission spectroscopy, and those of potassium by atomic absorption spectroscopy. The specific surface area of the muscovite was determined by BET surface area analysis using argon gas and was found to be $1.10 \mathrm{~m}^{2} \mathrm{~g}^{-1}$.

Based on their experimental results, Knauss and Wolery (1989 [DIRS 124300], p. 1500) derived a generalized rate expression describing the dissolution behavior of muscovite under far from equilibrium conditions and at any $\mathrm{pH}$ :

$$
r=10^{-14.7}\left[a_{H^{+}}\right]^{-0.37}+10^{-16.6}+10^{-18.1}\left[a_{H^{+}}\right]^{+0.22}
$$

The rate constant for near-neutral $\mathrm{pH}$ conditions at $25^{\circ} \mathrm{C}$ was calculated by assuming surface-controlled dissolution with an activation energy of $E_{a}=\left(14 \mathrm{kcal} \mathrm{mol}^{-1}\right)\left(4.184 \mathrm{~kJ} \mathrm{kcal}^{-1}\right)$ $=58.6 \mathrm{~kJ} \mathrm{~mol}^{-1}$, which yields $k_{+}=1.0 \times 10^{-14} \mathrm{~mol} \mathrm{~m}^{-2} \mathrm{~s}^{-1}$ (Knauss and Wolery 1989 [DIRS 124300], p. 1500).

The dissolution rate constant for illite was assumed to be the same as the dissolution rate constant given by Knauss and Wolery (1989 [DIRS 124300]) for muscovite. The rate constant was adjusted with respect to the number of oxygens per formula unit $\left(k_{+}\right.$multiplied by 2$)$ to account for differences in chemical formula between their muscovite and the illite stoichiometry, $\mathrm{K}_{0.5}\left(\mathrm{Mg}_{0.22} \mathrm{Al}_{1.78}\right)\left(\mathrm{Si}_{3.72} \mathrm{Al}_{0.28} \mathrm{O}_{10}\right)(\mathrm{OH})_{2}$, assumed here. The rate constants of the $\mathrm{Ca}, \mathrm{Mg}$, and $\mathrm{Na}$ smectites were assumed to be the same as that for illite (determined from muscovite), with a correction for the difference in the number of the oxygens per formula unit between muscovite and smectite (in this case, the original muscovite rate was multiplied by a factor of 2). The assumed smectite compositions are $\mathrm{Ca}_{0.145}\left(\mathrm{Mg}_{0.26} \mathrm{Al}_{1.74}\right)\left(\mathrm{Si}_{3.97} \mathrm{Al}_{0.03} \mathrm{O}_{10}\right)(\mathrm{OH})_{2}$, $\left(\mathrm{Mg}_{0.405} \mathrm{Al}_{1.74}\right)\left(\mathrm{Si}_{3.97} \mathrm{Al}_{0.03} \mathrm{O}_{10}\right)(\mathrm{OH})_{2}$, and $\mathrm{Na}_{0.29}\left(\mathrm{Mg}_{0.26} \mathrm{Al}_{1.74}\right)\left(\mathrm{Si}_{3.97} \mathrm{Al}_{0.03} \mathrm{O}_{10}\right)(\mathrm{OH})_{2}$, respectively.

No measurements were located for the rates of precipitation and dissolution of sepiolite in the aqueous phase. Because sepiolite belongs to the same class (phyllosilicates) as the clay minerals and mica, its estimated dissolution/precipitation rate constant was based on the rate constant of muscovite. The sepiolite formula of the TOUGHREACT V3.0 database (thermk1.01.dat, derived in DTN: LB0307THMDBRTM.001 [DIRS 164434]) contains 7.5 oxygens per formula unit, $\mathrm{Mg}_{2} \mathrm{Si}_{3} \mathrm{O}_{7.5} \mathrm{OH} \cdot 3 \mathrm{H}_{2} \mathrm{O}$, compared to 20 oxygens in the muscovite formula of Knauss and Wolery (1989 [DIRS 124300], p. 1495); therefore, the rate constant of Knauss and Wolery was consequently adjusted by a factor of $(20 / 7.5)=2.67$ to account for the difference in size between these structural units. 
The assessed value of $k_{+/-}$for ruby muscovite determined by Knauss and Wolery (1989 [DIRS 124300], p. 1500) at $70^{\circ} \mathrm{C}$ can be accepted with confidence. This technical assessment is based on the authors' detailed description of their use of a variety of experimental techniques to characterize the chemical and mineralogical composition of their muscovite sample and analyses of solution concentrations, along with the very detailed presentation of their experimental results. However, the value of $k_{+}$at $25^{\circ} \mathrm{C}$ is also based on an assumed value of the activation energy. The assessed dissolution rate constants in this report (Table H.3-1) for dissolution of most silicate minerals fall in the range of $k_{+}=1 \times 10^{-14} \mathrm{~mol} \mathrm{~m}^{-2} \mathrm{~s}^{-1}$ to $3 \times 10^{-12} \mathrm{~mol} \mathrm{~m}^{-2} \mathrm{~s}^{-1}$. The estimated values of $k_{+/}$for clay minerals in Table H.3-1 fall in this range and are likely to be correct within an order of magnitude.

\section{H.9 KAOLINITE}

The dissolution rate constant of kaolinite, $\mathrm{Al}_{2} \mathrm{Si}_{2} \mathrm{O}_{5}(\mathrm{OH})_{4}$, was estimated from a graph in Brady and Walther (1989 [DIRS 110748], Figure 6), based on measurements from their laboratory. According to this figure, the dissolution rate constant in the $\mathrm{pH}$ region between 5 and 8 is equal to $10^{-17.3} \mathrm{~mol} \mathrm{~cm}^{-2} \mathrm{~s}^{-1}$, which is equivalent to $k_{+}=5 \times 10^{-14} \mathrm{~mol} \mathrm{~m}^{-2} \mathrm{~s}^{-1}$. This value is supported by subsequent measurements of Carroll and Walther (1990 [DIRS 160681], Figure 2), which yield a value of $k_{+} \approx 10^{-12.9} \mathrm{~mol} \mathrm{~m}^{-2} \mathrm{~s}^{-1}=1.3 \times 10^{-13} \mathrm{~mol} \mathrm{~m}^{-2} \mathrm{~s}^{-1}$ at $\mathrm{pH}=7$. Carroll and Walther reported careful dissolution measurements for kaolinite at 25,60 , and $80^{\circ} \mathrm{C}$ in buffered solutions with a wide range of solution $\mathrm{pHs}(\mathrm{pH} \sim 1$ to 12$)$. The average value from these two studies is $(0.9 \pm 0.4) \times 10^{-13} \mathrm{~mol} \mathrm{~m} \mathrm{~m}^{-2} \mathrm{~s}^{-1}$, which was rounded off to $k_{+}=1 \times 10^{-13} \mathrm{~mol} \mathrm{~m}^{-2} \mathrm{~s}^{-1}$ for the accepted value. The values derived by Carroll and Walther (1990 [DIRS 160681], p. 797) for the activation energy vary strongly with $\mathrm{pH}$, and at $\mathrm{pH}=7$ the value is $E_{a}=\left(1.7 \mathrm{kcal} \mathrm{mol}^{-1}\right)\left(4.184 \mathrm{~kJ} \mathrm{kcal}^{-1}\right)=7.1 \mathrm{~kJ} \mathrm{~mol}^{-1}$. Because the results of the two studies yield results that corroborate each other, and because the measurements were made in Walther's laboratory (Walther is one of the leading researchers in mineral dissolution studies), the assessed results in Table H.3-1 can be accepted with confidence.

\section{H.10 ZEOLITES}

Ragnarsdóttir (1993 [DIRS 126601], pp. 2442 to 2447) determined the dissolution rates for heulandite in the $\mathrm{pH}$ range 2.0 to 12.2 and at $(25 \pm 2)^{\circ} \mathrm{C}$, at conditions maintained far from equilibrium, by measuring the concentrations of silica, aluminum, calcium, sodium, and potassium that were released into solution upon dissolution. The dissolution experiments were performed in fluidized-bed reactors using various solutions and buffers. The sieved grain size fraction used in the experiments ranged between 75 and $125 \mu \mathrm{m}$ with a surface area determined by krypton BET analysis being $1715 \pm 11 \mathrm{~cm}^{2} \mathrm{~g}^{-1}$. The structural formula of heulandite, $\mathrm{Na}_{2.2} \mathrm{~K}_{1.4} \mathrm{Ca}_{2.2} \mathrm{Al}_{14.2} \mathrm{Si}_{23.3} \mathrm{O}_{72} \cdot 24 \mathrm{H}_{2} \mathrm{O}$, was determined by electron microprobe analysis. The stability of various zeolites was described in terms of their dependence on $\mathrm{pH}$ and sodium concentration. Alumina and silica release at intermediate and high $\mathrm{pH}$ were approximately stoichiometric, whereas at low $\mathrm{pH} \mathrm{Al}$ was released preferentially compared to $\mathrm{Si}$, resulting in the formation of a residual Si-rich surface layer. Steady-state dissolution rates plotted as function of pH (see Ragnarsdóttir 1993 [DIRS 126601], Figure 9) show a characteristic U-shaped pattern, typical of most silicates, with decreasing rates from $\mathrm{pH} 2$ to about 5.5, a $\mathrm{pH}$-independent dissolution rate in the near-neutral and neutral $\mathrm{pH}$ region, and increasing rates in the high $\mathrm{pH}$ 
region ( $\mathrm{pH}=7$ to 12 ). The dissolution rate constant at $\mathrm{pH}=7.2$ is $k_{+}=10^{-11.8} \mathrm{~mol} \mathrm{~m}^{-2} \mathrm{~s}^{-1}$, or $1.585 \times 10^{-12} \mathrm{~mol} \mathrm{~m}^{-2} \mathrm{~s}^{-1}$. Because the steady-state dissolution rates for heulandite given by Ragnarsdóttir (1993 [DIRS 126601], pp. 2442 to 2447) were based on the rate of silica release into solution, the value of the rate constant was divided by a factor of 2.8 to give $k_{+}=5.66 \times$ $10^{-13} \mathrm{~mol} \mathrm{~m} \mathrm{~s}^{-2} \mathrm{~s}^{-1}$, corresponding to the number of silica formula units contained in the heulandite formula used here, $\mathrm{Ca}_{0.33} \mathrm{~K}_{0.04} \mathrm{Na}_{0.1} \mathrm{Al}_{0.8} \mathrm{Si}_{2.8} \mathrm{O}_{7.2} \cdot 2.6 \mathrm{H}_{2} \mathrm{O}$. The rate constants of stellerite and mordenite were taken as having the same value. Ragnarsdóttir assumed an activation energy of $E_{a}=58 \mathrm{~kJ} \mathrm{~mol}^{-1}$ for the dissolution of heulandite based on the value obtained by Savage et al. (1993 [DIRS 160198], p. 533) for laumontite, and this value was accepted for the other zeolites.

Murphy et al. (1996 [DIRS 142167], pp. 128 to 186) conducted long-term batch-type experiments to study the dissolution and growth kinetics of a Na-clinoptilolite that is isostructural with Ragnarsdóttir's (1993 [DIRS 126601]) heulandite. The measurements of Murphy et al. were made at $25^{\circ} \mathrm{C}$ and $\mathrm{pH} \approx 9$. The authors chose the 100 to 200 mesh size fraction $(75-150 \mu \mathrm{m})$ for their experiments, and the surface area of the Na-clinoptilolite was determined by $\mathrm{N}_{2}$ gas BET analysis to be $10.1 \pm 0.3 \mathrm{~m}^{2} \mathrm{~g}^{-1}$. The experimental system was open to atmospheric $\mathrm{CO}_{2}$, and the initial solutions $\left(\mathrm{NaCl}-\mathrm{NaHCO}_{3}\right.$ mixtures) were pre-equilibrated for several days before the solid was added. The authors reported very detailed analysis results for the solution concentrations of sodium, silica, and aluminum as a function of time. The $\mathrm{Na}$ concentrations were determined using a Na-ion selective electrode, and the $\mathrm{SiO}_{2}$ and $\mathrm{Al}$ were determined with their colored complexes using UV-visible spectrophotometry. The dissolution rate constant of Na-clinoptilolite given by these authors corresponds to $7.1 \times 10^{-14} \mathrm{~mol} \mathrm{~m}^{-2} \mathrm{~s}^{-1}$ and was determined for a chemical formula based on 24 structural oxygens per formula unit, $\mathrm{Na}_{2} \mathrm{Al}_{2} \mathrm{Si}_{10} \mathrm{O}_{24} \cdot 8 \mathrm{H}_{2} \mathrm{O}$. Because the clinoptilolite formula used here is based on 7.2 oxygens per formula unit, $\mathrm{Ca}_{0.28} \mathrm{~K}_{0.08} \mathrm{Na}_{0.04} \mathrm{Al}_{0.68} \mathrm{Si}_{2.92} \mathrm{O}_{7.2} \cdot 2.6 \mathrm{H}_{2} \mathrm{O}$, the rate constant was multiplied by a factor $(24 / 7.2)=3.33$ to account for the difference between these chemical formulas. An activation energy of $E_{a}=58 \mathrm{~kJ} \mathrm{~mol}^{-1}$ for the dissolution of Na-clinoptilolite is based on the value obtained by Savage et al. (1993 [DIRS 160198], p. 533) for laumontite.

The assessed results given in Table H.3-1 for $k_{+/-}$of heulandite and Na-clinoptilolite at $25^{\circ} \mathrm{C}$ can be accepted with confidence. This technical assessment is based on the authors' detailed description of their use of a variety of experimental techniques to characterize the chemical and mineralogical composition of their mineral, and the determination of the solution concentrations as a function of time. However, the values of $E_{a}$ are estimated from an experimental value for a chemically related mineral, as are $k_{+/}$values for other zeolites.

\section{H.11 CALCITE}

Svensson and Dreybrodt (1992 [DIRS 127978], pp. 129 to 145) investigated the dissolution kinetics of various natural carbonate samples (e.g., marbles, limestones, calcareous marine pelagic sediments) and National Bureau of Standards (NBS) synthetic calcite. The batch experiments (free drift technique) were conducted on the $100 \mu \mathrm{m}$ sieved fractions, at $20^{\circ} \mathrm{C}$ in aqueous $\mathrm{CO}_{2}$ solutions $\left(\mathrm{CO}_{2}\right.$ pressure of $\left.5 \times 10^{-3} \mathrm{~atm}\right)$ under close to equilibrium conditions with respect to calcite. Calcium and magnesium solution concentrations were analyzed using inductively coupled plasma mass spectrometry. The dissolution rates of the natural carbonate samples were fitted by the authors to an empirical rate law of the form: 


$$
\mathrm{R}_{\mathrm{EMP}}=\alpha_{1}\left(1-\mathrm{C} / \mathrm{C}_{\mathrm{s}}\right)^{\mathrm{n}}
$$

with values for $\mathrm{n}$ being different when $C \leq(0.6-0.8) C_{\mathrm{s}}$ and when $C>0.8 C_{\mathrm{s}}$, where $C$ denotes the $\mathrm{Ca}^{2+}$ concentration in the solution and $C_{\mathrm{s}}$ the equilibrium concentration of $\mathrm{Ca}^{2+}$ with respect to a saturated solution of calcite. The $\alpha$ denotes a rate constant. Literature data at 5,15 , and $25^{\circ} \mathrm{C}$ were analyzed with the same rate law. In contrast, NBS synthetic calcite was found to exhibit a linear-rate law of the form:

$$
\mathrm{R}=\alpha\left(1-\mathrm{C} / \mathrm{C}_{\mathrm{s}}\right)
$$

Furthermore, the results revealed lower rates for the natural samples than those of pure calcite. The different dissolution behavior of the natural samples and pure calcite is attributed to adsorbed impurities on the surface of the natural samples, as well as other unknown dissolution inhibitors that may have been present during the formation of these natural phases.

In the THC seepage model, because of the quite rapid calcite reaction rates, this mineral is set to precipitate under equilibrium conditions. In other THC simulations, the dissolution rate constant determined for the synthetic NBS calcite is used.

Svensson and Dreybrodt did not determine any activation energies for the dissolution reactions. Thus, an activation energy value of $E_{a}=48.1 \mathrm{~kJ} \mathrm{~mol}^{-1}$ determined by Inskeep and Bloom (1985 [DIRS 128129], p. 2165), from seeded calcite growth measurements, is used in those simulations where kinetics dissolution/precipitation are considered.

The assessed results given in Table H.3-1 for $E_{a}$ can be accepted with confidence. In the course of reviewing this document, however, it was discovered that that the accepted value of $k_{+/-}=1.60 \times 10^{-6} \mathrm{~mol} \mathrm{~m}^{-2} \mathrm{~s}^{-1}$ was appropriate for the experimental temperature of $20^{\circ} \mathrm{C}$ rather than the assumed $25^{\circ} \mathrm{C}$. Svensson and Dreybrodt (1992 [DIRS 127978], Table 2) also analyzed literature data and their results imply that $k_{+/-}=1.9 \times 10^{-6} \mathrm{~mol} \mathrm{~m}^{-2} \mathrm{~s}^{-1}$ is a more appropriate choice for $25^{\circ} \mathrm{C}$, which is $19 \%$ larger. This value was taken from Svensson and Dreybrodt (1992 [DIRS 127978], Table 2) for measurements made with a $\mathrm{CO}_{2}$ pressure of $3 \times 10^{-3} \mathrm{~atm}$. Given the experimental uncertainty in the dissolution rate constant of Svensson and Dreybrodt and other studies cited by them, the $19 \%$ difference between the two values is negligible compared to the experimental error.

\section{H.12 GYPSUM}

The dissolution/precipitation rate constant for gypsum, $\mathrm{CaSO}_{4} \cdot 2 \mathrm{H}_{2} \mathrm{O}$, is quite high: $k_{+/} \sim 10^{-3}$ mol m$~^{-2} \mathrm{~s}^{-1}$ (see Jeschke et al. 2001 [DIRS 161694], p. 27, and references cited by them). This rate constant is many orders of magnitude larger than the rate constants for other minerals in this report (which is expected behavior because of its larger solubility), and consequentially it may be assumed to be at equilibrium with its solutions for modeling purposes. Thus, no values of $k_{+/}$ and $E_{a}$ need to be assigned for gypsum. 


\section{H.13 FLUORITE}

Knowles-Van Cappellen et al. (1997 [DIRS 124306], pp. 1871 to 1877) conducted seeded fluorite $\left(\mathrm{CaF}_{2}\right)$ growth experiments at $\mathrm{T}=25 \pm 0.1{ }^{\circ} \mathrm{C}$ and $\mathrm{pH}$ values ranging between 5.1 and 5.6. (Experiments at lower $\mathrm{pH}$ values are not desirable because the dissolution rate and solubility are increased by formation of neutral HF in solution.) After pre-equilibration of the seeded solutions and initial saturation of solutions with respect to fluorite, the titrants $0.200 \mathrm{~mol}$ $\mathrm{L}^{-1} \mathrm{NaF}$ and $0.100 \mathrm{~mol} \mathrm{~L}^{-1} \mathrm{Ca}\left(\mathrm{NO}_{3}\right)_{2}$ were added at a constant rate and samples periodically taken for grain size analysis. The experiments were performed at three different initial ionic strengths of $0.01,0.085$ and $0.1 \mathrm{~mol} \mathrm{~L}^{-1}$, with $\mathrm{NaNO}_{3}$ being added to control the ionic strength. Two different seed crystal concentrations were used in order to study both aggregating and non-aggregating conditions. Dynamic light scattering was use to determine the size and size distribution of the crystals in solution, and the initial surface area of the particles was determined to be $11.3 \mathrm{~m}^{2} \mathrm{~g}^{-1}$ by BET $\mathrm{N}_{2}$ gas absorption measurements. The experimental results indicate that at low relative degrees of supersaturation, the precipitation of fluorite is a surface-controlled process that can be described by a second-order rate law of the form:

$$
v=k^{l}(\mathrm{~S}-1)^{2}
$$

where $v$ is the linear growth rate (of cubic grains), $k_{l}$ is the linear-growth rate constant, which was determined to range between $k_{l}=1.4 \times 10^{-3}$ and $3.8 \times 10^{-3} \mathrm{~nm} \mathrm{~s}^{-1}$, and $(\mathrm{S}-1)$ corresponds to the relative degree of supersaturation (Knowles-Van Cappellen et al. 1997 [DIRS 124306], Equation 2, p. 1873).

The rate constant for fluorite dissolution/precipitation was recalculated as follows from the linear growth rate constants of Sonnenthal (2000 [DIRS 154870], Scientific Notebook YMP-LBNLYWT-ELS-1, p. 44):

$$
\text { rate constant }=(\text { linear growth rate }) / \text { molar volume }
$$

Assuming an intermediate linear growth rate of $3.0 \times 10^{-3} \mathrm{~nm} \mathrm{~s}^{-1}$ (Knowles-Van Cappellen et al. 1997 [DIRS 124306], p. 1873) and a molar fluorite volume of $24.542 \mathrm{~cm}^{3} \mathrm{~mol}^{-1}$, the rate constant was calculated as follows:

$\left.k_{0}=\left(\frac{3 \cdot 10^{-3} \mathrm{~nm}}{\mathrm{~s}}\right) \cdot\left(\frac{10^{-9} \mathrm{~m}}{\mathrm{~nm}}\right) /\left(\frac{24.542 \mathrm{~cm}^{3}}{\mathrm{~mol}}\right) \cdot\left(\frac{10^{-6} \mathrm{~m}^{3}}{\mathrm{~cm}^{3}}\right)\right]=1.2224 \cdot 10^{-7} \mathrm{~mol} \mathrm{~m}^{-2} \mathrm{~s}^{-1}$

The same rate constant was assumed to apply to dissolution of fluorite. Because the study by Knowles-Van Cappellen et al. (1997 [DIRS 124306], pp. 1871 to 1877) was restricted to $25^{\circ} \mathrm{C}$, the value of $E_{a}$ was set equal to zero. However the dissolution/precipitation rate constants for most minerals have a strong dependence on temperature, and the use of $E_{a}=0$ is likely to significantly underestimate the value of $k_{+/-}$at high temperatures.

The experiments of Knowles-Van Cappellen et al. (1997 [DIRS 124306], pp. 1871 to 1877) were described in detail and appear to have been performed with care. Unfortunately, their experimental rate constants were not reported (i.e., the information was only presented 
graphically and as values of $k_{l}$ ). Yucca Mountain pore waters are generally saturated with respect to fluorite, and it is present in trace amounts in the rock. Therefore, fluoride concentrations are controlled by fluorite solubility (Section 6.2.2.2), and the assumption that $E_{a}=0$ is expected to have negligible effect on predicted fluoride concentrations.

\section{H.14 HEMATITE AND GEOTHITE}

Very little dissolution of minerals containing $\mathrm{Fe}(\mathrm{III})$, such as hematite $\mathrm{Fe}_{2} \mathrm{O}_{3}$ and goethite $\mathrm{FeOOH}$, occur under oxic conditions at near-neutral $\mathrm{pH}$ values because of the extremely low solubility of $\mathrm{Fe}(\mathrm{III})$. However, in the presence of high acidity and certain bidentate ligands, the dissolution of Fe(III) becomes much larger (e.g., Hersman et al. 1995 [DIRS 160190], pp. 3327, 3329 to 3330). The dissolution mechanisms and the solubility of iron oxide minerals have been extensively studied in the last decades. A consensus seems to exist that proton- and ligand-promoted dissolution of iron oxide minerals can be described by surface complexation models. Very little data, however, exist on the dissolution and precipitation kinetics of these minerals, and especially for hematite. Hersman et al. (1995 [DIRS 160190], pp. 3327 to 3330) studied the effect of siderophores (highly specific, bidentate, iron chelating ligands produced by microorganisms), $3 \times 10^{-3} \mathrm{~mol} \mathrm{~L}^{-1}$ oxalate, and $2 \times 10^{-3} \mathrm{~mol} \mathrm{~L}^{-1}$ ascorbate ligands on dissolution of hematite at $\mathrm{pH}=3$ and temperature $21 \pm 0.5^{\circ} \mathrm{C}$. They determined a dissolution rate constant of $k_{+}=1.4 \times 10^{-11} \mathrm{~mol} \mathrm{~m}^{-2} \mathrm{~s}^{-1}$ in the presence of oxalate and ascorbate, and $k_{+}=3 \times 10^{-12} \mathrm{~mol} \mathrm{~m}^{-2}$ $\mathrm{s}^{-1}$ in the presence of siderophores at concentrations comparable to those in natural systems.

The thermodynamics and kinetics of hematite dissolution in bicarbonate solutions under constant $\mathrm{CO}_{2}$ pressure $(0.3 \mathrm{~atm}$ and $0.97 \mathrm{~atm})$ were studied at $25^{\circ} \mathrm{C}$ by Bruno et al. (1992 [DIRS 160189], pp. 1139 to 1147). Results of their investigation reveal that the dissolution of hematite under the above-mentioned conditions and total bicarbonate concentrations higher than $3.2 \times 10^{-3} \mathrm{~mol} \mathrm{~L}^{-1}$ is surface controlled and enhanced by the presence of bicarbonate ions. The rate expression given in their paper for the dissolution of hematite in the presence of bicarbonate is:

$$
\text { Rate }=k_{+}\left[\mathrm{HCO}_{3}{ }^{-}\right]^{0.23}
$$

with $k_{+}=3.9 \times 10^{-11} \mathrm{~mol} \mathrm{~m}^{-2} \mathrm{~s}^{-1}$ (Bruno et al. 1992 [DIRS 160189], p. 1139). The authors also stated that in the absence of $\mathrm{CO}_{2}$ they were unable to detect dissolution of hematite below the iron detection limit of $\approx 10^{-8} \mathrm{~mol} \mathrm{~L}^{-1}$. In neither the study by Hersman et al. (1995 [DIRS 160190], pp. 3327 to 3330) nor the study by Bruno et al. (1992 [DIRS 160189]) were measurements made at higher temperatures.

Because the rate law incorporated in the TOUGHREACT code so far does not take into account the inhibiting and/or catalyzing effects of aqueous ligands on the dissolution/precipitation rates, the above-mentioned literature data cannot be used. Because hematite and goethite are minor minerals in the tuffs, and Fe solubility is very low under the chemical conditions of the pore waters (e.g., near-neutral $\mathrm{pH}$ ), the assumption that aqueous concentrations are controlled by local equilibrium with one of these phases is appropriate. Thus, no rate constants were used for either of these phases. For the THC seepage model simulations discussed in this document, hematite was assumed to be the controlling phase. 


\section{H.15 GLASS (VITROPHYRE)}

To get insight into the alteration mechanisms of clay based, silica-rich glass, Mazer et al. (1992 [DIRS 124354], pp. 573 to 576) examined naturally occurring tektites (Indochinite) by optical microscopy, transmission electron microscopy, selected-area electron microdiffraction, and energy-dispersive X-ray spectroscopy to determine mineral phases present. The overall chemical composition of the tektites was determined by dissolving a sample in acid solution followed by chemical analysis using an inductively coupled plasma analysis. They performed dissolution experiments with polished monoliths of tektite under selected laboratory conditions. The alteration experiments were performed in the temperature range between 150 and $225^{\circ} \mathrm{C}$ at $25^{\circ} \mathrm{C}$ intervals and for periods between 3 and 400 days. Results of these experiments reveal that the degree of corrosion of the tektites strongly depends on the glass surface-to-water volume ratio $(\mathrm{S} / \mathrm{V})$. Under high-dilution conditions (low $\mathrm{S} / \mathrm{V}$ ratio), etching of the outer glass surface is the dominant reaction process. Under conditions of restricted water contact (high $\mathrm{S} / \mathrm{V}$ ratios), such as would be expected to occur at Yucca Mountain, the alteration process is initiated by water diffusion into the glass, followed by in situ hydrolysis of the silica network and formation of a poorly crystalline surface layer, which restructures with time to form a complete clay layer. The rate at which the thickness of the altered layer grows was measured using optical microscopy and with dark-field imaging using transmission electron microscopy. In this case, the dissolution rate of silica-rich glass follows the dependence of water diffusion through a reaction-product layer.

Because the volcanic glass in the rocks at Yucca Mountain is 12.5 to 13 million years old (Sawyer et al. 1994 [DIRS 100075], p. 1305), and has undergone varying degrees of alteration, a constant-thickness product layer on the glass surface was assumed for recalculation of the dissolution rate constant at $25^{\circ} \mathrm{C}$. The layer cannot be thicker than a typical grain diameter $(100 \mu \mathrm{m})$. However, if it were too thin, a typical grain would be completely dissolved in less than 10 million years. A thickness of $10 \mu \mathrm{m}$ results in an inferred grain thickness dissolved of about $30 \mu \mathrm{m}$, thus satisfying both the above requirements.

The water diffusion rate (hydration rate) at $25^{\circ} \mathrm{C}$ was extrapolated from the data obtained for the studied temperature region yielding $1.6 \times 10^{-7} \mu \mathrm{m}^{2} \mathrm{~d}^{-1}$ or $1.85 \times 10^{-24} \mathrm{~m}^{2} \mathrm{~s}^{-1}$ (Mazer et al. 1992 [DIRS 124354], pp. 574). The selected dissolution rate constant for the glass, $k_{+}=7.72 \times 10^{-15}$ mol m $\mathrm{m}^{-2} \mathrm{~s}^{-1}$, was calculated by applying Fick's law, assuming a uniform alteration layer of 10 $\mu \mathrm{m}$ thickness and spherical grain geometry (Sonnenthal 2000 [DIRS 154870], Scientific Notebook SN-LBNL-SCI-109-V1, p. 43). The selected value $E_{a}=91 \mathrm{~kJ} \mathrm{~mol}^{-1}$ was the experimental activation energy for water diffusion determined by Mazer et al. (1992 [DIRS 124354], p. 574).

These dissolution rate values are corroborated by data from Yokoyama and Banfield (2002 [DIRS 171364], Section 5), who measured rhyolite glass dissolution rates in field studies and laboratory experiments. Their field value $\left(\sim 6 \times 10^{-19} \mathrm{~mol} \mathrm{~cm}^{-2} \mathrm{~s}^{-1}\right.$, or $\left.\sim 6 \times 10^{-15} \mathrm{~mol} \mathrm{~m}^{-2} \mathrm{~s}^{-1}\right)$ corresponds closely to the dissolution rate used here. Their experimentally determined rates were one-to-two orders of magnitude higher, which they attribute to changes in the surface properties of the rhyolite glass during crushing, and to differences between the natural and laboratory weathering conditions. Based upon the laboratory experiments, Yokoyama and Banfield (2002 [DIRS 171364], Section 4.6.1) determined an activation energy of $63 \mathrm{~kJ} \mathrm{~mol}^{-1}$. 
This value is lower than the value used here, but the differences in the field and laboratory dissolution rates suggest that it may not be applicable to dissolution under natural conditions.

A technical assessment of the methods used by Mazer et al. (1992 [DIRS 124354], p. 573-576) also suggests that these data are high quality, based on the authors' detailed description of their use of a variety of experimental techniques to characterize the chemical and mineralogical composition of their tektite sample, and the rate at which the surface was altered by water.

Based upon corroborative data and technical assessment, the results given in Table H.3-1 can be accepted with confidence. However, because of the natural chemical variability of tektites and volcanic glasses, the listed value of the experimental rate constant $k_{+}=7.72 \times 10^{-15} \mathrm{~mol} \mathrm{~m}^{-2} \mathrm{~s}^{-1}$ at $25^{\circ} \mathrm{C}$ should be considered uncertain by about a factor of 10 when applied to natural glasses from different locations having significantly different chemical compositions.

\section{H.16 FINDINGS OF DATA QUALIFICATION EFFORT}

As described in the sections above, all data in DTN: LB0307KNTDBRTM.001 [DIRS 164433] have been evaluated by comparisons with corroborative data and by use of technical assessment. In all cases, the qualification criteria have been met, such that the data can be accepted with confidence. Based upon the above evaluation, DTN: LB0307KNTDBRTM.001 [DIRS 164433] is qualified for use by the Yucca Mountain Project.

\section{H.17 DATA QUALIFICATION PLAN}

See Figure H-1. 


\begin{tabular}{|l|l|l|}
\hline \multirow{2}{*}{ BSC } & Data Qualfication PLaN & QA: QA \\
\cline { 3 - 3 } & Page 1 of 1 \\
\hline
\end{tabular}

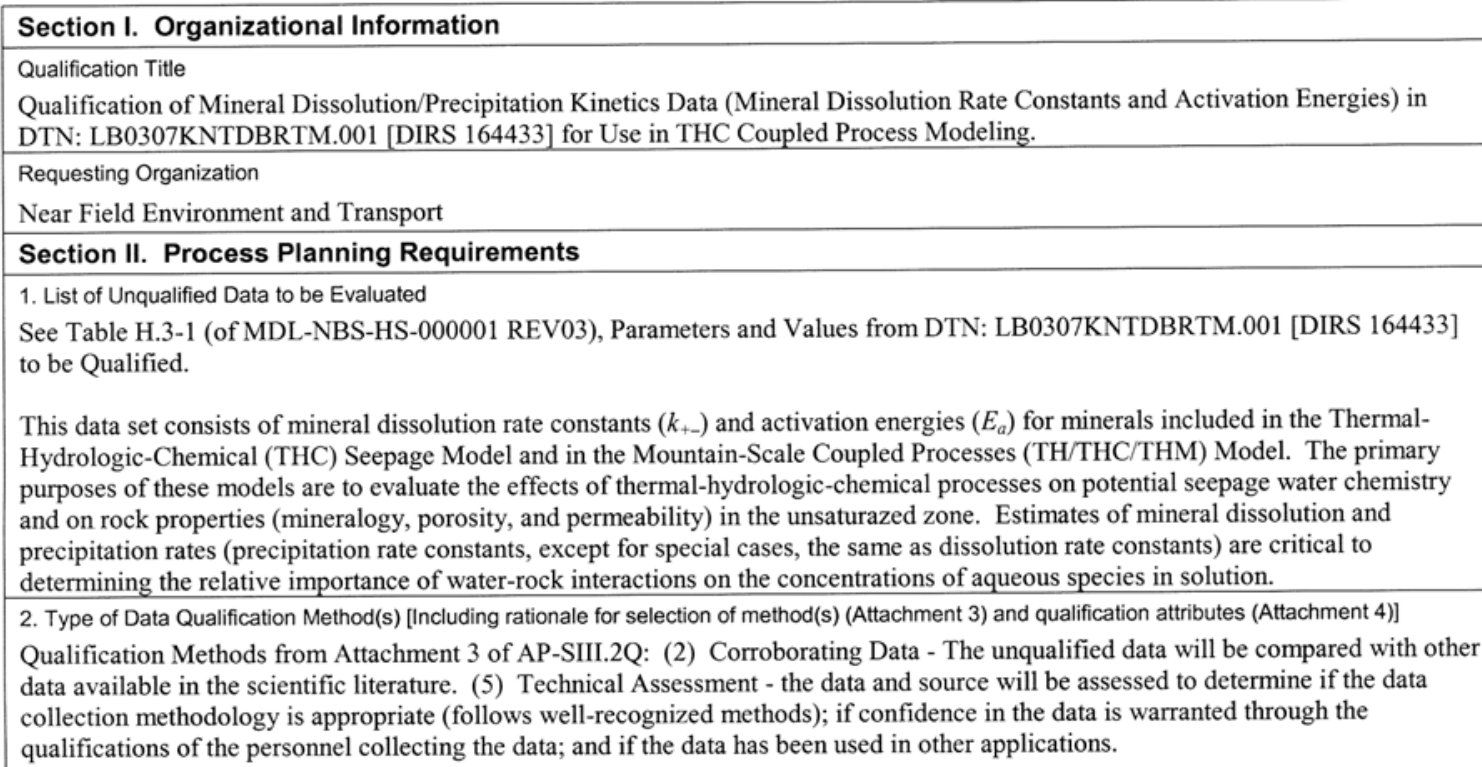

Method (1) in Attachment 3, Equivalent QA Program, cannot be used, because the data in question were not collected under a formal QA program; Method (3) Confirmatory Testing, and Method (4), Peer Review, cannot be used because project resources and scheduling are insufficuent.

Attributes used from Attachment 4 of AP-SIII.2Q: Item 3) The extent to which data demonstrate properties of interest; and Item 10) Extent and quality of corroborating data.

3. Data Qualification Chairperson and Additional Support Staff Required

Chairperson: Charles Bryan, Sandia National Laboratories

Technically competent individual: Joseph Rard

4. Data Evaluation Criteria

Data will be considered qualified for use if Corroborating Data are available, and if Technical Assessment shows that confidence in the data is justified for some or all of the following reasons: (1) the data were collected and developed using appropriate methodologies and under appropriate environmental conditions; (2) the data demonstrates the properties of interest; (3) data were collected by well-respected/well-trained personnel; (4) the data has been used in similar application in the scientific community..

5. Identification of Procedures Used

AP-SIII.10Q, Models

AP-SIII.2Q, Qualification of Unqualified Data

Section III. Approval

\begin{tabular}{|l|l|l|}
\hline Qualification Chairperson Printed Name & Qualification Chairperson Signature & Date \\
Charles Bryan & Responsible Manager Signature & Date \\
\hline Responsible Manager Printed Name & Ernest Hardin & $9 / 13 / 04$ \\
\hline
\end{tabular}




\section{INTENTIONALLY LEFT BLANK}




\section{APPENDIX I \\ QUALIFICATION OF IN-DRIFT CONFIGURATION, DIMENSIONS, AND COMPONENT PROPERTIES}


Drift-Scale THC Seepage Model 
This appendix documents the qualification of in-drift configuration, dimensions, and component properties listed in DTN: SN9908T0872799.004 [DIRS 108437], and serves as the data qualification report for that DTN. This data qualification effort has been carried out as described in the Data Qualification Plan that is included in the records package for this report. A facsimile of the Data Qualification Plan is included in Section I.8 of this appendix.

\section{I.1 PURPOSE OF DATA QUALIFICATION}

DTN: SN9908T0872799.004 [DIRS 108437] is the technical output of the calculation presented in Tabulated In-Drift Geometric and Thermal Properties Used in Drift-Scale Models for TSPA-SR (CRWMS M\&O 2000 [DIRS 171790], Table 2). Unqualifed inputs were used in the development of those results, which were thus identified by that report as requiring further verification. The purpose of this data qualification effort is to qualify the values derived from DTN: SN9908T0872799.004 [DIRS 108437], for the parameters shown in Table I-1, as adequate for their intended use in the modeling of THC seepage in this report. Some of the data from DTN: SN9908T0872799.004 [DIRS 108437], which have been used to develop the predictions in this report, have since been superseded. Even though these data have been superseded, the data are shown below to be qualified as adequate for their intended use in this report. This qualification is done following LP-SIII.2Q-BSC, Qualification of Unqualified Data.

Table I-1. Parameters and Values from DTN: SN9908T0872799.004 [DIRS 108437] to Be Qualified

\begin{tabular}{|l|l|}
\hline \multicolumn{1}{|c|}{ Parameter } & \multicolumn{1}{|c|}{ Value } \\
\hline Waste Package and Drip Shield Dimensions and Attributes & $1.945 \mathrm{~m}$ \\
\hline Location of waste package center above bottom of drift & $0.805 \mathrm{~m}$ \\
\hline Location of waste package center below the drift springline & $0.02 \mathrm{~m}$ \\
\hline Drip shield thickness & $0.396 \mathrm{~m}$ \\
\hline $\begin{array}{l}\text { Air gap between waste package surface and the inside of drip shield (only } \\
\text { used for collapsed drift scenarios in Section 6.2.5) }\end{array}$ & $1.231 \mathrm{~m}$ \\
\hline Inside radius of drip shield & $14.42 \mathrm{~W} / \mathrm{m} / \mathrm{K}$ \\
\hline Waste package thermal conductivity & $8189.2 \mathrm{~kg} / \mathrm{m}^{3}$ \\
\hline Waste package density & $488.86 \mathrm{~J} / \mathrm{kg} / \mathrm{K}$ \\
\hline Waste package specific heat & \\
\hline & \\
\hline Invert Properties & $6.152 \times 10^{-10} \mathrm{~m}^{2}$ \\
\hline Invert intrinsic permeability & 0.545 \\
\hline Invert porosity & $2530 \mathrm{~kg} / \mathrm{m}^{3}$ \\
\hline Invert grain density & $948 \mathrm{~J} / \mathrm{kg} / \mathrm{K}$ \\
\hline Invert specific heat & $833 \mathrm{~Pa}$ \\
\hline Invert capillarity & 0.1 \\
\hline Invert residual saturation & \\
\hline
\end{tabular}




\section{I.2 PURPOSE OF DATA BEING QUALIFIED}

The data being qualified in this appendix relate to dimensions, configuration, and properties of the in-drift materials for a typical emplacement drift. These data are needed to enable the development of the THC seepage model. The primary purpose (see Section 1) of the THC seepage model is to estimate the chemistry of seepage that could enter a repository drift. Hence, the configuration and properties that are assigned to the in-drift components (such as the waste packages and the invert) have little impact on the predictions of seepage chemistry by the model. Consequently, the data evaluation criteria presented below are based on reasonableness of the input data, both in terms of design changes as well as in the scientific sense, rather than actual input requirements of the model.

\section{I.3 QUALIFICATION METHODS}

Consistent with LP-SIII.2Q-BSC, the method selected to qualify the data in Table I-2 is adopted from Method 2 in Attachment 3 of the qualification procedure:

- Corroborating Data - The data to be qualified are compared with either more recent project data, or with similar data developed by duplicate or independent calculations since DTN: SN9908T0872799.004 [DIRS 108437] was developed. A comparison is made with current controlled YMP documentation or data in the TDMS for corroboration.

\section{I.4 QUALIFICATION PROCESS ATTRIBUTES}

Consistent with LP-SIII.2Q-BSC from Attachment 4, the attributes associated with this data qualification include:

3. The extent to which the data demonstrate the properties of interest (e.g., physical, chemical, geologic, mechanical).

This attribute is justified for application here because the data being qualified were developed specifically for the repository waste emplacement drifts.

10. Extent and quality of corroborating data or confirmatory testing results.

This attribute is appropriate because the availability of the newer project data that supersedes the data used in this report directly corroborate the values in DTN: SN9908T0872799.004 [DIRS 108437].

\section{I.5 DATA EVALUATION CRITERIA}

Consistent with LP-SIII.2Q-BSC, criteria have been established to evaluate the adequacy of the data being qualified. In general terms, the data selected to represent the in-drift environment must be reasonably consistent with either (1) the dimensions, geometry, and configuration of the current repository layout, or (2) the results of comparable calculations.

(1) The dimensions and properties associated with the waste package and drip shield associated with locations of components should be within a factor of 25 percent of 
the most recent values (if a single value is available) or within the suggested range from the most recent source;

(2) Because the properties of the invert have little impact on the model, the values that are used should be scientifically reasonable, and thus values of porosity, specific heat, capillarity, and density should be within 25 percent of the most recent values, if a single value is available for them. Or they should be located within the range of values obtained from the most recent source. The value of permeability should be within an order of magnitude of the most recent value, and the invert residual saturation should be within 0.20 of the current value.

\section{I.6 EVALUATION OF DATA TO BE QUALIFIED}

Table I-2 contains the input model data that is to be qualified. The model input value can be compared to values given in the corroborative information.

Table I-2. In-Drift Geometry and Property Choices for THC Seepage Model

\begin{tabular}{|c|c|c|c|}
\hline \multirow{2}{*}{ Parameter } & \multirow{2}{*}{$\begin{array}{l}\text { Model Input }^{(\mathrm{a})} \\
\text { Value }\end{array}$} & \multicolumn{2}{|c|}{ Corroborative Information } \\
\hline & & Value & Source \\
\hline \multicolumn{4}{|c|}{ Waste Package and Drip Shield Dimensions and Attributes } \\
\hline $\begin{array}{l}\text { Location of waste package } \\
\text { center above bottom of drift }\end{array}$ & $1.945 \mathrm{~m}$ & $1.75-2.15 \mathrm{~m}$ & $\begin{array}{l}\text { BSC } 2004 \text { [DIRS 168489] (center line of } \\
\text { waste package height above invert) and } \\
\text { BSC } 2004 \text { [DIRS 169776] (invert thickness) }\end{array}$ \\
\hline $\begin{array}{l}\text { Location of waste package } \\
\text { center below the drift } \\
\text { springline }\end{array}$ & $0.805 \mathrm{~m}$ & $0.6-1.0 \mathrm{~m}$ & $\begin{array}{l}\text { BSC } 2004 \text { [DIRS 168489] (drift diameter; } \\
\text { center line of waste package height above } \\
\text { invert) and BSC } 2004 \text { [DIRS 169776] (invert } \\
\text { thickness) }\end{array}$ \\
\hline Drip shield thickness & $0.02 \mathrm{~m}$ & 0.015 & BSC 2004 [DIRS 169220], Table 5 \\
\hline $\begin{array}{l}\text { Air gap between waste } \\
\text { package surface and the } \\
\text { inside of drip shield (only } \\
\text { used for collapsed drift } \\
\text { scenarios in Section } 6.2 .5 \text { ) }\end{array}$ & $0.396 \mathrm{~m}$ & $0.367-1.132 \mathrm{~m}$ & BSC 2004 [DIRS 168489], Figure 1 \\
\hline Inside radius of drip shield & $1.231 \mathrm{~m}$ & $1.285 \mathrm{~m}$ & BSC 2004 [DIRS 168283] \\
\hline $\begin{array}{l}\text { Waste package thermal } \\
\text { conductivity }\end{array}$ & $14.42 \mathrm{~W} / \mathrm{m} \mathrm{K}$ & $\begin{array}{l}10.1-15.5 \mathrm{~W} / \mathrm{m}^{*} \\
\mathrm{~K} \text { for Alloy } 22 \\
13.33-17.83 \\
\text { W/m*K for } 316 \\
\text { stainless steel } \\
\end{array}$ & $\begin{array}{l}\text { BSC } 2001 \text { [DIRS } 156276 \text { ], Table } 5-11 \text { (Alloy } \\
\left.\text { 22, for temperature range of } 48 \text { to } 300^{\circ} \mathrm{C}\right) \text {, } \\
\text { Table } 5-13(316 \text { stainless steel, temperature } \\
\left.\text { range of } 22.11 \text { to } 287.78^{\circ} \mathrm{C}\right)\end{array}$ \\
\hline $\begin{array}{l}\text { Waste package density } \\
\text { (see also Section 4.1.1.6) }\end{array}$ & $8189.2 \mathrm{~kg} / \mathrm{m}^{3}$ & $8690 \mathrm{~kg} / \mathrm{m}^{3}$ & $\begin{array}{l}\text { DTN: MO0003RIB00071.000 [DIRS 148850] } \\
\text { Mass density of Alloy } 22\end{array}$ \\
\hline $\begin{array}{l}\text { Waste package specific } \\
\text { heat }\end{array}$ & $488.86 \mathrm{~J} / \mathrm{kg} / \mathrm{K}$ & $378-731 \mathrm{~J} / \mathrm{kg} / \mathrm{K}$ & $\begin{array}{l}\text { BSC } 2004 \text { [DIRS 169990] (homogeneous } \\
\text { thermal properties for waste package } \\
\text { internal cylinder) }\end{array}$ \\
\hline
\end{tabular}


Table I-2. In-Drift Geometry and Property Choices for THC Seepage Model (Continued)

\begin{tabular}{|c|c|c|c|}
\hline \multirow{2}{*}{ Parameter } & \multirow{2}{*}{$\begin{array}{l}\text { Model Input }^{(\mathrm{a})} \\
\text { Value }\end{array}$} & \multicolumn{2}{|c|}{ Corroborative Information } \\
\hline & & Value & Source \\
\hline \multicolumn{4}{|l|}{ Invert Properties } \\
\hline Invert intrinsic permeability & $\begin{array}{l}6.152 \times 10^{-10} \mathrm{~m}^{2} \\
(2 \text { to } 4.75 \mathrm{~mm} \\
\text { particles) }\end{array}$ & $\begin{array}{l}6.0 \times 10^{-10} \mathrm{~m}^{2} \\
(3 \mathrm{~mm} \text { particle })\end{array}$ & $\begin{array}{l}\text { BSC } 2003 \text { [DIRS 170881], Section } 6.4 \text { and } \\
\text { Attachment XI }\end{array}$ \\
\hline Invert porosity & 0.545 & $0.55^{(b)}$ & BSC 2003 [DIRS 170881], Attachment XI \\
\hline Invert grain density & $2530 \mathrm{~kg} / \mathrm{m}^{3}$ & $2530 \mathrm{~kg} / \mathrm{m}^{3(\mathrm{c})}$ & BSC 2003 [DIRS 170881], Attachment XI \\
\hline Invert specific heat & $948 \mathrm{~J} / \mathrm{kg} / \mathrm{K}$ & $809 \mathrm{~J} / \mathrm{kg} / \mathrm{K}^{(\mathrm{d})}$ & DTN: GS000483351030.003 [DIRS 152932] \\
\hline Invert capillarity & $833 \mathrm{~Pa}$ & 24 to $1517 \mathrm{~Pa}^{(\mathrm{e})}$ & BSC 2003 [DIRS 170881] \\
\hline Invert residual saturation & 0.09 & $0.19^{(f)}$ & $\begin{array}{l}\text { DTN: LB0208UZDSCPMI.002 [DIRS } \\
\text { 161243] }\end{array}$ \\
\hline
\end{tabular}

(a) The source for model input is DTN: SN9908T0872799.004 [DIRS 108437], which is being qualified in this appendix.

(b) The porosity of the invert is calculated using measured data (from the sources cited) for grain density (2530 $\left.\mathrm{kg} / \mathrm{m}^{3}\right)$ and bulk density $\left(1150 \mathrm{~kg} / \mathrm{m}^{3}\right)$ of crushed tuff sieved between 2.00 to $4.75 \mathrm{~mm}$.

(c) The grain density of invert material is the measured (from the source cited) grain density of crushed tuff sieved between 2.00 and $4.75 \mathrm{~mm}$.

(d) The average specific heat (volumetric) of invert material for 11 samples (4-10 crushed tuff) listed in DTN: GS000483351030.003 [DIRS 152932] is $0.93 \mathrm{~J} / \mathrm{cm}^{3} /{ }^{\circ} \mathrm{C}$. Specific heat capacity (gravimetric) = volumetric heat capacity / bulk density. Bulk density $=$ invert grain density ${ }^{*}(1$-porosity $)=\left(2530 \mathrm{~kg} / \mathrm{m}^{3}\right)(1-0.545)=1150$ $\mathrm{kg} / \mathrm{m}^{3}=1.15 \mathrm{~g} / \mathrm{cm}^{3}$. Thus, specific heat capacity $=\left(0.93 \mathrm{~J} / \mathrm{cm}^{3} /{ }^{\circ} \mathrm{C}\right) / 1.15 \mathrm{~g} / \mathrm{cm}^{3}=0.810 \mathrm{~J} / \mathrm{g} /{ }^{\circ} \mathrm{C}=810 \mathrm{~J} / \mathrm{Kg} /{ }^{\circ} \mathrm{C}$.

(e) The van Genuchten Air Entry parameters for the intergranular void space of the invert are presented in Table 6.2 of Advection Versus Diffusion in the Invert (BSC 2003 [DIRS 170881]). The results are presented for a range of particle diameters from $0.317 \mathrm{~mm}$ to $20 \mathrm{~mm}$ and the parameters range between 65.9 (bars)-1 to 4160 (bars)-1, respectively. The air entry capillary pressure (referred to as capillarity in this report) equals the reciprocal of the air entry parameter and varies between $1517 \mathrm{~Pa}$ and $24 \mathrm{~Pa}$, respectively.

(f) Residual saturation measured from rock core for the TSwM4 layer (Topopah Spring Tuff middle non-lithophysal unit).

\section{I.7 FINDINGS OF DATA QUALIFICATION EFFORT}

The parameters grouped under "Waste Package and Drip Shield Dimensions and Attributes" in Table I-2 are repository design information that has evolved since the current THC seepage model was developed. The comparison of the model input data with the more recent values shows that all of the model input values are within 25 percent of the current values or that they reside within the range of values, and thus meet the criteria of acceptability for use in this report. The model input data are therefore demonstrated to be qualified for their application.

The input values for the parameters grouped under "Invert Properties" in Table I-2 can be corroborated by either the duplication of the calculations used in Tabulated In-Drift Geometric and Thermal Properties Used in Drift-Scale Models for TSPA-SR (CRWMS M\&O 2000 [DIRS 171790]) to generate the values used in the THC seepage model, or by comparable derivations of values. For the parameters of permeability, porosity, grain density, heat capacity, and capillarity of the invert, Advection Versus Diffusion in the Invert (BSC 2003 [DIRS 170881]) reproduced the same or similar calculations as those that were used as input to DTN: SN9908T0872799.004 [DIRS 108437]. This report has been developed, checked and approved under the current post-PVAR YMP QA procedures (BSC 2003 [DIRS 170881] was developed under AP-SIII.9Q). The comparison of the model input data for invert properties with 
the more recent values shows that all of the model input values meet the criteria of acceptability for use in the THC seepage model.

Based on the above assessment, the data shown on Table I-1 have been demonstrated to be qualified for their application as input to the THC seepage model.

\section{I.8 DATA QUALIFICATION PLAN}

See Figure I-1. 


\begin{tabular}{|l|l|l|}
\hline \multirow{2}{*}{ BSC } & DATA QUAlification PLAN & QA: QA \\
\cline { 3 - 3 } & Page 1 of 1 \\
\hline
\end{tabular}

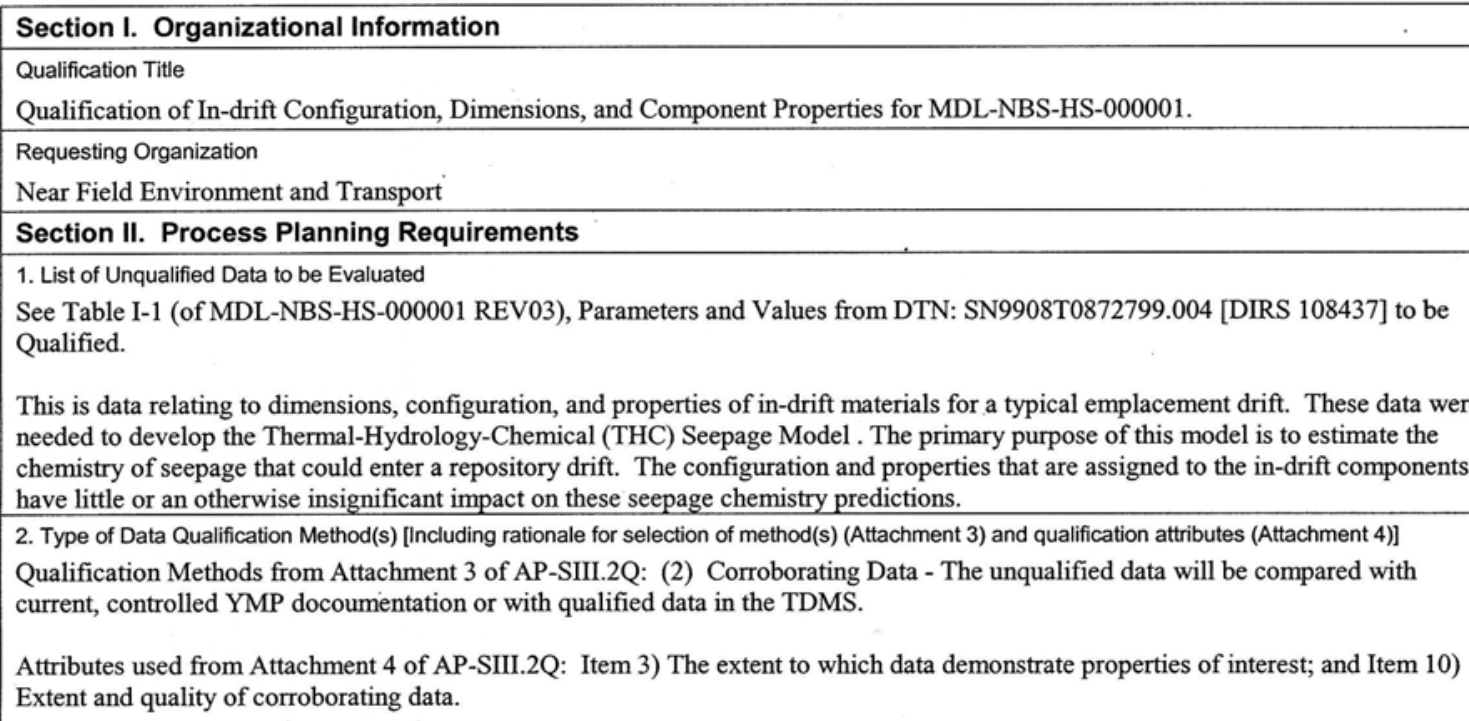

3. Data Qualification Chairperson and Additional Support Staff Required

Chairperson: Charles Bryan, Sandia National Laboratories

Technically competent individual: John Case

4. Data Evaluation Criteria

The THC Seepage Model is created such that all of the heat generated inside an emplacement drift is transmitted to the host rock. Thus the criteria for having acceptable data is:

1. The dimensions and properties associated with the waste package and drip shield associated with locations of components should be within a factor of 25 percent of the most recent values (if a single value is available) or within the suggested range from the most recent source;

2. Because the properties of the invert have little impact on the model, the values that were used should be scientifically reasonable, and thus values of porosity, specific heat, capillarity, and density should be within 25 percent of the most recent values, if a single value is available for them. Or they should be located within the range of values obtained from the most recent source. The value of permeability should be within an order of magnitude of the most recent value, and the invert residual saturation should be within 0.20 of the current value.

5. Identification of Procedures Used

AP-SIII.10Q, Models

AP-SIII.2Q, Qualification of Unqualified Data

\section{Section III. Approval}

\begin{tabular}{l|l|l|} 
Qualification Chairperson Printed Name & Qualification Chairperson Signature & Date \\
Charles Bryan & Responsible Manager Signature & Date \\
Responsible Manager Printed Name &
\end{tabular}

